\title{
THE EFFECT OF SPACER RIBS ON LEDINEGG TYPE FLOW INSTABILITIES (U)
}

by

D. A. Coutts

Westinghouse Savannah River Company

Savannah River Site

Aiken, South Carolina 29808

A document prepared for:

dissertation defense

at Columbia, SC

from 10/15/93

This paper was prepared in connection with work done under the above contract number with the $U$. S Department of Energy. By acceptance of this paper, the publisher and/or recipient acknowledges the U.S Government's right to retain a nonexclusive, royalty-free license in and to any copyright covering this paper, along with the right to reproduce and to authorize others to reproduce all or part of the copyrighted paper. 


\section{THE EFFECT OF SPACER RIBS ON LEDINEGG \\ TYPE FLOW INSTABILITIES}

David Allan Coutts

Bachelor of Science

Western New England College, 1980

Master of Engineering

University of South Carolina, 1985

Submitted in Partial Fulfillment of the Requirements

for the Degree of Doctor of Philosophy in the

College of Engineering

Department of Mechanical Engineering

University of South Carolina

1993

Major Professor

Committee Member

Chaiman,Examining Committee

Committee Member

Dean of Graduate School 


\section{DISCLAIMER}

This report was prepared as an account of work sponsored by an agency of the United States Government. Neither the United States Government nor any agency thereof, nor any of their employees, makes any warranty, express or implied, or assumes any legal liability or responsibility for the accuracy, completeness, or usefulness of any information, apparatus, product, or process disclosed, or represents that its use would not infringe privately owned rights. Reference herein to any specific commercial product, process, or service by trade name, trademark, manufacturer, or otherwise does not necessarily constitute or imply its endorsement, recommendation, or favoring by the United States Government or any agency thereof. The views and opinions of authors expressed herein do not necessarily state or reflect those of the United States Government or any agency thereof.

This report has been reproduced directly from the best available copy.

Available to DOE and DOE contractors from the Office of Scientific and Technical Information, P. O. Box 62, Oak Ridge, TN 37831; prices available from (615) $576-8401$.

Available to the public from the National Technical Information Service, U. S. Department of Commerce, 5285 Port Royal Rd., Springficld, VA 22161 


\section{Prellminary Data - 9 September 1993}

\section{ACKNOWLEDGMENTS}

I would like to express my thanks to the staff of the Heat Transfer Laboratory at the Department of Energy's Savannah River Site, who supported the test efforts presented in this dissertation. Deserving of special mention are the test engineer, Mark Fowley: the design engineer, George Richardson; the designer, Vince Walker: and the technician, Andy Foreman. Without their help this test program would not have been a success. I am also grateful to Drs. Steimke and Qureshi, and my manager Dave Muhlbaier, for their sound advice and support during the test program.

I would also like to express by sincere appreciation to my advisor, Prof. Larry Hawkins, for his advisement and help in the completing the program requirements and Phyllis Coleman who has supported APOGEE students so enthusiastically and efficiently.

Special thanks go to my grandparents, parents and brother for their nurturing which emphasized a love of learning and discovery.

In addition I would like to thank my wife, Nancy, for her unending patience, support, and understanding throughout the course of this endeavor. 
Preliminary Data _. 9 September 1993

\section{CONTENTS}

ACKNOWLEDGMENTS

CONTENTS.

ILLUSTRATIONS.

TABLES

ABBREVIATIONS

SYMBOLS

$x \times v i$

GLOSSARY.

ABSTRACT.

Chapter

1. INTRODUCTION ...........................................................................

Flow Excursion Predictions .................................................. 3

RIb Considerations ................................................................ 4

Summary of SRS OFI Program .......................................... 7

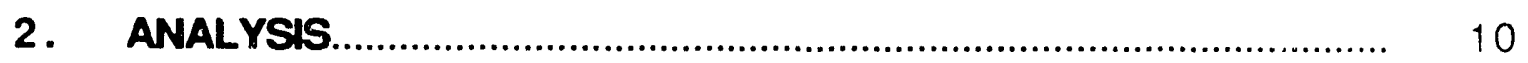

Demand Curves..................................................................... 10

Flow Instabilities.

Boiling Curves

Flow Obstruction Effects on OFI.

3 TEST FACIUTY.

Instrumentation Nomenclature.

Flow Loop.

Heated Channel

Data Management, and Reduction.

Uncertainty Analysis. 


\section{Preliminary Data -- 9 September 1993}

Table

4. RESULTS

Isothermal Test Results

Heater Inspection.

Diabatic Test Results

Visual Observation

Temperature Profiles

5. DISCUSSION 168

Demand Curve MInImum Conditions ............................. 168

Boiling Behavior ............................................................ 169

Wall Temparatures......................................................... 170

6 CONCLUSIONS................................................................... 172

Appendix

1. TEST CHANNEL GEOMETRY MEASUREMENTS............. 173

2. INSTRUMENT CALIBRATIONS ............................................. 185

3. MEASUREMENT UNCERTAINTY ANALYSIS .................... 220

4. TASK REFERENCE DOCUMENTS ...................................... 259

5. REFERENCE DATA .......................................................... 266

6. OPERATIONAL DETAILS .................................................. 272

7. Calculations and data REDUCtion......................... 281

8. TEST DATA .......................................................................... 301

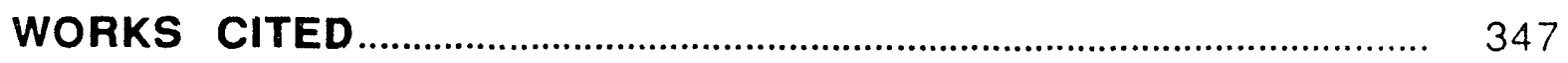




\section{ILLUSTRATIONS}

Figure Page

1. Demand curves for subcooled isothermal and diabatic systems ...... 2

2. SRS Mark 22 reactor fuel assembly...................................................... 5

3. Rib arrangements (a) rib root arrangement (b) rib tip arrangement.. 6

5. Heated channel nomenclature................................................................ 11

6. Demand curve prediction of operating conditions................................ 13

7. Diabatic demand curve characteristics.

8. Isothermal and diabatic velocity profiles

9. Subcooled boiling curves from Columbia University single tube uniformly heated tests, test sections 2.1, 4 and 7

10. Heated channel bubble formation milestones

11. OSV and OFI data from Tables $X X, X X$, and $X X, A p p e n d i x ~ 5$

12. Experimental OSV test data summarized by Dorra, Lee, and Bankoff.

13. Experimental OFI test data

14. Typical pool boiling curve

15. Typical forced convection boiling curves for subcooled liquid.

16. Forced convection boiling curve hysteresis, AFGHB for increasing heat flux, BHFA for decreasing heat flux.

17. Alternate transition boiling curves as suggested by Ramilison and Lienhard (1987)

18. Columbia University ribbed annulus demand curves.

19. Demand curves 


\section{Prellminary Data -. 9 September 1993}

Figure

20. Demand curve details

21. Q Qratio demand curves.

22. Average indicated temperatures for cemented TCs near the test section exit

23. Maximum indicated temperatures for cemented TCs near the test section exit

24. Boiling curve at end of test section for Columbia University ribbed annulus at a velocity of $4 \mathrm{~m} / \mathrm{s}$ and an exit pressure of $20 \mathrm{psig....}$

25. Nominal experimental wall superheat (20 psig)

26. Peak experimental wall superheat (20 psig)

27. Nominal experimental wall superheat (50 psig)

28. Peak experimental wall superheat (50 psig)

29. Superheat variation by date of test for a heat flux of $1.26 \mathrm{MW} / \mathrm{m}^{2}$ (0.4 MBtu/hr-ft2) and $20 \mathrm{psig}$ at the exit

30. Q Q ratio Demand curve for curve number 1 (run numbers 546 to 558)

31. Axial temperature profile for selected run numbers from curve number 1

32. Axial temperature profile details for run number 554 .

33. Axial temperature profile details for nun number 555.

34. Axial temperature profile details for nun number 556 .

35. Axial temperature profile details for nun number 558.

36. Axial temperature profiles for selected constant flow tests

37. Axial temperature profiles for selected constant flow tests

38. Axial temperature profile for a flow rate of $140 \mathrm{gpm}$

39. OFI data for geometries with spacer ribs

40. Schematic of Columbia University ribbed annuls burnout

41. Nomenclature as used for analysis by Jones, McAssey, and Yang.. 


\section{Preliminary Date -- 9 September 1993}

Figure

42. Schematic of subdivided flow channel

4.3. Test loop assembly -- Insulation is removed from the pump discharge header and the $2^{n}$ vertical supply (Photograph 931414-19)

44. Test loop schematic.

45. Test loop supply curve (pressure differential between pump suction and pump header) on 27 July 1993

46. Test channel cross section

47. Channel view port details -- Construction 2.0 at the end of the heated length (Photograph 93-1566-12).

48. Heater cross-section schematic

49. Test channel instrument port identification, positions 1 and 5 were not installed, position 3 was used to hold the rib in position

50. Fluid channel instrument port connections: (a) Blank, (b)

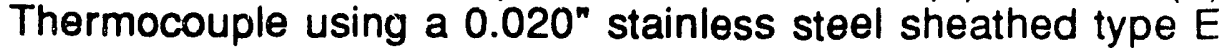
thermocouple, (c) Tube connection, $1 / 16^{n}$ NPT with a $1.59 \mathrm{~mm}$ through hole

51. Pressure transducer elevations

52. Test channel pressure instrumentation schematic

53. Thermocouple installation details (dimensions shown are nominal)

54. Heater base plate ready for installation of thermocouples (Photograph 92-1769-4)

55. Applied Power Instrument Schematic.

56. Rib details.

57. Rib support plugs

58. Basic instrument schematic

59. Isothermal demand curves for an inlet temperature range of 20 to $25^{\circ} \mathrm{C}$

59. Power calculation control volumes. 


\section{Prellminary Data _- 9 September 1993}

Figure

60. Isothermal demand curves for an inlet temperature range of 57.5 to $62.5^{\circ} \mathrm{C}$

61. Heater seal detail

62. Isothermal longitudinal pressure gradient for open channel from File FS_930723_0939 (Construction 4.0, $\mathrm{T}_{\text {in }}={ }^{\circ} \mathrm{C}, \phi=0.0$ $\mathrm{kW} / \mathrm{m}^{2}, \overline{\mathrm{Q}}=$ low flow $\mathrm{cm}^{3} / \mathrm{s}, \mathrm{P}_{\text {ehl }}=\mathrm{kPa}$ ).

63. Isothermal longitudinal pressure gradient for open channel from File FS_930723_1014 (Construction 4.0, $\mathrm{T}_{\text {in }}={ }^{\circ} \mathrm{C}, \phi=0.0$

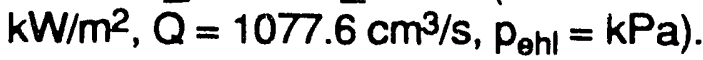

64. Isothermal longitudinal pressure gradient for open channel from File FS_930524_1138 (Construction 2.0, $\mathrm{T}_{\text {in }}={ }^{\circ} \mathrm{C}, \phi=0.0$ $\mathrm{kW} / \mathrm{m}^{2}, \overline{\mathrm{Q}}=$ low flow $\mathrm{cm}^{3} / \mathrm{s}, \mathrm{P}_{\text {ehl }}=\mathrm{kPa}$ ).

65. Isothermal longitudinal pressure gradient for open channel from File FS_930524_1158 (Construction 2.0, $T_{\text {in }}={ }^{\circ} \mathrm{C}, \phi=0.0$ $\mathrm{kW} / \mathrm{m}^{2}, \overline{\mathrm{Q}}=$ high flow $\mathrm{cm}^{3} / \mathrm{s}, \mathrm{P}_{\mathrm{g} / \mathrm{ll}}=\mathrm{kPa}$ )

66. Isothermal friction factor demand curves based on equivalent diameter calculated using Equation 25

67. Isothermal friction factor demand curves based on hydraulic diameter calculated using Equation 24

68. Heater inspection results.

69. Diabatic demand curve data for Constructions 2.0 and $4.0, T_{\text {in }}=$ $60 \cdot \mathrm{C}, \phi_{\text {open }}=330 \mathrm{~kW} / \mathrm{m}^{2}, \phi_{\text {rib }}=340 \mathrm{~kW} / \mathrm{m}^{2}, P=29 \mathrm{~kW}, p_{\text {ehl }}=$ $130 \mathrm{kPa}$

70. Minima region of the diabatic demand culve data for Constructions 2.0 and $4.0, T_{\text {in }}=60 \cdot \mathrm{C}, q=30.5 \mathrm{~kW} / \mathrm{m}^{2}, \mathrm{p}_{\text {ehl }}=i 30 \mathrm{kPa}$

71. Diabatic demand curve comparisons for Constructions $1.0,2.0$ and 4.0. (Curves 2.004, 2.009, 3.003, and 4.001 are shown)....

72. Minima region of the diabatic demand curve comparisons for Constructions 1.0, 2.0 and 4.0. (Curves 2.004, 2.009, 3.003, and 4.001 are shown)

73. Minima region of the diabatic demand curve comparisons for Constructions 2.0 (Curves 1.000, diamond, $3.001+, 3.003 X$, 3.003 Y, 4.001 Z) 


\section{Preliminary Data _- 9 September 1993}

Figure

74. Minima region of the diabatic demand curve comparisons for Constructions 2.0 (Curves 1.000, diamond, $3.001+3.003 X$, $3.003 \mathrm{Y}, 4.001 \mathrm{Z}$ ).

75. Minima region of the diabatic demand curve comparisons for Constructions 2.0 (Curves 1.000, diamond, $3.001+3.003 X$, $3.003 \mathrm{Y}, 4.001 \mathrm{Z})$

76. Pressure drop correlation for subcooled boiling

77. Isothermal longitudinal pressure gradient for diabatic open channel (File FS_930720_1446, Construction 4.0, $\mathrm{T}_{\text {in }}=$ $\left.59.29^{\circ} \mathrm{C}, \phi=327.6 \mathrm{~kW} / \mathrm{m}^{2}, Q=205.9 \mathrm{~cm}^{3} / \mathrm{s}, p_{\text {ehl }}=129.2 \mathrm{kPa}\right) \ldots$

78. Isothermal longitudinal pressure gradient for diabatic open channel (File FS_930720_1007, Construction 4.0, $\mathrm{T}_{\text {in }}={ }^{\circ} \mathrm{C}, \phi=$ $0.0 \mathrm{~kW} / \mathrm{m}^{2}, \mathrm{Q}=$ high $\mathrm{cm}^{3} / \mathrm{s}, P_{\text {ehl }}=\mathrm{kPa}$ )

79. Isothermal longitudinial pressure gradient for diabatic open channel with a longitudinal rib (File FS_9300601_1136. Construction $2.0, \mathrm{~T}_{\text {in }}=59.19^{\circ} \mathrm{C}, \phi=330.0 \mathrm{~kW} / \mathrm{m}^{2}, \mathrm{Q}=259.5$ $\mathrm{cm}^{3} / \mathrm{s}, p_{\text {ehl }}=129.0 \mathrm{kPa}$ ).

80. Longitudinal pressure gradient for diabatic channel with a longitudinal rib (File FS_930601_1545, Construction 2.0, $\mathrm{T}_{\text {in }}=$ ${ }^{\circ} \mathrm{C}, \phi=0.0 \mathrm{~kW} / \mathrm{m}^{2}, \mathrm{Q}=$ high flow $\mathrm{cm}^{3} / \mathrm{s}, \mathrm{p}_{\text {ehl }}=\mathrm{kPa}$ )

81. Vapor behavior at OFI, Construction 4.0, videotape LFIE-93-11-M, film time 3:00:04.7; a) frame 4, b) frame 5 (File FS_930720_1446, $T_{\text {in }}=59.29^{\circ} \mathrm{C}, \phi=327.6 \mathrm{~kW} / \mathrm{m}^{2}, \mathrm{Q}=$ $205.9 \mathrm{~cm}^{3} / \mathrm{s}, p_{\text {ehl }}=129.2 \mathrm{kPa}$ )

82. Vapor behavior at OFI, Construction 4.0, videotape LFIE-93-11-M:

a) film time 3:00:04.7, frame 6, b) film time 3:00:04.8, frame 1 (File FS_930720_1446, $T_{\text {in }}=59.29^{\circ} \mathrm{C}, \phi=327.6 \mathrm{~kW} / \mathrm{m}^{2}, \mathrm{Q}=$ $205.9 \mathrm{~cm}^{3} / \mathrm{s}, P_{\text {ehl }}=129.2 \mathrm{kPa}$ )

83. Vapor behavior at OFi, Construction 4.0, videotape LFIE-93-11-M, film time 3:00:04.8: a) frame 2, b) frame 3 (File FS_930720_1446, $T_{\text {in }}=59.29^{\circ} \mathrm{C}, \phi=327.6 \mathrm{~kW} / \mathrm{m}^{2}, \mathrm{Q}=$ $\left.205.9 \mathrm{~cm}^{3} / \mathrm{s}, p_{\text {ehl }}=129.2 \mathrm{kPa}\right)$

84. Vapor behavior at OFI, Construction 4.0, videotape LFIE-93-11-M, film time 3:00:04.8: a) frame 4, b) frame 5 (File 


\section{Preliminary Data _. 9 September 1993}

Figure

FS_930720_1446, $T_{\text {in }}=59.29^{\circ} \mathrm{C}, \phi=327.6 \mathrm{~kW} / \mathrm{m}^{2}, \mathrm{Q}=$ $\left.205.9 \mathrm{~cm}^{3} / \mathrm{s}, p_{\text {ehl }}=129.2 \mathrm{kPa}\right)$

85. ONB along rib, Construction 2.0, videotape LFIE-93-05-M, film time 38:25:3; a) frame 4, b) frame 5 (File FS_930601_1130, $\mathrm{T}_{\text {in }}=59.21^{\circ} \mathrm{C}, \phi=356.8 \mathrm{~kW} / \mathrm{m}^{2}, \mathrm{Q}=265.6 \mathrm{~cm}^{3} / \mathrm{s}, \mathrm{p}_{\mathrm{ehl}}=$ $129.1 \mathrm{kPa})$

86. Vapor behavior at OFI, Construction 2.0, videotape LFIE-93-05-M, film time 46:36:3; a) frame 2, b) frame 3 (File FS_930601_1136, $\mathrm{T}_{\text {in }}=59.19^{\circ} \mathrm{C}, \phi=330.0 \mathrm{~kW} / \mathrm{m}^{2}, \mathrm{Q}=$ $259.5 \mathrm{~cm}^{3} / \mathrm{s}, p_{\text {ehl }}=129.5 \mathrm{kPa}$ )

87. Vapor behavior at OFI, Construction 2.0, videotape LFIE-93-05-M, film time 46:36:3; a) frame 4, b) frame 5 (File FS_930601_1136, $T_{\text {in }}=59.19^{\circ} \mathrm{C}, \phi=330.0 \mathrm{~kW} / \mathrm{m}^{2}, Q=$ $259.5 \mathrm{~cm}^{3} / \mathrm{s}, \mathrm{p}_{\text {ehl }}=129.5 \mathrm{kPa}$ )

88. Vapor behavior at OFI, Construction 2.0, videotape LFIE-93-05-M, a) film time 46:36:3, frame 6, b) film time 46:36:4, frame 1 (File FS_930601_1136, $T_{\text {in }}=53.19^{\circ} \mathrm{C}, \phi=330.0 \mathrm{~kW} / \mathrm{m}^{2}, Q=$ $259.5 \mathrm{~cm}^{3} / \mathrm{s}, p_{\text {ehl }}=129.5 \mathrm{kPa}$ )

89. Vapor behavior at OFI, Construction 2.0, videotape LFIE-93-05-M, film time 46:36:3; a) frame 2, b) irame 3 (File FS_930601_1136, $T_{\text {in }}=59.19^{\circ} \mathrm{C}, \phi=330.0 \mathrm{~kW} / \mathrm{m}^{2}, \mathrm{Q}=$ $259.5 \mathrm{~cm}^{3} / \mathrm{s}, p_{\text {ehl }}=129.5 \mathrm{kPa}$ )

90. Longitudinal temperature profile from File FS_930720_1446 (Construction $4.0, \mathrm{~T}_{\text {in }}=59.29^{\circ} \mathrm{C}, \phi=327.6 \mathrm{~kW} / \mathrm{m}^{2}, \mathrm{Q}=$ $205.9 \mathrm{~cm}^{3} / \mathrm{s}, p_{\text {ehl }}=129.2 \mathrm{kPa}$ )

91. Normal temperature profile from File FS_930720_1446 (Construction $4.0, \mathrm{~T}_{\text {in }}=59.29^{\circ} \mathrm{C}, \phi=327.6 \mathrm{~kW} / \mathrm{m}^{2}, \mathrm{Q}=$ $\left.205.9 \mathrm{~cm}^{3} / \mathrm{s}, p_{\text {ehl }}=129.2 \mathrm{kPa}\right)$.

92. Lateral temperature profile from File FS_930720_1446

(Construction $4.0, \mathrm{~T}_{\text {in }}=59.29^{\circ} \mathrm{C}, \phi=327.6 \mathrm{~kW} / \mathrm{m}^{2}, \mathrm{Q}=$ $205.9 \mathrm{~cm}^{3} / \mathrm{s}, p_{\text {ehl }}=129.2 \mathrm{kPa}$ ).

93. Longitudinal temperature profile at EHL from File FS_930720_1446 (Construction 4.0, $T_{\text {in }}=59.29^{\circ} \mathrm{C}, \phi=$ $\left.327.6 \mathrm{~kW} / \mathrm{m}^{2}, Q=205.9 \mathrm{~cm}^{3} / \mathrm{s}, p_{\text {ehl }}=129.2 \mathrm{kPa}\right)$ 


\section{Prellminary Date _. 9 September 1993}

Figure

94. Normal temperature profile at EHL from File FS_930720_1446 (Construction 4.0, $T_{\text {in }}=59.29^{\circ} \mathrm{C}, \phi=327.6 \mathrm{~kW} / \mathrm{m}^{2}, Q=$ $205.9 \mathrm{~cm}^{3} / \mathrm{s}, P_{\text {ehl }}=129.2 \mathrm{kPa}$ )

95. Lateral temperature profile at EHL from File FS_930720_1446 (Construction $4.0, T_{\text {in }}=59.29^{\circ} \mathrm{C}, \phi=327.6 \mathrm{~kW} / \mathrm{m}^{2}, Q=$ $205.9 \mathrm{~cm}^{3} / \mathrm{s}, p_{\text {ehl }}=129.2 \mathrm{kPa}$ )

96. Longitudinal temperature profile from File FS_930601_1136 (Construction 2.0, $T_{\text {in }}=59.19^{\circ} \mathrm{C}, \phi=330.0 \mathrm{~kW} / \mathrm{m}^{2}, Q=$ $259.5 \mathrm{~cm}^{3} / \mathrm{s}, p_{\text {ehl }}=129.0 \mathrm{kPa}$ )

97. Normal temperature profile from File FS_930601_1136

(Construction 2.0, $\mathrm{T}_{\text {in }}=59.19^{\circ} \mathrm{C}, \phi=330.0 \mathrm{~kW} / \mathrm{m}^{2}, Q=$ $259.5 \mathrm{~cm}^{3} / \mathrm{s}, p_{\text {ehl }}=129.0 \mathrm{kPa}$ )

98. Lateral temperature profile from File FS_930601_1136 (Construction 2.0, $T_{\text {in }}=59.19^{\circ} \mathrm{C}, \phi=330.0 \mathrm{~kW} / \mathrm{m}^{2}, Q=$ $259.5 \mathrm{~cm}^{3} / \mathrm{s}, p_{\text {ehl }}=129.0 \mathrm{kPa}$ ).

99. Longitudinal temperature profile at EHL from File FS_930601_1136 (Construction 2.0, $T_{\text {in }}=59.19^{\circ} \mathrm{C}, \phi=$ $330.0 \mathrm{~kW} / \mathrm{m}^{\overline{2}}, \mathrm{Q}=259.5 \mathrm{~cm}^{3} / \mathrm{s}, \mathrm{P}_{\text {ehl }}=129.0 \mathrm{kPa}$ )

100. Normal temperature profile at EHL from File FS_930601_1136 (Construction 2.0, $\mathrm{T}_{\text {in }}=59.19^{\circ} \mathrm{C}, \phi=330.0 \mathrm{~kW} / \mathrm{m}^{2}, \mathrm{Q}=$ $259.5 \mathrm{~cm}^{3} / \mathrm{s}, p_{\text {ehl }}=129.0 \mathrm{kPa}$ ).

101. Lateral temperature profile at EHL from File FS_930601_1136 (Construction 2.0, $T_{\text {in }}=59.19^{\circ} \mathrm{C}, \phi=330.0 \mathrm{~kW} / \mathrm{m}^{2}, Q=$ $259.5 \mathrm{~cm}^{3} / \mathrm{s}, p_{\text {ehl }}=129.0 \mathrm{kPa}$ ).

102. Longitudinal temperature profile from File FS_930723_1014 (Construction $4.0, T_{\text {in }}={ }^{\circ} \mathrm{C}, \phi=0.00 \mathrm{~kW} / \mathrm{m}^{2}, Q=\mathrm{cm}^{3} / \mathrm{s}, p_{\mathrm{ehl}}=$ $\mathrm{kPa}$ ).

103. Normal temperature profile from File FS_930723_1014 (Construction $4.0, \mathrm{~T}_{\text {in }}={ }^{\circ} \mathrm{C}, \phi=0.0 \mathrm{~kW} / \mathrm{m}^{2}, Q=\mathrm{cm}^{3} / \mathrm{s}, P_{\text {ehl }}=$ $\mathrm{kPa}$ ).

104. Lateral temperature profile from File FS_930723_1014 (Construction $4.0, T_{\text {in }}=60^{\circ} \mathrm{C}, \phi=0.0 \mathrm{~kW} / \mathrm{m}^{2}, \mathrm{Q}=\mathrm{cm}^{3} / \mathrm{s}, p_{\text {ehl }}=$ $\mathrm{kPa}$ ). 


\section{Preliminary Data -- 9 September 1993}

Figure

1-1. Channel width measurement technique

1-2. Channel depth, b, for construction 2.0, 3.0, and 4.0.

2-1. Random curve fit uncertainty for FT01001

2-2. Fixed curve fit error for FT01001

2-3. FT01001 sample standard deviation during flow calibrations

2-4. FT01001 output during flow calibrations.

2-5. Random uncertainty component of curve fit for FT01002 in terms of

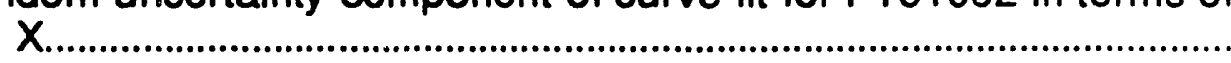

2-6. Systematic curve fit uncertainty.

2-7. Sample standard deviation of output for FT01002 during pretest calibration

2-8. Output of FT01002 during pretest flow calibration.

2-9. Confidence intervals for the mean response for WV00001

2-10. Fixed curve fit errors for WV00001

2-11. WV00001 sample standard deviation of output during calibrations .

2-12. WV00001 output during calibrations.

2-13. Confidence intervals for the mean response for WC00001

2-i4. Systematic fixed curve errors for WC00001

2-15. Sample standard deviation of output for WC00001 during pretest calibration.

2-16. Output of WC00001 during calibrations

2-17. Error distribution for thermocouples as compared with TT00001 (Excluding TC00001, TC00002, TC00003, and TL03002)

3-1. Specific heat estimates using alternate linearity assumptions

6-1. Typical daily check log sheet.

6-2. Typical steady-state log sheet

8-1. Demand curve 2.001, construction 1.0, open channel 


\section{Preliminary Data _- 9 September 1993}

Figure

8-2. Detail of minima region for demand curve 2.001, construction 1.0, open channel

8-3. Demand curve 2.002, construction 1.0, open channel.

8-4. Detail of minima region for demand curve 2.002, construction 1.0, open channel.

8-5. Demand curve 2.003, construction 1.0, open channel

8-6. Detail of minima region for demand curve 2.003, construction 1.0, open channel.

8-7. Demand curve 2.004, construction 1.0, open channel

8-8. Detail of minima region for demand curve 2.004, construction 1.0, open channel

8-9. Demand curve 3.001, construction 2.0, rib channel

8-10. Detail of minima region for demand curve 3.001, construction 2.0, rib channel.

8-11. Demand curve 3.002, construction 2.0, rib channel.

8-12. Detail of minima region for demand curve 3.002, construction 2.0, rib channel.

8-13. Demand curve 3.003, construction 2.0, rib channel.

8-14. Detail of minima region for demand curve 3.003, construction 2.0, rib channel.

8-15. Demand curve 3.004, construction 2.0, rib channel.

8-16. Detail of minima region for demand curve 3.004, construction 2.0, rib channel.

8-17. Demand curve 2.005, construction 4.0, open channel

8-18. Detail of minima region for demand curve 2.005, construction 4.0, open channel.

8-19. Demand curve 2.006, construction 4.0, open channel.

8-20. Detail of minima region for demand curve 2.006, construction 4.0, open channel.

8-21. Demand curve 2.007, construction 4.0, open channel 


\section{Prellminary Data _- 9 September 1993}

Figure

8-22. Detail of minima region for demand curve 2.007, construction 4.0, open channel

8-23. Demand curve 2.008, construction 4.0, open channel

8-24. Detail of minima region for demand curve 2.008, construction 4.0, open channel

8-25. Demand curve 2.009, construction 4.0, open channel

8-26. Detail of minima region for demand curve 2.009, construction 4.0, open channel.

8-27. Isothermal demand curve for construction 1.0, open channel,

8-28. Isothermal demand curve for construction 2.0, rib channel

8-29. Isothermal demand curve for construction 3.0, open channel

8-30. Isothermal demand curve for construction 4.0, open channel 


\section{Prellminary Data -. 9 September 1993}

\section{TABLES}

Table

1. SRS OFI program test matrix

2. Subcooled demand curve milestone correlations and models identified by Bankoff, Lee, and Knaani (4).

3. Mean Stanton numbers at OSV derived from data presented by Dorra, Lee, and Bankoff for Peclet numbers greater than 70,000

4. Mean Stanton numbers at OFI for open flow areas

5. Channel construction materials used in previous demand curve testing

6. Boundary condition separate effects evaluations on $\mathrm{OFI}$

7. Axial heat flux profiles evaluated by the Columbia University HTRF (29)

8. Static flow instability classifications suggested by Bouré, Bergles and Tong (10).

9. Experimental conditions investigated by Hodges (35)

10. Dynamic flow instability classifications as proposed by Bouré, Bergles and Tong (10)

11. Annular geometries used in OFI testing

12. Current measurement systematic uncertainties.

12. Summary of demand curve minimum data for open and ribbed channels

13. Rib effect in annuli equipped with spacer ribs

14. OFI predictions for Creare channel based on Equation 2. 


\section{Preliminary Data -- 9 September 1993}

Table

15. Nominal conditions used in analysis of Columbia University wall temperature effects

16. Demand curve descriptions

17. Cemented thermocouple locations for Columbia University annular OFI tests.

18. Columbia ribbed heater wall temperature gradient

19. Operating conditions for constant flow tests (Columbia University ribbed annulus).

20. DNB and burnout conditions in the Columbia University ribbed annulus test.

21. Instrument loop number first two letter nomenclature

22. Flow loop instrumentation

23. Channel dimensions

24. Channel temperature instrumentation

25. Flow loop instrumentation

26. File nomenclature

27. Water property equation coefficients for density, specific heat and thermal conductivity

28. Water property equation coefficients for viscosity and saturation temperature

32. Nominal elemental measurement uncertainties

33. Nominal elemental measurement uncertainties

33. Isothermal demand curve fits.

34. Diabatic demand curve OFI Conditions

35. Bubble formation sequence for the open channel, Construction 4.0 (File FS_930720_1446, $\mathrm{T}_{\text {in }}=59.29^{\circ} \mathrm{C}, \phi=327.6 \mathrm{~kW} / \mathrm{m}^{2}, \mathrm{Q}=$ $205.9 \mathrm{~cm}^{3} / \mathrm{s}, P_{e h l}=129.2 \mathrm{kPa}$, videotape LFIE-93-11-M)

35. Demand curve minimum results (nominal conditions: $T_{\text {in }}=60^{\circ} \mathrm{C}$, $\left.P_{\text {ehl }}=130 \mathrm{kPa}, P=\mathrm{kW}, \phi_{\text {open }}=330 \mathrm{~kW} / \mathrm{m}^{2}, \phi_{\text {rib }}=340 \mathrm{~kW} / \mathrm{m}^{2}\right) \ldots$ 


\section{Preliminary Data _- 9 September 1993}

Table

36. ONB along rib, Construction 2.0 (File FS_930601_1130, $\mathrm{T}_{\text {in }}=$ $59.21^{\circ} \mathrm{C}, \phi=356.8 \mathrm{~kW} / \mathrm{m}^{2}, Q=265.6 \mathrm{~cm}^{3} / \mathrm{s}, p_{e h l}=$ $129.1 \mathrm{kPa}$, videotape LFIE-93-05-M)

37. Bubble formation sequence along a rib, Construction 2.0 (File FS_930601_1136, $T_{\text {in }}=59.19^{\circ} \mathrm{C}, \phi=330.0 \mathrm{~kW} / \mathrm{m}^{2}, Q=$ $259.5 \mathrm{~cm}^{3} / \mathrm{s}, \mathrm{P}_{\text {ehl }}=129.0 \mathrm{kPa}$, Video tape LFIE-93-05-M)

38. Mean heater temperature based on lateral position from File FS_930720_1446 (Construction 4.0, $\mathrm{T}_{\text {in }}=59.29^{\circ} \mathrm{C}, \phi=$ $\left.32 \overline{7} .6 \mathrm{~kW} / \mathrm{m}^{2}, \mathrm{Q}=205.9 \mathrm{~cm}^{3} / \mathrm{s}, P_{\text {ehl }}=129.2 \mathrm{kPa}\right)$

39. Mean heater temperatures based on lateral position over the last $80 \mathrm{~mm}$ of the heated length; from File FS_930720_1446 (Construction $4.0, T_{\text {in }}=59.29^{\circ} \mathrm{C}, \phi=327.6 \mathrm{~kW} / \mathrm{m}^{2}, Q=$ $\left.205.9 \mathrm{~cm}^{3} / \mathrm{s}, p_{\text {ehl }}=129.2 \mathrm{kPa}\right)$.

40. Mean heater temperature based on lateral position from File FS_930601_1136 (Construction 2.0, $\mathrm{T}_{\text {in }}=59.19^{\circ} \mathrm{C}, \phi=$ $\left.330.0 \mathrm{~kW} / \mathrm{m}^{2}, \mathrm{Q}=259.5 \mathrm{~cm}^{3} / \mathrm{s}, \mathrm{P}_{\mathrm{ehl}}=129.0 \mathrm{kPa}\right)$

41. Mean heater temperatures based on lateral position over the last $80 \mathrm{~mm}$ of the heated length; from File FS_930601_1136 (Construction 2.0, $\mathrm{T}_{\text {in }}=59.19^{\circ} \mathrm{C}, \phi=330.0 \mathrm{~kW} / \mathrm{m}^{2}, \mathrm{Q}=$ $259.5 \mathrm{~cm}^{3} / \mathrm{s}, p_{\text {ehl }}=129.0 \mathrm{kPa}$ )

42. Mean heater temperature based on lateral position from File FS_930723_1014 (Construction $4.0, \mathrm{~T}_{\text {in }}=60^{\circ} \mathrm{C}$, TT00001 = $\left.60^{\circ} \mathrm{C}, \phi=0.0 \mathrm{~kW} / \mathrm{m}^{2}, \mathrm{Q}=\mathrm{cm}^{3} / \mathrm{s}, p_{\text {ehl }}=\mathrm{kPa}\right)$.

43. Mean heater temperatures based on lateral position over the last $80 \mathrm{~mm}$ of the heated length; from File FS_930723_1014 (Construction $4.0, T_{\text {in }}=60^{\circ} \mathrm{C}$, $T 00001=60^{\circ} \mathrm{C}, \phi=0.0 \mathrm{~kW} / \mathrm{m}^{2}$, $\left.\mathrm{Q}=\mathrm{cm}^{3} / \mathrm{s}, \mathrm{p}_{\text {ehl }}=\mathrm{kPa}\right)$

44. Bubble detachment parameters.

45. Wall temperature evaluation.

1-1. Channel dimensions

1-2. Directly measured channel dimensions.

1-3. Channel width measurements 


\section{Preliminary Data -- 9 September 1993}

Table

1-4. Channel width dimensions after installation of roll pins, 24 June 1993, prior to final assembly of construction 4.0

1-5. Face plate dimensions used for channel depth calculation, measured on 23 June 1993

1-6. Channel depth measurements, distance from front of face plate to front of heater

1-7. Channel depth measurements.

1-8. Channel depth measurements based on data presented in Figure 1-2

2-1. Instruments used in the loop calibration check of FT01001 and FT01002.

2-1. Measurement and test equipment (M\&TE) summary.

2-2. Operating parameters and elemental uncertainties for the loop calibration check of FT01001 and FT01002

2-3. Calibration standard uncertainties estimated from information presented in Table 2-2.

2-4. Uncertainty estimate for FT01001

2-5. Uncertainty estimate for FT01002

2-6. Pressure transducer slope estimates based on calibration information

2-7. Daily check files excluded from pressure transducer analysis

2-8. Pressure transducer behavior during daily zero and span checks...

2-8a. Pressure transducer systematic uncertainties.

2-9. Uncertainty estimate for applied voltage, WV00001, prior to 3 July 1993.

2-10. Uncertainty estimate for applied voltage, WV00001, on and after 3 July 1993.

2-11. Systematic uncertainty estimate for WC00001 loop calibration

2-13. Results from daily flow checks, temperature calculated from DAS mean as compared with TTO0001. 


\section{Preliminary Data -- 9 September 1993}

Table

2-14. Statistical information for data presented in Figure 2-17.

2-15. Statistical information for TC00003 where $\mid$ TT00001 - $\mathrm{T}_{\mathrm{amb}} \mid<2^{\circ} \mathrm{C}$

2-16. Statistical information for TLO3602 where $\mid$ TTOOno1 $-T_{\text {amb }} \mid<2^{\circ} \mathrm{C}$

2-17. Uncertainty estimate for TC00003, and TL03002

3-1. Friction factor sensitivity coefficient estimates for open channel, construction 4 , inlet temperature $60^{\circ} \mathrm{C}, \mathrm{Re}=10,000$

3-2. Friction factor sensitivity coefficient estimates for open channel, construction 4.0 , inlet temperature $60^{\circ} \mathrm{C}, \mathrm{Re}=20,000$.

3-3. Friction factor sensitivity cuefficient estimates for rib channel, construction 2 , inlet temperature $60^{\circ} \mathrm{C}, \mathrm{Re}=10,000$

3-4. Friction factor sensitivity coefficient estimates for rib channel, construction 2.0 , inlet temperature $60^{\circ} \mathrm{C}, R e=20,000$.

3-5. Friction factor systematic uncertainty estimate for open channel, construction 4 , inlet temperature $60^{\circ} \mathrm{C}, \mathrm{Re}=10,000$

3-6. Friction factor systematic uncertainty estimate for open channel, construction 4.0 , inlet temperature $60^{\circ} \mathrm{C}, \mathrm{Re}=20,000$

3-7. Friction factor systematic uncertainty estimate for rib channel, construction 2 , inlet temperature $60^{\circ} \mathrm{C}, \mathrm{Re}=10,000$

3-8. Friction factor systematic uncertainty estimate for rib channel, construction 2.0 , inlet temperature $60^{\circ} \mathrm{C}, R_{\theta}=20,000$.

3-8a. Specific heat estimates using alternate linearity assumptions ( $T_{\text {inlet }}$ $\left.=60^{\circ} \mathrm{C}\right)$

3-9. Energy balance ratio sensitivity coefficient estimates for construction 4 (open channel) at $7.5 \mathrm{gpm}$

3-10. Energy balance ratio sensitivity coefficient estimates for construction 4 (open channel) at $1260 \mathrm{~cm}^{3} / \mathrm{s}(20 \mathrm{gpm})$

3-13. Energy balance ratio systematic uncertainty estimate for construction 4 (open channel) at $473 \mathrm{~cm}^{3} / \mathrm{s}(7.5 \mathrm{gpm})$

3-14. Energy balance ratio systematic uncertainty estimate for construction 4 (open channel) at $1261 \mathrm{~cm}^{3} / \mathrm{s}(20 \mathrm{gpm})$ 


\section{Preliminary Data -- 9 September 1993}

Table

3-17a. Heat flux (electrical) sensitivity coefficient estimates for construction 4 (open channel) at $473 \mathrm{~cm}^{3} / \mathrm{s}(7.5 \mathrm{gpm}), 30.64$ $\mathrm{kW}$.

3-17b. Heat flux (electrical) sensitivity coefficient estimates for construction 2 (rib) at $473 \mathrm{~cm}^{3} / \mathrm{s}(7.5 \mathrm{gpm}), 30.64 \mathrm{~kW}$.

3-18. Heat flux (electrical) systematic uncertainty estimate for construction 2 (rib) at $7.5 \mathrm{gpm}$.

3-18a. Heat flux (electrical) systematic uncertainty estimate for construction 4 (open channel) at $473 \mathrm{~cm}^{3} / \mathrm{s}(7.5 \mathrm{gpm}), 30.64$ $\mathrm{kW}$.

3-19. Heat flux (fluid) sensitivity coefficient estimates for construction 4 (open channel) at $7.5 \mathrm{gpm}$.

3-20. Heat flux (fluid) systematic uncertainty estimate for construction 4 (open channel) at $7.5 \mathrm{gpm}$.

3-22. Heat flux (conduction) systematic uncertainty estimate for construction 4 (open channel) based on data presented in Table 403 for FS_930601_1136

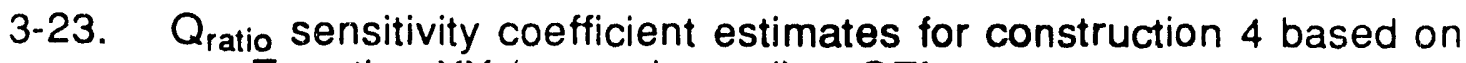
Equation $X X$ (open channel) at OFI

3-23. Q $Q_{\text {ratio }}$ sensitivity coefficient estimates for Equation $X X$ (construction 4 , open channel) at OFI

3-XX. Specific heat estimates used in $Q_{\text {ratio }}$ uncertainty analysis

3-24. $Q_{\text {ratio }}$ sensitivity coefficient estimates for construction 2 (rib channel) at OFI

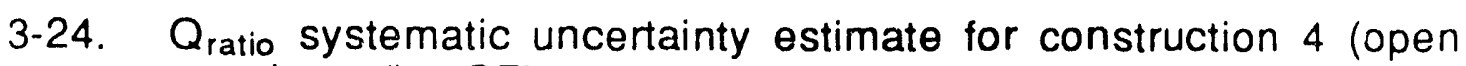
channel) at OFI

3-25. Qratio systematic uncertainty estimate for construction 4 (open channel) at $\mathrm{OFI}$

3-26. Q ratio systematic uncertainty estimate for construction 2 (rib channel) at OFI.

3-27. Q Qatio rib-effect-ratio sensitivity coefficient estimates for construction 2 (rib channel) at OFI 


\section{Preliminary Data -. 9 September 1993}

Table

3-28. $Q_{\text {ratio rib-effect-ratio systematic uncertainty estimate for }}$ construction 4 (open channel) at OFI.

3-28a. Stanton number rib-effect-ratio systematic uncertainty for rib channel, construction 2 at $\mathrm{OFI}$, inlet temperature $60^{\circ} \mathrm{C}$

3-29. Reynolds number sensitivity coefficient estimates for open channel, construction 4 , inlet temperature $60^{\circ} \mathrm{C}, \mathrm{Re}=10,000 \ldots$

3-30. Reynolds number sensitivity coefficient estimates for open channel, construction 4.0 , inlet temperature $60^{\circ} \mathrm{C}, \mathrm{Re}=$ 20,000 .

3-31. Reynolds number sensitivity coefficient estimates for rib channel, construction 2 , inlet temperature $60^{\circ} \mathrm{C}, \mathrm{Re}=10,000$

3-32. Reynolds rumber sensitivity coefficient estimates for rib channel, construction 2.0 , inlet temperature $60^{\circ} \mathrm{C}, \mathrm{Re}=20,000$.

3-33. Reynolds number systematic uncertainty estimate for open channel, construction 4 , inlet temperature $60^{\circ} \mathrm{C}, \mathrm{Re}=10,000 \ldots$

3-34. Reynolds number systematic uncertainty estimate for open channel, construction 4.0 , inlet temperature $60^{\circ} \mathrm{C}, \mathrm{Re}=$ 20,000 .

3-35. Reynolds number systematic uncertainty estimate for rib channel, construction 2 , inlet temperature $60^{\circ} \mathrm{C}, \mathrm{Re}=10,000$

3-36. Reynolds number systematic uncertainty estimate for rib channel, construction 2.0 , inlet temperature $60^{\circ} \mathrm{C}, \operatorname{Re}=20,000$.

3-37. Stanton number sensitivity coefficient estimates for open channel, construction 4 at $\mathrm{OFI}$, inlet temperature $60^{\circ} \mathrm{C}$

3-38. Stanton number sensitivity coefficient estimates for rib channel, construction 2 at $\mathrm{OFI}$, inlet temperature $60^{\circ} \mathrm{C}$

3-39. Stanton number rib-effect-ratio systematic uncertainty for open charinel, construction 4 at $\mathrm{OFI}$, inlet temperature $60^{\circ} \mathrm{C}$.

3-40. Stanton number rib-effect-ratio systematic uncertainty for rib channel, construction 2 at $\mathrm{OFI}$, inlet temperature $60^{\circ} \mathrm{C}$.

3-41. Stanton number ratio sensitivity coefficient estimates at OFI, inlet temperature $60^{\circ} \mathrm{C}$ 


\section{Preliminary Data -- 9 September 1993}

Table

3-42. Stanton number rib-effect-ratio systematic uncertainty for rib channel, construction 2 at $\mathrm{OFI}$, inlet temperature $60^{\circ} \mathrm{C}$

3-43. Stanton number rib-effect-ratio systematic uncertainty for rib channel, construction 2 at $\mathrm{OFI}$, inlet temperature $60^{\circ} \mathrm{C}$

4-1. Procedures and Test Plans.

4-2. Design drawings

4-3. Photographs

4-4. Video Tapes.

4-5. Data Files Listing

5-1. Experimental OSV data calculated from the tables prepared by Dorra, Lee, and Bankoff (XX)

5-2. Selected data from Columbia University tube tests (WSRC-RP-89870).

5-3. OFI data derived from the work of Whittle and Forgan.

5-4. Conditions at the demand curve minimums for the Creare OFI program (9).

5-5. Demand curve minimum data from work of Johnston and Neff $(\mathrm{XX})$.

6-1. Test phase descriptions.

6-2. Valving arrangements for zero, span and flow function checks

6-3. Standard valving arrangements

6-4. Phase 1 and 2 test conditions

7-1. Raw data and reduced data file columns and formats.

7-2. Engineering Units Conversions

7-3. Demand Curve Inputs JMP Worksheet Description.

7-4. Deriland Curves JMP Worksheet Description

7-5. Temperature profiles JMP Worksheet Description

7-6. Pressure profiles JMP Worksheet Description. 


\section{Preliminary Data _. 9 September 1993}

Table

8-1. Boundary conditions for demand curve 2.001, construction 1.0, open channel

8-2. Test data for demand curve 2.001, construction 1.0, open channel .

8-3. Boundary conditions for demand curve 2.002, construction 1.0, open channel

8-4. Test data for demand curve 2.002, construction 1.0, open channel .

8-5. Boundary conditions for demand curve 2.003, construction 1.0, open channel

8-6. Test data for demand curve 2.003, construction 1.0, open channel .

8-7. Boundary conditions for demand curve 2.004, construction 1.0, open channel.

8-8. Test data for demand curve 2.004, construction 1.0, open channel.

8-9. Boundary conditions for demand curve 3.001, construction 2.0, rib channel.

8-10. Test data for demand curve 3.001, construction 2.0, rib channel......

8-11. Boundary conditions for demand curve 3.002, construction 2.0, rib channel.

8-12. Test data for demand curve 3.002, construction 2.0, rib channel......

8-13. Boundary conditions for demand curve 3.003, construction 2.0, rib channel.

8-14. Test data for demand curve 3.003 , construction 2.0 , rib channel......

8-15. Boundary conditions for demand curve 4.001, construction 2.0, rib channel.

8-16. Test data for demand curve 4.001, construction 2.0, rib channel......

8-17. Boundary conditions for demand curve 2.005, construction 4.0, open channel.

8-18. Test data for demand curve 2.005, construction 4.0, open channel.

8-19. Boundary conditions for demand curve 2.006, construction 4.0, open channel.

8-20. Test data for demand curve 2.006, construction 4.0, open channel . 


\section{Preliminary Data -- 9 September 1993}

Table

8-21. Boundary conditions for demand curve 2.007, construction 4.0, open channel

8-22. Test data for demand curve 2.007, construction 4.0, open channel.

8-23. Boundary conditions for demand curve 2.008, construction 4.0, open channel

8-24. Test data for demand curve 2.008, construction 4.0, open channel .

8-25. Boundary conditions for demanś curve 2.009, construction 4.0, open channel

8-26. Test data for demand curve 2.009, construction 4.0, open channel. 


\section{Prellminary Data _. 9 September 1993}

\section{ABBREV:ATIONS}

$\begin{array}{ll}\text { CHF } & \text { Critical heat flux } \\ \text { DNB } & \text { Departure from nucleate boiling } \\ \text { EHL } & \text { End of heated length } \\ \text { FI } & \text { Flow instability } \\ \text { HTL } & \text { Savannah River Site Heat Transfer Laboratory } \\ \text { HTRF } & \text { Heat Transfer Research Facility (Columbia University) } \\ \text { UD } & \text { Length to diameter ratio } \\ \text { M\&TE } & \text { Measurement and testing equipment } \\ \text { NVG } & \text { Net vapor generation } \\ \text { OFI } & \text { Onset of flow instability } \\ \text { ONE } & \text { Onset of nucleate boiling } \\ \text { OSV } & \text { Onset of significant void } \\ \text { SHL } & \text { Start of heated length } \\ \text { SI } & \text { Le Système International d'Unitès } \\ \text { SHS } & \text { Savannah River Site }\end{array}$




\section{SYMBOLS}

\begin{tabular}{|c|c|}
\hline$A_{f}$ & flow area $\left[\mathrm{m}^{2}\right]$ \\
\hline$A_{h}$ & heated area $\left[\mathrm{m}^{2}\right]$ \\
\hline a & width of I idular cross-section [m] \\
\hline b & depth of rectangular cross-section [m] \\
\hline$c_{f}$ & specific heat of inner liquid $[\mathrm{J} / \mathrm{kg} \cdot \mathrm{C}]$ \\
\hline D & $\begin{array}{l}\text { channel diameter for round tubes or hydraulic diameter for non- } \\
\text { circular cross-sections [m] }\end{array}$ \\
\hline$D_{e}$ & equivalent diameter defined in equation $X X[\mathrm{~m}]$ \\
\hline$D_{h}$ & heated equivalent diameter $[\mathrm{m}]$ \\
\hline G & mass velocity, $\left[\mathrm{kg} / \mathrm{m}^{2} \cdot \mathrm{s}\right]$ \\
\hline g & acceleration due to gravity \\
\hline$\Delta h_{i}$ & inlet subcooling in terms of enthalpy $[\mathrm{kJ} / \mathrm{kg}]$ \\
\hline$h_{f g}$ & latent heat of vaporization $[\mathrm{kJ} / \mathrm{kg}]$ \\
\hline$\Delta L$ & differential length [m] \\
\hline L & length \\
\hline$L_{b}$ & distance from incipient boiling to the heated section exit \\
\hline$L_{b, s}$ & $\begin{array}{l}\text { distance required to bring the fluid from } T_{\text {ib }} \text { to } T_{\text {sat }} \text { where } T_{\text {sat }} \text { is } \\
\text { evaluated at the exit conditions. }\end{array}$ \\
\hline$L_{h}$ & length of heated plate $[\mathrm{m}]$ \\
\hline$N$ & number of samples \\
\hline$\left(d p_{t} / d z\right)_{L O}$ & $\begin{array}{l}\text { frictional pressure gradient for flow with total mass flux and liq } \\
\text { phase properties }\end{array}$ \\
\hline
\end{tabular}




\section{Preliminary Data _- 9 September 1993}

\begin{tabular}{|c|c|}
\hline$\Delta p$ & pressure drop [Pa] \\
\hline$\Delta \mathrm{p}_{0-1}$ & $\begin{array}{l}\text { inlet pressure loss from plenum to heated channel caused by } \\
\text { contraction }\end{array}$ \\
\hline$\Delta \mathrm{p}_{1-2}$ & heated section pressure drop \\
\hline$\Delta \mathrm{p}_{2-3}$ & exit pressure loss from heated channel caused by expansion \\
\hline$\Delta \mathrm{p}_{\mathrm{b}}$ & pressure drop over length $L_{b}$ due to friction and momentum \\
\hline$\Delta p_{b, s}$ & $\begin{array}{l}\text { pressure drop for an adiabatic tube with a fluid temperature at } T_{\text {ib }} \\
\text { and a length } L_{b, s}\end{array}$ \\
\hline$d p_{t} / d z$ & frictional pressure gradient \\
\hline$\Delta \mathrm{p}_{\mathrm{t}}$ & pressure drop $[\mathrm{Pa}]$ \\
\hline$p$ & pressure [Pa] \\
\hline$P_{\text {ehl }}$ & pressure at end of the heated length [Pa] \\
\hline$p_{\text {in }}$ & inlet pressure \\
\hline $\mathrm{P}_{\mathrm{L}}$ & pressure in the liquid feed piping \\
\hline po & time averaged pressure. \\
\hline$Q$ & volumetric flow rate $\left[\mathrm{m}^{3} / \mathrm{s}\right]$ \\
\hline$q$ & rate of heat transfer \\
\hline$S$ & sample standard deviation, $\sum_{i=1}^{N} \frac{\left(x_{i}-\bar{X}\right)^{2}}{N-1}$ \\
\hline$t_{\alpha / 2}$ & two-t:ailed Student-t value at $95 \%$ confidence \\
\hline$\Delta T_{\text {sat }}$ & $\begin{array}{l}\text { wall superheat; difference between the wall temperature and the } \\
\text { saturation temperature of the fluid }\left[{ }^{\circ} \mathrm{C}\right]\end{array}$ \\
\hline$\Delta T_{\text {sub }}$ & $\begin{array}{l}\text { subcooling; difference between saturation temperature and coolant } \\
\text { temperature }\left[{ }^{\circ} \mathrm{C}\right]\end{array}$ \\
\hline$T_{\text {ib }}$ & bulk fluid temperature at incipient boiling \\
\hline sat & ature at a specified local pressure \\
\hline
\end{tabular}




\section{Preliminary Data _- 9 September 1993}

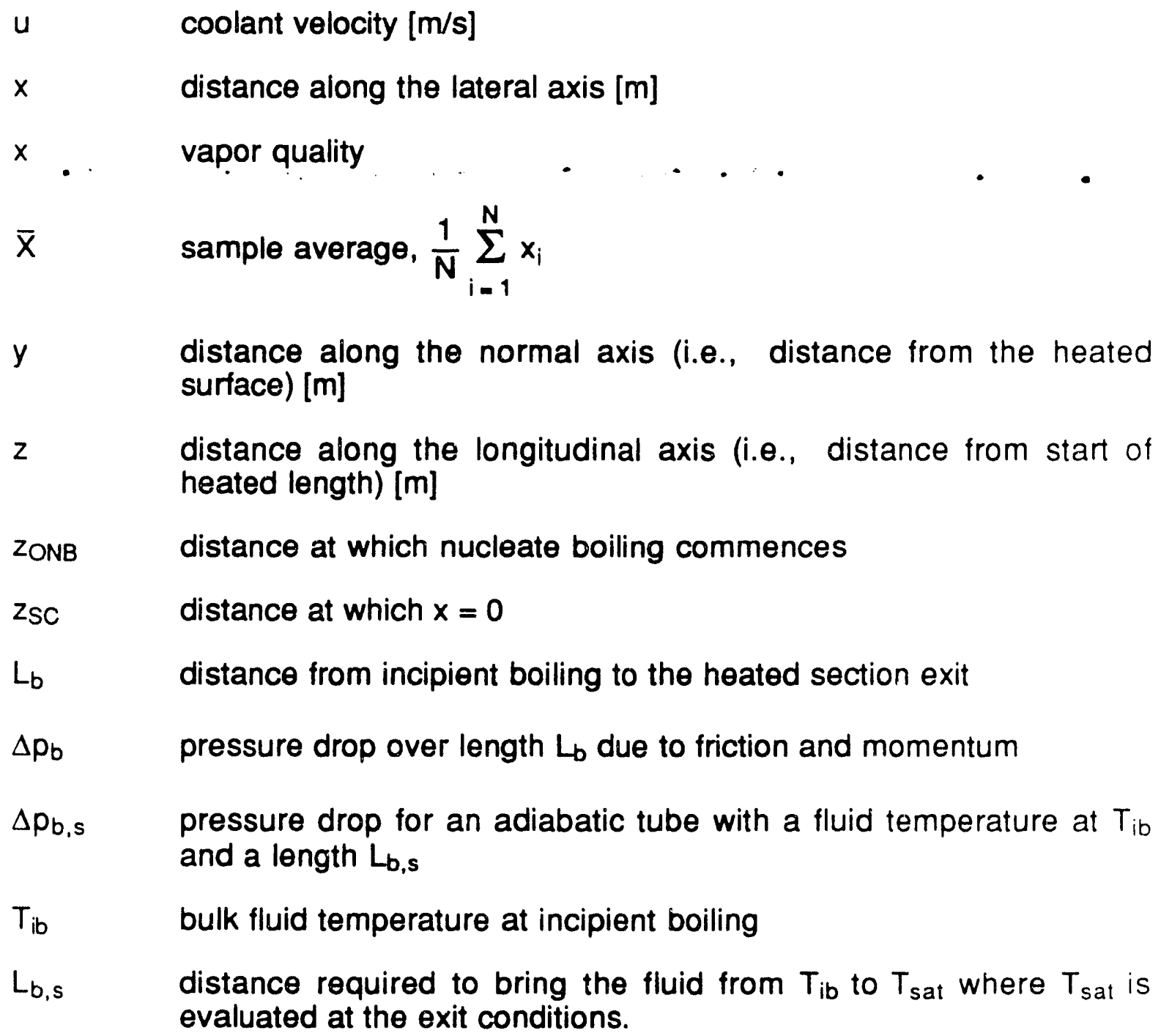

\section{Greek}

$\alpha \quad$ vapor volume fraction (e.g., void fraction)

$\varepsilon \quad$ surface roughness

$\phi \quad$ heat flux

$\phi_{B O} \quad$ heat flux at burnout [pcu/hr.ft2] (Note: $A$ pcu is the energy required to raise 1 pound of water, $1^{\circ} \mathrm{C}$. Therefore $1.0 \mathrm{pcu}=1.8 \mathrm{Btu}$.)

$\phi_{c} \quad$ critical heat flux $\left[\mathrm{W} / \mathrm{m}^{2}\right]$

$\phi_{c 0} \quad$ basic critical heat flux $\left(\phi_{c}\right.$ for $\left.\Delta h_{i}=0\right)\left[W / m^{2}\right]$ 
bubble detachment parameter

$\mu_{b} \quad$ dynamic viscosity based on bulk fluid conditions

$\mu G$ gas-phase viscosity

$\mu \quad$ liquid-phase viscosity

$\mu_{w} \quad$ dynamic viscosity based on wall conditions

$\theta \quad$ time [s]

$\rho \quad$ density $\left[\mathrm{kg} / \mathrm{m}^{3}\right]$

$\rho_{f} \quad$ liquid density $\left[\mathrm{kg} / \mathrm{m}^{3}\right]$

$\rho_{G} \quad$ vapor density $\left[\mathrm{kg} / \mathrm{m}^{3}\right]$

$\rho_{v} \quad$ vapor density $\left[\mathrm{kg} / \mathrm{m}^{3}\right]$

$\rho_{m} \quad$ mixture density $\left[\mathrm{kg} / \mathrm{m}^{3}\right]$

$\rho_{\infty} \quad$ impulse line density $\left[\mathrm{kg} / \mathrm{m}^{3}\right]$

$\sigma$

surface tension $\left[\mathrm{N} / \mathrm{m}^{2}\right]$

$\psi \quad$ undefined function

\section{Dimensionless Numbers}

$f \quad$ friction factor

$f_{G O} \quad$ friction factor for total mass flux with gas properties

$f_{\text {iso }} \quad$ friction factor for isothermal conditions

fLo friction factor for total mass flux with liquid properties

\$LO pressure drop multiplier defined in equation $\mathrm{XX}$

$\Gamma \quad$ error fraction $\left[\left(\psi-\psi_{f}\right) /\left(\psi_{i}-\psi_{f}\right)\right]$

Nu Nusselt number [hD/k]

Pr Prandtl number $\left[c_{p} \mu / k\right]$ 


\section{Preliminary Data -- 9 September 1993}

\begin{tabular}{|c|c|}
\hline$Q_{\text {ratio }}$ & heat flux ratio, defined in equation $X X$ \\
\hline $\mathrm{R}$ & temperature ratio at $O F I$, defined in equation $X X$ \\
\hline $\begin{array}{l}\mathrm{Re} \\
\mathrm{St}\end{array}$ & $\begin{array}{l}\text { Reynolds number }[G D / \mu] \\
\text { Stanton number }\left[\phi / G c_{p} \Delta T_{\lambda}\right]\end{array}$ \\
\hline & Subscripts \\
\hline $0,1,2$ & property or state at location $0,1,2$, refer to Figure 2 \\
\hline 1 & property or state at location 1, refer to Figure 2 \\
\hline 01,24 & property, state or parameter between location 0 and 1,2 and 4 \\
\hline 2 & property or state at location 2 , refer to Figure 2 \\
\hline 3 & propenty or state at location 3 , refer to Figure 2 \\
\hline 4 & property or state at location 4 , refer to Figure 2 \\
\hline ehl & end of heated length \\
\hline $\exp$ & experimental \\
\hline in & channel inlet \\
\hline 1 & liquid properties \\
\hline $\mathrm{m}$ & mixture properties \\
\hline $\max$ & maximum \\
\hline $\min$ & minimum \\
\hline ONB & onset of nucleate boiling \\
\hline out & channel outlet \\
\hline$v$ & vapor properties \\
\hline
\end{tabular}




\section{GLOSSARY}

Burnout. An inordinate increase in surface temperature resulting from the change in one of the parameters of the system (e.g., heat flux, mass velocity, fluid temperature) which results in channel failure.

Burnout point. The longitudinal axis position when the liquid film flow on a heated channel wall decreases to zero.

Critical heat flux (CHF). A sudden rise in wall temperature or substantial $\left(>20^{\circ} \mathrm{F}\right)$ fluctuations above the nucleate boiling wall temperature.

Demand curve minimum. The minimum pressure drop as specified by the demand curve for flow in a heated channel.

Departure from nucleate boiling (DNB). A shift in the heat transfer mechanism from nucleate boiling where liquid contacts the heated surface to film boiling where liquid contact with the heated surface is prevented and a vapor film forms.

Dryout. A condition where there is no liquid contact with the wall.

Fundamental instability. An instability is fundamental when the mechanism can be identified and studied separately.

Lateral axis. The coordinate axis orthogonal with the longitudinal and normal axes.

Longitudinal axis. The coordinate axis in the direction of flow.

Net vapor generation (NVG). The onset of significant void.

Normal axis. The coordinate axis perpendicular to the heated surface.

Onset of flow instability (OFI). The demand curve minimum in a diabatic channel. This is the threshold for Ledinegg instability.

Onset of nucleate boiling (ONB). The condition where bubbles first start to form on the heated channel surface.

Onset of significant void (OSV). The condition where significant vapor generated starts with the mixing of bubbles in the subcooled liquid core. 


\section{Preliminary Data -- 9 September 1993}

Saturated DNB. When the bulk fluid is at saturated conditions at the location where DNB occurs.

Steady flow. The system parameters are functions of space variables, only small fluctuations (due to turbulence, nucleation, or slug flow) exist.

Steady-oscillatory. Flow conditions at a point are ideally repeated at a fixed time interval.

Subcooled DNB. When the bulk fluid is subcooled at the location where DNB occurs.

Transient. System parameters vary as a function of time. 


\section{Prellminary Data -- 9 September 1993}

\section{ABSTRACT}

An experimental program has been completed which evaluated the effect of a flow obstruction in a heated channel on the onset of flow instability (OFI). The test channel was rectangular $(80 \times 3 \mathrm{~mm})$, heated on one surface, and equipped with view ports. Tests were conducted in a flow controlled mode at heat fluxes of $370 \mathrm{~kW} / \mathrm{m}^{2}$, and $610 \mathrm{~kW} / \mathrm{m}^{2}$. Direct comparisons were made between the demand curve minimum for the unobstructed channel and a channel equipped with a $2.07 \mathrm{~mm}$ wide rib that was parallel to the flow and in contact with the heated surface.

Data at OFI is presented in the nondimensional terms of $Q_{\text {ratio }}$ (ratio of heat. flux applied to heat flux required to achieve saturated liquid conditions at the exit), and the local Stanton number at the channel exit for each channel arrangement. The $\mathrm{Q}_{\text {ratio }}$ and Stanton number values for the unobstructed channel and the rib equipped channel are then compared to produce an estimate of the rib effect. 


\section{Preliminary Data -. 9 September 1993}

\section{CHAPTER 1 \\ INTRODUCTION}

The coolant in production nuclear reactor assemblies such as in the Savannah River Site (SRS) reactors is circulated as a subcooled liquid under normal operating conditions. This coolant is evenly distributed throughout multiple annular flow channels with a uniform pressure profile across each coolant flow channel. Subcooled flow in such a heated channel may exhibit a demand curve with a negative sloped region and a relative maximum and minimum as shown in Figure 1. This type of behavior is common in low pressure water systems (48). The relative minimum is the result of the flow acceleration created by the change in fluid density, and an increase in the frictional pressure loss created by vapor nucleating on the heater surface and effectively increasing the flow channel roughness.

The operating condition for any flow system can be determined by the intersection of the supply and demand curves. For turbulent subcooled isothermal systems only one operating point exists. This is shown as condition a in Figure 1. When a system demand curve has a negatively slope region it is possible that three different operating conditions might exist. Conditions $b$ and $d$ are stable, condition $c$ as shown in Figure 1 is not stable. Attempted operation at condition c will result in an excursion to condition d. Ledinegg (50) identified the threshold limit for subcooled flow in a heated channel to undergo a flow instability as the minimum in the demand curve. When flow is reduced below the demand curve minimum it will undergo a sudden large amplitude excursion 


\section{Preliminary Data -. 9 September 1993}

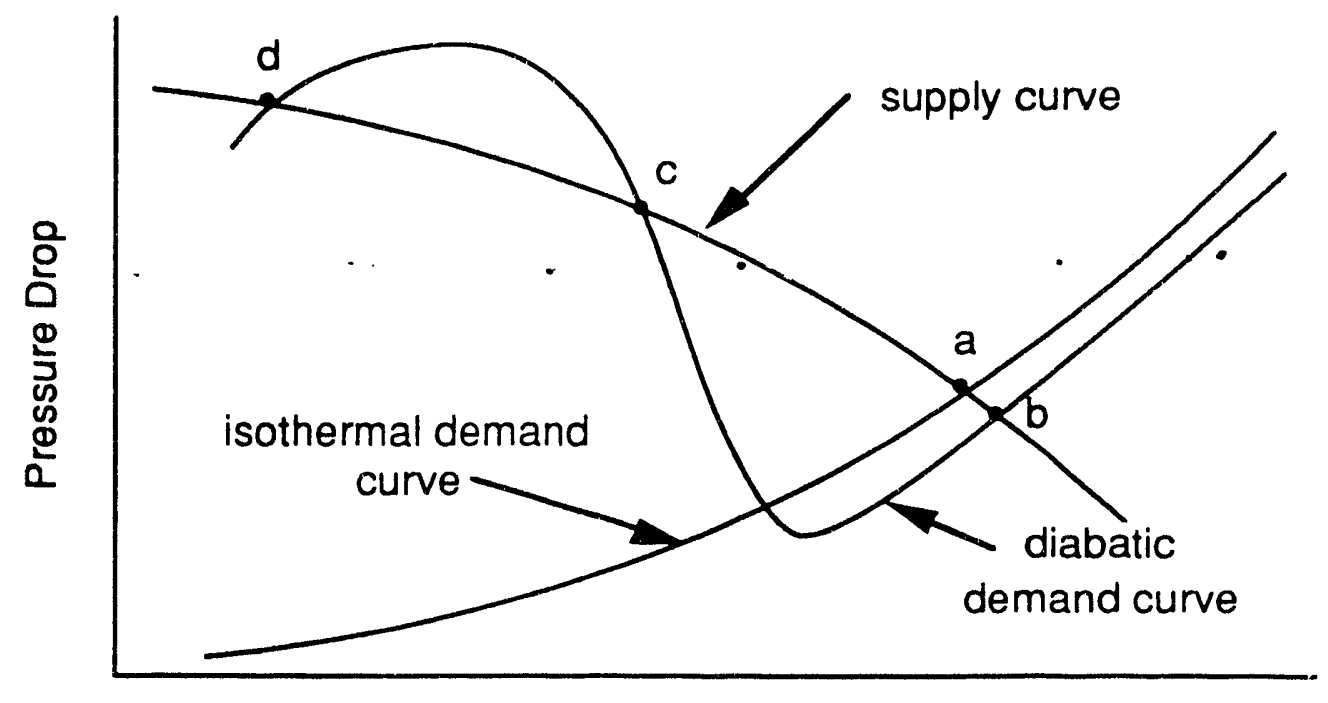

Mass Flux

Figure 1. Demand curves for subcooled isothermal and diabatic systems

to a new, stable operating condition. This instability is characterized by a rapid shift in the operating condition from subcooled boiling to high quality steam. Ledinegg analytically demonstrated that the conditions for OFI were a function of channel geometry, friction coefficient, system operating pressure, and inlet subcooling. The OFI threshold was shown to be essentially independent of flow rate, and heat flux.

Operation at condition c in Figure 1 is possible if the supply system is adequate. If the slope of the supply curve is steeper (more negative) than the demand curve (sum of the friction, acceleration, and elevation terms) a Ledinegg type flow instability will not occur (52). The equation for this is:

$$
\frac{\partial p_{\text {supply }}}{\partial Q}-\frac{\partial p_{\text {demand }}}{\partial Q} \leq 0
$$




\section{Preliminary Data -- 9 September 1993}

For constant pressure systems $\left(\partial p_{\text {supply }} / \partial Q=0\right)$ operation at the demand curve minimum is stable for small increases in flow but unstable for small flow decreases. Attempted operation at a flow below the demand curve minimum flow will result in an excursion to the left side of the demand curve. Because of this many researchers have referred to the demand curve minimum condition as the onset of flow instability (OFI) condition. This nomenclature wi!l be used in this report.

In multi-channel parallel flow systems the slope of the supply curve for each individual channel is effectively flat. When flow is reduced to the parallel flow network, the flow through all of the flow channels will decrease. If there are no geometric, heat transfer or power dissimilarities the flow to each channel will be equally reduced. In practice the reactor geometry, heat transfer behavior and power flux are not uniform. Some flow channels may be exposed to higher power levels and greater flow restrictions. Because the pressure drop across each channel is the same (plenum-to-plenum pressure difference), as the pressure drop decreases across the entire network some channels will be more susceptible to unstable flow excursions. If an excursion were to occur in one channel the resulting diversion in flow would be distributed through the other parallel channels and create a negligible increase in network pressure drop.

\section{Flow Excursion Predictions}

A Ledinegg flow excursion will result in higher channel operating temperatures which could result iii equipment damage. One of the techniques used to assure safe operation during a flow reduction transient such as a defined loss of coolant accident (LOCA) is to operate at a power level below that necessary to initiate a flow excursion. Several correlations have been 


\section{Preliminary Data .. 9 September 1993}

developed to predict OFI. Whittle and Forgan (67) demonstrated that OFI occurs at:

$$
\frac{T_{\text {exit @ OFI }}-T_{\text {inlet }}}{T_{\text {sat }}-T_{\text {inlet }}}=R
$$$$
\text { where: } \dot{R}=\frac{1}{1+\frac{\eta}{L_{h} / D_{h}}}
$$

It is important to note that the value of $R$ is constant for any given geometry and the outlet temperature at the minimum can be predicted based solely on the inlet temperature, saturation temperature, and geometry.

A second correlation to predict OFI and the one used to calculate SRS reactor operating limits is based on a correlation developed by Saha and Zuber (62) to predict the onset of significant void (OSV). Since OSV occurs at a higher flow than OFI, OSV will occur prior to OFI. The equation to predict OSV at high Peclat numbers, based on local conditions is (62):

$$
S t=\frac{\phi}{G c_{p}\left(T_{\text {sat }}-T_{\text {bulk }}\right)}=0.0065
$$

The SRS design criteria is set at a Stanton number of 0.00455 which is $30 \%$ below the best estimate value listed in Equation 3 .

\section{Rib Considerations}

The assemblies in the SRS reactors consist of concentric aluminum or aluminum clad tubes which form annular flow channels as shown in Figure 2. The annular spacing is maintained by four ribs in each flow channel. The width of these ribs at the tip range from $1.4 \mathrm{~mm}$ to $1.7 \mathrm{~mm}$ for a Mark 22 assembly. Since the ribs and tube walls are constructed of aluminum (a poor neutron absorber) virtually all of the heat generation occurs in the core of the tubes. 


\section{Prellminary Data -. 9 September 1993}

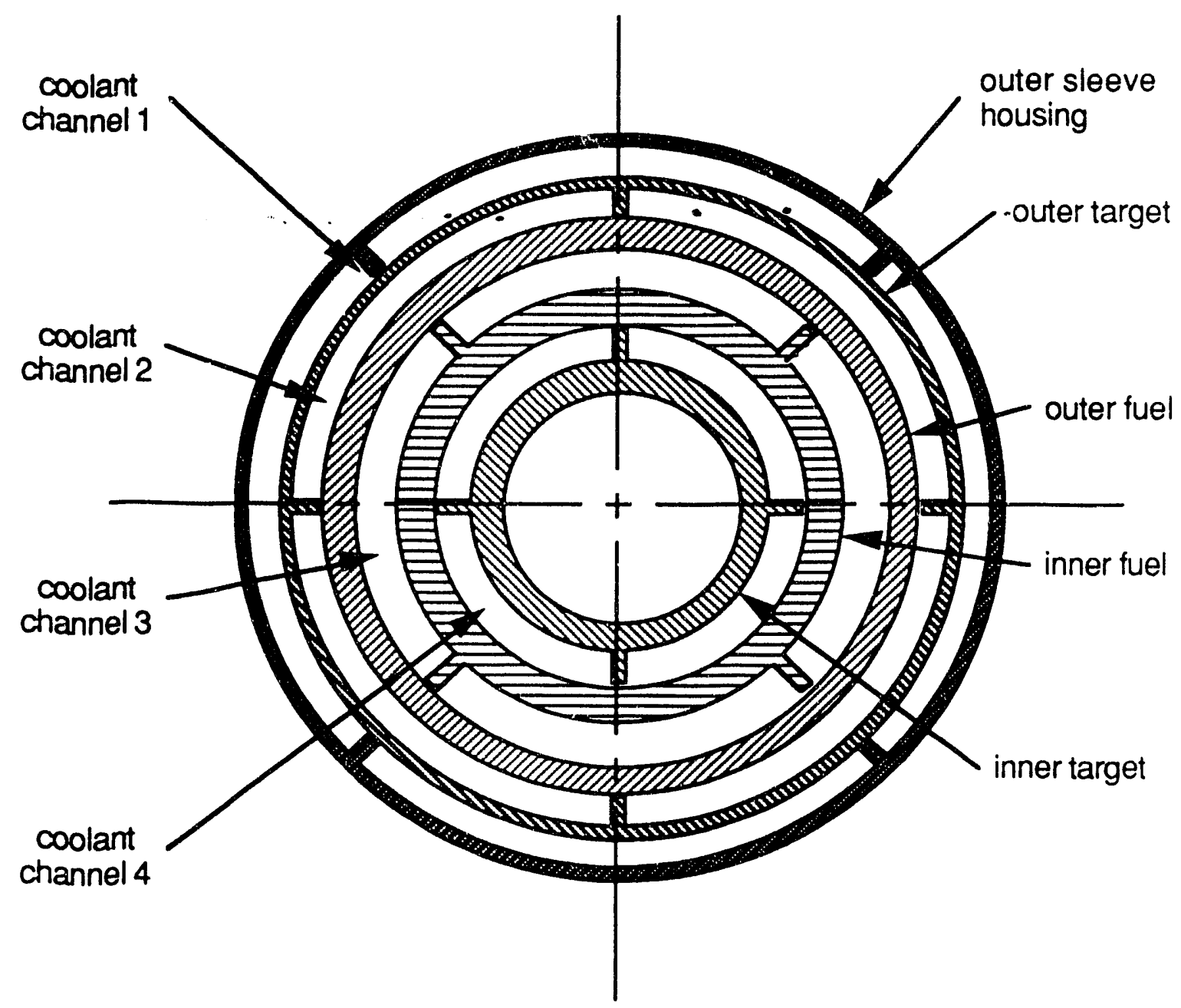

Figure 2. SRS Mark 22 reactor fuel assembly

The ribs will change the local heat transfer in their immediate vicinity. A rib will produce a viscous drag which will reduce the fluid velocity and heat transfer near the rib. The rib in Figure 3a will tend to act as a fin to remove heat from the tube while the rib in Figure $3 b$ where the rib tip approaches the wall may allow the formation of vapor that will tend to insulate a portion of the wall and inhibit heat removal from the wall.

The combined viscous, fin, and insulation effect of the ribs is difficult to predict analytically. The rib presence in the SRS annuli will create an azimuthal 


\section{Prelliminary Data _- 9 September 1993}

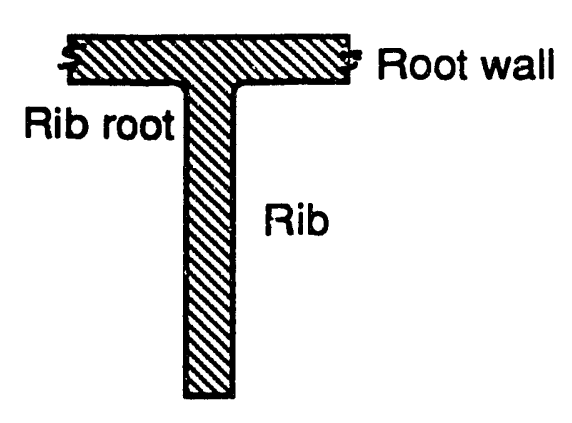

a

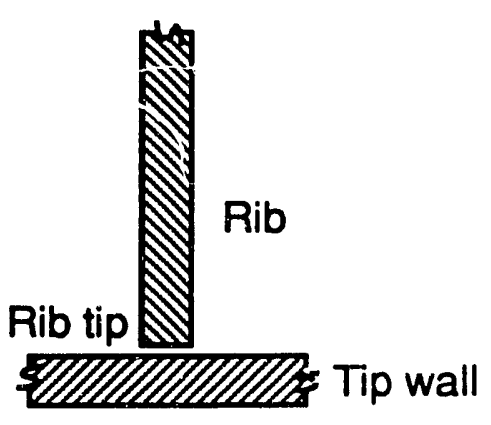

b

Figure 3. Rib arrangements (a) rib root arrangement (b) rib tip arrangement

heat flux profile and an azimuthal variation in the local Stanton number. io account for this variation the SRS limits methodology (49) reduces the OSV design value of 0.00455 by a rib peaking factor. The rib peaking factor presently in use (49) is 1.209. The resulting equivalent Stanton number OSV limit is therefore 0.00376 . While this design value adjusted for rib peaking has been demonstrated as conservative by comparison with benchmarking data produced by Columbia University (20), Creare (49), and Babcock \& Wilcox (21), using the SRS FLOWTRAN program; it is desirable to quantify the rib effect experimentally. This will require a separate effects test where a single channel is operated both with a rib and without a rib. This would allow a direct comparison between the two geometries and the calculation of a rib effect.

In the SRS reactors the four centering ribs for any channel are not all in intimate contact with the rib tip wall. Minor amounts of bowing, eccentricity, and kinking in the fuel tubes and targets results in intermittent contact between the rib tip and rib tip wall. This intermittent contact allows flow redistribution between subchannels formed by the spacer ribs. Flow between adjacent subchannels across a rib is referred to as rib flow. In addition to rib flow the 


\section{Preliminary Data -- 9 September 1993}

intermittent contact will result in areas of stagnate fluid between the rib tip and the rib tip wall. This area of stagnant fluid may allow the development of an insulating layer of vapor.

The coolant channel opposite the rib tip will accept an increase in the heat from the tip wall. This will reduce the peaking factor effect created by the rib. Hodges (34) suggested that the heat split could be estimated based using Equation 3. This rib side heat flux perturbation (RSHFP) factor is the ratio of heat generated under the rib which is transfer:ed to the ribbed channel when compared with the heat which would have be convected to the ribbed channel if the rib were not present.

$$
\text { RSHFP }=12.53 y^{0.56}, \quad y \leq 0.0109 f t
$$

Heat flux peaking factor and similar factors can be generated analytically using a variety of methods. These analytic solutions do not provide information on if the heat flux peaking in the presence of a rib results in premature OSV or Ledinegg instability.

\section{Summary of SRS OFI Program}

The SRS conducted a five year research effort to investigate Ledinegg flow instability in reactor assemblies. This effort included contributions from the Savannah River Technology Center (SRTC), Columbia University, Creare Inc., Babcock and Wilcox, Stern Laboratories, Villanova University, and Northwestern University (27). The goal of the SRS OFI program was to develop a database that consisted of steady-state and transient flow instability behavior that could be used to benchmark the SRS OSV design correlation. This effort required the construction of six different test loops, and multiple test channels. 


\section{Preliminary Data -- 9 September 1993}

Steady-state demand curves were produced for annular flow channels, annular flow channels with spacer ribs, and six different tube diameters. Transient flow and heat flux data were produced for a single annulus and for a Mark-22 fuel assembly geometry.

The tube tests were conducted at Columbia University $(14,15,16)$ to allow separate evaluation of the parameters listed in Table 1. The single annulus and single annulus with spacer ribs also were also separate effects tests which allowed evaluation of the parameters listed in Table 1. They were conducted by both Columbia University $(17,19)$ and Creare, Inc $(9)$. The Babcock and Wilcox test rig evaluated the behavior of a multi-annular assembly (61). This test produced integrated effects data which allowed benchmarking of the FLOWTRAN computer code (21) for a complicated geometry but provided little parameter effects knowledge.

Table 1.--SRS OFI program test mat:iix

\begin{tabular}{|c|c|c|c|c|c|c|}
\hline & \multicolumn{3}{|c|}{ Columbia University } & \multicolumn{2}{|c|}{ Creare Inc. } & \multirow{2}{*}{$\begin{array}{c}\text { Babcock } \\
\text { \& Wilcox } \\
\text { Multi- } \\
\text { annulus }\end{array}$} \\
\hline & tube & annulus & $\begin{array}{l}\text { ribbed } \\
\text { annulus }\end{array}$ & annulus & $\begin{array}{l}\text { ribbed } \\
\text { annulus } \\
\end{array}$ & \\
\hline Pressure control & & & & & & \\
\hline vs. flow control & $\sqrt{ }$ & $\sqrt{ }$ & ... & $\cdots$ & $\cdots$ & ‥ \\
\hline Transient flow & $\cdots$ & $\sqrt{ }$ & ... & $\cdots$ & $\cdots$ & $\sqrt{ }$ \\
\hline $\begin{array}{l}\text { High heat flux } \\
\text { Axial heat flux }\end{array}$ & $\sqrt{ }$ & $\sqrt{ }$ & $\sqrt{ }$ & $\cdots$ & $\cdots$ & $v$ \\
\hline $\begin{array}{c}\text { profile } \\
\text { Azimuthal heat flux }\end{array}$ & ... & $\cdots$ & $\cdots$ & ... & ... & $\sqrt{ }$ \\
\hline $\begin{array}{l}\text { profile (power } \\
\text { tilt) }\end{array}$ & ... & $\cdots$ & ... & $\sqrt{ }$ & $\sqrt{ }$ & $\cdots$ \\
\hline Dissolved helium & ... & $\cdots$ & ... & $\sqrt{ }$ & $\sqrt{ }$ & $\cdots$ \\
\hline transfer surface & $\ldots$ & $\ldots$ & $\ldots$ & $\sqrt{ }$ & $\sqrt{ }$ & $\cdots$ \\
\hline
\end{tabular}




\section{Preliminary Data -- 9 September 1993}

The ribbed annulus tests did demonstrate that OFI occurred in ribbed annuli at less severe conditions than for similar non-ribbed annuli. It is not clear however if this is the result of a rib effect or non-symmetry between the subchannels. Since the subchannels were not fully isolated, rib flow between the channels precluded exact determination of the subchannel flow rate. This required the assumption that the flow rate was equally distributed to each flow channel. In addition the local heat flux, saturation temperature, and bulk fluid temperature were not well known. With four subchannels it is also possible for one subchannel to go into instability resulting in flow diverting to the other three.

The test channel designs did not facilitate operation of any annulus both with and without a rib. This introduced an additional unknown: channelto-channel similarity. Analysis of the Columbia University ribbed and open annular data indicate wetted surface temperatures in excess of that expected for nucleate boiling conditions (27). Since the "open" annulus included spacers to maintain concentricity both types of channels had flow obstructions. This DNB at obstructions has not been previously noted in the literature and warranted further evaluation. Principle unknowns which remain after the completion of the SRS OFI program are:

- What is the effect of spacer ribs on Ledinegg instability?

- Does DNB occur in the presence of flow obstructions?

- What is the effect of flow transients on Ledinegg instability?

The test facility described in Chapter 3 was constructed to investigate these three questions. The study presented in this report is directed at the investigation of the first two open issues. 


\title{
CHAPTER 2
}

\begin{abstract}
ANALYSIS
The evaluation of the effect on flow channel obstructions on Ledinegg instability requires consideration of alternate flow instabilities phenomena and heat transfer behavior in addition to hydrodynamic considerations. Each of these subjects is developed separately in the following pages. Their effect on a diabatic flow channel is then presented in the last section of this chapter.
\end{abstract}

\section{Demand Curves}

The pressure gradient in a heated channel may be separated into three individual components: elevation, acceleration, and friction.

$$
\left(\frac{\Delta p}{\Delta L}\right)_{t}=\left(\frac{\Delta p}{\Delta L}\right)_{g}+\left(\frac{\Delta p}{\Delta L}\right)_{a}+\left(\frac{\Delta p}{\Delta L}\right)_{f}
$$

For downflow in a vertical channel the gravitational term represents a pressure recovery. Klausner, et al. (46) defined a mixture density term, $\rho_{m}=\alpha \rho_{v}+(1-\alpha) \rho_{1}$. The recovery is:

$$
\left(\frac{\Delta p}{\Delta L}\right)_{g}=+\overline{\rho_{m}} g
$$

Acceleration is primarily the result of density changes as the fluid temperature increases as the channel exit is approached. It is not until voiding occurs that the acceleration becomes significant. The frictional pressure gradient term that 


\section{Prellminary Data _. 9 September 1993}

represents the nonrecoverable pressure losses can be further separated into three terms: inlet (contraction) losses, friction losses, and exit (expansion) losses.

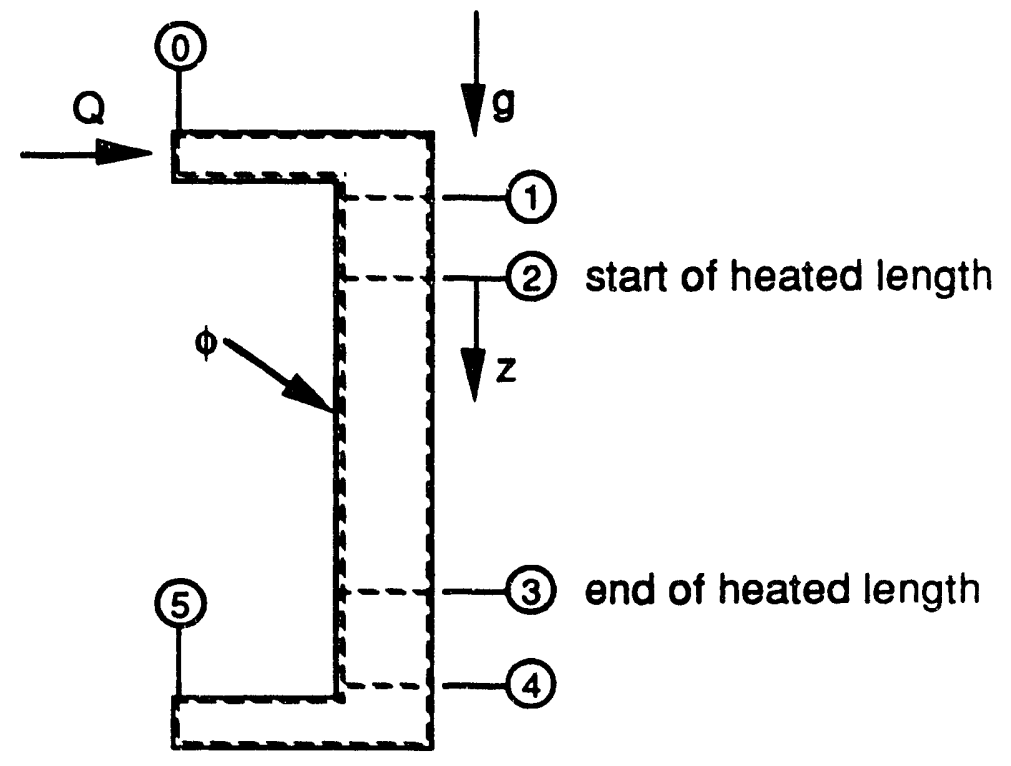

Figure 5, Heated channel nomenclature

Demand curves such as shown in Figure 1 are normally generated by incrementally reducing the flow and measuring the steady state pressure at each flow. This type of test may be conducted for both isothermal and diabatic flows. Demand curves generated for diabatic flows where the heat flux is held constant will normally take the form presented in Figure 6 . The pressure gradient relation for this behavior, Equation 5, may be derived from Euler's equation of motion along a streamline (64). The solution is initially developed assuming no frictional losses.

$$
\frac{d p}{p}+g d z+u d u=0
$$




\section{Proliminary Data -- 9 September 1993}

Multiplying through by the density term, replacing the velocity term, $u$, with $G / \rho$ and integrating:

$$
\int_{1}^{2} d p+\int_{1}^{2} g \rho d z+\int_{1}^{2}-\left(\frac{G}{\rho}\right)^{2} d \rho=0
$$

Completing the integration assuming a constant flow area, and using the definition for the length averaged density.

$$
\frac{p_{2}-P_{1}}{\Delta L}-g \bar{\rho}+\frac{G^{2}}{\Delta L}\left(\frac{1}{\rho_{2}}-\frac{1}{\rho_{1}}\right)=0
$$

Introducing a loss term and rearranging:

$$
\frac{\Delta p}{\Delta L}=g \bar{\rho}-\frac{G^{2}}{\Delta L}\left(\frac{1}{\rho_{2}}-\frac{1}{\rho_{1}}\right)-\text { losses }
$$

$$
\text { Isothermal Behavior }
$$

In isothermal flow the density is constant so the length average density is constant for any geometry and the acceleration term is zero. The demand curve would be as shown in Figure 6. The flow for a closed system can be predicted by the intersection of the demand and supply curves. 


\section{Preliminary Data -- 9 September 1993}

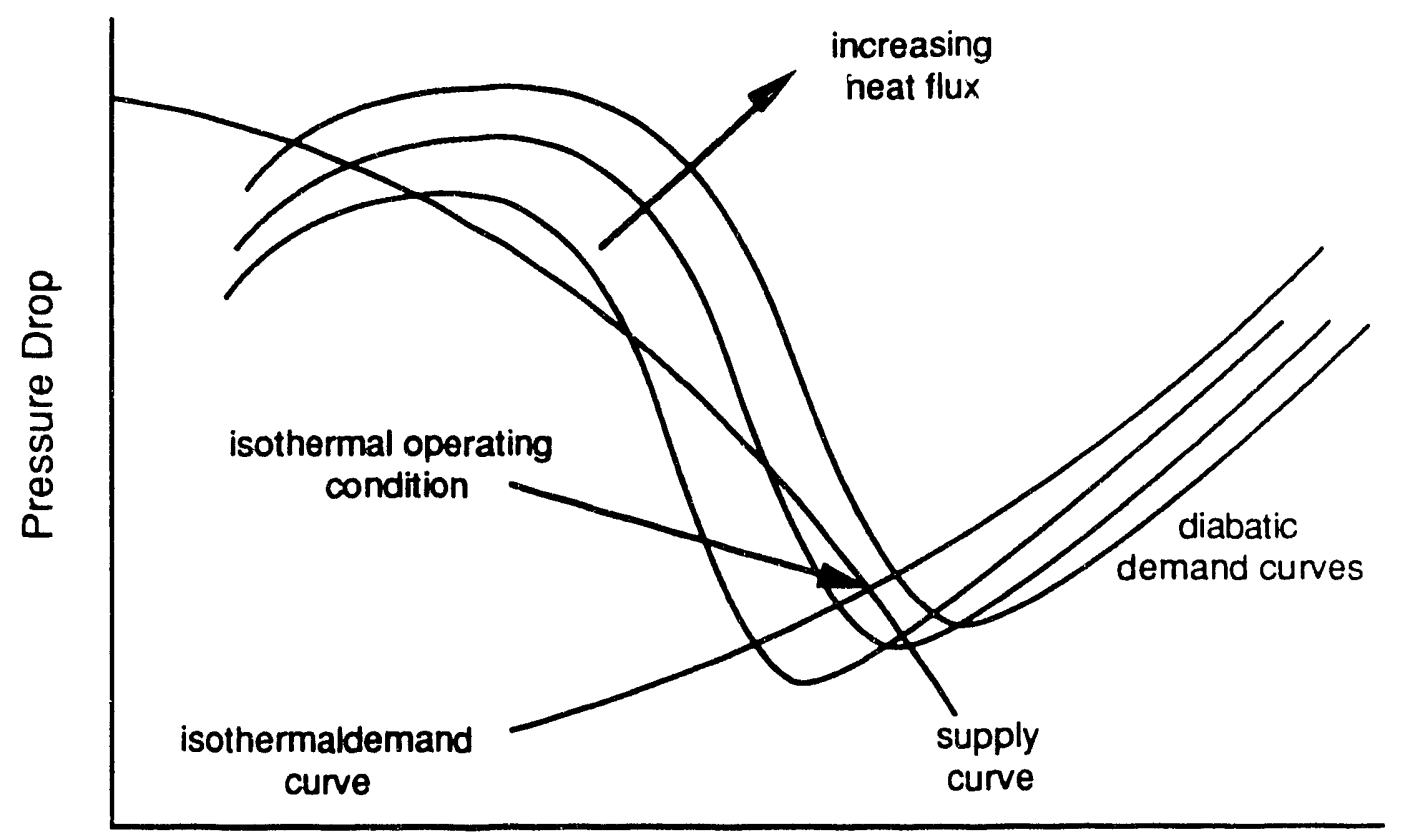

Mass Flux

Figure 6, Demand curve prediction of operating conditions

\section{Inlet losses}

Maulbetsch and Griffith (52) had good success in predicting the inlet losses using the common expression presented by Rohsenow and Choi (60) where $K_{C}$ was assumed as 0.5 .

$$
\begin{gathered}
\Delta p_{0-1}=\frac{\rho u_{i n}^{2}}{2}\left(1+K_{c}\right) \\
\frac{p_{0}-p_{1}}{\rho_{01}}+\frac{u_{0}^{2}-u_{1}^{2}}{2}=K_{c} \frac{u_{1}^{2}}{2}
\end{gathered}
$$

where:

$$
K_{c}=\frac{1-\frac{C_{c}^{2}}{\beta_{0}}\left(\frac{A_{1}}{A_{0}}\right)^{2}-2 C_{c}+2\left(\frac{C_{c}^{2}}{\beta_{1}}\right)^{2}}{C_{c}{ }^{2}}-1+\left(\frac{A_{1}}{A_{0}}\right)^{2}
$$




\section{Preliminary Data -- 9 September 1993}

$$
\frac{1}{\beta}=\frac{1}{A} \int_{A}\left(\frac{U}{U}\right)^{3} d A
$$

For highly turtulent flow $\beta=1$ and for parabolic flow in a circular pipe $\beta=0.5$.

\section{Exit Losses}

For the conditions studied by Maulbetsch and Griffith the pressure recovery was stated to be small (less than 1 psi). The expansion relation presented by Rohsenow and Choi (60) is:

$$
\frac{p_{2}-p_{3}}{\rho_{23}}+\frac{u_{2}{ }^{2}-u_{3}{ }^{2}}{2}=K_{\theta} \frac{u_{2}{ }^{2}}{2}
$$

where:

$$
\begin{gathered}
K_{\theta}=1-\frac{2}{\alpha_{2}} \frac{A_{2}}{A_{3}}+\left(\frac{A_{2}}{A_{3}}\right)^{2}\left(\frac{2}{\alpha_{3}}-1\right) \\
\frac{1}{\alpha}=\frac{1}{A} \int_{A}\left(\frac{u}{U}\right)^{2} d A
\end{gathered}
$$

For highly turbulent flow $\alpha=1$ and for parabolic flow in a circular pipe $\alpha=0.75$.

\section{Frictional Losses}

The frictional pressure losses may be estimated using the friction factor relationship.

$$
f \equiv \frac{\Delta p}{(L D)\left(\rho V^{2} / 2\right)}
$$

For laminar flow the friction factor is independent of the relative roughness $(8 ;$;

$$
f=64 / \operatorname{Re}
$$




\section{Preliminary Data -- 9 September 1993}

Zigrang and Sylvester (68) have developed an explicit solution for the friction factor that was found useful for two-phase diabatic modeling by Block, et al. (9):

$$
\begin{gathered}
f=\left[-2.0 \log \left\{\frac{\varepsilon / D_{e}}{3.7}-\left[\frac{5.02}{R e}\right] \log \left[\frac{\varepsilon / D_{\theta}}{3.7}+\frac{13}{R e}\right]\right]\right]^{-2} \\
\pm 1.9 \%(95 \% \text { coverage })
\end{gathered}
$$

A more accurate version also suggested by Zigrang and Sylvester (68) is:

$$
\begin{gathered}
f=\left[-2.0 \log \left\{\frac{\varepsilon / D_{e}}{3.7}-\left[\frac{5.02}{R e}\right] \log \left[\frac{\varepsilon / D_{e}}{3.7}-\log \left(\frac{\varepsilon / D_{\theta}}{3.7}+\frac{13}{R e}\right)\right]\right\}\right]^{-2} \\
\pm 0.22 \%(95 \% \text { coverage })
\end{gathered}
$$

For smooth pipes in turbulent flow the friction factor can be approximated as $(60)$ :

$$
\begin{array}{ll}
f=\frac{0.316}{R e^{0.25}} & 3 \times 10^{3}<R e<2 \times 10^{4} \\
f=\frac{0.184}{R e^{0.20}} & 2 \times 10^{4}<R e<5 \times 10^{5}
\end{array}
$$

The flow relationships discussed above were developed for circular flow channels. When the flow cross section is not circular then an equivalent hydraulic diameter, D, must be estimated. For turbulent flow:

$$
D=\frac{4 A_{f}}{P}=\frac{4 \text { (flow area) }}{\text { wetted perimeter }}
$$

Blevins (8) suggests that errors have been demonstrated using this approach and that more accurate results may be obtained using an equivalent diameter, $D_{e}$, defined by: 


\section{Prellminary Data - 9 September 1993}

$$
D_{\theta}=\frac{64}{k} D
$$

where the value $\mathrm{k}$ is the friction coefficient for laminar flow (i.e., $\mathrm{k}=f \mathrm{Re}$ ). For a rectangular cross-section (where $b \leq a$ ) the friction coefficient is $(8)$ :

$$
k=\frac{64}{\frac{2}{3}+\frac{11}{24} \frac{b}{a}\left(2-\frac{b}{a}\right)}
$$

\section{Combined Flow Losses}

The overall channel frictional loss may then be estimated as:

$$
\begin{gathered}
\left(\frac{\Delta P}{\Delta L}\right)_{f}=\left[\frac{\rho_{01} u_{1}^{2}}{2}\left(K_{c}+1\right)-\frac{\rho_{01} u_{0}^{2}}{2}\right]+\left[\frac{2 f G^{2}}{D_{\theta} \rho}\right]+\left[\frac{\rho_{23} U_{2}^{2}}{2}\left(K_{e}-1\right)+\frac{\rho_{23} U_{3}^{2}}{2}\right] \\
\text { or } \\
\left(\frac{\Delta P}{\Delta L}\right)_{f}=\frac{K_{c} G^{2}}{2 \rho_{01}}+\frac{2 f G^{2}}{D_{\theta} \rho}+\frac{K_{\theta} G^{2}}{2 \rho_{23}}
\end{gathered}
$$

\section{Diabatic Behavior}

When heat is added to a flowing channel the demand curve may pass through a minimum and maximum as shown in Figure 6 . This behavior is common in low pressure water systems; for high system pressures the minimum will not occur (48). The demand curve for any geometry shifts to the right and upward for an increase in heat flux. Increasing the exit pressure has a similar effect.

The flow can be predicted using the intersection of the demand and supply curves as was discussed for the isothermal case. For a flow controlled test the supply curve is vertical as shown in Figure 7, supply curve number 1. 


\section{Preliminary Data _.. 9 September 1993}

The operating condition is at point a. As the flow is decreased it is possible to follow the entire demand curve. For a pressure controlled test the supply curve is horizontal, supply curve number 2 . For parallel channel flow with a large number of flow paths the supply curve will approach that of a pressure controlled system. The initial operating condition is at point $b$, the right intercept between the supply and demand curve since the flow was established prior to the heat. When the pressure is decreased to point $c$ a small decrease in pressure will no longer be possible with a corresponding small change in flow rate. If a pressure decrease is attempted the system will jump to point $d$. The design limit of most previous test apparatuses has been such that the operation of the heated channels at this condition has not been possible. If interlocks were not in place rig failure (channel burnout) occurred.

A typical supply curve is presented by supply curve number 3 in Figure 7. The initial operating point will be at location e. When the demand curve slope is steeper than the supply curve slope it is no longer possible to operate on the negative sloped region of the demand curve.

$$
\frac{\partial\left(\Delta p_{\text {suppy }}\right)}{\partial Q}-\frac{\partial\left[\Delta p_{0-1}+\Delta p_{1-2}+\Delta p_{2-3}\right]}{\partial Q} \geq 0
$$

When this criterion is exceeded an excursive flow insatiability will occur.

Maulbetsch and Griffith (52) considered the channel pressure drop to occur over only the heated section; entrance and exit losses were accounted for as part of the external system.

\section{Inlet and Exit Losses}

The inlet and exit loss relationships for subcooled flow with no void present will be the same as for isothermal subcooled flow which was discussed 


\section{Preliminary Data -- 9 September 1993}

earlier. When voids are present at the exit the isothermal relation will no longer hold. Maulbetsch and Griffith (52) estimated the exit loss using a relation by Romie:

$$
\Delta p_{2-3}=\frac{-V_{\text {exit }}^{2}}{2}\left(\frac{A_{F}}{A_{P L}}\right)^{2}\left(\frac{2}{1-\alpha}\right)
$$

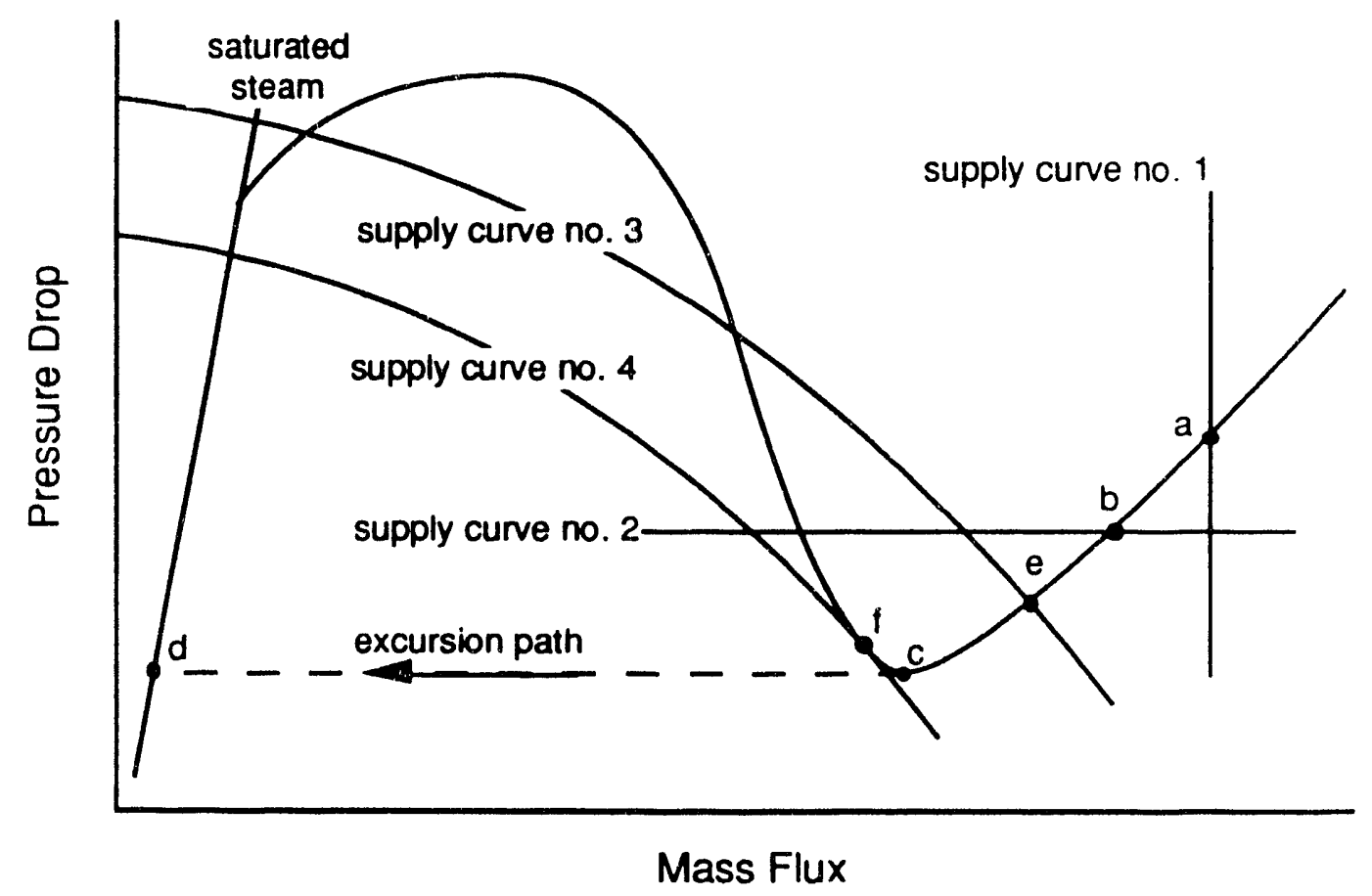

Figure 7, Diabatic demand curve characteristics

\section{Heated Wall Effect}

The viscosity of most liquids decreases with increasing temperature. This effect leads to a distortion of the velocity profile (60) for non-isothermal flow. For laminar liquid flow the parabolic profile will flatten as shown in Figure 8. The opposite effect occurs for gases. The result of this profile distortion is that the pressure drop for subcooled diabatic non-boiling flows will be lower 


\section{Preliminary Data _- 9 September 1993}

than for adiabatic flows at the same inlet conditions. While other factors contribute to this effect the primary variable is viscosity (52).

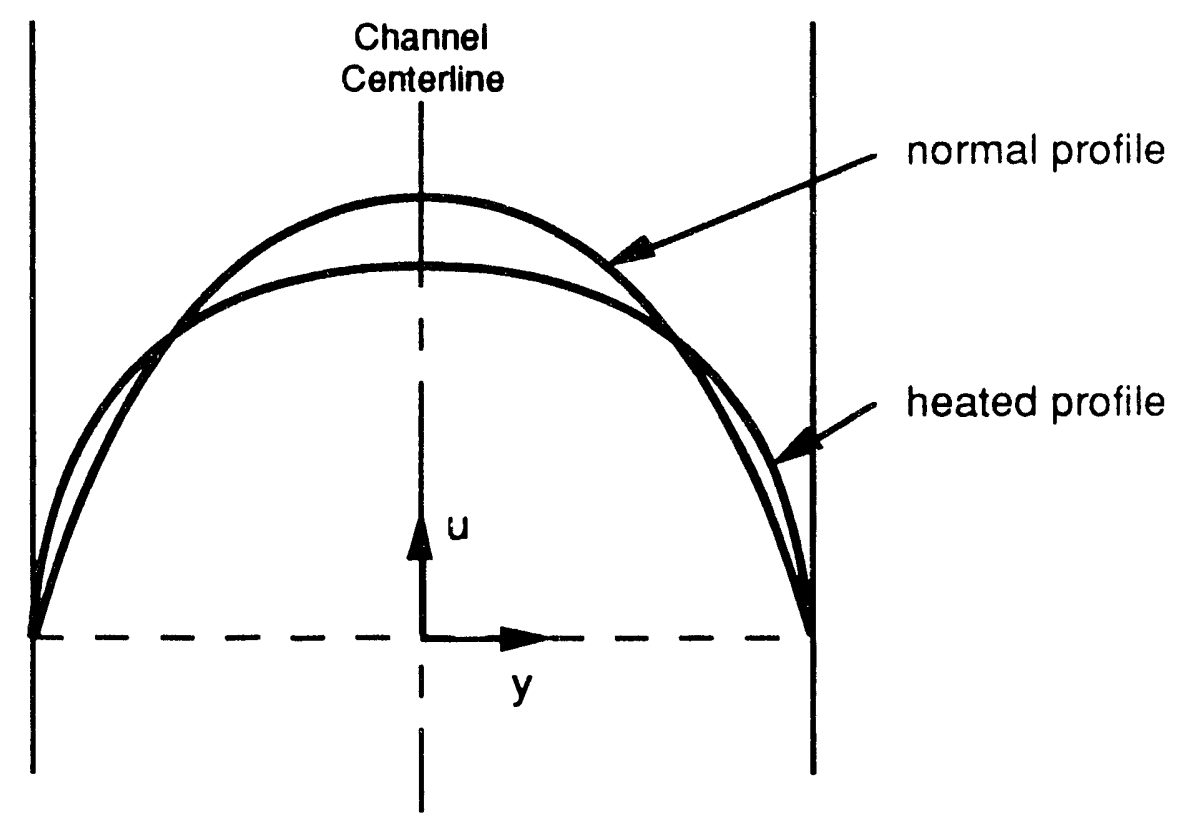

Figure 8 , isothermal and diabatic velocity profiles

Bergles and Dormer (7) present a correlation to predict pressure drop in diabatic non-boiling systems by substituting the adiabatic friction factor with:

$$
f=0.107 R e^{-0.28}\left(\frac{\mu_{w}}{\mu}\right)^{0.35}
$$

In an earlier report (28) the authors state an alternate of this relation that was successfully used by Maulbetsch and Griffith.

$$
\frac{f}{f_{\text {iso }}}=\left(\frac{\mu_{w}}{\mu_{b}}\right)^{0.35}
$$




\section{Preliminary Data -. 9 September 1993}

\section{Friction Multipliers}

The friction pressure drop in two-phase flow has commonly been evaluated using a friction multiplier to predict the two-phase frictional pressure gradient using the frictional pressure gradient for flow based on the total mass flux and liquid, hase properties (24).

$$
\phi L O^{2}=\frac{\left(\frac{d p}{d z}\right)_{z d}}{\left(\frac{d p}{d z}\right)_{L O}}
$$

Isothermal Friction Multipliers

Collier (24) lists eleven two-phase pressure drop models and correlations. Some are considered acceptable if the standard deviation is in the range of 25 to $50 \%$. Hewitt (32) identifies at least 5 different alternative approaches to estimating pressure drop. Hewitt (32) suggests that most twophase pressure drop correlations are not very accurate and credits Whalley with the recommended selection process:

"1. For $\mu_{L} / \mu_{G}<1000$, the Friedel (1979) correlation should be used.

"2. For $\mu_{L} / \mu_{G}>1000$, and $G>100\left(\mathrm{~kg} / \mathrm{s} \cdot \mathrm{m}^{2}\right)$, the Chesholm (1973) correlation should be used.

"3. For $\mu_{\mathrm{L}} / \mu_{\mathrm{G}}>1000$, and $\mathrm{G}<100\left(\mathrm{~kg} / \mathrm{s} \cdot \mathrm{m}^{2}\right)$, the Martinelli correlation (Lockhart \& Martinelli 1949; Martinelli \& Nelson 1948) should be used."

Each of thie above methods uses a form of Equation 33 in the estimation of twophașa pressure drop. 


\section{Preliminary Data - 9 September 1993}

Heated Frictional Multiplier

For diabatic two-phase flows the vapor void fraction will not be constant. For moderate and high flow rates vapor bubbles will be swept along in the direction of flow so the void fraction will increase along the heated length. For low flow rate in downflow the bubble rise velocity may be greater than the net channel velocity so vapor may collect at the top of the heated section.

Collier (24) states that the frictional pressure gradient will increase over that of an unheated tube for lower quality flow. He attributes to Tarasova a relationship for steam-water systems:

$$
\left[\phi_{\text {to }}\right]_{\text {heated tube }}^{2}=\left[\phi_{\text {io }}\right]_{\text {unheated tube }}^{2}\left[1+4.4 \times 10^{-3}\left(\frac{\phi}{\mathrm{G}}\right)^{0.7}\right]
$$

where $\phi$ is in watts $/ \mathrm{m}^{2}$ and $\mathrm{G}$ is in $\mathrm{kg} / \mathrm{m}^{2} \cdot \mathrm{s}$.

Dormer and Bergles (28) developed a correlation that relates the ratio of the pressure drop in subcooled boiling and the pressure drop in unheated flow $\left(\Delta \mathrm{p}_{S C B} / \Delta \mathrm{P}_{A D B}\right)$, with the ratio of the actual heat flux and the heat flux to produce saturated water at the exit $\left(\phi / \phi_{\text {sat }}\right)$. This relationship was later used in the Columbia University OFI test program $(14,15,16,17,18,19)$. The relationship is dependent on the channel geometry and :c, shown in Figure 9. The effect of $L / D$ is most significant with a lesser effect of channel diameter. The effect of $L D$ decreases as the $L D$ increases. The range of $L / D$ evaluated was 25 to 2 ก. 


\section{Preliminary Data .. 9 September 1993}

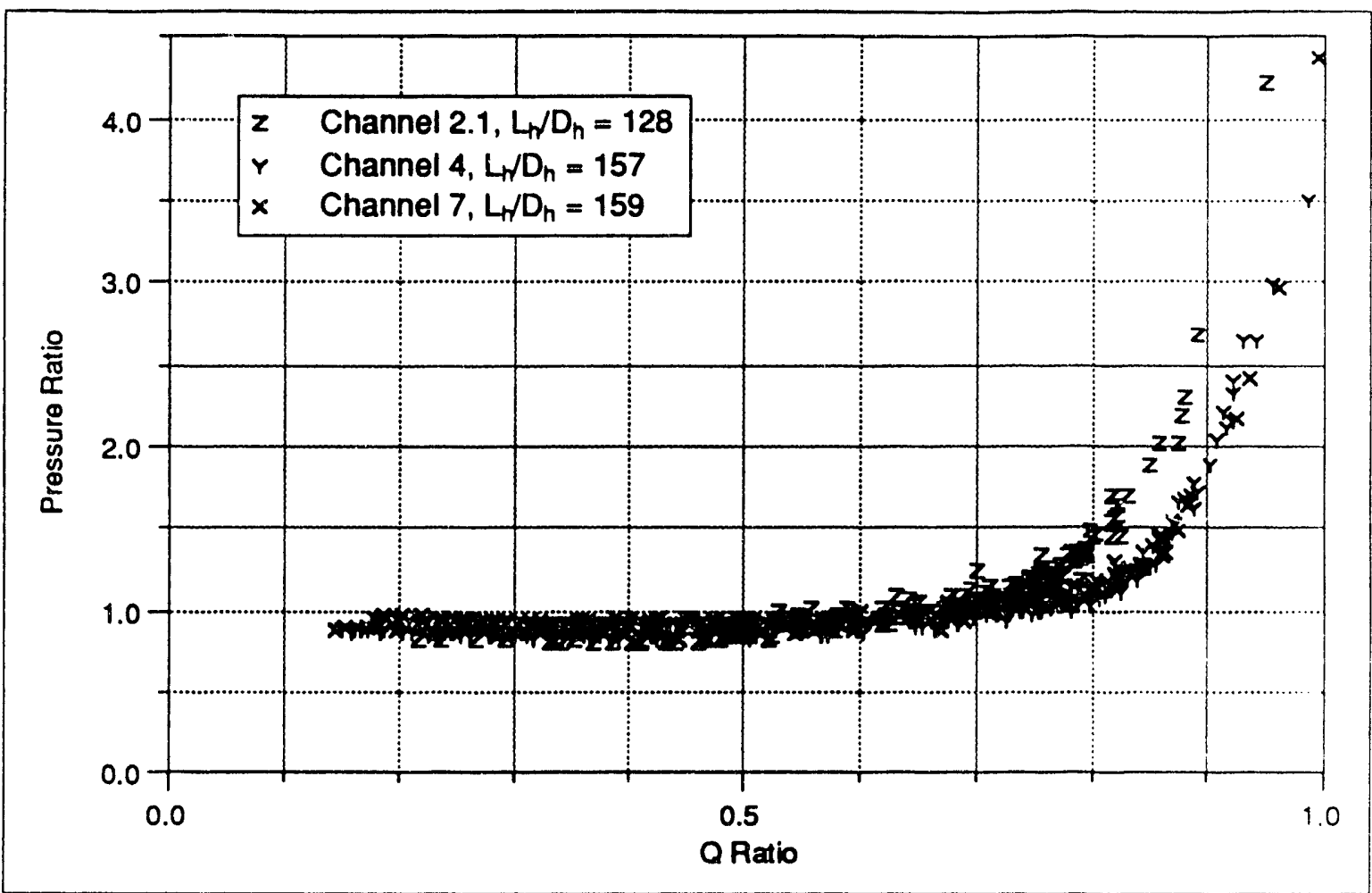

Figure 9, Subcooled boiling curves from Columbia University single tube uniformly heated tests, test sections $2.1,4$ and 7

Bergles and Dormer (7) presented an alternate form of this work which piotied the ratio of the pressure drop over the boiling length, and the pressure drop over the boiling length at saturated conditions $\left(\Delta \mathrm{p}_{\mathrm{b}} / \Delta \mathrm{p}_{\mathrm{b}, \mathrm{s}}\right)$; as a function of the ratio of the boiling length, and the length required to bring the fluid to saturated conditions at the end of the test section $\left(L_{b} / L_{b, s}\right)$. For short boiling lengths the pressure ratio approaches zero. The plots presented in this fashion again all tend to vary based on the hydraulic diameter and the $L / D$ ratio where the later is the more significant effect.

The non-boiling length for tubes was estimated using a heat balance and an empirical heat transfer correlation: 


\section{Preliminary Data _- 9 September 1993}

$$
\begin{gathered}
L_{n b}=\left[T_{w, b}-T_{i}-\frac{q^{n}}{h}\right]\left(\frac{w c}{q^{n} \pi D}\right) \\
\frac{N U}{P r^{0.4}}=0.0157 \operatorname{Re}^{0.85}
\end{gathered}
$$

Much of the data appears to be for systems where all of the tube length is in boiling. (i.e., The incipient boiling conditions were met at the tube entrance.) There is a slight variation in the pressure drop ratios for tubes which are in partial boiling when compared to a tube with the same $L_{b} / L_{b, s}$ in total boiling. This variation was attributed to the adiabatic reference; a tube in partial boiling will have a higher bulk fluid temperature.

Researchers at Columbia University (15) defined the ratio of the heat flux to the heat flux required to attain saturated conditions at the channel exit as the $Q_{\text {ratio. }}$ The ratio of the heated section pressure drop to the heated section pressure drop at zero heat flux evaluated using inlet condition properties was defined as the pressure ratio.

\section{Demand Curve Milestones}

Bankoff, Lee and Knaani (1991) identified four ONB models, and eleven OSV models. Most of this work was published in the 1960's and early 1970's. These works are listed in Table 2. All of the works are based on steady-state forced-convection, subcooled nucleate boiling. The most successful are discussed below. 


\section{Preliminary Data -9 September 1993}

Table 2.--Subcooled demand curve milestone correlations and models identified by Bankoff, Lee, and Knaani (4)

\begin{tabular}{|c|c|c|}
\hline Researcher(s) & Date & Comment \\
\hline \multicolumn{3}{|c|}{ ONB Models } \\
\hline 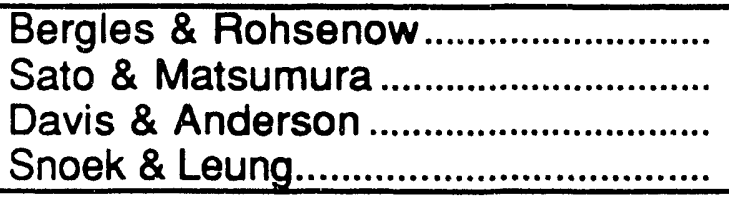 & $\begin{array}{l}1964 \\
1964 \\
1966 \\
1968 \\
\end{array}$ & $\begin{array}{l}\text { Theoretical } \\
\text { Theoretical } \\
\text { Theoretical } \\
\text { Empirical }\end{array}$ \\
\hline \multicolumn{3}{|c|}{ OSV Models } \\
\hline 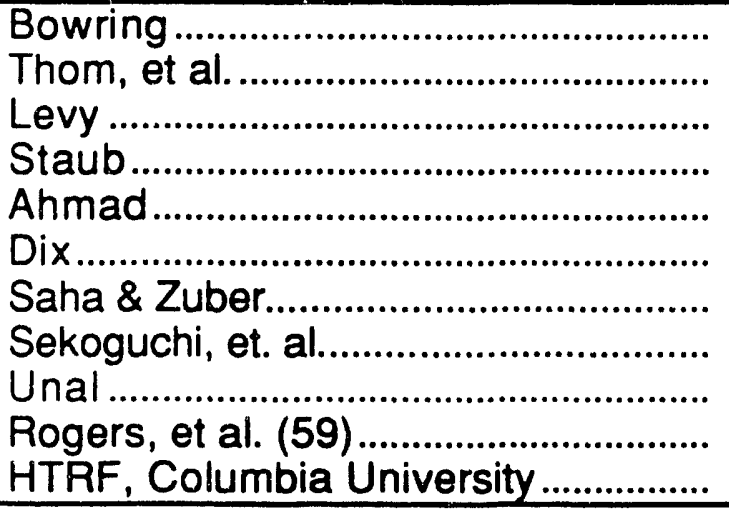 & $\begin{array}{l}1962 \\
1965 \\
1967 \\
1968 \\
1970 \\
1971 \\
1974 \\
1974 \\
1975 \\
1987 \\
1990 \\
\end{array}$ & $\begin{array}{l}\text { Empirical } \\
\text { Empirical } \\
\text { Theoretical } \\
\text { Theoretical } \\
\text { Empirical } \\
\text { Empirical } \\
\text { Empirical } \\
\text { Empirical } \\
\text { Empirical } \\
\text { Theoretical } \\
\text { Empirical }\end{array}$ \\
\hline
\end{tabular}

\section{Onset of Nucleate Boilling}

The condition when vapor first forms on the heated surface is referred to as the onset of nucleate boiling (4). These bubbles tend to be stable, neither moving or growing in size. Care must be taken in the application of this definition to experimental work since dissolved gases in the subcooled fluid may result in the evolution of bubbles that are not the vapor phase of the working fluid. Many researchers have successfully predicted the wall temperature at incipient boiling using Bergles and Rohsenow ONB correlation (24):

$$
q^{n}{ }_{i b}=15.60 p^{1.156}\left(T_{w}-T_{s}\right)^{2.30 p^{0.0234}}
$$




\section{Preliminary Data _- 9 September 1993}

The units for this equation are: psia, ${ }^{\circ} \mathrm{F}$, and Btu/hr.ft². Collier (24) presents an alternate form in SI units:

$$
\left(\Delta \mathrm{T}_{\text {SAT }}\right)_{\text {ONB }}=0.556\left(\frac{\phi_{\text {ONB }}}{1082\left(\mathrm{p} / 10^{5}\right)^{1.156}}\right)^{0.0463\left(\mathrm{p} / 10^{5}\right)^{0.023}}
$$

Researchers at the Columbia University HTRF observed a depression in the axial surface temperature gradient during tube tests (16); this depression occurred near the conditions predicted for ONB by Equation 37. Equation 37 also compared well with the visually observed ONB in test conducted by Johnston (44).

During the OFI testing in annuli by Creare (1990), it was observed that the pressure gradient in a subcooled heated channel will increase after the wall temperature reaches the fluid saturation temperature. The gradient will be linear prior to and after this change. It was suggested that this change in gradient was an effect of ONB and the resulting eifective increase in wall roughness because of the presence of vapor bubbles. These tests were conducted in annuli.

\section{Onset of Significant Volding}

Small amounts of vapor will depart a heated surface prior to the demand curve minimum. This vapor may slide along the surface or enter the liquid core and condense. When a threshold is reached significant vapor generation and mixing of the vapor bubbles in the liquid core will occur (4) defined OSV as "significant vapor generation and mixing of bubbles with the core liquid." 


\section{Preliminary Data _- 9 September 1993}

Bowring (11) suggested that the conditions for bubble detachment could be predicted using a bubble detachment parameter, $\eta$. The correlation was prepared using test data from rectangular channels with gaps of 2.2, 2.5, $2.6,6.4$, and $12.7 \mathrm{~mm}$. The data covered a wide range of operating pressures, from 1.1 to $13.8 \mathrm{MPa}$. The operating pressures for the smallest channels (2.2 to $2.6 \mathrm{~mm}$ ) did not overlap with the operating pressures for the 6.4 and $12.7 \mathrm{~mm}$ channels. Data for the smallest channel size only included data above $8.3 \mathrm{MPa}$ while the data for the other two sizes were for operating pressures below 4.3 $\mathrm{MPa}$. The correlation suggested by Bowring to estimate the bubble detachment parameter was:

$$
\eta=\frac{u \Delta T_{\lambda}}{\phi}=14+0.1 p
$$

where the units are $\mathrm{cm} / \mathrm{s}, \mathrm{C}, W / \mathrm{cm}^{2}$, and atmospheres.

The uncertainty bands for the low pressure data do not overlap. While Equation 39 does lie within the uncertainty bands for the $12.7 \mathrm{~mm}$ channel the calculated bubble detachment parameters for the $6.4 \mathrm{~mm}$ channel data is all higher than Equation 39. The calculated bubble detachment parameters for a $6.4 \mathrm{~mm}$ channel ranged from 15.52 to 30.55 at a pressure of $1.1 \mathrm{MPa}$.

Saha and Zuber developed a correlation to predict the average vapor void fraction in subcooled boiling systems. The relation is based on establishing the local equilibrium quality at the point of Net Vapor Generation (NVG). Figure 10 shows how the average vapor void fraction varies with axial position. Region I is characterized by a wall temperature in excess of $T_{\text {sat }}$ and a subcooled bulk temperature; bubbles will nucleate along the wall but the bubble layer will remain small. 


\section{Preliminary Data -- 9 September 1993}

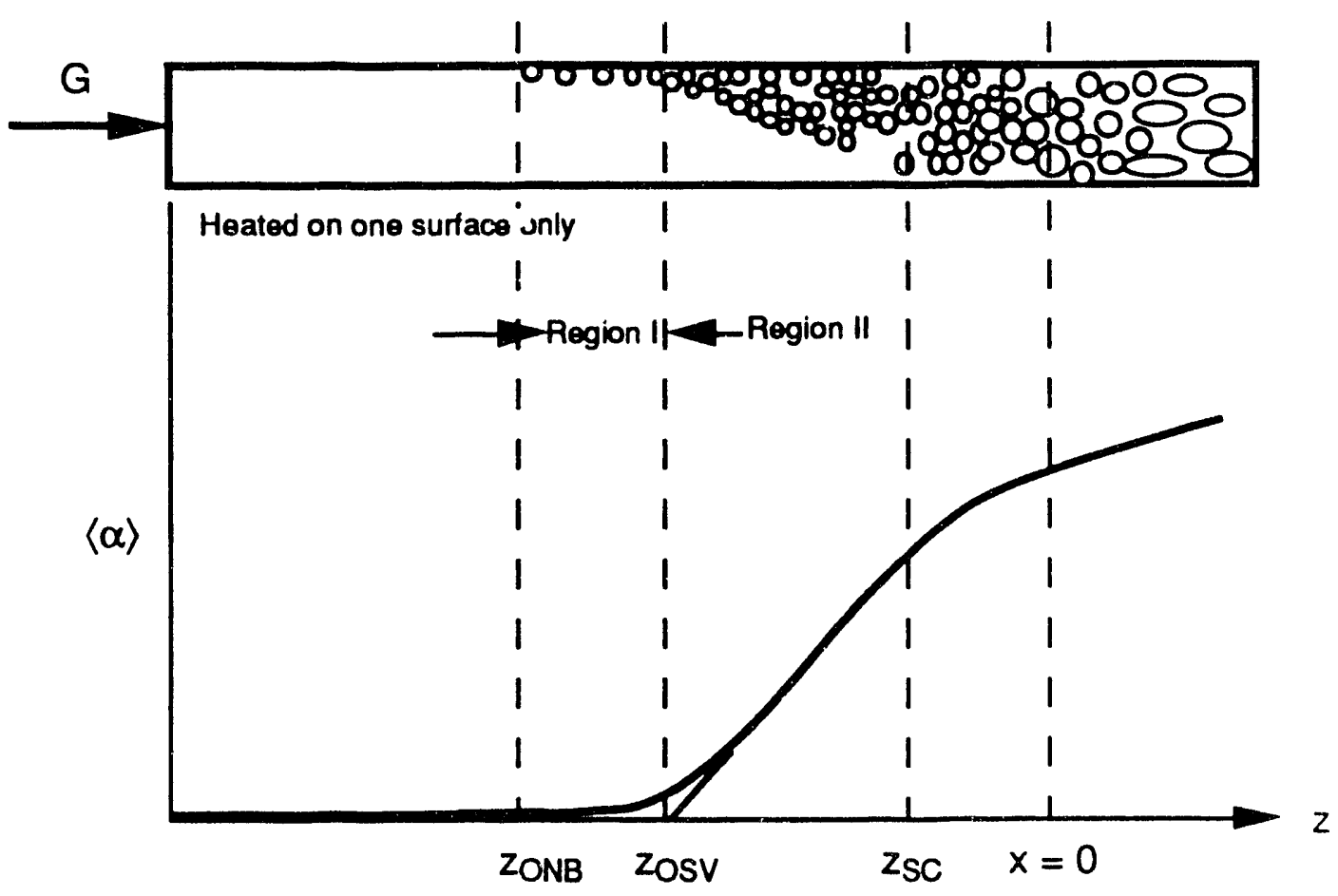

Figure 10, Heated channel bubble formation milestones

It was suggested that the point of NVG does not vary for high and moderate inlet subcoolings. At the point of NVG two criteria must be met:

The bubbles must detach from the wall, and (2) The evaporation rate must be greater than the condensation rate as bubbles enter the liquid core. Under different flow conditions one of these two criteria will be controlling. The point of NVG can be predicted using local fluid conditions from:

$$
\begin{gathered}
\mathrm{Nu}=\frac{\phi D_{e}}{k_{f} \Delta T_{\lambda}}=455 \text { if } \mathrm{Pe} \leq 70,000 \\
\mathrm{St}=\frac{\phi}{G c_{p t} \Delta T_{\lambda}}=0.0065 \text { if } \mathrm{Pe}>70,000
\end{gathered}
$$




\section{Preliminary Data _- 9 September 1993}

where:

$$
P e=\frac{N u}{S t}=\frac{G D_{\theta} C_{p t}}{k_{f}}
$$

The Nusselt number represents the relationship between the evaporation and condensation rates and the Stanton number represents the bubble detachment phenomena criteria. When the mass flow is low (local Peclet number $<70,000$ ) the condensation is governed by a diffusion process and the evaporation and condensation rates will be controlling. This is referred to as the thermally controlled region. The Stanton number criteria will be met before the Nusselt number criteria is met. When the local subcooling is large, vapor bubbles that depart from the wall will condense in the liquid core. Vapor bubbles will only travel in a narrow band close to the heated wall since they condense in the liquid core. The local subcooling will decrease along the flow path. When the local Nusselt number along the flow path reaches 455 the condensation rate of vapor entering the liquid core no longer exceeds the evaporation rate and a significant increase in the void fraction will occur.

When the mass flow is high (local Peclet number $>70,000$ ) the local Nusselt number is already higher than 455 and as soon as the local Stanton number exceeds 0.0065 vapor bubbles will readily enter the liquid core and not condense. This is referred to as the hydrodynamicly controlled region. It was reported that the characteristic value of roughness parameter when bubble detachment occurs is about 0.02 . This equates to a Stanton number of 0.0065 for a Prandtl number of 1.

The data used to evaluate the correlation included three fluids (water. Freon 22 and freon 114) and three geometries (tube, channel and annulus) The Stanton number ranged from about 0.0045 to 0.10 and the Peclet number from 5000 to 40,000 . Most of the data fell in an error band of $25 \%$. 


\section{Prellminary Data _. 9 September 1993}

The point of NVG is synonymous to the Onset of Significant Void (OSV). Since OSV has been found to precede flow excursion the NVG correlation may be used to predict the local conditions which precede flow instability. The point of NVG critical may be restated in terms of OSV: For OSV to occur the Nusselt number must be greater than 455 and the Stanton number must be greater than 0.0065 .

\section{Demand Curve Minimum}

When demand curves in diabatic systems are generated under controlled flow conditions it is possible to operate at flows which are less than the flows at the minimum pressure drop. The pressure drop minimum will occur sometime between the ONB and saturated bulk conditions (quality equal to zero) at the exit. Maulbetsch and Griffith (52) reported that the minimum pressure drop occurred at well subcooled conditions $\left(-28^{\circ} \mathrm{C}\right)$ with little nonequilibrium void fraction (i.e., vapor) present. They attributed the increased pressure to the left of the demand curve minimum to "increased wall friction caused by agitation at the wall when bubbles are growing and collapsing very rapidly" rather than Bernoulli-type acceleration.

Whittle and Forgan (67) noted that the demand curve slope changes were abrupt for all of the controlled flow tests. A description from a visual test states "as the flow rate was reduced though the value corresponding to the Scurve [demand curve] minimum, the steam void fraction near the channel exit increased very rapidly." (67) They suggested that this minimum might coincide with the detachment of water vapor from the channel walls.

Dorra, Lee, and Bankoff (69) reviewed eight sets of OFI and OSV data and present the data in terms of hydraulic diameter, local pressure, heat flux, mass flux, subcooling at minimum, and saturation temperature. Using this data 


\section{Prellminary Date ... 9 September 1993}

it is possible to calculate both the Stanton number and Peclet number. Table 3 presents this calculated information for selected data sets. Table 4 presents the OFI data presented by Whittle and Forgan. The OFI and OSV data have been plotted separately in Figures 12 and 13. Using portions of this data Gehrke and Bankoff (77) prepared an altenate OFI correlation.

$$
S t=0.076 P e^{-1 / 5}
$$

Table 3.--Mean Stanton numbers at OSV derived from data presented by Dorra, Lee, and Bankoff for Peclet numbers greater than 70,000

\begin{tabular}{l|c|c|c|c}
\hline Data set & Geometry & $\begin{array}{c}\text { Number of } \\
\text { data sets } \\
\text { where } \\
\text { Pe>70,000 }\end{array}$ & $\begin{array}{c}\text { Mean } \\
\text { Stanton } \\
\text { number }\end{array}$ & $\begin{array}{c}\text { Sample } \\
\text { standard } \\
\text { deviation }\end{array}$ \\
\hline Edelman \& Elias* & tube & 0 & 0.1049 & 0.0617 \\
Evangelisti \& Lupolit & $\begin{array}{c}\text { annulus } \\
\text { tube }\end{array}$ & 2 & 0.0064 & 0.0008 \\
Ferrellt & 1 & 0.0102 & $\ldots$ \\
Rogers, et al. & annulus & 0 & 0.0601 & 0.0372 \\
Sekoguchi, et al. & tube & 3 & 0.0032 & 0.0009 \\
Staub, et al. & rectangle & 8 & 0.0214 & 0.0023 \\
\hline
\end{tabular}

The Peclet numbers for all of this data set were below 70,000 .

tPeclet numbers were both above and below 70,000 , only data for Peclet numbers above 70,000 were used in the calculations. 


\section{Preliminary Data ... 9 September 1993}

Table 4.--Mean Stanton numbers at OFI for open flow areas

\begin{tabular}{l|c|c|c|c}
\hline \multicolumn{1}{c|}{ Data set } & Geometry & $\mathrm{N}$ & $\begin{array}{c}\text { Mean } \\
\text { Stanton } \\
\text { number }\end{array}$ & $\begin{array}{c}\text { Sample } \\
\text { standard } \\
\text { deviation }\end{array}$ \\
\hline Columbia (20) & tube & 48 & 0.0063 & 0.0008 \\
Whittle \& Forgan (67) & rectangle \\
Whittle \& Forgan (67) & 57 & 0.0101 & 0.0012 \\
& tube & 9 & 0.0076 & 0.0008 \\
\hline
\end{tabular}

"Stanton numbers below 0.003 as listed in Table XX. Appendix 5 were not used in the calculation of the sample number, sample mean, or sample standard deviation.

tData where the Peclet number was below 70,000 as listed in Table $X X$, Appendix 5 were not used in the calculation of the sample number, sample mean, or sample standard deviation.

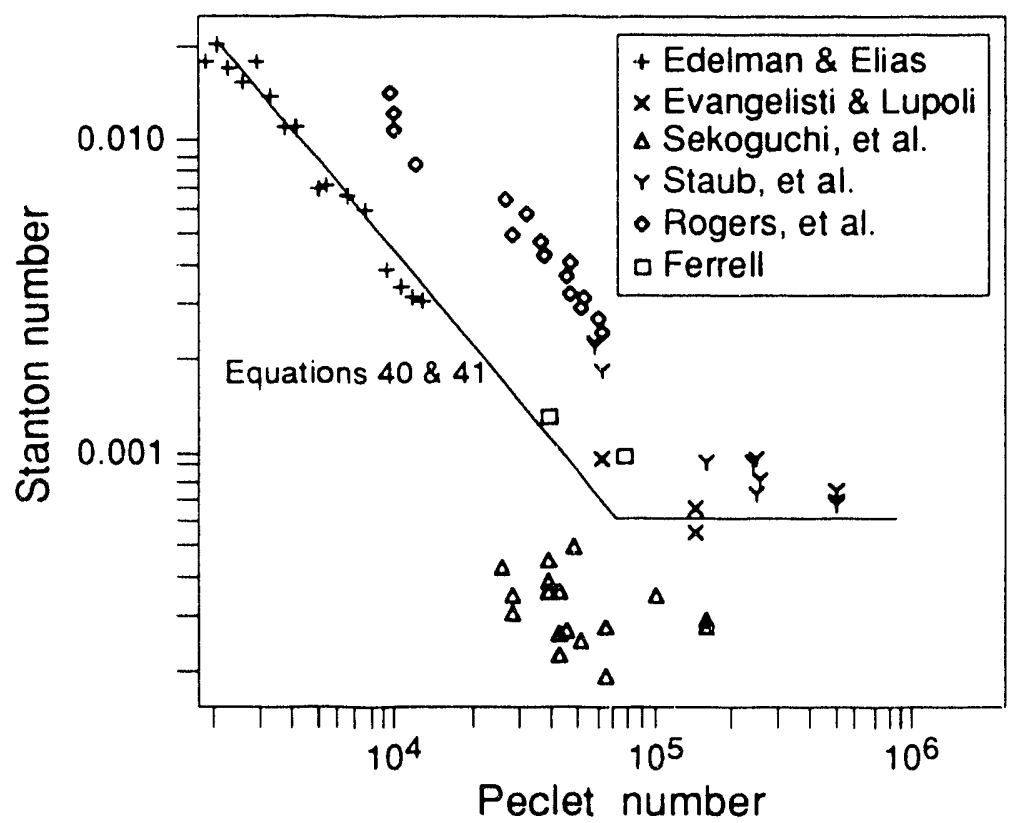

Figure 12, Experimental OSV test data summarized by Dorra, Lee, and Bankoff (69) See Table 5-1. 


\section{Preliminary Data -- 9 September 1993}

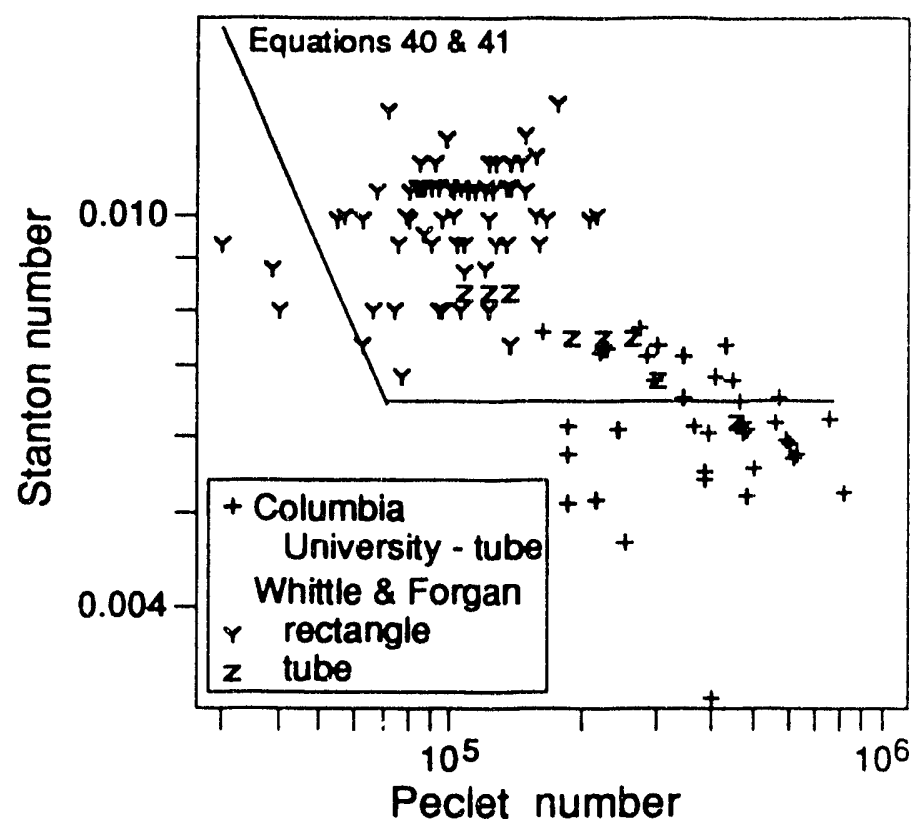

Figure 13, Experimental OFI test data

\section{Heater Channel Construction}

Whittle and Forgan (67), Maulbetsch and Grifth (52), and researchers at Columbia University (16) used direct heating of the flow channel by applying a DC voltage between both ends of the heated length. The construction materials used by these researchers are listed in Table 5 . No significant thermo-hydraulic differences are apparent when comparing the various construction materials used. Columbia University HTRF completed a separate effects test (tube program) to compare the OFI for 304 stainless steel tubes and 600 series Inconnel. Little variation was observed. (16) 


\section{Prelliminary Data -- 9 September 1993}

Table 5.--Channel construction materials used in previous demand curve testing

\begin{tabular}{|c|c|c|}
\hline & Channel material & $\begin{array}{l}\text { Channel } \\
\text { geometry }\end{array}$ \\
\hline 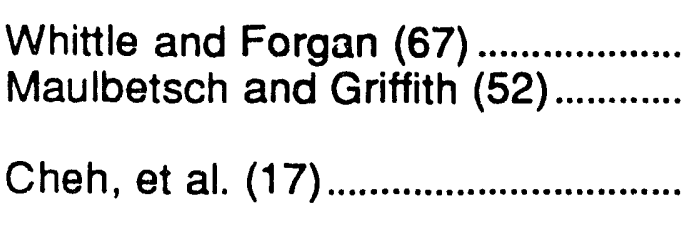 & $\begin{array}{c}\text { phosphor bronze } \\
304 \text { stainless steel } \\
\text { or nickel* } \\
304 \text { stainless steel } \\
\text { and Inconnel }\end{array}$ & $\begin{array}{l}\text { rectangular } \\
\text { tube } \\
\text { tube }\end{array}$ \\
\hline
\end{tabular}

- The test section construction material was not explicitly stated, however reference is made to the description by Dormer and Bergles (1964) where both 304 stainless steal and nickel were used in the construction of the lest section.

Researchers at Creare (9) conducted a series of steady state tests in indirectly heated aluminum channels. Resistance element heaters were installed in the inner and outer annular wall. These heaters were electrically isolated from the wetted aluminum. No change in demand curve behavior was observed when compared to directly heated test sections.

\section{Heater Channel Geometry}

Whittle and Forgan (67) generated demand curves for four different rectangular geometries and one round tube. The rectangular sections were heated on two surfaces with less than 1 percent of the heat transmitted to the fluid from the gap walls. Based on these tests a correlation to predict the onset of flow instability (minimum demand curve pressure drop) was developed.

$$
R=\frac{1}{1+\frac{\eta}{L_{h} / D_{h}}}=\frac{T_{\text {OfI }}-T_{\text {inlet }}}{T_{\text {sat }}-T_{\text {inlet }}}
$$




\section{Preliminary Data _- 9 September 1993}

The bubble detachment parameter, $\eta$, corresponds with that suggested by Bowring (11) which is defined in Equation 39. For the two operating pressures evaluated by Whittle and Forgan the bubble detachment parameter is either 14.1 or 14.2 . With such a small variation it is doubtful that a pressure effect would be observed. A better fit of the test data (29) was obtained using a value of 25 .

The form of Equation 43 is the same form as the $Q_{\text {ratio }}$ which was defined earlier in Equation 33. If the OFI temperature occurs at the exit then the $Q_{\text {ratio }}$ is equal to the temperature ratio, $R$.

$$
\begin{aligned}
Q_{\text {rabo }} & =\frac{\phi}{\dot{m} c_{p}\left(T_{\text {set }}-T_{\text {in }}\right)} \\
& =\frac{\dot{m} c_{p}\left(T_{\text {out }}-T_{\text {in }}\right)}{\dot{m} c_{p}\left(T_{\text {sat }}-T_{\text {in }}\right)} \\
& =\frac{T_{\text {out }}-T_{\text {in }}}{T_{\text {sat }}-T_{\text {in }}}
\end{aligned}
$$

Researchers at Columbia University (29) produced 116 downflow deionized water demand curves during 1988 and 1990 as part of the SS OFI program. The diameters of these tubes range from 9.1 to $28.4 \mathrm{~mm}$. The bubble detachment parameter, $\eta$, estimated using a least square fit for this data 41.93 . The operating pressures for these tests were $240 \mathrm{kPa}$ and $450 \mathrm{kPa}$ abs. The bubble detachment parameter predicted by Equation 39 would be 14.2 and 14.4. While the bubble detachment criterion for the Whittle and Forgan data does fall within the band of the data used by Bowring (11) to develop Equation 39 , the parameter predicted for the Columbia University tube data does not.

For channel with a uniform heat flux the Stanton number as defined by Saha and Zuber (62) can be compared with Equation 39. To demonstrate how 


\section{Preliminary Data _- 9 September 1993}

the concept of a constant Stanton number local phenomena agrees with the constant $R$ value that is a global phenomena.

$$
S t=\frac{\phi}{u p c_{p} \Delta T_{\lambda}}=\frac{1}{\rho c_{p} \eta}
$$

Since the product of the density and specific heat varies only slightly with temperature a Stanton number at OFI can be predicted using the bubble departure parameter, $\eta$. At one atmosphere over at temperature range of 20 to $150^{\circ} \mathrm{C}$ the Stanton number estimate will range from 0.0170 to 0.0178 . This is much higher than suggested by Saha and Zuber (62). For the bubble detachment parameter of $\mathbf{4 1 . 9 3}$ the Stanton number ranges from $\mathrm{C} .0057$ to 0.0060 . Bowring's (11) low value bubble detachment parameter might be explained best by a review of the Peclet numbers for some of the data used in his analysis. One set of tests for a hydraulic diameter of $20.3 \mathrm{~mm}$ operated at $1.1 \mathrm{MPa}$ abs, the operating velocity ranged from 0.40 to $0.85 \mathrm{~m} / \mathrm{s}$. Since the subcoolings only varied from 2 to $19^{\circ} \mathrm{C}$ the value of $\rho \cdot c_{p} / k$ may be considered as $5,800,000 \mathrm{~s} / \mathrm{m}^{2}$. This translates into a range of Peclet numbers between 47,000 to 100,000 . For a small channel (hydraulic diameter of $11.3 \mathrm{~mm}$ ) the Peclet numbers range from 36,000 to 82,000 .

A modified form of Equation 44 for the $Q_{\text {ratio }}$ at the demand curve minimum was suggested by Dougherty, et al. (29) using the previously mentioned Columbia tube data.

$$
Q_{\text {ratio }}=\frac{1}{1+\frac{0.25}{\operatorname{St}(L D)}}
$$

For a majority of the data $(L D=86,96,129,156$, and 160 ) the predicted heat flux at the demand curve minimum is shown to be well predicted the Equation 


\section{Prellminary Data _- 9 September 1993}

43 with $\eta=41.93$ and Equation 46 , and was over predicted by Equation 43 with $\eta=25$. The heat flux for higher L/D (154 and 267) is better predicted by Equation 43 with $\eta=25$ and under predicted by the other two equations (Equation 43 with $\eta=41.93$ and Equation 46 ).

Equation 46 is specific to tube geometries. Appendix $X X$ presents the development of a more general form.

$$
Q_{\text {rabo }}=\frac{1}{1+\frac{A_{1}}{A_{1} S t}}
$$

Researchers at Columbia University $(17,19)$ conducted downflow OFI tests as part of the SRS OFI program in a uniformly heated annulus channel (59.61 $\mathrm{mm} \times 73.63 \mathrm{~mm} \times 3.66 \mathrm{~m}$ long) constructed of two Inconel 625 tubes which were electrically isolated. The outer tube was also thermally insulated. The demand curve minimum for a round tube with the same LD (260) under the same boundary conditions will occur at a slightly lower flow rate than the annular section.

The demand curve minimum occurring at the same $Q_{\text {ratio }}$ for any given heat flux and heater geometry has been demonstrated to hold for the variations listed in Table 6. 


\section{Preliminary Data -. 9 September 1993}

Table 6.--Boundary condition separate effects evaluations on OF!

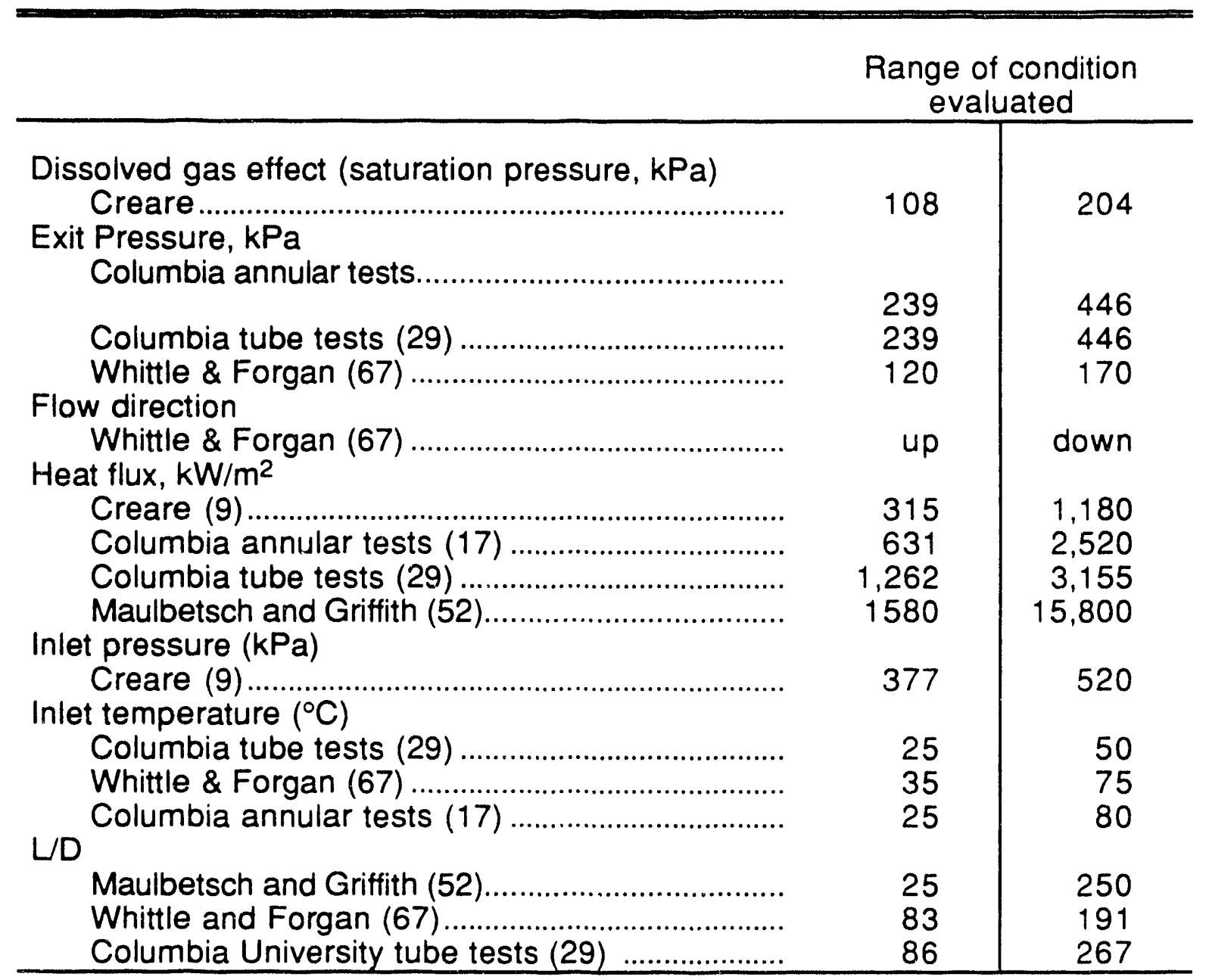

\section{Behavior Comparison of Flow and Pressure Controlled Systems}

The behavior of dabatic channel is very dependent on the control scheme used in the operation the test loop. For pressure controlled systems where the demand curve is traced by incrementally decreasing the supply pressure (normally by increasing the flow through a bypass line in parallel with the heated test channel) when the pressure decreases below the demand curve minimum a flow excursion will occur. For flow controlled systems flow is incrementally decreased to generate the demand curve. If the supply system is 


\section{Prellminary Data _- 9 September 1993}

adequate, operation at flows below the OFI flow is possible and an excursion will not occur.

Maulbetsch and Griffith (52), and Whittle and Forgan (67) demonstrated no variation between the flow at excursive instability for pressure controlled test and the demand curve minimum for flow controlled tests. During the Columbia University HTRF tube tests (29) no flow instabilities (excursions) were observed during controlled flow tests, however FI did occur during each controlled pressure test.

\section{Heater Channel Flux Profile}

Whittle and Forgan (67) tested one rectangular channel with a nonuniform heat flux. The axial heat flux variation had no significant effect on the $Q_{\text {ratio }}$ at the demand curve minimum. Researchers at the Columbia University HTRF (29) completed a series of downflow tests (14) with deionized water as the working fluid, a heated length of $2.44 \mathrm{~m}$ and an L/D of 154 with directed heated inconnel 625 tubes. Four different profiles were evaluated. These profiles are listed in Table 7. The tests were conducted for a heat flux range of 0 to $3155 \mathrm{~kW} / \mathrm{m}^{2}, 240$ and $450 \mathrm{kPa}$ at the channel exit, and 19 and $103^{\circ} \mathrm{C}$ inlet temperature. The Peclet numbers for these tests were in excess of 100,000 . The observed effect of heat flux profiles was considered minimal. For the same average heat flux the OFI flow was within $10 \%$ of the uniformly heated demand curve flow. 


\section{Preliminary Data _- 9 September 1993}

Table 7.--Axial heat flux profiles evaluated by the Columbia University HTRF (29)

\begin{tabular}{|c|c|c|c|c|}
\hline & \multirow[t]{2}{*}{ Profile description } & \multicolumn{3}{|c|}{ Observed effect on OFI } \\
\hline & & $\bar{N}$ & $\overline{\bar{x}}$ & S \\
\hline Uniform & $\begin{array}{l}\text { Heat flux was uniform over heated } \\
\text { length }\end{array}$ & 11 & 0.816 & 0.037 \\
\hline Cosine & $\begin{array}{l}\text { A chopped cosine wave with a } \\
\text { maximum flux equal to } 1.26 \text { times the } \\
\text { average heat flux. }\end{array}$ & 10 & 0.878 & 0.038 \\
\hline $\begin{array}{l}\text { Double } \\
\text { Peak }\end{array}$ & $\begin{array}{l}\text { A flux peak occurs at } z / L \text { equal to } 0.2 \\
\text { and } 0.8 \text { with a maximum flux that is } \\
1.2 \text { times the average heat flux. }\end{array}$ & 4 & 0.836 & 0.043 \\
\hline Exit Peak & $\begin{array}{l}\text { The flux peak occurs at } z / L \text { equal to } \\
0.6 \text { with a maximum flux that is } 1.5 \\
\text { times the average heat flux. }\end{array}$ & 4 & 0.836 & 0.037 \\
\hline
\end{tabular}

In the Columbia University Annular tests (17) both uniform and asymmetric heating were evaluated. Asymmetric heating consisted of providing heat to only one annulus wall or providing an unequal heat to each wall. It was observed that the flow rate at OFI will be higher for a non-symmetric heated annulus. Part of the Creare program was to investigate the effect of azimuthal variations in the heat flux profile of an annular channel; little effect on the demand curve minimum was observed.

Operation on the Negative Portion of the Demand Curve

All of the experimental test data for flow controlled OF tests include subcooled flows below the OFI flow. Mirshak $(53,54)$ presents demand curves in heated tubes where test data has been obtained both at the demand curve minimum and the local maximum. Mirshak (54) attributes to Toyoda the criteria 


\section{Preliminary Data _- 9 September 1993}

for stable operation on the negative portion of the demand curve. For stable operation Equation 48 must be true.

$$
\frac{\partial p_{\text {supply }}}{\partial Q} \leq \frac{\partial p_{\text {demand }}}{\partial Q}
$$

Maulbetsch and Griffith (52) presented an analytical development of this criterion for stability. When restated the criterion is: If the slope of the demand curve is steeper than the supply curve, an excursive flow instability could occur.

\section{Flow Instabilities}

The Ledinegg instability is not the only flow instability that can occur in a diabatic system. Bouré, Bergles and Tong (10) separated two-phase flow instabilities into two types: static and dynamic. A static instability can lead to either an alternate steady state condition or an oscillatory condition. A Ledinegg instability is a fundamental static flow instability where a small Fluctuation in flow conditions results in a new steady state conditions substantially different from the initial condition. There are several other static flow instabilities. These are listed in Table 8.

Instabilities are considered fundamental when the instability mechanism can be identified and evaluated without interaction with other thermal-hydraulic instability behaviors. A Ledinegg instability also fits into this classification. 


\section{Preliminary Data - 9 September 1993}

Table 8.--Static flow instability classifications suggested by Bouré, Bergles and Tong (10)

Description

Fundamental

Ledinegg instability $\quad$ The fluid supply system cannot provide an adequate pressure and flow to meet demand curve of the heated section.

Boiling crisis

The heat removal mechanism is not able to remove the amount of energy being transmitted to the heated surface.

Fundamental relation instability

Flow pattern transition instability

The flow oscillates from one regime to a second created by variations in the heat transfer efficiency and pressure gradient between the two regimes

Compound relaxation instability

Bumping

The heat transfer mechanism transitions between natural convection and boiling.

Geysering

Liquid and vapor are cyclically expelled from a closed end tube.

Chugging

Flow is cyclically expelled from the ends of a heated flow channel.

\section{Boiling Crisis}

Bouré, Bergles and Tong (10) characterize boiling crisis as the ineffective removal of heat from the heated surface and suggest that this crisis is characterized by excursions of the wall temperatures and flow oscillations. Leung's (51) statement on CHF illustrates how the definition of CHF has varied in the literature:

Critical heat flux (CHF) condition in a forced convection boiling system is characterized by a sudden reduction in the heat transfer 


\section{Prellminary Data _. 9 September 1993}

coefficient as indicated by a temperature oscillation or excursion of the heated surface. Other names such as burnout, boiling crisis, dryout and boiling transition have been used. The maximum heat flux just before this crisis occurs is termed the critical heat flux."

Collier (24) suggests that dryout is when "complete evaporation of the liquid film occurs" during annular flow. It is thus limited to events where the heat transfer mechanism is principally evaporation of the liquid. Leung (51) suggests that dryout occurs when the film thickness becomes very thin and breaks down allowing dry patches to form. The wall temperature during dryout will only experience a moderate temperature excursion.

DNB occurs in flows where convection is the primary heat transfer mechanism between the wall surface and the liquid. It is characterized by extreme wall temperature excursions and flow oscillations. Collier (24) describes three types of CHF: Dryout, subcooled DNB, and saturated DNB. Subcooled DNB occurs "when the bulk fluid is subcooled at the location where the critical heat flux is exceeded." Saturated DNB occurs when the bulk fluid is at saturated conditions at the location where critical heat flux is exceeded.

Leung's (51) description of DNB is limited to bubbly flow when the bubbly boundary layer prevents liquid from contacting the hot surface. This creates a vapor film. The wall temperature will increase as a result of the increased heat transfer resistance. The wall temperature will often increase in an excursive manner.

Bergles, Lopina, and Fiori (6) evaluated the flow regime in small diameter $(<6.15 \mathrm{~mm}$ ) diabatic tubes. The test section was equipped with an electric void probe and a sight glass section at the test section exit. For low pressure systems ( $<240,000 \mathrm{~Pa}, 35 \mathrm{psia}$ ) the flow regime will transition from bubbly to slug flow. The exit quality at this transition varied from approximately -2 to -1 percent exit quality for L/D's greater than 60 . This relationship was 


\section{Preliminary Data _- 9 September 1993}

evaluated over a mass flux range from 270 to $3400 \mathrm{~kg} / \mathrm{m}^{2} \cdot \mathrm{s}(0.2$ to 2.5 $\left.M \#_{m} / \mathrm{hr} \cdot \mathrm{ft}^{2}\right)$. The heat flux was approximately $3 \mathrm{~kW} / \mathrm{m}^{2}$. A transition from slug to annular flow did not occur until the exit quality was greater than zero. For subcooled exit conditions the critical heat flux decreased with tube diameter and the quality at the exit. The critical heat flux verses exit quality was observed to pass though a minimum near an exit quality of zero. This minimum disappeared at the exit pressure increase above $280,000 \mathrm{~Pa}(40 \mathrm{psia}$ ). The slug flow in this region was composed of irregular vapor bubbles that were several tube diameters long and separated by liquid containing small bubbles. The flow and pressure both experience pressure pulsations at the end of the test section.

Kawamura, Tachibana, and Akiyama (45) provide a good description of a DNB event: "After a void setback, many small bubbles grow and collapse repeatedly on a heating surface. Test piece surface temperature rises very slowly in this nucleate boiling region. After a certain time interval, some of the small bubbles coalesce to form a vapor film on the surface. The rising rate of the surface temperature increases again at that time. This the critical point or the DNB point in the transient boiling. After the DNB point, the vapor film once spreads to cover the surface."

Hodges $(34,35)$ evaluated the effect of ribs on burnout in rectangular channels that were equipped with flat aluminum strips mounted on one wall serving as the heaters. The rib was a rectangular nonconducting fiberglass that was in contact with the heated surface. The parameters for this testing are listed in Table 9. Two different modes of heater failure were identified during the testing: (1) near the rib tip at the liquid surface, and (2) local melting under the rib. The transition between these two failure modes was predictable using a 


\section{Prelliminary Data _. 9 September 1993}

finning parameter, $x_{0} / \sqrt{k y}$, and the heat flux paralle! to the surface at the edge of the rib, $\phi x_{0} / y$. For aluminum the finning parameter is

$$
P=\frac{x_{0}}{\sqrt{k y}}
$$

The region of operation that resulted in true burnout (failure mode 1) was for finning parameters that were less than 0.003 to $0.004 \mathrm{~m} \cdot\left({ }^{\circ} \mathrm{C} / \mathrm{W}\right)^{1 / 2}(0.007$ to $\left.0.009 \mathrm{ft} \cdot\left(\mathrm{hr} \cdot{ }^{\circ} \mathrm{C} / \mathrm{pcu}\right)^{1 / 2}\right)$.

Table 9.--Expermental conditions investigated by Hodges (35)

\begin{tabular}{l|c}
\hline Heat flux & $2.499 \mathrm{pcu} / \mathrm{ft}^{2} \cdot \mathrm{hr}$ \\
Flow velocity & 5.5 to $42.5 \mathrm{fps}$ \\
Subcooling & 20 to $107 \cdot \mathrm{C}$ \\
Pressure & 40 to $80 \mathrm{psig}$ \\
Hydraulic diameter, D & 0.44 to $0.5^{n}$ \\
Channel width, a & 1 to $2.05^{\prime \prime}$ \\
Rib width, $x_{0}$ & 0 to $0.25^{\prime \prime}$ \\
\hline
\end{tabular}

Fundamental Relation Instability

Flow instabilities can be created in systems where two or more flow regimes can exist. The flow pattern may oscillate between annular, and bubbly or slug flow. The pressure drop in bubbly-slug flow is greater than in annular flow. The higher pressure drop in bubbly flow will result in flow decrease, an increase in the void fraction, and a transition to annular flow. If the vapor generation rate in not adequate to maintain annular flow then bubbly flow will reoccur. The flow pattern will then oscillate between these two flow regimes (10).

During slug flow as the vapor portion passes over a section of wall, the wall temperature will rise because of the low heat transfer coefficient. The wall 


\section{Preliminary Data _- 9 September 1993}

will then be quenched by the following liquid slug. If the heater wall temperature is not sufficiently lowered by the liquid slug burnout can occur. For low pressure systems "this flow pattern is encountered only at very low qualities of the order of 0 to $7 \% "(52)$.

\section{Compound Relaxation Instability}

Repetitive expulsion of coolant from the heated channel can be caused by the sudden vaporization of the liquid phase and the corresponding rapid increase in the specific volume of the mixture. Alternate names for this instability are: Bumping, geysering, and chugging (10). This behavior while repetitive is not necessary periodic. These instabilities are created by restrictions to efficient heat transfer that are metastable.

Maulbetsch and Griffith (52) identity two different mechanisms for nucleation instabilities or "flashing" instabilities. Both mechanisms produce a sudden and rapid vaporization of the liquid phase which a corresponding rapid increase in the specific volume of the mixture. When there is a deficit of nucleation sites (e.g., a smooth, clean surface) a large wall superheat can be expected. "Under these conditions, when a bubble does stant to grow, it will grow violently and eject liquid from the heated channel. This process will cool the remaining liquid and the heater surface with the result that further nucleation will be snuffed out, until the required degree of superheat is reestablished. Such behavior can be sustained at a frequency associated with the timie required for bubble growth, ejection and runback of the liquid, and reestablishment of the superheat" (52). Bouré, Bergles and Tong (10) referred to this mechanism as a vapor burst.

The second "flashing" mechanism occurs when a large reservoir is above a vertical heated channel. A description of this situation is: "When a 


\section{Preliminary Data -. 9 September 1993}

bubble does start to grow it would be displaced into the reservoir. This caused the pressure at the bubble, which was just comprised of the hydrostatic head of the liquid above it, to drop. The reservoir was large enough so that the pressure there remained constant. Hence, near the bubble, the local saturation temperature would decrease, raising the superheat and causing the bubble to grow faster. The end result would be the violent ejection of the liquid from the tube followed by runback of cold water and reinitiation of nucleation. This behavior would continue indefinitely at a fairly regular frequency." (52)

Bouré, Bergles and Tong (10) suggest that the term chugging be reserved for flow channels where fluid can be expelled from one or both ends, while the term geysering is more appropriate for closed end tubes. Bumping refers to an irregular cyclic transition between natural convection and boiling most commonly observed in liquid metals.

\section{Dynamic Instabilities}

Dynamic instabilities occur in flows where the inertia and other feedback effects are part of the instability process. In such cases the application of steady-state solutions is not sufficient to predict system behavior, or event the event for threshold prediction (10). The instability is considered compound since several elementary mechanisms interact and cannot be evaluated separately. Several types of compound instabilities are listed in Table 10. 


\section{Preliminary Data -. 9 September 1993}

Table 10.--Dynamic flow instability classifications as proposed by Bouré,

Bergles and Tong (10)

\begin{tabular}{|c|c|}
\hline & Description \\
\hline \multicolumn{2}{|c|}{ Fundamental dynamic instabilities } \\
\hline $\begin{array}{l}\text { Acoustic oscillations } \\
\text { Density wave } \\
\text { oscillations }\end{array}$ & $\begin{array}{l}\text { Resonance of pressure waves induces oscillations. } \\
\text { Interactions betiveen flow rate, density, and } \\
\text { pressure drop create oscillating behavior. }\end{array}$ \\
\hline \multicolumn{2}{|r|}{ Compound dynamic instabilities } \\
\hline $\begin{array}{l}\text { Thermal oscillations } \\
\text { BWR instability }\end{array}$ & $\begin{array}{l}\text { Variable heat transfer caused by shifting of flow } \\
\text { transition locations creates thermal oscillations. } \\
\text { Interaction of void reactivity coupling with flow } \\
\text { dynamic and heat transfer to create flow and power } \\
\text { oscillations. } \\
\text { literaction between parallel channe's where the } \\
\text { flow regimes vary in each channel with time. }\end{array}$ \\
\hline \multicolumn{2}{|c|}{ Compound dynamic instability as a secondary phenomena } \\
\hline $\begin{array}{c}\text { Pressure drop } \\
\text { oscillations }\end{array}$ & $\begin{array}{l}\text { A flow excursion is initiates because of a dynamic } \\
\text { interaction between the heated channel and } \\
\text { compressible volume. }\end{array}$ \\
\hline
\end{tabular}

\section{Fundamental Dynamic Instabilities}

High frequencies are the characteristic of acoustic or pressure wave oscillations. The oscillation period is normally of the same magnitude as the pressure wave system residence time. (Time for pressure wave to travel through system.) The reported frequency range for this instability is 10 to $10,000 \mathrm{~Hz}(10)$.

There are several alternative names for density wave oscillations. These include: flow-void feedback instabilities; time-delay oscillations; density wave oscillations, and density effect mechanism. The behavior is described by Bouré, Bergles and Tong (10):

A temporary reduction of inlet flow in a heated channel increases the rate of enthalp' rise, thereby reducing the average density. This 


\section{Preliminary Data -- 9 September 1993}

disturbance affects the pressure drop as well as the heat transfer behavior... For boiling systems, the oscillations are dues to multiple regenerative feedbacks between the flow rate, vapor generation rate, and pressure drop... These low frequency oscillations in which the period is approximately one to two times the time required for a fluid particle to travel though the channel.

\section{Compound Dynamic Instabilities}

For constant heat flux systems that are operating with film boiling present, large amplitude thermal oscillations have been observed. These oscillations are attributed to dryout point shifting location and local conditions alternating between film boiling and transition boiling. Bouré, Bergles and Tong (10) suggest that a primary phenomenon such as density wave oscillations must be required to destabilize the film boiling is caused by an interaction between hydraulic and power generation. If the time constant for the hydraulic oscillation is similar to the time constant of the nuclear fuel element nuclearcoupled flow instability can occur.

Oscillatory behavior has been observed for two-phase flow conditions in parallel channe! systems. Ozawa, Akagawa, and Sakaguchi (56) identified two types of pressure drop oscillations for an adiabatic gas-liquid flow sistem (air and water) with compressibilities in both the gas and liquid sysiems: Relaxation oscillation and quasi-state oscillatinn. During relaxation oscillation the volumetric liquid flux is constant or nearly constant and the gas flow and pressure drop will oscillate. During quasi-state oscillation the liquid flow rate, gas flow rate and pressure drop will oscillate. This secrnd type of instability occurs in the presence of relatively high compressibility in the liquid feed pipe.

\section{Compound Dynamic Instability as a Secondary Phenomena}

Maulhetsch and Girffith (52) suggest that pressure drop oscillatory instaturity is a result of an energy storage mechanism such as superheated 


\section{Prellminary Data -- 9 September 1993}

liquid, heat capacity of the heated surface or a compressible volume located just upstream, or in the diabatic channel. These oscillations occur during operation on the negative sloped portion of the demand curve (10). This phenomenon is characterized by very low frequencies $(0.1 \mathrm{~Hz})$. Maulbetsch and Griffith (52) demonstrated that a pressure drop instability will not occur unless the Ledinegg instability limit is also exceeded. The failure mechanisms for Ledinegg and compressible volume oscillatory burnout tests were run to destruction of the test section. Maulbetsch and Griffith (52) describe the failure mechanisms as quite different:

In the excursion case [pressure controlled OFI], the tubes, after burnout, were quite ragged and showed evidence of overheating along most of their length. This is typical of burnout caused by sudden flow starvation. The tubes which failed due to the presence of a compressible volume, on the other hand, exhibited a very clean break, with no evidence of overheating outside of a very narrow region on either side of the burnout location. In this respect they were similar to the ordinar' stable burnout tests."

\section{Boiling Curves}

Boiling cures are classified into two categories based on the fluid boundary conditions. Pool boiling curves represent the behavior of a heated surface which is immersed in a standing fluid. In this situation fluid density is a significant factor, and natural convection is the mode of heat transfer prior to vapor forming. The second category of boiling curve is for a subcooled liquid flowing over a heated surface. The surface may be a heated channel or an obstiuction inserted into the flow stream. The sffect of density is normally negligible and the turbulerice of the subconled liquid tends to increase the heat transfer effectiveness. 


\section{Preliminary Data _- 9 September 1993}

\section{Pool Boiling}

Pool boiling curves such as shown in Figure 14 are generated in several different ways. The most common is to incrementally increase the heat flux for a uniformly heated surface starting with natural convection heat transfer ( $A$ to $B$ ), transitioning to nucleate boiling until point $C$ is reached. At this point any additional increase in heat flux will result in an excursion to point $E$. During this transition the heater normally melts hence point $C$ is commonly referred to as the burnout point. It has been possible to operate in the transition region ( $C$ to D) using a condensing-vapor for heat generation rather than electrical heating (Rohsenow \& Choi) such that the system is wall temperature controlled.

Collier (24) suggests that the peak pool boiling heat flux can be estimated from:

$$
\phi_{\text {peak }}=K h_{\text {fg }} \rho_{v}\left[\frac{\sigma g\left(\rho_{1}-\rho_{v}\right)}{\rho_{v}{ }^{2}}\right]^{1 / 4}
$$

where the value of $K$ ranges from $\pi / 24$ to 0.149 . 


\section{Preliminary Data _- 9 September 1993}

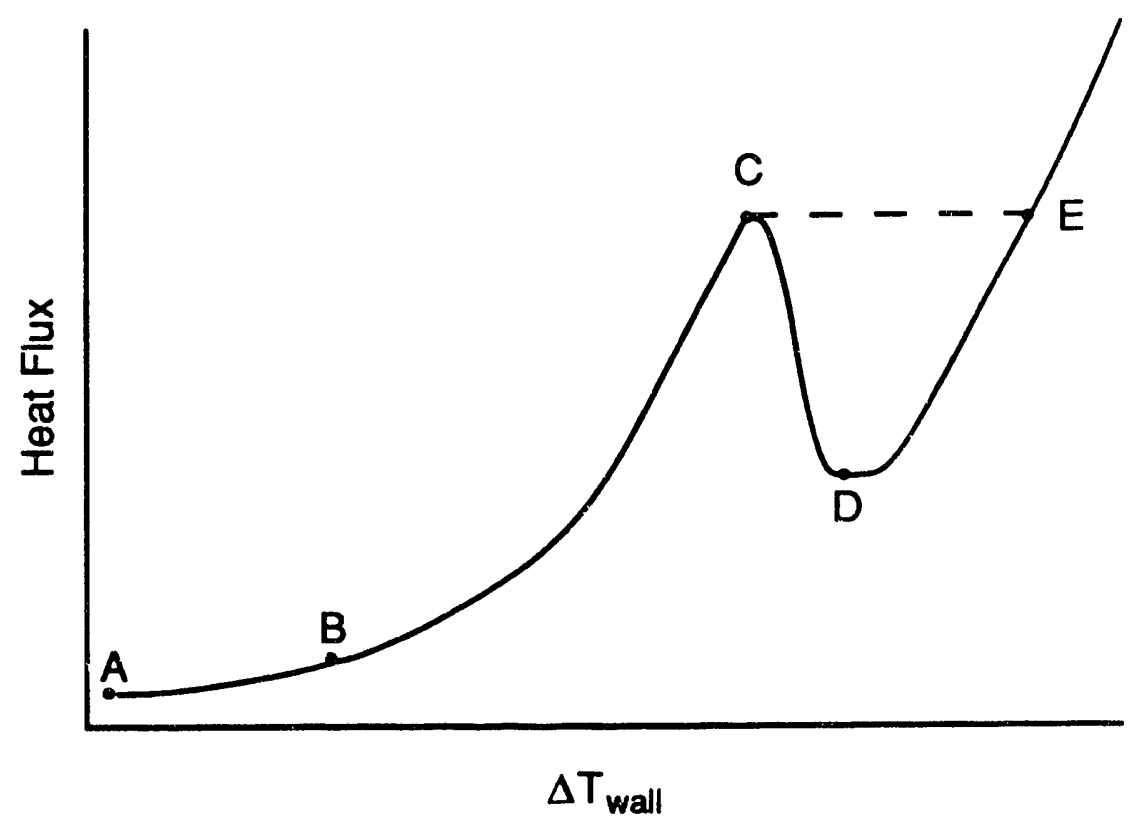

Figure 14. Typical pool boiling curve

\section{Forced Convection Boiling}

The flow of a subcooled liquid across a heated surface will increase the heat transfer effectiveness as compared with natural convection and pool boiling. A typical forced convection boiling curve is shown in Figure 15. This curve is for a single flow velocity. The region from $A$ to $B$ is non-boiling forced convection. The wall temperature may be predicted using the Dittus-Boelter equation (Thom, et al.):

$$
\mathrm{Nu}=\left[\frac{\phi D_{\theta}}{k_{f}\left(T_{w}-T_{\text {sat }}\right)}\right]=0.023 R e^{0.8} \operatorname{Pr}_{f}{ }^{0.4}
$$

Fully developed nucleate boiling is present in the region between $C$ and $D$ in Figure 15. Thom et al. (72) present a correlation for water to predict the wall superheat $\left(T_{w}-T_{\text {sat }}\right)$ in this region 


\section{Preliminary Data -- 9 September 1993}

$$
\Delta T_{\text {sat }}=\frac{0.072 \phi^{0.5}}{e^{p / 1260}}
$$

where temperature, $T$, is in ${ }^{\circ} F$, heat flux, $\phi$, is in Btu/hr. $\mathrm{ft}^{2}$ and pressure, $p$, is in psia. An alternate form of Equation 52 in SI units presented by Collier (24) is:

$$
\left(T_{w}-T_{\text {sat }}\right)=22.65\left(\frac{\phi}{10^{6}}\right)^{0.5} e^{-p / 8,700,000}
$$

The region between $B$ and $C$ is a transition region; the wall heat transfer in this region was successfully predicted by Block et al. (9) based on a relation by Bowring (11).

$$
\phi=\phi_{\mathrm{sb}}+\phi_{\mathrm{fc}}
$$

Hino and Ueda (33) investigated alternative relations to Equation 54 comparing them with experimental data produced with Refrigerant 113. The alternative, more complex, correlations provided only slightly improved accuracy. Hino and Ueda (33) noted on their boiling curves the point of OSV and CHF. OSV occurred at the transition between partial nucleate boiling and fully developed nucleate boiling. CHF occurred at a point hig: on the nucleate boiling curve.

The region $D$ to $E$ in Figure 15 is a transition region from nucleate boiling to film boiling while the region beyond point $E$ is in film boiling. Several researchers have developed boiling curves by using a transient technique (22). A large metal block is heated to a predetermined temperature. The test is initiated by diverting flow into the hot block. This flow cools the block; temperature data is recorded as a function of time. The heat flux is then 


\section{Preliminary Data -. 9 September 1993}

calculated based on the thermal mass of the block and the measured temperatures. For distilled water at a mass flux of $136 \mathrm{~kg} / \mathrm{m}^{2} \cdot \mathrm{s}$, and subcoulings which range from 0 to $27.8^{\circ} \mathrm{C}, \mathrm{Cheg}, \mathrm{Ng}$, and $\mathrm{Heng}$ (23) measured a film heal flux ranging from 300 to $800 \mathrm{~kW} / \mathrm{m}^{2}$. The film heat flux increased with increased subcooling. The peak heat flux (point $D$ in Figure 15) was relatively insensitive to subcooling and was approximately $2,000 \mathrm{~kW} / \mathrm{m}^{2}$. The wall temperature at the peak heat flux was approximately $150^{\circ} \mathrm{C}$. The peak heat flux was found to increase with mass flux although at $203 \mathrm{~kg} / \mathrm{m}^{2} \cdot \mathrm{s}$ and $0^{\circ} \mathrm{C}$ subcooling the value was still about $2,000 \mathrm{~kW} / \mathrm{m}^{2}$.

Feng, and Johannsen (30) evaluated the maximum transition boiling temperature (MTBT) between transition boiling and film boiling. The point of MTBT occurred at the wall heat flux minima. The axial location of this minima varied with the inlet conditions and heat flux. While the majority of the data presented was for positive local equilibrium quality some data was for subcooled local conditions. For large subcoolings $\left(30^{\circ} \mathrm{C}\right)$ at $700 \mathrm{kPa}$ the MTBT did not vary with local equilibrium quality. The MTBT did increase with increasing heat flux. For a subcooling of $15^{\circ} \mathrm{C}$ the MTBT increased as the local equilibrium increased (became less negative). For a mass flux of $300 \mathrm{~kg} / \mathrm{s} \cdot \mathrm{m}^{2}$ the MTBT was approximately $380^{\circ} \mathrm{C}$. 


\section{Prellminary Data -- 9 September 1993}

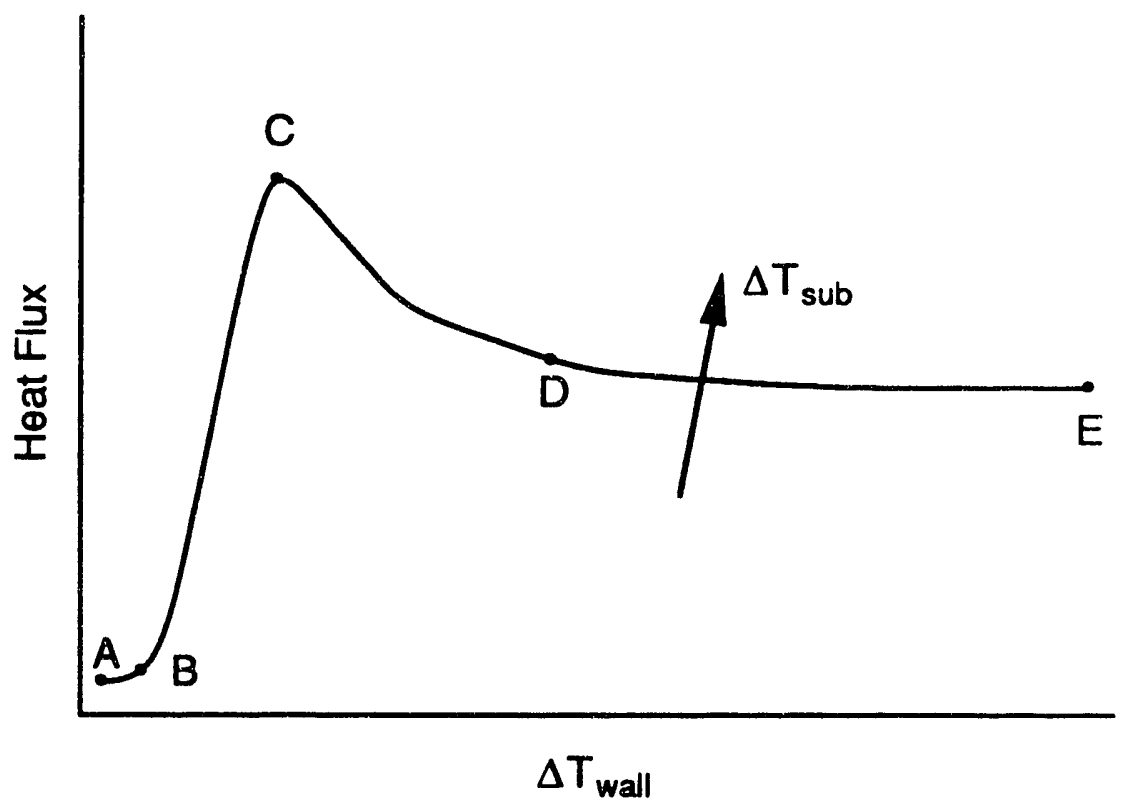

Figure 15. Typical forced convection boiling curves for subcooled liquid

\section{Boiling Curve Hysterises}

The boiling curve shown in Figure 15 does not indicate an important behavior which occurs during the transition between forced non-boiling convection and fully developed nucleate boiling. For a channel where the heat flux is increasing nucleate boiling may not readily occur until an adequate number of cavities activated. Activation of the'se sites requires more energy than would be required to maintain the sites as active. Figure 16 presents the variation between increasing and decreasing heat flux behavior. Hino and Ueda demonstrated that the region of increasing heat flux the boiling curve trajectory follows the path A-F-G. The path by Equation 55 .

$$
\frac{\phi D_{e}}{k_{l}\left(T_{w}-T_{1}\right)}=0.023 \operatorname{Re}^{0.8} \operatorname{Pr}^{1 / 3}
$$




\section{Preliminary Data -. 9 September 1993}

When the necessary number of activation sites is available the wall superheat will decrease to that of location $\mathrm{H}$, where the boiling curve trajectory will then follow the path described earlier. For decreasing heat flux the boiling curve trajectory will be B-H-F-A. The cession of vapor formation coincides approximately with the point of ONB.

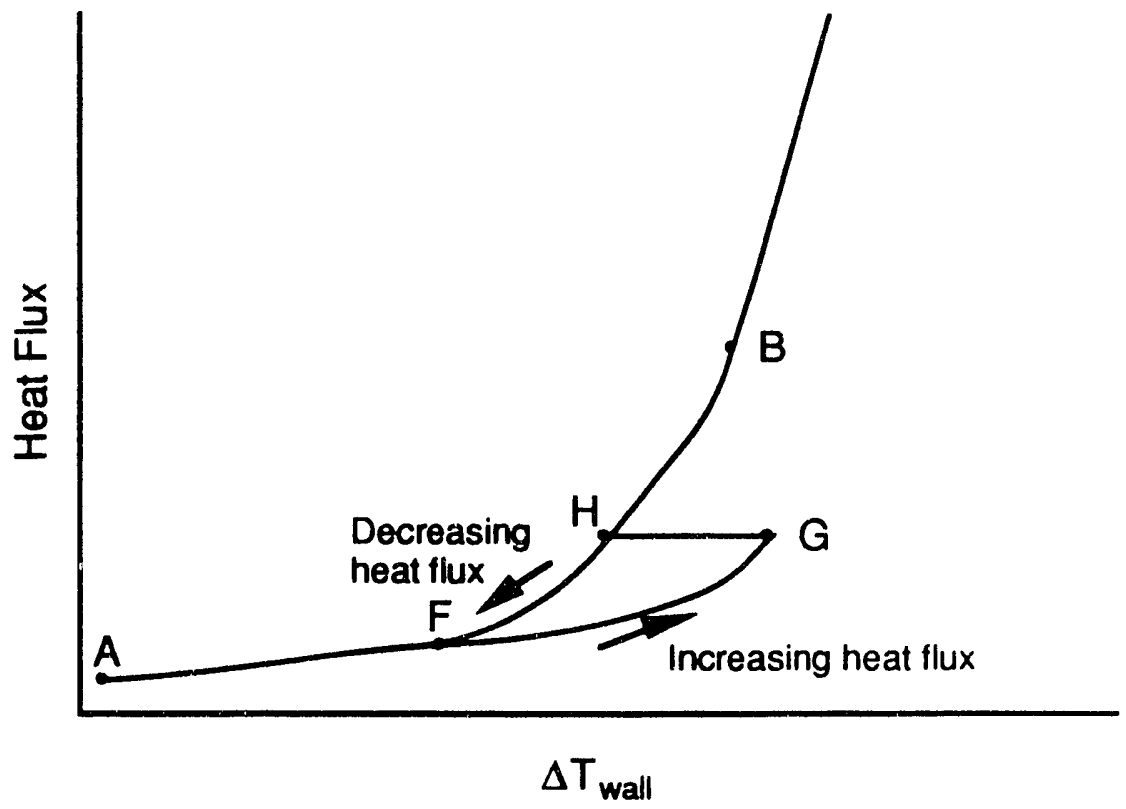

Figure 16. Forced convection boiling curve hysteresis, AFGHB for increasing heat flux, BrFA for decreasing heat flux

\section{Alternate Transition Boiling Curve}

Witte and Lienhard, 1982, based on studies with n-pentane suggested that there were possibly two transition boiling curves. The first curve is approached from the left as shown in Figure 17. The second curve lies below the first and is approachiod from the right. The investigation of alternate

transition curves was expanded by Ramilison, 1985. Ramilison and Lienhard (1987) suggested that when the effect of the condensation process is included the form of the alternate transition curve would be as shown in Figure 17. The 


\section{Preliminary Data -- 9 September 1993}

effect was found to be more pronounced for rough surfaces and the minimum heat flux (point $J$ in Figure 17) was lower than the maximum heat flux (point $C$ in Figure 17) The lowest measured wall superheat on the film boiling curve was approximately twice the wall superheat at the peak heat flux (point $C$, Figure 17).

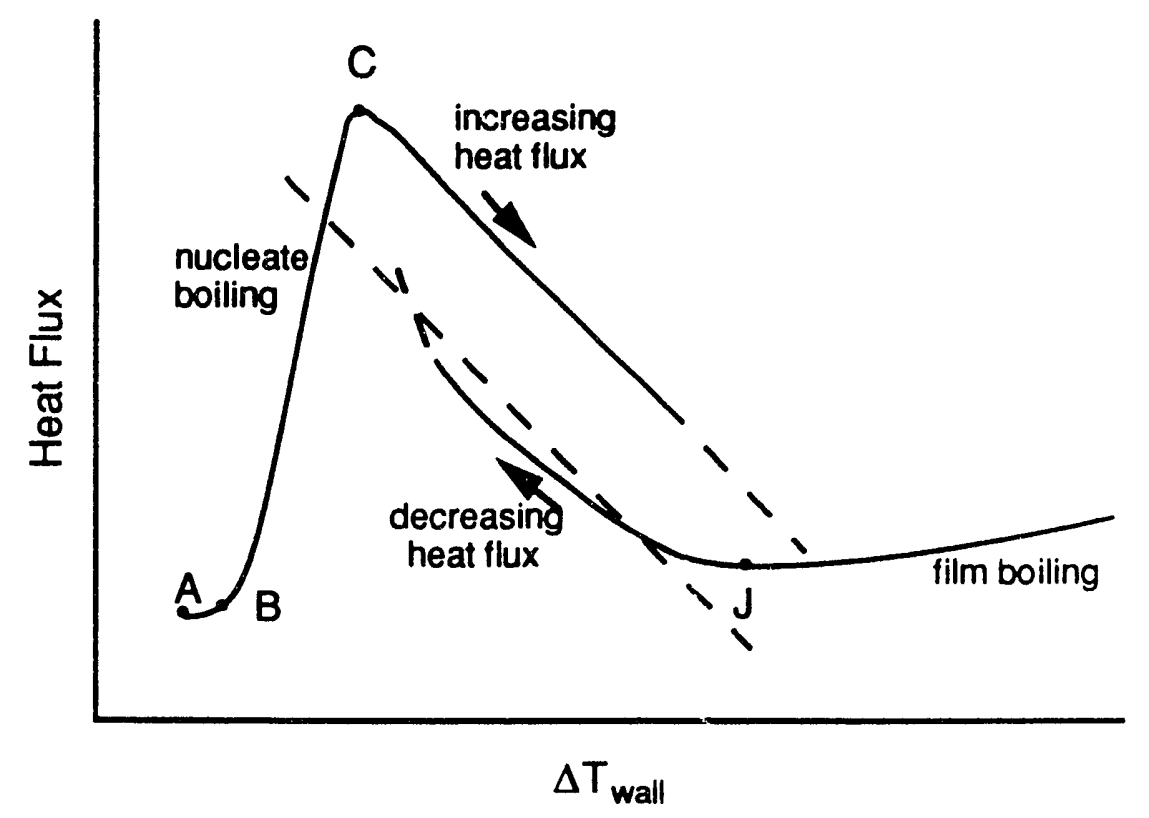

Figure 17. Alternate transition boiling curves as suggested by Ramilison and Lienhard (1987)

\section{Obstruction Effects on Boiling}

Ishibashi, and Nishikawa (37) evaluated the effect of a surface placed near a heated surface during pool boiling. It was demonstrated that below a gap of $3 \mathrm{~mm}$ the boiling behavior was significantly different from larger gaps. In narrow gaps vapor coalesced to blanket the heated surface, for larger gaps only isolated bubbles formed. It was shown in this work by using both water and water solutions that the bubble behavior for narrow gaps was independent of surface tension. 


\section{Preliminary Data -. 9 September 1993}

Sharon, Chen, and Bankoff (63) observed that the wall superheat at ONB on the outside of a heated tube at a tubesheet occurs at very low wall superheats. The lower values occurred for the gap of $0.191 \mathrm{~mm}$ (typically $0.2^{\circ} \mathrm{C}$ ), while the higher value occurs for a gap of $0.317 \mathrm{~mm}$ (typically $3^{\circ} \mathrm{C}$ ). The tube diameter was $19.05 \mathrm{~mm}$ and the plate thickness was $19.05 \mathrm{~mm}$. For the conditions (heat flux and local pressure) where ONB was observed the expected range of superheat based on the Bergles and Rosenhow ONB correlation is 2 or $3^{\circ} \mathrm{C}$. 


\section{Preliminary Data -- 9 September 1993}

\section{Flow Obstruction Effects on OFI}

Ribbed flow channel behavior prior to burnout has been described and filmed by Hodges (35). He describes three regions of boiling behavior in a rectangular heated channel with an insulating rib. A small region near the rib is in stable film boiling. This was attributed to the reduced fluid velocity near the rib. Adjacent to this is a region of intermittent film boiling which was $6 \mathrm{~mm}$ (1/4") wide while the remainder of the channel remains in nucleate boiling. At $20 \mathrm{fps}$ and 55 psia the intermittent vapor films were 6 to $13 \mathrm{~mm}(1 / 4$ " to $1 / 2 ")$ long, and appeared to move upward while the bulk flow direction was downward. Hodges (DPST-73-206) presents a hydrodynamic explanation for this behavior.

This apparent upward film motion is explained as follows: the film forms and tries to spread in all directions. A boundary layer develops on the film surface. Tl is boundary layer is laminar along the forward (upstream) part of the film but becomes turbulent after a short distance and transition to turbulent flow occurs at approximately the same Reynolds' number as for a flat plate $\left(3 \times 10^{5}\right)$, the stable film length is calculated to be approximately 0.4 inch, which agrees well with the observed length. The film spreads upward (and appears to move upwards) because it is growing upwards and is being destroyed downstream.

Johnston and Neff observed that in a downward flow uniformly heated ribbed annuli the variation between subchannels of the wall superheats at the test section exit were negligible except at the demand curve minimum. At the minimum the unheated wall temperature for the subchannel with the highest wall temperature was the same at the top and bottom. They suggested that a flow redistribution had occurred and that the flow in the hot channel was stalled. This redistribution was the result of vapor forming at the rib tip with the accompanying density change creating increased resistance to flow in the affected subchannel thus creating a Ledinegg instability within the test channel. 
The presence of fins can enhance the removal of heat during nucleate boiling. Kowalski, Mills, and Shim (47) evaluated the effect of a conducting rib on ONB, OSV, and heat transfer. The test apparatus consisted of an outer glass tube surrounding the inner ribbed heated tube. Eight ribs were equally spaced around the heater. These ribs were $1.027 \mathrm{~mm}$ high, $0.822 \mathrm{~mm}$ wide. The annular gap appears to have been $4.111 \mathrm{~mm}$. Both ONB and OSV occurred first in the space between the ribs on the primary surface. For high mass flux (>1500 $\mathrm{kg} / \mathrm{m}^{2} \cdot \mathrm{s}$ ) the bubble detachment occurred after the bubbles first slid along the inner wall. The Peclet number at this transition is 66,000 . For this testing the range of operation included: mass fluxes of 1000 to $5900 \mathrm{~kg} / \mathrm{m}^{2} \cdot \mathrm{s}$, pressures of 110 to $350 \mathrm{kPa}$, and inlet subcoolings of 30 to $80^{\circ} \mathrm{C}$. The Peclet number for these conditions is approximately 44,000 to 261,000 . Kowalski, Mills, and Shim (47) suggested Equation 56 as a best fit of the data from their work.

$$
S t=0.0446 P e^{-0.18}
$$

\section{Conducting Spacer Ribs}

Block, et al. as part of the SRS OFI program, constructed and operated test channels with aluminum heat transfer surfaces. Two different annular geometries were evaluated: Ribbed and ribless, and two test sections of each type were tested. The ribless channel was a "pure" annulus with tne exception of centering pins $\left(0.094^{\prime \prime}\right.$ dia neter for first construction and $0.109 " \times 0.75$ " long for second construction) which were used to hold the inner annulus pipe in position. The flow area was held constant for these tests. Four ribs were an integral part of the inner annular wall for the ribbed tests. The average 


\section{Preliminary Data -. 9 September 1993}

clearance between the ribs and the outer wall ranged from 0.020 to 0.045 inches. The geometries for the test sections are provided in Table 11.

Table 11.--Annular geometries used in OFI testing

\begin{tabular}{l|c|c}
\hline & $\begin{array}{c}\text { Non-ribbed } \\
\text { geometry }\end{array}$ & Ribbed geometry \\
\hline Creare & 60.15 & 59.79 \\
Inner diameter, mm & 73.46 & 73.55 \\
Outer diameter, mm & 3.96 & 3.96 \\
Heated length, m & 13.35 & 11.89 \\
Hydraulic diameter, mm & $\ldots$ & aluminum \\
Spacer rib material & 1403 & 1394 \\
Flow area, mm² & 59.61 & 59.61 \\
Columbia University & 73.63 & 73.46 \\
Inner diameter, mm & 3.66 & 3.66 \\
Outer diameter, mm & 14.02 & 14.00 \\
Heated length, m & $\ldots .$. & 1.59 \\
Hydraulic diameter, mm & $\ldots$ & 1400 \\
Spacer rib material & 1465 & 80.09 \\
Rib width, mm & & 83.24 \\
Flow area, mm² & 80.09 & 0.59 \\
Johnston \& Neff & 83.24 & $\ldots$ \\
Inner diameter, mm & 0.59 & phenolic asbestos \\
Outer diameter, mm & 3.15 & $\ldots$ \\
Heated length, m & $\ldots$ & fiberglass \\
Hydraulic diameter, mm & 404 & \\
Spacer rib material & & \\
Flow area, mm² & & \\
\hline
\end{tabular}




\section{Preliminary Data _. 9 September 1993}

Table 12.--Summary of demand curve minimum data for open and ribbed channels

\begin{tabular}{l|c|c|c}
\hline \hline & $\begin{array}{c}\text { Number of } \\
\text { samples }\end{array}$ & $\begin{array}{c}Q_{\text {ratio at minimum }} \pm t_{\alpha / 2} \cdot S_{m} \\
\text { Stanton number } \\
\pm t_{\alpha / 2} \cdot S_{m}\end{array}$ \\
\hline $\begin{array}{c}\text { open annulus } \\
\text { Creare }\end{array}$ & 5 & $0.889 \pm 0.067$ & $0.0080 \pm 0.0044$ \\
Columbia & 14 & $0.937 \pm 0.020$ & $0.0063 \pm 0.0023$ \\
$\quad$ Heated both sides & 1 & $0.839 \pm 0.305$ & $0.0084 \pm 0.0022$ \\
$\quad$ Heated on inside & 2 & $0.891 \pm 0.314$ & $0.0082 \pm 0.0040$ \\
Heated on outside & 2 & $\cdots$ & $0.0075 \pm 0.0005$ \\
Johnston \& Neff & 22 & & \\
& & & \\
ribbed annulus & 14 & $0.826 \pm 0.015$ & $0.0042 \pm 0.0004$ \\
Creare & 9 & $0.879 \pm 0.017$ & $0.0052 \pm 0.0009$ \\
Columbia & 18 & $\cdots$ & $0.0055 \pm 0.0005$ \\
Johnston \& Neff & & &
\end{tabular}

Table 13.--Expermental rib-effect-ratios for annuli equipped with spacer ribs

\begin{tabular}{l|c|c}
\hline \hline & $\frac{\left(Q_{\text {ratio }}\right)_{\text {ribbed }}}{\left(Q_{\text {ratio }}\right)_{\text {open }}}$ & $\frac{S t_{\text {ribbed }}}{S t_{\text {open }}}$ \\
\hline Creare & 0.929 & 0.525 \\
Columbia & 0.938 & 0.667 \\
Johnston \& Neff & $\ldots$ & 0.733 \\
\hline
\end{tabular}

The hydraulic perimeters of the non-ribbed and conducting rib geometry have been calculated from given flow area and hydraulic diameter. The hydraulic perimeter for the insulating rib is estimated based on a rib height of:

$$
\frac{2.896 "-2.353^{\prime \prime}}{2}=0.272^{\prime \prime} \quad(4 \text { ribs }=0.181 \mathrm{ft} .)
$$




\section{Prelliminary Data - 9 September 1993}

The hydraulic diameter for the insulating rib is based on this perimeter. All of the LD values were calculated. The predicted heat flux ratio at the demand curve minimum is almost the same for all three geometries in Table 14. The data as presented in Table 12 shows that a significant rib effect exists which is not predicted by the present theory.

The exit fluid temperature in each flow subchannel was monitored during the ribbed tests. One channel consistently was hotter than the average fluid temperature. The variation between an individual subchannel temperature and the average for the four appears very consistent with the magnitude of the difference increasing as the minimum is approached. Near the minimum the subchannel temperature differences tended to decrease and then return to their previous relationship with decreasing flow. This was very apparent for a test at a heat flux of $375 \mathrm{kBtu} / \mathrm{hr}-\mathrm{ft} 2$ when the fluid temperature difference decreased by 50 percent as the minimum was approached. This might be the result of flow redistribution as the vapor generation reached significant levels.

Table 14.--OFI predictions for Creare channel based on Equation 2

\begin{tabular}{l|c|c|c}
\hline \hline & \multirow{2}{*}{$\begin{array}{c}\text { Non-ribbed, } \\
\text { build 2 }\end{array}$} & \multicolumn{2}{|c}{ Ribbed, build 4 } \\
\cline { 3 - 4 } & & Conducting rib & Insulating rib \\
\hline Hydraulic diameter, mm & 13.4 & 11.9 & \\
Heated diameter, $D_{h}, \mathrm{~mm}$ & 13.4 & 11.9 & 11.9 \\
$L_{h} / D_{h}$ & 292 & 328 & 13.5 \\
$R(\eta=25)$ & 0.921 & 0.929 & 289 \\
\hline
\end{tabular}

Non-Conducting Spacer Ribs

Columbia University built and operated two annular channels as part of the SRS OFI program. The first rig was constructed to represent and "open" 


\section{Preliminary Data -- 9 September 1993}

annulus. Both surfaces of the annulus were constructed on Inconnel tubes and directed heated. The inner heater was centered and supported in the outer heater using $5.46 \mathrm{~mm}$ diameter insulating pins (36). The dimensions of the channel are listed in Table 11. The simulated spacer ribs were $1 / 16$ " thick phenolic asbestos and held in place with small clips.

The mean of the $Q_{\text {ratio }}$ at the demand curve minimum for the Columbia University ribbed annulus data is $0.879 \pm 0.017$ (95\% coverage). For an $L_{h} / D_{h}$ of 270 the critical temperature ratio predicted by Equation 2 would be 0.915 . This is outside the range of the mean predicted by the test data. The mean of the Stanton number calculated at the demand curve minimum conditions was $0.0052 \pm 0.0009$ ( $95 \%$ coverage). This range is below the 0.0065 suggested by Saha and Zuber. If the non-uniform heat flux curve is neglected (the curve that was produced at rig $b$ cout) the mean Stanton number at OFI is $0.00496 \pm$ 0.0006 (95\% coverage). 


\section{Prellminary Data - 9 September 1993}

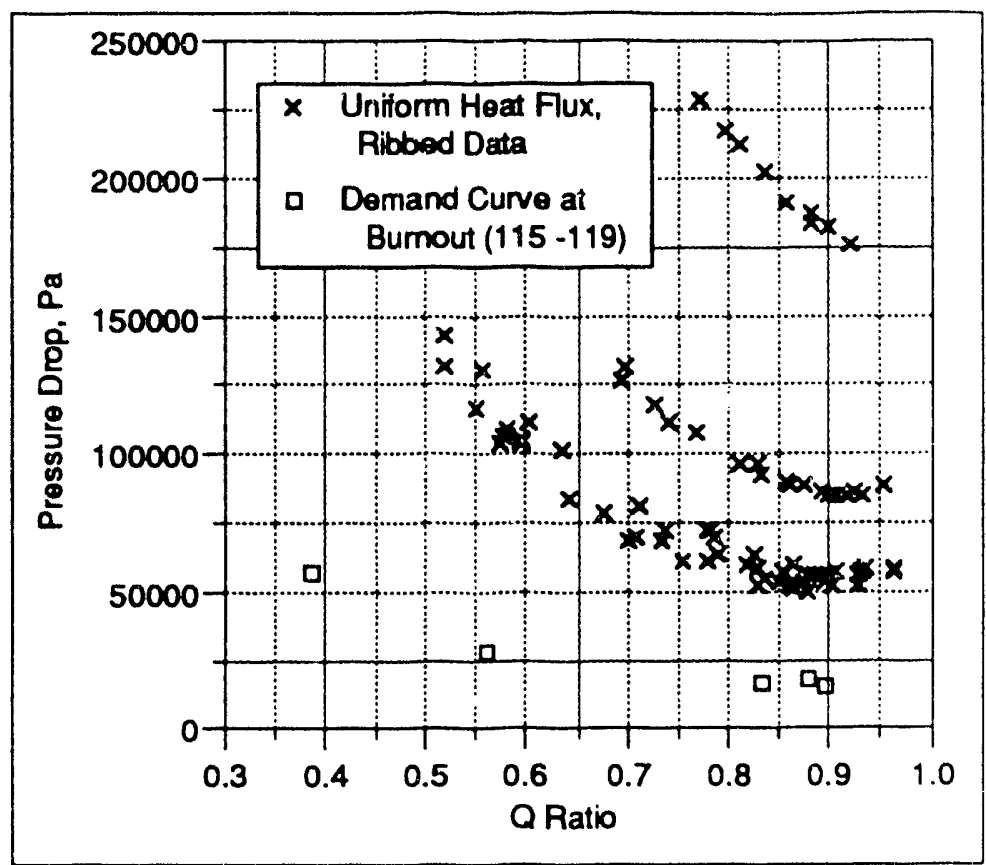

Figure 18, Columbia University ribbed annulus demand curves

To allow a more detailed comparison between the Columbia University OFI test program ribbed and open annuli, tests at the conditions described in Table 15 have been compared. For these conditions there is one documented demand curve for the open annulus (Reference 1) and five (one is not complete because of premature thermal trips, Reference 2) demand curves in the ribbed annulus. These are listed in Table 16.

Table 15.--Nominal conditions used in analysis of Columbia University wall temperature effects

\begin{tabular}{c|c|c}
\hline \hline Inner heat flux & $400,000 \mathrm{Btu} / \mathrm{hr} \cdot \mathrm{ft} 2$ & $127 \mathrm{~kW} / \mathrm{m}^{2}$ \\
Outer heat flux & $400,000 \mathrm{Btu} / \mathrm{hr} \cdot \mathrm{ft} 2$ & $127 \mathrm{~kW} / \mathrm{m}^{2}$ \\
Inlet temperature & $25^{\circ} \mathrm{C}$ & $25^{\circ} \mathrm{C}$ \\
Outlet pressure & $20 \mathrm{psig}$ & $240,000 \mathrm{~N} / \mathrm{m}^{2} \mathrm{abs}$ \\
\hline
\end{tabular}




\section{Preliminary Data .. 9 September 1993}

Table 16.--Demand curve descriptions

\begin{tabular}{c|c|c|l}
\hline \hline $\begin{array}{c}\text { Curve } \\
\text { number }\end{array}$ & Date & $\begin{array}{c}\text { Test } \\
\text { section }\end{array}$ & \multicolumn{1}{|c}{ Description (reference) } \\
\hline \hline 0 & $5 / 18 / 90$ & 1.0 & ribless annulus (17) \\
1 & $2 / 1 / 92$ & 3.0 & ribbed annulus (19) \\
2 & $3 / 6 / 92$ & 3.1 & ribbed annulus (19) \\
3 & $3 / 7 / 92$ & 3.1 & ribbed annulus with bypass (19) \\
4 & $3 / 7 / 92$ & 3.1 & ribbed annulus with bypass (19) \\
5 & $6 / 13 / 92$ & 3.2 & ribbed annulus (19) \\
\hline
\end{tabular}

The mass flux-pressure loss demand curves are plotted in Figure 19. Figure 20 provides a detail of the minima region. The curves are consistent and display no unanticipated behavior. Figure 21 presents the pressure loss as a

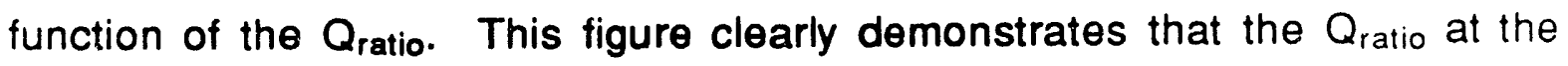
demand curve minimum is not the same for the ribbed and ribless annuli. The estimated value of the $Q_{\text {ratio }}$ for the ribbed and ribless annuli based on Equation 2 is 0.913 and 0.915 (LD $=261$ and 270). The observed variation in Figure 21 is not expected from basic theory and no explanation for this discrepancy other than the existance of a rib effect is readily apparent. 


\section{Preliminary Data -- 9 September 1993}

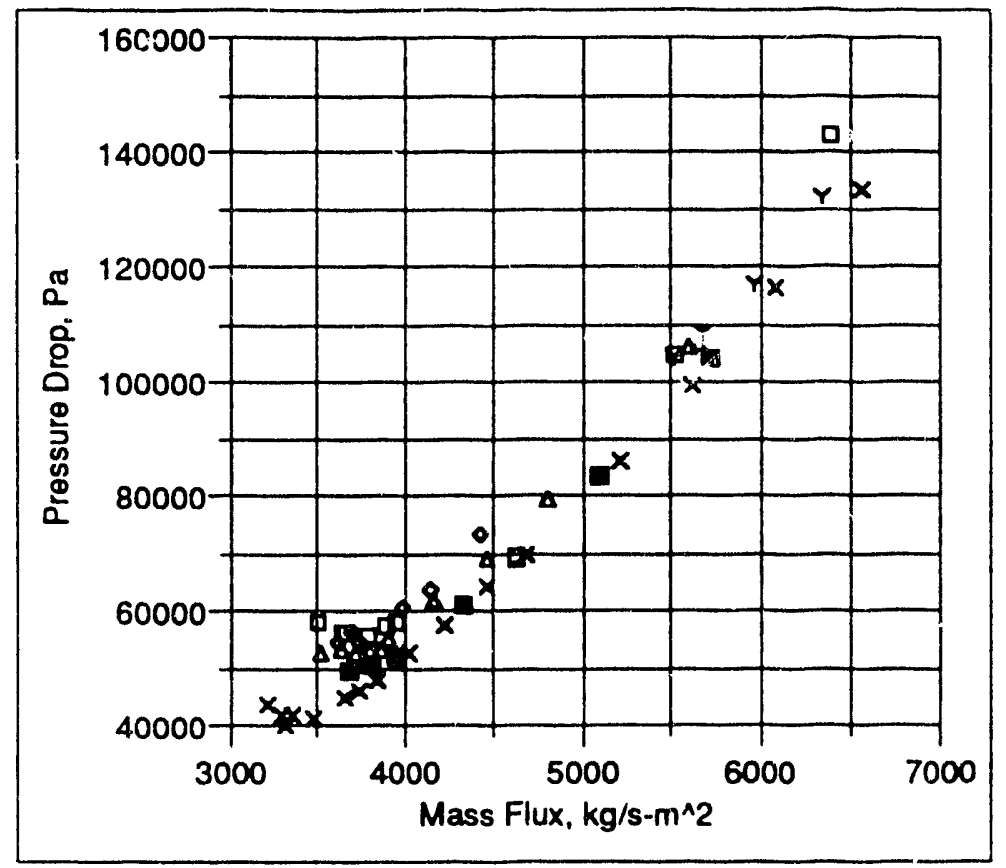

$x$ Ribless, Curve 0

- Ribbed, Curve 1

- Ribbed, Curve 2

ه Ribbed, Curve 3

- Ribbed, Curve 4

Y Ribbed, Curve 5

Figure 19, Demand curves

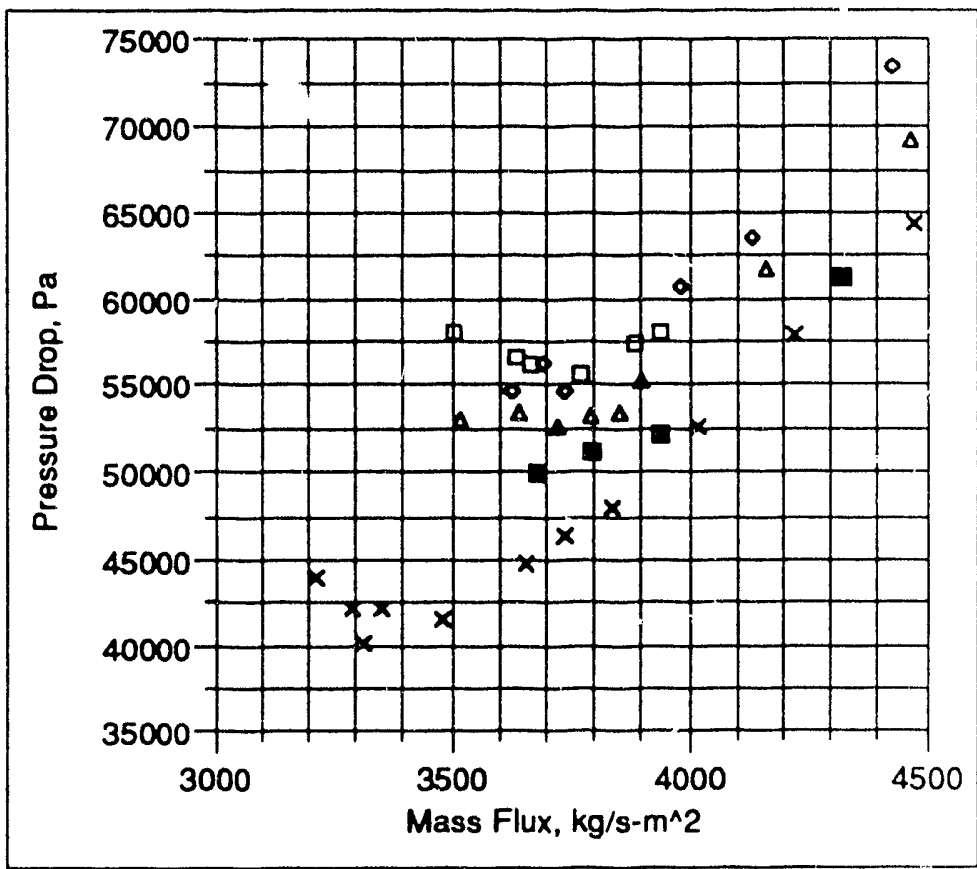

Figure 20, Demand curve details 
Prellminary Data -- 9 September 1993

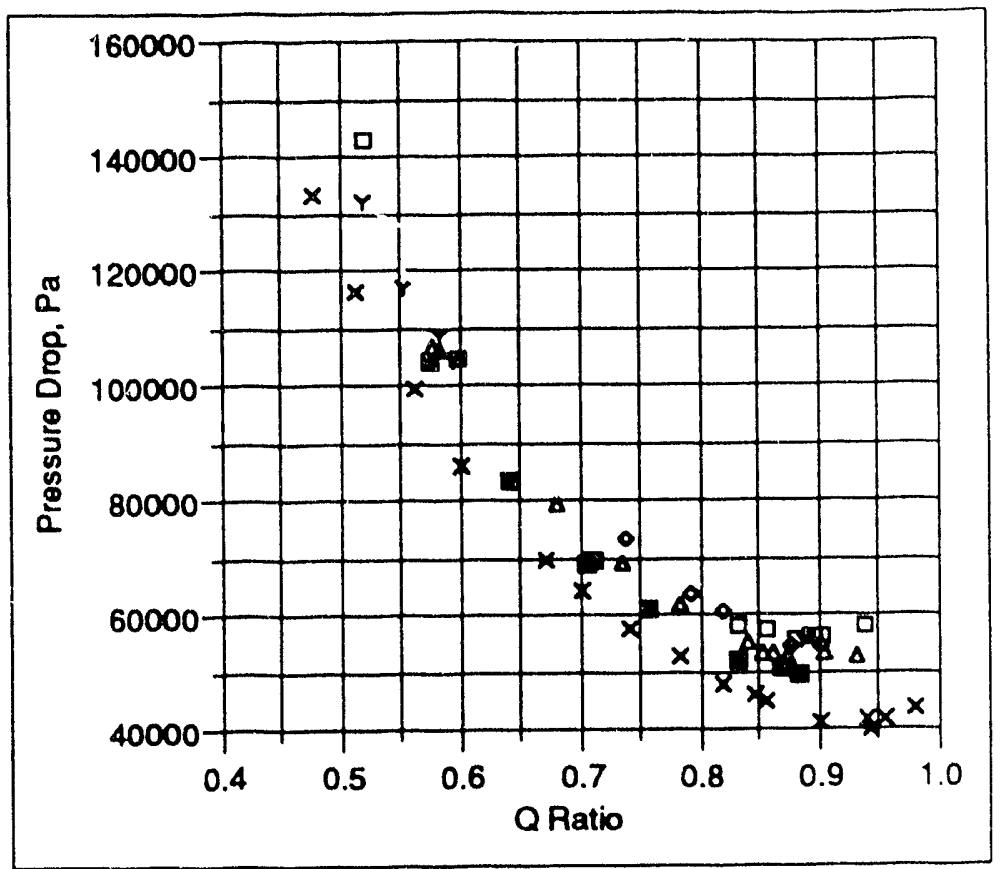

Figure 21, $Q_{\text {ratio }}$ demand curves

\section{Wall Temperature Evaluation}

The wall temperatures measured during the Columbia University OFI program were measured with both brazed and cemented thermocouples. The cemented thermocouples were considered the most accurate $(X X)$. Figures 22 and 23 present the averaged and maximum indicated temperatures for the cemented thermocouples described in Table 17. These thermocouples were located just above the stan of the heated length. These figures show that the indicated wall temperatures are not consistent; for curves 1 and 4 ; there appears to be a rapid increase in wall temperature as the demand curve minimum is approached. 


\section{Preliminary Data -- 9 September 1993}

Table 17.--Cemented thermocouple locations for Columbia University annular OFI tests

\begin{tabular}{l|c|c|c|c}
\hline \multirow{2}{*}{} & \multicolumn{2}{|c|}{ Ribless } & \multicolumn{2}{c}{ Ribbed } \\
\cline { 2 - 5 } & Channel & Location & Channel & Location \\
\hline \multirow{3}{*}{ Inner heater } & $\ldots$ & $\ldots$ & 77 & $132 \mathrm{w}$ \\
& $\ldots$ & $\ldots$ & 78 & $132 \mathrm{nw}$ \\
& $\ldots$ & $\ldots$ & 79 & $132 \mathrm{e}$ \\
& $\ldots$ & $\ldots$ & 80 & $132 \mathrm{se}$ \\
& $\ldots$ & $143 \mathrm{n}$ & 101 & $143 \mathrm{sw}$ \\
& 94 & $143 \mathrm{se}$ & 102 & $143 \mathrm{se}$ \\
& 95 & $142 \mathrm{n}$ & 103 & $143 \mathrm{ne}$ \\
& 96 & $142 \mathrm{se}$ & 104 & $143 \mathrm{nw}$ \\
\hline
\end{tabular}

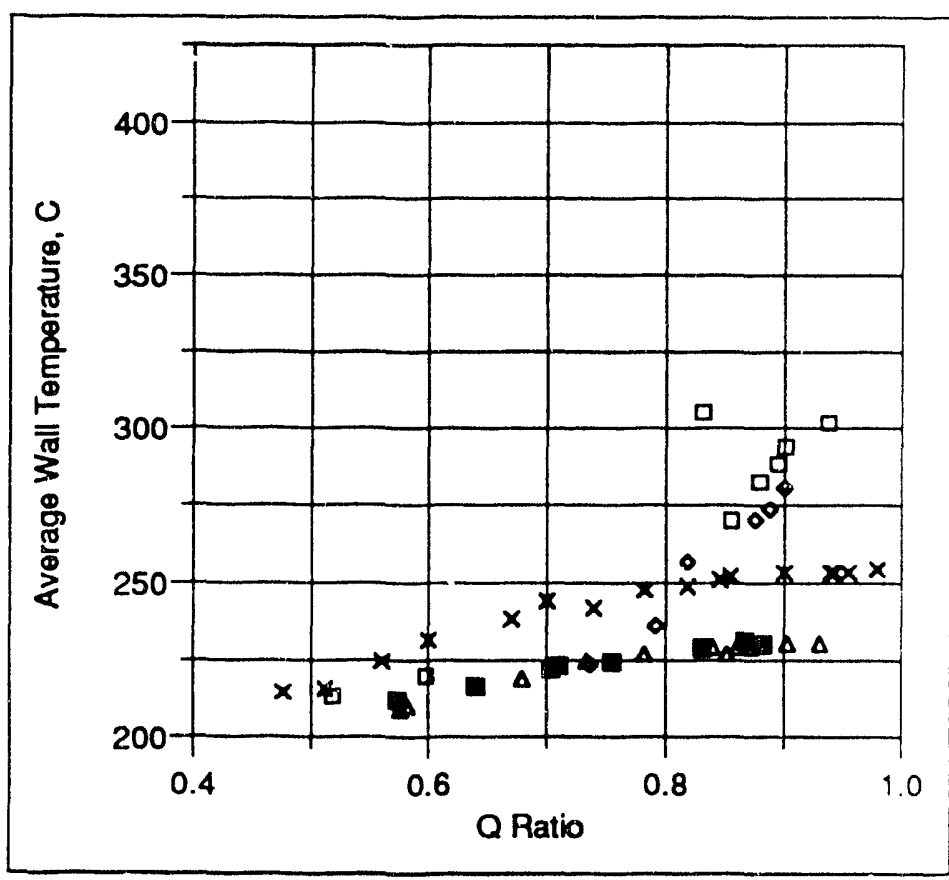

Figure 22, Average indicated temperatures for cemented TCs near the test section exit 


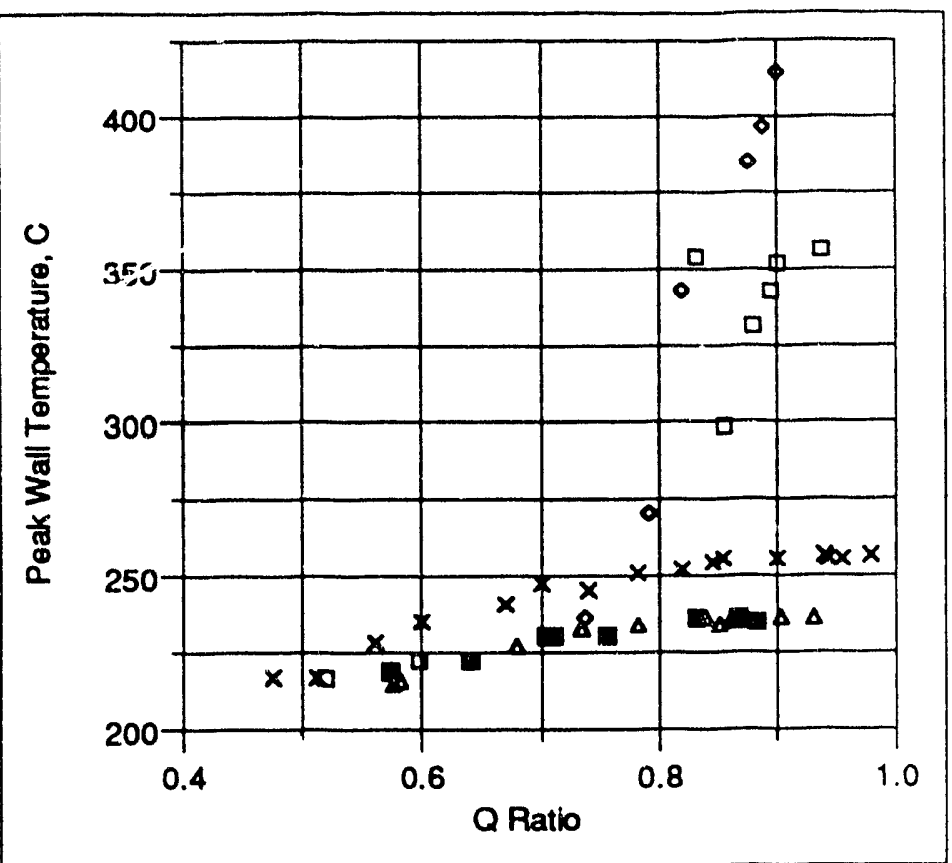

Figure 2s, Maximum indicated temperatures for cemented TCs near the test section exit

Table 18.--Columbia ribbed heater wall temperature grddient

\begin{tabular}{c|c|c|c|c}
\hline $\begin{array}{c}\text { Heat flux } \\
\mathrm{kW} / \mathrm{m}^{2}\end{array}$ & $\mathrm{~T}_{\mathrm{drv}},{ }^{\circ} \mathrm{C}$ & $\mathrm{T}_{\mathrm{ave}},{ }^{\circ} \mathrm{C}$ & $\begin{array}{c}\mathrm{k}(74) \\
\mathrm{kW} / \mathrm{m}^{2}\end{array}$ & $\begin{array}{c}\text { Temperature } \\
\text { gradient, }{ }^{\circ} \mathrm{C}\end{array}$ \\
\hline 127 & 255 & 213 & 12.5 & -83 \\
127 & 364 & 327 & 14.2 & -73 \\
190 & 335 & 276 & 13.2 & -118 \\
190 & 410 & 375 & 14.7 & -106 \\
\hline
\end{tabular}

Wall Superheat Predictions

The wetted wall temperature may be estimated using a onedimensional heat conduction analysis based on Fourier's law of heat conduction. Since the geometry is fixed, the temperature correction can be estimated for any combination of outer wall temperature (which dictates the 


\section{Preliminary Date - 9 September 1993}

thermal conductivity) and heat flux. If the behavior is assumed linear, a temperature correction term can be calculated by fitting the data in Table 18:

$$
\begin{array}{rlr}
\Delta T & =106.4-0.0917 \mathrm{~T}_{\mathrm{dry}} & \left(127 \mathrm{~kW} / \mathrm{m}^{2}\right) \\
\Delta \mathrm{T}=171.6-0.160 \mathrm{~T}_{\mathrm{dry}} & \left(190 \mathrm{~kW} / \mathrm{m}^{2}\right)
\end{array}
$$

The wall superheat can then be estimated based on the local saturation temperature and measured wall temperature. Figure 24 shows how a boiling curve can be produced by combining Equations 51, 53, and 54. Figures 25, 26. 27 , and 28 illustrate how the experimental wetted wall temperatures vary from nucleate boiling theory at the test section exits. All ribbed annulus data for 127 and $190 \mathrm{~kW} / \mathrm{m}^{2}\left(0.4\right.$ and $\left.0.6 \mathrm{MBtu} / \mathrm{hr} \cdot \mathrm{ft}^{2}\right)$ tests is presented in the respective plots. No pattern is readily apparent. Figure 29 presents a boiling curve on alternate coordinates for four different dates of operation. For lower velocities the predicted temperatures follow the boiling curve theory as observed for the same data in Figure 29. The two curves where deviation was observed in Figure 22 also deviate from theory in Figure 29. The poor behavior in the transition from forced convection to nucleate boiling is probably due to boiling curve hysteresis as discussed by Hino and Ueda (33).

A thin nonuniform layer of deposits formed on the heater surface during the ribbed testing. Holman suggests a design value fouling factor for distilled water of $0.00088^{\circ} \mathrm{C} \cdot \mathrm{m}^{2} \mathrm{~W}$. For a heat flux of $127 \mathrm{~kW} / \mathrm{m}^{2}\left(0.4 \mathrm{MBtu} / \mathrm{hr} \cdot \mathrm{ft}^{2}\right)$ the expected temperature gradient due to this level of fouling would be $111^{\circ} \mathrm{C}$. The gradient would be expected to remain relatively constant, independent of the wall temperature or to gradually increase with time. Figure 29 indicates this is not the case. 


\section{Prellminary Data -. 9 September 1993}

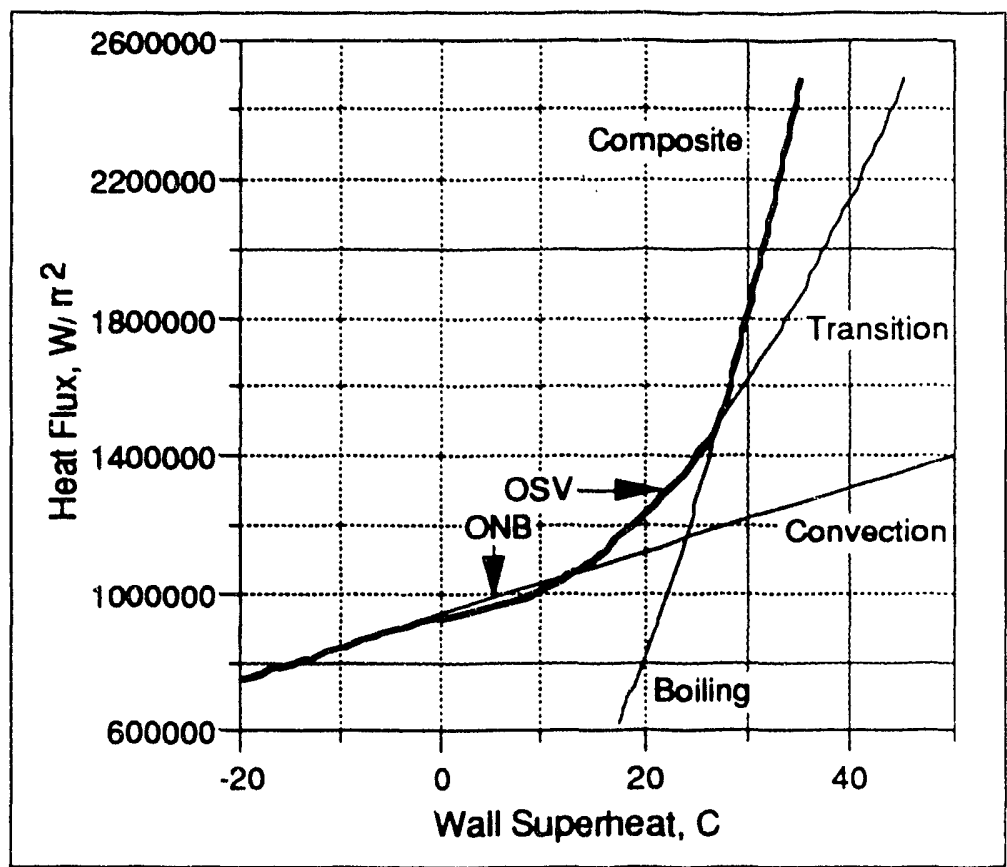

Figure 24, Boiling curve at end of test section for Columbia University ribbed annulus at a velocity of $4 \mathrm{~m} / \mathrm{s}$ and an exit pressure of $20 \mathrm{psig}$

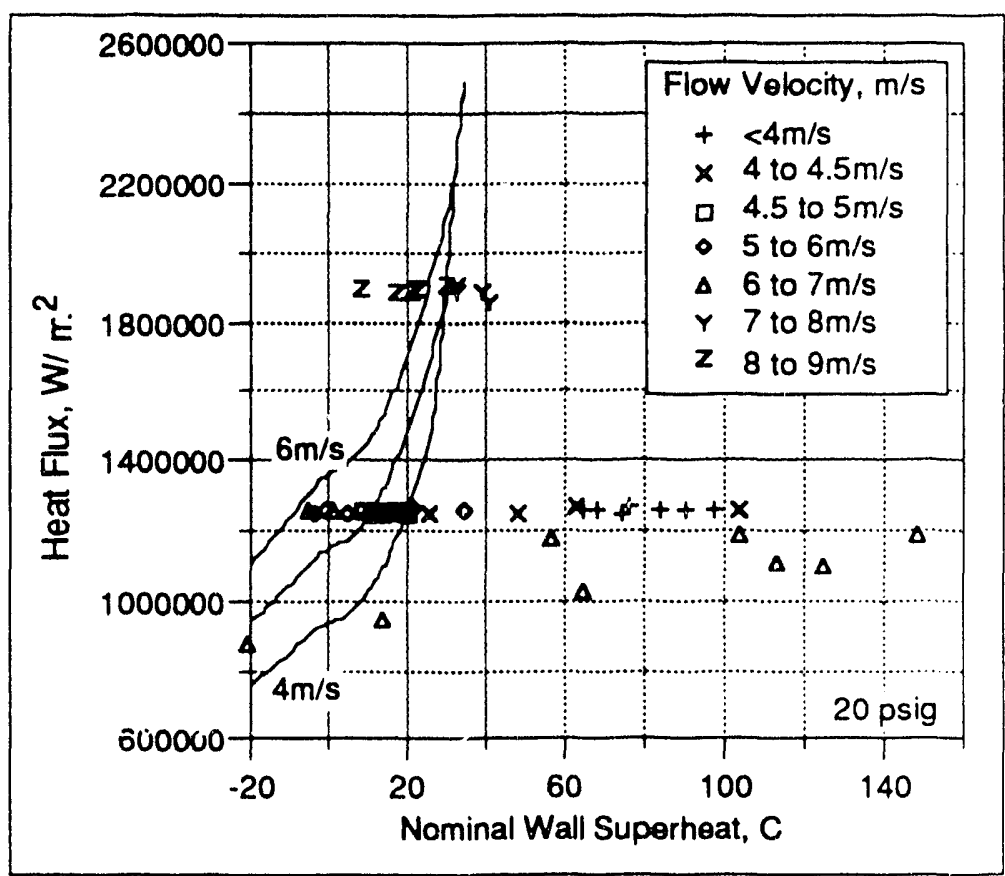

Figure 25, Nominal experimental wall superheat (20 psig) 


\section{Preliminary Data _- 9 September 1993}

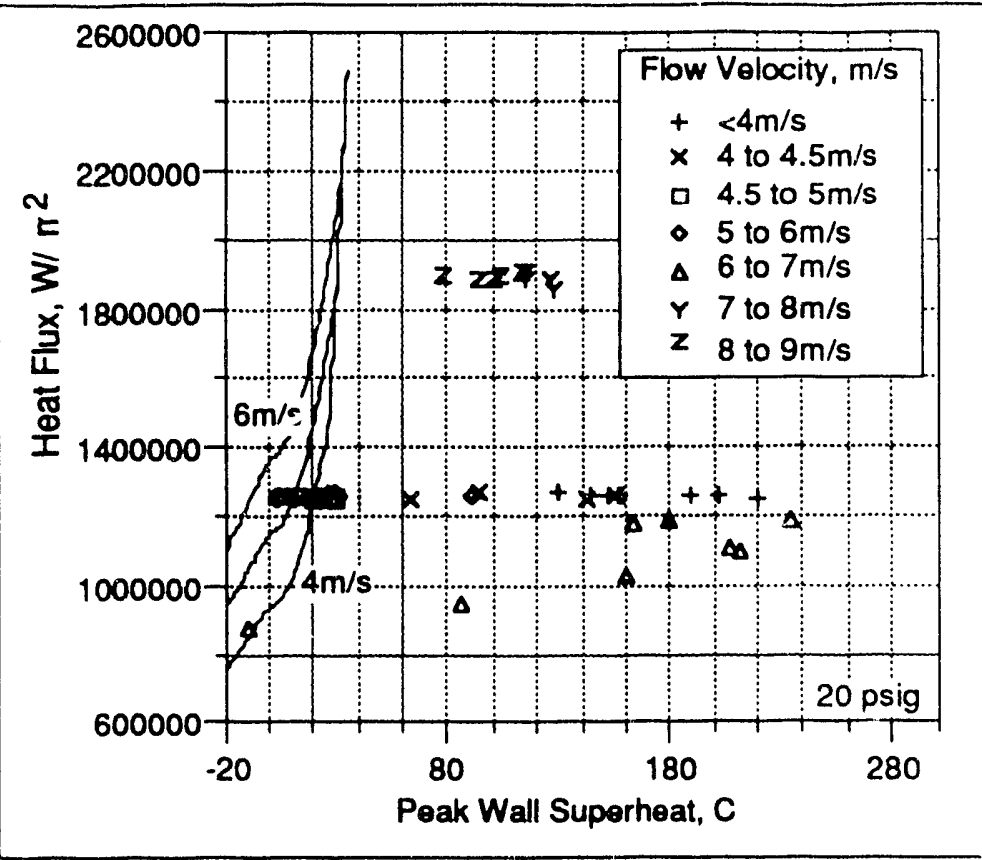

Figure 26, Peak experimental wall superheat (20 psig)

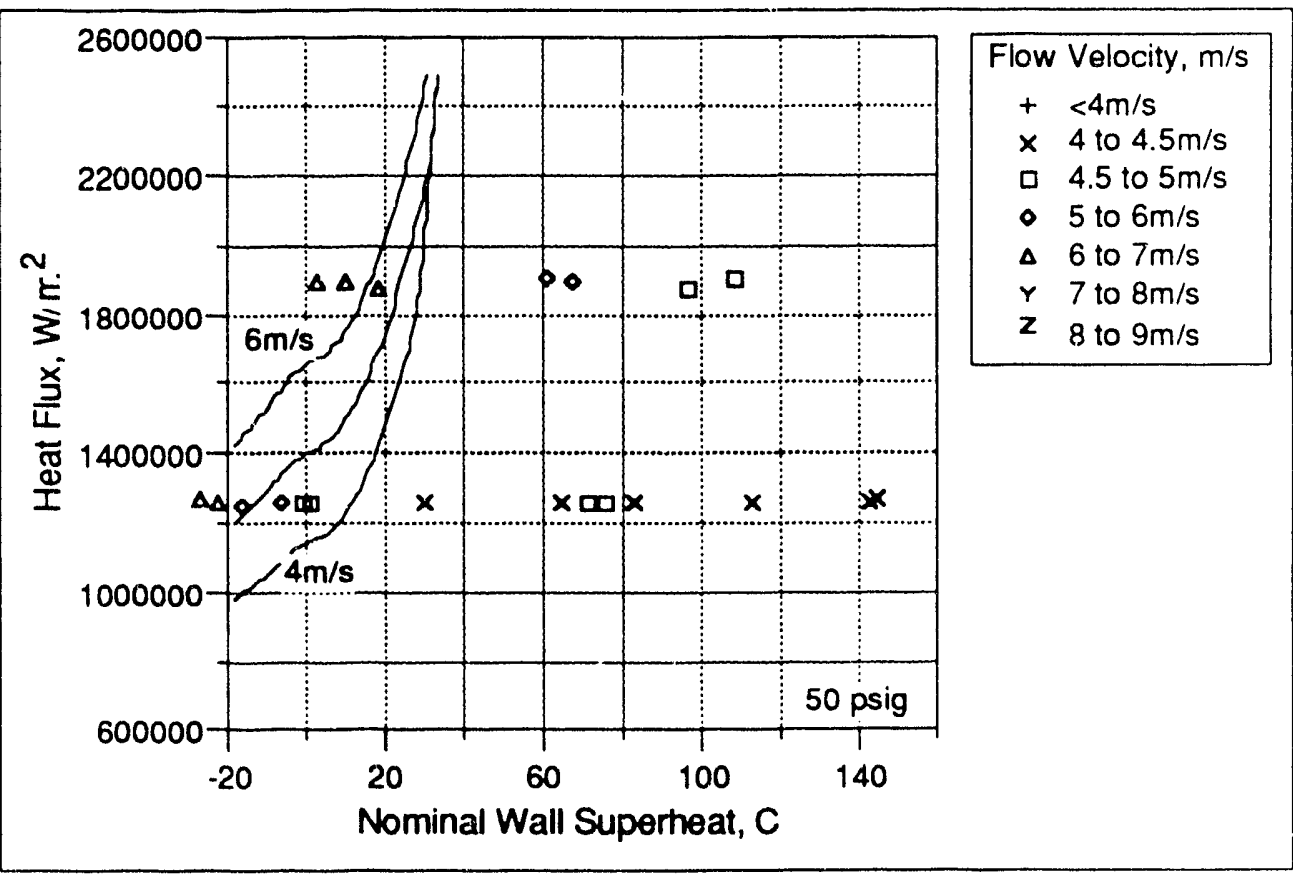

Figure 27, Nominal experimental wall superheat (50 psig) 


\section{Proliminary Data -- 9 September 1993}

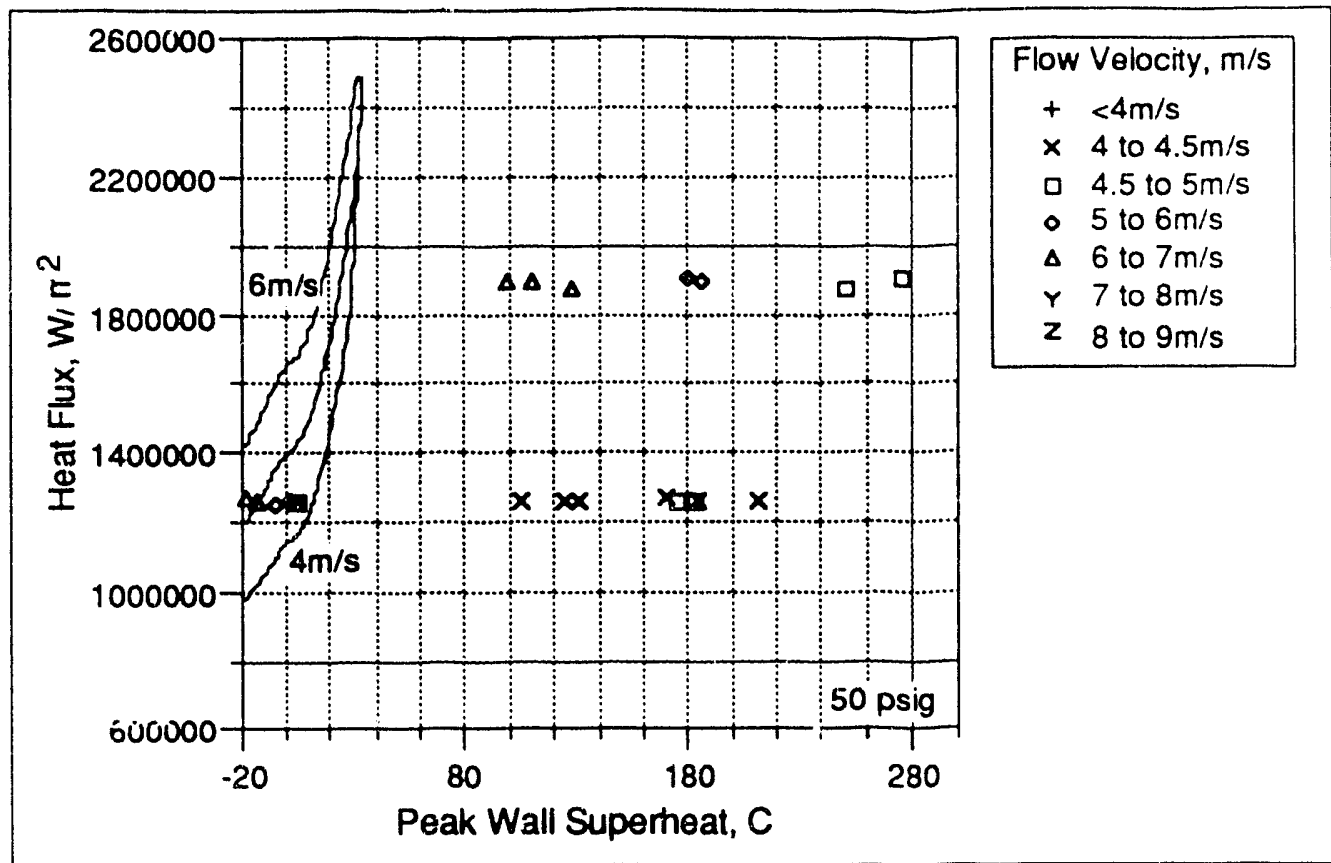

Figure 28, Peak experimental wall superheat (50 psig)

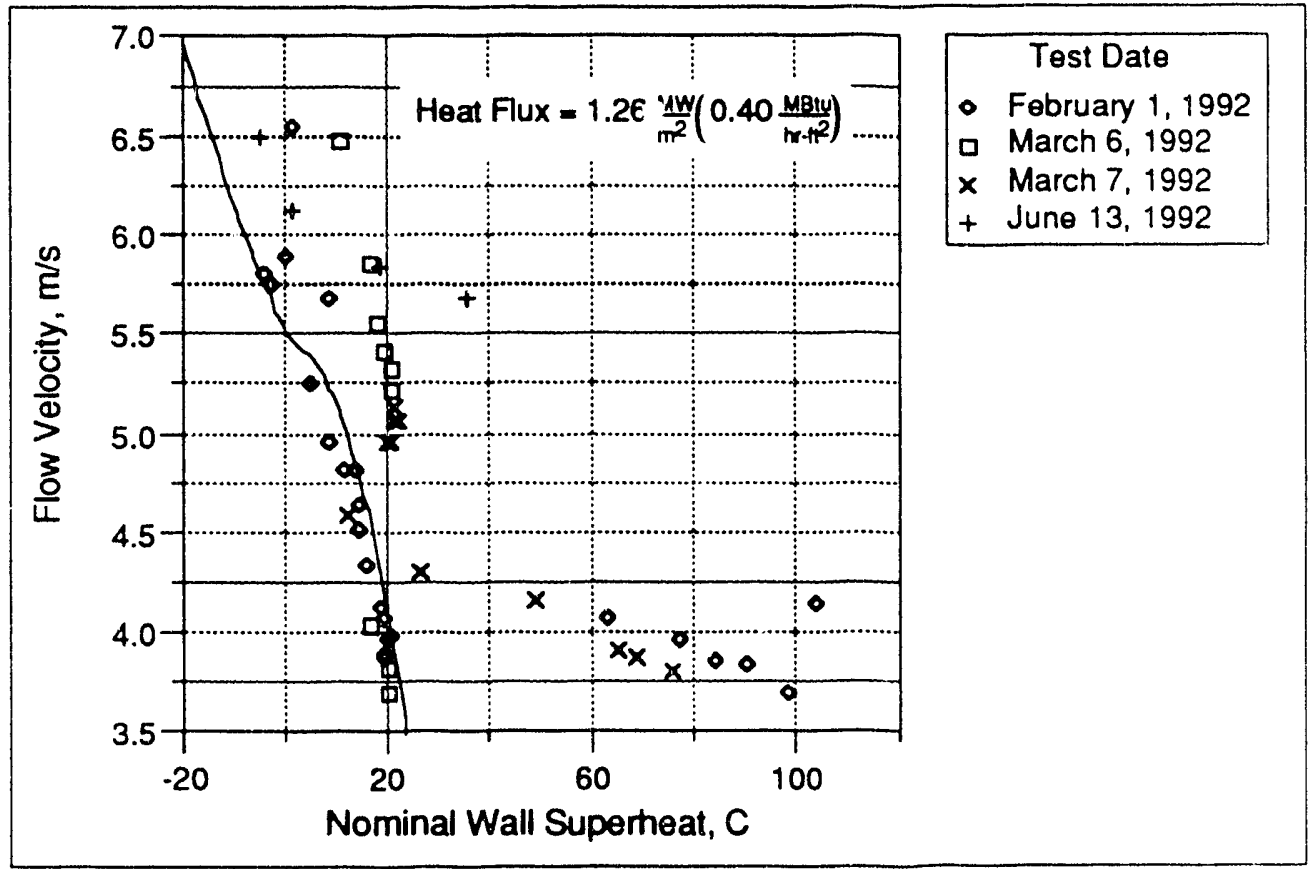

Figure 29 , Superheat variation by date of test for a heat flux of $1.26 \mathrm{MW} / \mathrm{m}^{2}(0.4$ $\left.\mathrm{MBtu} / \mathrm{hr}-\mathrm{ft}^{2}\right)$ and $20 \mathrm{psig}$ at the exit. 


\section{Preliminary Data _- 9 September 1993}

Wall Temperature Hysterisis

Figure 30 provides the $Q_{\text {ratio }}$ Demand Curve for Curve 1 in Table 16. The numbers in this figure refer to the consecutive Run Numbers that are assigned to each steady-state data set. The demand curve minimum occurred at Run Number 554. The flow was decreased beyond this minimum to the operating point at Run Number 555. The flow was then increased to operating condition 556 and the demand curve was traced a second time. Run Number 558 occurs at the same boundary conditions as Run Number 554. Figure 31 presents the axial temperature profile for Run Numbers 546, 549, 554 and 556. The highest wall temperatures shown in this figure do not occur at the demand curve minimum but occur for Run Number 556; the operating condition that was approached by increasing the flow after the demand curve minimum was reached. Figures $32,33,34$, and 35 present the indicated wall temperatures at the demand curve minimum (Run Number 554), beyond the demand curve minimum (Run Number 555), the recovered flow conditions (Run Number 556) and the second demand curve minimum operation point (Run Number 558). The indicated wall temperature profiles for the two demand curve minimum conditions are different. The recovered flow condition while displaying no hysteresis in the measured pressure drop (Figure 30 ) has a few wall temperatures (both at rib locations and flow channel centerlines) that are higher than it the demand curve minimum. It is possible that a condition occurred at a flow in the region of the demand curve minimum flow that changed the heat transfer conditions near the ribs and that recovery from this condition did not occur after increasing the flow. 


\section{Preliminary Data _- 9 September 1993}

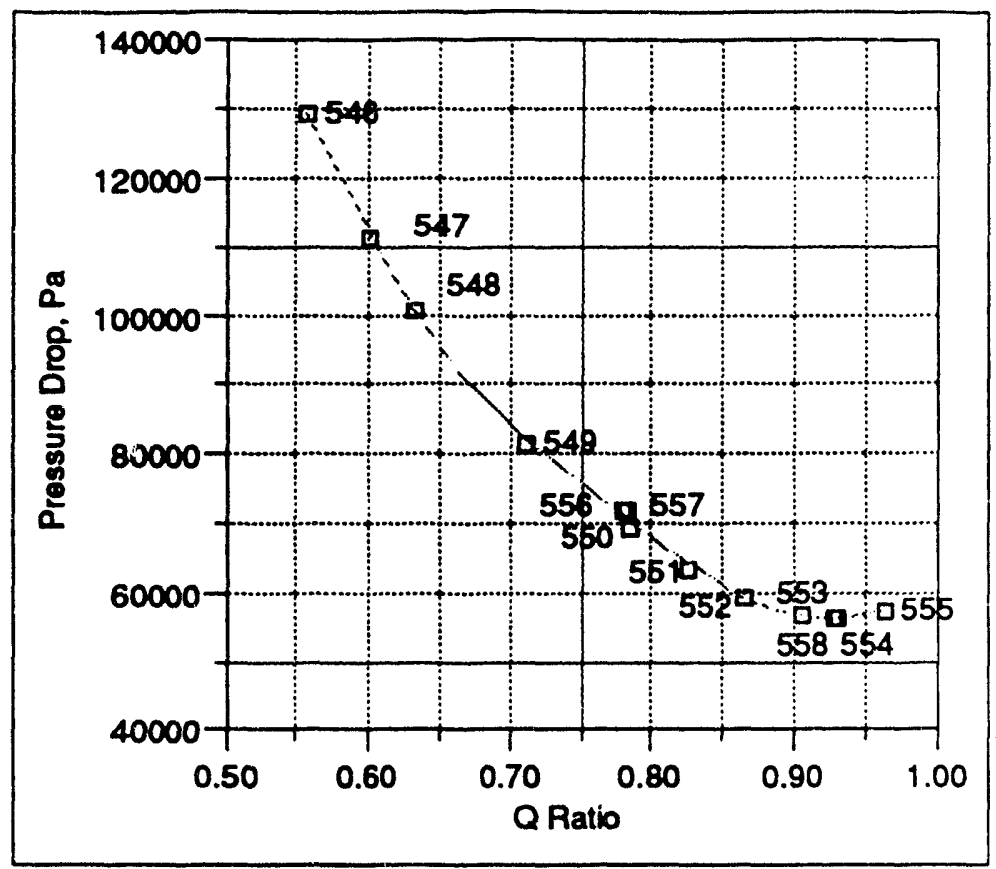

Figure 30, Q $Q_{\text {ratio }}$ Demand curve for curve number 1 (run numbers 546 to 558 )

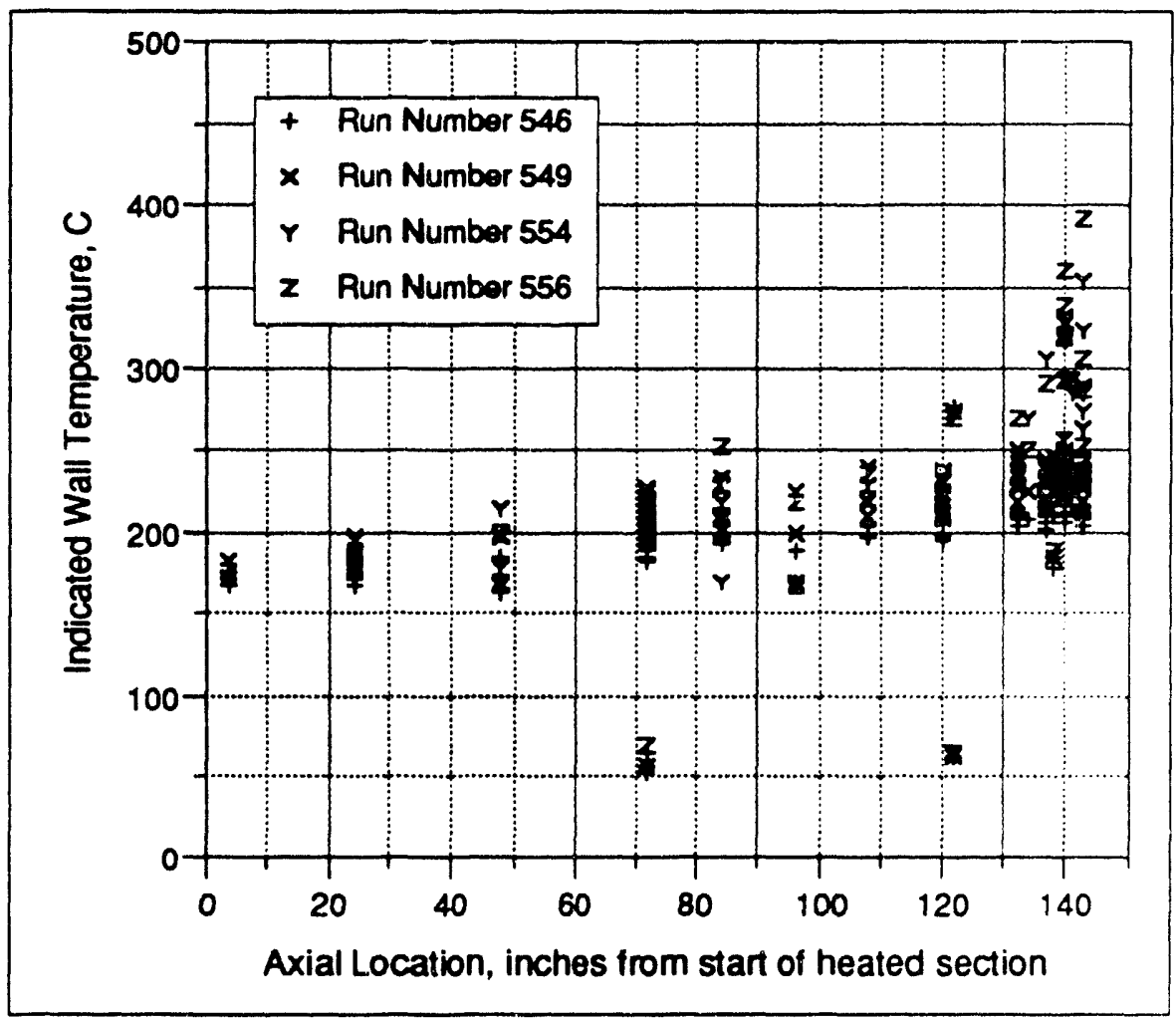

Figure 31, Axial temperature profile for selected run numbers from curve number 1 
Prellminary Data _- 9 September 1993

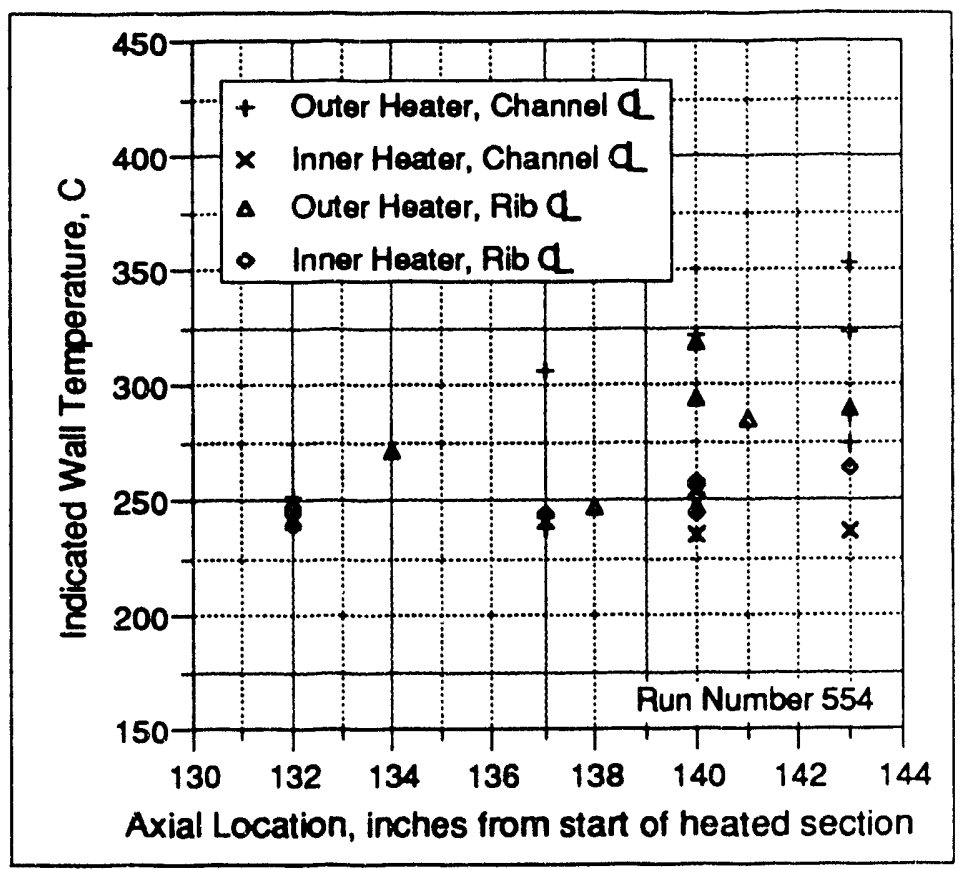

Figure 32, Axial temperature profile details for run number 554

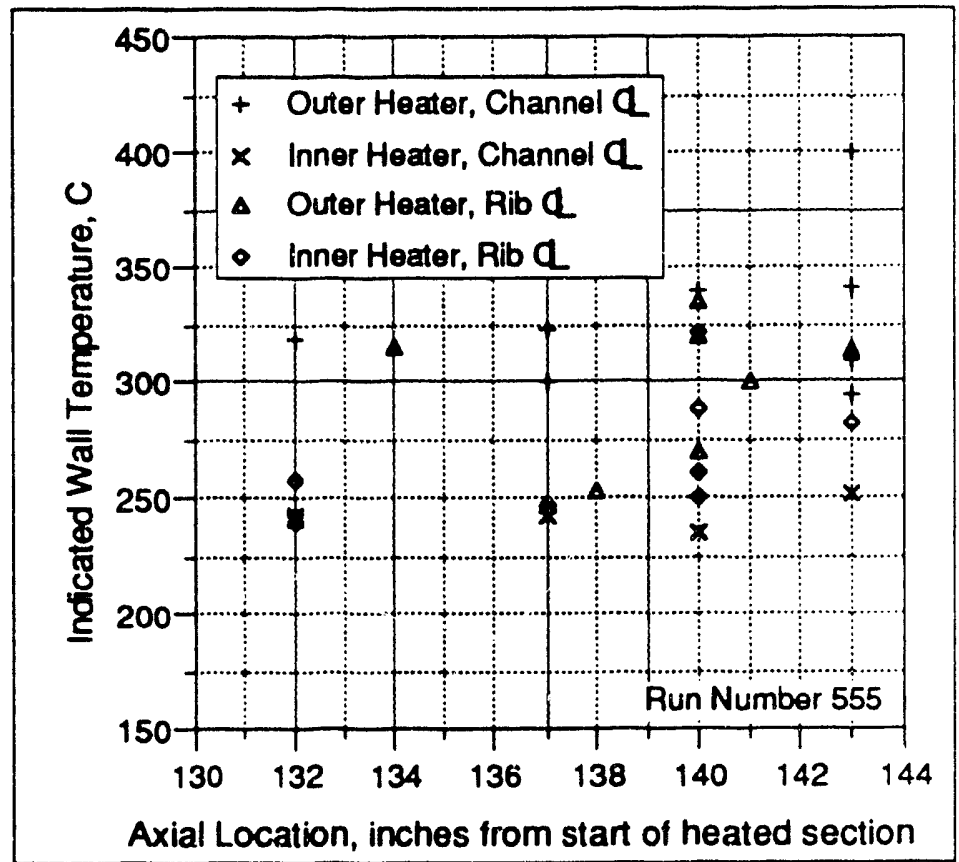

Figure 33, Axial temperature profile details for run number 555 
Prellminary Data -- 9 September 1993

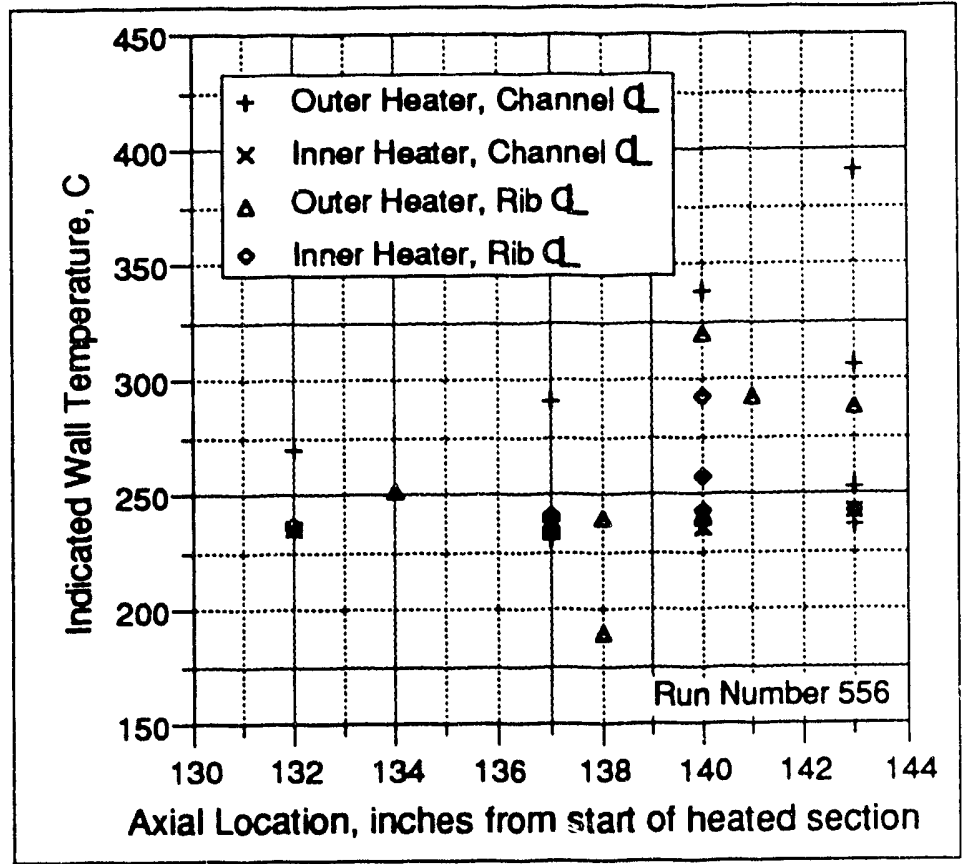

Figure 34, Axial temperature profile details for run number 556

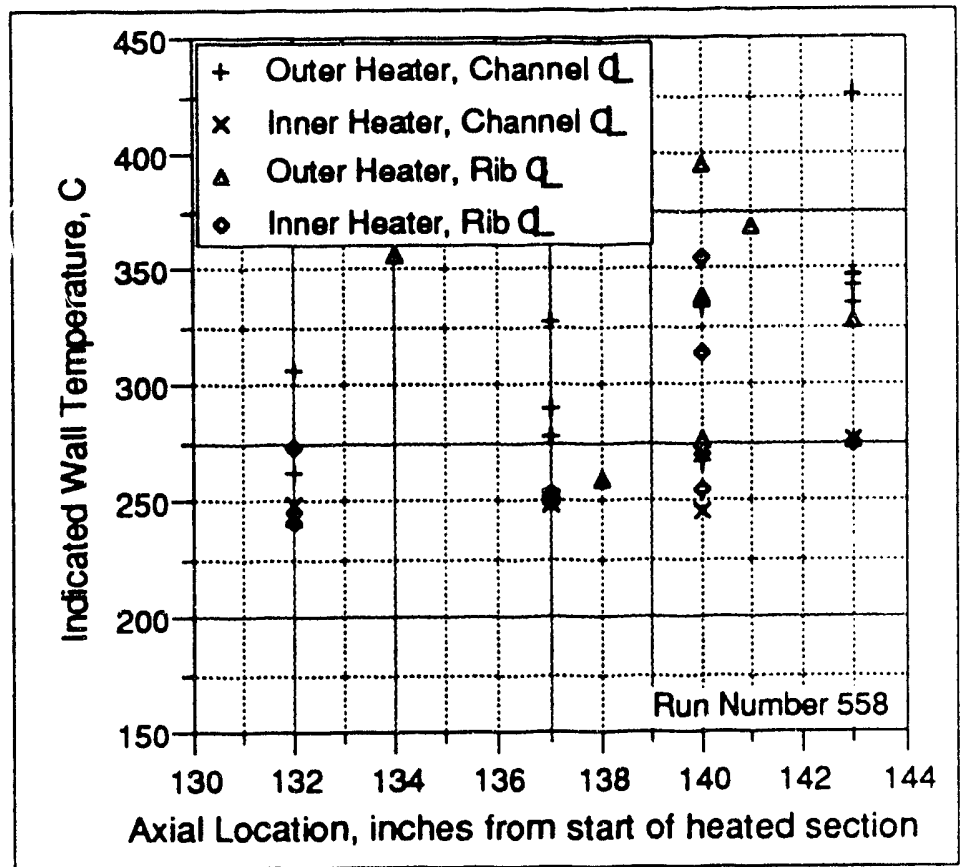

Figure 35, Axial temperature profile details for run number 558 


\section{Preliminary Data _- 9 September 1993}

Constant Flow with Increasing Heat Flux

Several test runs were made where the flow was held constant at 140 $\mathrm{gpm}$ and the heat flux was slowly increased. These test runs are presented in Table 19. Figures 36 and 37 plot the actual measured wall temperature (dry side) as a variable of the axial position. A deviation from nucleate boiling occurs between run numbers 1 and 2 (Figure 36). This is at a heat flux between 0.88 and $0.94 \mathrm{MW} / \mathrm{m}^{2}\left(0.278\right.$ and $\left.0.299 \mathrm{MBtu} / \mathrm{hr} \cdot \mathrm{ft}^{2}\right)$. The exit subcooling ( $T_{\text {sat }}$ $\left.T_{\text {bulk }}\right)$ for these runs varied from 52 to $65^{\circ} \mathrm{C}$. The mass flux was $6400 \mathrm{~kg} / \mathrm{s} \cdot \mathrm{m}^{2}$.

The heat balance of run number 6 is lower than run number 7 . This is because at run number 6 the test channel was still coming to steady state equilibrium after a power increase. This condition seems to have created hot spots (Figure 37) during the transient between two steady state conditions. These hot spots might precipitate the development of a localized stable vapor film where steady state theory would only indicate nucleate boiling.

The unpredicted wall temperature behavior has not been limited to the Columbia University ribbed annulus (27). Deviations from nucleate boiling theory were also observed in the non-ribbed annulus. In some cases these

deviations occur in the heat fluxes of $1.3 \mathrm{MW} / \mathrm{m}^{2}$. Variations were also observed in Creare tests (9). 


\section{Preliminary Data - 9 September 1993}

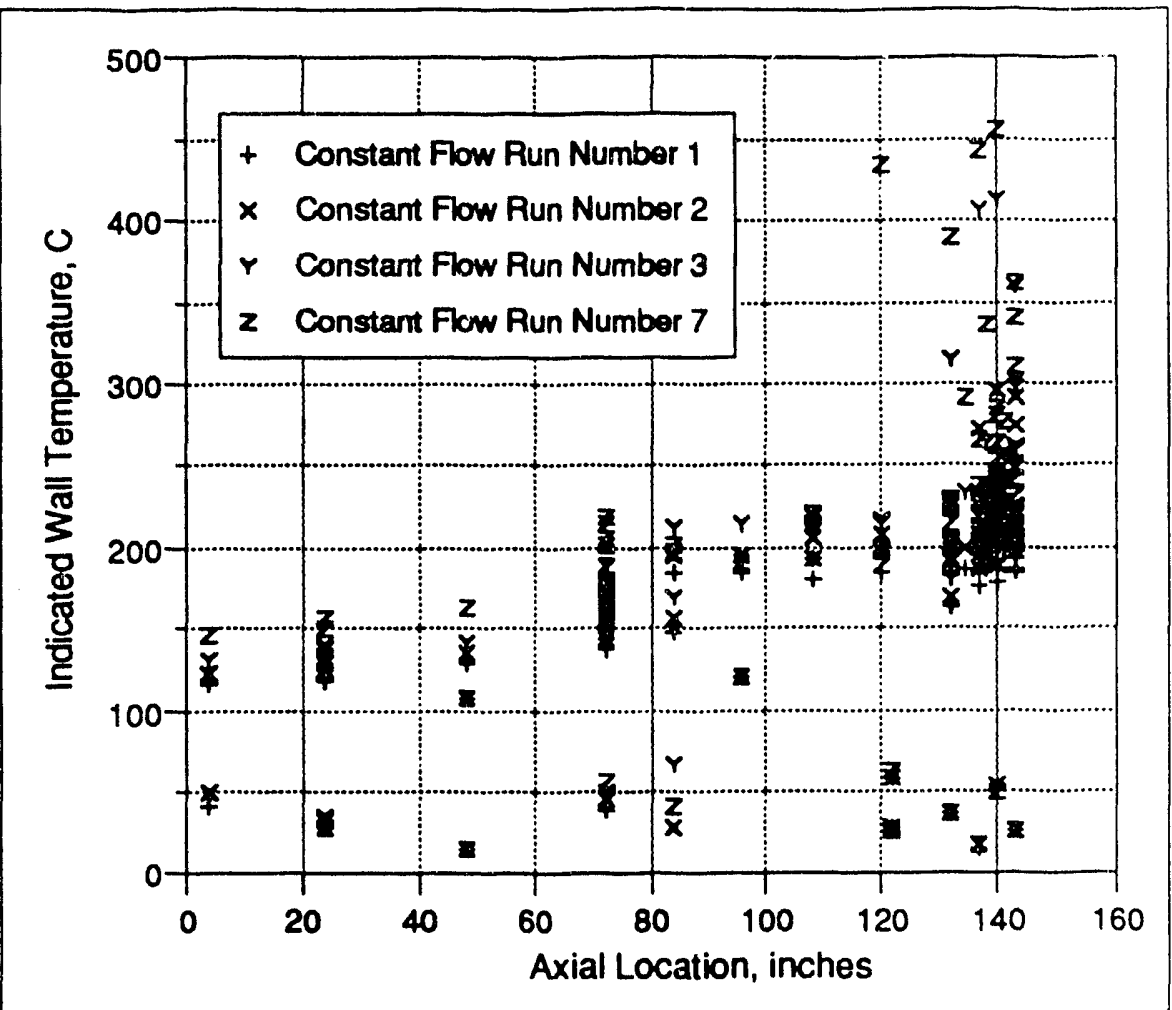

Figure 36, Axial temperature profiles for selected constant flow tests 


\section{Preliminary Date $=9$ September 1993}

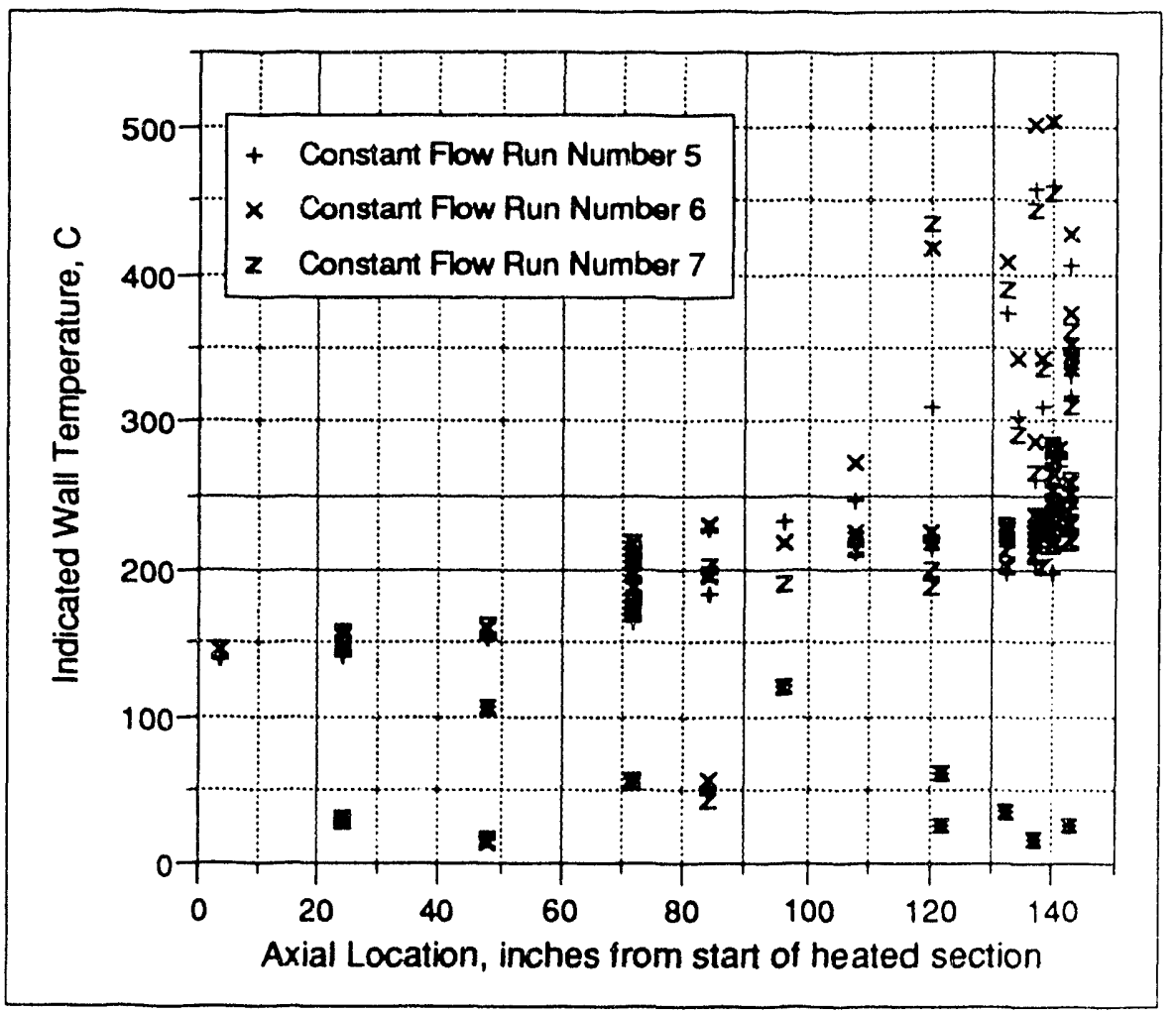

Figure 37, Axial temperature profiles for selected constant flow tests

Table 19. Operating conditions for constant flow tests (Columbia University ribbed annulus)

\begin{tabular}{c|c|c|c|c|c}
\hline $\begin{array}{c}\text { Run } \\
\text { Number }\end{array}$ & $\begin{array}{c}\text { Inner } \\
\text { Heat Flux } \\
\text { Btu/hr-ft2 }\end{array}$ & $\begin{array}{c}\text { Outer } \\
\text { Heat Flux } \\
\text { Btu/hr-ft2 }\end{array}$ & $\begin{array}{c}\text { Pressure } \\
\text { Ratio }\end{array}$ & Qratio & $\begin{array}{c}\text { Heat } \\
\text { Balance }\end{array}$ \\
\hline 1 & 0.276 & 0.278 & 0.8970 & 0.3581 & 0.9816 \\
2 & 0.303 & 0.299 & 0.8966 & 0.3858 & 0.9762 \\
3 & 0.328 & 0.326 & 0.8985 & 0.4197 & 0.9627 \\
4 & 0.347 & 0.352 & 0.9167 & 0.4508 & 0.9647 \\
5 & 0.353 & 0.349 & 0.9201 & 0.4531 & 0.9737 \\
6 & 0.374 & 0.378 & 0.9372 & 0.4881 & 0.9640 \\
7 & 0.372 & 0.374 & 0.9597 & 0.4845 & 0.9924 \\
8 & 0.399 & 0.376 & 0.9466 & 0.5035 & 0.9630 \\
\hline
\end{tabular}




\section{Prellminary Data -- 9 September 1993}

Three run numbers $(546,570$, and 629$)$ satisfy the conditions listed in Table 15 and are at a flow rate of $140 \mathrm{gpm}$. The Run Number 7 from the constant flow rate test has the same flow rate and a heat flux approaching the heat flux in Table 15 (375,000 vs. 400,000 Btu/hr-ft²). The temperature profiles for each of these four runs is presented in Figure 17. The temperature profile for Run Number 7 is similar to the non-nucleate boiling temperature profiles in Figure 4 although the temperatures near the end of the heated section are much higher.

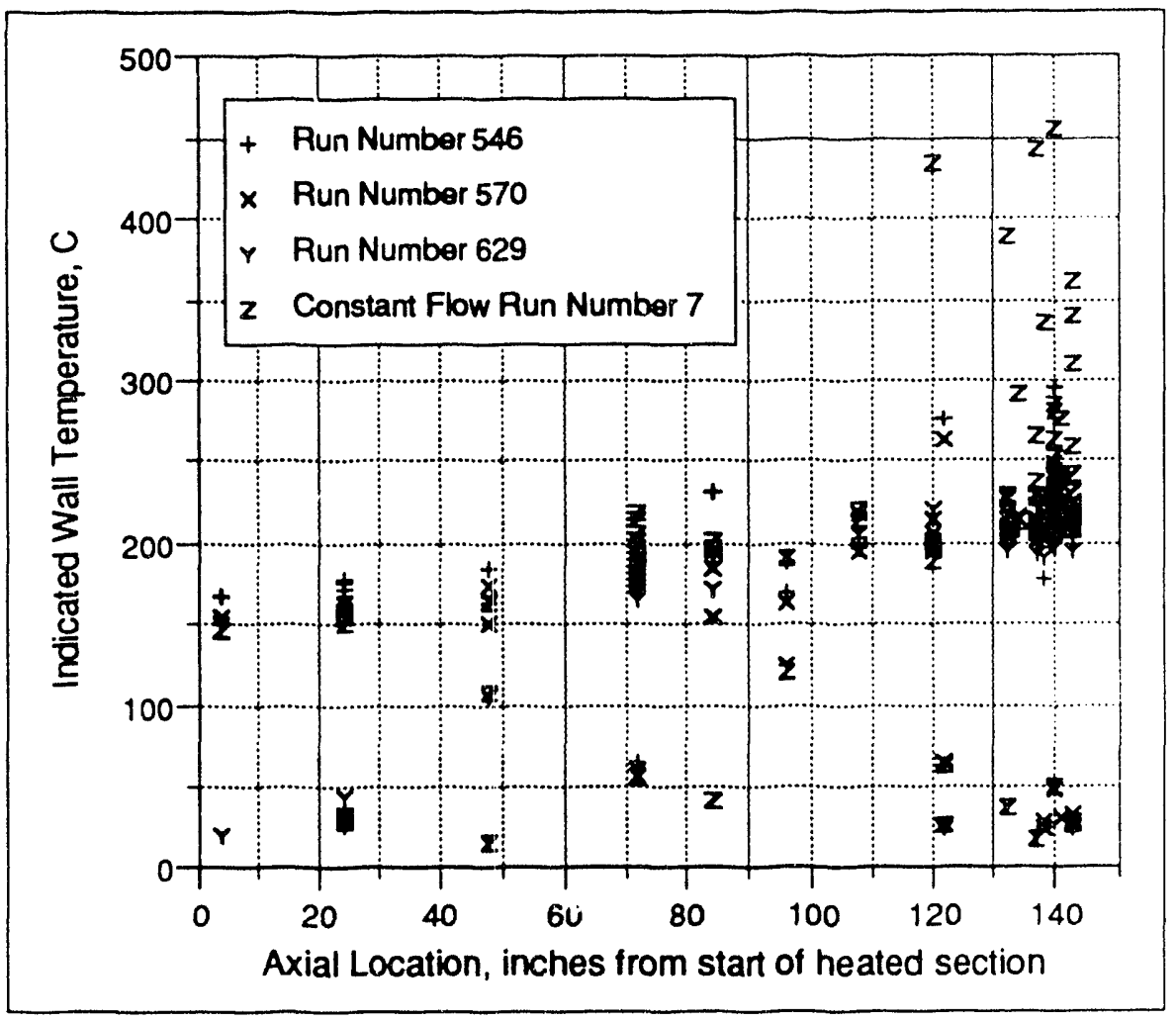

Figure 38, Axial temperature profile for a flow rate of $140 \mathrm{gpm}$ 


\section{Preliminary Data -- 9 September 1993}

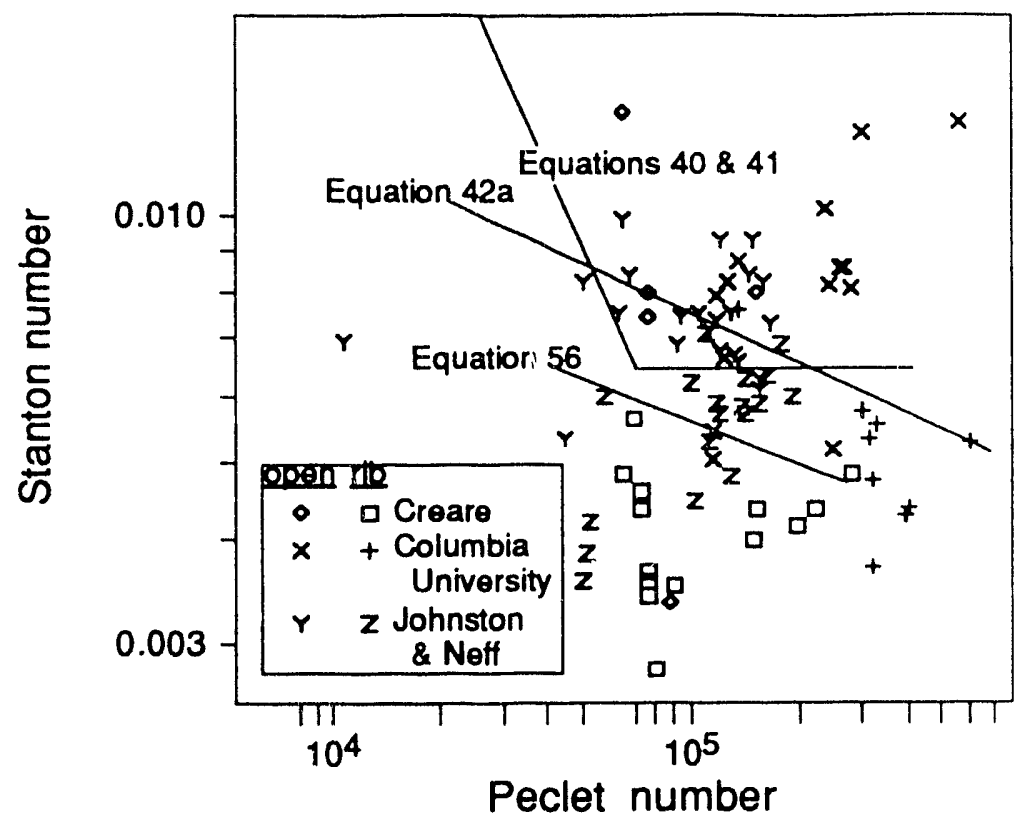

Figure 39. OFI data for geometries with spacer ribs

This behavior although describing conditions near burnout can be used to explain the behavior observed during rib testing at Columbia University. Because of the reduced velocity near the rib normal nucleate boiling correlations probably do not hold. In the limit, the region near the rib tip will approach pool boiling conditions.

While the ribbed channels in OFI testing are heat flux controlled the local phenomena in the vicinity of the rib will behave in a temperature controlled mode. The local heat transfer at the rib will transition between convection, nucleate and film boiling regimes depending on the local conditions. Once film boiling is established near the rib it will probably be stable and will remain in place until the heat flux is reduced below the limit shown in Figure 17. As discussed earlier in the section on transition boiling this threshold could be as low as $300 \mathrm{~kW} / \mathrm{m}^{2}$. 


\section{Preliminary Data -- 9 September 1993}

\section{Ribbed Annular Excursions at Columbla University}

During the ribbed annular tests conducted at the HTRF at Columbia University several DNB events occurred (19). These events were not anticipated by pretest analysis, however in retrospect it is apparent that the OFI operating limit was close to the CHF limit when a peaking factor is considered. Yang (75) suggested that the first excursion took place between 180 and 205 gpm and an inlet condition between 27 and $38^{\circ} \mathrm{C}$. The analysis will be completed for the conditions listed in Table 20.

The exit temperature is first computed using an energy balance:

$$
\begin{aligned}
T_{\text {out }} & =\frac{\phi A_{h}}{Q \rho c_{p}}+T_{\text {in }} \\
& =\frac{\left(2.52 \frac{\mathrm{ww}}{\mathrm{m}^{2}}\right)\left(1.529 \mathrm{~m}^{2}\right)}{\left(0.0121 \frac{\mathrm{m}^{3}}{\mathrm{~s}}\right)\left(997 \frac{\mathrm{kg}}{\mathrm{m}^{3}}\right)\left(4191 \frac{\mathrm{J}}{\mathrm{kg} \cdot \mathrm{K}}\right)}+32.2^{\circ} \mathrm{C} \\
& =108^{\circ} \mathrm{C}
\end{aligned}
$$

The bulk fluid temperature would then be:

$$
\mathrm{T}_{\text {bulk }}=\frac{148^{\circ} \mathrm{C}-32.2^{\circ} \mathrm{C}}{2} \approx 72^{\circ} \mathrm{C}
$$

The heat flux necessary to bring the system to saturation may be computed using an energy balance.

$$
\begin{aligned}
\phi_{\text {sat }} & =\frac{Q \rho C_{p}}{A_{h}}\left(T_{\text {sat }}-T_{\text {in }}\right) \\
& =\frac{\left(0.0121 \frac{\mathrm{m}^{3}}{\mathrm{~s}}\right)\left(997 \frac{\mathrm{ko}}{\mathrm{m}^{3}}\right)\left(4191 \frac{\mathrm{J} \cdot \mathrm{k}}{\mathrm{kg} \cdot \mathrm{K}}\right)}{\left(1.529 \mathrm{~m}^{2}\right)}\left(148^{\circ} \mathrm{C}-32.2^{\circ} \mathrm{C}\right) \\
& =3.83 \frac{\mathrm{mw}}{\mathrm{m}^{2}} \\
& =1.21 \frac{\mathrm{MBw}}{\mathrm{hr} \cdot \mathrm{t}^{2}}
\end{aligned}
$$




\section{Preliminary Deta -- 9 September 1993}

Using the most recent CHF correlation developed by Columbia University for Inconnel is (18):

$$
\begin{aligned}
\phi_{C H F} & =0.591\left(1.21 \frac{\mathrm{MBw}}{\mathrm{hr} \cdot \mathrm{h}^{2}}\right)+0.628 \\
& =1.34 \frac{\mathrm{MBw}}{\mathrm{hr} \cdot \mathrm{H}^{2}} \\
& =4.24 \frac{\mathrm{m}}{\mathrm{m}^{2}}
\end{aligned}
$$

The rib effect as propsed by Yang (75) would then be:

$$
\mathrm{K}_{\text {rib }}=\frac{2.52 \frac{\mathrm{mW}}{\mathrm{m}^{2}}}{4.24 \frac{\mathrm{mW}}{\mathrm{m}^{2}}}=0.594
$$

\begin{tabular}{|c|c|c|c|}
\hline & $\begin{array}{c}\text { First } \\
\text { DNB event } \\
\end{array}$ & $\begin{array}{c}\text { Second } \\
\text { DNB event }\end{array}$ & Burnout \\
\hline 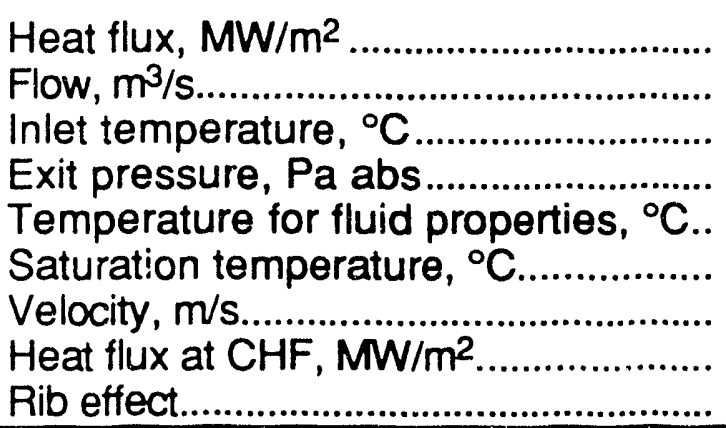 & $\begin{array}{c}2.52 \\
0.0121 \\
32.2 \\
446,000 \\
72 \\
148 \\
8.6 \\
4.24 \\
0.594 \\
\end{array}$ & $\begin{array}{c}1.91 \\
0.00630 \\
27.3 \\
442,000 \\
78 \\
147 \\
4.88 \\
3.22 \\
0.594 \\
\end{array}$ & $\begin{array}{c}1.40 \\
0.00221 \\
25.1 \\
447,000 \\
75 \\
148 \\
1.71 \\
2.97 \\
0.471 \\
\end{array}$ \\
\hline
\end{tabular}

Table 2n.--DNB and burnout conditions in the Columbia University ribbed annulus test

A second temperature excursion occurred during the third demand curve test (runs 614 to 620 ) near the OFI flow rate (99 gpm). 47 The conditions near excursion are listed in Table 20. 


\section{Preliminary Data -29 September 1993}

The last demand curve attempted using the ribbed annular rib resulted in a burrout. Figure 1 presents a schematic of the heater damage. The horizontal crack was 11-1/2" from the end of the heater. An 18" long black burn mark started 23-3/8" from the end of the heater. Near the horizontal crack the burn was $1-1 / 2^{n}$ wide. It is not clear if this failure was the result of $\mathrm{CHF}$ or pressure drop oscillations. The heater damage is similar to that observed by Maulbetch and Griffith (52) in their investigation of the pressure drop oscillation FI. The heated diameter increased for this test to $1.18^{n}$ with an $L_{h} / D_{h}$ of 122 , since only the inner wall is heated. The revised heated area would be 0.685 $\mathrm{m}^{2}$. The $Q_{\text {ratio }}$ would then be 0.83 . At the excursion the $Q_{\text {ratio }}$ was 0.84 . Figure 20 does not indicate a minimum had been reached, however, the curve is so flat it is possible that operation was at a flow below the minimum. The conditions just prior to the burnout are listed in Table 20. 


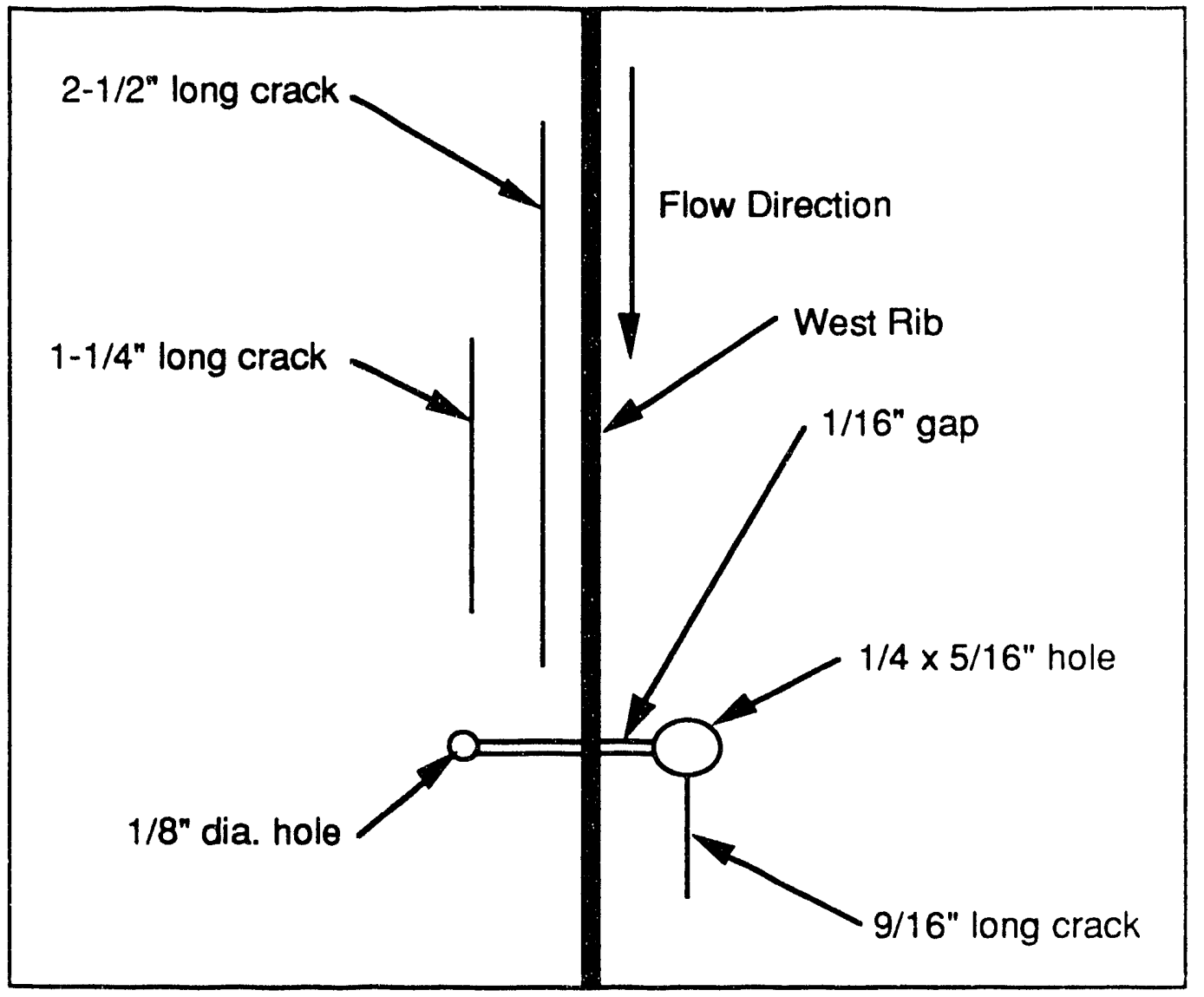

Figure 40 , Schematic of Columbia University ribbed annuls burnout

Jones, Mc.Assey, and Yang (38) developed an analytical solution for the peaking factor in the presence of a non-conducting rib. Their basic assumption is that the heat transfer at the rib tip must be zero and the solution is of the form:

$$
\frac{B i(x)}{B i_{0}}=\left(1+0.001 \eta_{v}^{-p}\right)^{-1}
$$

where the Biot number is defined as $B i(x)=h\left(\eta_{v}\right) y_{\text {plate }} / k_{\text {plate }}$, and $\eta_{v}$ is the nondimensionalized distance $\left(x / H_{v}\right)$ from the rib as shown in Figure 41 . The solution was for uniform internal heat generation it is interesting that the 


\section{Preliminary Date -- 9 September 1993}

peaking factor estimate did not vary appreciably for a wide range of values of both $p$ and $\eta_{v}$. The calculated rib effect was , this is consistant with the three DNB events during the Columbia University ribbed annulus testing. While

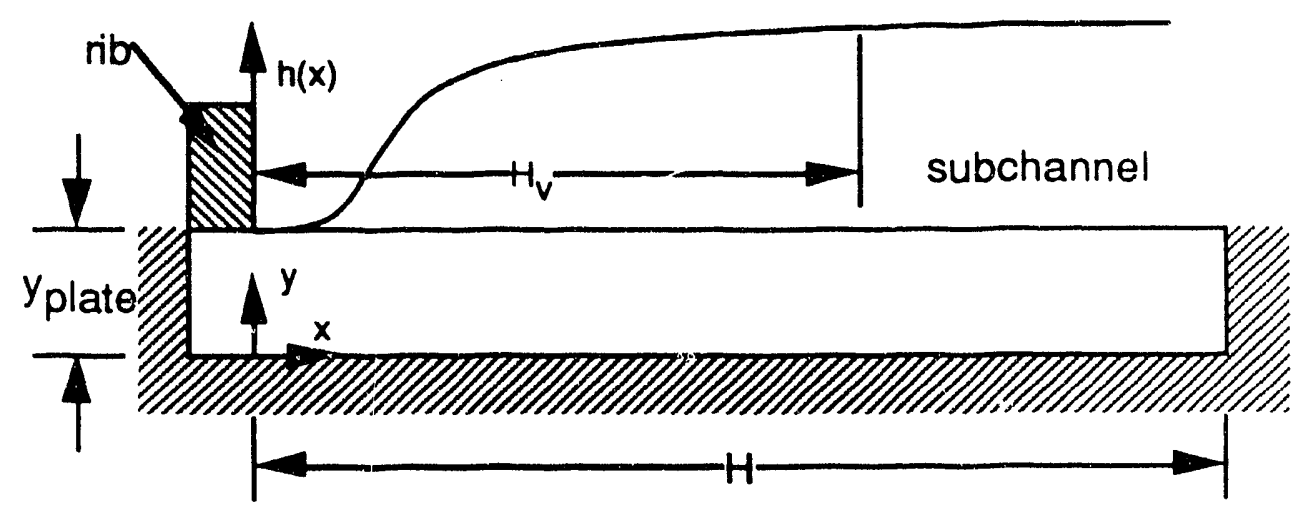

Figure 41. Nomenclature as used for analysis by Jones, McAssey, and Yang.

Rib Effects on Channel Hydraulics

The effect of placing an obstruction such as a rib in a channel to create two subchannels will be an increase in the frictional pressure drop. This can be demonstrated using the following example. The frictional pressure loss in a channel is proportional to the mass flux squared and the inverse of the hydraulic diameter.

$$
\Delta p \propto \frac{G^{2}}{D_{\theta}}
$$

For a rectangular channel ( $a$ by $b$ ) at a given mass flux:

$$
\Delta p \propto \frac{a+b}{2 a \cdot b}
$$




\section{Preliminary Data $=2$ September 1993}

A thin rib inserted in the flow channel will increase the hydraulic diameter such that:

$$
\Delta p \propto \frac{2+2 \dot{b}}{2 a \cdot b}
$$

A rib effect based on the hydraulic diameter effects would than be:

$$
K_{\text {rib }}=\frac{\Delta p_{\text {rib }}}{\Delta p_{\text {open }}}=\frac{a+2 b}{a+b}
$$

When the rib thickness, $x_{0}$, is included:

$$
K_{\text {rib }}=\frac{a\left(a+2 b-2 x_{0}\right)}{(a+b)\left(a-x_{0}\right)}
$$

For the test section used in this program the hydraulic diameter rib effect would be 1.016 or a 1.6 percent increase in pressure drop for a give set of mass flux conditions.

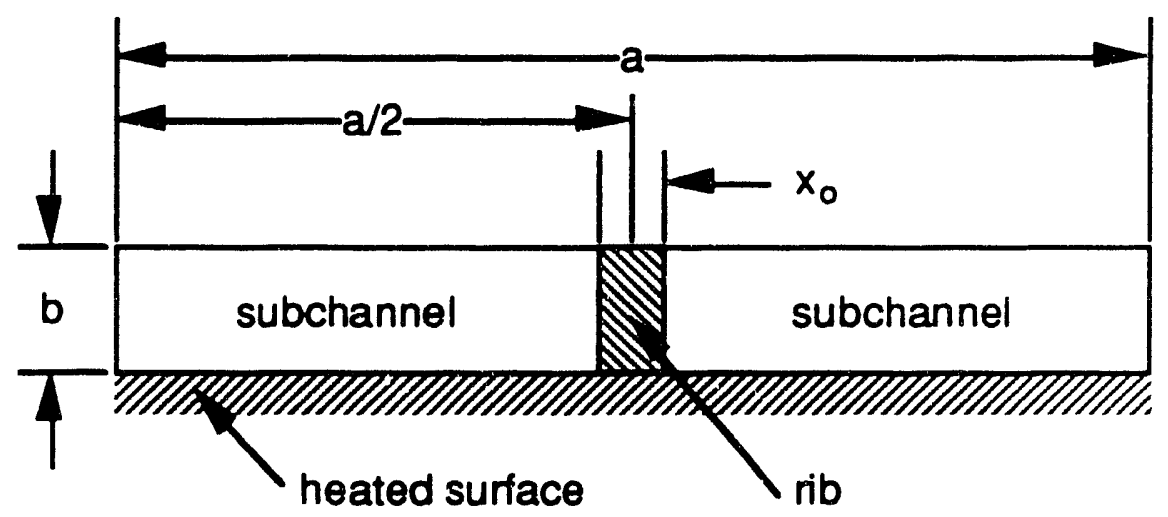

Figure 42. Schematic of subdivided flow channel 


\section{Prellminary Date _- 9 September 1993}

Using Equation 2, OFI Q Q ratio for a rectangular flow channel with and without a rib can be predicted. The heated diameters of the open and ribbed channël shòwn in Figüre 42 arè equal.

$$
\begin{gathered}
\left.D_{h}\right|_{\text {open }}=\frac{4 a b}{a}=4 b \\
\left.J_{h}\right|_{\text {ribbed }}=\frac{4\left(a b-b x_{0}\right)}{a-x_{0}}=4 b \\
\left.D_{h}\right|_{\text {subchannel }}=\frac{4 \frac{\left(a b-b x_{0}\right)}{2}}{\frac{a}{2}-\frac{x_{0}}{2}}=4 b
\end{gathered}
$$

Using the relation by Whittle and Forgan no rib effect would be predicted however because of non-similarities (hot spots, mechanical imperfections, etc.) between the subchannels a flow excursion would be expected to first occur in one subchannel. 


\section{Preliminary Date .- 9 September 1993}

\section{CHAPTER 3}

\section{TEST FACILITY}

The test facility used for all of the diabatic tests was a closed loop system which could be operated in both a steady state and transient mode. The system was designed to allow independent control of flow rate, exit pressure, inlet temperature and heat flux. Typical measurements made during testing included: volumetric flow rate, channel exit pressure, channel pressure drop, fluid inlet temperature, channel fluid exit temperature, heater surface temperature, heater electrical current, and heater voltage. These measurements were made using a Macintosh II, computer. The flow loop was installed at in the Heat Transfer Laboratory, Building 786-A at the Savannah River Site in Aiken, South Carolina. The test loop is pictured in Figure 43.

\section{Instrumentation Nomenclature}

The nomenclature used in assigning the instrument numbers is presented in Table 21. This nomenclature was maintained in all of the DAS data collection worksheets, data reduction programs, and data analysis work.

\section{Flow Loop}

Figure 44 provides the flow loop schematic. Table 22 lists the principle loop components. The three supply pumps provided an almost constant supply pressure at the pump discharge header. The flow controller valve was designed to maintain a set flow regardless of downstream pressure variations. The nominal flow dimensions for the heated channel were $3.2 \mathrm{~mm}$ by $76 \mathrm{~mm}$ 
Preliminary Data -. 9 September 1993

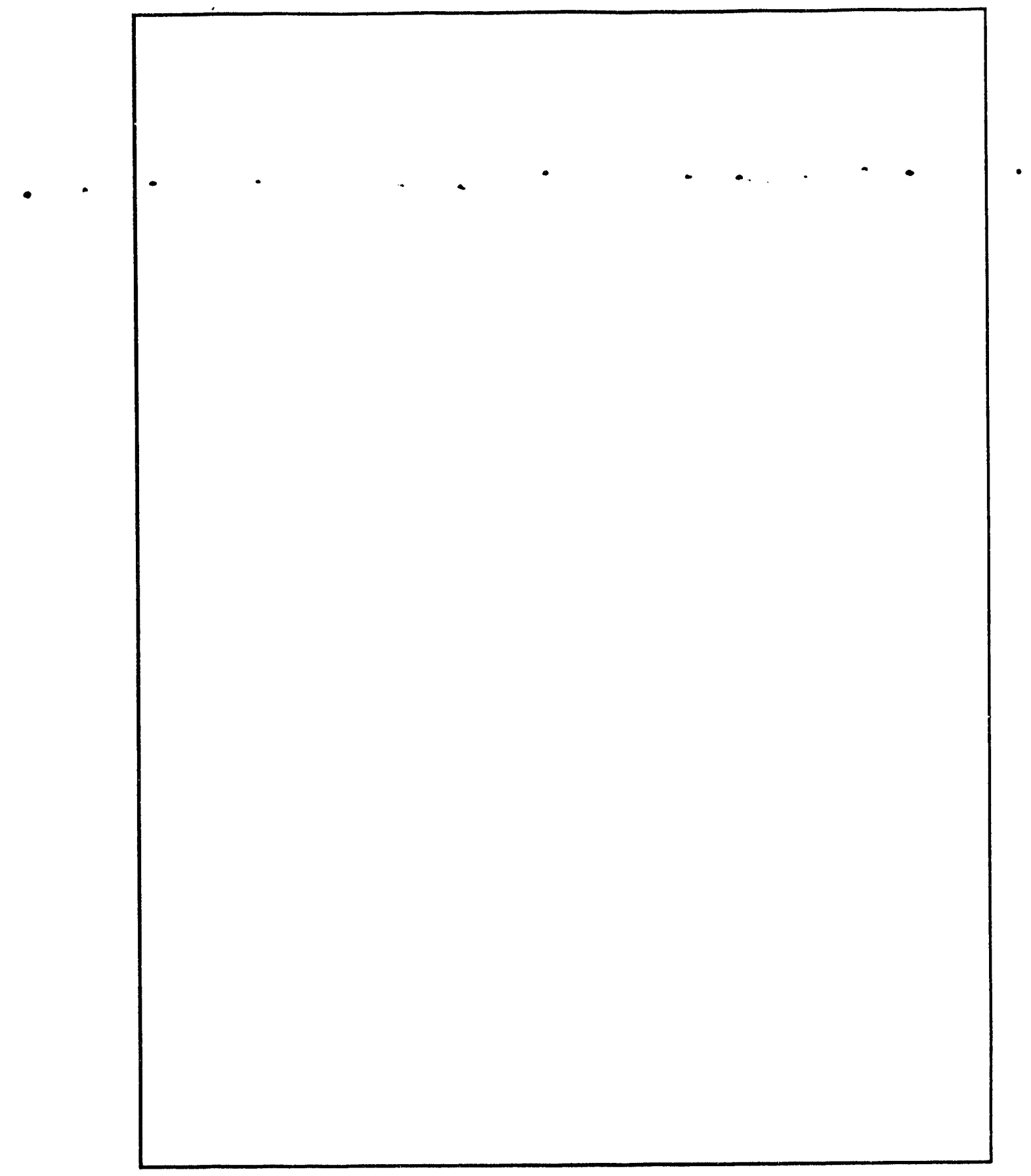

Figure 43, Test loop assembly -- Insulation is removed from the pump disch.rge header and the 2" vertical supply (Photograph 93-1414-19) 


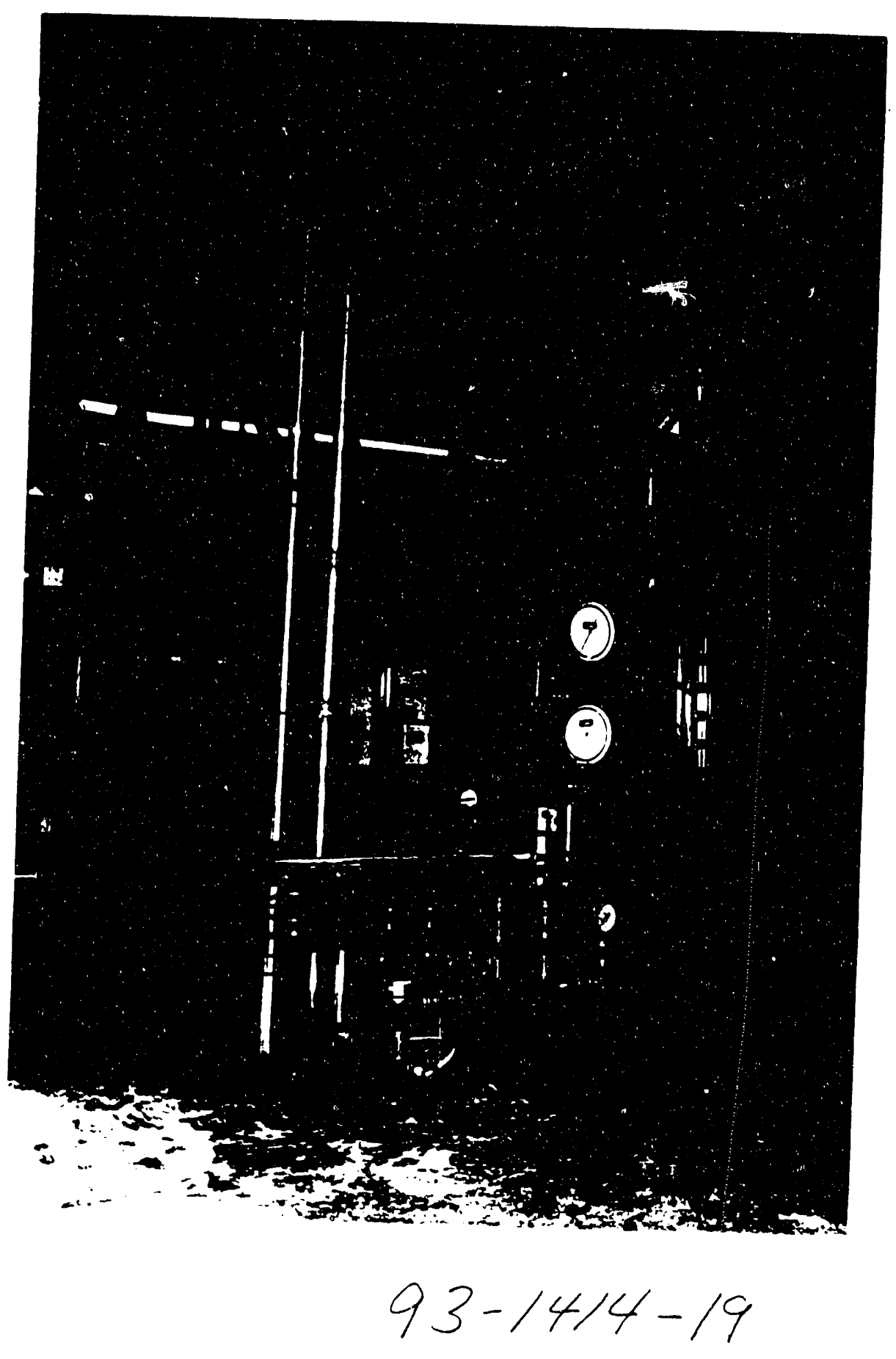




\section{Preliminary Data .- 9 September 1993}

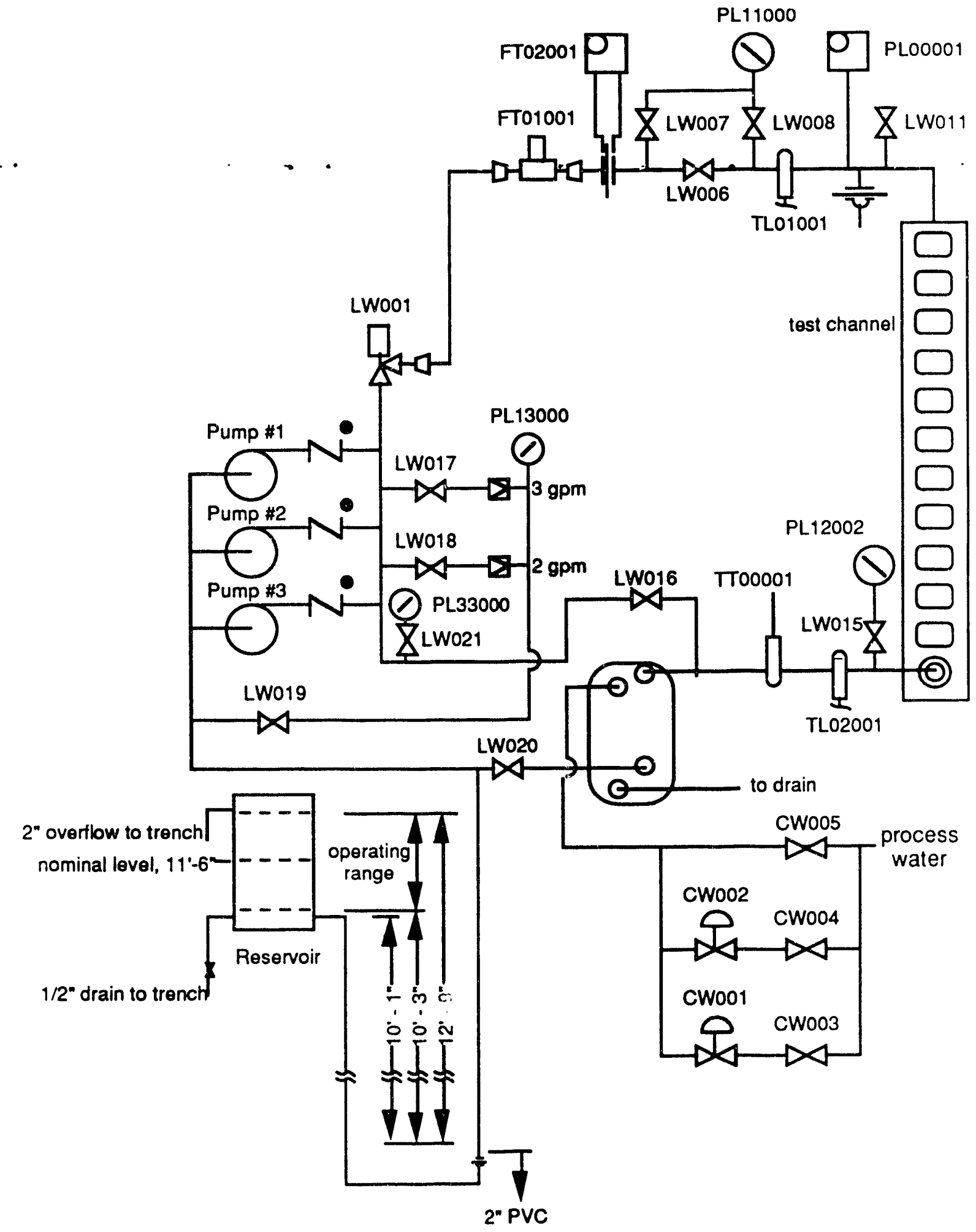

Figure 44, Test loop schematic 
Table 21.--Instrument loop number first two letter nomenclature

\begin{tabular}{l|l|l}
\hline & \multicolumn{1}{|c|}{ Measurement type } & \multicolumn{1}{|c}{ Measurement location } \\
\hline FT & Fluid flow & Flow loop \\
PB & Barometric pressure & Building \\
PD & Differential pressure & Heated channel \\
PG & Local channel pressure & Heated channel \\
PL & Local pressure & Flow loop \\
TC & Temperature & Channel structure \\
TF & Fluid temperature & Heated channel \\
TL & Fluid temperature & Flow loop \\
TP & Temperature & Heater plate \\
TT & Thermometer temperature & Flow loop \\
WC & Heater current & Rectifier controller \\
WV & Heater voltage & Heater buss connections \\
\hline
\end{tabular}

Table 22.--Flow loop instrumentation

\begin{tabular}{c|c|l}
\hline $\begin{array}{c}\text { Instrument } \\
\text { loop } \\
\text { number }\end{array}$ & $\begin{array}{c}\text { Channel } \\
\text { number }\end{array}$ & \multicolumn{1}{|c}{ Instrument description } \\
\hline PL11000 & $\ldots$ & Pressure gauge, channel inlet pressure \\
PL12002 & $\ldots$ & $\begin{array}{l}\text { Pressure gauge, channel exit pressure } \\
\text { Pressure gauge, pump suntion pressure }\end{array}$ \\
PL13000 & $\ldots$ & Pressure gauge, pump discharge pressure \\
PL33000 & $\ldots$ & Thermometer, channel exit temperature \\
TT00001 & $\ldots$ & Thermocouple, Impulse line temperature \\
TC00003 & 39 & Thermocouple, channel inlet temperature \\
TL01001 & 52 & Thermocouple, channel exit temperature \\
TL02001 & 53 & Thermocouple, pump discharge temperature \\
TL03001 & 54 & Thermocouple, head tank temperature \\
TL03002 & 55 & Orifice flow meter, loop flow \\
FT01002 & 63 & Turbine flow meter, loop floe \\
FT01001 & 73 & Secondary coolant regulator, 40.6 to $62.8^{\circ} \mathrm{C}$ \\
CW001 & $\ldots$ & Secondary coolant regulator, 65.6 to $87.8^{\circ} \mathrm{C}$ \\
CW002 & $\ldots$ &
\end{tabular}




\section{Preliminary Data _- 9 September 1993}

$\left(0.125^{n} \times 3^{n}\right)$. Flow exiting the heated channel was directed into a flat plate heat exchanger for cooling. The pressure at the discharge of the heat exchanger was regulated using a standpipe. The height of the standpipe was adjusted to achieve the desired test section exit pressure.

\section{Supply System}

The booster pumps used in the flow loop were model 2PC45 manufactured by Dayton Electrical Manufacturing Company. The nominal rating of these pumps is $560 \mathrm{gph}$ at $140 \mathrm{psig}$ (65). The system supply curve is provided in Figure 45 . The flow controller valve was a Kates, model GB11T-A valve with a range of 1.5 to $20 \mathrm{gpm}$. This valve was designed to maintain a set flow regardless of downstream pressure variations. Flow was regulated by manually positioning this flow controller.

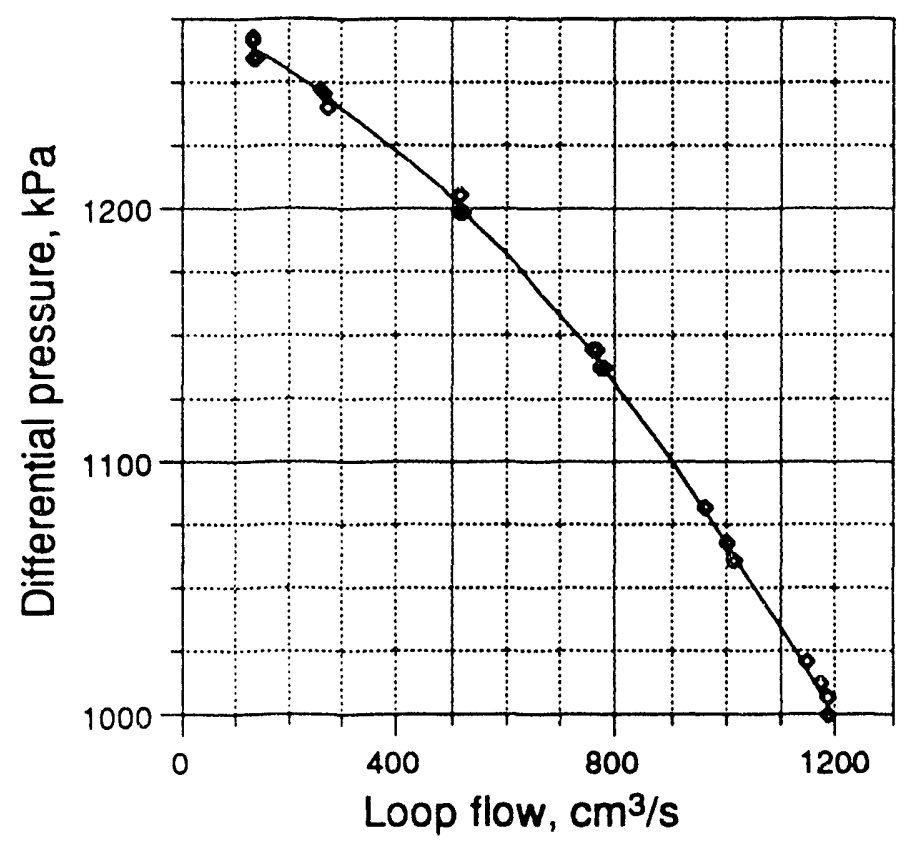

Figure 45. Test loop supply curve (pressure differential between pump suction and pump header) on 27 July 1993. 


\section{Preliminary Data -- 9 September 1993}

\section{Loop Instrumentation}

The flow supplied to the heated channel was measured using two devices, a turbine flow meter, instrument number FT01001, and an orifice meter. FT01002. 'The turbirie meter was a $3 / 4^{\prime \prime}$ model FT-12NEXW-LAD-1, manufactured by Flow Technology Inc. The rated capacity of this meter was $1600 \mathrm{~cm}^{3} / \mathrm{s}(25 \mathrm{gpm})$. The orifice meter consisted of a standard 1-1/2" $300 \#$ flange tap assembly with a $0.435^{\prime \prime}$ orifice diameter. The pressure transducer was a model 1151DP manufactured by Rosemount. The calibration curves used for data reduction are presented in Appendix 7, Table 7-2. The calibration calculations are presented in Appendix 2.

\section{Heat Rejection}

Heat was removed from the flow loop using a Alfa-Laval type M10-BFG flat plate heat exchanger. The secondary coolant fluid was building process water. The temperature of this water is nominally $22 \pm 4^{\circ} \mathrm{C}$. The secondary coolant flow rate was designed to be controlled using one of two reverse acting (temperature rise opens valve) temperature control valves that were equipped with capillary tubes. The capillary tubes were inserted into the piping at the heat exchanger exit. The ranges of these control valves are listed in Table 22.

While these control valves could maintain temperatures during steady state operation, their response was too sluggish to be of use during diabatic demand curve testing. Secondary cooling during diabatic demand curve testing was accomplished manually using valve CW006. The need for this valve was identified during the debugging stage of the experiment. Except for operations below $25^{\circ} \mathrm{C}$ the secondary valves CW003, CW004, and CW005 remained closed. 


\section{Preliminary Data -. 9 September 1993}

\section{Exit Pressure Control}

The pressure at the exit of the heat exchanger was regulated by use of the standpipe shown in Figure 44. The nominal water level was $3.5 \mathrm{~m}\left(138^{\prime \prime}\right)$ above the pump suction, $1.78 \mathrm{~m}\left(70^{\prime \prime}\right)$ above the nominal SHL, $3.00 \mathrm{~m}$ (118") above the nominal EHL, and $3.30 \mathrm{~m}\left(130^{n}\right)$ above the centerline of the test section exit. Since the reservoir level was set to achieve a specified heated channel exit pressure, density variations in the water column have been accounted for.

\section{Process Fluid Chemistry}

Deionized water was used in the flow loop to limit contamination of the heated surface. Virtually all of the wetted components were aluminum or stainless steel. These two dissimilar metals were kept electrically isolated. Other materials in the flow loop included plastic pump parts, neoprene seals, and RTV seals. Water was sampled and analyzed for conductivity during the test program. The conductivity did not exceed $3 \mu \mathrm{S} / \mathrm{cm}$.

\section{Heated Channel}

The heated rectangular channel was nominally 79.38 (3.125") wide, and $3.18 \mathrm{~mm}(0.125 ")$ deep. The flow channel cross section is presented in Figure 46. The nominal heated length was $1.219 \mathrm{~m}\left(48^{\prime \prime}\right)$. The best estimate channel dimensions are presented in Table 23.

The heater formed one side of the flow channel. The opposite side was an aluminum plate fitted with eleven $3 / 8^{n}$ thick glass view ports. (See Figure 47.) These view ports were each $79.5 \mathrm{~mm}\left(3.13^{n}\right)$ wide and $101.6 \mathrm{~mm}$ (4.00") long. The side with the view ports was considered the "front" of the channel. The two remaining sides were formed with Lexan. The thickness of the Lexan was too great to allow viewing. 


\section{Preliminary Data -. 9 September 1993}

Table 23.--Channel dimensions

\begin{tabular}{|c|c|c|c|c|}
\hline \multirow{2}{*}{ Construction: } & \multicolumn{3}{|c|}{ open channels } & rib channel \\
\hline & 1 & 3 & 4 & 2 \\
\hline $\begin{array}{l}\text { Channel width, } a, \mathrm{~mm} \\
\text { Channel depth, } \mathrm{b}, \mathrm{mm} \\
\text { Rib width, } x_{0}, \mathrm{~mm} \\
\text { Length, hydraulic, L, m } \\
\text { Length, heated, } L_{h}, \mathrm{~m} \\
\text { Heated width, } a_{h}, \mathrm{~mm} \\
\text { Hydraulic diameter, } \mathrm{D}, \mathrm{mm} \\
\text { Equivalent diameter, } \mathrm{D}_{e}, \mathrm{~mm} \\
\text { Heated diameter, } \mathrm{D}_{h}, \mathrm{~m} \\
\mathrm{k}=f \text { Re, Equation } 26 \\
\text { Flow area, } \mathrm{A}_{\mathrm{f}}, \mathrm{mm}^{2} \\
\text { Heated area, } \mathrm{A}_{h}, \mathrm{~m}^{2} \\
\text { Hydraulic } \mathrm{L} \mathrm{D} \\
\text { Heated LD }\end{array}$ & $\begin{array}{c}79.7 \\
2.90 \\
\cdots \\
1.3970 \\
1.156 \\
76.2 \\
5.60 \\
3.91 \\
12.1 \\
91.5 \\
231.1 \\
0.0881 \\
250 \\
95.3\end{array}$ & $\begin{array}{c}79.6 \\
2.45 \\
\ldots \\
1.3970 \\
\ldots \\
\ldots \\
4.75 \\
3.30 \\
\ldots \\
92.2 \\
195.0 \\
\ldots \\
294 \\
\ldots\end{array}$ & $\begin{array}{c}79.8 \\
3.16 \\
\cdots \\
1.3970 \\
1.156 \\
76.2 \\
6.08 \\
4.27 \\
13.2 \\
91.1 \\
252.2 \\
0.0881 \\
230 \\
87.3\end{array}$ & $\begin{array}{c}79.6 \\
3.09 \\
2.07 \\
1.3970 \\
1.156 \\
74.1 \\
5.72 \\
4.22 \\
12.9 \\
86.9 \\
239.6 \\
0.0857 \\
244 \\
89.4\end{array}$ \\
\hline
\end{tabular}

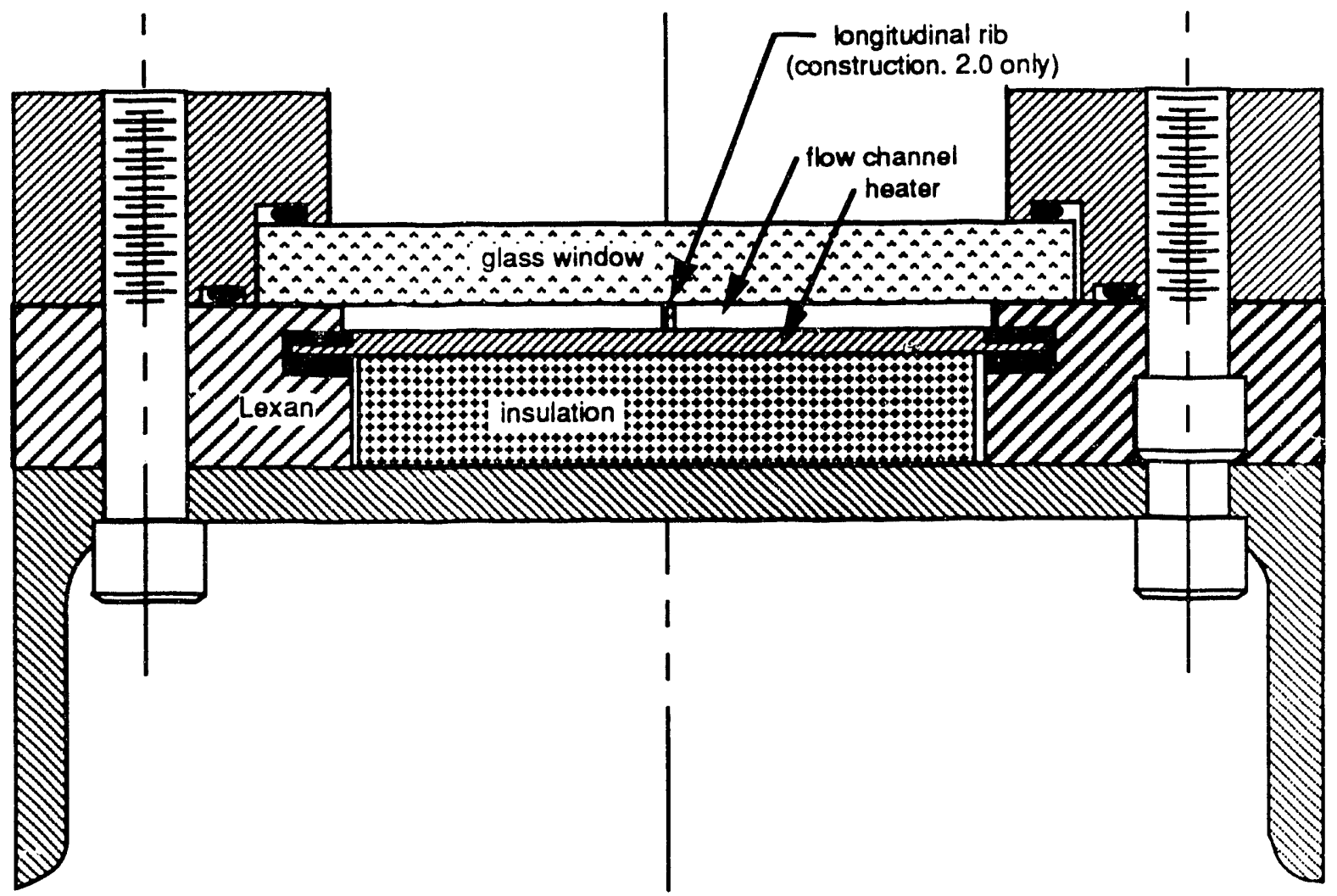


Preliminary Data -. 9 September 1993

Figure 46 Test channel cross section

Figure 47, Channel view port details -- Construction 2.0 at the end of the heated length (Photograph 93-1566-12) 


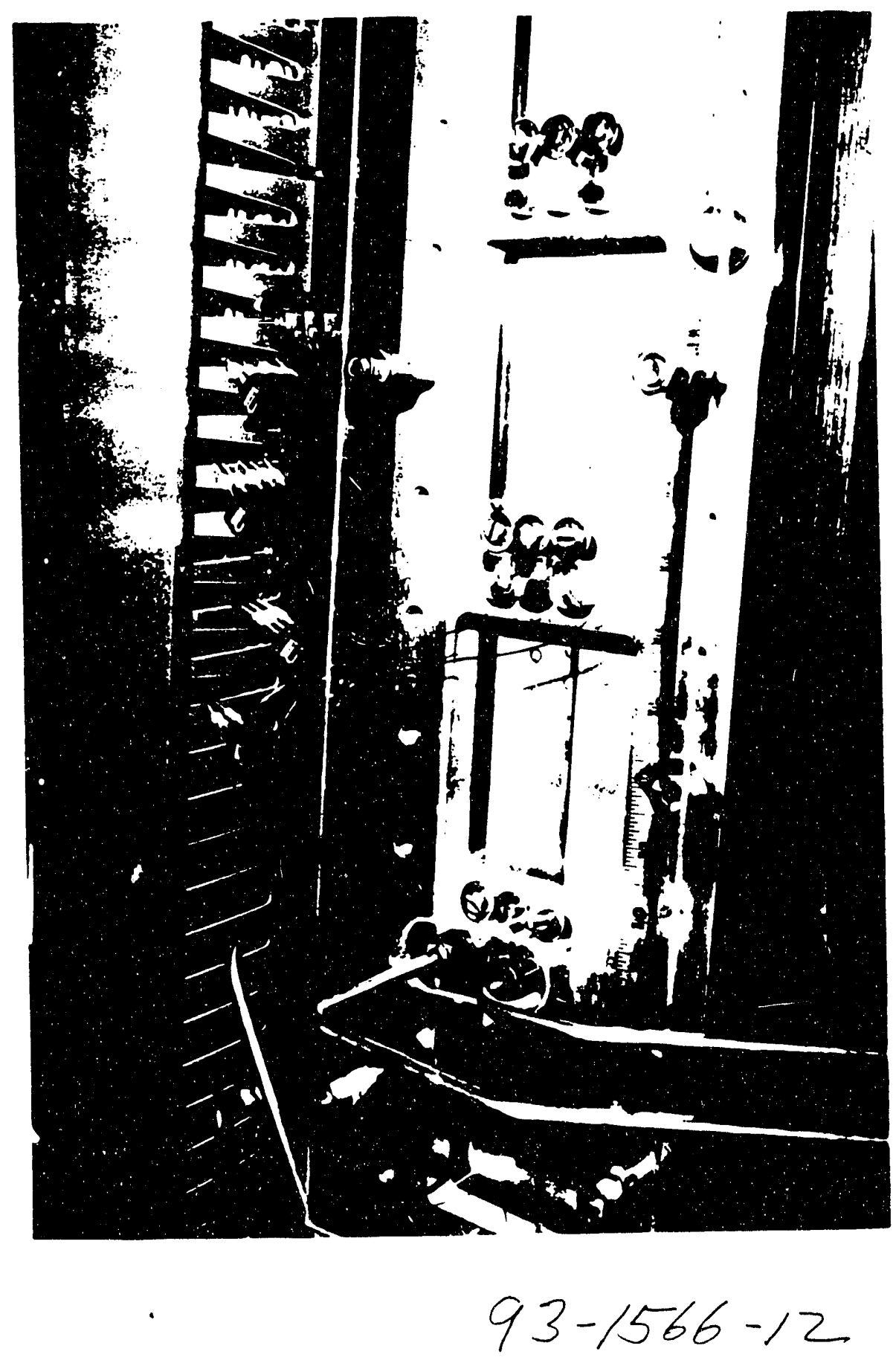




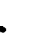

- 


\section{Preliminary Data _- 9 September 1993}

\section{Channel Heater}

The channel heater utilized a plasma sprayed design which allowed indirect heating of the wetted surface. The heater consisted of 3 layers. These layers are presented schematically in Figure 48 . Heat is generated in the conductive layer by electric resistance heating. The core layer was $3.20 \pm 0.04$ $\mathrm{mm}(0.125 \pm 0.002 ")$ thick with a total electrical resistance of $37.0 \mathrm{~m} \Omega$. This resistance measurement was completed at ambient conditions. The resistance under powered operation varied from this measurement. Power to generate this heat was provided by DC rectifiers which were capable of generating $1<J$ volts and 5000 amps. The heater core was electrically isolated from the wetted surface by an electrically resistive aluminum oxide and titanium oxide layer. This layer was approximately $0.27 \pm 0.04 \mathrm{~mm}$ thick. The bond coat was 0.07 $\mathrm{mm}$ thick while the conductive layer of nickel aluminum was $0.21 \mathrm{~mm}$ thick.

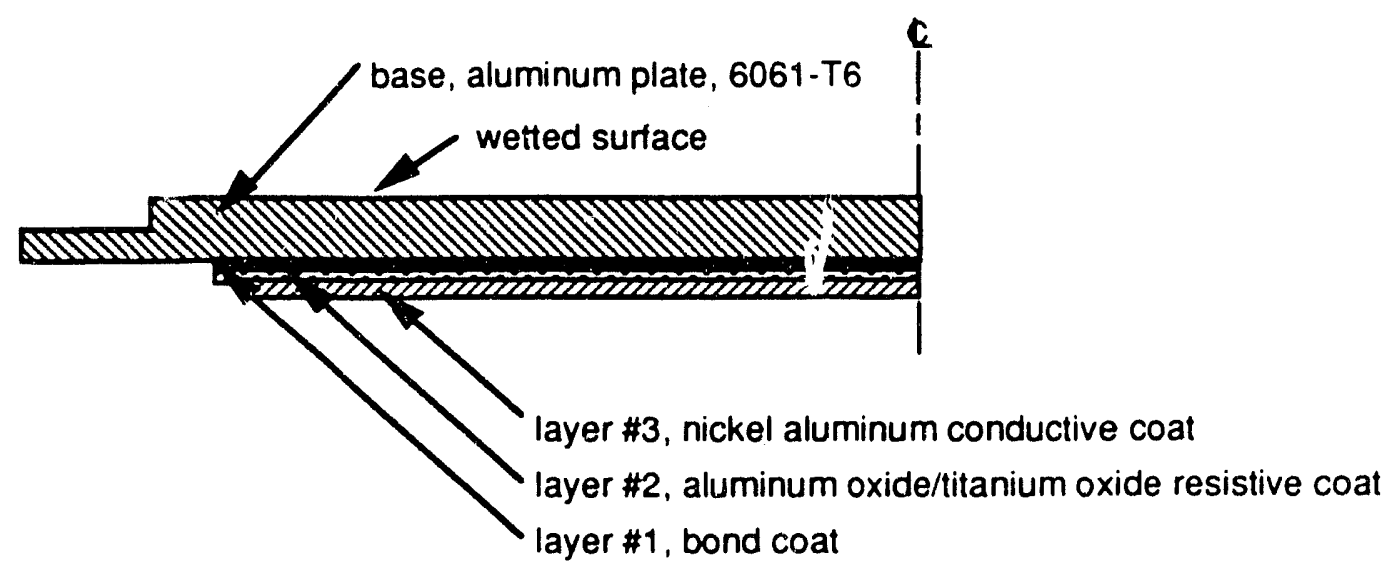

Figure 48. Heater cross-section schematic

Instrumentation

The fluid channel and heater wall temperatures were measured using type $E$ thermocouples. The locations where these measurements were made 


\section{Preliminary Data .- 9 September 1993}

are listed in Table 24. Table 25 summarized the other types of channel instrumentation. Channel pressure measurements included differential, absolute, and gauge pressures. The differential measurements were used to produce both isothermal and diabatic demand curves. The absolute transducers were used to estimate the local saturation temperature, and the gauge transducers were used for operation diagnostics. Instrumentation ports were installed between each of the glass viewports as shown in Figure 49. Different instrument inserts were used to support temperature and pressure measurements. These inserts are shown in Figure 50. Blank inserts were installed in all unused ports.

In addition to temperature and pressure measurements, channel instrumentation included both heater voltage and heater current measurements. These measurements were used to compute heater power and heat flux.

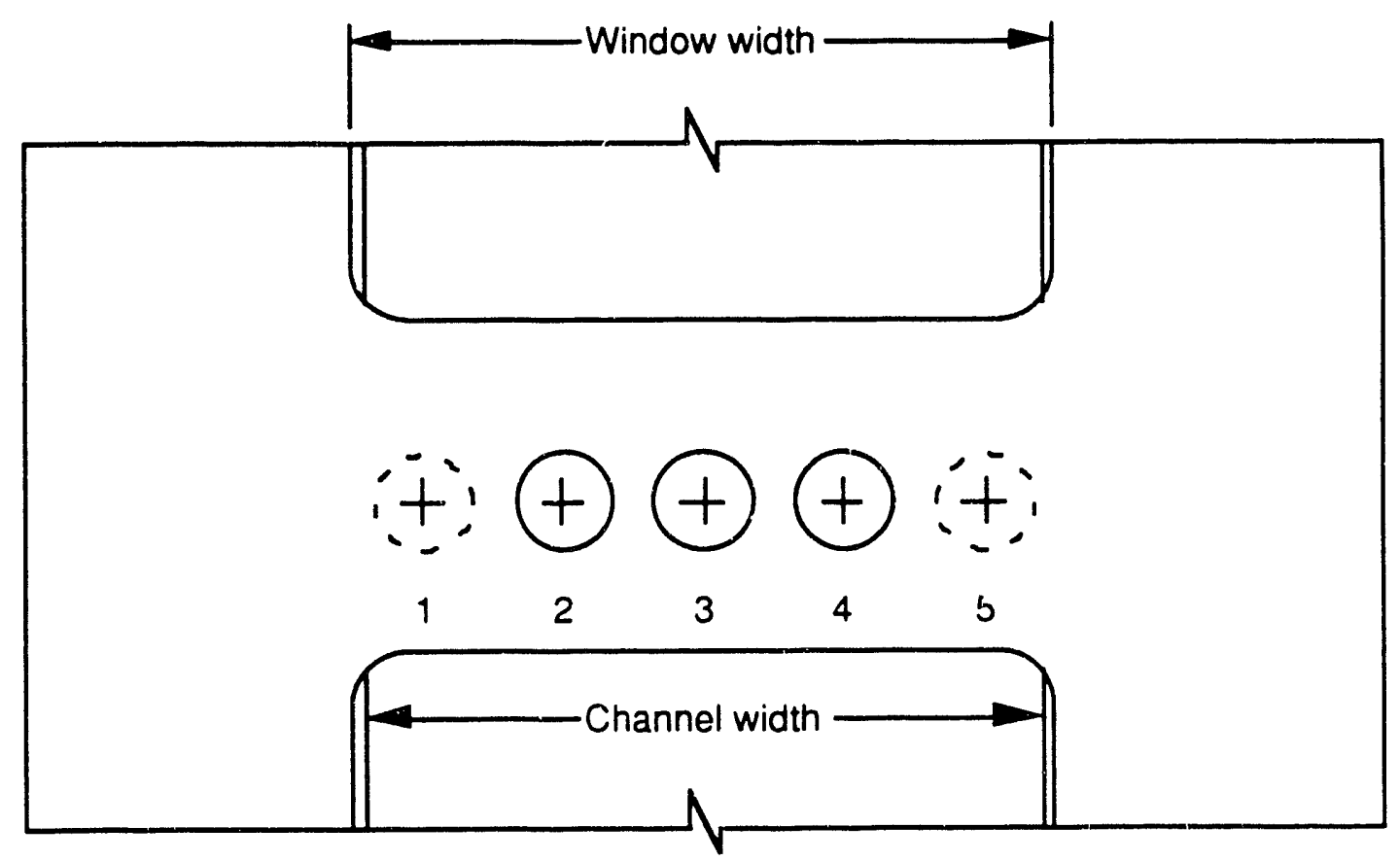

Figure 49. Test channel instrument port identification, positions 1 and 5 were not installed, position 3 was used to hold the rib in position 
Preliminary Data -- 9 September 1993

Table 24.---Channel temperature instrumentation

\begin{tabular}{|c|c|c|c|c|c|}
\hline $\begin{array}{c}\text { Instrument } \\
\text { number }\end{array}$ & $\begin{array}{l}\text { Channel } \\
\text { number }\end{array}$ & $\begin{array}{c}z \\
\text { meters }\end{array}$ & $\begin{array}{c}y \\
\mathrm{~mm}\end{array}$ & $\begin{array}{c}\mathrm{x} \\
\mathrm{mm}\end{array}$ & comment \\
\hline 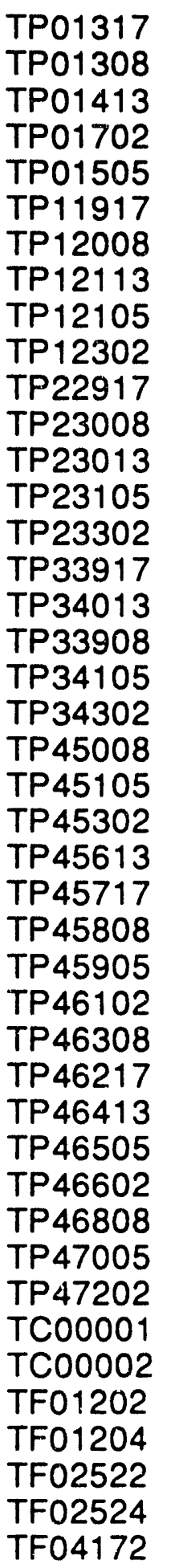 & $\begin{array}{l}1 \\
2 \\
3 \\
4 \\
5 \\
6 \\
7 \\
8 \\
9 \\
10 \\
11 \\
12 \\
13 \\
14 \\
15 \\
16 \\
17 \\
18 \\
19 \\
20 \\
21 \\
22 \\
23 \\
24 \\
25 \\
26 \\
27 \\
28 \\
29 \\
30 \\
31 \\
32 \\
33 \\
34 \\
35 \\
36 \\
37 \\
38 \\
40 \\
41 \\
42 \\
43 \\
44\end{array}$ & 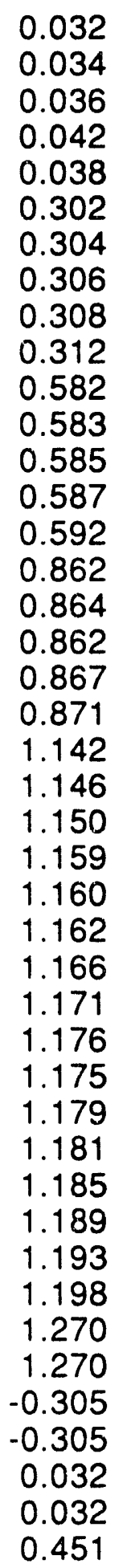 & $\begin{array}{l}-2.92 \\
-0.41 \\
-2.92 \\
-0.42 \\
-0.43 \\
-2.92 \\
-0.43 \\
-2.92 \\
-0.43 \\
-0.41 \\
-2.92 \\
-0.47 \\
-2.92 \\
-0.46 \\
-0.47 \\
-2.92 \\
-2.92 \\
-0.52 \\
-0.50 \\
-0.47 \\
-0.18 \\
-0.18 \\
-0.18 \\
-2.92 \\
-2.92 \\
-0.18 \\
-0.20 \\
-0.20 \\
-0.30 \\
-2.92 \\
-2.92 \\
-0.16 \\
-0.18 \\
-0.16 \\
-0.19 \\
-0.20 \\
-5.60 \\
-5.60 \\
1.59 \\
1.59 \\
1.59 \\
1.59 \\
1.59\end{array}$ & $\begin{array}{l}42.60 \\
53.72 \\
26.72 \\
21.97 \\
37.85 \\
42.60 \\
53.72 \\
26.72 \\
37.85 \\
21.97 \\
42.60 \\
53.72 \\
26.72 \\
37.85 \\
21.97 \\
42.60 \\
26.72 \\
53.72 \\
37.85 \\
21.97 \\
53.72 \\
37.85 \\
21.97 \\
26.72 \\
42.60 \\
53.72 \\
37.85 \\
21.97 \\
53.72 \\
42.60 \\
26.72 \\
37.85 \\
21.97 \\
53.72 \\
37.85 \\
21.97 \\
76.20 \\
76.20 \\
22.23 \\
53.98 \\
22.23 \\
53.98 \\
22.23\end{array}$ & $\begin{array}{l}\text { Heater, dry side } \\
\text { Heater, wet side } \\
\text { Heater, dry side } \\
\text { Heater, wet side } \\
\text { Heater, wet side } \\
\text { Heater, dry side } \\
\text { Heater, wet side } \\
\text { Heater, dry side } \\
\text { Heater, wet side } \\
\text { Heater, wet side } \\
\text { Heater, dry side } \\
\text { Heater, wet side } \\
\text { Heater, dry side } \\
\text { Heater, wet side } \\
\text { Heater, wet side } \\
\text { Heater, dry side } \\
\text { Heater, dry side } \\
\text { Heater, wet side } \\
\text { Heater, wet side } \\
\text { Heater, wet side } \\
\text { H.ater, wet side } \\
\text { Heater, wet side } \\
\text { Heater, wet side } \\
\text { Heater, dry side } \\
\text { Heater, dry side } \\
\text { Heater, wet side } \\
\text { Heater, wet side } \\
\text { Heater, wet side } \\
\text { Heater, wet side } \\
\text { Heater, dry side } \\
\text { Heater, dry side } \\
\text { Heater, wet side } \\
\text { Heater, wet side } \\
\text { Heater, wet side } \\
\text { Heater, wet side } \\
\text { Heater, wet side } \\
\text { Channel seal } \\
\text { Channel seal } \\
\text { Channel fluid } \\
\text { Channel fluid } \\
\text { Channel fluid } \\
\text { Channel fluid } \\
\text { Channel fluid }\end{array}$ \\
\hline
\end{tabular}




\section{Preliminary Data -. 9 September 1993}

Table 24.---Continued

\begin{tabular}{c|c|c|c|c|l}
\hline $\begin{array}{c}\text { Instrument } \\
\text { number }\end{array}$ & $\begin{array}{c}\text { Channel } \\
\text { number }\end{array}$ & $\begin{array}{c}z \\
\text { meters }\end{array}$ & $\begin{array}{c}y \\
\mathrm{~mm}\end{array}$ & $\begin{array}{c}\mathrm{x} \\
\mathrm{mm}\end{array}$ & \multicolumn{1}{c}{ comment } \\
\hline TF04174 & 45 & 0.451 & 1.59 & 53.98 & Channel fluid \\
TF05822 & 46 & 0.870 & 1.59 & 22.23 & Channel fluid \\
TF05824 & 47 & 0.870 & 1.59 & 53.98 & Channel fluid \\
TF06922 & 48 & 1.149 & 1.59 & 22.23 & Channel fluid \\
TF06924 & 49 & 1.149 & 1.59 & 53.98 & Channel fluid \\
TF08022 & 50 & 1.429 & 1.59 & 22.23 & Channel fluid \\
TF08024 & 51 & 1.429 & 1.59 & 53.98 & Channel fluid \\
\hline
\end{tabular}

Table 25.--Flow loop instrumentation

\begin{tabular}{|c|c|c|}
\hline $\begin{array}{c}\text { Instrument } \\
\text { loop } \\
\text { number }\end{array}$ & $\begin{array}{l}\text { Channel } \\
\text { number }\end{array}$ & Instrument description \\
\hline PA20072 & 61 & $\begin{array}{l}\text { Absolute pressure, left side of channel, } 1.29 \mathrm{~m} \text { from } \\
\text { the start of the heated length }(\mathrm{SHL})\end{array}$ \\
\hline PD22472 & 62 & $\begin{array}{l}\text { Differential pressure, left side of channel, between } \\
-0.11 \text { and } 1.29 \mathrm{~m} \text { from the SHL }\end{array}$ \\
\hline PG00024 & 64 & $\begin{array}{l}\text { Local gauge pressure, right side of channel, }-0.11 \\
\text { from the SHL }\end{array}$ \\
\hline PD00024 & 66 & $\begin{array}{l}\text { Differential pressure, right side of channel, between } \\
-0.55 \text { and }-0.11 \mathrm{~m} \text { from the } \mathrm{SHL}\end{array}$ \\
\hline PA00072 & 67 & $\begin{array}{l}\text { Absolute pressure, right side of channel, } 1.29 \mathrm{~m} \\
\text { from the SHL }\end{array}$ \\
\hline PD02472 & 68 & $\begin{array}{l}\text { Differential pressure, right side of channel between } \\
-0.11 \text { and } 1.29 \mathrm{~m} \text { from the } S H L\end{array}$ \\
\hline PD00072 & 69 & $\begin{array}{l}\text { Differential pressure, right side of channel, between } \\
-0.55 \text { and } 1.29 \mathrm{~m} \text { from the } \mathrm{SHL}\end{array}$ \\
\hline PL00002 & 70 & $\begin{array}{l}\text { Local gauge pressure at test channel exit } 1.52 \mathrm{~m} \\
\text { from the SHL (after expansion) }\end{array}$ \\
\hline PD07284 & 71 & $\begin{array}{l}\text { Differential pressure, right side of channel, between } \\
1.29 \text { and } 1.52 \mathrm{~m} \text { from the } \mathrm{SHL}\end{array}$ \\
\hline PD00084 & 72 & $\begin{array}{l}\text { Differential pressure, right side of channel, between } \\
-0.55 \text { and } 1.52 \mathrm{~m} \text { from the } \mathrm{SHL}\end{array}$ \\
\hline $\begin{array}{l}\text { WV00001 } \\
\text { WC00001 }\end{array}$ & $\begin{array}{l}74 \\
75 \\
\end{array}$ & $\begin{array}{l}\text { Heater voltage (buss block to buss block) } \\
\text { Heater current }\end{array}$ \\
\hline
\end{tabular}



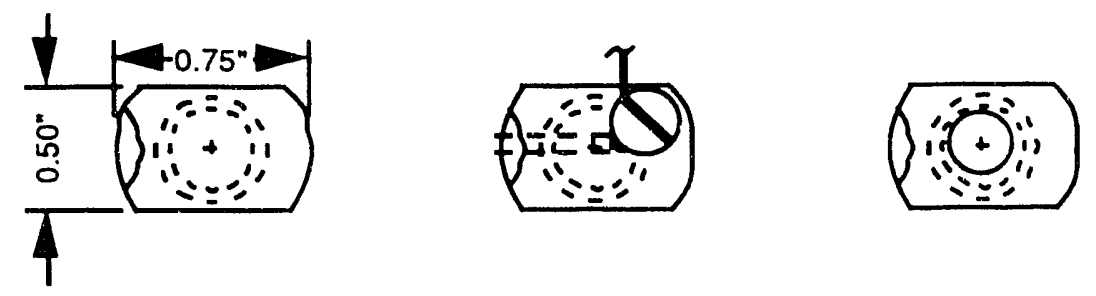

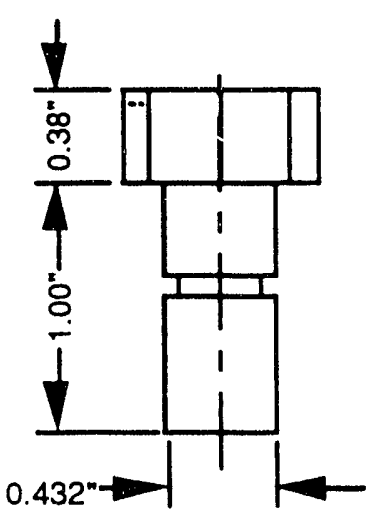

a

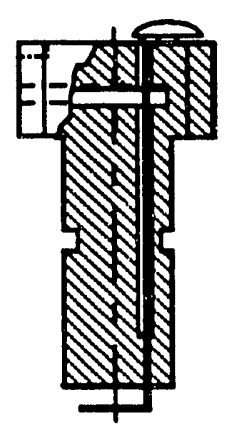

b

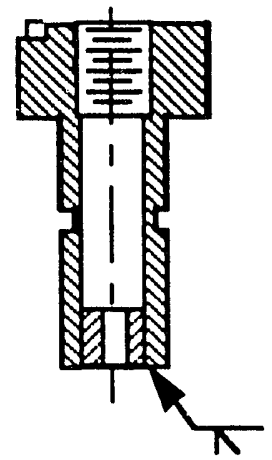

C

Figure 50. Fluid channel instrument port connections: (a) Blank, (b) Thermocouple using a 0.020 " stainless steel sheathed type $E$ thermocouple, (c) Tube connection, 1/16" NPT with a $1.59 \mathrm{~mm}$ through hole.

\section{Fluid Instrumentation}

Fluid temperature measurements were made using 0.020" type $E$ thermocouples. Three different styles were used. These are listed in Appendix 2, Table 2-1. The preferred type was a grounded tip, the other types were used because of availability. These thermocouples were installed through the instrument ports on the front of the test channel. The thermocouples were held in place using the instrument inserts shown in Figure 49b.

The local absolute pressure at the end of the heated length was measured using Rosemount 1151 AP pressure transducers. The instrument port was equipped with the instrument insert shown in Figure 50c. This port was located $2.75 \mathrm{~mm}$ ( 0.1 inches) from the end of the nominal heated length. The local gauge pressures were measured using a .Rosemount 1144 pressure 


\section{Preliminary Data _. 9 September 1993}

transducer using a Figure $50 \mathrm{c}$ instrument insert near the start of the heated length. A second gauge pressure measurement was made in the 2" pipe which served as the channel exit.

Six differential pressures were measured in the heated channel using Rosemount 1151DP pressure transducers. Figure 50c inserts were used for these pressure measurements. The locations of the ports used for these measurements is shown in Figure 52. The arrangement of the transducer rack is presented in Figure 51.

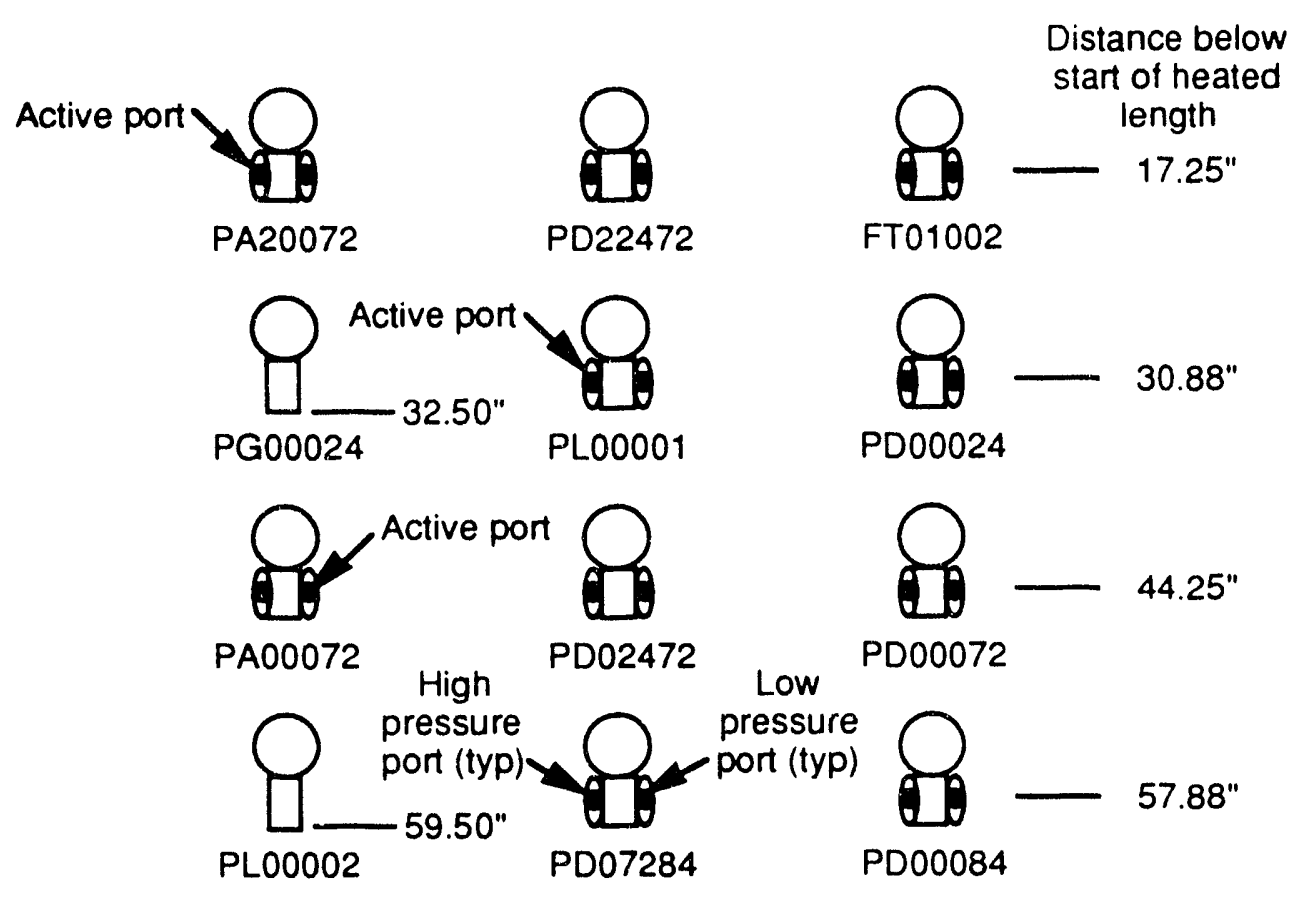

Figure 51. Pressure transducer elevations

\section{Heater Instrumentation}

The internal temperature of the heater plate was measured using 0.020 " sheathed, grounded type $E$ thermocouples. These were mounted as shown in Figure 53. The wetted wall thermocouples were inserted into the 
Preliminary Data -- 9 September 1993

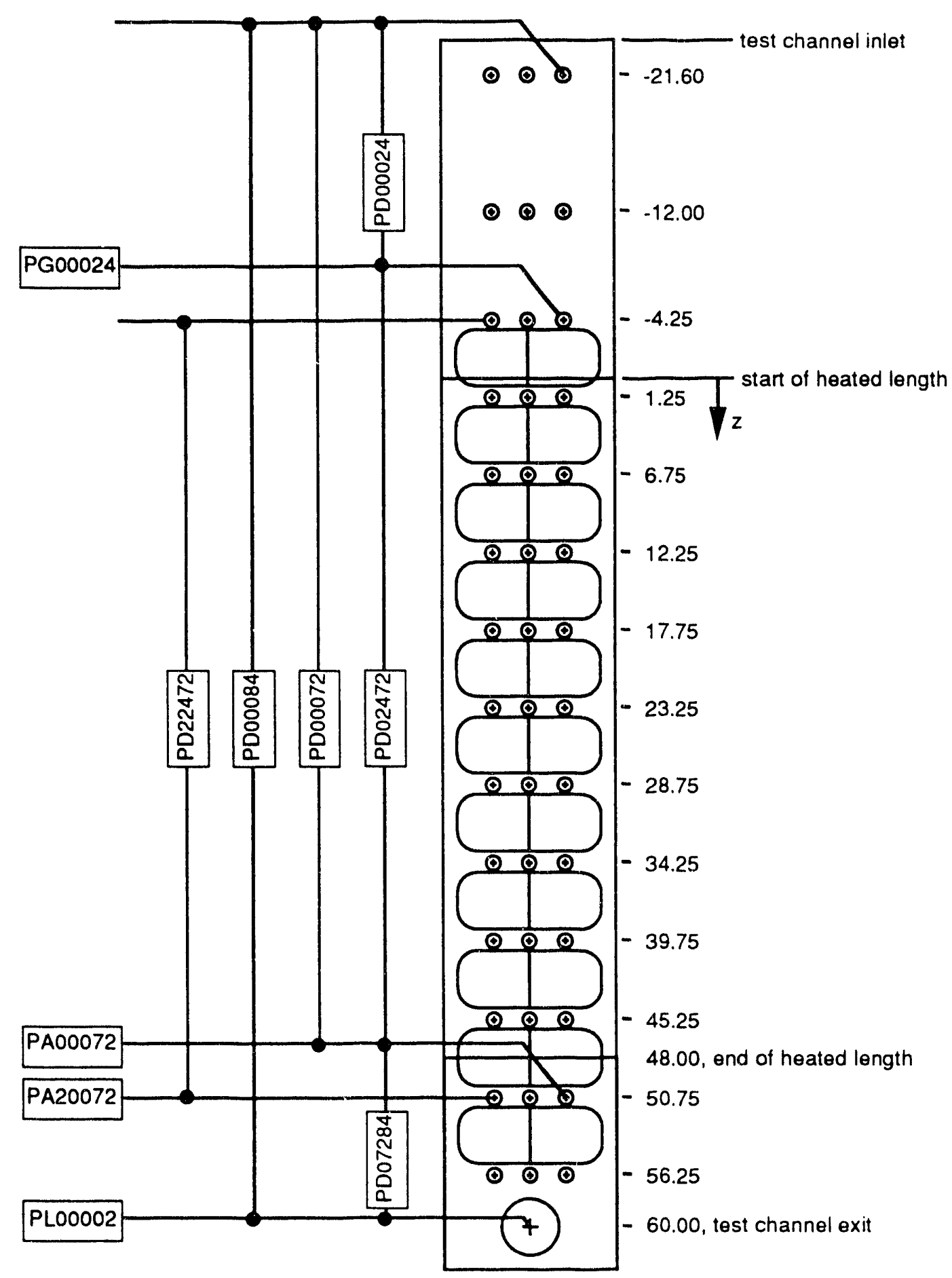

Figure 52, Test channel pressure instrumentation schematic 


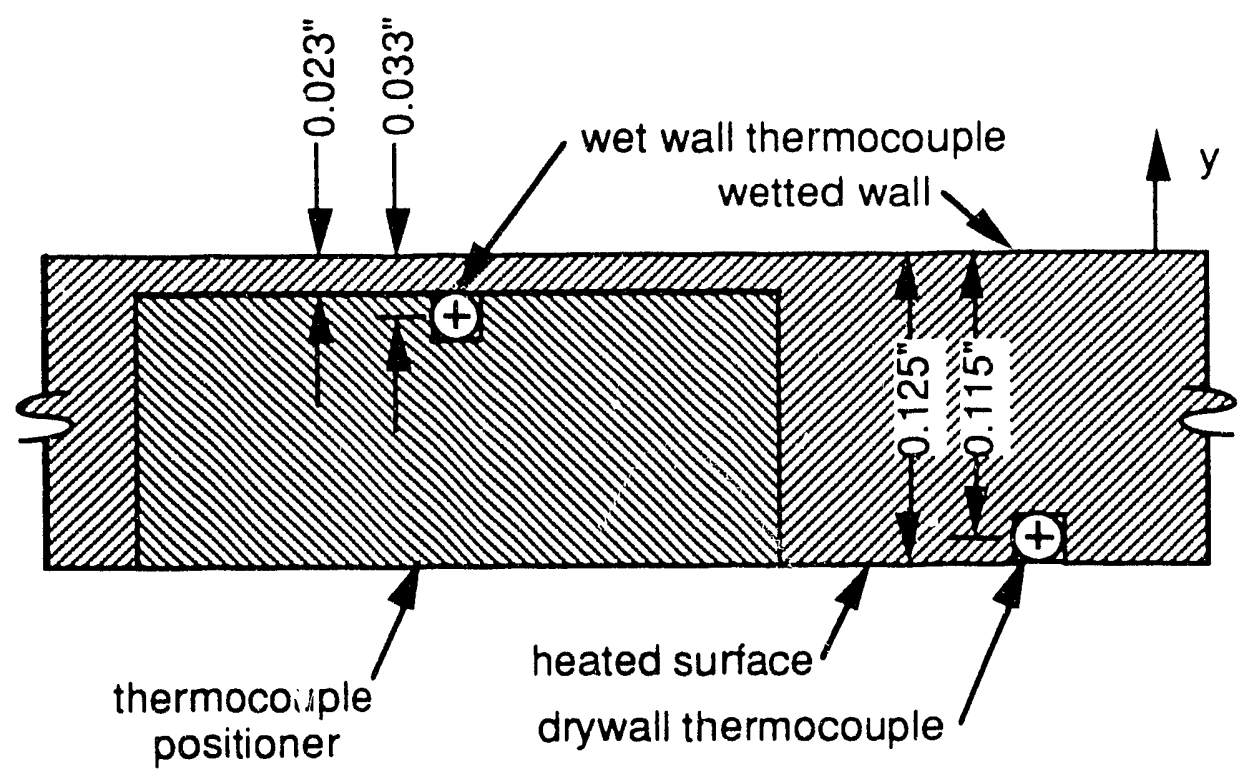

Figure 53. Thermocouple installation details (dimensions shown are nominal)

holes shown in Figure 54 and held in positions using aluminum buttons. Dry wall thermocouples and the leads from the wetted wall thermocouples were pressed into the slots and held in position by rolling the slot edges over the thermocouple sheaths.. After installation of these thermocouples the plasma spayed layers were installed.

\section{Power Instrumentation}

The electrical power measurement instrumentation schematic is shown in Figure 55. Both the applied voltage and the resulting current were measured. The power was calculated using the equation. The voltage was measured across the buss connections using a voltage transducer. Two different transducers were used. On 2 June 1993 the original transducer with a range of 0 to 50 volts was replace with a unit with a range of 0 to $150 \mathrm{~V}$. All data collected on 3 June 1993 and thereafter was collected using the second 
Preliminary Data -- 9 September 1993

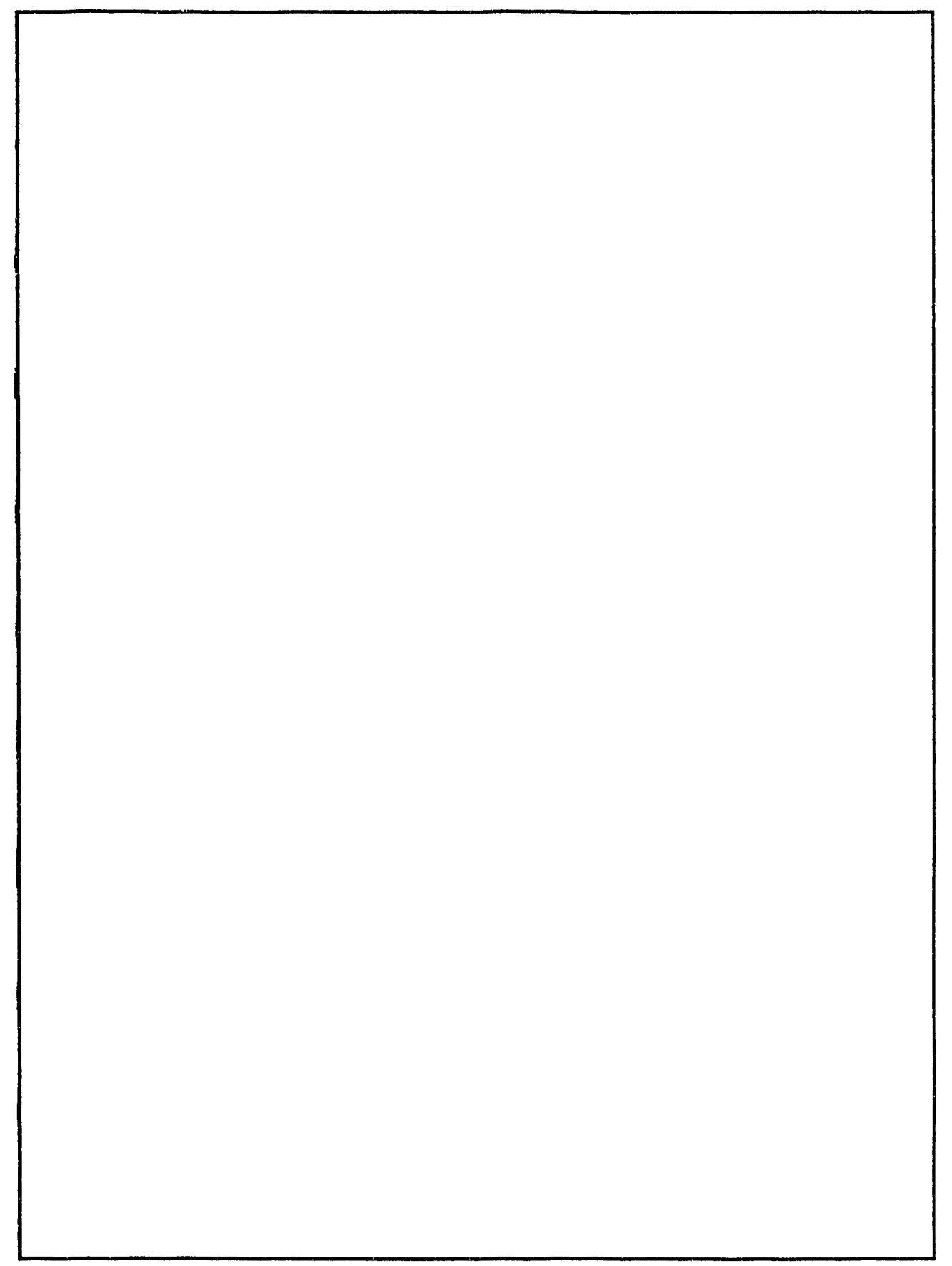

Figure 54, Heater base plate ready for installation of thermocouples (Photograph 92-1769-4) 


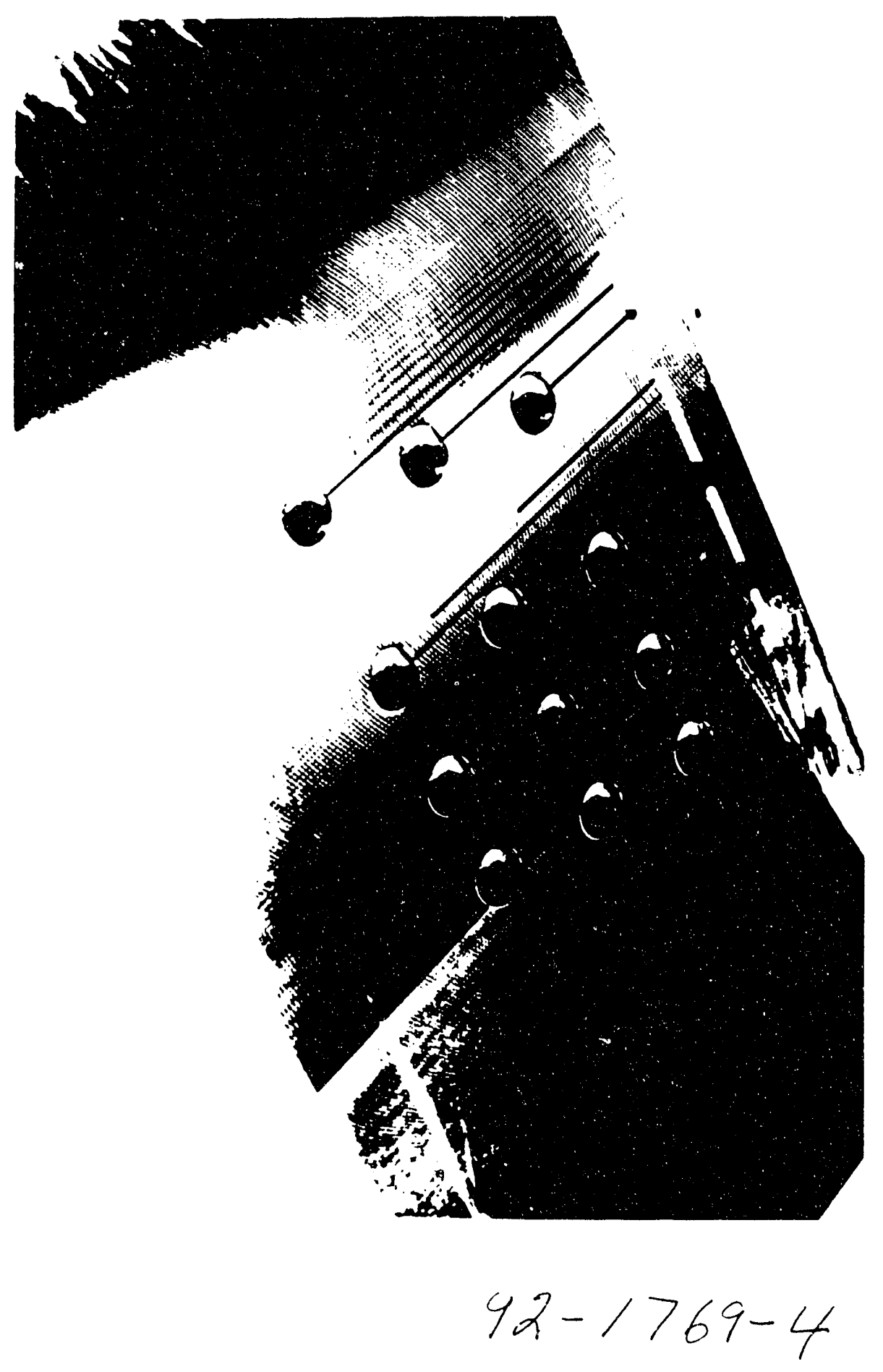




\section{Preliminary Data .. 9 September 1993}

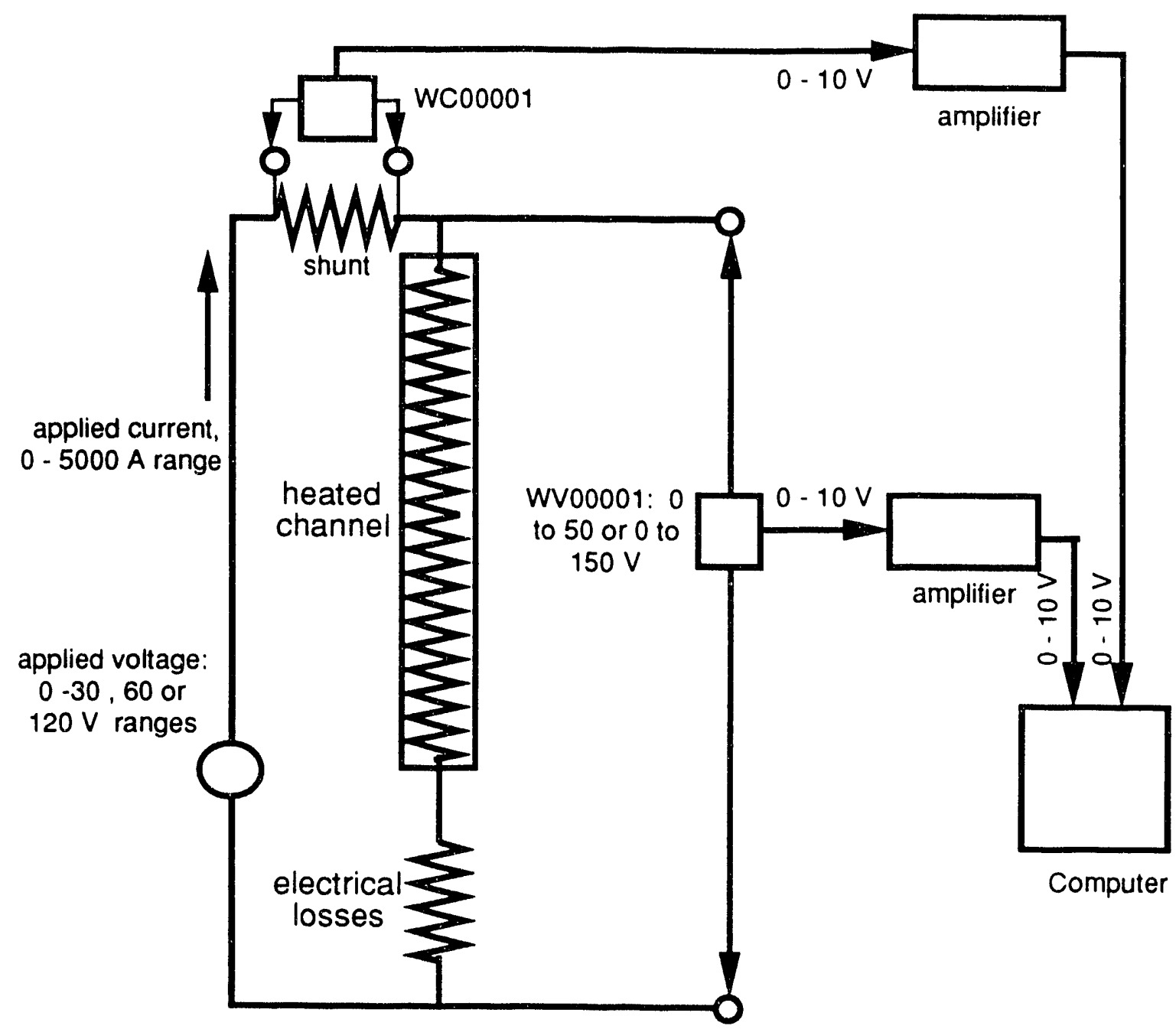

Figure 55, Applied Power Instrument Schematic

transducer. The calibration curves for both transducers are provided in Appendix 2.

\section{Struciural Instrumentation}

Temperature measurements were made at two additional locations in the heated channel structure. The primary purpose of these thermocouples was to verify the operating temperatures and to ensure that seals were not operated outside of their design limits. TC00001 was place against the heater $114 \mathrm{~mm}$ 


\section{Prellminary Data - 9 September 1993}

above the end of the heated length near the right RTV seal. TC00002 was also placed in a similar manner $30 \mathrm{~mm}$ below the end of the heated length at the buss connection.

\section{Rib Details}

A rib was installed in Construction 2.0 as shown in Figure 47 . The rib details are provided in Figure 56 with the nol :linal rib dimensions. The rib was held in position using modified instrument port plugs. (See Figure 57.) The rib

holder inserts were inserted into the slots shown in Figure 56 . The slots permitted longitudinal rib expansion. Longitudinal movement of the rib was restrained at the lowest slot which was only slightly larger than the rib holder insert.

\section{Data Acquisition}

The test loop was operated to obtain both isothermal and diabatic demand curves. The types of curves were generated by incrementally varying the flow over a specified range and recording the conditions at each operating set-point. The conditions at each set-point were held steady for a minimum of tow minutes prior to recording data. When this condition was meet a one minute long data sut was recorded and assigned a filename as described in Table 26. Each file contains approximately 120 samples per instrument. Appendix 6 presents a detailed description of the test operation procedures.

The data acquisition system consisted of a Macintosh II computer equipped with WorkBench ${ }^{\mathrm{TM}}$ software (73). Field instrumentation signals were conditioned using amplifiers as shown in Figure 58. The amplifiers were equipped with $300 \mathrm{~Hz}$ filters designed to minimize the effect of electrical noise produced by the heater power circuits. Instrument measurements were collected and recorded in voltage units. The DAS produced raw data files that 

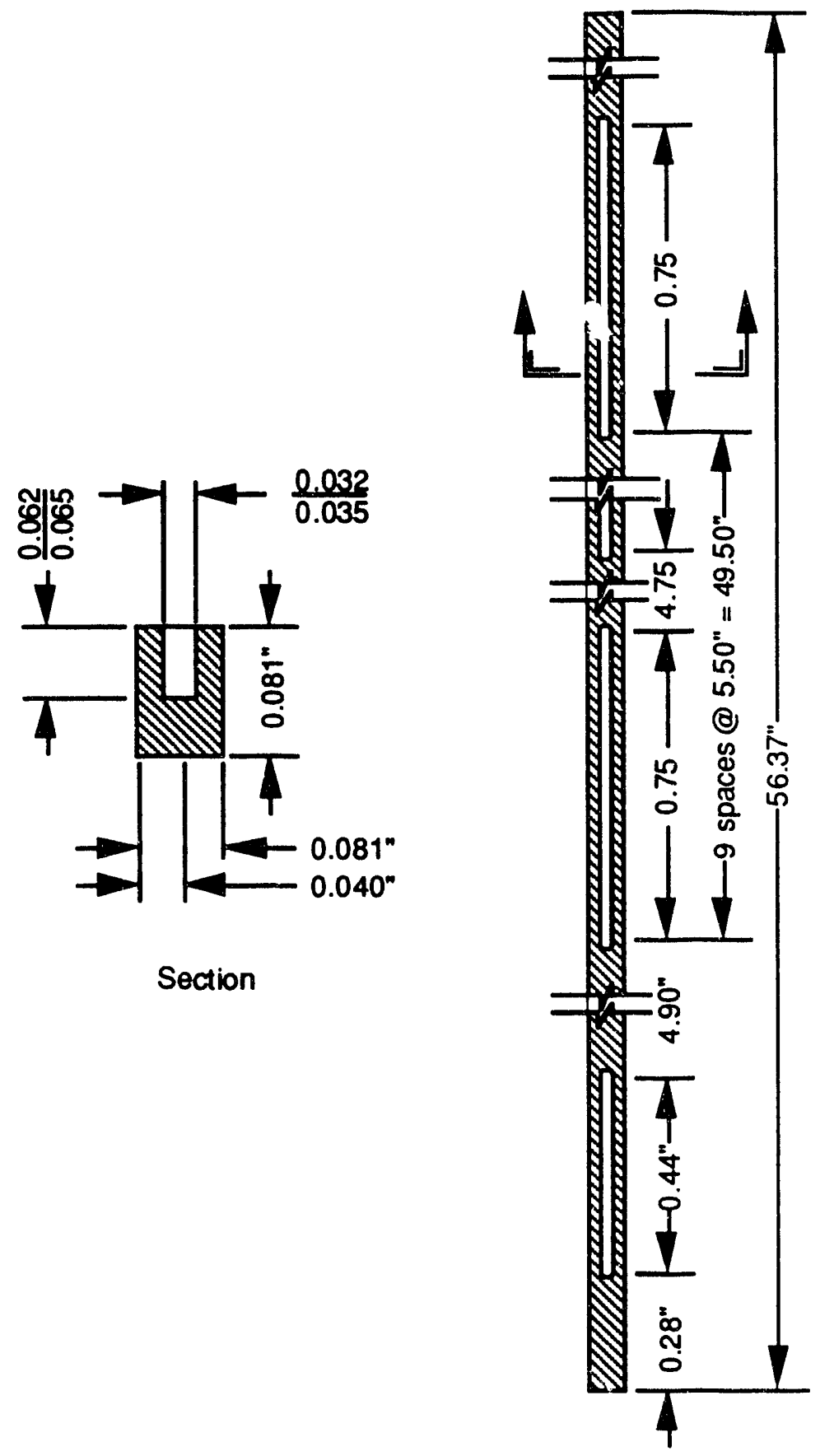

Figure 56, Rib details 
Preliminary Data _- 9 September 1993

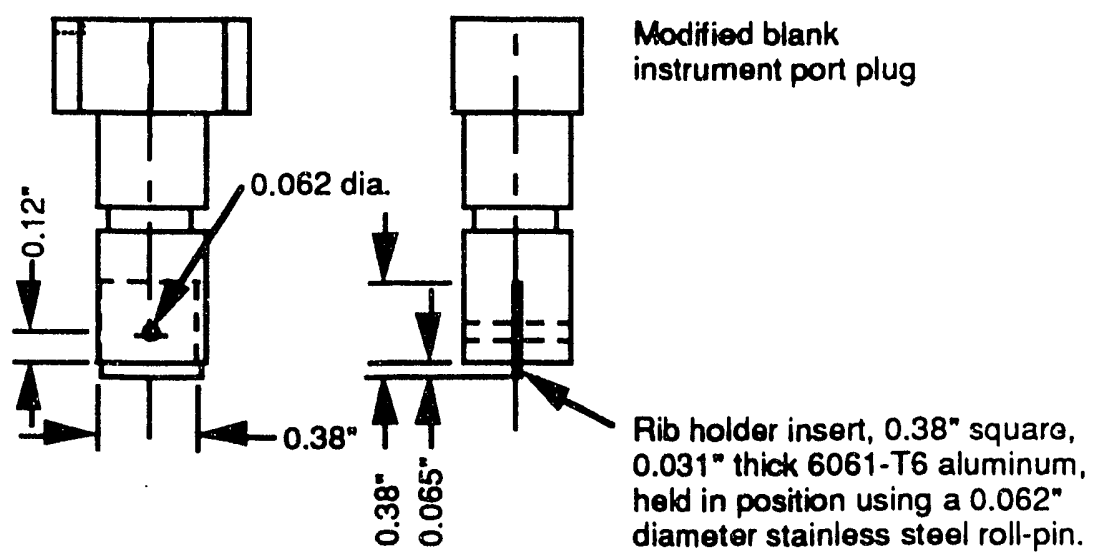

Figure 57, Rib support plugs
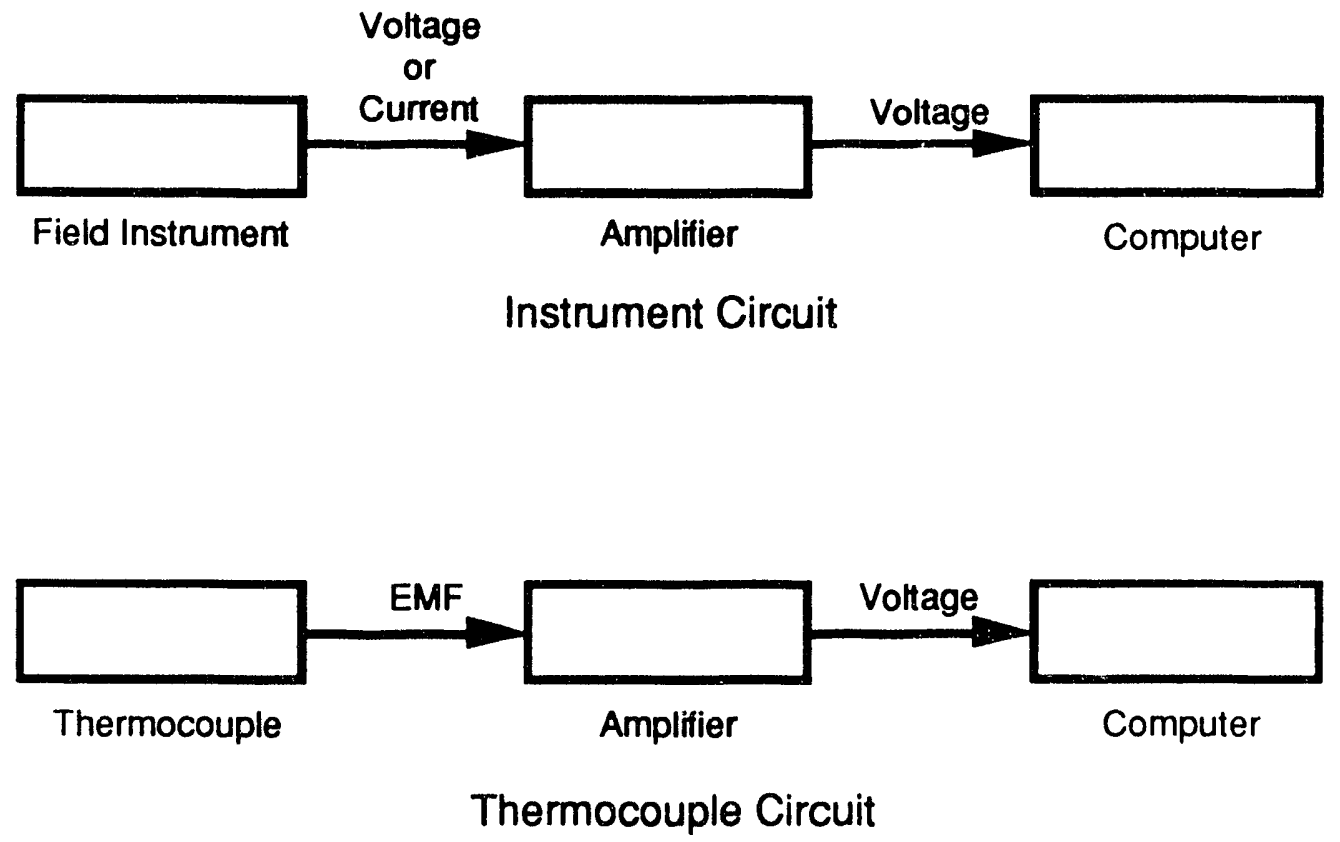

Figure 58, Basic instrument schematic 


\section{Preliminary Data _. 9 September 1993}

Table 26.--File nomenclature

\begin{tabular}{cc|l}
\hline WW_YYMMDD_HHHH & \multicolumn{1}{|c}{ Description } \\
\hline file prefix & \\
LP & SN & loop calibration file \\
& daily span calibration check file \\
& daily zero calibration check file \\
& daily flow calibration check file \\
& FS & steady state flow data file \\
& FT & transient flow data file \\
& SF & special file \\
YYMMDD & date created & year, month and day \\
HHHH & time created & military time \\
\hline
\end{tabular}

were tab delimited with the headers listed in Appendix 7, Table 7-1. These files were considered the raw data files.

\section{Data Management, and Reduction}

The raw data files were imported into the statistical software program. JMP (39). A column was added to each raw data file which consisted of the file name. The raw data file was then stored as a JMP data file. The column means and sample standard deviations listed in Appendix 7, Table 7-1 were then calculated for each JMP data file. The column means and sample standard deviations were then appended into a reduced raw data file consisting of the columns listed in Appendix 7, Table 7-1. This file was considered the reduced raw data file and was still in voltage units.

Data was converted from voltage units to engineering units using the formulas listed in Appendix 7, Table 7-2. The development of these formulas is presented in Appendix 2. Selected engineering units were then placed in the JMP data tables listed in Appendix 7 (Tables 7-3, 7-4, 7-5, and 7-6). Each of these JMP data tables was used to evaluate specific aspects of the channel 


\section{Prellminary Data -. 9 September 1993}

behavior. The data reduction equations used in these data tables are presented in Appendix 7.

\section{Primary Measurements}

Flow data reported in this report, except where specifically noted, is based on the turbine flowmeter, FT01001. This simplification was made to reduce the data reduction effort and because the turbine meter had a lower systematic uncertainty then the orifice meter, FT02001. Voltage measurements were made with two separate instruments. All data collected prior to 3 June 1993 should be converted to engineering units using the first equation listed in Appendix 7, Table 7-2, data taken on or after that date should be converted using the second equation.

Pressure measurements reported ir. this report include a correction to account for the static head of the impulse lines. This correction is based on Equation 5. The fluid density was calculated using the temperature indicated by the thermocouple TC00003. The elevation corrections were computed based on the data in Figures 51 and 5?.

\section{Fluid Properties}

\section{Density}

Equation 74 presents a correlation to predict the density of water at saturated conditions based on temperature (76). The coefficients for this equaticn are defined in Table 27. This equation has been used in the data reduction to estimate the fluid density. An implied assumption in its use is that the density of subcooled water is the same as water at saturated conditions.

$$
\rho=\sum_{i=1}^{4} c_{i} T^{(i-1)}\left[\frac{\mathrm{kg}}{\mathrm{m}^{3}}\right] 10 \leq T \leq 300^{\circ} \mathrm{C}
$$




\section{Prellminary Data _. 9 September 1993}

Table 27--Water property equation coefficients for density, specific heat and thermal conductivity

\begin{tabular}{|c|c|c|c|}
\hline $\mathrm{i}$ & Density & Specific heat & Thermal conductivity \\
\hline $\begin{array}{l}1 \\
2 \\
3 \\
4\end{array}$ & $\begin{array}{r}1004.8897 \\
-0.26847207 \\
-0.18136391 \theta-2 \\
-0.17041217 \theta-5\end{array}$ & $\begin{array}{c}5615.8 \\
-9.02077 \\
0.014177 \\
\ldots\end{array}$ & $\begin{array}{l}570.32432 \\
1.7996615 \\
-0.72881959 e-2 \\
0.32412245 e-5 \\
\end{array}$ \\
\hline
\end{tabular}

\section{Specific Heat}

Equation 75 presents a correlation to predict the specific heat of water at saturated conditions based on temperature (31). The coefficients for this equation are defined in Table 27. This equation has been used in the data reduction to estimate the fluid specific heat. An implied assumption in its use is that the specific heat of subcooled water is the same as water at saturated conditions.

$$
c_{p}=\sum_{i=1}^{3} c_{i} T^{(i-1)}\left[\frac{J}{k g-K}\right] 273.15 \leq T \leq 373.15 K
$$

\section{Thermal Conductivity}

Equation 76 presents a correlation to predict the thermal conductivity of water at saturated conditions based on temperature (76). The coefficients for this equation are defined in Table 27. This equation has been used in the data reduction to estimate the fluid thermal conductivity. An implied assumption in its use is that the thermal conductivity of subcooled water is the same as water at saturated conditions. 


\section{Preliminary Data _- 9 September 1993}

$$
k=\sum_{i=1}^{4} G_{i} T^{(i-1)}\left[\frac{w}{m-k}\right] 10 \leq T \leq 300^{\circ} \mathrm{C}
$$

\section{Dynamic Viscosity}

Equation 77 presents a correlation to predict the dynamic viscosity of water at saturated conditions based on temperature (76). The coefficients for this equation are defined in Table 28. This equation has been used in the data reduction to estimate the fluid viscosity. An implied assumption in its use is that the viscosity of subcooled water is the same as water at saturated conditions.

$$
\mu=\exp \sum_{i=1}^{6} q_{i}\left(\frac{1}{T_{r}}-1\right)^{(i-1)}\left[\frac{\mu N-s}{m^{2}}\right] \quad 283.15 \leq T \leq 573.15 \mathrm{~K}
$$

where:

$$
T_{r}=\frac{T}{647.14 K}
$$

Table 28--Water property equation coefficients for viscosity and saturation temperature

\begin{tabular}{l|r|l}
\hline \hline$i$ & Viscosity & $\begin{array}{c}\text { Saturation } \\
\text { temperature }\end{array}$ \\
\hline 1 & 4.2529199 & 375.46530 \\
2 & 2.3790677 & 89.679811 \\
3 & -3.8810805 & 11.149468 \\
4 & 8.0014055 & 0.99075812 \\
5 & -6.2882872 & 0.052882025 \\
6 & 1.8383557 & 0.0012471856 \\
\hline
\end{tabular}

\section{Saturation Temperature}

Equation 78 presents a correlation to predict the saturation temperature of water based on the local pressure (76). The coefficients for this equation are 


\section{Preliminary Data - 9 September 1993}

defined in Table 28. This equation has been used in the data reduction to estimate the saturation temperature at the end of the heated length based on the pressure transducers PA00024, and PA20024.

$$
\mathrm{T}_{\text {sat }}=\sum_{i=1}^{6} \mathrm{G}_{i} \mathrm{Y}^{i-1}\left[{ }^{\circ} \mathrm{C}\right] \quad 1.2277 \mathrm{kPa} \leq \mathrm{P} \leq 8.592 \mathrm{MPa}
$$

where:

$$
Y=\ln \left(\frac{P}{22.064 \mathrm{MPa}}\right)
$$

\section{Bulk Fluid Temperature}

The bulk fluid temperature was estimated as the mean of the inlet temperature as measured by TL00001, and the exit temperature as measured by TL00002.

\section{Demand Curve Analyses}

Demand curves were plotted in four different formats: (1) measured pressure drop versus measured flow, (2) friction factor versus Reynolds number,

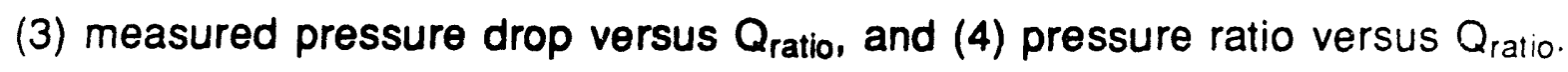
The pressure drop plotted in these figures is the measured pressure difference between the ports, $\Delta p_{23}$, shown in Figure 52 for the instruments PD02472, and PD22472. The stated pressure would include elevation recovery, acceleration effects, and frictional pressure losses. The measured frictional pressure loss, $\Delta p_{f}$, was calculated using Equation 79 winere the acceleration term has been neglected.

$$
\Delta p_{f}=\Delta p_{23}+g \overline{\rho_{m}}\left|L_{23}\right|
$$




\section{Prellminary Data _. 9 September 1993}

The friction factor has been calculated using Equation 18 and the frictional pressure loss from Equation 79. The fluid properties for the friction factor and Reynolds number calculations were estimated using the bulk temperature. Table 23 presents the flow geometry dimensions which were used for the calculations. The diameter has been calculated using Equation 24; the hydraulic diameter, except where specifically noted.

The $Q_{\text {ratio }}$ was calculated using the same relation as the temperature ratio, $R$ (Equation 2). The pressure ratio is based on Equation 33. It is a ratio of the isothermal frictional pressure loss (where fluid properties are calculated at the inlet conditions) and the measured frictional pressure loss. An elevation recovery term is included in estimating the frictional pressure loss. The isothermal friction factor was estimated using Equation 22.

\section{System Continuity Checks}

Several continuity checks were possible for this test program. Comparison of independent measurements was done to quantify the uncertainties of the experiment and verify system operation. Two independent power calculations were possible: (1) electrical power applied to heater, and (2) heat transferred by the fluid. Three heat flux calculations were possible. Two were from the electrical and fluid power calculation, the third from the temperature gradient in the heater plate. The control boundary diagrams for each of these calculations is presented in Figure 59. In addition to these checks, the isothermal data was compared with accepted theories, and daily instrument checks were made to demonstrate consistency. 


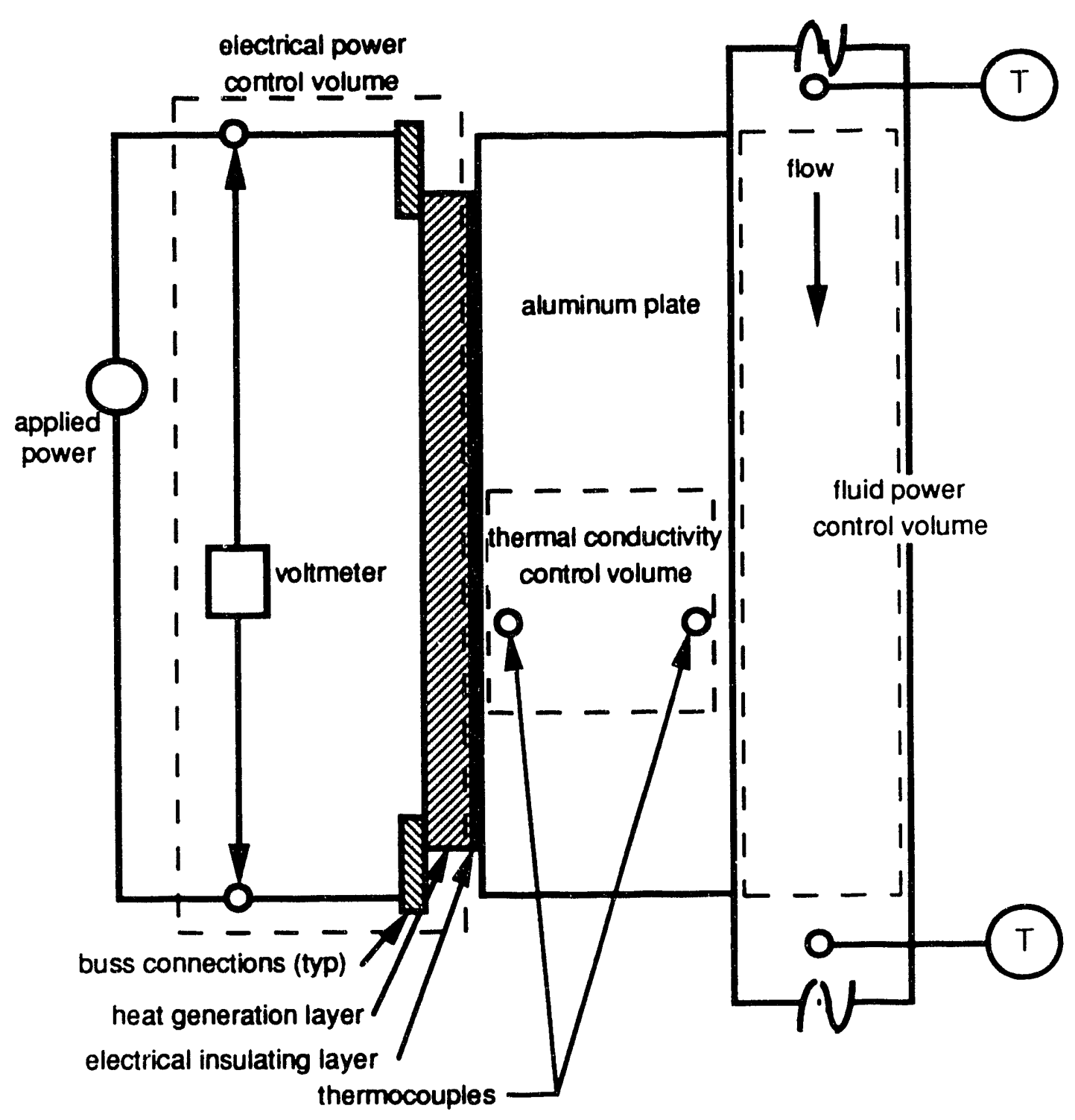

Figure 59. Power calculation control volumes

\section{Temperature and Pressure Profiles}

Temperature profile plots were prepared from raw engineering units data. No adjustments for installation effects (e.g., stem conduction) have been made. Pressure profile plots present the measured pressure indication with a correction for the static head in the impulse lines. The absolute pressures were adjusted to gauge by deducting the barometric pressure. The barometric 


\section{Preliminary Data _. 9 September 1993}

pressure was taken at the measured value if available, or at the mean of the daily checks for that day.

The theoretical pressure profiles were assumed linear through the rectangular flow channel; only frictional losses and elevation recovery were considered. The profile was forced though the mean of PA00072 and PA20072. Acceleration effects where considered negligible. The entrance and exit losses were assumed negligible. Equations 8, 17, and 22 were used in calculating the profile.

\section{Uncertainty Analysis}

Appendix 3 contains a detailed analysis of the systematic measurement uncertainties for this test program. The random measurement uncertainties have been considered negligible. Since the final analysis includes a term for the variability of the resultants random measurement uncertainty has be folded into the final analysis. Geometric uncertainty estimates are presented in Appendix 1. Instrument measurement uncertainties have been estimated from the daily checks and the calibration information. This information is presented in Appendix 2.

The systematic uncertainties presented in Appendices 1, 2, and 3 have been propagated to resultants (25) using Equation 80.

$$
B_{r}^{2}=\sum_{i=1}^{J}\left[\theta_{i}^{2} B_{i}^{2}+\sum_{k=1}^{J} \theta_{i} \theta_{k} \rho_{i k} B_{i} B_{k}\left(1-\delta_{i k}\right)\right]
$$

where:

$$
\delta_{i k}= \begin{cases}1 & i=k \\ 0 & i \neq k\end{cases}
$$




\section{Prellminary Data _- 9 September 1993}

The term $\rho_{i k}$ is the coefficient of correlation between the terms $x_{i}$ and $x_{k}$. If the errors are completely correlated $\rho_{\text {ik }}$ is equal to 1 . If the terms are not correlated (i.e., not independent) the value of $\rho_{i k}$ is equal to 0 . For most of the uncertainty estimates the elemental parameters, i, have been assumed independent. Correlated uncertainties have been discussed where they are known to exist. It should be noted that $\rho_{i k}=\rho_{k i}$.

\section{Absolute Uncertainties}

The absolute uncertainty in the context of this report is the uncertainty which exists in a stated measurement as compared with a defined true value (e.g., a known condition or correlation). Table 32 summarizes the systematic elemental measurement uncertainties for this test program. The random uncertainties for individual measurements have been assumed negligible. The random components for resultants have been estimated based on the variability of the resultant using the Equation 81.

$$
P_{r}=\frac{t_{v} S_{r}}{\sqrt{N}}
$$

where: $t$ is the Student- $t$ value at $95 \%$ confidence and the degrees of freedom, $v$, is taken as $\mathrm{N}-1$. The total measurement uncertainty, $U$, is then estimated using Equation 82.

$$
U_{r}=\sqrt{B_{r}^{2}+P_{r}^{2}}
$$

Table 33 summarizes the combined resultant measurement uncertainties for the data presented in this report. 


\section{Preliminary Data _. 9 September 1993}

Table 32--Nominal elemental measurement uncertainties

\begin{tabular}{l|c|c|c|c}
\hline \hline & units & $\begin{array}{c}\text { instrument } \\
\text { loop } \\
\text { number }\end{array}$ & $x$ & $\mathrm{~B}$ \\
\hline Flow & $\mathrm{cm}^{3 / \mathrm{s}}$ & FT01001 & 200 & 1.4 \\
Pressure, absolute & $\mathrm{kPa}$ & PA00072 & 400 & 1.2 \\
& $\mathrm{KPa}$ & PA20072 & $\ldots$ & 0.46 \\
Pressure, differential & PA00072 & $\ldots$ & 0.46 \\
& $\mathrm{~K}$ & PA20072 & $\ldots$ & 0.4 \\
Temperature & ${ }^{\circ} \mathrm{C}$ & $\ldots$ & $\ldots$ & 0.4 \\
Voltage & $\mathrm{V}$ & WV00001 & $\ldots$ & 0.001 \\
Current & $\mathrm{A}$ & WC00001 & $\ldots$ & 0.1 \\
\hline
\end{tabular}

Table 33--Nominal elemental measurement uncertainties

\begin{tabular}{l|c|c|c|c|c}
\hline & Const. & $\mathrm{R}$ & $\mathrm{B}_{\mathrm{r}}$ & $\mathrm{P}_{\mathrm{r}}$ & $\mathrm{U}_{\mathrm{r}}$ \\
\hline Isothermal resultants & & & & & \\
Friction factor & 4 & 0.0316 & 0.0083 & & \\
& 2 & 0.0266 & 0.0046 & & \\
Reynolds number & 4 & 0.0316 & 0.0077 & & \\
& 2 & 10,000 & 0.0052 & & \\
& & 10,000 & 173 & & \\
Diabatic resultants & & 20,000 & 120 & & \\
Energy balance ratio & & & & & \\
$\mathrm{Q}=495 \mathrm{~cm}^{3 / \mathrm{s}}$ & & 0.97 & 0.042 & & \\
$\mathrm{Q}=1260 \mathrm{~cm}^{3 / \mathrm{s}}$ & & 0.97 & 0.10 & & \\
Heat flux, $\mathrm{kW}$ & 4 & 330 & 7 & & \\
Resultants at OFI & 2 & 339 & 15.6 & & \\
$\mathrm{Q}_{\text {ratio }}$ & 4 & 0.7616 & 0.011 & & \\
Stanton number & 2 & 0.6195 & 0.011 & & \\
& 4 & 0.00844 & 0.00079 & & \\
\hline
\end{tabular}




\section{Prellminary Data -- 9 September 1993}

\section{Comparative Uncertainties}

Correlation of terms is an important consideration in comparison testing (13) where two different operating conditions or constructions are being compared by use of a ratio.

$$
\eta=\frac{\Psi_{\text {alt }}}{\Psi_{\text {control }}}
$$

The uncertainty of the comparison ratio, $\eta$, when all of the systematic uncertainty terms are correlated and the corresponding sensitivity coefficients are equal (i.e. $q_{i}$, alt $=q_{i}$, control) is zero. It is this reason that back-to-back comparison testing can be such a powerful method to identify slight variations between two different configurations. For Equation 83 the uncertainty term summation based on Equation 80 is:

$$
\begin{aligned}
B_{\eta}{ }^{2} & =\left(\frac{\partial \eta}{\partial \psi_{a}}\right)^{2} B_{\psi_{a}}{ }^{2}+\left(\frac{\partial \eta}{\partial \psi_{c}}\right)^{2} B_{\psi_{c}}{ }^{2}+2\left(\frac{\partial \eta}{\partial \psi_{a}}\right)\left(\frac{\partial \eta}{\partial \psi_{c}}\right) B_{\psi_{a}} B_{\psi_{c}}{ }^{2} \\
& =\left(\frac{\eta}{\psi_{a}}\right)^{2} B_{\psi_{a}}{ }^{2}+\left(\frac{-\eta}{\psi_{c}}\right)^{2} B_{\psi_{c}}{ }^{2}+2\left(\frac{\eta}{\psi_{a}}\right)\left(\frac{-\eta}{\psi_{c}}\right) B_{\psi_{a}} B_{\psi_{c}}{ }^{2}
\end{aligned}
$$

If there is no variation between the two configurations $\Psi_{a}=\Psi_{c}$ and if the systematic uncertainties are also equal (i.e., $B \Psi_{\mathrm{a}}=\mathrm{B} \Psi_{\mathrm{c}}$ ) then the combined systematic uncertainty would be zero. In practice there will always be some variation between the alternate and the control so some systematic uncertainty will always exist. 


\section{CHAPTER 4}

\section{RESULTS}

The results presented in this section have been separated into five different categories: (1) isothermal test results, (2) diabatic demand curve results, (3) diabatic pressure profiles, (4) visual observations at OFI, and (5) temperature profiles. Ledinegg flow instabilities when operating a flow below the OFI flow were avoided since the channel was operated in a flow controlled mode. Some dryout patches were observed during demand curve 3.003 for Construction 2. No significant difference in the operating conditions has been identified which would have resulted in dryout for this curve and not for curves at equivalent operating conditions.

\section{Isothermal Test Results}

Figures 59 and 60 present the isothermal demand curve for the four different constructions evaluated during this study. The pressure drop for Construction 1 (open channel) was higher than for Constriction 2 (ribbed channel). This decrease in pressure drop after adding the rib was considered the result of an increase in flow area when the rib was added. Figure 61 provides a detail of the heater seal. During the operation of Construction 1 the rig began to leak. The eight bolts which hold the channel to the strong back were tightened the leak was substantially reduced, however, the pressure drop increased significantly. It appears that tightening the strongback bolts provided a preload on the heater seal. This could only occur if the heater insulation pressed on the back of the heater. 


\section{Preliminary Data -- 9 September 1993}

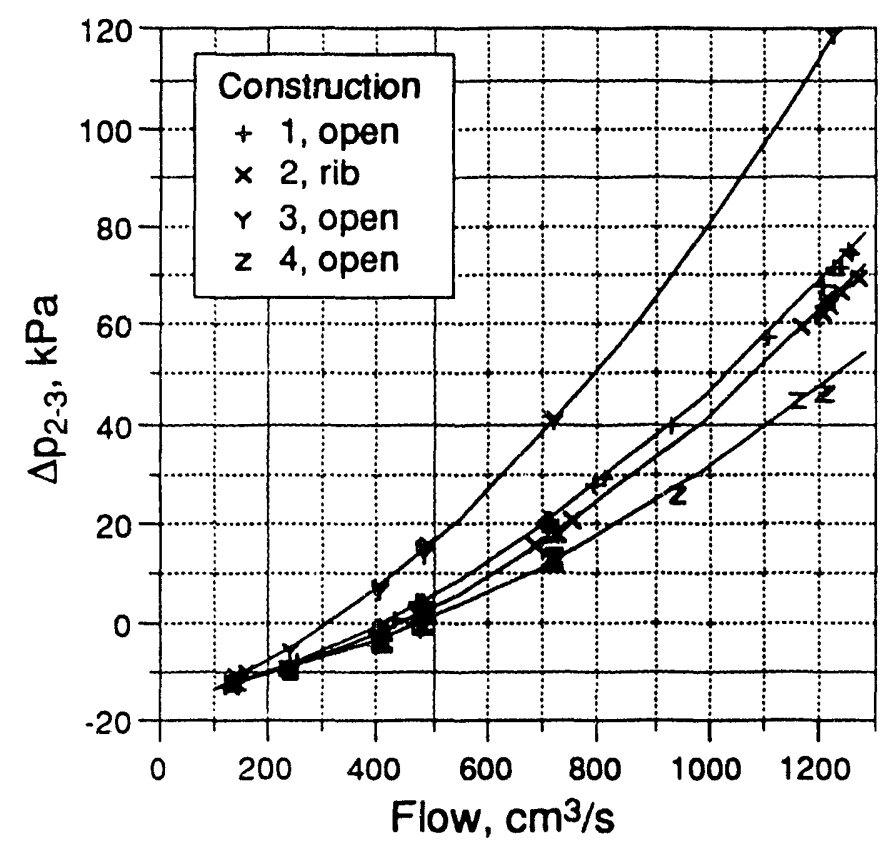

Figure 59, Isothermal demand curves for an inlet temperature range of 20 to $25^{\circ} \mathrm{C}$

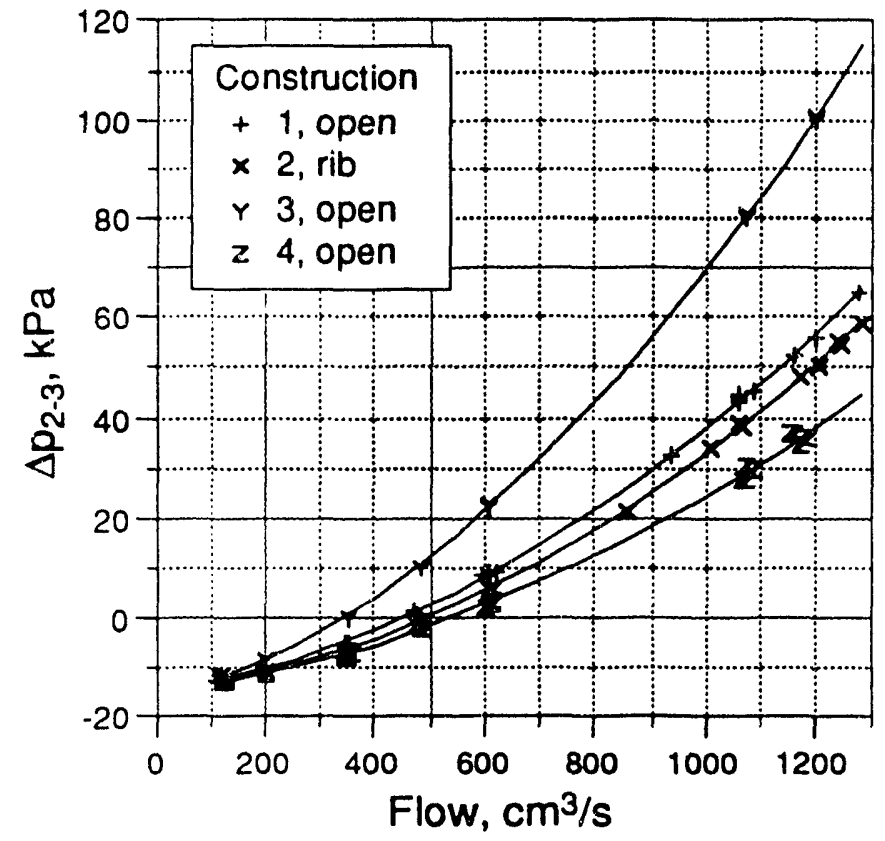

Figure 60, Isothermal demand curves for an inlet temperature range of 57.5 to $62.5^{\circ} \mathrm{C}$ 


\section{Preliminary Data -. 9 September 1993}

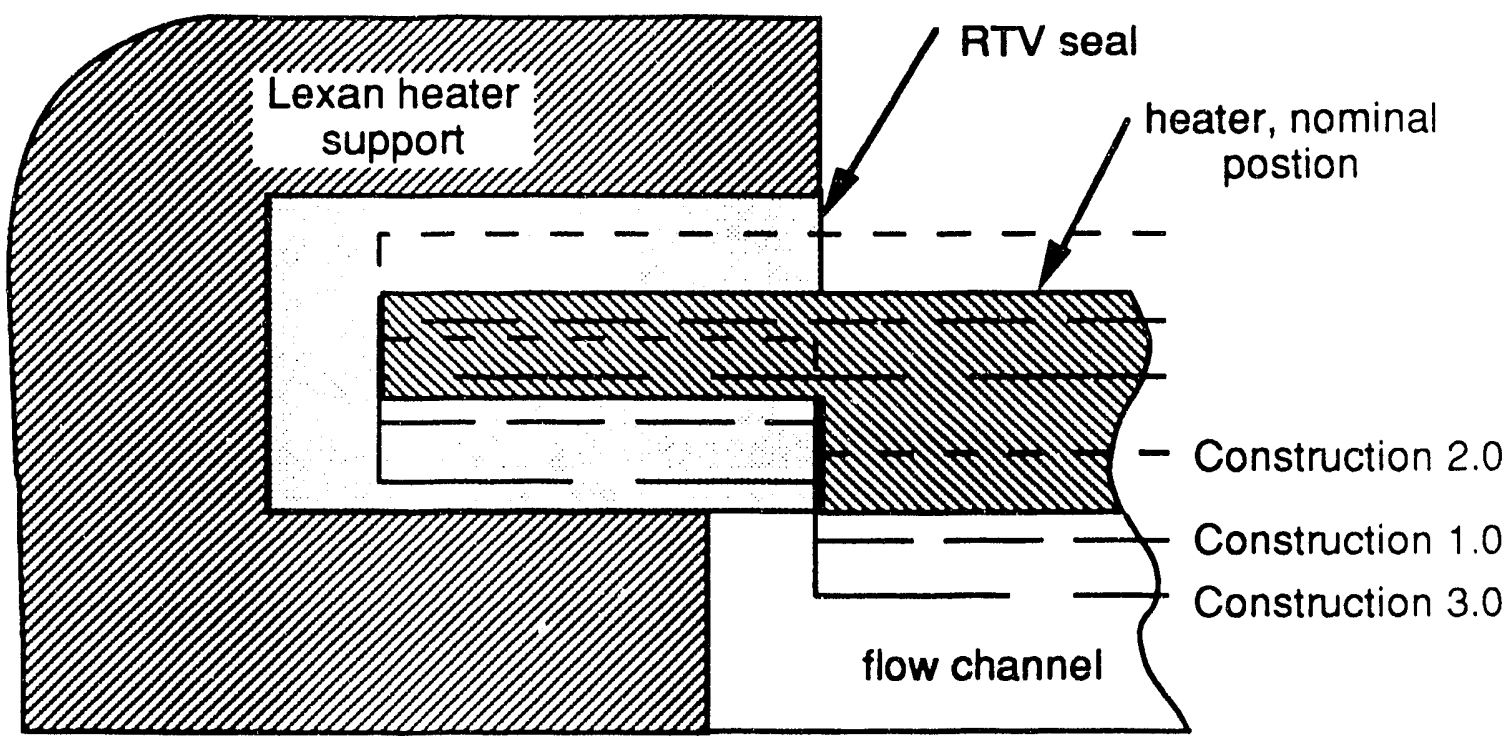

Figure 61, Heater seal detail

When the rib was installed the original heater gasket was reused. This was done to minimize any variation between the channel geometries. The rib required a fixed minimum distance between the faceplate and the heater. Since the rib height was $3.20 \mathrm{~mm}\left(0.126^{\prime \prime}\right)$ the channel depth was increased above the nominal $3.18 \mathrm{~mm}(0.125 ")$. This shift in the heater position shifted the strongback loading. The strongback now pressed on the insulation rather than the Lexan heater supports. The heater was therefore sandwiched between the rib and the ceramic insulation blocks. As a result the heater seal did not have any preload beyond the designed interference fit. This agrees with the observed leak rate during channel operation. When operating at ambient temperature the rig leaked approximately $1 \mathrm{~cm} 3 / \mathrm{hr}$ at a flow of $1260 \mathrm{~cm}^{3} / \mathrm{s}$. When the operating temperature was increased to $60^{\circ} \mathrm{C}$ thermal expansion sealed virtually all of the leakage.

The increase in channel depth when the rib was added was not readily apparent until Figures 59 and 60 were available. To diagnose the problem the 
rib was removed from the channel. To accomplish this the strongback was removed; the ceramic insulation was higher than the Lexan side supports. This verified that the strongback was indirectly pressing on the heater and compressing the reater against the rib ather than the Lexan heater supports. The rib support plugs were removed, and the bolts which held Lexan heater supports to the face plate (which holds the view ports) loosened one-half turn. This allowed the rib to be slipped out through the bottom of the channel. The channel was then reassembled as Construction 3.0. The channel depth measurements were measurer using a depth micrometer. The distance from the front of the face plate to the wetted surface of the heater at multiple instrument ports. The channel depth was then calculated by deducting the thickness of the faceplate. The depth measurements are presented in Appendix 1.

The channel depth for Construction 1 was estimated to provide a friction factor demand curve which coincided with the friction factor demand curves for Constructions 3.0 and 4.0. Justification for the remainder of the channel dimensions is presented in Appendix 1.

\section{Pressure Profiles}

Figure 62 presents a typical pressure profile for the isothermal tests. Note the lack of variation between the duplicate pressure instruments (i.e.. PD02472, and PD22472; and PA00072, and PA20072). For low flows such as shown in Figure 62 the elevation recovery exceed the frictional pressure loss

and the pressure increased in the longitudinal direction. Figure 63 provides a profile for a high flow where the pressure gradient is negative since the frictional pressure drop exceeds the elevation recovery. 


\section{Preliminary Data -- 9 September 1993}

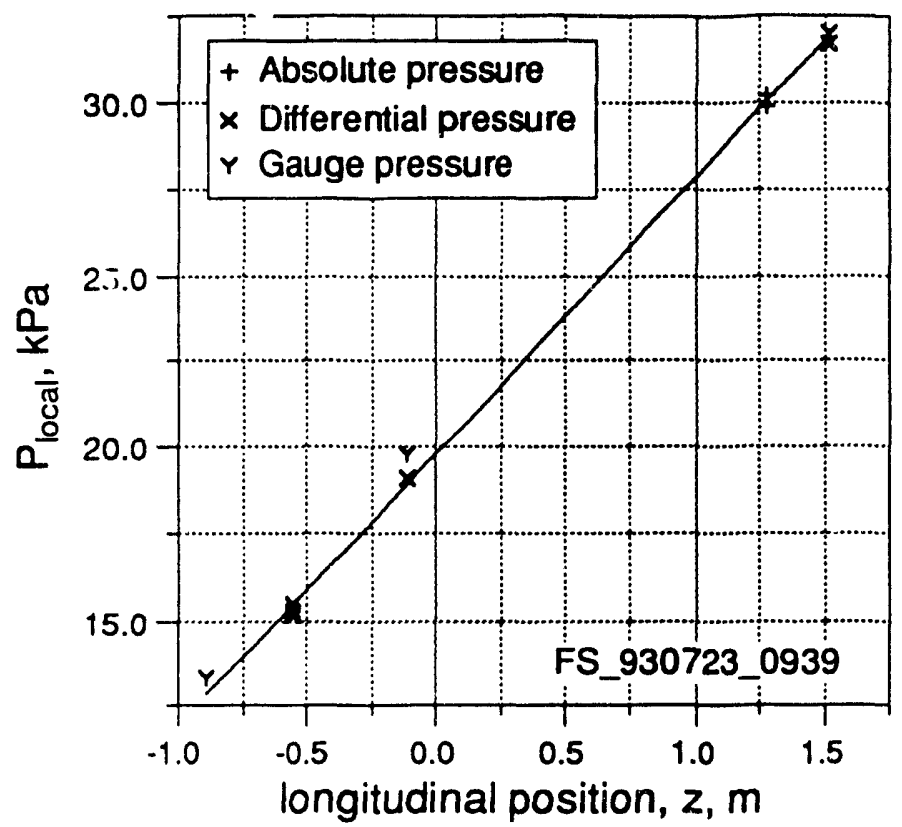

Figure 62, Isothermal longitudinal pressure gradient for open channel from File FS_930723_0939 (Construction $4.0, \mathrm{~T}_{\text {in }}={ }^{\circ} \mathrm{C}, \phi=0.0 \mathrm{~kW} / \mathrm{m}^{2}, \mathrm{Q}=$ low flow $\mathrm{cm}^{3} / \mathrm{s}$, $\mathrm{P}_{\mathrm{ehl}}=\mathrm{kPa}$ )

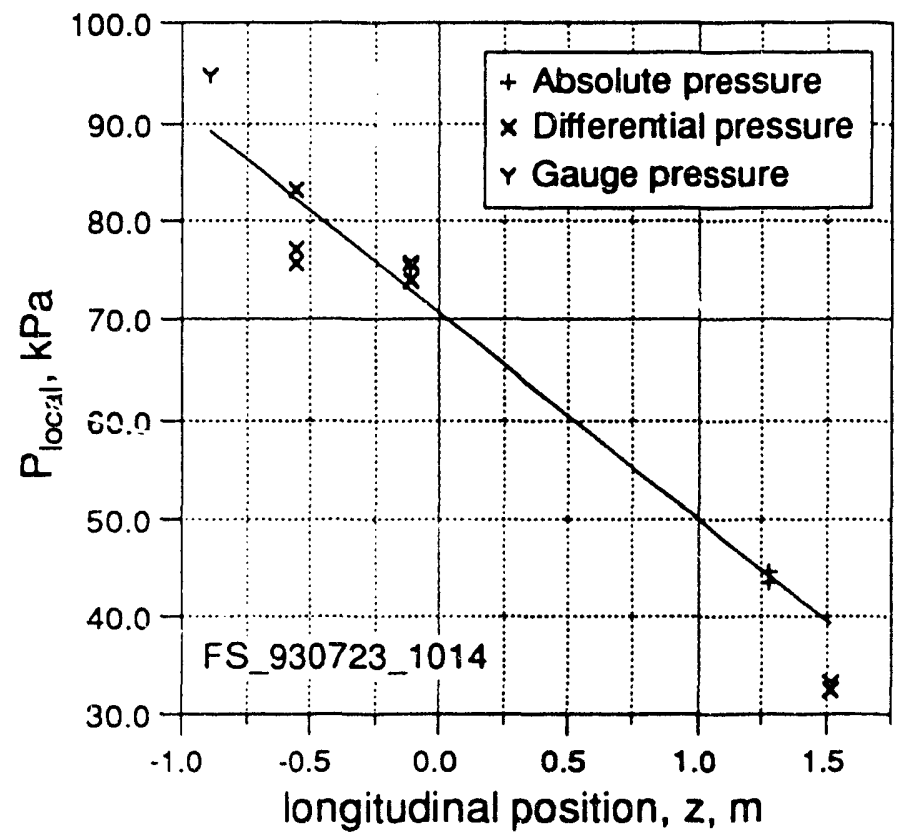

Figure 63, Isothermal longitudinal pressure gradient for open channel from File FS_930723_1014 (Construction $4.0, \mathrm{~T}_{\text {in }}={ }^{\circ} \mathrm{C}, \phi=0.0 \mathrm{~kW} / \mathrm{m}^{2}, \mathrm{Q}=1077.6 \mathrm{~cm}^{3} / \mathrm{s}$, $\left.\mathrm{p}_{\mathrm{ehl}}=\mathrm{kPa}\right)$ 


\section{Preliminary Data .- 9 September 1993}

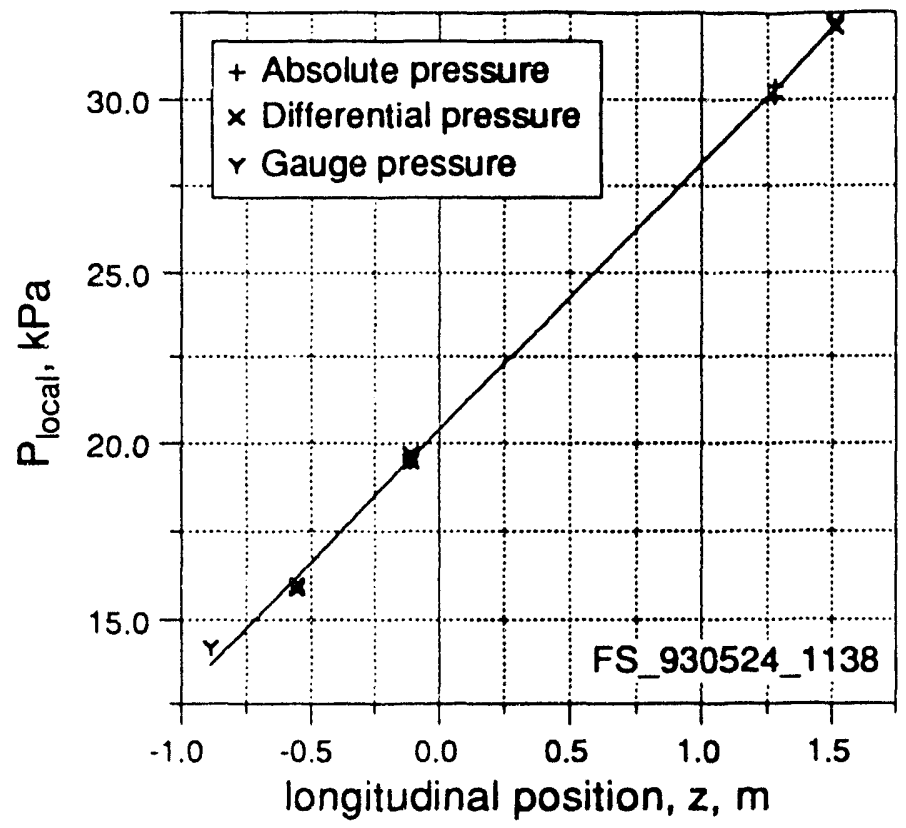

Figure 64, Isothermal lorigitudinal pressure gradient for open channel from File FS_930524_1138 (Construction 2.0, $T_{\text {in }}={ }^{\circ} \mathrm{C}, \phi=0.0 \mathrm{~kW} / \mathrm{m}^{2}, Q=$ low flow $\mathrm{cm}^{3} / \mathrm{s}$, $\left.\mathrm{p}_{\mathrm{ehl}}=\mathrm{kPa}\right)$

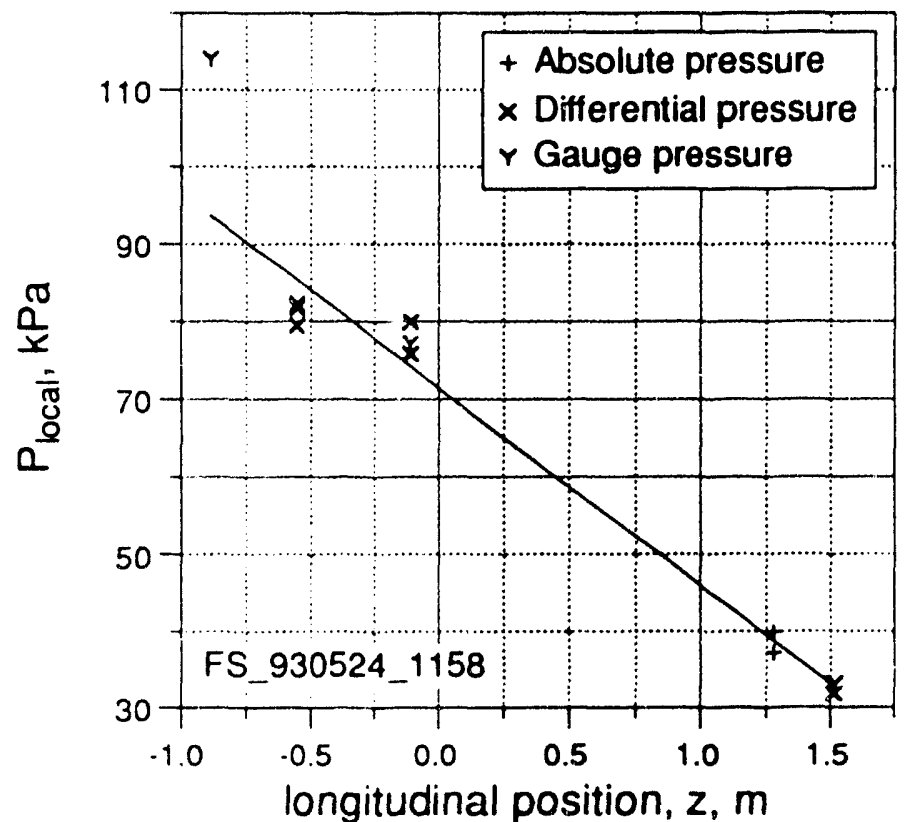

Figure 65, Isothermal longitudinal pressure gradient for open channel from File FS_930524_1158 (Construction $2.0, T_{\text {in }}={ }^{\circ} \mathrm{C}, \phi=0.0 \mathrm{~kW} / \mathrm{m}^{2}, Q=$ high flow $\mathrm{cm}^{3} / \mathrm{s}, \mathrm{p}_{\mathrm{ehl}}=\mathrm{kPa}$ ) 


\section{Preliminary Data .- 9 September 1993}

Figures 64 and 65 provide pressure profiles for similar conditions to those in Figures 62 and 63 and allow a comparison of the channel behavior with and without a rib. There is little variation between the pressures measured by PD02472 and PD22472 at the lower flows. At higher flows some variation does occur but the effect is not significant enough to allow a conclusion.

\section{Effective Channel Diameter}

Two different methods were used to estimate the hydraulic diameter. Figure 66 presents the friction factor demand curve where the effective channel diameter has been estimated using the effective diameter defined by Equation 25. The results do not approach that expected for a smooth channel. The hydraulic diameter calculated using Equation 24 was used to produce Figure 67. The results for Constructions 3.0 and 4.0 compare favorably with smooth channel behavior. Since the channel geometry of Construction 1 was selected to match the friction factor demand curves of the other open channel data sets their results are expected.

The friction factor for the ribbed channel was higher than the open channel for any given flow conditions. This would be expected since flow between the subchannels was observed. This flow between subchannels would probably increase the turbulence near the rib and result in an increase in non-recoverable losses. A linear fit of the data in Figure 67 was made for each construction. Equation 85 provides the final form for this fit. The results are presented in Table 33. The results agree very well with Equation 22.

$$
f=\mathrm{C}_{1} \mathrm{Re}^{\mathrm{C}_{2}}
$$




\section{Preliminary Dais _- 9 September 1993}

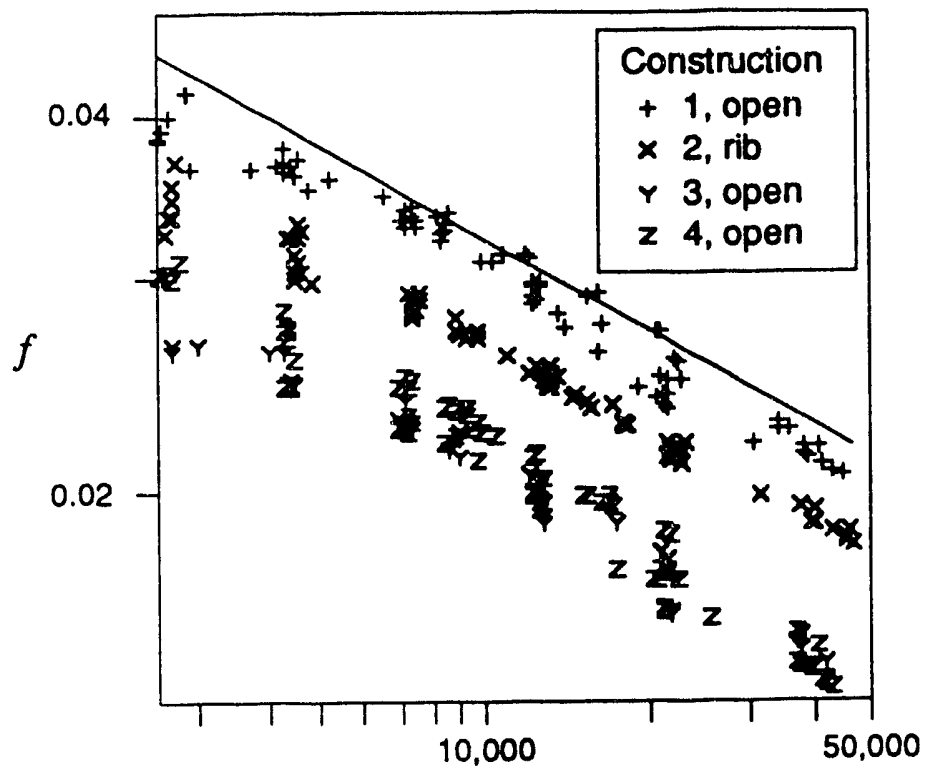

Re

Figure 66, Isothermal friction factor demand curves based on equivalent diameter calculated using Equation 25.

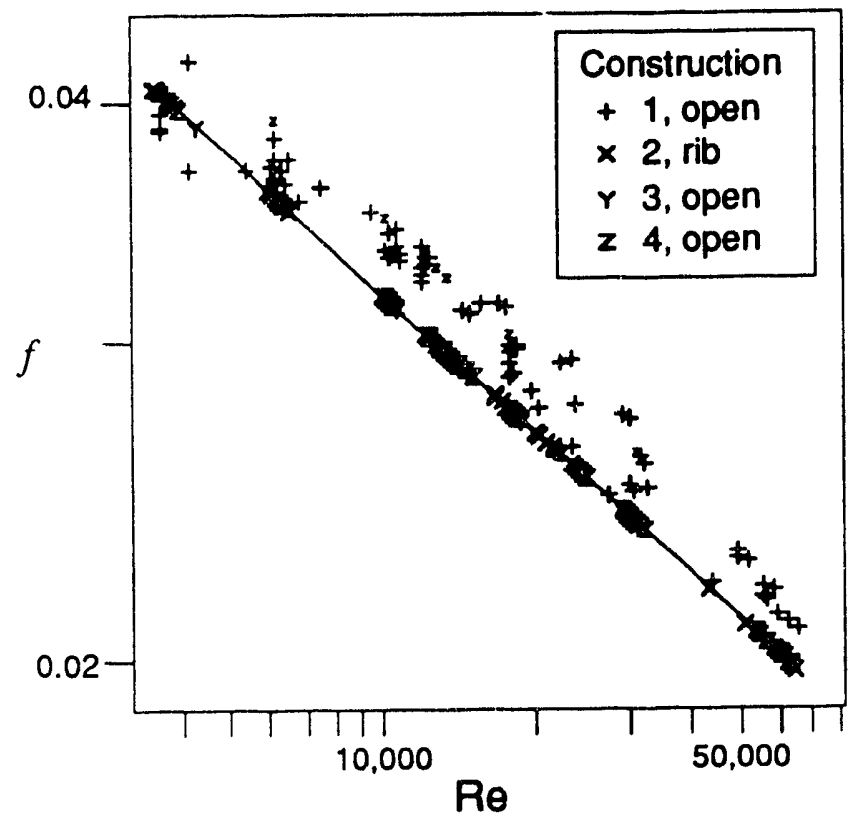

Figure 67, Isothermal friction factor demand curves based on hydraulic diameter calculated using Equation 24. 


\section{Preliminary Data -- 9 September 1993}

Table 33.--Isothermal demand curve fits

\begin{tabular}{c|c|c|c}
\hline Construction & Geometry & C1 & C2 \\
\hline 1 & open & 0.28905 & -0.23520 \\
2 & rib & 0.25625 & -0.22542 \\
3 & open & 0.26566 & -0.22996 \\
4 & open & 0.38427 & -0.26657 \\
\hline Equation 22 & $\ldots$ & 0.316 & -0.25 \\
\hline
\end{tabular}

\section{Heater Inspection}

After disassembly of Construction 3 the heater was visually inspected. The heater portion had turned a dull golden color. With just two exceptions the discoloration increased uniformly along the longitudinal axis. Highlights of the inspection are presented in Figure 68. The discoloration at the end of the heated length did not stop abruptly. Discoloration occurred downstream of the end of the heated length. This is probably the result of axial conduction in the heater and the high water temperature in this region. A detailed discussion of the heated area dimensions is included in Appendix 1.

\section{Diabatic Test Results}

Nine diabatic demand curves were generated in open channels and four diabatic demand curves in a channel with a longitudinal rib. Two different constructions were tested in the open configuration. The channel depth of these two open channels bracketed the channel depth with a rib present. The rib had a significant effect on the heated channel behavior. The presence of a longitudinal rib increased the flow at the demand curve minimum when compared with an open channel of similar construction. This is shown in Figures 69 and 70 . Figure 69 shows a typical overall demand curve for 


\section{Preliminary Data -- 9 September 1993}

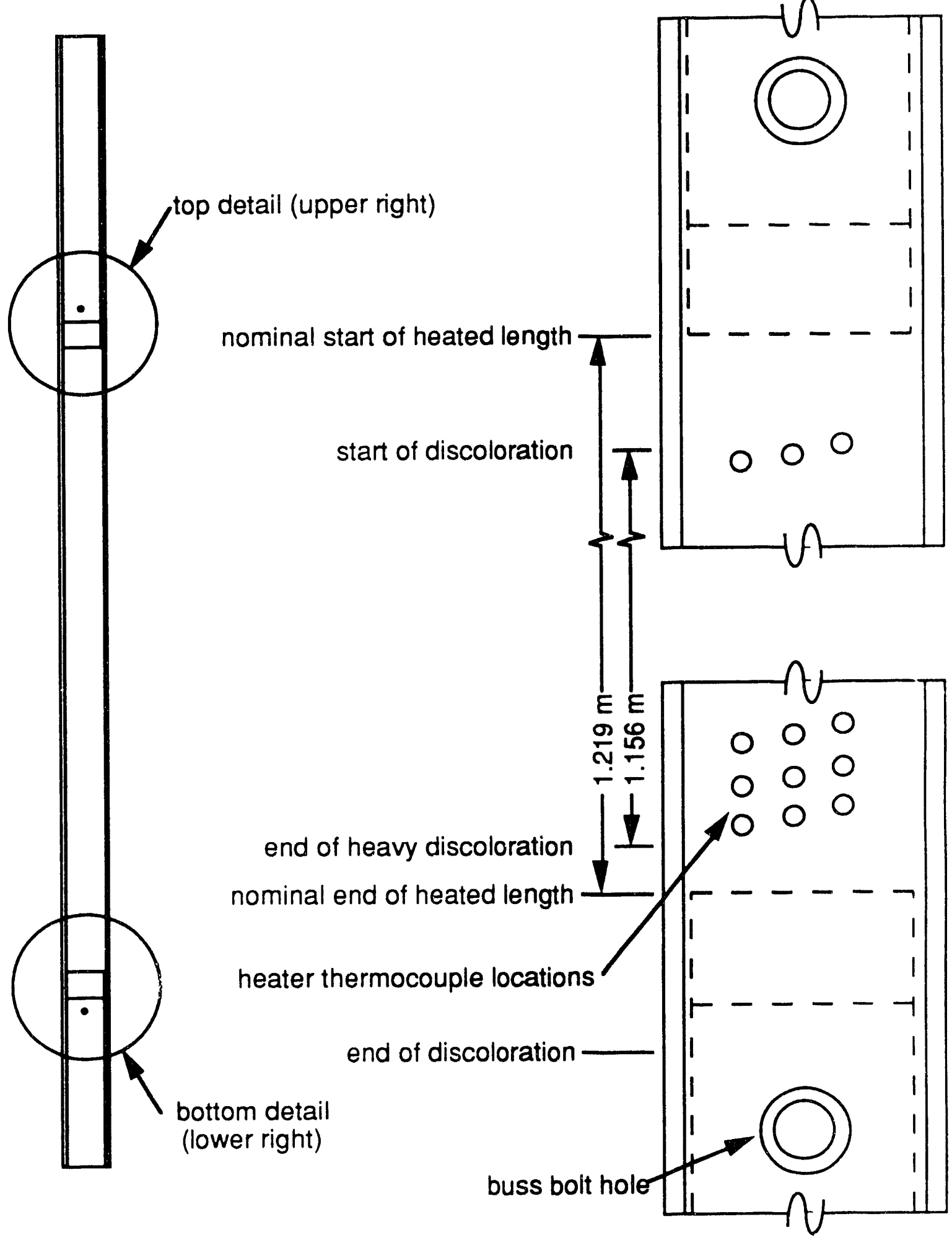

Figure 68. Heater inspection results 


\section{Preliminary Data .- 9 September 1993}

Constructions 2.0 and 4.0. The demand curve minimum for the ribbed channel occurs at a higher flow rate in the ribbed channel than for the open channel.

\section{Demand Curve Comparisons}

The Qratio demand curve is presented in Figure 71 for the three constructions. As has been seen in other work the demand curve shifts up for higher power leve!s (compare demand curves 3.003 and 4.001). The minima region for Figure 71 is presented in Figure 72 . The Qratio at the demand curve minimum for Construction 2.0 (demand curve 2.004) and Construction 4.0 (demand curve 2.009) do not vary significantly. This follows the theory that the Qratio is dependent on the heat LD rather than the hydraulic LD.

A comparison of the diabatic demand curves for Construction 2.0 with the isothermal demand curve indicates little difference in the test section pressure drop for a given flow rate. (See Figure 73.) At flows slightly higher than at OFI the test section pressure drop was slightly lower for diabatic demand curves. This is expected as discussed in Chapter 2. The Qratio at the demand curve minimum did not vary with a change of heat flux with the longitudinal rib present. (See Figure 75.) The pressure drop multiplier as a function of the Qratio is presented in Figure 76. There is a general trend that suggests that the multiplier is constant for a given geometry.

Table 34 presents a summary of the OFI data for the thirteen demand curves which were generated. Replication of the demand curves for the three different constructions was very successful. Table 35 presents a summary of the most significant OFI parameters with the applicable uncertainty terms. The presence of the rib tends to decrease the exit temperature, Qratio, and Stanton number at OFI when compared to the open channels. The Qratio at OFI for the 
Preliminary Data _- 9 September 1993

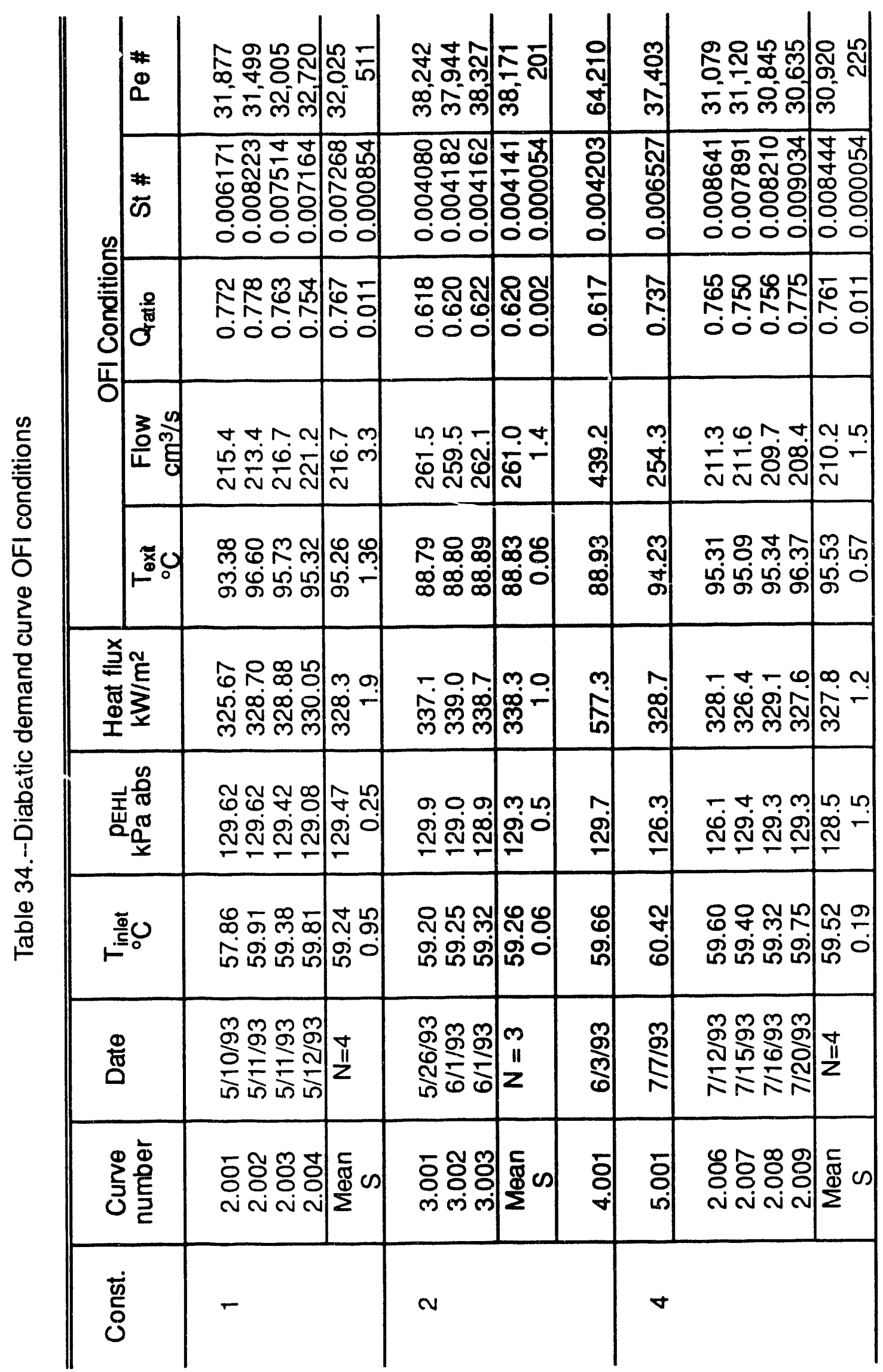




\section{Preliminary Data -. 9 September 1993}

Table 35.--Demand curve minimum results (nominal conditions: $T_{\text {in }}=60^{\circ} \mathrm{C}, P_{\text {ehl }}$ $=130 \mathrm{kPa}, \mathrm{P}=, \phi_{\text {open }}=330 \mathrm{~kW} / \mathrm{m}^{2}, \phi_{\text {rib }}=340 \mathrm{~kW} / \mathrm{m}^{2}$ )

\begin{tabular}{|c|c|c|c|c|c|}
\hline & Const. & Mean & $\mathrm{P}$ & B & $U$ \\
\hline$T_{\text {exit }}{ }^{\circ} \mathrm{C}$ & $\begin{array}{l}1 \\
2\end{array}$ & $\begin{array}{l}95.26 \\
88.83\end{array}$ & $\begin{array}{l}2.16376 \\
0.149060 \\
29\end{array}$ & $\begin{array}{l}0.50 \\
0.50\end{array}$ & $\begin{array}{l}2.22 \\
0.52\end{array}$ \\
\hline Flow, $\mathrm{cm}^{3} / \mathrm{s}$ & $\begin{array}{l}4 \\
1 \\
2 \\
4\end{array}$ & $\begin{array}{l}95.53 \\
216.7 \\
261 \\
210.2\end{array}$ & $\begin{array}{l}0.90687 \\
5.3 \\
3.5 \\
2.4\end{array}$ & $\begin{array}{l}0.50 \\
1.4 \\
1.4 \\
1.4\end{array}$ & $\begin{array}{l}1.04 \\
5.4 \\
3.7 \\
2.8\end{array}$ \\
\hline Qratio & $\begin{array}{l}1 \\
2 \\
4\end{array}$ & $\begin{array}{l}0.767 \\
0.620 \\
0.761\end{array}$ & $\begin{array}{l}0.018 \\
0.005 \\
0.018\end{array}$ & $\begin{array}{l}0.011 \\
0.014 \\
0.011\end{array}$ & $\begin{array}{l}0.021 \\
0.015 \\
0.021\end{array}$ \\
\hline Stanton number & $\begin{array}{l}1 \\
2 \\
4\end{array}$ & $\begin{array}{l}0.00727 \\
0.00414 \\
0.00844\end{array}$ & $\begin{array}{l}0.00136 \\
0.00013 \\
0.00009\end{array}$ & $\begin{array}{l}0.00079 \\
0.00037 \\
0.00079\end{array}$ & $\begin{array}{l}0.00157 \\
0.00039 \\
0.00079\end{array}$ \\
\hline
\end{tabular}

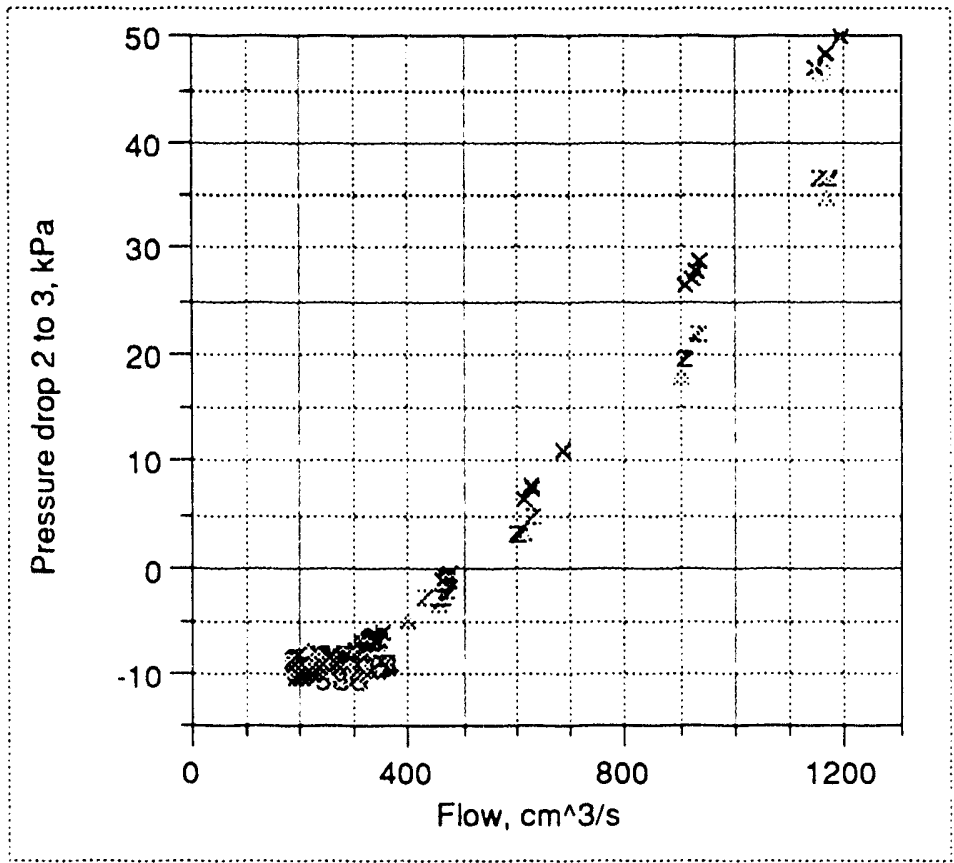

Figure 69, Diabatic demand curve data for Constructions 2.0 and 4.0, $\mathrm{T}_{\text {in }}=$ $60^{\circ} \mathrm{C}, \phi_{\text {open }}=330 \mathrm{~kW} / \mathrm{m}^{2}, \phi_{\text {rib }}=340 \mathrm{~kW} / \mathrm{m}^{2}, \mathrm{P}=29 \mathrm{~kW}, p_{\text {ehl }}=130 \mathrm{kPa}$ 


\section{Preliminary Data -- 9 September 1993}

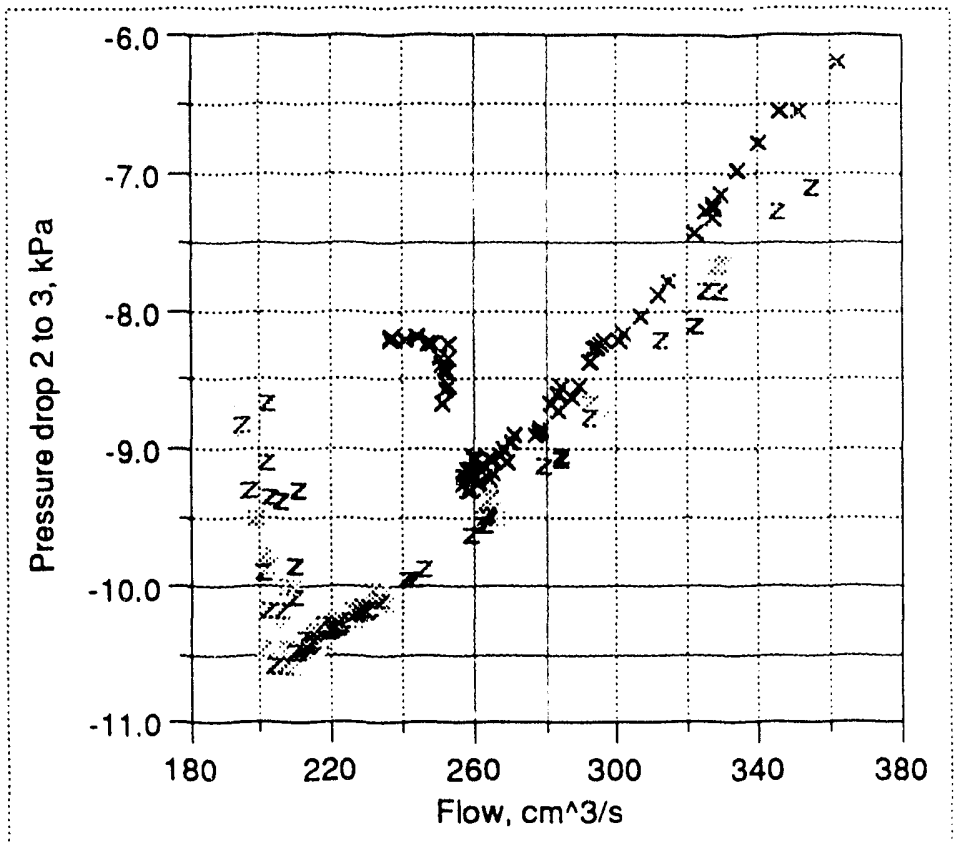

Figure 70, Minima region of the diabatic demand curve data for Constructions 2.0 and $4.0, T_{\text {in }}=60^{\circ} \mathrm{C}, q=30.5 \mathrm{~kW} / \mathrm{m}^{2}, p_{\text {ehl }}=130 \mathrm{kPa}$

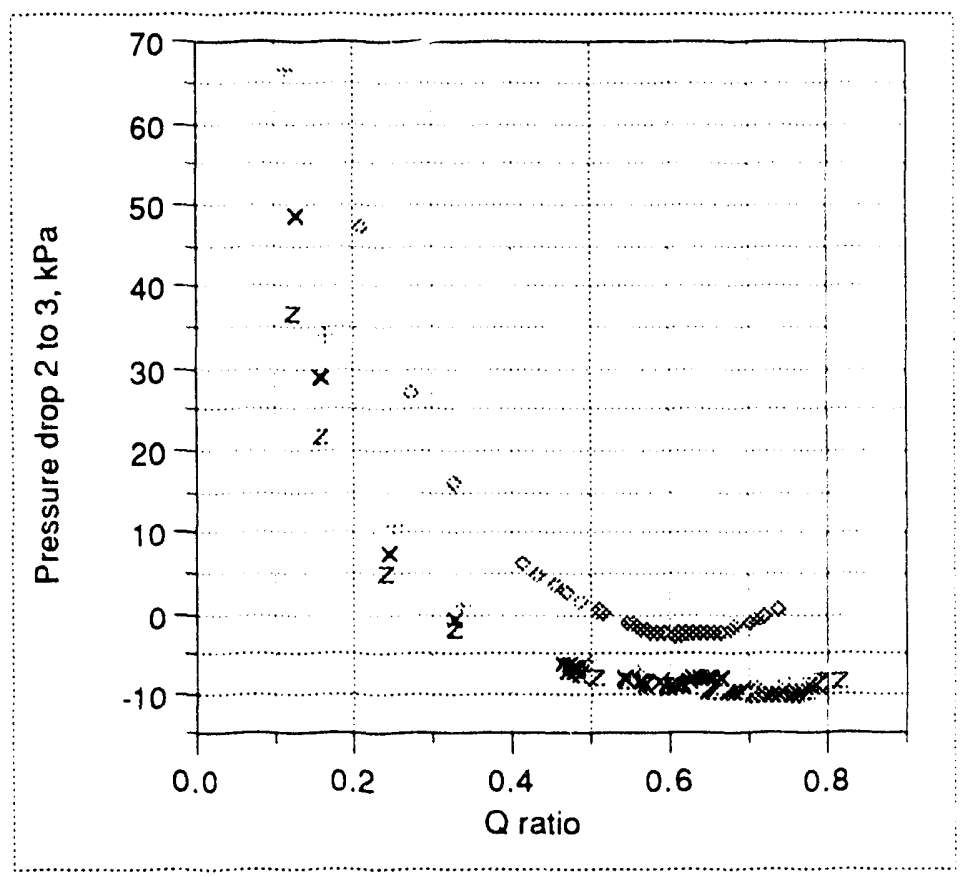

Figure 71, Diabatic demand curve comparisons for Constructions 1.0, 2.0 and 4.0. (Curves 2.004, 2.009, 3.003, and 4.001 are shown) 


\section{Preliminary Data .- 9 September 1993}

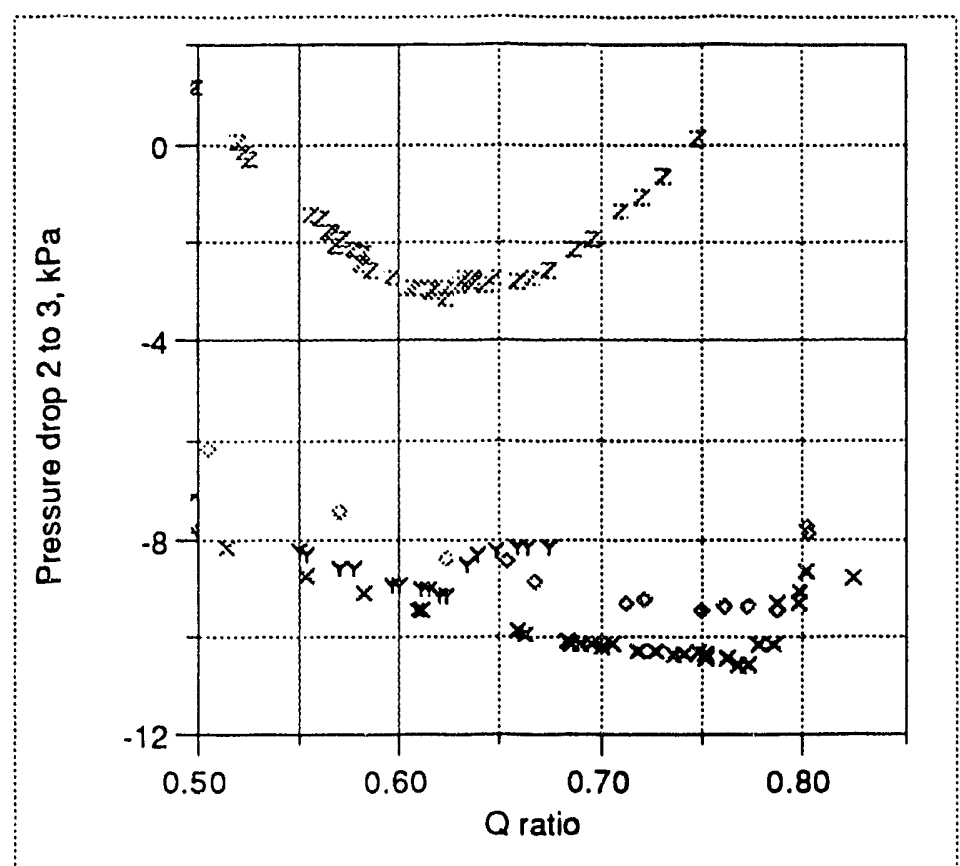

Figure 72, Minima region of the diabatic demand curve comparisons for Constructions 1.0, 2.0 and 4.0. (Curves 2.004, 2.009, 3.003, and 4.001 are shown)

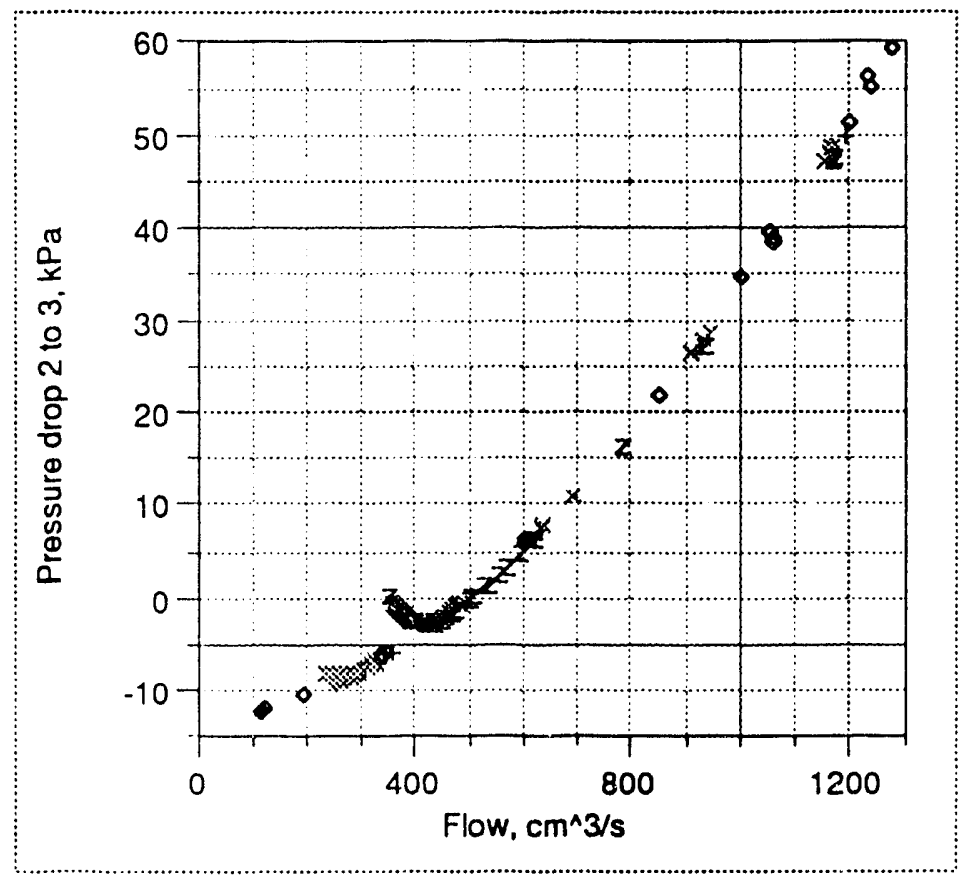

Figure 73, Minima region of the diabatic demand curve comparisons for Constructions 2.0 (Curves 1.000, diamond, $3.001+, 3.002 \mathrm{X}, 3.003 \mathrm{Y}, 4.001 \mathrm{Z}$ ) 


\section{Preliminary Data -- 9 September 1993}

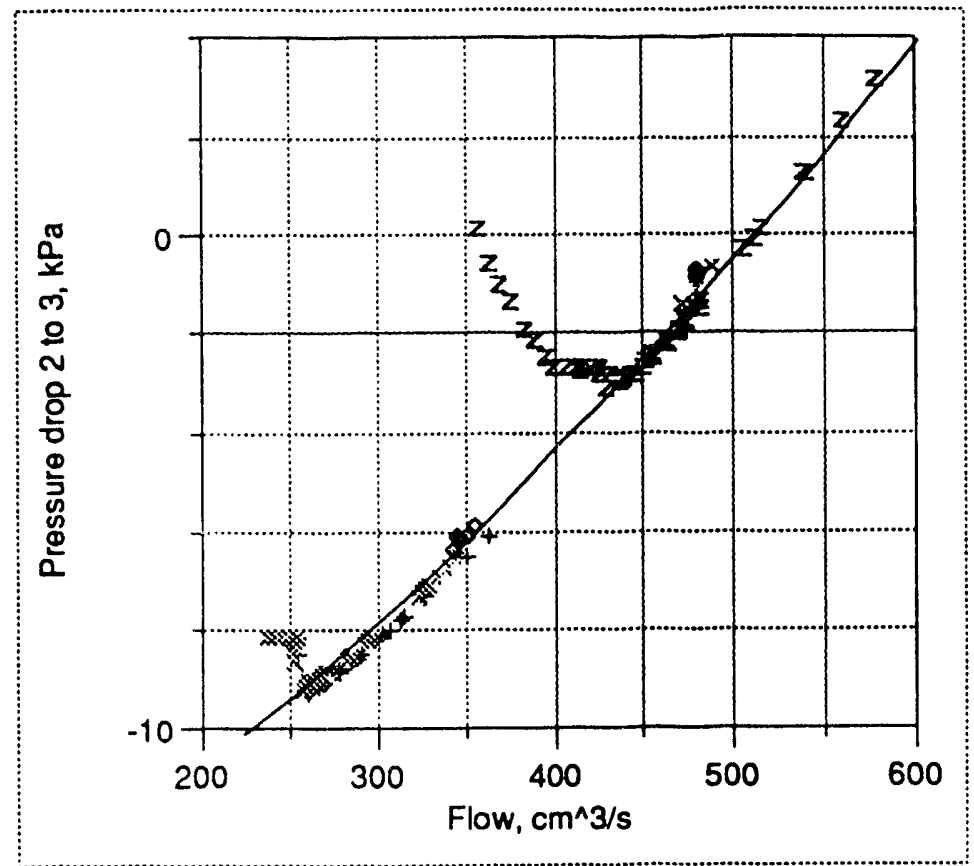

Figure 74, Minima region of the diabatic demand curve comparisons for Constructions 2.0 (Curves 1.000, diamond, $3.001+, 3.002 \mathrm{X}, 3.003 \mathrm{Y}, 4.001 \mathrm{Z}$ )

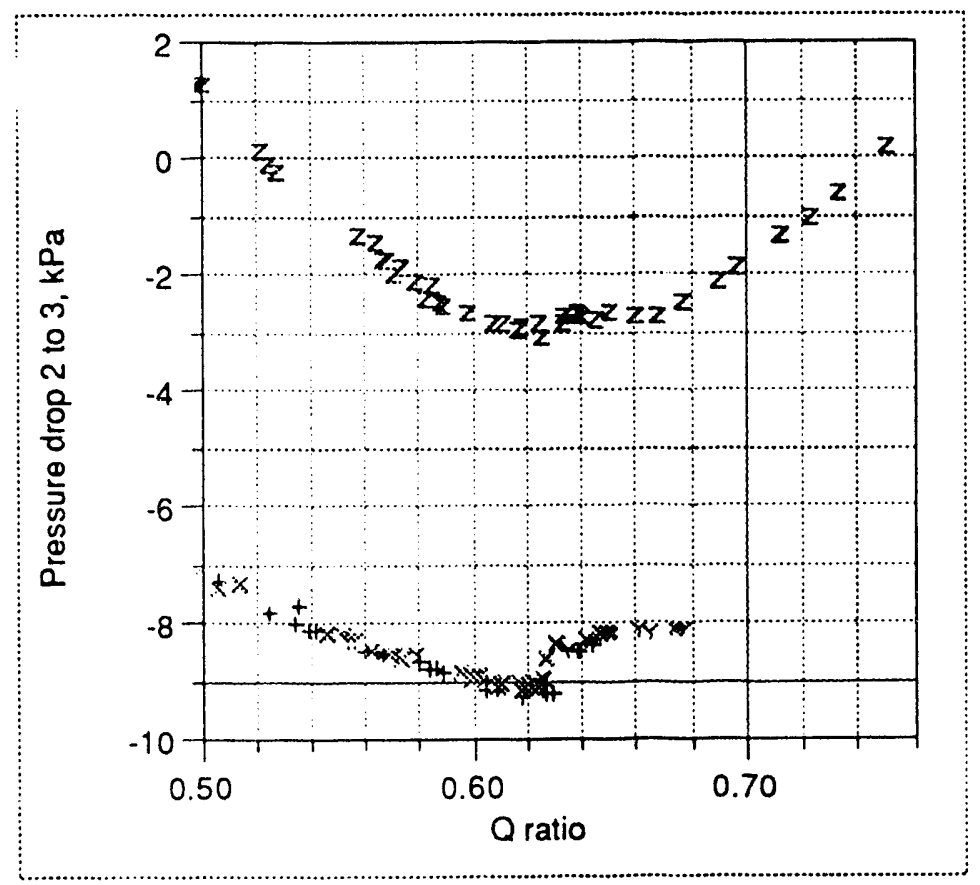

Figure 75, Minima region of the diabatic demand curve comparisons for Constructions 2.0 (Curves 1.000, diamond, $3.001+, 3.002 \mathrm{X}, 3.003 \mathrm{Y}, 4.001 \mathrm{Z}$ ) 


\section{Preliminary Data -- 9 September 1993}

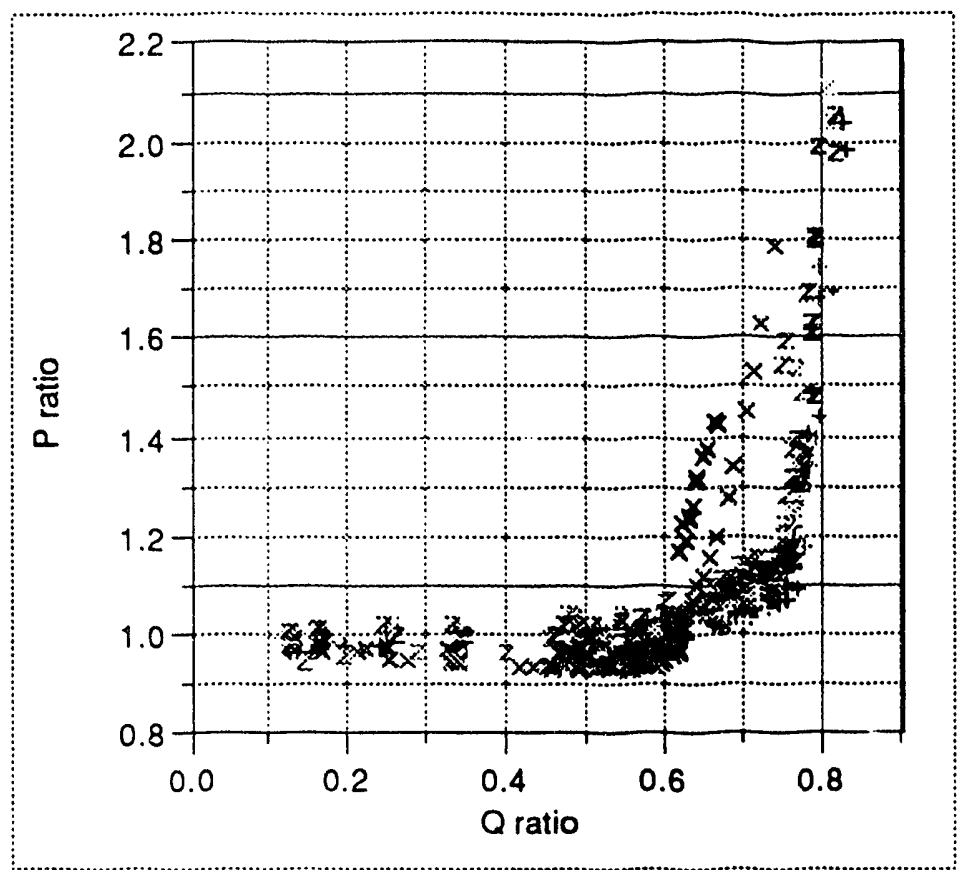

Figure 76, Pressure drop correlation for subcooled boiling

two open constructions was almost identical. For the open channels the Stanton number at OFI was lower for the rib with the smaller depth (Construction 1).

\section{Qratio rib-effect-ratio}

The Qratio rib-effect-ratio for channel with the longitudinal rib (Construction 2) when compared with the open channel (Construction 2) is 0.817 . Equation 86 presents the random uncertainty estimate for this rib-effectratio.

$$
\begin{aligned}
P_{\eta} & =\left\{\left[\frac{\partial \eta}{\partial Q_{\text {ratio, rib }}} P_{\text {ratio, rib }}\right]^{2}+\left[\frac{\partial \eta}{\partial Q_{\text {ratio, open }}} P_{\text {ratio, open }}\right]^{2}\right\}^{1 / 2} \\
& =\left\{[(1.318)(0.005)]^{2}+[(-1.076)(0.018)]^{2}\right\}^{1 / 2} \\
& =0.02 .0
\end{aligned}
$$




\section{Preliminary Data -- 9 September 1993}

The partial differential solutions presented in Equation 86 are estimated in Appendix 3. The total uncertainty of the Qrario rib-effect-ratio would then be:

$$
U_{\eta}=\left\{[0.020]^{2}+[0.019]^{2}\right\}^{1 / 2}=0.028
$$

If no rib effect existed the Qratio rib-effect-ratio would be 1 . Since the ribeffect-ratio is less than unity by more than the uncertainty calculated in Equation 87 a longitudinal rib effect is considered to exist.

\section{Stanton number rib-effect-ratio}

The Stanton number rib-effect-ratio for channel with the longitudinal rib (Construction 2) when compared with the open channel (Constriction 2) is 0.490 . The random uncertainty estimate for this rib-effect-ratio is calculated as was done for the Qratic rib-effect-ratio.

$$
\begin{aligned}
P_{\eta} & =\left\{\left[\frac{\partial \eta}{\partial S t_{\text {rib }}} P_{\text {ratio, rib }}\right]^{2}+\left[\frac{\partial \eta}{\partial S} P_{\text {open }} P_{\text {ratio, owan }}\right]^{2}\right\}^{1 / 2} \\
& =\left\{[(118.4)(0.00039)]^{2}+[(-58.08)(0.00079)]^{2}\right\}^{1 / 2} \\
& =0.065
\end{aligned}
$$

$$
U_{\eta}=\left\{[0.065]^{2}+[0.026]^{2}\right\}^{1 / 2}=0.070
$$

If no rib effect existed the Stanton number rib-effect-ratio would be 1. Since the rib effect ratis is less than unity by more than the uncertainty calculated in Equation 89 a longitudinal rib effect is considered to exist. 


\section{Preliminary Data -. 9 September 1993}

\section{Pressure Profiles}

Pressure profiles for Construction 2 and 4 arc presented in Figures 77, 78,79 , and 80 . There is no noticeable variation betwean the duplicate pressure instruments (i.e., PD02472, and PD22472; and PA00072, and PA20072). This indicates that a significant pressure gradient did not exist across the rib. The large difference between the predicted local pressure and the gauge pressure readings shown in Figure 79 may partially be due to an error in the barometric pressure. The gradient parallels the gauge readings near the start of the heated length and at the channel exit. Since the gradient is forced through the mean of the absolute gauges (corrected lor barometric pressure) a variation in the barometric pressure could have created the shift.

It does not appear that the installation of a longitudinal rib in a rectangular channel has an unanticipated impact on the pressure gradient during subcooled diaberic flow.

\section{Visual Observations}

\section{Open Channel}

Bubble nucleation behavior in the open channel was similar to that discussed in the literature. Simall vapor bubbles $(\sim 1 \mathrm{~mm}$ in diameter) rormed at specific sites along the heated surface. As the flow through the test channel was reduced bubble nucleation would first occur near the end of the heated sextion. The first nucleation sites would move up (opposite flow) the channel as the flow was further redisced. The vapor nucleation sites were distinct. Vapor bubbles would grow and collapse at specific locations on the heater. These sites siemed to remain consistent for the test program. 


\section{Preliminary Data .- 9 September 1993}

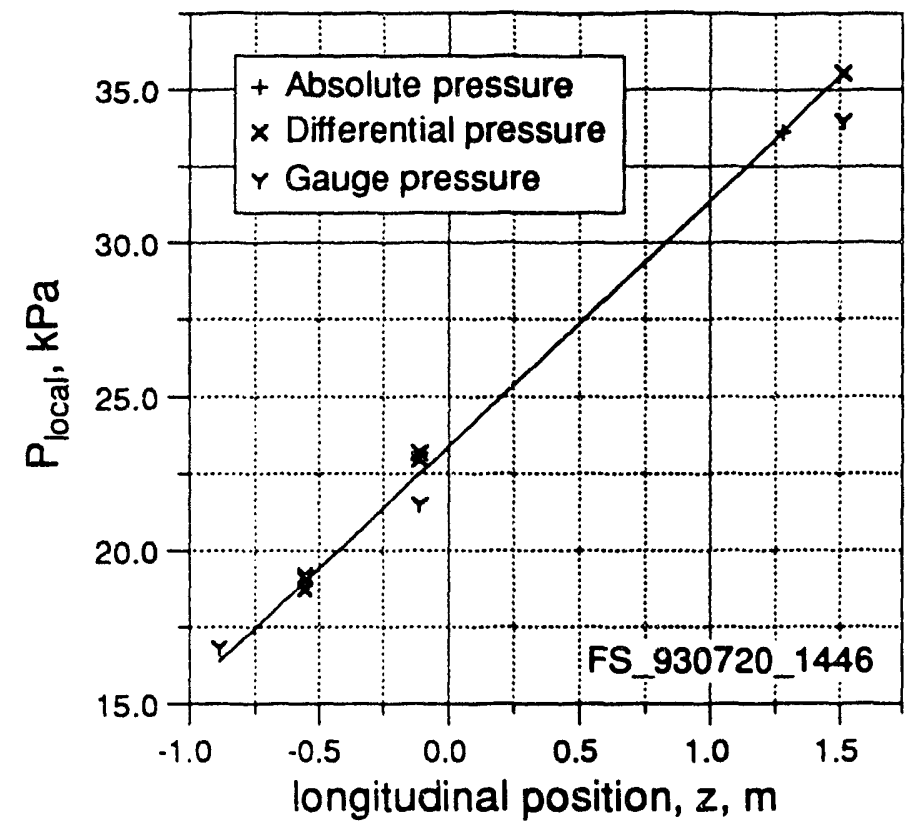

Figure 77, Longitudinal pressure gradient for diabatic open channel (File FS_930720_1446, Construction $4.0, T_{\text {in }}=59.29^{\circ} \mathrm{C}, \phi=327.6 \mathrm{~kW} / \mathrm{m}^{2}, Q=205.9$ $\mathrm{cm}^{3} / \mathrm{s}, \mathrm{p}_{\mathrm{ehl}}=129.2 \mathrm{kPa}$ )

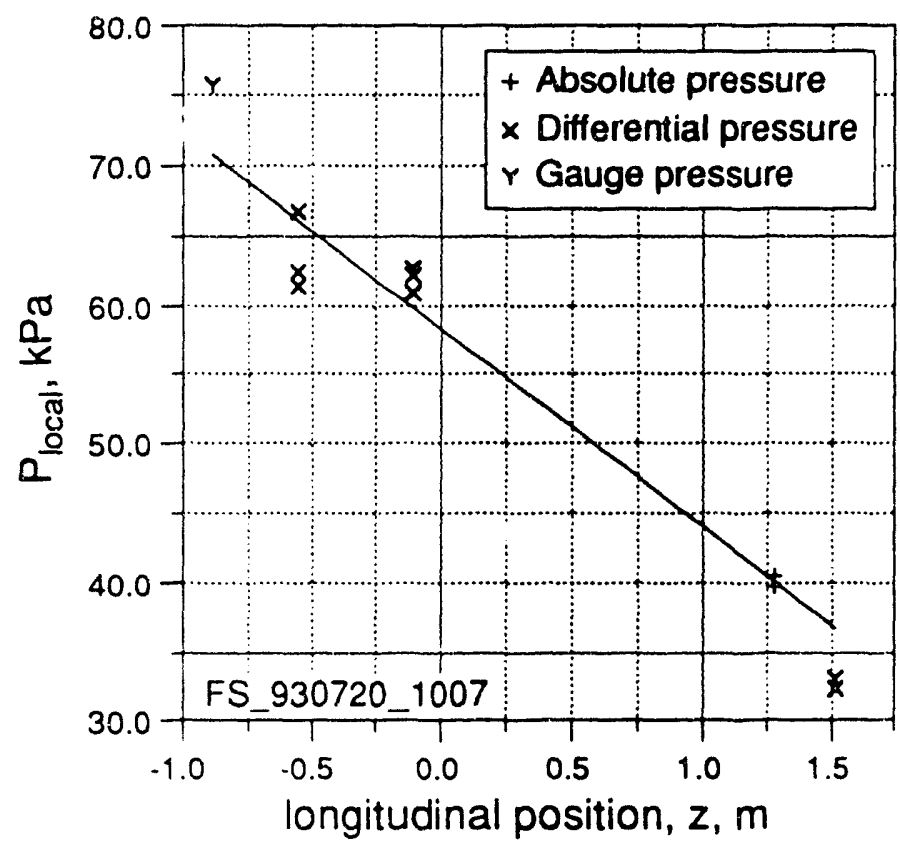

Figure 78, Longitudinal pressure gradient for diabatic open channel (File FS_930720_1007, Construction $4.0, T_{\text {in }}={ }^{\circ} \mathrm{C}, \phi=\mathrm{kW} / \mathrm{m}^{2}, Q=$ high $\mathrm{cm}^{3} / \mathrm{s}, P_{\text {ehl }}=$ $\mathrm{kPa}$ ) 


\section{Preliminary Data -. 9 September 1993}

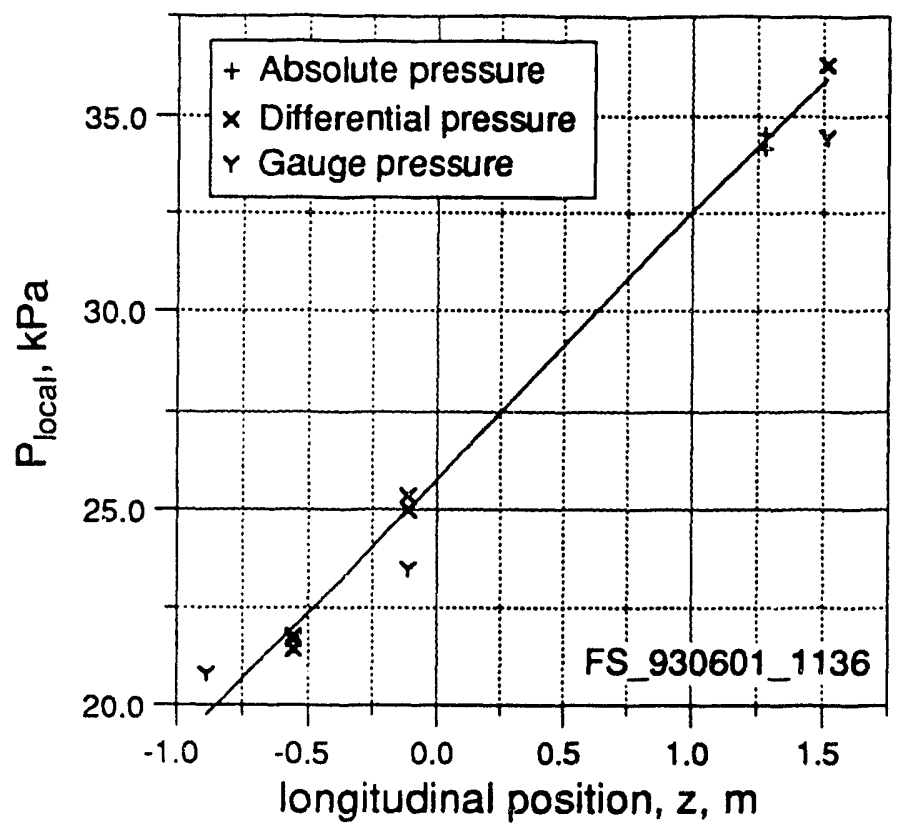

Figure 79, Longitudina' pressure gradient for diabatic open channel with a longitudinal rib (File FS_3300601_1136, Construction 2.0, $\mathrm{T}_{\text {in }}=59.19^{\circ} \mathrm{C}, \phi=$ $330.0 \mathrm{~kW} / \mathrm{m}^{2}, Q=259.5 \mathrm{~cm}^{3} / \mathrm{s}, p_{\text {ehl }}=129.0 \mathrm{kPa}$ )

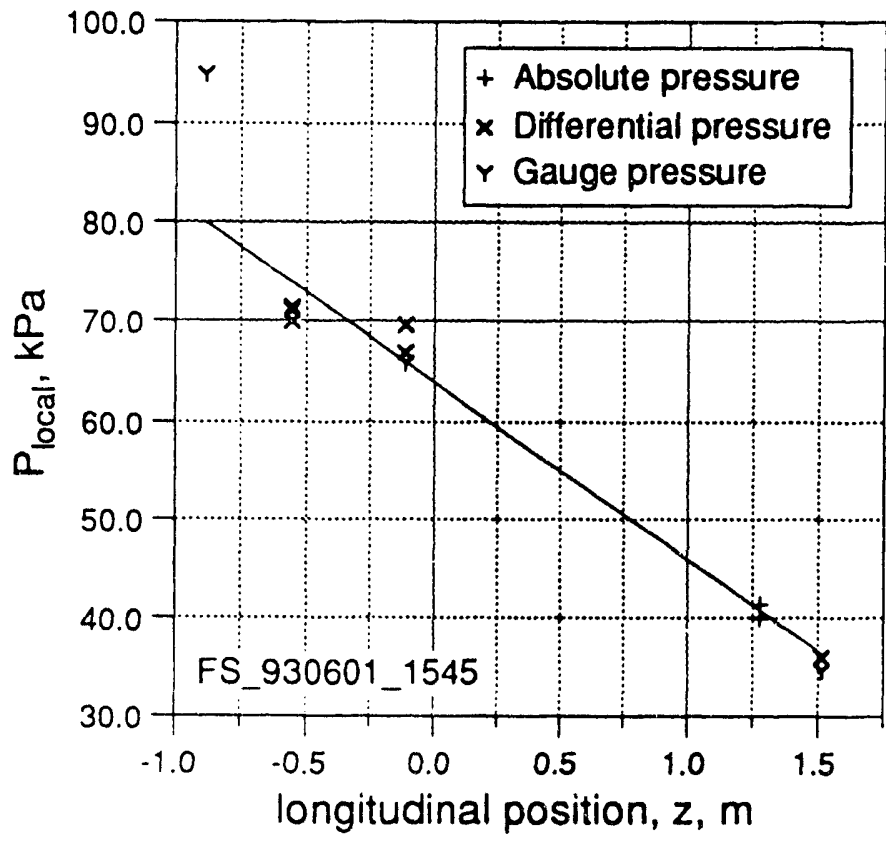

Figure 80 , Longitudinal pressure gradient for diabatic channel with a longitudinal rib (File FS_930601_1545, Construction 2.0, $\mathrm{T}_{\text {in }}={ }^{\circ} \mathrm{C}, \phi=0.0$ $\mathrm{kW} / \mathrm{m}^{2}, \mathrm{Q}=$ high flow $\mathrm{cm}^{3} / \mathrm{s}, P_{\text {ehl }}=\mathrm{kPa}$ ) 


\section{Pleliminary Data - 9 September 1993}

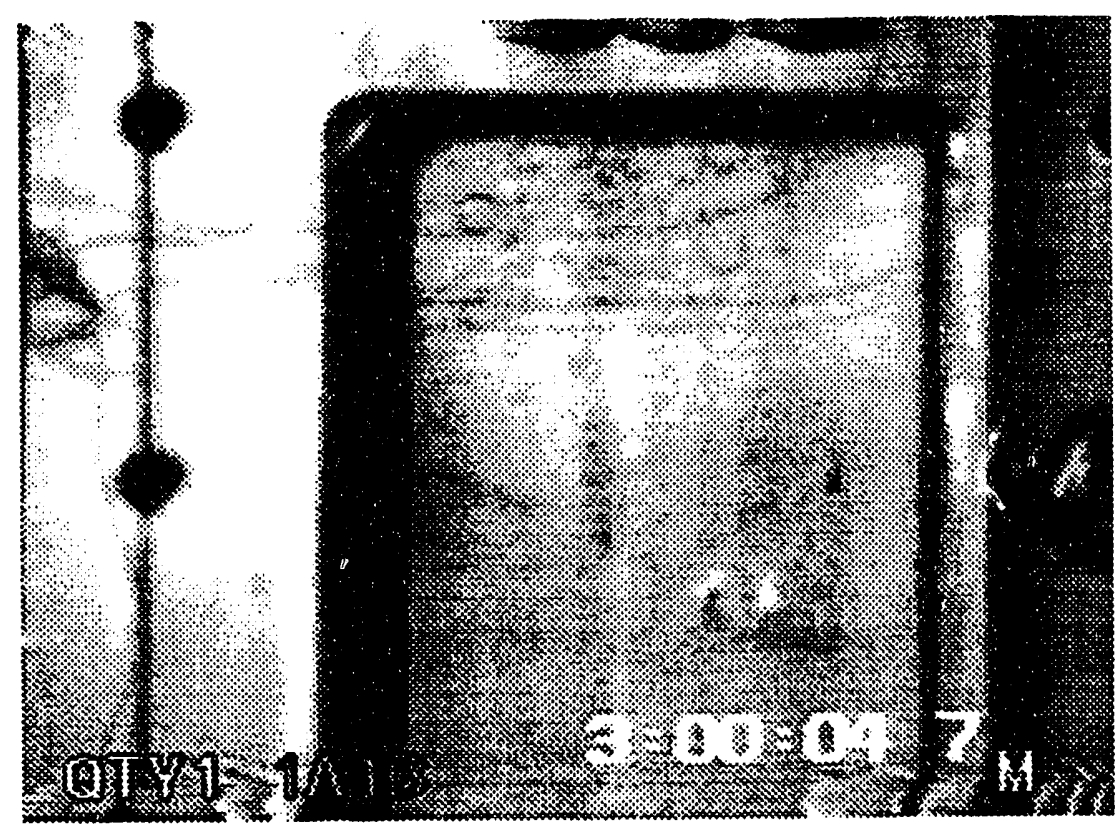

a

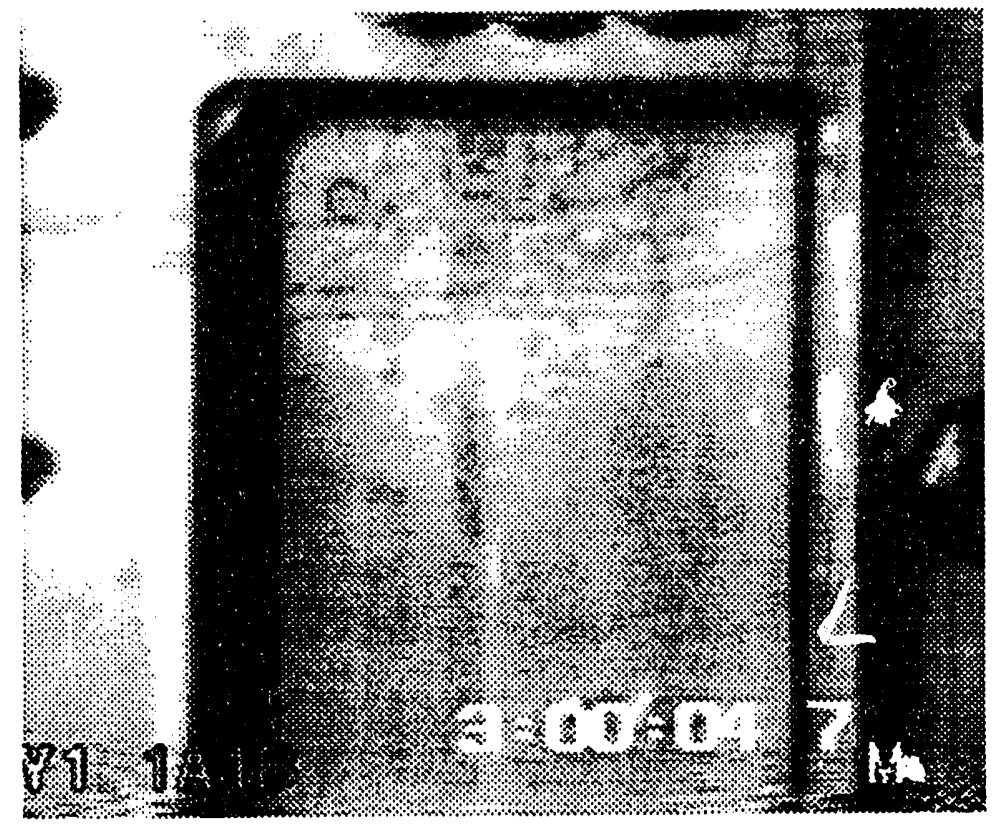

b

Figure 81, Vapor behavior at OFI, Construction 4.0, videotape LFIE-93-11-M, film time 3:00:04.7; a) frame 4, b) frame 5 (File FS_930720_1446, $T_{\text {in }}=$ $\left.59.29^{\circ} \mathrm{C}, \phi=327.6 \mathrm{~kW} / \mathrm{m}^{2}, Q=205.9 \mathrm{~cm}^{3} / \mathrm{s}, p_{\text {ehl }}=129.2 \mathrm{kPa}\right)$ 


\section{Preliminary Data _- 9 September 1993}

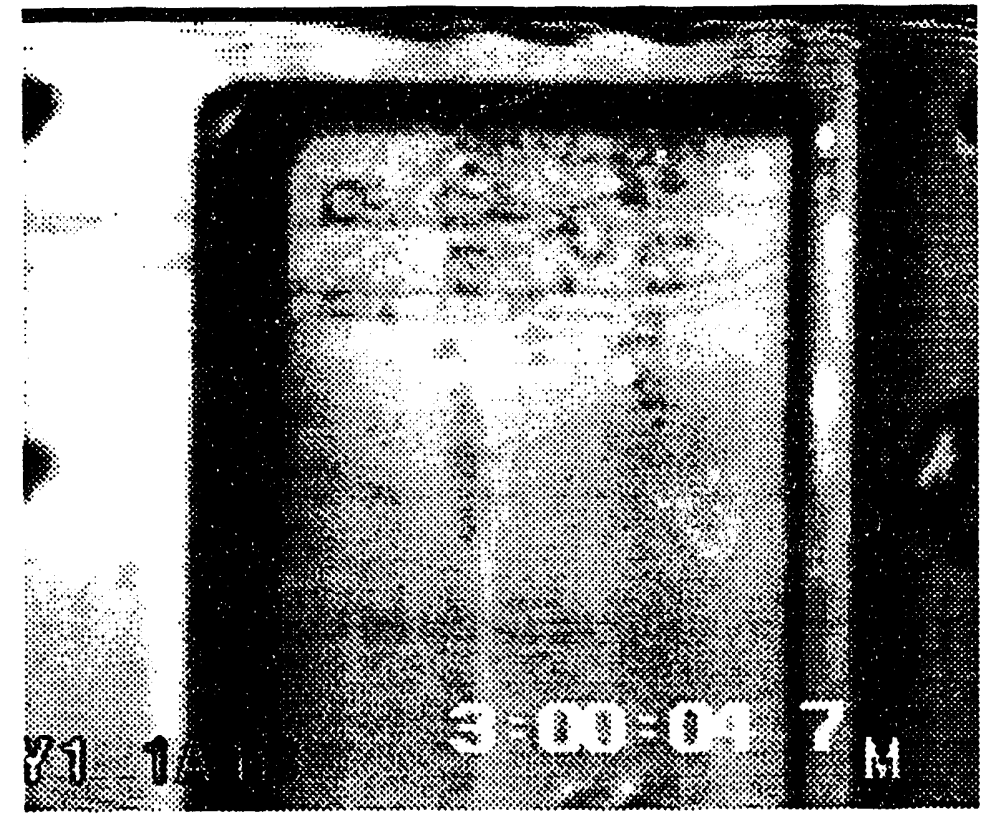

a

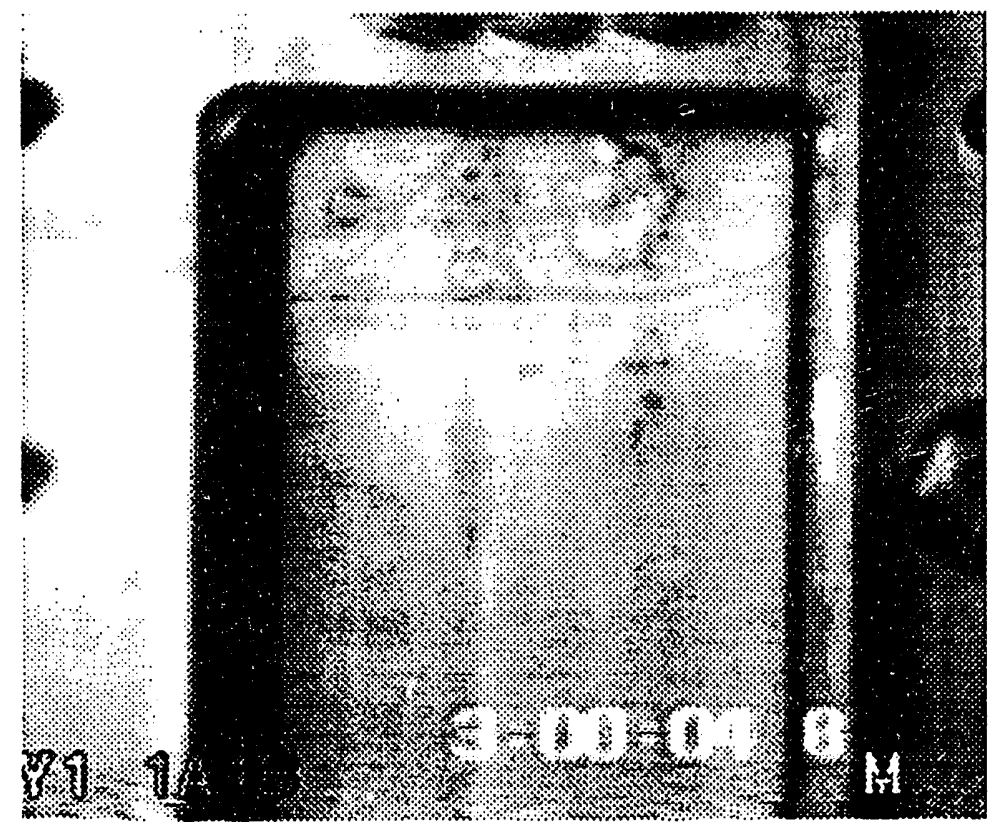

b

Figure 82, Vapor behavior at OFI, Construction 4.0, videotape LFIE-93-11-M: a) film time 3:00:04.7, frame 6, b) film time 3:00:04.8, frame 1 (File FS 930720_1446, $T_{\text {in }}=59.29^{\circ} \mathrm{C}, \phi=327.6 \mathrm{~kW} / \mathrm{m}^{2}, Q=205.9 \mathrm{~cm}^{3} / \mathrm{s}, \mathrm{P}_{\text {ehl }}=$ $129.2 \mathrm{kPa})$ 


\section{Preliminary Data _- 9 September 1993}

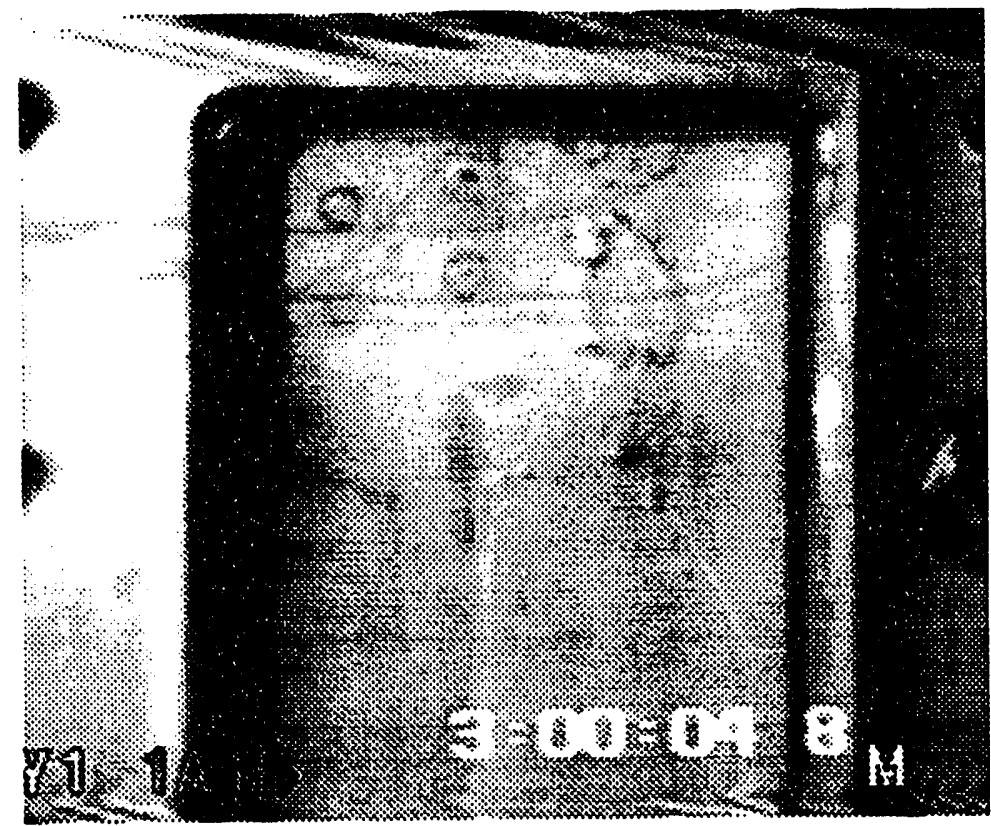

a

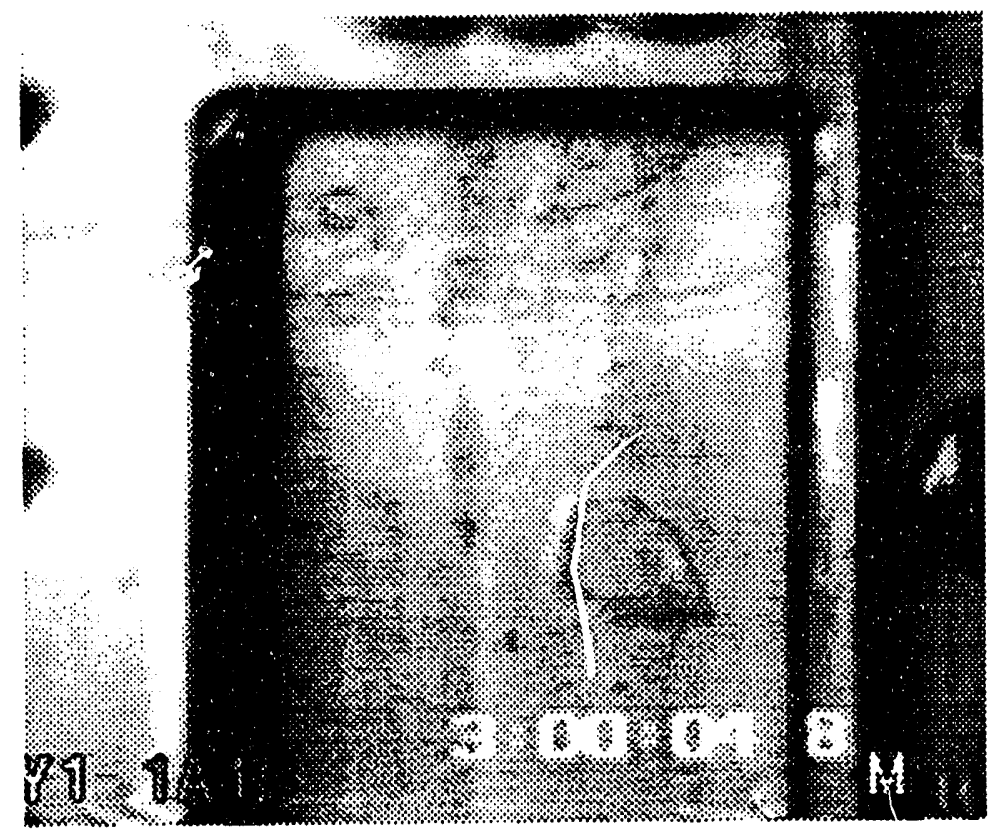

b

Figure 83, Vapor behavior at OFI, Construction 4.0, videotape LFIE-93-11-M, film time 3:00:04.8: a) frame 2, b) frame 3 (File FS_930720_1446, $T_{\text {in }}=$ $\left.59.29^{\circ} \mathrm{C}, \phi=327.6 \mathrm{~kW} / \mathrm{m}^{2}, Q=205.9 \mathrm{~cm}^{3} / \mathrm{s}, p_{\text {ehl }}=129.2 \mathrm{kPa}\right)$ 


\section{Prellminary Data _- 9 September 1993}

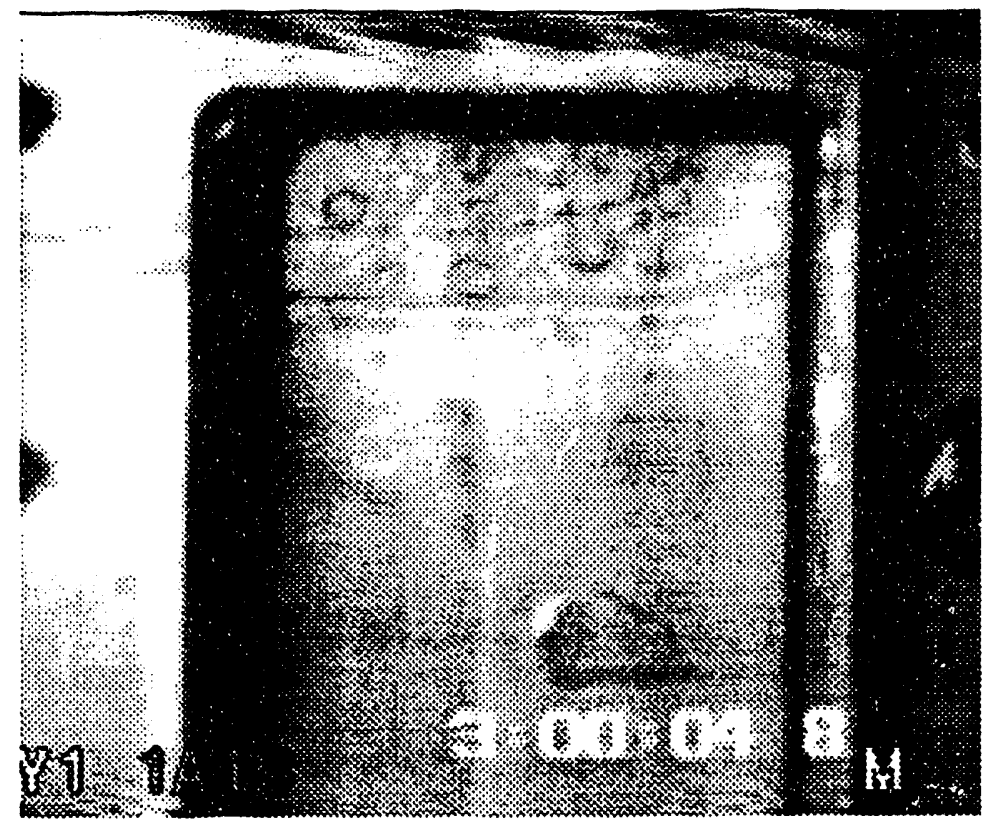

a

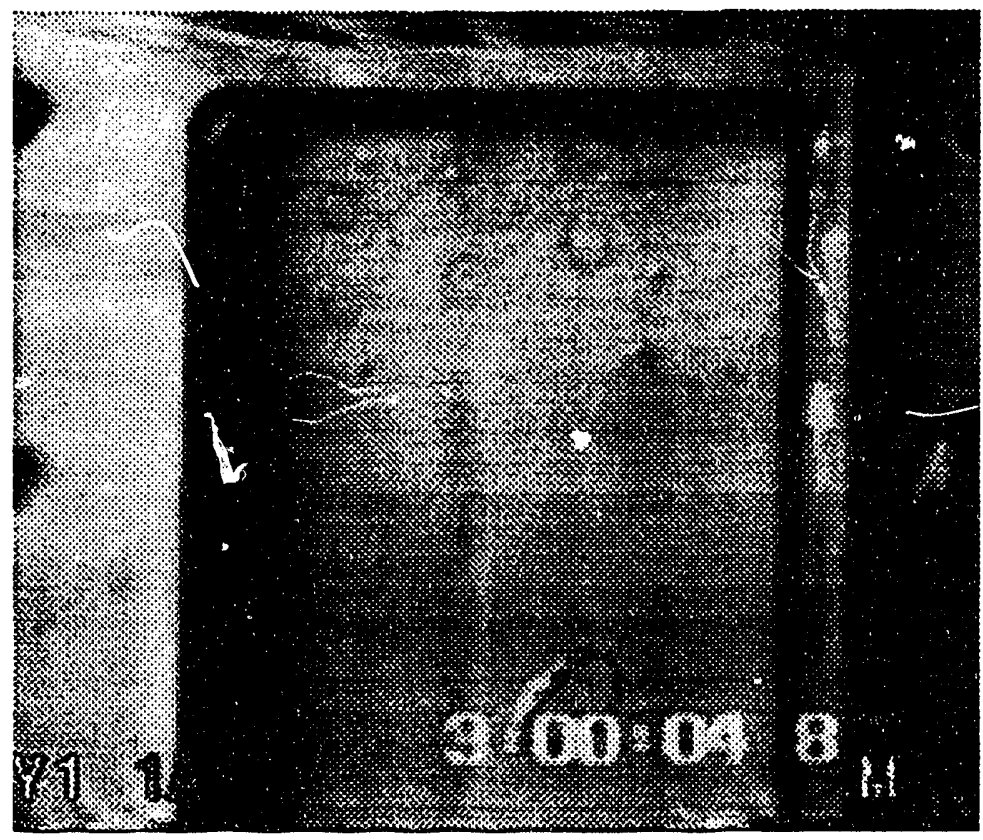

b

Figure 84, Vapor behavior at OFI, Construction 4.0, videotape LFIE-93-11-M, film time 3:00:04.8: a) frame 4, b) frame 5 (File FS_930720_1446, $T_{\text {in }}=$ $59.29^{\circ} \mathrm{C}, \phi=327.6 \mathrm{~kW} / \mathrm{m}^{2}, Q=205.9 \mathrm{~cm}^{3} / \mathrm{s}, p_{\text {ehl }}=129.2 \mathrm{kPa}$ ) 


\section{Preliminary Data -. 9 Sentember 1993}

Occasionally bubbles formed at the corners of the heated channel where the RTV seal and the hear plate abut. These nucleation sites exhibited a different behavior than the nucleation sites in the free-stream area of the plate. The bubble width was about $1 \mathrm{~mm}$. These bubbles varied in length sometimes exceeding $10 \mathrm{~mm}$. They also appeared to slide along the surface in the direction of flow.

The first signs of vapor depan sre from the heated surface also occur near the end of the heated section. The bubbles at departure were approximately $1 \mathrm{~mm}$ diameter. Departure occurred in two modes. (1) Bubbles would depart the heated surface into the flow at the bubble nucleation site. (2) Bubbles would slide along the heater surface ( 5 to $20 \mathrm{~mm}$ ) prior to departing the heated surface.

The boiling behavior at OFI changed appreciably. Near the bottom of the heated section the bubbles departing the heated surface would coalesce, forming distinct large vapor bubbles. These bubbles were approximately 200 $\mathrm{mm}$ in diameter with a depth which approached the flow channel depth. These vapor bubbles would then be swept out of the heated region of the test channel where they would collapse. Figures 81,82 , and 83 present as series of photographs which were transcribed from videotape which demonstrate this cyclic nature of this bubble formation. Table 35 presents a description of each frame. Since the film speed is 60 frames per second each frame represents a change of 0.01667 seconds. The bubbie in Figure $81 \mathrm{a}$ is well formed and moving downward. This bubble is just leaving the field of view in Figuie 82a. in Figure $82 a$ vapor departing the heated surface (over the last $100 \mathrm{~mm}$ ) displays a disorganized pattern different from the discrete nucleation sites described earlier. Emerging from this chaotic pattern discrete bubbles start to form. 


\section{Preliminary Data -- 9 September 1993}

Table 35.--Bubble formation sequence for the upen channel, Construction 4.0 (File FS_930720_1446, $\mathrm{T}_{\text {in }}=59.29^{\circ} \mathrm{C}, \phi=327.6 \mathrm{~kW} / \mathrm{m}^{2}, Q=205.9 \mathrm{~cm}^{3} / \mathrm{s}, p_{\text {ehl }}$ $=129.2 \mathrm{kPa}$, videotape LFIE-93-11-M)

\begin{tabular}{|c|c|c|c|}
\hline Film time & Frame & Figure & Description \\
\hline \multirow[t]{3}{*}{$3: 00: 04.7$} & 4 & $81 a$ & $\begin{array}{l}\text { Well-formed bubble on right side of channel } \\
\text { approximately } 40 \mathrm{~mm} \text { below the end of the } \\
\text { heated length. }\end{array}$ \\
\hline & 5 & $81 b$ & $\begin{array}{c}\text { Chaotic vapor at end of heated section, original } \\
\text { bubble in Fiaure } 81 \text { a is moving downward. }\end{array}$ \\
\hline & 6 & $82 a$ & $\begin{array}{l}\text { Vapor starts to coalesce, original bubble is } \\
\text { exiting the field of view. }\end{array}$ \\
\hline \multirow[t]{3}{*}{$3: 00: 04.8$} & $\begin{array}{l}1 \\
2\end{array}$ & $\begin{array}{l}82 b \\
83 a\end{array}$ & $\begin{array}{l}\text { Single large bubble starting to form. } \\
\text { All small bubbles are gone, one large bubble is } \\
\text { visible at the end of the heated section. }\end{array}$ \\
\hline & $\begin{array}{l}3 \\
4\end{array}$ & $\begin{array}{l}83 b \\
84 a\end{array}$ & $\begin{array}{l}\text { New bubble moves down through channel } \\
\text { Chaotic vapor starts to form at end of heated } \\
\text { section. The new bubble is near the position } \\
\text { of the original bubble in Figure } 81 \text { a. }\end{array}$ \\
\hline & 5 & $84 b$ & $\begin{array}{l}\text { The new bubble continues to travel in the } \\
\text { direction of flow. }\end{array}$ \\
\hline
\end{tabular}

These discrete bubbles coalesce to form a single bubble in Figure 83a. At this point the heater section over the last $100 \mathrm{~mm}$ is relatively free of nucleating bubbles. The vapor formation pattern was cyclic with a frequency of approximately $10 \mathrm{~Hz}$.

Channel with Longitudinal Rib

The installation of a longitudinal rib changed the vapor generation pattern significantly. ONB was first initiated at the corner formed by the heater and rib. Vapor nucleating along this surface would form intermittent bubbles that extended to the end of the heated section. These bubbles were normally less than $15 \mathrm{~mm}$ in length. Figure 85 presents two consecutive videotape frames of nucleate boiling behavior. A description of these frames is presented in Table 36. Bubbles traveled in the direction of flow along the rib. As they 
Table 36.--ONB along rib, Construction 2.0 (File FS_930601_1130, $T_{\text {in }}=$ $59.21^{\circ} \mathrm{C}, \phi=356.8 \mathrm{~kW} / \mathrm{m}^{2}, Q=265.6 \mathrm{~cm}^{3} / \mathrm{s}, P_{\text {ehl }}=129.1 \mathrm{kPa}$, videotape LFIE93-05-M)

\begin{tabular}{c|c|c|c}
\hline \hline Film time & Frame & Figure & Description \\
\hline $38: 25: 3$ & 4 & $85 a$ & $\begin{array}{c}\text { Vapor bubbles cover most of the region near the } \\
\text { end of the heated length (iop third of picture). } \\
\text { A gap appears in the bubble flow on the right } \\
\text { side of the rib, near the heated length. Note } \\
\text { the bubble that is in the process of collapsing } \\
\text { near the end of the bottom of the picture. }\end{array}$ \\
\hline
\end{tabular}

exited the heated section they would collapse. During this bubble movement the rib remained wetted. While the bubble movement was intermittent, it did not appear to be cyclic.

As flow was decreased bubble nucleation sites on the free-stream portions of the heated plate would be activated. These nucleation sites exhibited the same boiling behavior as the nucleation sites in the open channel.

The bubble movement at OFI was distinctly different from that observed for the open channel. Figures 86 through 89 provide as series of videotape stills for the flow channel with the longitudinal rib. Long bubbles would slide along the rib in the direction of flow. These bubbles would separate from the rib and start to form fronts which as shown in Figure $86 \mathrm{~b}$. The cross section of the bubble at the end of the heated length would vary from about $1 \mathrm{~mm}$ to the 15 mim shown in Figure 89a. During this variable bubble formation the rib remained wetted. In some cases the flow was reduced below the OFI flow such that more than half the flow channel was filled with vapor. The vapor tended to travel along the rib while the liquid moved on the outer edges of the channel. Even under this demanding condition the rib visually appeared to remain wetted. 


\section{Preliminary Data -- 9 September 1993}

Table 37.--Bubble formation sequence along a rib, Construction 2.0 (File FS_930601_1136, $T_{\text {in }}=59.19^{\circ} \mathrm{C}, \phi=330.0 \mathrm{~kW} / \mathrm{m}^{2}, Q=259.5 \mathrm{~cm}^{3} / \mathrm{s}, p_{\text {ehl }}=$ $129.0 \mathrm{kPa}$, Video tape LFIE-93-05-M)

\begin{tabular}{|c|c|c|c|}
\hline Film time & Frame & Figure & Description \\
\hline \multirow[t]{4}{*}{$46: 36: 3$} & 2 & $86 a$ & $\begin{array}{l}\text { Left side of rib at end of heated section has } \\
\text { minimal amount of vapor, right side has large } \\
\text { vapor bubble moving down the channel }\end{array}$ \\
\hline & 3 & $86 b$ & $\begin{array}{l}\text { Vapor staring to coalesce in left channel, vapor } \\
\text { bubble exiting heated section right channel }\end{array}$ \\
\hline & 4 & $87 a$ & $\begin{array}{l}\text { Vapor is still coalescing on the left side of the rib } \\
\text { while there is little vapor on the right side }\end{array}$ \\
\hline & $\begin{array}{l}5 \\
6\end{array}$ & $\begin{array}{l}87 b \\
88 a\end{array}$ & $\begin{array}{l}\text { Both sides of the rib are covered by a bubble. } \\
\text { The bubbles are starting to move past the end of } \\
\text { the heated length. }\end{array}$ \\
\hline \multirow[t]{3}{*}{$46: 36: 4$} & 1 & $88 b$ & $\begin{array}{l}\text { The large bubbles are exiting the field of view } \\
\text { and new bubbles are expanding at the end of } \\
\text { the heated length. }\end{array}$ \\
\hline & 2 & $89 a$ & $\begin{array}{l}\text { The bubbles at the end of the heated length } \\
\text { continue to expand. }\end{array}$ \\
\hline & 3 & $89 b$ & $\begin{array}{l}\text { The expanded bubbles start to exit the heated } \\
\text { section. }\end{array}$ \\
\hline
\end{tabular}




\section{Prellminary Data _- 9 September 1993}

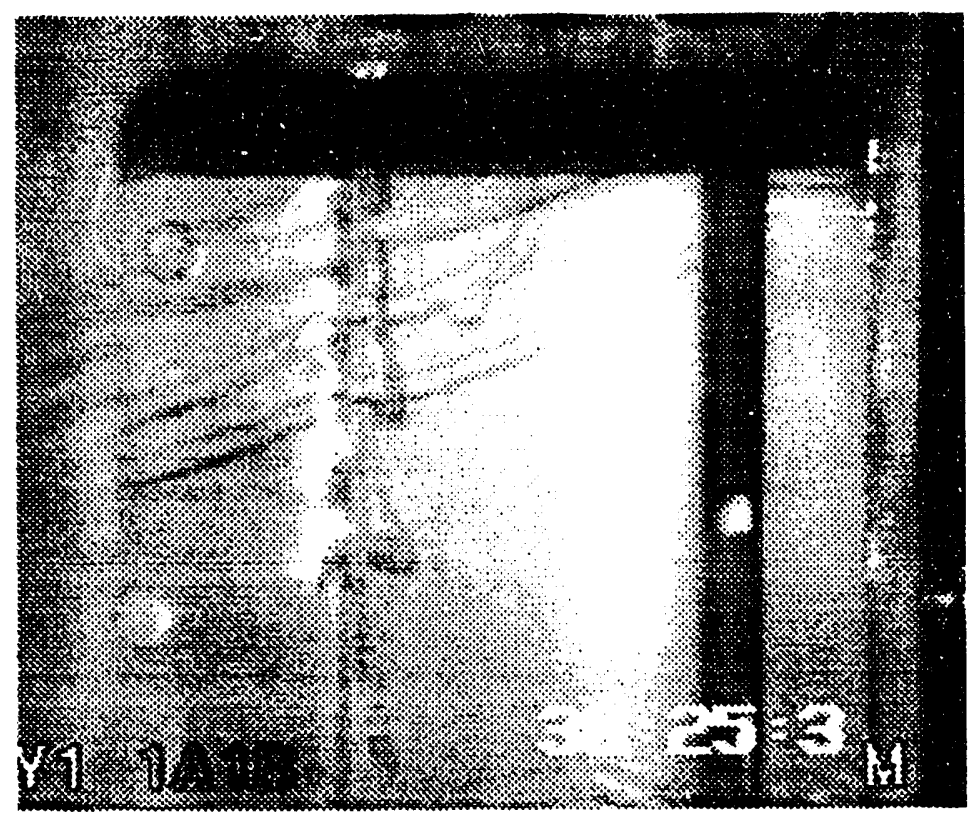

a

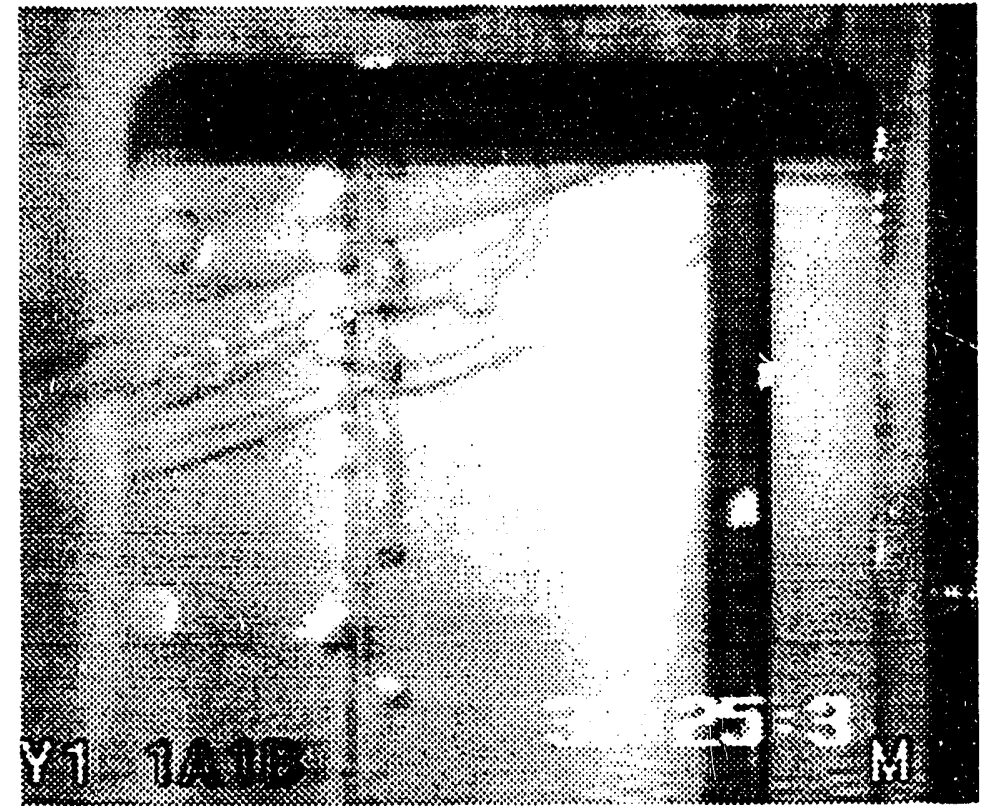

b

Figure 85, ONB along rib, Construction 2.0, videotape LFIE-93-05-M, film time 38:25:3; a) frame 4, b) frame 5 (File FS_930601_1130, $\mathrm{T}_{\text {in }}=59.21^{\circ} \mathrm{C}, \phi=$ $356.8 \mathrm{~kW} / \mathrm{m}^{2}, \mathrm{Q}=265.6 \mathrm{~cm}^{\overline{3}} / \mathrm{s}, \mathrm{P}_{\text {ehl }}=129.1 \mathrm{kPa}$ ) 


\section{Prellminary Data -- 9 September 1993}

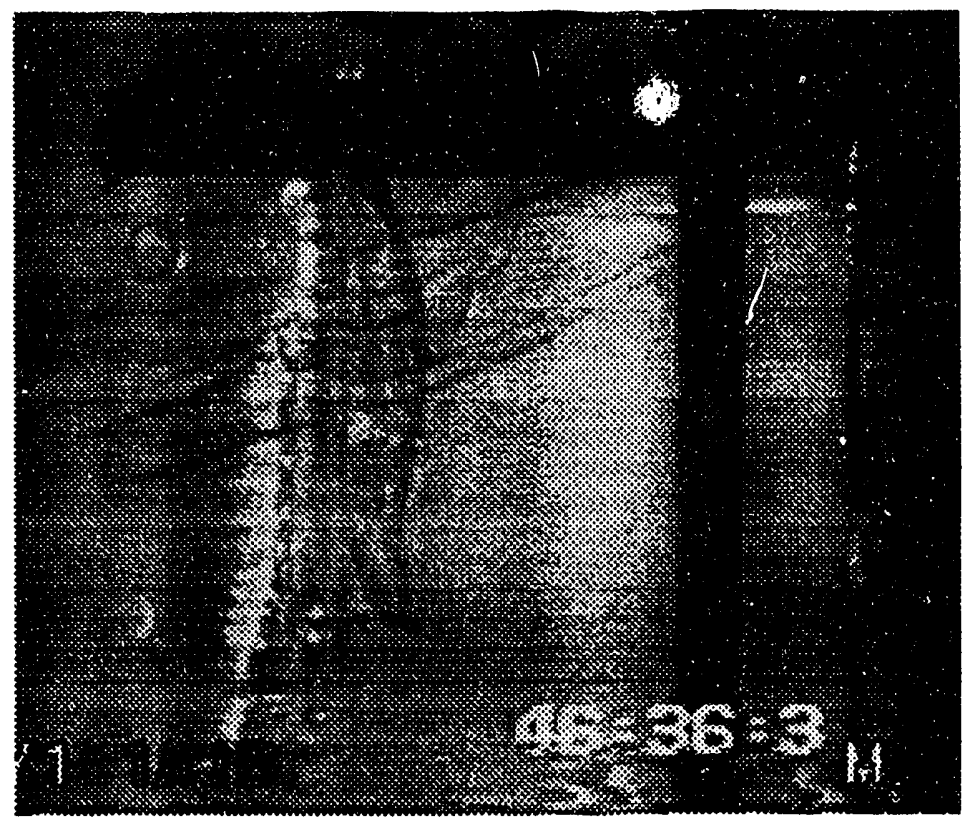

a

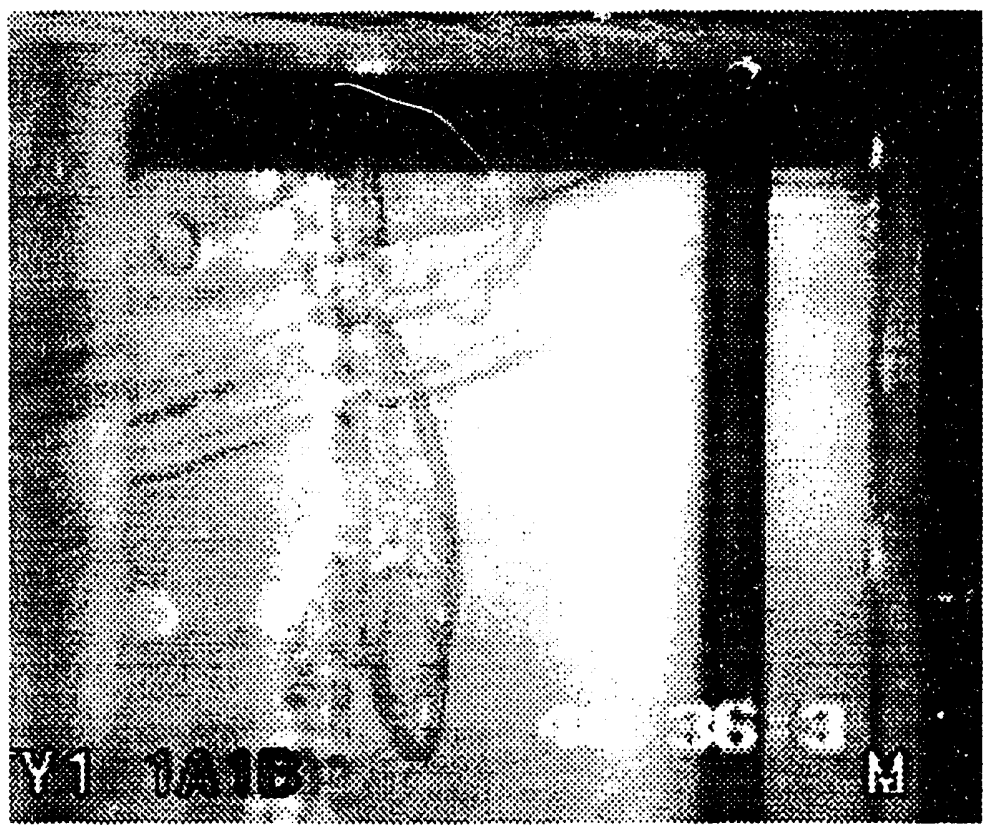

b

Figure 86, Vapor behavior at OFI, Construction 2.0, videotape LFIE-93-05-M, film time 46:36:3; a) frame 2, b) frame 3 (File FS_930601_1136, $T_{\text {in }}=59.19^{\circ} \mathrm{C}$, $\phi=330.0 \mathrm{~kW} / \mathrm{m}^{2}, Q=259.5 \mathrm{~cm}^{3} / \mathrm{s}, P_{\text {ehl }}=129.5 \mathrm{kPa}$ ) 


\section{Proliminary Data _- 9 September 1993}

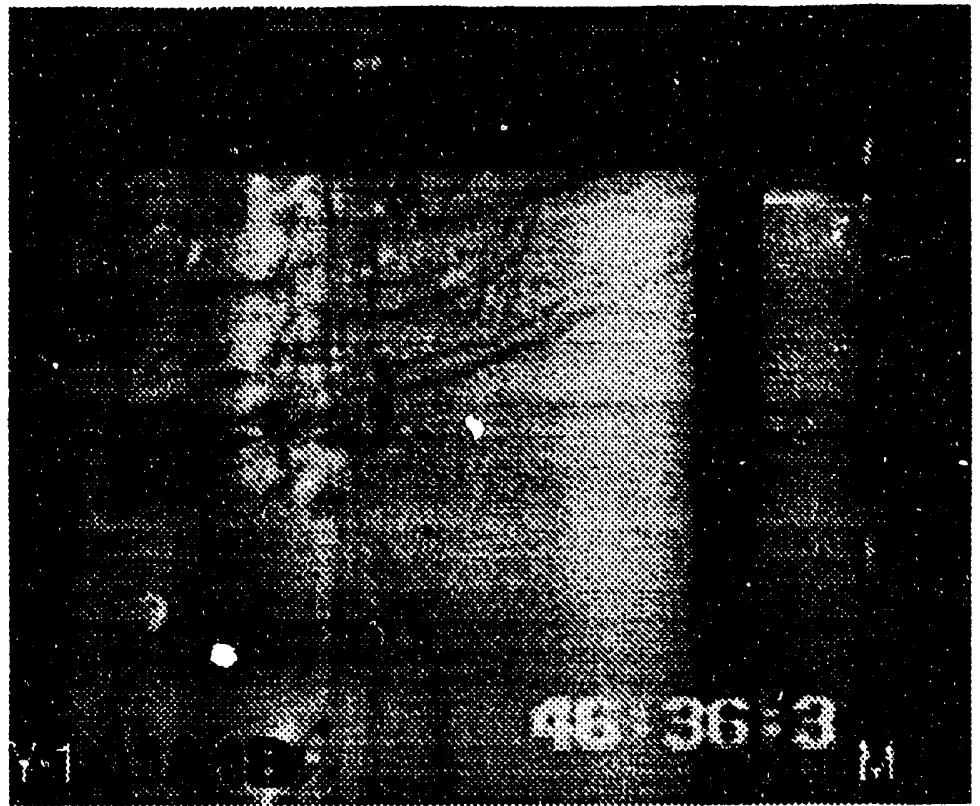

a

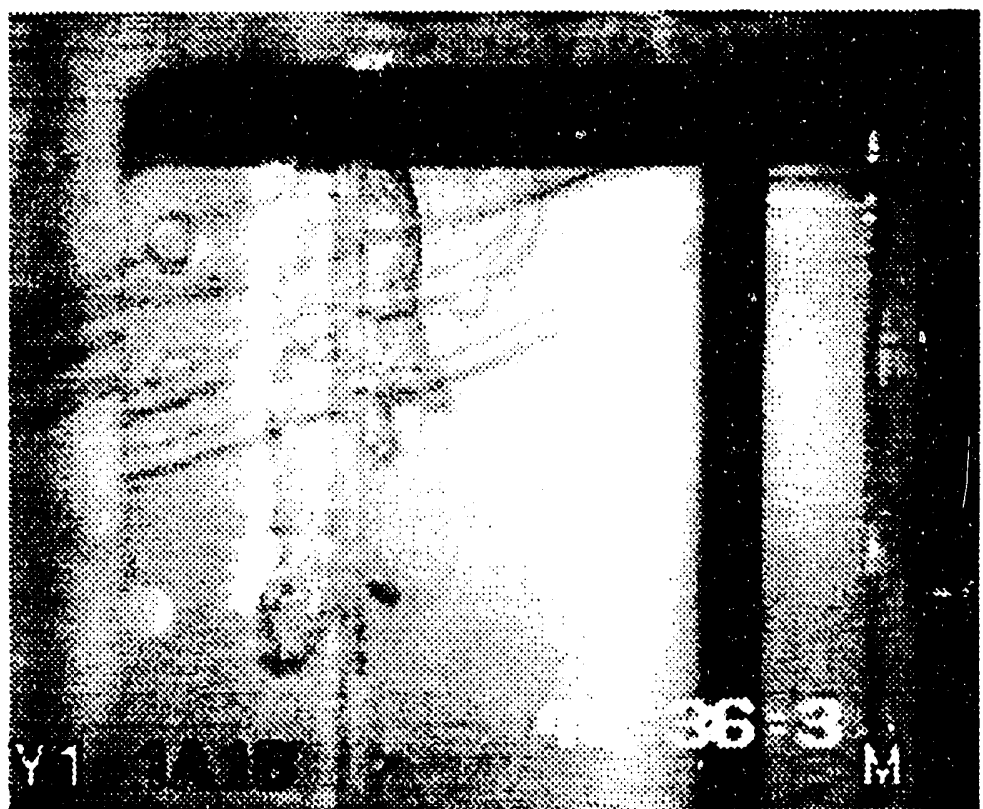

b

Figure 87, Vapor behavior at OFI, Construction 2.0, videotape LFIE-93-05-M, film time 46:36:3; a) frame 4, b) frame 5 (File FS_930601_1136, $T_{\text {in }}=59.19^{\circ} \mathrm{C}$,

$$
\left.\phi=330.0 \mathrm{~kW} / \mathrm{m}^{2}, Q=259.5 \mathrm{~cm}^{3} / \mathrm{s}, P_{\text {ehl }}=129.5 \mathrm{kPa}\right)
$$




\section{Preliminary Data _. 9 September 1993}

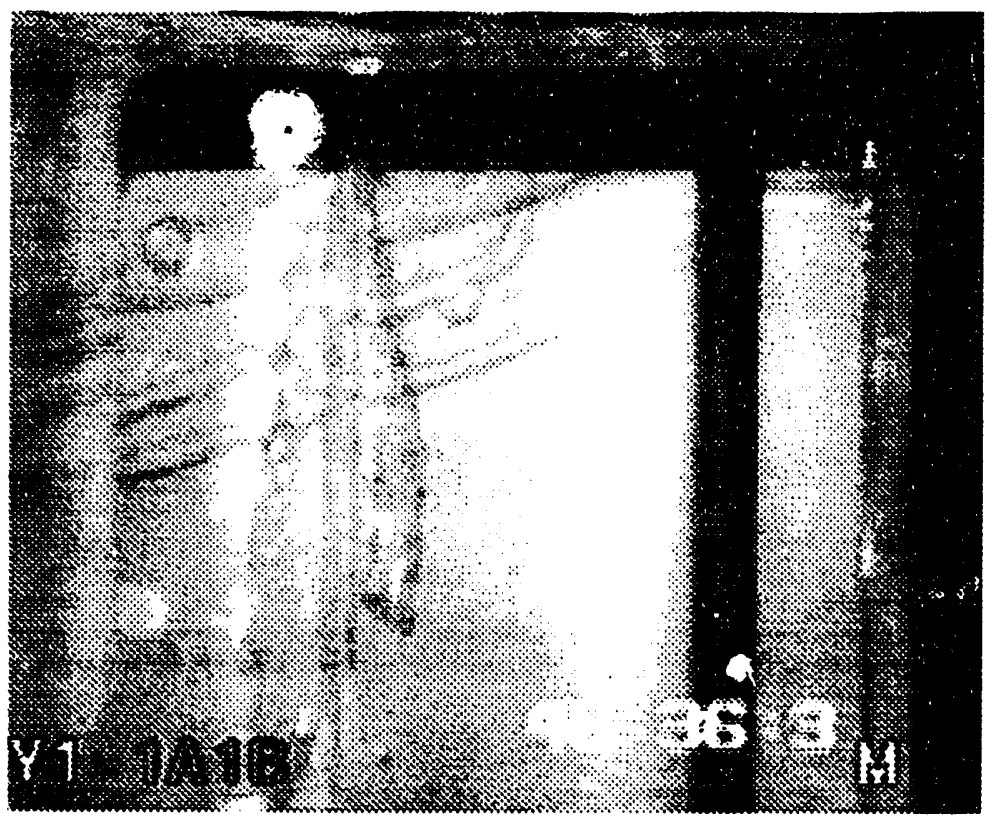

a

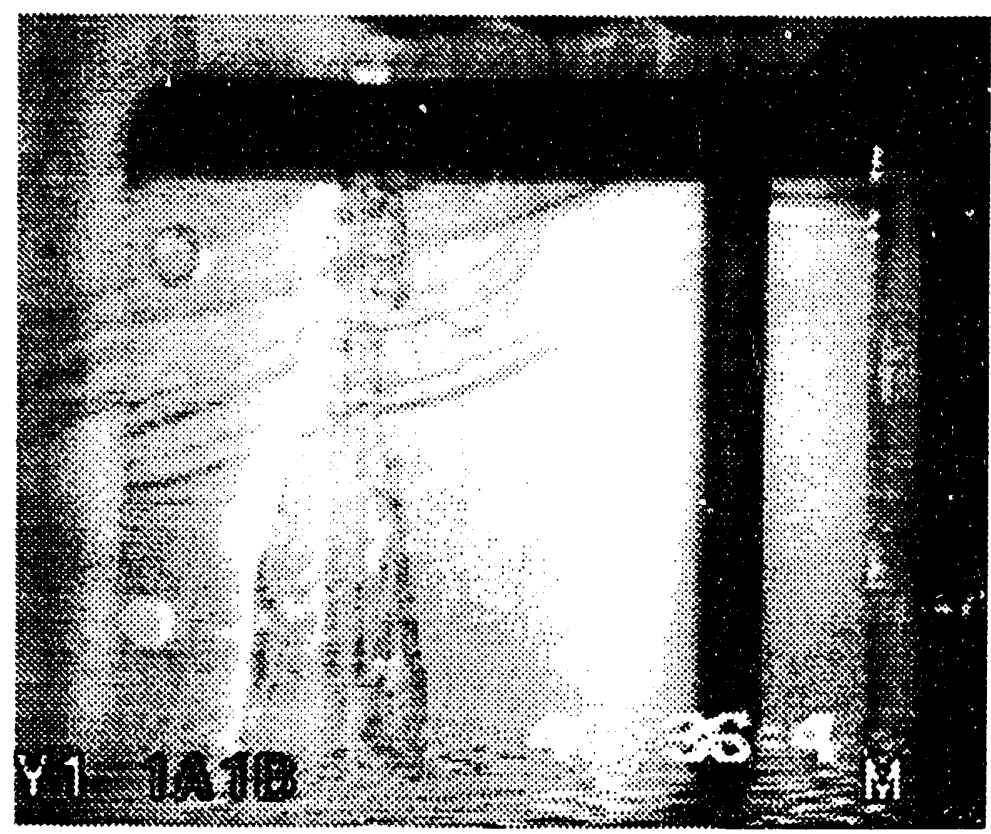

b

Figure 88, Vapor behavio at OFI, Construction 2.0, videotape LFIE-93-05-M, a) film time 46:36:3, frame 6, b) film time 46:36:4, frame 1 (File FS_930601_1136,

$$
\left.\mathrm{T}_{\text {in }}=59.19^{\circ} \mathrm{C}, \phi=330.0 \mathrm{~kW} / \mathrm{m}^{2}, \mathrm{Q}=259.5 \mathrm{~cm}^{3} / \mathrm{s}, \mathrm{p}_{\text {ehl }}=129.5 \mathrm{kPa}\right)
$$




\section{Preliminary Data -- 9 September 1993}

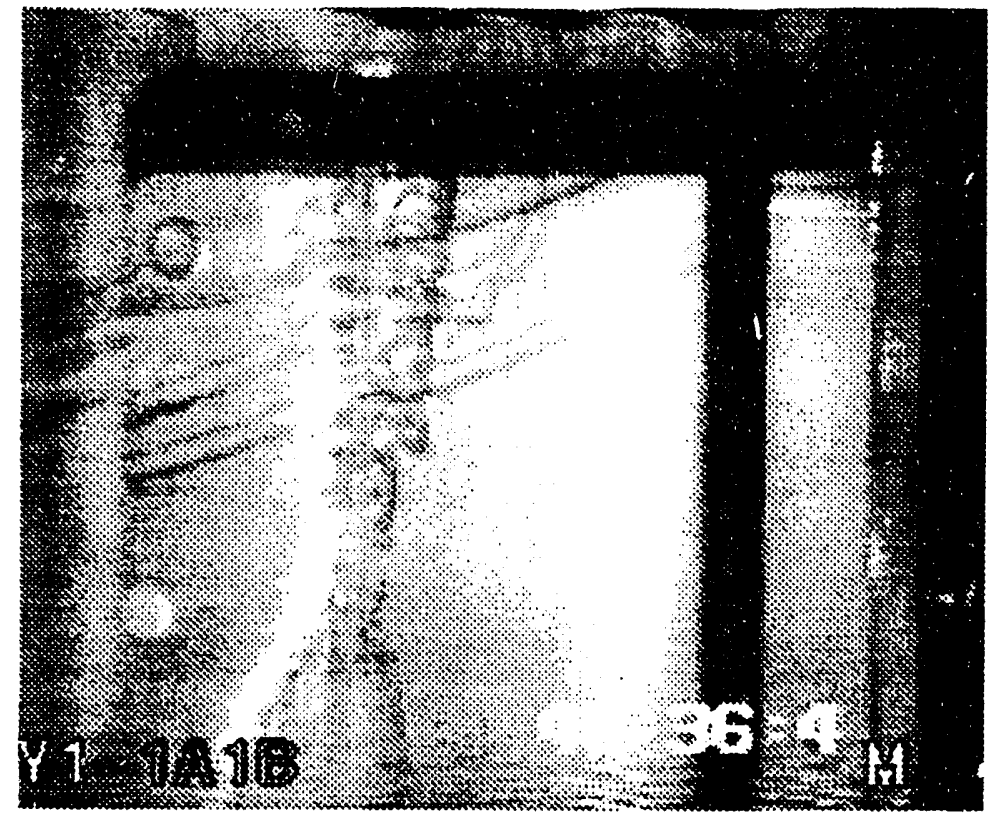

a

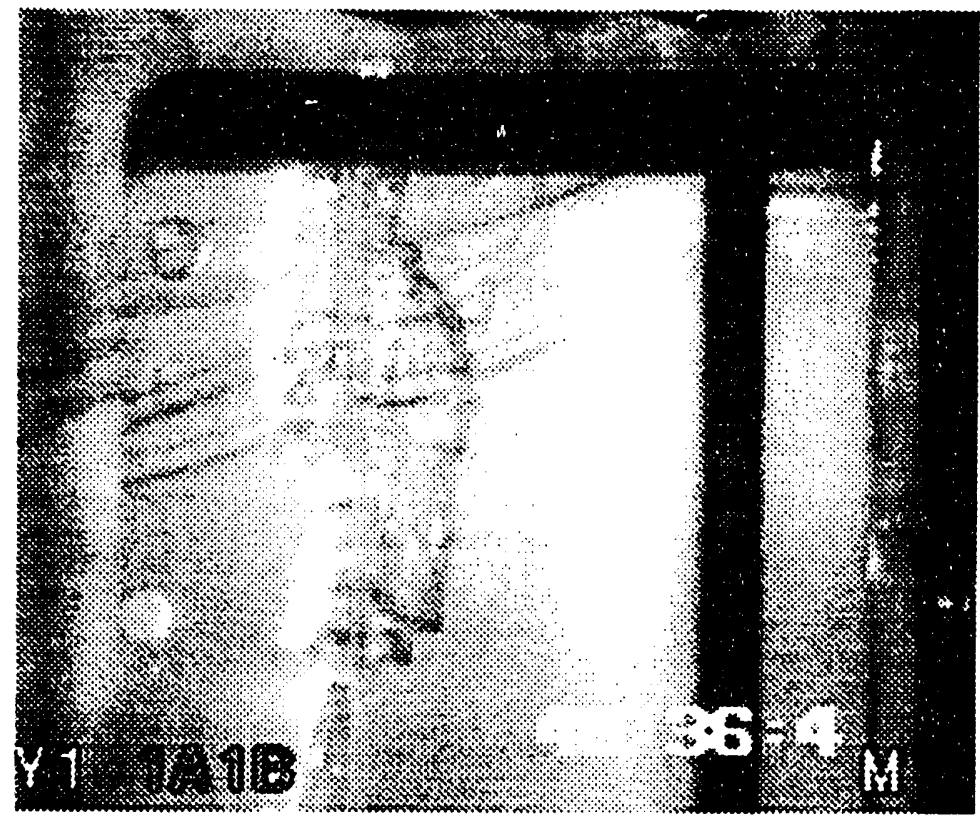

b

Figure 89, Vapor behavior at OFI, Construction 2.0, videotape LFIE-93-05-M, film time 46:36:3; a) frame 2, b) frame 3 (File FS_930601_1136, $\mathrm{T}_{\text {in }}=59.19^{\circ} \mathrm{C}$,

$$
\phi=330.0 \mathrm{~kW} / \mathrm{m}^{2}, Q=259.5 \mathrm{~cm}^{3} / \mathrm{s}, p_{\text {ehl }}=129.5 \mathrm{kPa} \text { ) }
$$




\section{Preliminary Data -. 9 September 1993}

\section{Temperature Profiles}

The heated wall and fluid temperatures were measured in multiple locations during the testing. In general both the fluid, and wall temperatures increased in the longitudinal direction during diabatic flow. As expected the dry side wall temperatures were higher than the wet side wall temperatures when the heater was operating. In addition the wet wall temperatures were higher than the fluid temperatures during diabatic flow. The temperature profiles were basically symmetric in the lateral direction for all of the tests that were reviewed.

\section{Open Channel Temperature Profiles}

Figures 90, 91, and 92 present the temperature profile information at the OFI for Cun's 2.009. This test was conducted using Construction 4.0, which did not contain any obstructions. The fluid temperature increased along the longitudinal direction. This increase was very close to linear with axial position. This is expected since the fluid density and specific heat vary little with temperature. The wall temperature did not increase consistently in the longitudinal direction. There is a noticeable temperature decrease for the thermocouples between 0.582 and $0.592 \mathrm{~m}$ from the SHL. This depression in the longitudinal temperature profile is probably the result of the ONB effect.

Figures 93,94 , and 95 present the temperatures over the last $80 \mathrm{~mm}$ of the heated length. The wall temperatures are relatively uniform in both the longitudinal and lateral directions.

Tables 38 and 39 summarize the temperature data from File FS_930720_1446. Differences in the dry wall temperatures were negligible. The wet wall temperature on the left side of the cannel was slightly cooler $\left(\sim 2^{\circ} \mathrm{C}\right)$ than the center and right locations. Since the heater spray was applied 


\section{Proliminary Data -- 9 September 1993}

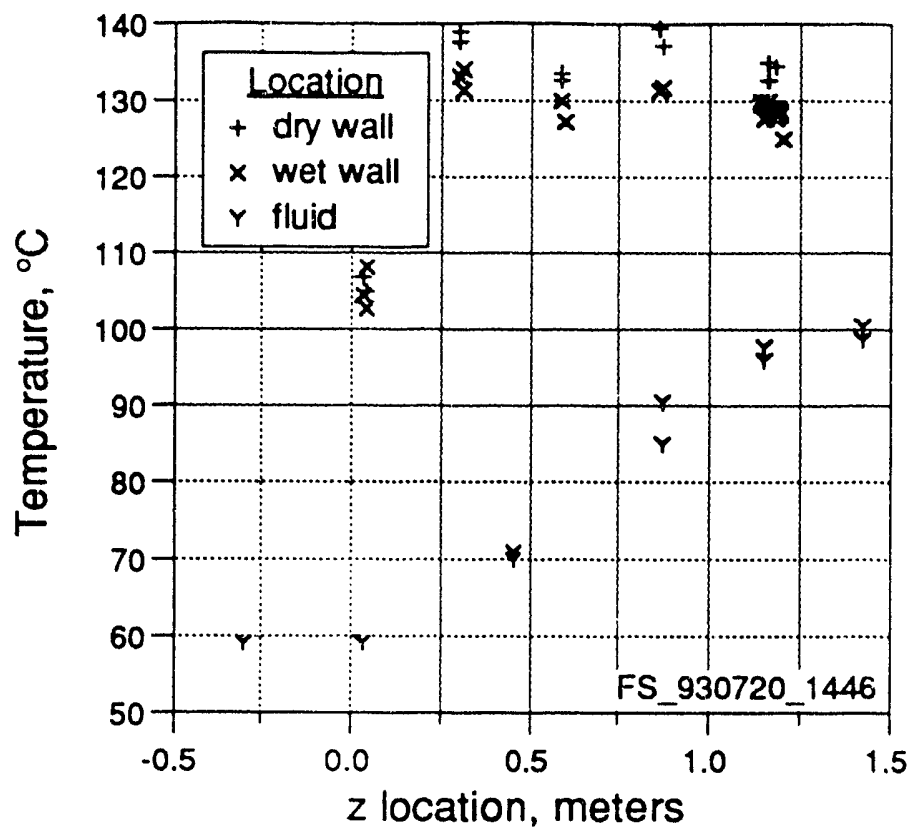

Figure 90, Longitudinal temperature profile from File FS_930720_1446 (Construction 4.0, $T_{\text {in }}=59.29^{\circ} \mathrm{C}, \phi=327.6 \mathrm{~kW} / \mathrm{m}^{2}, Q=205.9 \mathrm{~cm}^{3} / \mathrm{s}, p_{\text {ehl }}=$ $129.2 \mathrm{kPa}$ )

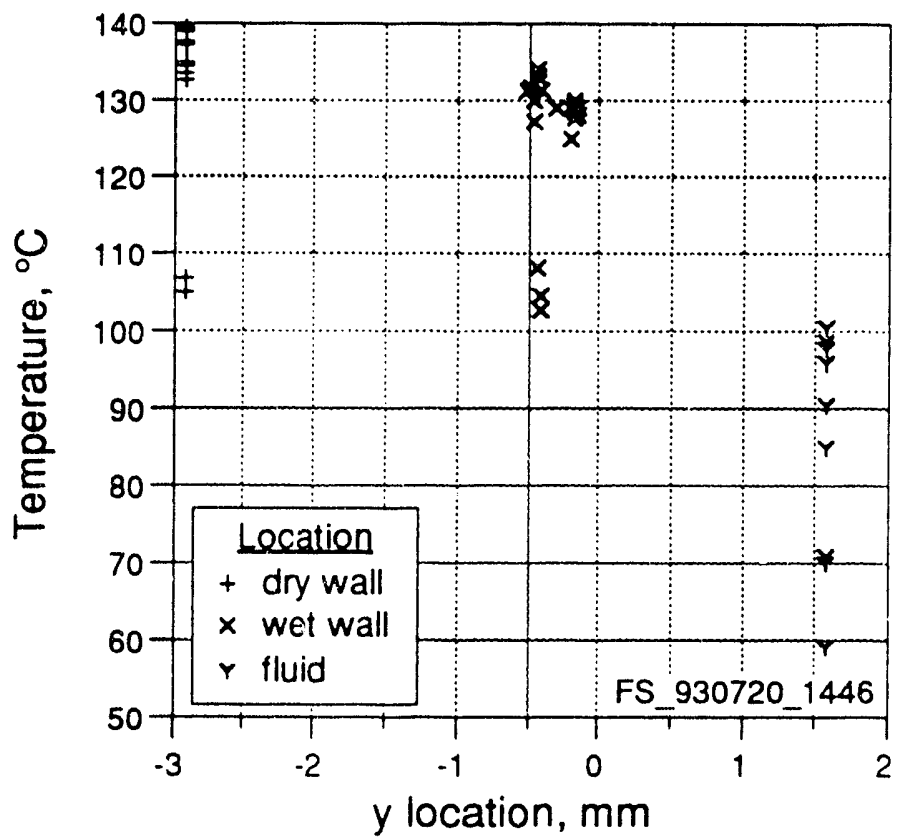

Figure 91, Normal temperature profile from File FS_930720_1446 (Construction $4.0, \mathrm{~T}_{\text {in }}=59.29^{\circ} \mathrm{C}, \phi=327.6 \mathrm{~kW} / \mathrm{m}^{2}, \mathrm{Q}=205.9 \mathrm{~cm}^{3} / \mathrm{s}, \mathrm{P}_{\mathrm{ehl}}=$ $129.2 \mathrm{kPa})$ 


\section{Preliminary Data -. 9 September 1993}

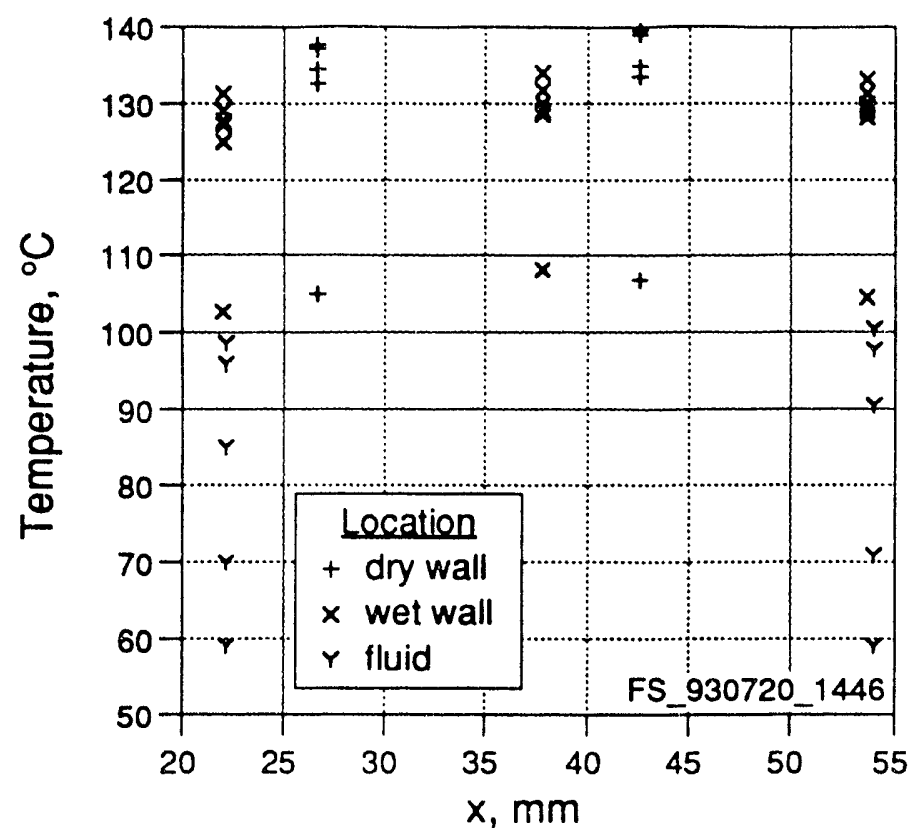

Figure 92, Lateral temperature profile from File FS_930720_1446 (Construction $\left.4.0, T_{\text {in }}=59.29^{\circ} \mathrm{C}, \phi=327.6 \mathrm{~kW} / \mathrm{m}^{2}, Q=205.9 \mathrm{~cm}^{3} / \mathrm{s}, \mathrm{p}_{\text {ehl }}=129.2 \mathrm{kPa}\right)$

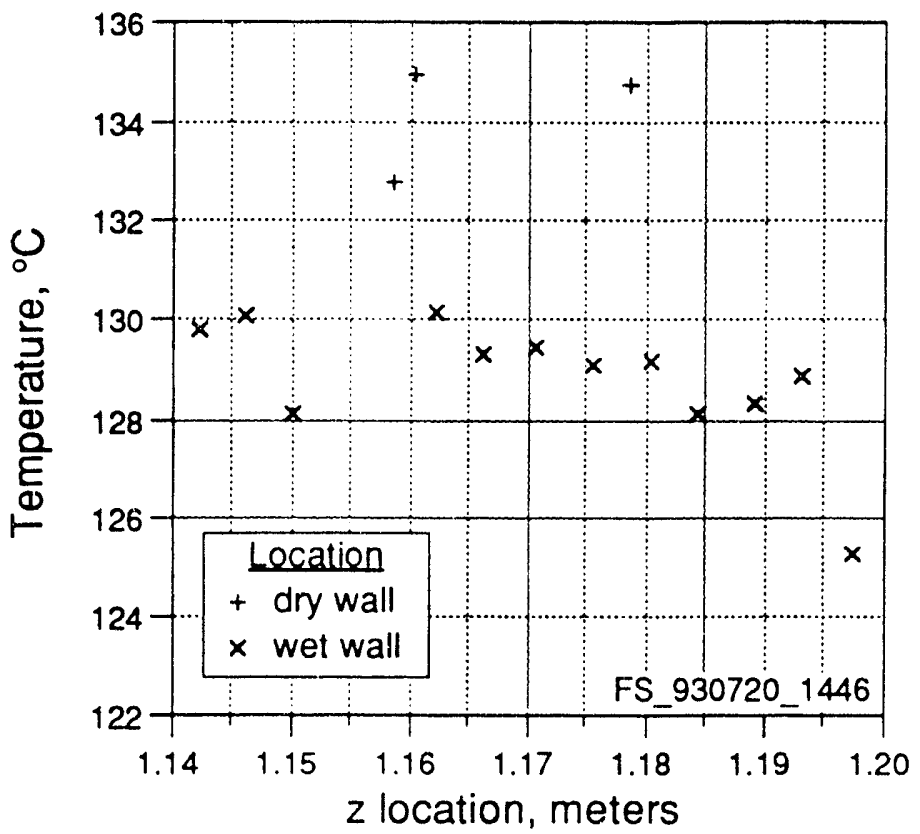

Figure 93, Longitudinal temperature profile at EHL from File FS_930720_1446 (Construction $4.0, \mathrm{~T}_{\mathrm{in}}=59.29^{\circ} \mathrm{C}, \phi=327.6 \mathrm{~kW} / \mathrm{m}^{2}, \mathrm{Q}=205.9 \mathrm{~cm}^{3} / \mathrm{s}, \mathrm{p}_{\mathrm{ehl}}=$ $129.2 \mathrm{kPa}$ ) 


\section{Preliminary Data -- 9 September 1993}

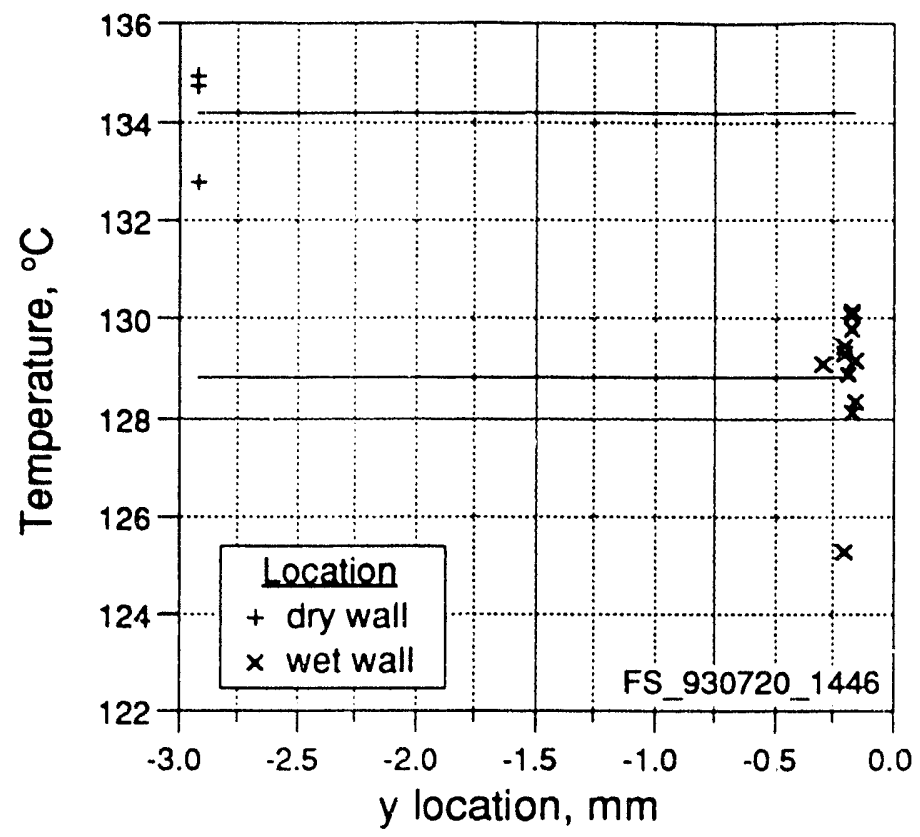

Figure 94, Normal temperature profile at EHL from File FS_930720_1446 (Construction $4.0, T_{\text {in }}=59.29^{\circ} \mathrm{C}, \phi=327.6 \mathrm{~kW} / \mathrm{m}^{2}, Q=205.9 \mathrm{~cm}^{3} / \mathrm{s}, p_{\text {ehl }}=$ $129.2 \mathrm{kPa}$ )

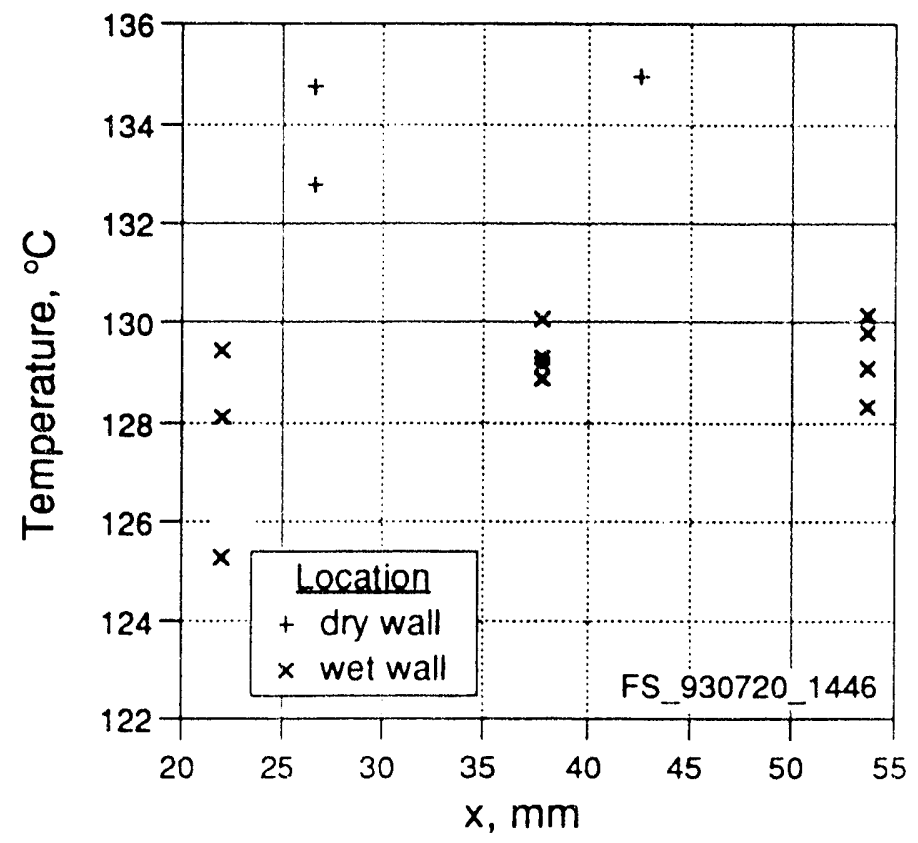

Figure 95, Lateral temperature profile at EHL from File FS_930720_1446 (Construction $4.0, T_{\text {in }}=59.29^{\circ} \mathrm{C}, \phi=327.6 \mathrm{~kW} / \mathrm{m}^{2}, Q=205.9 \mathrm{~cm}^{3} / \mathrm{s}, \mathrm{p}_{\mathrm{ehl}}=$ $129.2 \mathrm{kPa})$ 


\section{Preliminary Data -. 9 September 1993}

Table 38.--Mean heater temperature based on lateral position from File FS_930720_1446 (Construction 4.0, $\mathrm{T}_{\text {in }}=59.29^{\circ} \mathrm{C}, \phi=327.6 \mathrm{~kW} / \mathrm{m}^{2}, \mathrm{Q}=$ $205.9 \mathrm{~cm}^{3} / \mathrm{s}, p_{\text {ehl }}=129.2 \mathrm{kPa}$ )

\begin{tabular}{c|c|c|c|c|c}
\hline \hline & $\mathrm{N}$ & $\begin{array}{c}\mathrm{x} \\
\mathrm{mm}\end{array}$ & $\begin{array}{c}\overline{\mathrm{T}} \\
{ }^{\circ} \mathrm{C}\end{array}$ & $\begin{array}{c}\mathrm{S} \\
{ }^{\circ} \mathrm{C}\end{array}$ & $\begin{array}{c}\mathrm{S}_{\mathrm{m}} \\
{ }^{\circ} \mathrm{C}\end{array}$ \\
\hline dry & 5 & 26.72 & 135.25 & 2.58 & 1.15 \\
dry & 4 & 42.60 & 136.91 & 2.93 & 1.47 \\
wet & 6 & 21.97 & 128.37 & 2.08 & 0.85 \\
wet & 7 & 37.85 & 130.61 & 1.96 & 0.74 \\
wet & 6 & 53.72 & 130.50 & 1.89 & 0.77 \\
\hline mean, dry & 9 & $\cdots$ & 135.99 & 2.70 & 0.90 \\
mean, wet & 19 & $\ldots$ & 129.87 & 2.14 & 0.49 \\
\hline
\end{tabular}

Table 39.--Mean heater temperatures based on lateral position over the last $80 \mathrm{~mm}$ of the heated length; from File FS_930720_1446 (Construction 4.0, $\mathrm{T}_{\text {in }}$ $\left.=59.29^{\circ} \mathrm{C}, \phi=327.6 \mathrm{~kW} / \mathrm{m}^{2}, Q=205.9 \mathrm{~cm}^{3} / \mathrm{s}, p_{\mathrm{ehl}}=129.2 \mathrm{kPa}\right)$

\begin{tabular}{c|c|c|c|c|c}
\hline & $\mathrm{N}$ & $\begin{array}{c}\mathrm{x} \\
\mathrm{mm}\end{array}$ & $\begin{array}{c}\overline{\mathrm{T}} \\
{ }^{\circ} \mathrm{C}\end{array}$ & $\begin{array}{c}\mathrm{S} \\
{ }^{\circ} \mathrm{C}\end{array}$ & $\begin{array}{c}\mathrm{S}_{\mathrm{m}} \\
{ }^{\circ} \mathrm{C}\end{array}$ \\
\hline dry & 2 & 26.72 & 133.82 & 1.42 & 1.01 \\
dry & 1 & 42.60 & 135.06 & $\cdots$ & $\cdots$ \\
wet & 4 & 21.97 & 127.81 & 1.77 & 0.88 \\
wet & 4 & 37.85 & 129.42 & 0.52 & 0.26 \\
wet & 4 & 53.72 & 129.41 & 0.80 & 0.40 \\
\hline mean, dry & 3 & $\cdots$ & 134.23 & 1.24 & 0.71 \\
mean, wet & 12 & $\ldots$ & 128.88 & 1.31 & 0.38 \\
\hline
\end{tabular}

by moving laterally, heater fabrication techniques should not have produced this variation. Further work with plasma spray heater technology is necessary to evaluate if this is the reason for the variation. As expected the dry wall temperature was higher than the wet wall temperature. 


\section{Preliminciy Data -- 9 September 1993}

Rib Channel Temperature Profiles

Figures 96,97 , and 98 present the temperature profile information at the OFI for Curve 3.002. This test was conducted using Construction 2.0, which included the longitudinal rib. The fluid temperature increased along the longitudinal direction. This increase was very close to linear with axial position. This is expected since the fluid density and specific heat vary little with temperature. The wall temperature did not increase consistently in the longitudinal direction. There is a noticeable temperature decrease for the thermocouples between 0.582 and $0.592 \mathrm{~m}$ from the SHL. This depression in the longitudinal temperature profile is probably the result of the ONB effect.

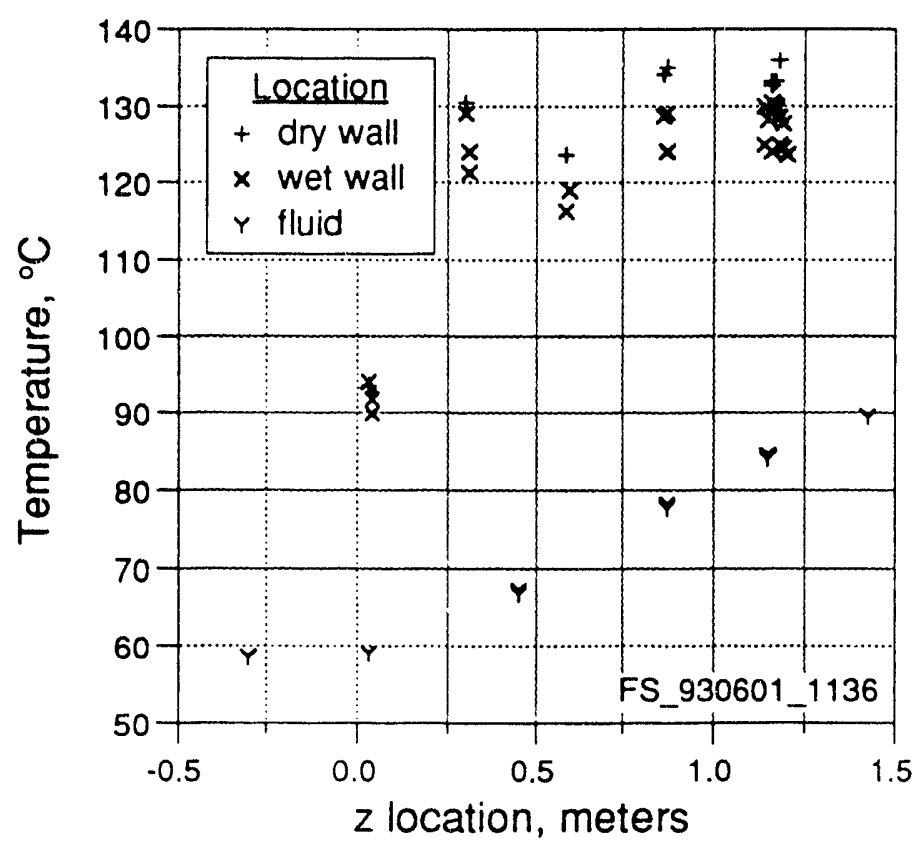

Figure 96, Longitudinal temperature profile from File FS_930601_1136 (Construction 2.0, $\mathrm{T}_{\text {in }}=59.19^{\circ} \mathrm{C}, \phi=330.0 \mathrm{~kW} / \mathrm{m}^{2}, Q=259.5 \mathrm{~cm}^{3} / \mathrm{s}, \mathrm{p}_{\text {ehl }}=$ $129.0 \mathrm{kPa}$ ) 


\section{Preliminary Data _- 9 September 1993}

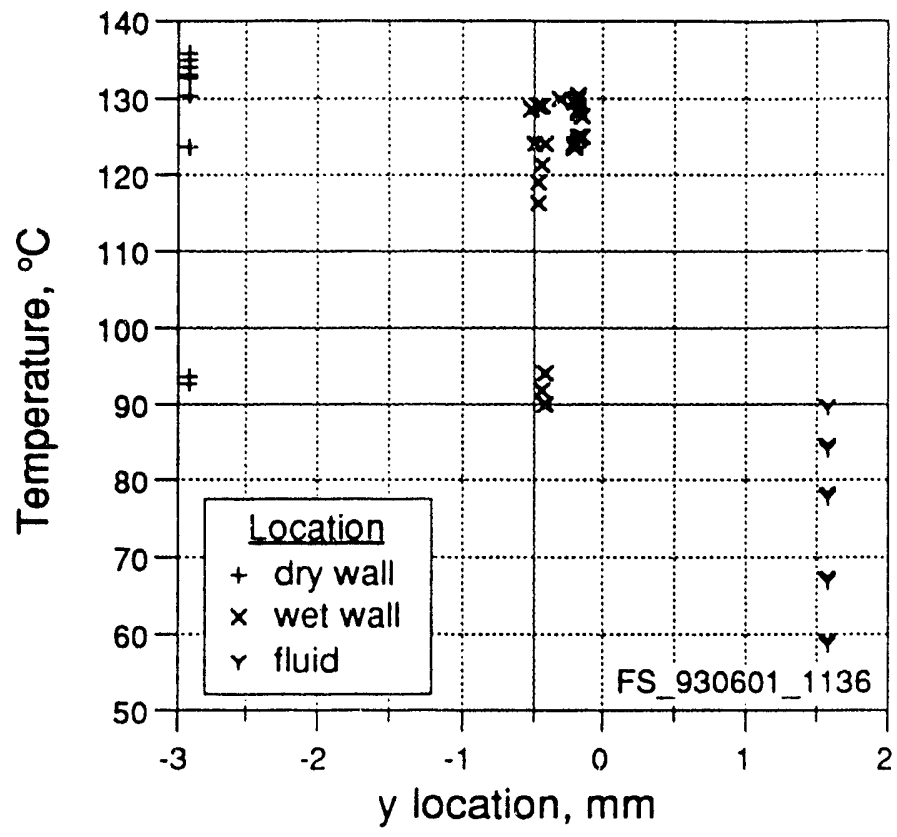

Figure 97, Normal temperature profile from File FS_930601_1136 (Construction 2.0, $\mathrm{T}_{\text {in }}=59.19^{\circ} \mathrm{C}, \phi=330.0 \mathrm{~kW} / \mathrm{m}^{2}, Q=259.5 \mathrm{~cm}^{3} / \mathrm{s}, p_{\text {ehl }}=$ $129.0 \mathrm{kPa})$

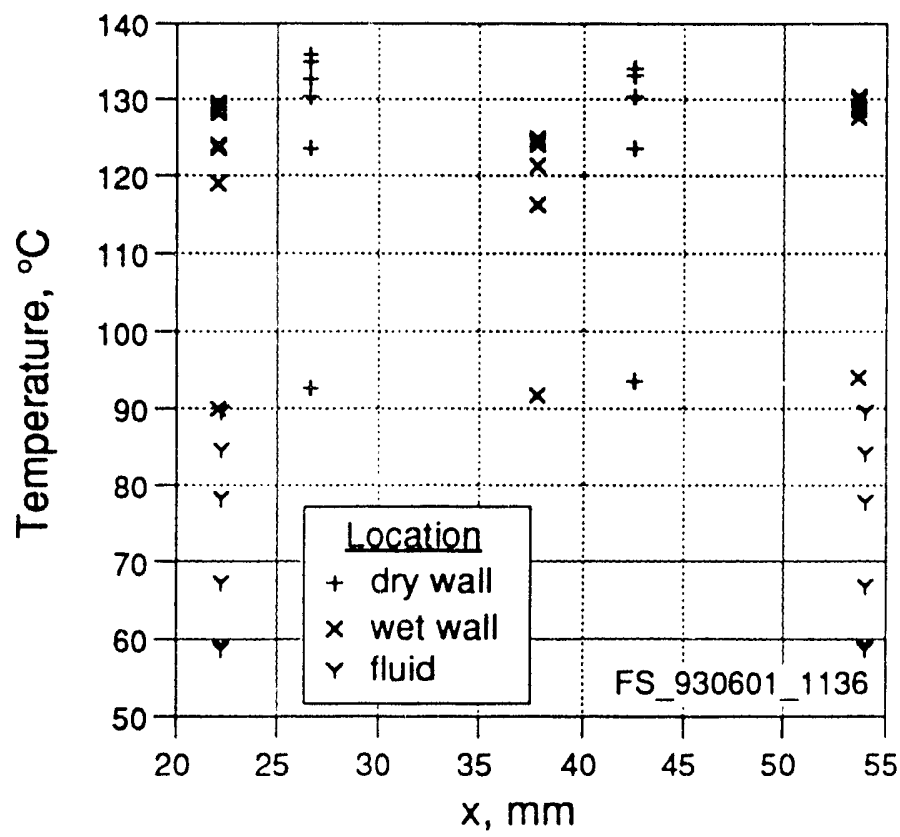

Figure 98, Lateral temperature profile from File FS_930601_1136 (Construction 2.0. $\left.\mathrm{T}_{\text {in }}=59.19^{\circ} \mathrm{C}, \phi=330.0 \mathrm{~kW} / \mathrm{m}^{2}, Q=259.5 \mathrm{~cm}^{3} / \mathrm{s}, p_{\text {ehl }}=129.0 \mathrm{kPa}\right)$ 
Preliminary Data .- 9 September 1993

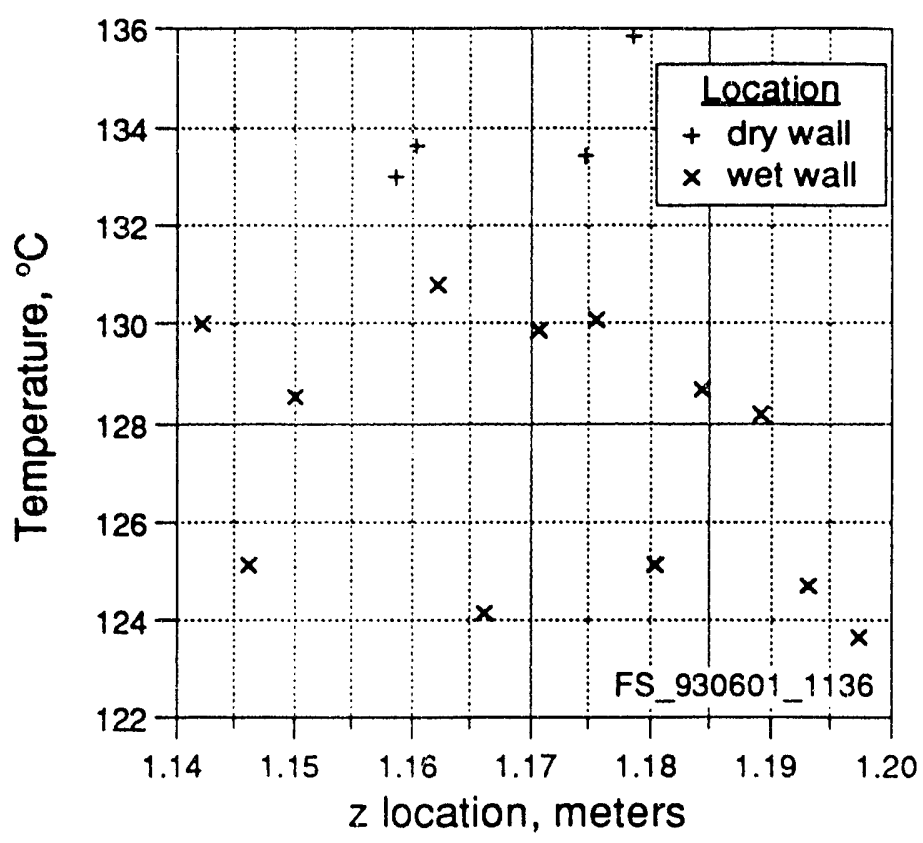

Figure 99, Longitudinal temperature profile at EHL from File FS_930601_1136 (Construction 2.0, $T_{\text {in }}=59.19^{\circ} \mathrm{C}, \phi=330.0 \mathrm{~kW} / \mathrm{m}^{2}, Q=259.5 \mathrm{~cm}^{3} / \mathrm{s}, \mathrm{P}_{\text {ehl }}=$ $129.0 \mathrm{kPa})$

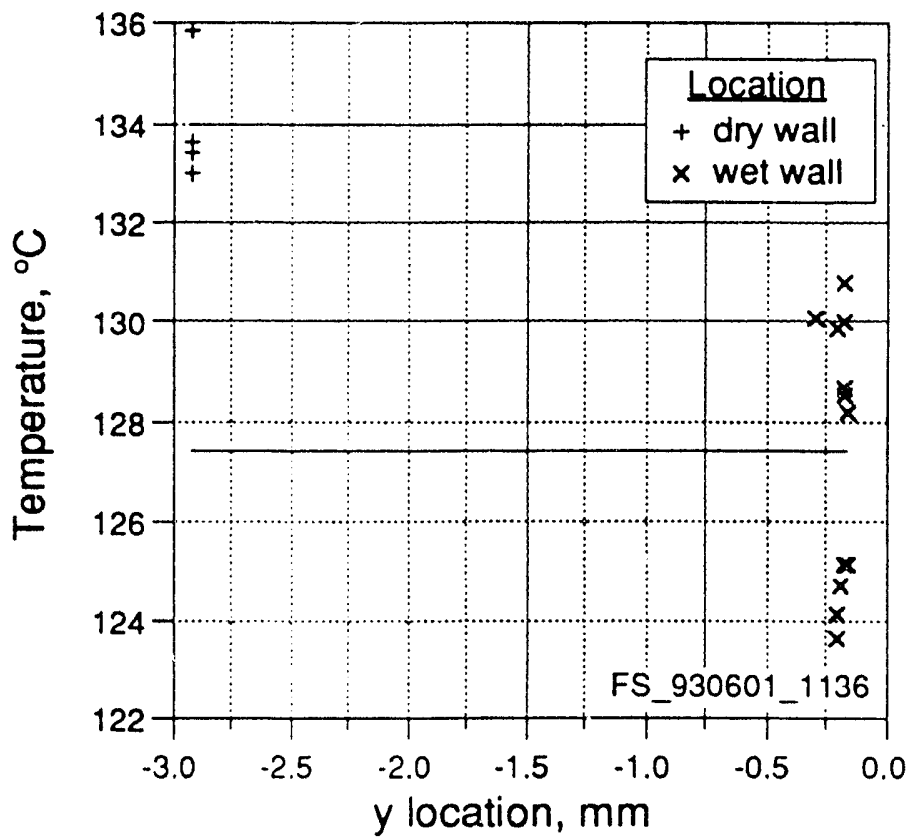

Figure 100, Normal temperature profile at EHL from File FS_930601_1136 (Construction $2.0, T_{\text {in }}=59.19^{\circ} \mathrm{C}, \phi=330.0 \mathrm{~kW} / \mathrm{m}^{2}, Q=259.5 \mathrm{~cm}^{3} / \mathrm{s}, \bar{p}_{\text {ehl }}=$ $129.0 \mathrm{kPa}$ ) 
Preliminary Data .- 9 September 1993

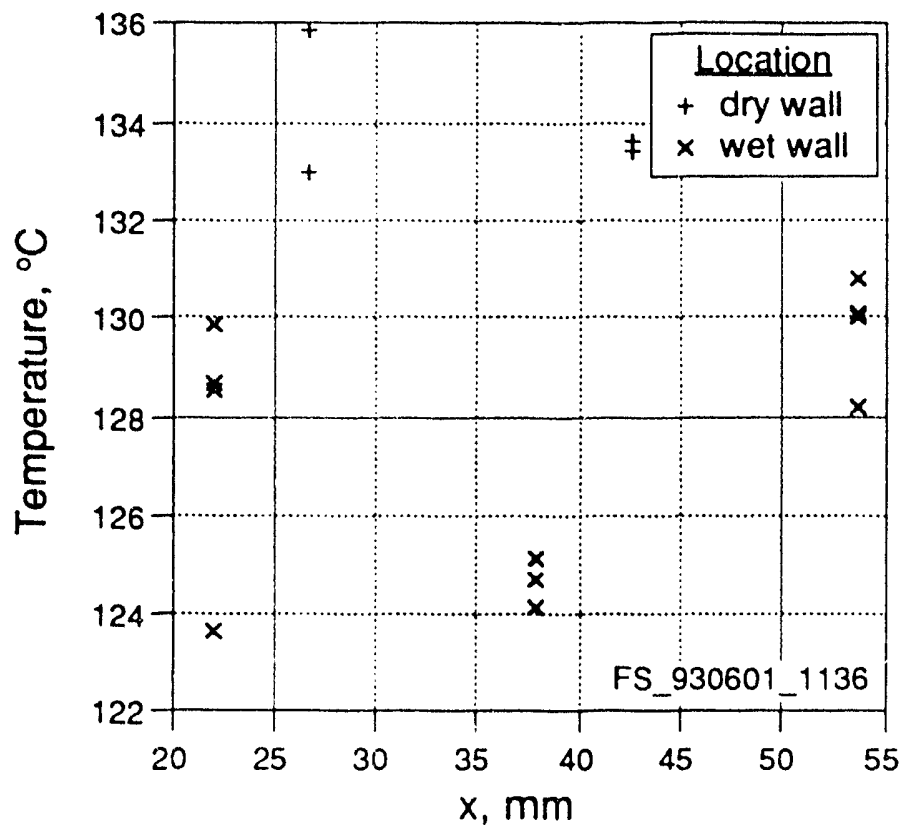

Figure 101, Lateral temperature profile at EHL from File FS_930601_1136 (Construction 2.0, $T_{\text {in }}=59.19^{\circ} \mathrm{r}, \phi=330.0 \mathrm{~kW} / \mathrm{m}^{2}, Q=259.5 \mathrm{~cm}^{3} / \mathrm{s}, \mathrm{p}_{\mathrm{ehl}}=$ $129.0 \mathrm{kPa}$ )

Figures 99,100 , and 101 present the temperatures over the last $80 \mathrm{~mm}$ of the heated length. The wall temperature near the rib is lower than that of the lateral positions that are away from the rib. This difference is $3.9^{\circ} \mathrm{C}$ over the 80 $\mathrm{mm}$ of heated length and $4.7^{\circ} \mathrm{C}$ over most of the heated section. Tables 40 and 41 summarize this information.

\section{Isothermal Temperature Profiles}

Figures 102, 103, and 104 present the temperature profile information for an isothermal condition where the fluid temperature was held at $60^{\circ} \mathrm{C}$. This test was conducted using Construction 4.0, which did not contain any obstructions. Tables 42 and 43 present a summary of the temperature data in 


\section{Preliminary Data -. 9 September 1993}

Table 40.--Mean heater temperature based on lateral position from File FS_930601_1136 (Construction 2.0, $T_{\text {in }}=59.19^{\circ} \mathrm{C}, \phi=330.0 \mathrm{~kW} / \mathrm{m}^{2}, Q=$ $259.5 \mathrm{~cm}^{3} / \mathrm{s}, P_{\text {ehl }}=129.0 \mathrm{kPa}$ )

\begin{tabular}{c|c|c|c|c|c}
\hline \hline & $\mathrm{N}$ & $\begin{array}{c}\mathrm{x} \\
\mathrm{mm}\end{array}$ & $\begin{array}{c}\overline{\mathrm{T}} \\
{ }^{\circ} \mathrm{C}\end{array}$ & $\begin{array}{c}\mathrm{S} \\
{ }^{\circ} \mathrm{C}\end{array}$ & $\begin{array}{c}\mathrm{S}_{\mathrm{m}} \\
{ }^{\circ} \mathrm{C}\end{array}$ \\
\hline dry & 5 & 26.72 & 131.77 & 4.80 & 2.15 \\
dy & 5 & 42.60 & 131.17 & 4.39 & 1.96 \\
wet & 7 & 21.97 & 126.22 & 3.98 & 1.50 \\
wet at rib & 7 & 37.85 & 123.13 & 3.11 & 1.18 \\
wet & 6 & 53.72 & 129.53 & 0.95 & 0.39 \\
\hline mean, dry & 10 & $\cdots$ & 131.47 & 4.35 & 1.38 \\
miean, wet & 20 & $\ldots$ & 126.13 & 3.91 & 0.87 \\
\hline
\end{tabular}

Table 41.--Mean heater temperatures based on lateral position over the last $80 \mathrm{~mm}$ of the heated length; from File FS_930601_1136 (Construction 2.0, $T_{\text {in }}$ $\left.=59.19^{\circ} \mathrm{C}, \phi=330.0 \mathrm{~kW} / \mathrm{m}^{2}, Q=259.5 \mathrm{~cm}^{3} / \mathrm{s}, p_{\text {ehl }}=129.0 \mathrm{kPa}\right)$

\begin{tabular}{c|c|c|c|c|c}
\hline & $\mathrm{N}$ & $\begin{array}{c}\mathrm{x} \\
\mathrm{mm}\end{array}$ & $\begin{array}{c}\overline{\bar{T}} \\
{ }^{\circ} \mathrm{C}\end{array}$ & $\begin{array}{c}\mathrm{S} \\
{ }^{\circ} \mathrm{C}\end{array}$ & $\begin{array}{c}\mathrm{S}_{\mathrm{m}} \\
{ }^{\circ} \mathrm{C}\end{array}$ \\
\hline dry & 2 & 26.72 & 134.44 & 2.09 & 1.48 \\
dry & 2 & 42.60 & 133.52 & 0.18 & 0.13 \\
wet & 4 & 21.97 & 127.68 & 2.74 & 1.37 \\
wet at rib & 4 & 37.85 & 124.82 & 0.47 & 0.23 \\
wet & 4 & 53.72 & 129.77 & 1.13 & 0.56 \\
\hline mean, dry & 4 & $\cdots$ & 133.98 & 1.32 & 0.66 \\
mean, wet & 12 & $\ldots$ & 127.42 & 2.63 & 0.76 \\
\hline
\end{tabular}

the same format as the earlier temperature profile information was presented. These tables and the three figures indicate that the temperature behaviors discussed earlier in this section are not the result of thermocouple variations. 
Preliminary Data -- 9 September 1993

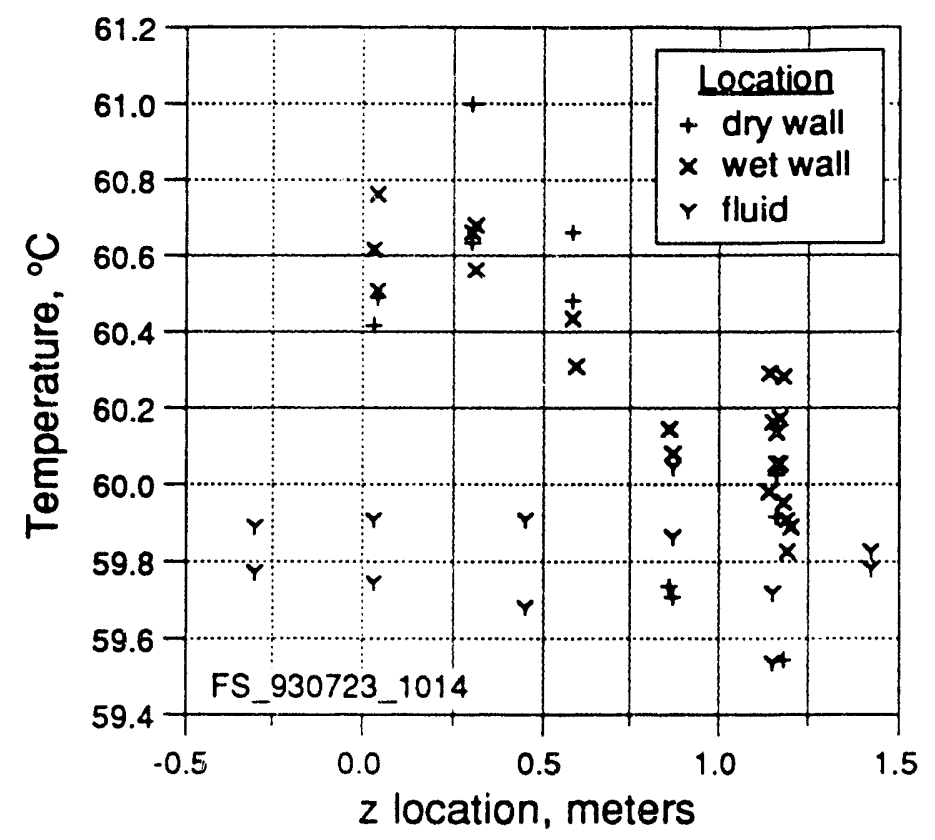

Figure 102, Longitudinal temperature profile from File FS_930723_1014 (Construction $4.0, T_{\text {in }}={ }^{\circ} \mathrm{C}, \phi=0.00 \mathrm{~kW} / \mathrm{m}^{2}, \mathrm{Q}=\mathrm{cm}^{3} / \mathrm{s}, \mathrm{p}_{\mathrm{ehl}}=\mathrm{kPa}$ )

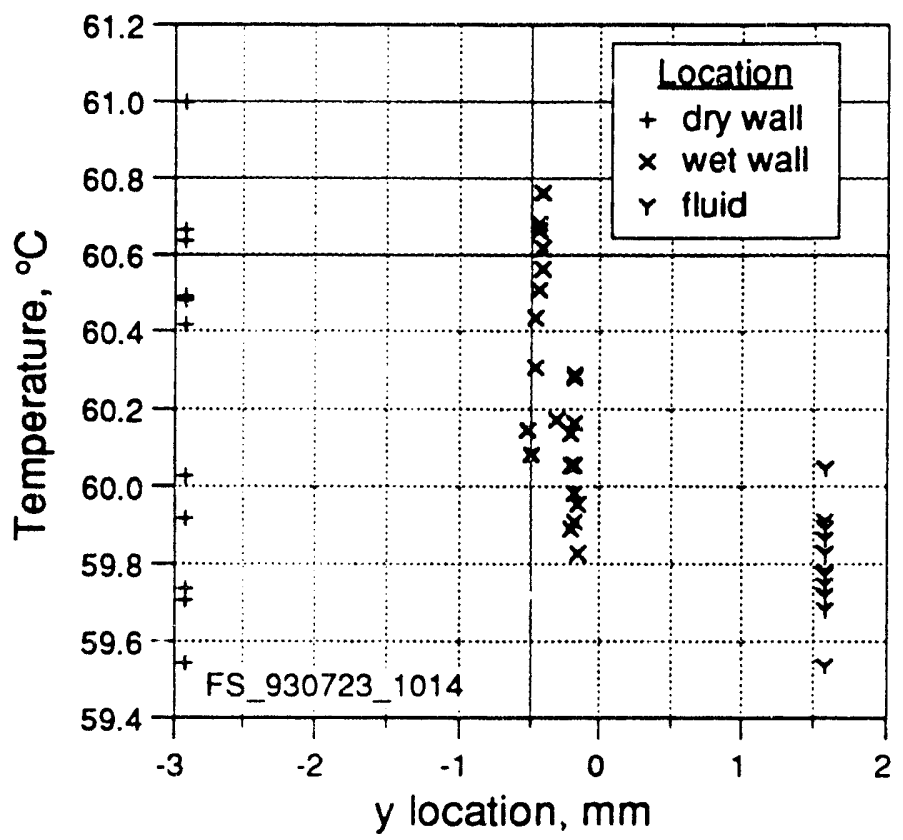

Figure 103, Normal temperature profile from File FS_930723_1014 (Construction $4.0, \mathrm{~T}_{\text {in }}={ }^{\circ} \mathrm{C}, \phi=0.0 \mathrm{~kW} / \mathrm{m}^{2}, \mathrm{Q}=\mathrm{cm}^{3} / \mathrm{s}, \mathrm{P}_{\text {ehl }}=\mathrm{kPa}$ ) 


\section{Preliminary Data .. 9 September 1993}

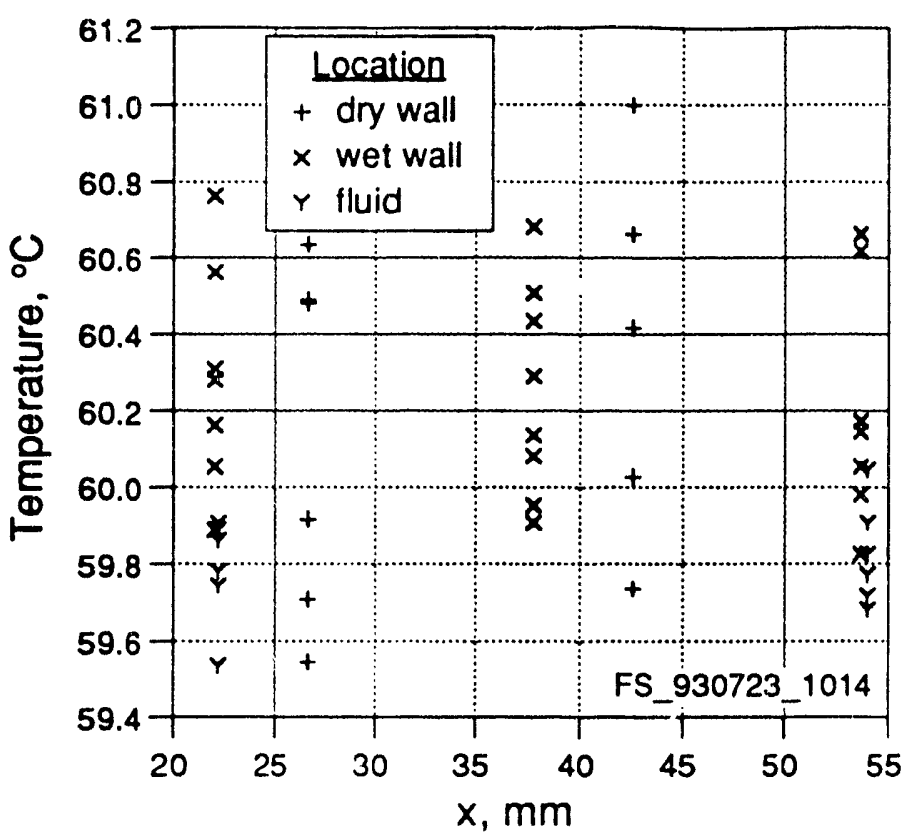

Figure 104, Lateral temperature profile from File FS_930723_1014 (Construction $4.0, T_{\text {in }}=60^{\circ} \mathrm{C}, \phi=0.0 \mathrm{~kW} / \mathrm{m}^{2}, Q=\mathrm{cm}^{3} / \mathrm{s}, p_{\text {ehl }}=\mathrm{kPa}$ )

Table 42.--Mean heater temperature based on lateral position from File FS_930723_1014 (Construction $4.0, T_{\text {in }}=60^{\circ} \mathrm{C}, T T 00001=60^{\circ} \mathrm{C}, \phi=0.0$ $\mathrm{kW} / \mathrm{m}^{2}, \mathrm{Q}=\mathrm{cm}^{3} / \mathrm{s}, p_{\text {ehl }}=\mathrm{kPa}$ )

\begin{tabular}{c|c|c|c|c|c}
\hline \hline & $\mathrm{N}$ & $\begin{array}{c}\mathrm{x} \\
\mathrm{mm}\end{array}$ & $\begin{array}{c}\overline{\mathrm{T}} \\
{ }^{\circ} \mathrm{C}\end{array}$ & $\begin{array}{c}\mathrm{S} \\
{ }^{\circ} \mathrm{C}\end{array}$ & $\begin{array}{c}\mathrm{S}_{\mathrm{m}} \\
{ }^{\circ} \mathrm{C}\end{array}$ \\
\hline dry & 5 & 26.72 & 60.06 & 0.48 & 0.22 \\
dry & 4 & 42.60 & 60.36 & 0.58 & 0.29 \\
wet & 6 & 21.97 & 60.22 & 0.23 & 0.09 \\
wet & 7 & 37.85 & 60.22 & 0.28 & 0.10 \\
wet & 6 & 53.72 & 60.15 & 0.28 & 0.12 \\
\hline mean, dry & 9 & $\cdots$ & 60.20 & 0.52 & 0.17 \\
mean, wet & 19 & $\ldots$ & 60.20 & 0.25 & 0.06 \\
mean, fluid & 12 & $\ldots$ & 59.81 & 0.13 & 0.04 \\
\hline
\end{tabular}




\section{Preliminary Data -- 9 September 1993}

Table 43.--Mean heater temperatures based on lateral position over the last $80 \mathrm{~mm}$ of the heated length; from File FS_930723_1014 (Construction 4.0, $T_{\text {in }}$ $=60^{\circ} \mathrm{C}, T T 00001=60^{\circ} \mathrm{C}, \phi=0.0 \mathrm{~kW} / \mathrm{m}^{2}, Q=\mathrm{cm}^{3} / \mathrm{s}, p_{\text {ehl }}=\mathrm{kPa}$ )

\begin{tabular}{c|c|c|c|c|c}
\hline & $\mathrm{N}$ & $\begin{array}{c}\mathrm{x} \\
\mathrm{mm}\end{array}$ & $\begin{array}{c}\overline{\mathrm{T}} \\
{ }^{\circ} \mathrm{C}\end{array}$ & $\begin{array}{c}\mathrm{S} \\
{ }^{\circ} \mathrm{C}\end{array}$ & $\begin{array}{c}\mathrm{S}_{\mathrm{m}} \\
{ }^{\circ} \mathrm{C}\end{array}$ \\
\hline dry & 2 & 26.72 & 59.73 & 0.26 & 0.19 \\
dry & 1 & 42.60 & 60.03 & $\cdots$ & $\cdots$ \\
wet & 4 & 21.97 & 60.10 & 0.17 & 0.08 \\
wet & 4 & 37.85 & 60.08 & 0.17 & 0.09 \\
wet & 4 & 53.72 & 60.02 & 0.14 & 0.07 \\
\hline mean, dry & 3 & $\cdots$ & 59.83 & 0.25 & 0.15 \\
mean, wet & 12 & $\ldots$ & 60.07 & 0.15 & 0.15 \\
mean, fluid & 2 & $\ldots$ & 59.63 & 0.12 & 0.09 \\
\hline
\end{tabular}




\section{Preliminary Data -. 9 September 1993}

\section{CHAPTER 5 \\ DISCUSSION}

\section{Demand Curve Minimum Conditions}

The $Q_{\text {ratio }}$ was demonstrated to be independent of the heat flux for the channel with the longitudinal rib. This is further confirmation of the work presented by the researchers at Columbia University. The bubble detachment parameter, $\eta$, defined by Equation 2 has been estimated for the three constructions using the data presented in Table 35. This information is presented in Table 44. The values calculated for the open channels compare favorably with the value of 25 suggested by Whittle and Forgan. The value for the ribbed channel was much higher than can be explained by present theory.

The Stanton numbers at OFI are higher than expected for the open channels. For the channel with the logitudianl rib hey are lower than the nominal 0.0065 value suggested by Saha and Zuber. The Nusselt numbers evaluated during this test program range from 156 to 277 . These are well below the 455 criteria (Equation 40) necessary to allow vapor to enter the liquid core. The narrow depth of the test channel might create a situation where the core survival mechanism inherent in Equation 40 does not hold. 


\section{Preliminary Data -- 9 September 1993}

Table 44.--Bubble detachment parameters

\begin{tabular}{c|c|c|c|c|c}
\hline Geometry & Construction & $L_{h} / D_{h}$ & $N$ & $\eta$ & $S_{\eta}$ \\
\hline \multirow{2}{*}{ Open } & 1 & 95.3 & 4 & 29.0 & 1.7 \\
& 4 & 89.4 & 5 & 28.8 & 2.3 \\
Rib & 2 & 87.3 & 4 & 53.7 & 0.5 \\
\hline
\end{tabular}

The introduction of a longitudinal spacer rib in a rectangular heated channel will change the behavior of the test channel at OFI. For the comparison of Construction 2 with Construction 4 the $Q_{\text {ratio }}$ rib-effect-ratio is $0.817 \pm 0.028$. The Stanton number rib-effect-ratio is $0.49 \pm 0.07$. Both of these values are more severe than has been observed in annuli equipped with spacer ribs. (See Table 13.) This variation may not be the result of the rectangular channel test but the presence of centering pins in the "open" annuli which may depress the $Q_{\text {ratio }}$ and Stanton number values at OFI.

\section{Boiling Behavior}

The boiling behavior observed prior to OFI in the open channel conformed with expectations for nucleate boiling behavior. The cyclic formation of vapor bubbles at OFI conditions can probably be attributed to a form of flow pattern transition instability. It appears that avoidance of OFI conditions will also prevent this form of flow instability.

The boiling behavior for the channel equipped with the longitudinal rib conformed with the mechanisms which Hodges (35) used to explain his observations in a similar te geometry. The behavior did differ in that bubbles could be observed breakir: free from the corner surfaces and traveling down the heated channel. For the bubbles presented in Figure 85 the flat plate turbulent length would be: 


\section{Preliminary Data ... 9 September 1993}

$$
z=\frac{\operatorname{Re} \mu}{u \rho}=\frac{(3.2 e 5)(386.3 \mu \mathrm{Pa} \cdot \mathrm{s})}{\left(1.1086 \frac{\mathrm{m}}{\mathrm{s}}\right)\left(974.5 \frac{\mathrm{kg}}{\mathrm{m}^{3}}\right)}=114 \mathrm{~mm}
$$

The observed bubble lengths are much shorter than the value in Equation 90 so some other characteristic length, as used to define the critical Reynolds number, is probably more appropriate.

\section{Wall Temperatures}

The wall temperature at the water to liquid interface will be slightly lower than the measured temperature since the thermocouple is set back into the heated surface. A correction can be estimated using a conduction analysis. Equation 91 provides a corrected temperature at the wall-to-liquid interface.

$$
T_{\text {wall }}=T_{d r y}-y_{d r y} \frac{T_{d r y}-T_{\text {wet }}}{y_{d r y}-Y_{\text {wet }}}
$$

The corrected wall temperatures and the wall temperatures calculated using the Thom, et al. correlation (Equation 53) for the previously discussed files are presented in Table 45. The wall temperature estimated using equation 91 is higher then that estimated using Equation 53. While temperature measurement uncertainty may create some of this discrepancy it is more likely that the difference exists for other reasons. The evaluation of these reasons would require further testing that is beyond the scope of this program. 


\section{Preliminary Data -- 9 September 1993}

Table 45.--Wall temperature evaluation

\begin{tabular}{r|c|c}
\hline File name: & FS_930601_1136 & FS_930720_1446 \\
\hline $\begin{array}{l}\text { Dry wall temperature }(y=-2.92 \mathrm{~mm}) \\
\text { Wet wall temperature }(y=-0.322 \mathrm{~mm})\end{array}$ & 131.47 & 135.99 \\
$\begin{array}{c}\text { Temperature at wall-to-liquid interface } \\
\text { (Equation 91) }\end{array}$ & 126.13 & 129.87 \\
$\begin{array}{c}\text { Nucleate boiling temperature (Thom, } \\
\text { et al. correlation, Equation 53) }\end{array}$ & 125.47 & 129.11 \\
ONB temperature (Equation 38) & 120.13 & 120.12 \\
\hline
\end{tabular}




\section{CHAPTER 6}

\section{CONCLUSIONS}

The existence of a rib effect on Ledinegg instability has been demonstrated. For the configuration tested the effect in terms of $Q_{\text {ratio }}$ is $0.82 \pm$ 0.03 . In terms of Stanton number the effect is $0.49 \pm 0.07$. These values are applicable only to the configuration tested. It appears that the vapor generation and movement near the vicinity of the rib lowers both the $Q_{\text {ratio }}$ and Stanton number at OFI.

The data generated during this program can be used to benchmark the rib effect calculations necessary to evaluate fuel assemblies with spacer ribs. The rib effect in previous data sets has been confounded with other parameters such as centering pins, annulus concentricity, and rig-to-rig geometry variations. These effects were eliminated by the use of a rectangular geometry that eliminated the need for centering pins. The test channel was fabricated to allow installation and removal of the rib thus significantly reducing the previous rig-torig geometry effects. 
Preliminary Data -. 9 September 1993

\author{
APPENDIX 1 \\ TEST CHANNEL GeOMETRY MEASUREMENTS
}




\section{Prollminary Data $\ldots 9$ September 1993}

Direct measurement of the channel dimensions was found to be a considerable challenge during the first two constructions. This measurement problem is more fully described in Chapter 4 . Because the test results are sensitive to the correctness of the channel geometry a detailed description of the channel configuration estimates is warranted. This appendix presents a detailed description of the measurement techniques used to evaluate the channel geometry. With the exception of the rib width, rib height, and hydraulic length all channel dimensions rave been calculated from multiple measurements or derived from operating post-test inspections. Table 23 summarizes the channel geometry measurements. Table 1-2 presents details of the non-calculated channel dimensions.

Table 1-2.--Directly measured channel dimensions

\begin{tabular}{l|c|c|c|c}
\hline & $\mathrm{N}$ & $\bar{X}$ & $\mathrm{~S}$ & \multicolumn{1}{c|}{$\mathrm{B}$} \\
\hline Rib width, $x_{0}, \mathrm{~mm}$ & 6 & 2.07 & 0.01 & 0.04 \\
Rib height, $\mathrm{b}_{0}, \mathrm{~mm}$ & 6 & 3.25 & 0.00 & 0.03 \\
Length, hydraulic, L, m & 1 & 1.3970 & $\ldots$ & 0.0008 \\
$\begin{array}{l}\text { Length, heated, Lh, m } \\
\text { Heated width, open }\end{array}$ & 1 & 1.156 & $\ldots$ & 0.001 \\
$\quad$ channel, $\mathrm{a}_{h}, \mathrm{~mm}$ & 1 & 76.2 & $\ldots$ & 1.6 \\
\hline
\end{tabular}

\section{Channel Width, a}

The open channel width was estimated by measuring the overall width of the channel as shown in Figure 1-1. The width of the heater supports was then deducted to determine the overall channel width, a. Table 1-3 presents the results of the overall channel measurements. During the disassembly of Construction 3 roll pins were added as shown in Figure 1-1. These pins were installed $-0.110(-4.31), 0.635$ (25.00), and $1.289 \mathrm{~m}$ (50.75 inches) from the start 


\section{Preliminary Data -- 9 September 1993}

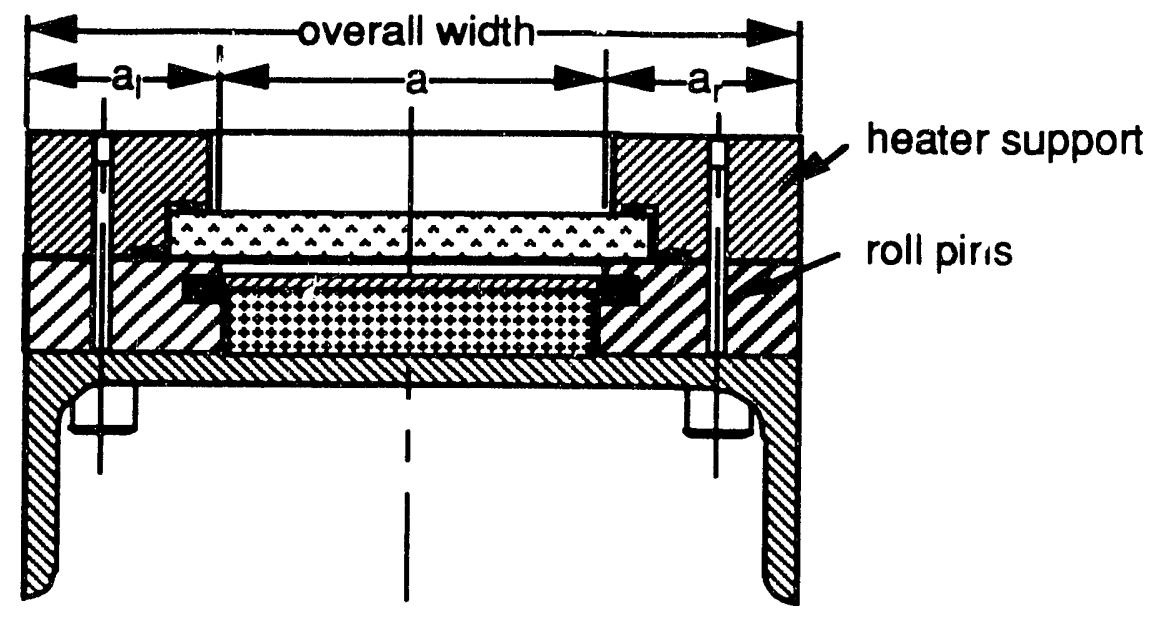

Figure 1-1, Channel width measurement technique

of the heated length. The first and third locations coincide with the location of the pressure ports for the heated section pressure drop measurements. Dimensions measured after the pins were installed are presented in Table 1-4. These dimensions were used to estimate the heater support widths. For construction 1 and 2 the means of the heater support widths were used rather than the widths for the specific location since the overall channel widths were made at different longitudinal positions.

\section{Channel Depth, b}

Direct measurement of the channel depth has been difficult. The original estimate was made by measuring the gap at the top to verify the manufacturing tolerances. The appropriateness of this method was demonstrated as inadequate when an attempt was made to slide the rib into place from the end of the channel without disassembly. The rib struck the bottom piece of glass firmly. After reassembly of the channel with the rib in place, it was apparent that the rib height was actually greater than the original cha.nnel depth as measured from the heater to the glass. 


\section{Preliminary Data -- 9 September 1993}

Table 1-3.--Channel width measurements

\begin{tabular}{|c|c|c|c|c|}
\hline $\begin{array}{c}\text { Distance from } \\
\text { start of heated } \\
\text { length, } m\end{array}$ & Date & $\begin{array}{c}\text { Overall } \\
\text { channel width, } \\
\mathrm{mm}\end{array}$ & $\begin{array}{c}\text { Total heater } \\
\text { support width, } \\
\mathrm{mm}\end{array}$ & $\mathrm{a}, \mathrm{mm}$ \\
\hline \multicolumn{5}{|c|}{ Construction 1 , open } \\
\hline $\begin{array}{l}-0.53 \\
-0.23 \\
0.08 \\
0.38 \\
0.69 \\
0.99 \\
1.30 \\
1.53\end{array}$ & $\begin{array}{l}14 \text { May '93 } \\
14 \text { May '93 } \\
14 \text { May '93 } \\
14 \text { May '93 } \\
14 \text { May '93 } \\
14 \text { May '93 } \\
14 \text { May '93 } \\
14 \text { May '93 }\end{array}$ & $\begin{array}{l}152.88 \\
152.55 \\
152.76 \\
152.86 \\
152.96 \\
152.86 \\
152.91 \\
152.65\end{array}$ & $\begin{array}{l}73.069 \\
73.069 \\
73.069 \\
73.069 \\
73.069 \\
73.069 \\
73.069 \\
73.069\end{array}$ & $\begin{array}{l}79.814 \\
79.484 \\
79.687 \\
79.789 \\
79.890 \\
79.789 \\
79.839 \\
79.585\end{array}$ \\
\hline \multicolumn{4}{|c|}{$\begin{array}{l}\text { Mean } \\
\text { Sample standard deviation, } \mathrm{S}\end{array}$} & $\begin{array}{r}79.735 \\
0.139 \\
\end{array}$ \\
\hline \multicolumn{5}{|c|}{ Construction 2, rib } \\
\hline $\begin{array}{l}-0.53 \\
-0.23 \\
0.08 \\
0.38 \\
0.69 \\
0.99 \\
1.30 \\
1.53 \\
-0.53 \\
-0.23 \\
0.08 \\
0.38 \\
0.69 \\
0.99 \\
1.30 \\
1.53\end{array}$ & $\begin{array}{l}14 \text { May '93 } \\
14 \text { May '93 } \\
14 \text { May '93 } \\
14 \text { May '93 } \\
14 \text { May '93 } \\
14 \text { May '93 } \\
14 \text { May '93 } \\
14 \text { May '93 } \\
15 \text { June '93 } \\
15 \text { June '93 } \\
15 \text { June '93 } \\
15 \text { June '93 } \\
15 \text { June '93 } \\
15 \text { June '93 } \\
15 \text { June '93 } \\
15 \text { June '93 }\end{array}$ & $\begin{array}{l}152.58 \\
152.58 \\
152.53 \\
152.71 \\
152.76 \\
152.73 \\
152.55 \\
152.48 \\
152.78 \\
152.60 \\
152.58 \\
152.88 \\
152.76 \\
152.76 \\
152.58 \\
152.68\end{array}$ & $\begin{array}{l}73.069 \\
73.069 \\
73.069 \\
73.069 \\
73.069 \\
73.069 \\
73.069 \\
73.069 \\
73.069 \\
73.069 \\
73.069 \\
73.069 \\
73.069 \\
73.069 \\
73.069 \\
73.069\end{array}$ & $\begin{array}{l}79.509 \\
79.509 \\
79.458 \\
79.636 \\
79.687 \\
79.662 \\
79.484 \\
79.408 \\
79.713 \\
79.535 \\
79.509 \\
79.814 \\
79.687 \\
79.687 \\
79.509 \\
79.611\end{array}$ \\
\hline \multicolumn{4}{|c|}{$\begin{array}{l}\text { Mean } \\
\text { Sample standard deviation, S }\end{array}$} & $\begin{array}{r}79.589 \\
0.113\end{array}$ \\
\hline
\end{tabular}


Preliminary Data -. 9 September 1993

Table 1-3.---Continued

\begin{tabular}{|c|c|c|c|c|}
\hline $\begin{array}{l}\text { Distance from } \\
\text { start of heated } \\
\text { length, } m\end{array}$ & Date & $\begin{array}{c}\text { Overall } \\
\text { channel width, } \\
\text { mrn }\end{array}$ & $\begin{array}{c}\text { Heater } \\
\text { support width, } \\
\text { mm }\end{array}$ & a, $\mathrm{mm}$ \\
\hline \multicolumn{5}{|c|}{ Construction 3 , open } \\
\hline $\begin{array}{r}-0.30 \\
-0.10 \\
0.18 \\
0.58 \\
1.02 \\
1.30 \\
1.42 \\
\end{array}$ & $\begin{array}{l}22 \text { June '93 } \\
22 \text { June '93 } \\
22 \text { June '93 } \\
22 \text { June '93 } \\
22 \text { June '93 } \\
22 \text { June '93 } \\
22 \text { June '93 }\end{array}$ & $\begin{array}{l}152.55 \\
152.55 \\
152.78 \\
152.91 \\
152.76 \\
152.45 \\
152.53\end{array}$ & $\begin{array}{l}73.051 \\
72.974 \\
73.051 \\
73.101 \\
73.000 \\
73.203 \\
73.101\end{array}$ & $\begin{array}{l}79.502 \\
79.578 \\
79.731 \\
79.807 \\
79.756 \\
79.248 \\
79.426\end{array}$ \\
\hline \multicolumn{4}{|c|}{$\begin{array}{l}\text { Mean } \\
\text { Sample standard deviation, } \mathrm{S}\end{array}$} & $\begin{array}{r}79.578 \\
0.202 \\
\end{array}$ \\
\hline \multicolumn{5}{|c|}{ Construction 4, open } \\
\hline $\begin{array}{r}-0.30 \\
-0.10 \\
0.18 \\
0.58 \\
1.02 \\
1.30 \\
1.42 \\
\end{array}$ & $\begin{array}{l}29 \text { June '93 } \\
29 \text { June '93 } \\
29 \text { June '93 } \\
29 \text { June '93 } \\
29 \text { June '93 } \\
29 \text { June ' } 93 \\
29 \text { June ' } 93 \\
\end{array}$ & $\begin{array}{l}152.91 \\
152.71 \\
152.83 \\
152.98 \\
153.01 \\
152.55 \\
152.88\end{array}$ & $\begin{array}{l}73.051 \\
72.974 \\
73.051 \\
73.101 \\
73.000 \\
73.203 \\
73.101\end{array}$ & $\begin{array}{l}79.858 \\
79.731 \\
79.782 \\
79.883 \\
80.010 \\
79.350 \\
79.782\end{array}$ \\
\hline \multicolumn{4}{|c|}{$\begin{array}{l}\text { Mean } \\
\text { Sample standard deviation, } S\end{array}$} & $\begin{array}{r}79.771 \\
0.207\end{array}$ \\
\hline
\end{tabular}

The thickness of the faceplate was measured using a depth micrometer from the front of the faceplate. The bottom positions were established by placing a flat bar across the opening. The results from this measurement are presented in Table 1-5. Table 1-6 presents the raw as-measured data. Table 1-7 presents the channel depth estimates based on the data in Tables 1-5 and 1-6. 


\section{Preliminary Data -- 9 September 1993}

Table 1-4.--Channel width dimensions after installation of roll pins, 24 June 1993, prior to final assembly of construction 4.0

\begin{tabular}{|c|c|c|c|c|c|c|}
\hline \multirow{2}{*}{$\begin{array}{c}\text { Nominal } \\
\text { longitudinal } \\
\text { position } \\
m\end{array}$} & \multirow{2}{*}{$\begin{array}{c}\text { Overall } \\
\text { assembly } \\
\text { width } \\
\mathrm{mm} \\
\end{array}$} & \multicolumn{2}{|c|}{$\begin{array}{l}\text { Heater support } \\
\text { width, mm }\end{array}$} & \multicolumn{3}{|c|}{$a, m m$} \\
\hline & & left & right & measured & calculated & delta \\
\hline $\begin{array}{l}-0.30 \\
-0.11 \\
0.17 \\
0.59 \\
1.01 \\
1.29 \\
1.43\end{array}$ & $\begin{array}{l}152.27 \\
152.40 \\
152.83 \\
152.91 \\
153.11 \\
152.71 \\
152.40\end{array}$ & $\begin{array}{l}36.551 \\
36.474 \\
36.525 \\
36.576 \\
36.449 \\
36.601 \\
36.551\end{array}$ & $\begin{array}{l}36.500 \\
36.500 \\
36.525 \\
36.525 \\
36.551 \\
36.601 \\
36.551\end{array}$ & $\begin{array}{l}79.324 \\
79.578 \\
79.807 \\
79.807 \\
80.010 \\
79.502 \\
79.451\end{array}$ & $\begin{array}{l}79.223 \\
79.426 \\
79.782 \\
79.807 \\
80.112 \\
79.502 \\
79.299\end{array}$ & $\begin{array}{r}0.102 \\
0.152 \\
0.025 \\
0.000 \\
-0.102 \\
0.000 \\
0.152 \\
\end{array}$ \\
\hline $\begin{array}{l}\text { Mean } \\
\mathrm{S}\end{array}$ & & $\begin{array}{r}6.533 \\
0.054 \\
\end{array}$ & $\begin{array}{r}36.536 \\
0.035 \\
\end{array}$ & $\begin{array}{r}79.640 \\
0.242 \\
\end{array}$ & $\begin{array}{r}79.593 \\
0.319 \\
\end{array}$ & $\begin{array}{l}0.047 \\
0.093 \\
\end{array}$ \\
\hline
\end{tabular}

Table 1-5.--Face plate dimensions used for channel depth calculation, measured on 23 June 1993

\begin{tabular}{c|c|c|c}
\hline \multirow{2}{*}{$\begin{array}{c}\text { Longitudinal } \\
\text { position } \\
\mathrm{m}\end{array}$} & Lateral position & \multicolumn{2}{|c}{ Face plate thickness } \\
\cline { 3 - 4 } & $\mathrm{mm}$ & inch & $\mathrm{mm}$ \\
\hline-0.30 & 53.98 & 1.003 & 10.742 \\
-0.30 & 22.23 & 1.002 & 10.731 \\
-0.11 & 53.98 & 1.006 & 10.774 \\
-0.11 & 22.23 & 1.005 & 10.764 \\
0.17 & 53.98 & 1.006 & 10.774 \\
0.17 & 22.23 & 1.004 & 10.753 \\
0.59 & 53.98 & 1.005 & 10.764 \\
0.59 & 22.23 & 1.005 & 10.764 \\
1.01 & 53.98 & 1.007 & 10.785 \\
1.01 & 22.23 & 1.007 & 10.785 \\
1.29 & 53.98 & 1.012 & 10.839 \\
1.29 & 22.23 & 1.009 & 10.806 \\
1.43 & 53.98 & 1.012 & 10.839 \\
1.43 & 22.23 & 1.011 & 10.828 \\
\hline
\end{tabular}




\section{Preliminary Data -- 9 September 1993}

Table 1-6.--Channel depth measurements, distance from front of face plate to front of heater

\begin{tabular}{|c|c|c|c|c|c|}
\hline \multirow{4}{*}{$\begin{array}{c}\text { Longitudinal } \\
\text { position } \\
z \\
m \\
\end{array}$} & \multirow{4}{*}{$\begin{array}{c}\text { Lateral } \\
\text { position } \\
x \\
\mathrm{~mm}\end{array}$} & \multicolumn{4}{|c|}{ Distance from face plate to heater, inch } \\
\hline & & & & & $\therefore$ \\
\hline & & \multicolumn{2}{|c|}{ Pretest } & \multicolumn{2}{|c|}{ Post-test } \\
\hline & & horizontal & vertical & horizontal & vertical \\
\hline \multicolumn{6}{|c|}{ Construction 2.0 , ribbed } \\
\hline & & $\cdots$ & $\cdots$ & 14 June '93 & 14 June '93 \\
\hline $\begin{array}{l}-0.11 \\
-0.11 \\
0.17 \\
0.17 \\
0.59 \\
0.59 \\
1.01 \\
1.01 \\
1.29 \\
1.29 \\
\end{array}$ & $\begin{array}{l}53.98 \\
22.23 \\
53.98 \\
22.23 \\
53.98 \\
22.23 \\
53.98 \\
22.23 \\
53.98 \\
22.23 \\
\end{array}$ & $\begin{array}{l}\ldots \\
\ldots \\
\ldots \\
\ldots \\
\ldots \\
\ldots \\
\ldots \\
\ldots \\
\ldots \\
\ldots\end{array}$ & $\begin{array}{l}\cdots \\
\cdots \\
\cdots \\
\cdots \\
\cdots \\
\cdots \\
\cdots \\
\cdots \\
\cdots \\
\end{array}$ & $\begin{array}{l}1.132 \\
1.127 \\
1.130 \\
1.121 \\
1.129 \\
1.120 \\
1.129 \\
1.123 \\
1.135 \\
1.131 \\
\end{array}$ & $\begin{array}{l}1.134 \\
1.129 \\
1.129 \\
1.122 \\
1.129 \\
1.121 \\
1.128 \\
1.122 \\
1.135 \\
1.132\end{array}$ \\
\hline \multicolumn{6}{|c|}{ Construction 3.0, open } \\
\hline & & 16 June '93 & 17 June '93 & 22 June '93 & $\ldots$ \\
\hline $\begin{array}{l}-0.30 \\
-0.30 \\
-0.11 \\
-0.11 \\
0.17 \\
0.17 \\
0.59 \\
0.59 \\
1.01 \\
1.01 \\
1.29 \\
1.29 \\
1.43 \\
1.43 \\
\end{array}$ & $\begin{array}{l}53.98 \\
22.23 \\
53.98 \\
22.23 \\
53.98 \\
22.23 \\
53.98 \\
22.23 \\
53.98 \\
22.23 \\
53.98 \\
22.23 \\
53.98 \\
22.23 \\
\end{array}$ & $\begin{array}{c}\ldots \\
\ldots \\
1.125 \\
\ldots \\
1.100 \\
1.095 \\
1.101 \\
1.097 \\
1.102 \\
1.099 \\
1.130 \\
1.129 \\
\ldots \\
\ldots\end{array}$ & $\begin{array}{l}1.127 \\
1.123 \\
1.126 \\
1.122 \\
1.100 \\
1.097 \\
1.100 \\
1.096 \\
1.101 \\
1.098 \\
1.118 \\
1.117 \\
1.130 \\
1.128\end{array}$ & $\begin{array}{l}1.129 \\
1.123 \\
1.125 \\
1.119 \\
1.100 \\
1.094 \\
1.099 \\
1.096 \\
1.102 \\
1.098 \\
1.114 \\
1.113 \\
1.131 \\
1.131\end{array}$ & $\begin{array}{l}\ldots \\
\ldots \\
\ldots \\
\ldots \\
\ldots \\
\ldots \\
\ldots \\
\ldots \\
\ldots \\
\ldots \\
\ldots \\
\ldots \\
\ldots\end{array}$ \\
\hline
\end{tabular}




\section{Prelliminary Data _. 9 September 1993}

Table 1-6.--Continued

\begin{tabular}{|c|c|c|c|c|c|}
\hline \multirow{3}{*}{$\begin{array}{c}\text { Longitudinal } \\
\text { position } \\
\mathbf{z} \\
\mathbf{m} \\
\end{array}$} & \multirow{3}{*}{$\begin{array}{c}\text { Lateral } \\
\text { position } \\
\cdot x \\
\mathrm{~mm} \\
\end{array}$} & \multicolumn{4}{|c|}{ Distance from face plate to heater. inch } \\
\hline & & \multicolumn{2}{|c|}{ Pretest } & \multicolumn{2}{|c|}{ - Post-test. . } \\
\hline & & horizontal & vertical & horizontal & vertical \\
\hline \multicolumn{6}{|c|}{ Construction 4.0, open } \\
\hline & & 29 June '93 & 1 July '93 & $\cdots$ & 23 July '93 \\
\hline $\begin{array}{r}-0.30 \\
-0.30 \\
-0.11 \\
-0.11 \\
0.17 \\
0.17 \\
0.59 \\
0.59 \\
1.01 \\
1.01 \\
1.29 \\
1.29 \\
1.43 \\
1.43\end{array}$ & $\begin{array}{l}53.98 \\
22.23 \\
53.98 \\
22.23 \\
53.98 \\
22.23 \\
53.98 \\
22.23 \\
53.98 \\
22.23 \\
53.98 \\
22.23 \\
53.98 \\
22.23\end{array}$ & $\begin{array}{l}1.130 \\
1.132 \\
1.132 \\
1.133 \\
1.131 \\
1.132 \\
1.128 \\
1.128 \\
1.130 \\
1.132 \\
1.134 \\
1.135 \\
1.134 \\
1.134\end{array}$ & $\begin{array}{l}1.130 \\
1.132 \\
1.132 \\
1.133 \\
1.132 \\
1.132 \\
1.129 \\
1.128 \\
1.130 \\
1.132 \\
1.132 \\
1.133 \\
1.130 \\
1.129\end{array}$ & $\begin{array}{l}\ldots \\
\ldots \\
\ldots \\
\ldots \\
\ldots \\
\ldots \\
\ldots \\
\ldots \\
\ldots \\
\ldots \\
\ldots \\
\ldots \\
\ldots\end{array}$ & $\begin{array}{l}1.139 \\
1.138 \\
1.138 \\
1.139 \\
1.136 \\
1.134 \\
1.127 \\
1.125 \\
1.129 \\
1.130 \\
1.129 \\
1.127 \\
1.119 \\
1.117\end{array}$ \\
\hline
\end{tabular}

The height of the rib was measured as $3.25 \mathrm{~mm}$ (0.128 inches) using a micrometer. No variation was observed along the rib's length. Since the channel depth measurement estimate presented in Table 1-7 suggest that the depth of construction 2.0 was $3.08 \mathrm{~mm}$ ( 0.122 inches) it is possible that a bias exists in the depth measurement. While it is possible that a bias exists in the channel depth measurement it is more likely that the two subchannels were not the same depth except at the rib.

Figure 1-2 presents the variation in channel depth in the longitudinal direction. For construction 3.0 the mean of the channel depth a presented in Table 1-7 is much larger than the channel depth over the heated portion of the channel. Table 1-8 presents the channel depth mean for the longitudinal measurements between -0.11 and $1.29 \mathrm{~m}$. 


\section{Preliminary Data _- 9 September 1993}

Table 1-7.--Channel depth measurements

\begin{tabular}{|c|c|c|c|c|c|}
\hline \multirow{3}{*}{$\begin{array}{l}\text { Longitudinal } \\
\text { position } \\
\text { z } \\
\text { m }\end{array}$} & \multirow{3}{*}{$\begin{array}{c}\text { Lateral } \\
\text { position } \\
\mathrm{x} \\
\mathrm{mm}\end{array}$} & \multicolumn{4}{|c|}{$\begin{array}{l}\text { Channel depth, } \mathrm{mm} \text { (Arithmetic difference of } \\
\text { tabulated data in Table 1-6 and face plate thickness } \\
\text { as presented in Table } 1-5 \text {.) }\end{array}$} \\
\hline & & \multicolumn{2}{|c|}{ Pretest } & \multicolumn{2}{|c|}{ Post-test } \\
\hline & & horizontal & vertical & horizontal & vertical \\
\hline \multicolumn{6}{|c|}{ Construction 2.0, ribbed } \\
\hline & & $\cdots$ & $\cdots$ & 14 June '93 & 14 June '93 \\
\hline $\begin{array}{l}-0.11 \\
-0.11 \\
0.17 \\
0.17 \\
0.59 \\
0.59 \\
1.01 \\
1.01 \\
1.29 \\
1.29 \\
\end{array}$ & $\begin{array}{l}53.98 \\
22.23 \\
53.98 \\
22.23 \\
53.98 \\
22.23 \\
53.98 \\
22.23 \\
53.98 \\
22.23 \\
\end{array}$ & $\begin{array}{l}\cdots \\
\ldots \\
\ldots \\
\ldots \\
\ldots \\
\ldots \\
\ldots \\
\ldots \\
\ldots \\
\end{array}$ & $\begin{array}{l}\ldots \\
\ldots \\
\ldots \\
\ldots \\
\ldots \\
\ldots \\
\ldots \\
\ldots \\
\ldots \\
\end{array}$ & $\begin{array}{l}3.200 \\
3.099 \\
3.150 \\
2.972 \\
3.150 \\
2.921 \\
3.099 \\
2.946 \\
3.124 \\
3.099 \\
\end{array}$ & $\begin{array}{l}3.251 \\
3.150 \\
3.124 \\
2.997 \\
3.150 \\
2.946 \\
3.073 \\
2.921 \\
3.124 \\
3.124 \\
\end{array}$ \\
\hline $\begin{array}{l}\text { Mean } \\
\text { Standard d }\end{array}$ & viation, $\sigma$ & $\cdots$ & $\begin{array}{l}\cdots \\
\cdots\end{array}$ & $\begin{array}{l}3.076 \\
0.095 \\
\end{array}$ & $\begin{array}{l}3.086 \\
0.102 \\
\end{array}$ \\
\hline \multicolumn{6}{|c|}{ Construction 3.0, open } \\
\hline & & 16 June '93 & 17 June '93 & 22 June '93 & $\ldots$ \\
\hline $\begin{array}{r}-0.30 \\
-0.30 \\
-0.11 \\
-0.11 \\
0.17 \\
0.17 \\
0.59 \\
0.59 \\
1.01 \\
1.01 \\
1.29 \\
1.29 \\
1.43 \\
1.43 \\
\end{array}$ & $\begin{array}{l}53.98 \\
22.23 \\
53.98 \\
22.23 \\
53.98 \\
22.23 \\
53.98 \\
22.23 \\
53.98 \\
22.23 \\
53.98 \\
22.23 \\
53.98 \\
22.23\end{array}$ & $\begin{array}{c}\ldots \\
\ldots .023 \\
\ldots \\
2.388 \\
2.311 \\
2.438 \\
2.337 \\
2.413 \\
2.337 \\
2.997 \\
3.048 \\
\ldots \\
\ldots \\
\end{array}$ & $\begin{array}{l}3.150 \\
3.073 \\
3.048 \\
2.972 \\
2.388 \\
2.362 \\
2.413 \\
2.311 \\
2.388 \\
2.311 \\
2.692 \\
2.743 \\
2.997 \\
2.972\end{array}$ & $\begin{array}{l}3.200 \\
3.073 \\
3.023 \\
2.896 \\
2.388 \\
2.286 \\
2.388 \\
2.311 \\
2.413 \\
2.311 \\
2.591 \\
2.642 \\
3.023 \\
3.048\end{array}$ & $\begin{array}{l}\ldots \\
\ldots \\
\ldots \\
\ldots \\
\ldots \\
\ldots \\
\ldots \\
\ldots \\
\ldots \\
\ldots \\
\ldots \\
\ldots \\
\ldots \\
\ldots\end{array}$ \\
\hline \multicolumn{2}{|c|}{$\begin{array}{l}\text { Mean } \\
\text { Standard deviation, } \sigma\end{array}$} & $\begin{array}{l}2.588 \\
0.329\end{array}$ & $\begin{array}{l}2.701 \\
0.328\end{array}$ & $\begin{array}{l}2.685 \\
0.342 \\
\end{array}$ & $\begin{array}{l}\cdots \\
\cdots\end{array}$ \\
\hline
\end{tabular}




\section{Preliminary Data -- 9 September 1993}

Table 1-7.--Centinued

\begin{tabular}{|c|c|c|c|c|c|}
\hline \multirow{3}{*}{$\begin{array}{l}\text { Longitudinal } \\
\text { position } \\
\mathbf{z} \\
\mathrm{m}\end{array}$} & \multirow{3}{*}{$\begin{array}{c}\text { Lateral } \\
\text { position } \\
\mathrm{x} \\
\mathrm{mm}\end{array}$} & \multicolumn{4}{|c|}{$\begin{array}{c}\text { Channel depth, mm (Arithmetic difference of } \\
\text { tabulated data in Table 1-6 and face plate thickness } \\
\text { as presented in Table 1-5.) }\end{array}$} \\
\hline & & \multicolumn{2}{|c|}{ Pretest } & \multicolumn{2}{|c|}{ Post-test } \\
\hline & & horizontal & vertical & horizontal & vertical \\
\hline \multicolumn{6}{|c|}{ Construction 4.0 , open } \\
\hline & & 29 June '93 & 1 July '93 & $\cdots$ & 23 July '93 \\
\hline $\begin{array}{l}-0.30 \\
-0.30 \\
-0.11 \\
-0.11 \\
0.17 \\
0.17 \\
0.59 \\
0.59 \\
1.01 \\
1.01 \\
1.29 \\
1.29 \\
1.43 \\
1.43\end{array}$ & $\begin{array}{l}53.98 \\
22.23 \\
53.98 \\
22.23 \\
53.98 \\
22.23 \\
53.98 \\
22.23 \\
53.98 \\
22.23 \\
53.98 \\
22.23 \\
53.98 \\
22.23\end{array}$ & $\begin{array}{l}3.226 \\
3.302 \\
3.200 \\
3.251 \\
3.175 \\
3.251 \\
3.124 \\
3.124 \\
3.124 \\
3.175 \\
3.099 \\
3.200 \\
3.099 \\
3.124\end{array}$ & $\begin{array}{l}3.226 \\
3.302 \\
3.200 \\
3.251 \\
3.200 \\
3.251 \\
3.150 \\
3.124 \\
3.124 \\
3.175 \\
3.048 \\
3.150 \\
2.997 \\
2.997\end{array}$ & $\begin{array}{l}\ldots \\
\ldots \\
\ldots \\
\ldots \\
\ldots \\
\ldots \\
\ldots \\
\ldots \\
\ldots \\
\ldots \\
\ldots \\
\ldots \\
\ldots\end{array}$ & $\begin{array}{l}3.457 \\
3.454 \\
3.353 \\
3.404 \\
3.302 \\
3.302 \\
3.099 \\
3.048 \\
3.099 \\
3.124 \\
2.972 \\
2.997 \\
2.718 \\
2.692\end{array}$ \\
\hline \multicolumn{2}{|c|}{$\begin{array}{l}\text { Mean } \\
\text { Standard deviation, } \sigma\end{array}$} & $\begin{array}{l}3.177 \\
0.064\end{array}$ & $\begin{array}{l}3.157 \\
0.093\end{array}$ & $\cdots$ & $\begin{array}{l}3.144 \\
0.249\end{array}$ \\
\hline
\end{tabular}

Table 1-8.--Channel depth measurements based on data presented in

Figure 1-2

\begin{tabular}{c|c|c|c}
\hline Construction & $\mathrm{N}^{*}$ & $\begin{array}{c}\text { Mean } \\
\mathrm{mm}\end{array}$ & $\begin{array}{c}\text { Sample standard } \\
\text { deviation, } \mathrm{mm}\end{array}$ \\
\hline 2 & 10 & 3.09 & 0.10 \\
$3 t$ & 10 & 2.45 & 0.16 \\
4 & 10 & 3.16 & 0.09 \\
\hline
\end{tabular}

"Only longitudinal measurements between -0.11 and $1.29 \mathrm{~m}$ were used in the calculation of the mean.

tThe values at -0.11 and $1.29 \mathrm{~m}$ were weighted at 0.333 while the remainder were weighted at 1.000 . 


\section{Preliminary Data .- 9 September 1993}

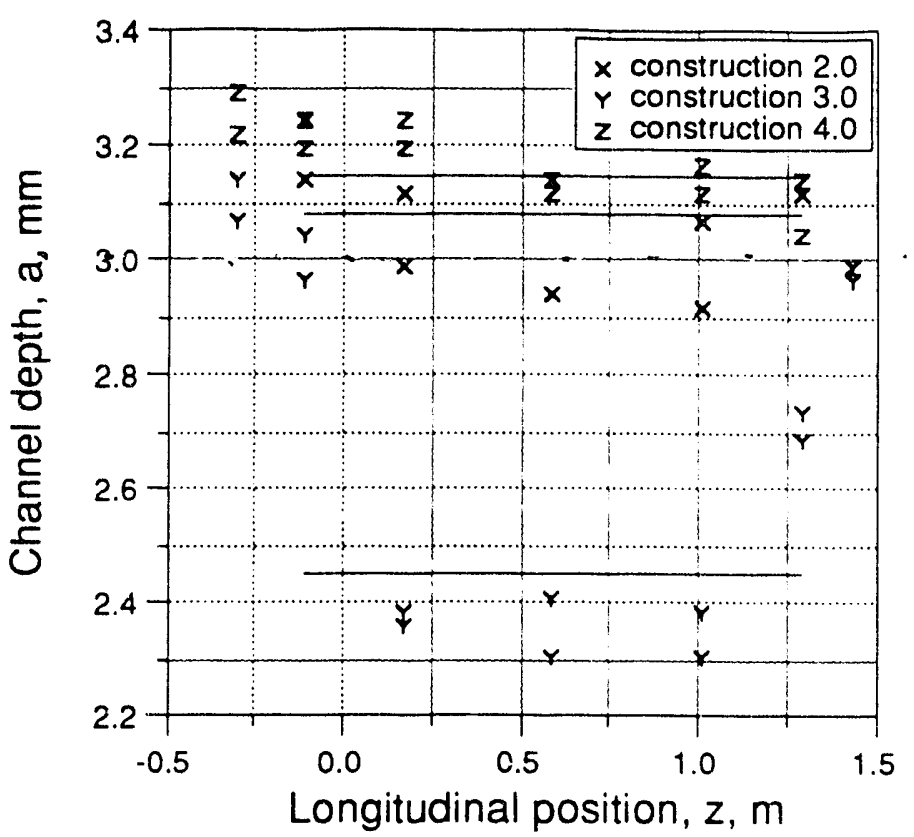

Figure 1-2, Channel depth, b, for construction 2.0 (14 June 1993), 3.0 (17 June 1993), and 4.0 (1 July 1993)

\section{Hydraulic Length, L}

The hydraulic length is the distance between the instrument ports which were connected to instruments PD02472, and PD22472. This distance was directly measured using a tape measure. The distance was $1.3970 \pm 0.0008 \mathrm{~m}$ (55.00 \pm 0.03 inches).

\section{Rib Thickness}

The rib thickness was directly measured using a micrometer. The rib thickness was $3.25 \mathrm{~mm}$ ( 0.128 inches). Additional information is presented in Table 1-2. 


\section{Preliminary Data - 9 September 1993}

\section{Channel Heated Width, $a_{h}$}

The width of the heated area was estimated as the width of the wetted aluminum surface. This width is $76.2 \mathrm{~mm}$ ( 3 inches). This is $3.4 \mathrm{~mm}$ (0.01 inch) smaller than the overall channel width for construction $\dot{4}$.

\section{Channel Heated Length, $L_{h}$}

The channel heated length was estimated from the heater inspection results described in Chapter 4. The nominal heater length was $1.219 \mathrm{~m}$ (48 inches). The effective heater length as estimated by the distance between the start and end of the most significant discoloration described in Chapter 3 was $1.156 \mathrm{~m}$ ( 45.51 inches). The effective start of the heated length is $48 \pm 2 \mathrm{~mm}$ (1.88 inches) below the nominal start of the heated length. 
Preliminary Data _- 9 September 1993

$$
\text { APPENDIX } 2
$$

INSTRUMENT CALIBRATIONS 


\section{Preliminary Data - 9 September 1993}

Measurements used during this test program included volumetric flow, local pressure, differential pressure, absolute pressure, heater voltage, heater current, heater temperature, and fluid temperature. This appendix presents the methods used to develop the engineëring unit transformation equations. The final equations are summarized in Appendix 7, Table 7-2. Table 2-1 provides a coss-index between the instrument loop numbers used during the test program and the Measurement and Teste Equipment (M\&TE) numbers used in tracking instrument histories in the HTL.

\section{Flow Calibrations}

Flow Calibration Uncertainty

The turbine flow meter (instrument FT01001) and the orifice flow meter (instrument FT01002) were loop calibration checked using a weigh tank method. Water was flowed through the meters for approximately three minutes. During this period all of the flow was caught in a weigh tank. The mass of this water could then be used to estimate the standard flow using Equation 2-1

$$
Q=\frac{W}{t \rho}
$$

The instruments used in this effort are listed in Table 2-1. The elemental uncertainties for the measurements are listed in Table 2-2. The systematic uncertainties for the temperature and time measurements are based on the HTL tolerances. The systematic error for the displacement was assumed based on twice the maximum error observed during the previous calibration for the scale. The density curve fit bias is established by DPSTM-140. The random uncertainties for the displacement and temperature measurements are 
Table 2-0.--Measurement and test equipment (M\&TE) summary.

\begin{tabular}{|c|c|c|c|}
\hline $\begin{array}{l}\text { Instrument } \\
\text { loop } \\
\text { number. }\end{array}$ & $\begin{array}{l}\text { Channel } \\
\text { number }\end{array}$ & $\begin{array}{c}\text { M\&TE } \\
\text { number }\end{array}$ & Description \\
\hline $\begin{array}{l}\text { PL111000 } \\
\text { PL12000 } \\
\text { PL13000 } \\
\text { PL33000 } \\
\text { TT00001 } \\
\text { TP01317 } \\
\text { TP01308 } \\
\text { TP01413 } \\
\text { TP01702 } \\
\text { TP01505 } \\
\text { TP11917 } \\
\text { TP12008 } \\
\text { TP12113 } \\
\text { TP12105 } \\
\text { TP12302 } \\
\text { TP22917 } \\
\text { TP23008 } \\
\text { TP23013 } \\
\text { TP23105 } \\
\text { TP23302 } \\
\text { TP33917 } \\
\text { TP34013 } \\
\text { TP33908 } \\
\text { TP34105 } \\
\text { TP34302 } \\
\text { TP45008 } \\
\text { TP45105 } \\
\text { TP45302 } \\
\text { TP45613 } \\
\text { TP45717 } \\
\text { TP45808 } \\
\text { TP45905 } \\
\text { TP46102 } \\
\text { TP46308 } \\
\text { TP46217 } \\
\text { TP46413 } \\
\text { TP46505 } \\
\text { TP46602 } \\
\text { TP46808 } \\
\text { TP47005 } \\
\text { TP47202 }\end{array}$ & $\begin{array}{r}\ldots \\
\ldots \\
\ldots \\
\ldots \\
\ldots \\
1 \\
2 \\
3 \\
4 \\
5 \\
6 \\
7 \\
8 \\
9 \\
10 \\
11 \\
12 \\
13 \\
14 \\
15 \\
16 \\
17 \\
18 \\
19 \\
20 \\
21 \\
22 \\
23 \\
24 \\
25 \\
26 \\
27 \\
28 \\
29 \\
30 \\
31 \\
32 \\
33 \\
34 \\
35 \\
36\end{array}$ & \begin{tabular}{|c} 
TR-419 \\
TR-418 \\
$\ldots .$. \\
TR-2256 \\
TR-2833 \\
TR-2831 \\
TR-2832 \\
TR-2829 \\
TR-2830 \\
TR-2838 \\
TR-2836 \\
TR-2837 \\
TR-2835 \\
TR-2834 \\
TR-2843 \\
TR-2841 \\
TR-2842 \\
TR-2840 \\
TR-2839 \\
TR-2848 \\
TR-2847 \\
TR-2846 \\
TR-2845 \\
TR-2844 \\
TR-2853 \\
TR-2852 \\
TR-2851 \\
TR-2849 \\
TR-2850 \\
TR-2856 \\
TR-2855 \\
TR-2854 \\
TR-2861 \\
TR-2858 \\
TR-2857 \\
TR-2860 \\
TR-2859 \\
TR-2864 \\
TR-2863 \\
TR-2862
\end{tabular} & $\begin{array}{l}\text { Pressure gauge } \\
\text { Pressure gauge } \\
\text { Pressure gauge } \\
\text { Pressure gauge } \\
\text { Thermometer } \\
\text { Thermocouple, EMQSS-020G-12 } \\
\text { Thermocouple, EMQSS-020G-12 } \\
\text { Thermocouple, EMQSS-020G-12 } \\
\text { Thermocouple, EMQSS-020G-12 } \\
\text { Thermocouple, EMQSS-020G-12 } \\
\text { Thermocouple, EMQSS-020G-12 } \\
\text { Thermocouple, EMQSS-020G-12 } \\
\text { Thermocouple, EMQSS-020G-12 } \\
\text { Thermocouple, EMQSS-020G-12 } \\
\text { Thermocouple, EMQSS-020G-12 } \\
\text { Thermocouple, EMQSS-020G-12 } \\
\text { Thermocouple, EMQSS-020G-12 } \\
\text { Thermocouple, EMQSS-020G-12 } \\
\text { Thermocouple, EMQSS-020G-12 } \\
\text { Thermocouple, EMQSS-020G-12 } \\
\text { Thermocouple, EMQSS-020G-12 } \\
\text { Thermocouple, EMQSS-020G-12 } \\
\text { Thermocouple, EMQSS-020G-12 } \\
\text { Thermocouple, EMQSS-020G-12 } \\
\text { Thermocouple, EMQSS-020G-12 } \\
\text { Thermocouple, EMQSS-020G-12 } \\
\text { Thermocouple, EMQSS-020G-12 } \\
\text { Thermocouple, EMQSS-020G-12 } \\
\text { Thermocouple, EMQSS-020G-12 } \\
\text { Thermocouple, EMQSS-020G-12 } \\
\text { Thermocouple, EMQSS-020G-12 } \\
\text { Thermocouple, EMQSS-020G-12 } \\
\text { Thermocouple, EMQSS-020G-12 } \\
\text { Thermocouple, EMQSS-020G-12 } \\
\text { Thermocouple, EMQSS-020G-12 } \\
\text { Thermocouple, EMQSS-020G-12 } \\
\text { Thermocouple, EMQSS-020G-12 } \\
\text { Thermocouple, EMQSS-020G-12 } \\
\text { Thermocouple, EMQSS-020G-12 } \\
\text { Thermocouple, EMQSS-020G-12 } \\
\text { Thermocouple, EMQSS-020G-12 }\end{array}$ \\
\hline
\end{tabular}


Preliminary Data -- 9 September 1993

Table 2-0.--Centinued

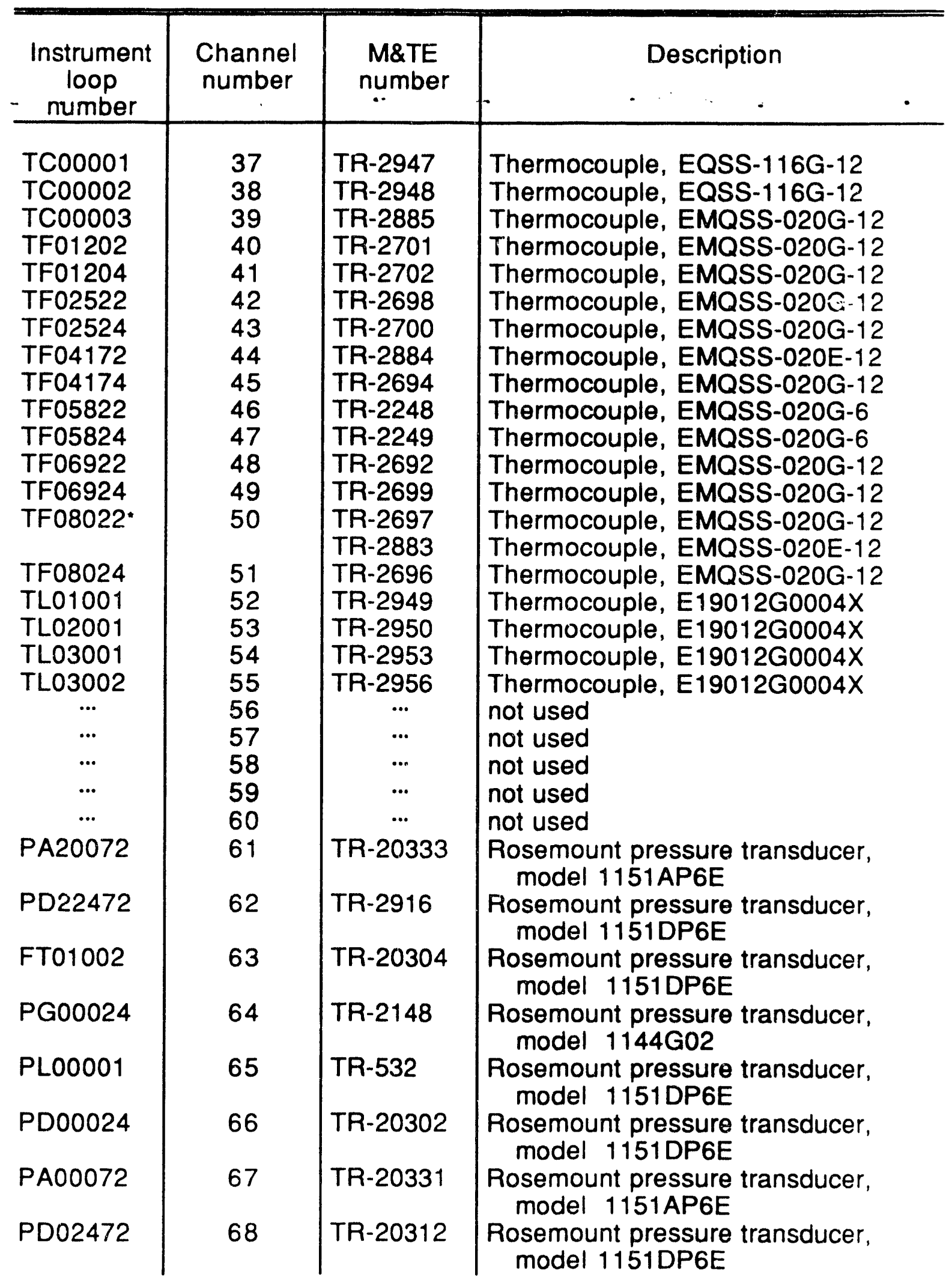




\section{Preliminary Data .. 9 September 1993}

Table 2-0.--Continued

\begin{tabular}{|c|c|c|c|}
\hline $\begin{array}{c}\text { Instrument } \\
\text { loop } \\
\text { number }\end{array}$ & $\begin{array}{l}\text { Channel } \\
\text { number }\end{array}$ & $\begin{array}{l}\text { M\&TE } \\
\text { number } \\
\end{array}$ & $\begin{array}{c}\text { Description } \\
\end{array}$ \\
\hline PD00072 & 69 & TR-20305 & $\begin{array}{l}\text { Rosemount pressure transducer, } \\
\text { model 1151DP6E }\end{array}$ \\
\hline PL00002 & 70 & TR-2146 & $\begin{array}{l}\text { Rosemount pressure transducer, } \\
\text { model } 1144 \mathrm{G} 02\end{array}$ \\
\hline PD07284 & 71 & TR-20303 & $\begin{array}{l}\text { Rosemount pressure transducer, } \\
\text { model 1151DP6E }\end{array}$ \\
\hline PD00084 & 72 & TR-20313 & $\begin{array}{l}\text { Rosemount pressure transducer, } \\
\text { model 1151DP6E }\end{array}$ \\
\hline FT01001 & 73 & TR-076 & $\begin{array}{l}\text { Flow Technology turbine flow meter, } \\
\text { model FT-12NEXW-LAD-1 }\end{array}$ \\
\hline WV00001 & $\begin{array}{l}74 \\
74\end{array}$ & $\begin{array}{l}\text { TR-30013 } \\
\text { TR-30032 }\end{array}$ & Voltage transducer \\
\hline WC00001 & 75 & TR-295 & Shunt \\
\hline
\end{tabular}

"After Constuction 2.0 this thermocouple was switched from M\&TE number TR2697 to TR-2883.

estimated as half the minimum discernible increment. The random component for time is based on the recommendation in ASME 19.12.

The partial differentials for Equation 2-1 are:

$$
\begin{gathered}
\frac{\partial Q}{\partial W}=\frac{Q}{W} \quad \frac{\partial Q}{\partial t}=\frac{-Q}{t} \quad \frac{\partial Q}{\partial \rho}=\frac{-Q}{\rho} \\
\frac{\partial \rho}{\partial T}=-0.2685-0.003627 T-\frac{0.51123 T^{2}}{10^{5}}
\end{gathered}
$$




\section{Preliminary Data -- 9 September 1993}

Table 2-1.--Instruments used in the loop calibration check of FT01001 and FT01002

\begin{tabular}{|c|c|c|c|}
\hline Element & Description & $\begin{array}{c}\text { M\&TE } \\
\text { Number }\end{array}$ & HTL Tolerance \\
\hline \multicolumn{4}{|c|}{ Pretest calibration, 15 and 16 April 1993} \\
\hline $\begin{array}{l}\text { Displacement } \\
\text { Temperature } \\
\text { Time } \\
\end{array}$ & $\begin{array}{l}0 \text { to } 1000 \# \text { scale } \\
-1 \text { to } 101^{\circ} \mathrm{C} \text { thermometer } \\
\text { stopwatch }\end{array}$ & \begin{tabular}{|l|} 
TR-30076 \\
TR-2897 \\
TR-2235 \\
\end{tabular} & $\begin{array}{l} \pm 1 \text { pound" } \\
\pm 0.2^{\circ} \mathrm{C} \\
\pm 500 \mu \mathrm{sec} / \text { second }\end{array}$ \\
\hline \multicolumn{4}{|c|}{ Mid-test calibration, 10 June 1993} \\
\hline $\begin{array}{l}\text { Displacement } \\
\text { Temperature } \\
\text { Time } \\
\end{array}$ & $\begin{array}{l}0 \text { to } 1000 \# \text { scale } \\
0 \text { to } 50^{\circ} \mathrm{C} \text { thermometer } \\
\text { stopwatch }\end{array}$ & \begin{tabular}{|l|} 
TR-30076 \\
TR-320 \\
TR-2269 \\
\end{tabular} & $\begin{array}{l} \pm 1 \text { pound } \\
\pm 1^{\circ} \mathrm{C} \\
\pm 500 \mu \mathrm{sec} / \text { second }\end{array}$ \\
\hline \multicolumn{4}{|c|}{ Post-test calibration, 27 July 1993} \\
\hline $\begin{array}{l}\text { Displacement } \\
\text { Temperature } \\
\text { Time }\end{array}$ & $\begin{array}{l}0 \text { to } 1000 \# \text { scale } \\
0 \text { to } 50^{\circ} \mathrm{C} \text { thermometer } \\
\text { stopwatch }\end{array}$ & \begin{tabular}{|l|} 
TR-30076 \\
TR-320 \\
TR-2269 \\
\end{tabular} & $\begin{array}{l} \pm 1 \text { pound } \\
\pm 1^{\circ} \mathrm{C} \\
\pm 500 \mu \mathrm{sec} / \text { second }\end{array}$ \\
\hline
\end{tabular}

"The maximum error during the pre-test calibration for this scale was $0.1 \#$

Table 2-2.--Operating parameters and elemental uncertainties for the loop calibration check of FT01001 and FT01002

\begin{tabular}{c|c|c|c|c|c}
\hline \hline Element & Median & Minimum & Maximum & B & P \\
\hline Displacement $(\#)$ & 208.05 & 54.1 & 495.50 & 0.2 & 0.05 \\
Temperature $\left({ }^{\circ} \mathrm{C}\right)$ & 24.3 & 20.5 & 28.1 & 0.2 & 0.05 \\
Time $($ seconds) & 180.31 & 179.72 & 180.70 & 0.09 & 0.2 \\
Density $(\mathrm{kg} / \mathrm{m} 3)$ & 997.27 & 995.88 & 998.61 & 0.50 & $\ldots$ \\
\hline
\end{tabular}

The total uncertainty for the applied flow can be estimated using the Equation 2-2. Calculated values are presented in Table 2-3.

$$
\omega_{Q}=\sqrt{\left(\frac{\partial Q}{\partial W} \omega_{W}\right)^{2}+\left(\frac{\partial Q}{\partial t} \omega_{t}\right)^{2}+\left(\frac{\partial Q}{\partial \rho} \omega_{\rho}\right)^{2}+\left(\frac{\partial Q}{\partial \rho} \frac{\partial \rho}{\partial T} \omega_{T}\right)^{2}}
$$




\section{Preliminary Data .. 9 September 1993}

Table 2-3.--Calibration standard uncertainties estimated from information presented in Table 2-2.

\begin{tabular}{l|c|c|c|c}
\hline \hline & $\begin{array}{c}\text { Flow } \\
\mathrm{cm}^{3} / \mathrm{s}\end{array}$ & $\begin{array}{c}\text { Displacement } \\
\#\end{array}$ & $\begin{array}{c}\mathrm{B} \\
\mathrm{cm}^{3 / 5}\end{array}$ & $\begin{array}{c}\mathrm{P} \\
\mathrm{cm}^{3 / \mathrm{s}}\end{array}$ \\
\hline Minimum & 136 & 54.1 & 0.5 & 0.2 \\
Median & 525 & 208.1 & 0.6 & 0.6 \\
Maximum & 1250 & 495.5 & 1.1 & 1.4 \\
\hline
\end{tabular}

Instrument FT01001

The turbine meter, FT01001 is a linear device that can be evaluated using the method presented in WSRC-TR-91-106. A least-square-mean fit of the three calibration data sets was made after pooling the data as suggested by WSRC-TR-91-435. The uncertainty estimates of these fits were made using the methodology presented in Appendix C of WSRC-TR-91-106. The confidence interval to contain the mean was used to evaluate the random curve fit uncertainty and has been treated as a systematic error. This is presented in Figure 2-1. The fixed curve uncertainty is presented in Figure 2-2. The system noise (See Figure 2-3.) was evaluated as a random uncertainty. Figure 2-4 presents the conversion equation. The combined uncertainty estimaie is presented in Table 2-4. 


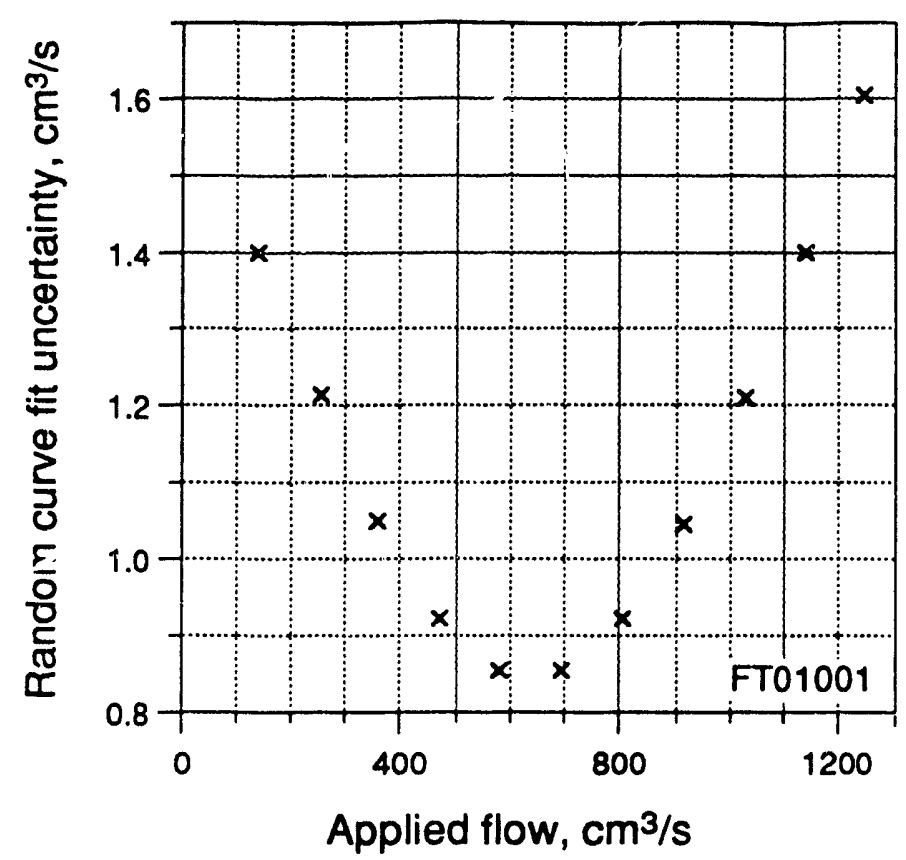

Figure 2-1. Random curve fit uncertainty for FT01001

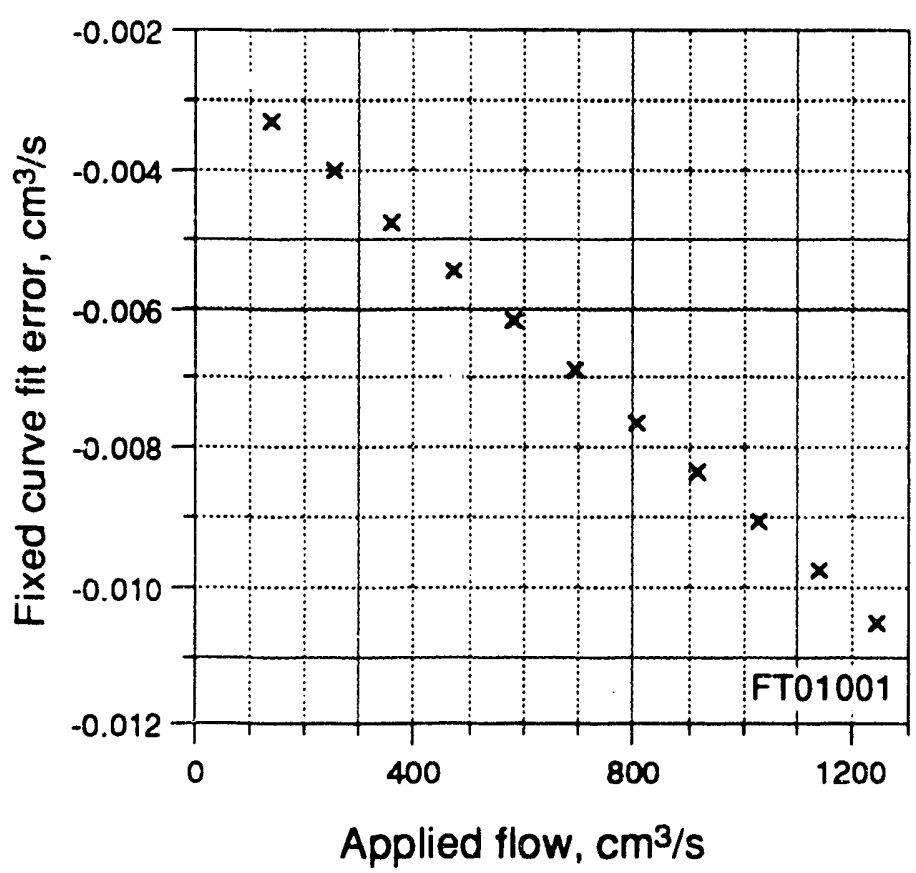

Figure 2-2. Fixed curve fit error for FT01001. 


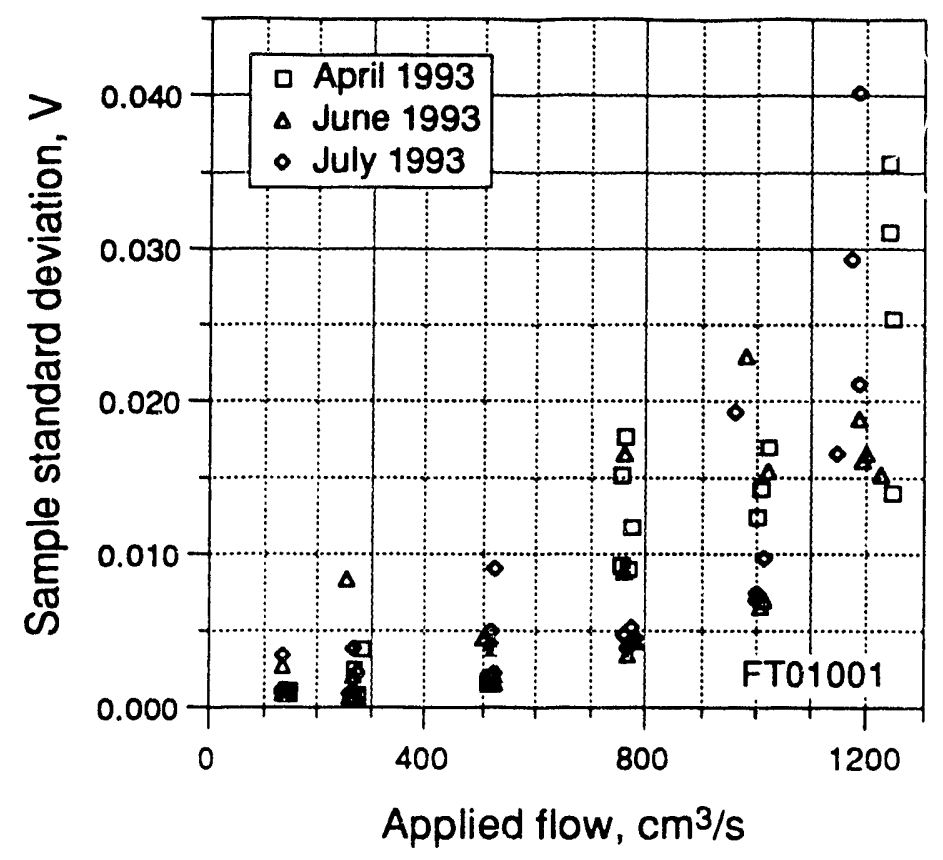

Figure 2-3, FT01001 sample standard deviation during flow calibrations

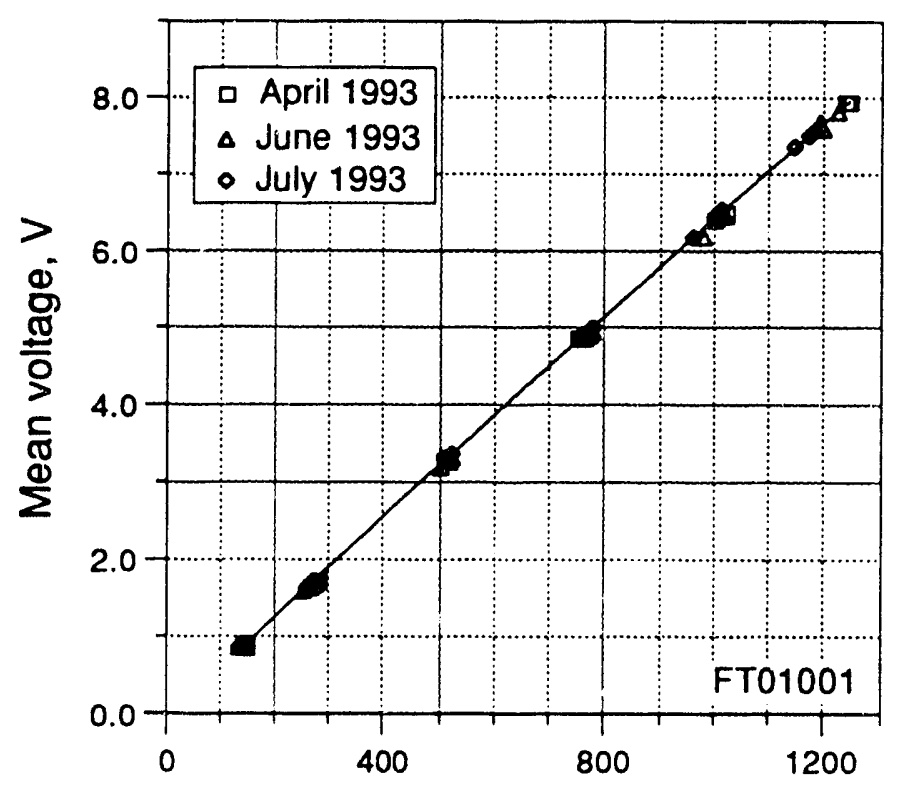

Applied flow, $\mathrm{cm}^{3} / \mathrm{s}$

Figure 2-4, FT01001 output during flow calibrations. 


\section{Preliminary Data -- 9 September 1993}

Table 2-4.--Uncertainty estimate for FT01001

\begin{tabular}{|c|c|c|c|}
\hline $\begin{array}{l}\text { Flow, } \mathrm{cm}^{3} / \mathrm{s} \\
\text { Flow, gpm }\end{array}$ & $\begin{array}{c}126 \\
2 \\
\end{array}$ & $\begin{array}{c}631 \\
10 \\
\end{array}$ & $\begin{array}{c}1262 \\
20 \\
\end{array}$ \\
\hline \multirow{2}{*}{$\begin{array}{l}\text { Systematic Uncertainty } \\
\text { Calibration Standard Uncertainty, } \\
\mathrm{cm}^{3} / \mathrm{s} \text { (Table 2-3) } \\
\text { Random curve fit uncertainty, } \mathrm{cm}^{3} / \mathrm{s} \\
\text { (Figure } 2-1 \text { ) } \\
\text { Fixed curve uncertainty, } \mathrm{cm}^{3} / \mathrm{s} \\
\text { (Figure 2-2) } \\
\text { Combined Systematic } \\
\text { Uncertainty, } \mathrm{cm}^{3} / \mathrm{s}\end{array}$} & $\begin{array}{l}0.5 \\
1.43 \\
0.0\end{array}$ & $\begin{array}{l}0.6 \\
0.85 \\
0.01\end{array}$ & $\begin{array}{l}1.1 \\
1.63 \\
0.01\end{array}$ \\
\hline & 1.5 & 1.0 & 2.0 \\
\hline \multirow{2}{*}{$\begin{array}{l}\text { Random Uncertainty } \\
\text { System noise, volts (Figure 2-3) } \\
\text { Combined Random Uncertainty, } \\
\mathrm{cm}^{3} / \mathrm{s}\end{array}$} & 0.003 & 0.007 & 0.030 \\
\hline & 0.3 & 1.1 & 4.7 \\
\hline
\end{tabular}

Instrument FT02002

The orifice meter, FT01002 is an intrinsically linear device that can be evaluated using the method presented in TR-91-iú where the confidence interval to contain the mean is used to evaluate the random curve fit uncertainty. The system noise is evaluated as a random component. The non-linear form of the calibration equation is:

$$
V=a+b U^{m}
$$

linearized form of the calibration equation is:

$$
\begin{aligned}
\log (V-a) & =\log (b)+m \cdot \log (Q) \\
Y & =B+m X
\end{aligned}
$$

The value $a$ is taken as the mean of the outputs at zero flow, 0.7580 volts. The values of $B$ and $m$ are then 6.7449 and 2.00828. The random curve fit 


\section{Preliminary Data _- 9 September 1993}

uncertainty term must be converted from an uncertainty of the value $X$ to an uncertainty in terms of $Q$.

$$
\begin{gathered}
Q=10^{X} \\
\frac{\partial Q}{\partial X}=2.30310^{X}
\end{gathered}
$$

$$
\frac{\partial Q}{\partial X}=2.303 Q
$$

The uncertainty of $Q$ is then:

$$
\omega_{Q}=\frac{\partial Q}{\partial X} \omega_{X}
$$

The fixed curve uncertainty is computed using:

$$
\begin{aligned}
Q & =10^{x} \\
\omega_{F} & =\left|Q-Q_{F}\right|=\left|\left(\frac{b_{F}}{b} Q_{F}^{2}\right)^{y / m}-Q_{F}\right|
\end{aligned}
$$

The systematic uncertainties are combined using:

$$
\omega_{Q}=\sqrt{\omega_{C}^{2}+\left(\frac{\partial Q}{\partial X} \omega_{X}\right)^{2}+\omega_{F}^{2}}
$$

The random error is computed from the standard deviation of the system noise using Equation 2-9.

$$
\omega_{P}=\frac{\partial Q}{\partial V} \omega_{V}=\frac{1}{b m Q} \omega_{V}=\frac{t_{\alpha / 2} \sigma_{V}}{b m Q}
$$

the confidence interval to contain the mean was used to evaluate the random curve fit uncertainty and has been treated as systematic error it is 
presented in Figure 2-5. The fixed curve uncertainty is presented in Figure 2-6. The system noise (See Figure 2-7.) was evaluated as a random uncertainty. Figure 2-8 presents the conversion equation. The combined uncertainty estimate is presented in Table 2-5.

Table 2-5.--Uncertainty estimate for FT01002

\begin{tabular}{|c|c|c|c|}
\hline $\begin{array}{r}\text { Flow, } \mathrm{cm}^{3} / \mathrm{s} \\
\text { Flow, gpm } \\
\log (Q)\end{array}$ & $\begin{array}{c}126 \\
2 \\
-3.900 \\
\end{array}$ & $\begin{array}{r}631 \\
10 \\
-3.200 \\
\end{array}$ & $\begin{array}{c}1262 \\
20 \\
-2.899 \\
\end{array}$ \\
\hline \multirow{2}{*}{$\begin{array}{l}\text { Systematic Uncertainty } \\
\text { Calibration Standard Uncertainty, } \\
\mathrm{cm}^{3} / \mathrm{s} \text { (Table 2-3) } \\
\text { Random curve fit uncertainty, } \mathrm{cm}^{3 / \mathrm{s}} \\
\text { (Figure } 2-5 \text { ) } \\
\text { Fixed curve uncertainty, } \mathrm{cm}^{3} / \mathrm{s} \\
\text { (Figure } 2-6 \text { ) } \\
\text { Combined Systematic } \\
\text { Uncertainty, } \mathrm{cm}^{3} / \mathrm{s}\end{array}$} & $\begin{array}{c}0.5 \\
0.0176 \\
4.7\end{array}$ & $\begin{array}{c}0.6 \\
0.0086 \\
19.5\end{array}$ & $\begin{array}{c}1.1 \\
0.0128 \\
35.2\end{array}$ \\
\hline & 7.0 & 23.2 & 51.2 \\
\hline \multirow{2}{*}{$\begin{array}{l}\text { Random Uncertainty } \\
\text { System noise, volts (Figure } 2-7 \text { ) } \\
\text { Combined Random Uncertainty, } \\
\mathrm{cm}^{3} / \mathrm{s}\end{array}$} & .005 & .028 & 0.07 \\
\hline & 7.1 & 8.0 & 10.0 \\
\hline
\end{tabular}




\section{Preliminary Data -. 9 September 1993}

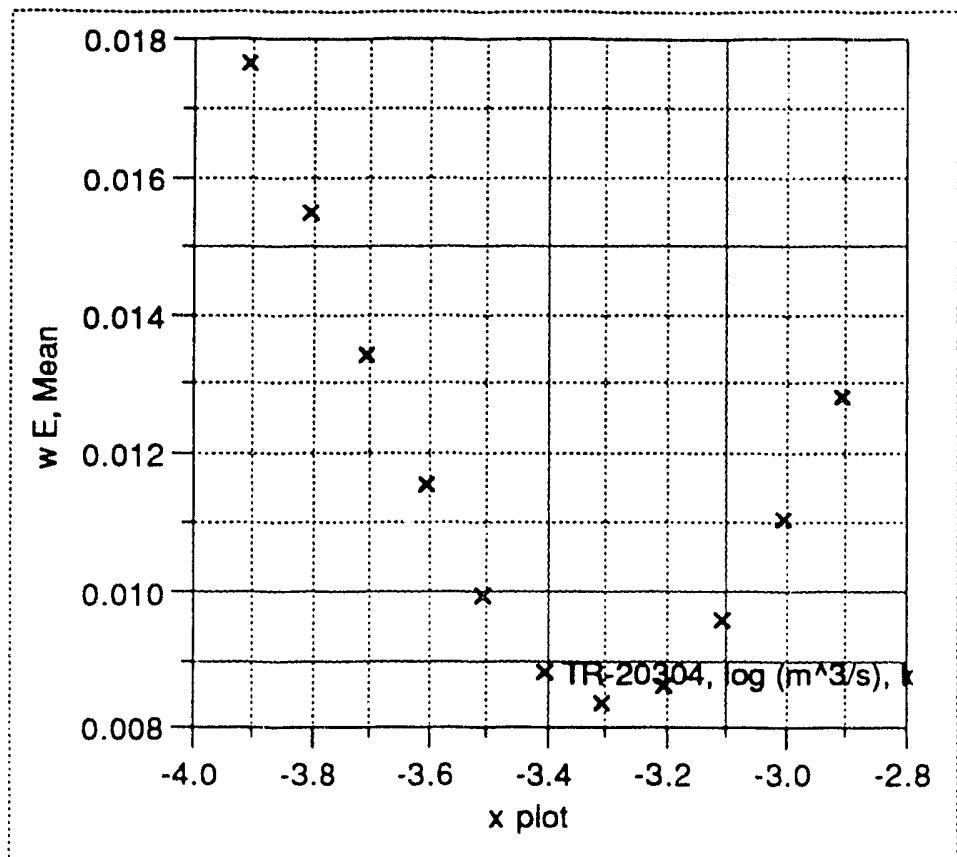

Figure 2-5. Random uncertainty component of curve fit for FT01002 in terms of $\mathrm{X}$

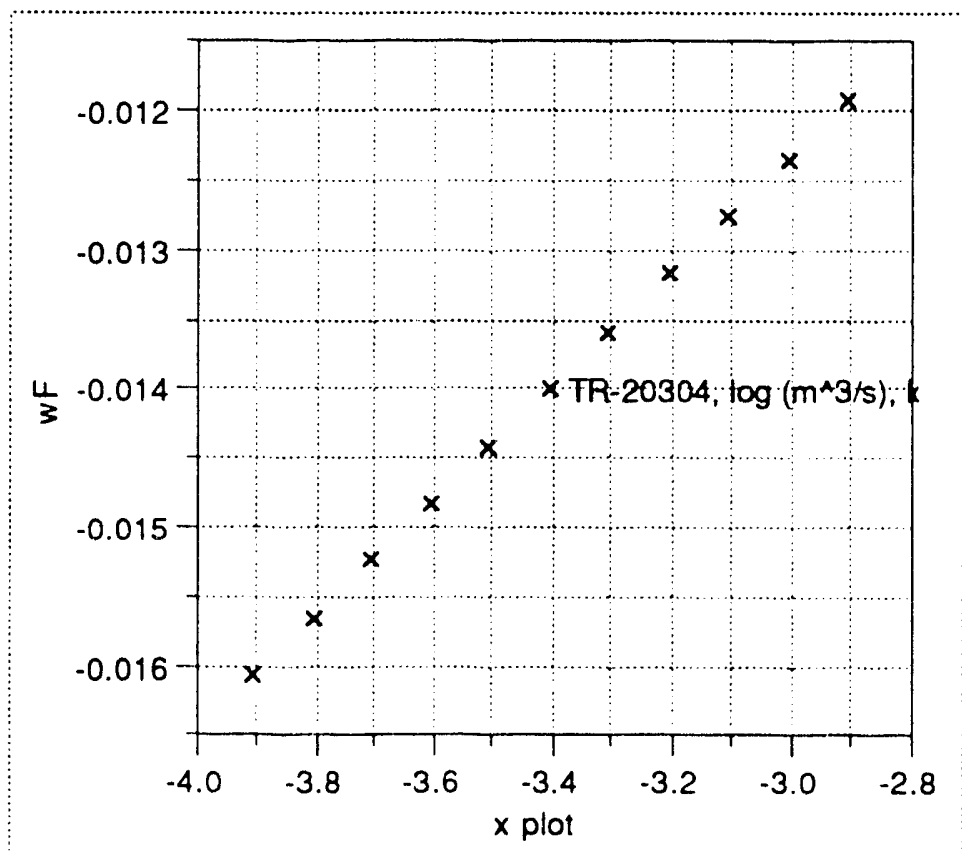

Figure 2-6. Systematic curve fit uncertainty 
Preliminary Data -- 9 September 1993

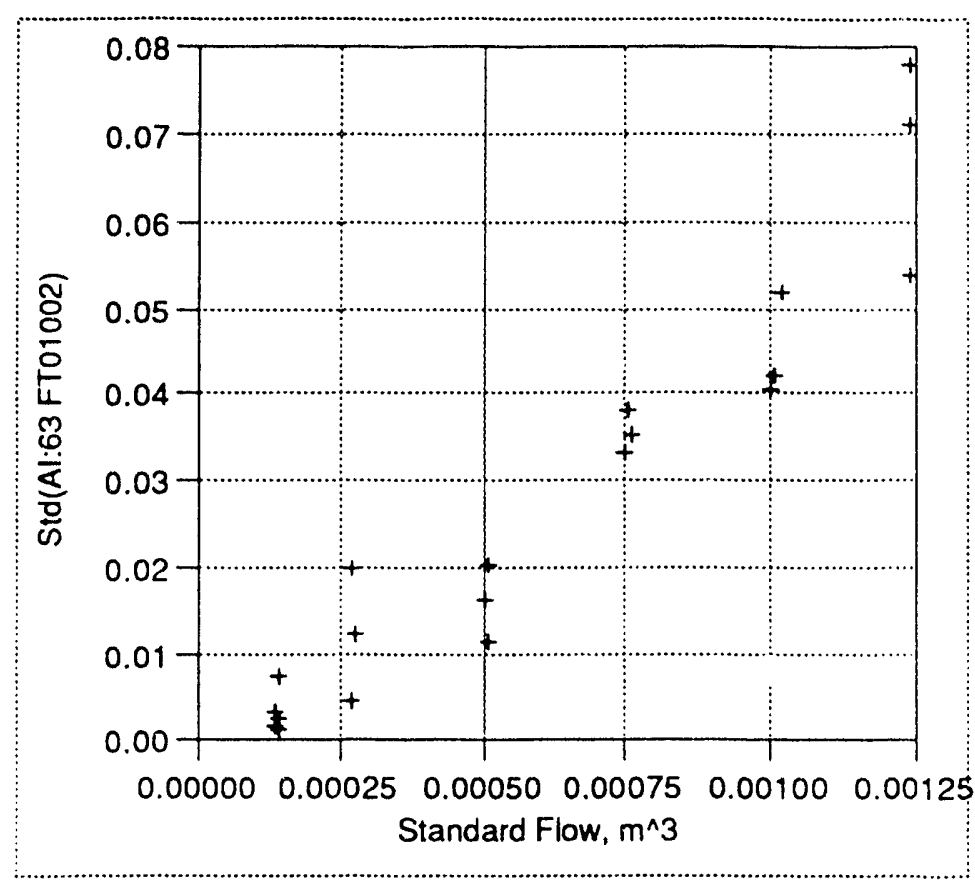

Figure 2-7. Sample standard deviation of output for FT01002 during pretest calibration

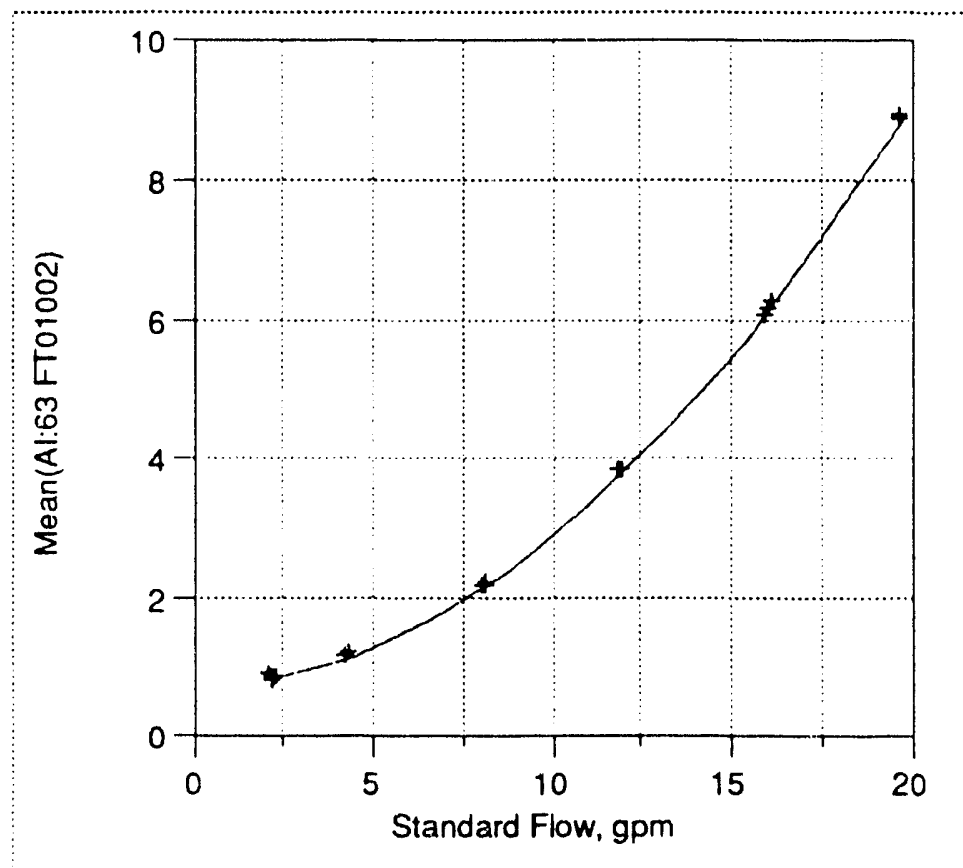

Figure 2.8 Output of FT01002 during pretest flow calibration 


\section{Preliminary Data -. 9 September 1993}

\section{Pressure Transducer Calibrations}

Pressure Transducer Calibration Uncertainty

Zero and span checks were completed for each pressure transducer at the start and end of each day's testing. This resulted in an extensive set of data for each transducer at two different operating conditions: open to atmosphere and under a static head tank pressure. In addition each pressure transducer was calibrated using a pneumatic dead-weight tester. The slope of the data reduction curve specified in Tables 2-6 and 7-2 were established by the calibration curves as specified in Table 2-6. The zero specified in Table 7-2 was taken from Table 2-8 for the daily zero check data. Since the calculated quantities in Table 2-8 were based on the data reduction curve in Table 7-2, the errors for the zero checks will identically go to zero. The span checks will then exhibit a small systematic error. This systematic error was then assumed constant over the entire range of the transducer.

Table 2-6.--Pressure transducer slope estimates based on calibration data

\begin{tabular}{|c|c|c|c|c|c|}
\hline \multirow[t]{2}{*}{$\begin{array}{l}\text { Instrument } \\
\text { loop } \\
\text { number }\end{array}$} & \multicolumn{2}{|c|}{$\begin{array}{l}\text { Slope from calibration } \\
\text { data, } \mathrm{mA} / \mathrm{psi}\end{array}$} & \multirow{2}{*}{$\begin{array}{c}\text { Pressure, } \\
\text { Pa } \\
\mathrm{b}, \mu \mathrm{V} / \mathrm{Pa} \\
\end{array}$} & \multicolumn{2}{|c|}{$\begin{array}{l}\text { Elevations from SHL for } \\
\text { pressure transducer } \\
\text { analysis, inches }\end{array}$} \\
\hline & Pretest & Post-test & & gauge & channel tap \\
\hline $\begin{array}{l}\text { PA20072 } \\
\text { PD22472 } \\
\text { PG00024 } \\
\text { PL00001 } \\
\text { PD00024 } \\
\text { PAO0072 } \\
\text { PD02472 } \\
\text { PD00072 } \\
\text { PL00002 } \\
\text { PD07284 } \\
\text { PD00084 }\end{array}$ & $\begin{array}{l}0.2909 \\
0.2908 \\
0.3182 \\
0.0800 \\
1.9991 \\
0.2910 \\
0.2910 \\
0.1601 \\
0.3190 \\
0.9411 \\
0.2910\end{array}$ & $\begin{array}{c}0.2908 \\
0.2908 \\
\ldots \\
\ldots \\
\ldots \\
0.2910 \\
0.2910 \\
\ldots \\
\ldots \\
\ldots \\
\ldots\end{array}$ & $\begin{array}{r}26.37 \\
26.36 \\
28.84 \\
7.25 \\
181.22 \\
26.38 \\
26.38 \\
14.51 \\
28.92 \\
85.31 \\
26.38\end{array}$ & $\begin{array}{l}-17.25 \\
-17.25 \\
-32.50 \\
-30.88 \\
-30.88 \\
-44.25 \\
-44.25 \\
-44.25 \\
-57.88 \\
-57.88 \\
-59.5\end{array}$ & $\begin{array}{c}-50.75 \\
4.25 \\
4.25 \\
34.5 \\
21.6 \\
-50.75 \\
4.25 \\
-50.75 \\
-60.00 \\
-50.75 \\
21.6\end{array}$ \\
\hline
\end{tabular}




\section{Preliminary Data .- 9 September 1993}

Table 2-7.--Daily check files excluded from pressure transducer analysis

\begin{tabular}{c|l|l}
\hline \hline File name & Instrument loop number & \multicolumn{1}{c}{ Comment } \\
\hline SN_930.430_1350 & PD02472 & \\
SN_930430_1605 & PD02472 & \\
SN_930505_1610 & PD00024 & \\
SN_930528_1333 & PD00072 & \\
SN_930712_1911 & PD22472, PD00024, & Pata is not constant with \\
& PD02472, PD00072, & $\begin{array}{l}\text { expected results. This } \\
\text { PDpears to be the result of a } \\
\text { valving error. }\end{array}$ \\
ZO_930430_1328 & PD02472 & \\
ZO_930430_1610 & PD02472 & Excluded by information on \\
ZO_930506_1613 & PL00001 & data sheet \\
\hline
\end{tabular}

The zero voltages for the absolute pressure transducers (PA00072, and PA20072) must be converted based on the barometric pressure. The mean barometric pressure during the zero checks was $29.691 \mathrm{~m} H \mathrm{Hg}$. The zero voltages would then be calculated using Equation 2-10.

$$
V_{0}=a+b\left(29.69 " H g \cdot 3.3864 \frac{k P a}{" H g}\right)
$$

The zero adjustments for PA00072 and PA20072 are listed below:

\begin{tabular}{c|c|c|c|c|c}
\hline \hline & $\mathrm{N}$ & $\mathrm{b}, \mu \mathrm{V} / \mathrm{Pa}$ & $\mathrm{V}_{0}, \mathrm{~V}$ & $\mathrm{~S}, \mathrm{~V}$ & $\mathrm{a}, \mathrm{V}$ \\
\hline PA00072 & 55 & 26.38 & 0.8305 & 0.0118 & -1.8218 \\
PA20072 & 55 & 26.37 & 0.8161 & 0.0126 & -1.8352 \\
\hline
\end{tabular}

The sample standard deviation for the barometric pressure was $0.126 " \mathrm{Hg}$. The HTL tolerance for the barometric standard is $0.072 \mathrm{Hg}$. The uncertainty of this measurement is calculated in Equation 2-11. 


\section{Preliminary Data _- 9 September 1993}

Table 2-8.--Pressure transducer behavior during daily zero and span checks

\begin{tabular}{l|c|c|r|r|r|r}
\hline \multirow{2}{*}{$\begin{array}{c}\text { Instrument } \\
\text { loop } \\
\text { number }\end{array}$} & $\mathrm{N}$ & \multicolumn{2}{|c|}{ Voltage, $\mathrm{V}$} & \multicolumn{3}{|c|}{ Pressure*, kPa } \\
\cline { 3 - 7 } & & $\overline{\mathrm{X}}$ & $\mathrm{S}$ & $\overline{\mathrm{X}}$ & \multicolumn{1}{c}{ calc. } & $\mathrm{S}$ \\
\hline & & & & & & \\
PA20072 & 55 & 1.3884 & 0.0299 & 122.43 & 122.25 & 0.18 \\
& 55 & 0.8161 & 0.0120 & 100.55 & 100.54 & 0.00 \\
PD22472 & 54 & 1.4683 & 0.0318 & 21.92 & 21.70 & 0.22 \\
& 55 & 0.8963 & 0.0020 & 0.00 & -0.00 & 0.00 \\
PG00024 & 55 & 0.6426 & 0.0382 & 25.73 & 25.48 & 0.25 \\
& 55 & -0.0922 & 0.0330 & 0.00 & 0.00 & -0.00 \\
PL00001 & 55 & 0.1833 & 0.0088 & 25.35 & 25.06 & 0.29 \\
& 54 & 0.0016 & 0.0010 & 0.00 & -0.01 & 0.01 \\
PD00024 & 53 & 5.7294 & 0.2221 & 25.33 & 25.09 & 0.24 \\
& 55 & 1.1821 & 0.0060 & 0.00 & 0.00 & -0.00 \\
PA00072 & 55 & 1.5849 & 0.0298 & 129.13 & 129.14 & -0.00 \\
& 55 & 0.8305 & 0.0118 & 100.55 & 100.54 & 0.00 \\
PD02472 & 52 & 1.6637 & 0.0319 & 28.70 & 28.54 & 0.15 \\
& 53 & 0.9108 & 0.0010 & 0.00 & 0.00 & -0.00 \\
PD00072 & 53 & 0.4004 & 0.0178 & 28.60 & 28.59 & 0.01 \\
& 55 & -0.0145 & 0.0009 & 0.00 & -0.00 & 0.00 \\
PL00002 & 55 & 0.7645 & 0.0347 & 31.98 & 32.03 & -0.05 \\
& 55 & -0.1618 & 0.0267 & 0.00 & 0.00 & -0.00 \\
PD07284 & 54 & 2.7765 & 0.0976 & 31.97 & 31.76 & 0.21 \\
& 55 & 0.0671 & 0.0065 & 0.00 & 0.00 & -0.00 \\
PD00084 & 54 & 1.7559 & 0.0319 & 32.43 & 31.87 & 0.56 \\
& 55 & 0.9152 & 0.0015 & 0.00 & -0.00 & 0.00 \\
\hline
\end{tabular}

- The pressure measured by PL12002 was found to read low by $1.25 \mathrm{kPa}$. This is documented by tests conducted on 28 May, and 1 June 1993.

$$
\begin{aligned}
U_{\text {bar }} & =\sqrt{(0.072 " \mathrm{Hg})^{2}+\left(\frac{2 \cdot 0.126 " \mathrm{Hg}}{\sqrt{55}}\right)^{2}} \\
& =0.08 \mathrm{Hg} \\
& =0.27 \mathrm{kPa}
\end{aligned}
$$

The total systematic pressure measurement uncertainties are estimated in Table 2-8a. The systematic uncertainty for the calibration standard is estimated as $0.34 \mathrm{kPa}(0.05 \mathrm{psi})$ which is based on the uncertainty of PL12002. 
Preliminary Data -- 9 September 1993

Table 2-8a.--Pressure transducer systematic uncertainties

\begin{tabular}{c|c|c|c|c}
\hline $\begin{array}{c}\text { Instrument } \\
\text { loop } \\
\text { number }\end{array}$ & $\begin{array}{c}\text { Calibration standard } \\
\text { uncertainties } \\
\mathrm{kPa}\end{array}$ & $\begin{array}{c}\text { Error from } \\
\text { Table 2-8 } \\
\mathrm{kPa}\end{array}$ & $\begin{array}{c}\mathrm{B} \\
\mathrm{kPa}\end{array}$ \\
\cline { 2 - 3 } & Gauge & Barometric & & \\
\hline PA20072 & 0.34 & 0.27 & 0.00 & 0.43 \\
PD22472 & 0.34 & 0.00 & 0.18 & 0.38 \\
PG00024 & 0.34 & 0.00 & 0.24 & 0.42 \\
PL00001 & 0.34 & 0.00 & 0.01 & 0.34 \\
PD00024 & 0.34 & 0.00 & 0.56 & 0.66 \\
PA00072 & 0.34 & 0.27 & 0.15 & 0.46 \\
PD02472 & 0.34 & 0.00 & 0.21 & 0.40 \\
PD00072 & 0.34 & 0.00 & 0.22 & 0.40 \\
PL00002 & 0.34 & 0.00 & 0.25 & 0.42 \\
PD07284 & 0.34 & 0.00 & 0.29 & 0.44 \\
PD00084 & 0.34 & 0.00 & 0.05 & 0.34 \\
\hline
\end{tabular}




\section{Preliminary Data -. 9 September 1993}

\section{Voltage Transducer Calibration}

The rig voltage was measured using a voltage transducer that was connected to the DAS through an amplifier. Two different transducers were used during the test program. On 3 June 1993 the transducer, M\&TE number TR-30013 was replaced with the transducer TR-30032. This increased the range of WV00001 from 50 to 150 volts. To reduce the uncertainty of the voltage measurements the instrument loop was calibration checked by applying a signal across the connections at the DAS-amplifier panel and recording the DAS response in a standard 1 minute log ( 120 samples).

Linear least-square-mean fits of the pooled calibration data sets for each transducer were completed as suggested by WSRC-TR-91-435. The uncertainty estimates of these fits were made using the methodology presented in Appendix C of WSRC-TR-91-106. Equation 2-12 should be used to transform the raw data collected prior to 3 June 1993. Equation 2-13 should be used to reduce raw data collected on or after this date.

$$
\begin{aligned}
& V_{\text {DAS }}=-0.0001+0.20075 V_{\text {applied }} \\
& V_{D A S}=0.0003+0.06668 V_{\text {applied }}
\end{aligned}
$$

TR-30013

TR-30032

Tables 2-9 and 2-10 provide an estimate of the elemental and combined uncertainty estimates for the voltage measurements. The uncertainty of the meter used to measure the applied voltage was $9 \mathrm{ppm}+100 \mu \mathrm{V}$. This estimate is based on the HTL theoretical tolerance. The random component of the curve fit has also been treated as a bias and was estimated based on the confidence interval of the mean. (See Figure 2-9.) The fixed curve error was computed as described in Appendix C of WSRC-TR-106. (See Figure 2-10). 


\section{Preliminary Data -. 9 September 1993}

The random error was estimated from Figure 2-11. Figure 2-12 presents the conversion equations.

The heater voltage measurements were accomplished by terminals connected to the buss connector blocks. The measured voltage therefore includes the voltage drop between the buss blocks and the heater plate. The buss-to-buss resistance was measured as $36.99 \pm 0.09 \mathrm{~m} \Omega$, the heater resistance was measured as $36.7 \pm 0.1 \mathrm{~m} \Omega$. The buss losses can therefore be estimated from Equation 2-14.

$$
\frac{36.99-36.7}{36.99} \cdot 100 \%=0.8 \%
$$

The buss loss will be handled separately from the voltage uncertainty estimate as discussed in Appendix 3.

Table 2-9.--Uncertainty estimate for applied voltage, WV00001, prior to 3 July 1993

\begin{tabular}{l|c|c|c}
\hline \hline Applied voltage, V & $40 \mathrm{~V}$ & $45 \mathrm{~V}$ & $50 \mathrm{~V}$ \\
DAS voltage, V & 8.0299 & 9.0336 & 10.0374 \\
\hline $\begin{array}{l}\text { Systematic uncertainty } \\
\text { Calibration standard uncertainty, V }\end{array}$ & 0.0005 & 0.0005 & 0.0006 \\
$\begin{array}{l}\text { Random curve fit uncertainty, V (Figure } \\
\text { 2-9) }\end{array}$ & 0.0083 & 0.0091 & 0.0104 \\
$\begin{array}{l}\text { Fixed curve uncertainty, V (Figure } \\
\text { 2-10) }\end{array}$ & 0.0000 & 0.0000 & 0.0000 \\
\begin{tabular}{c} 
Combined systematic uncertainty, V \\
\cline { 2 - 4 }
\end{tabular} & 0.0083 & 0.0091 & 0.0104 \\
\cline { 2 - 4 } $\begin{array}{c}\text { Random Uncertainty } \\
\text { System noise, V (Figure 2-11) } \\
\text { Combined random uncertainty, V }\end{array}$ & 0.0012 & 0.0013 & 0.0014 \\
\hline
\end{tabular}




\section{Preliminary Data -. 9 September 1993}

Table 2-10.--Uncertainty estimate for applied voltage, WV00001, on and after 3 July 1993

\begin{tabular}{l|c|c|c}
\hline \hline Applied voltage, V & $40 \mathrm{~V}$ & $45 \mathrm{~V}$ & $60 \mathrm{~V}$ \\
DAS voltage, V & 8.0317 & 9.0357 & 10.0397 \\
\hline $\begin{array}{l}\text { Systematic uncertainty } \\
\text { Calibration standard uncertainty, V }\end{array}$ & 0.0005 & 0.0005 & 0.0006 \\
$\begin{array}{l}\text { Random curve fit uncertainty, V (Figure } \\
2-9)\end{array}$ & 0.0074 & 0.0077 & 0.0101 \\
$\begin{array}{l}\text { Fixed curve uncertainty, V (Figure } \\
2-10)\end{array}$ & -0.0007 & -0.0008 & -0.0011 \\
$\quad$\begin{tabular}{l} 
Combined systematic uncertainty, V \\
\cline { 2 - 4 }
\end{tabular} & 0.0074 & 0.0078 & 0.0102 \\
\cline { 2 - 4 } $\begin{array}{l}\text { Random Uncertainty } \\
\text { System noise, V (Figure 2-11) } \\
\text { Combined random uncertainty, V }\end{array}$ & 0.0006 & 0.0008 & 0.0008 \\
\cline { 2 - 4 } & 0.0006 & 0.0008 & 0.0008 \\
\hline
\end{tabular}

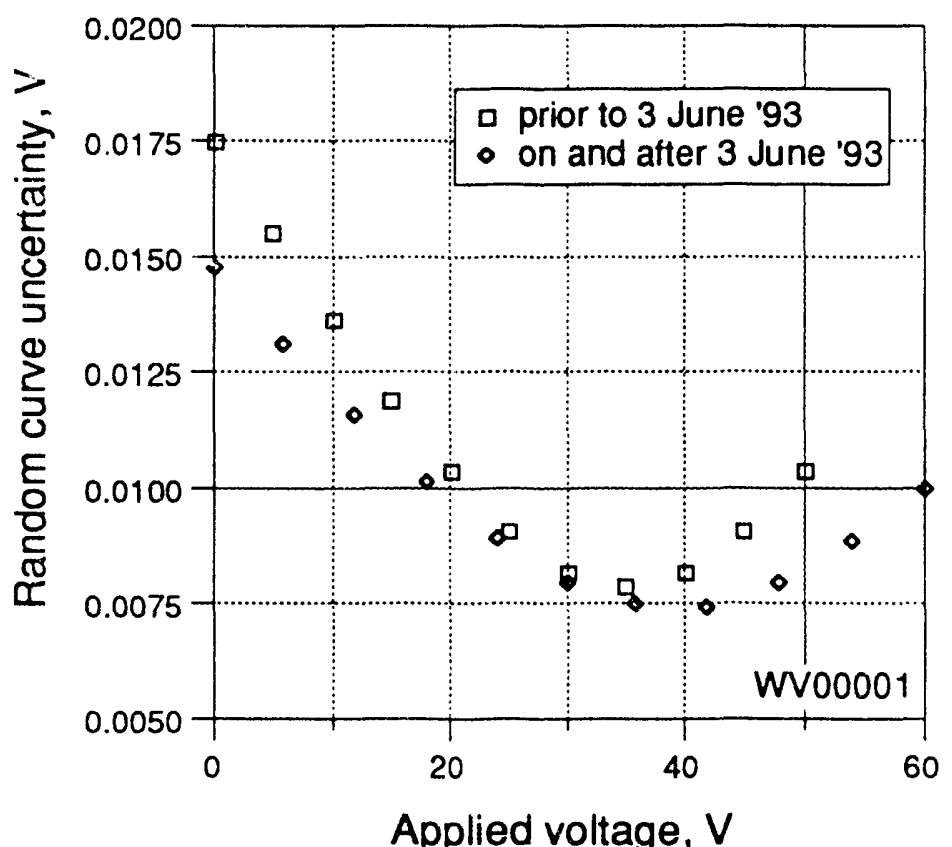

Figure 2-9. Confidence intervals for the mean response for WV00001 
Preliminary Data -. 9 September 1993

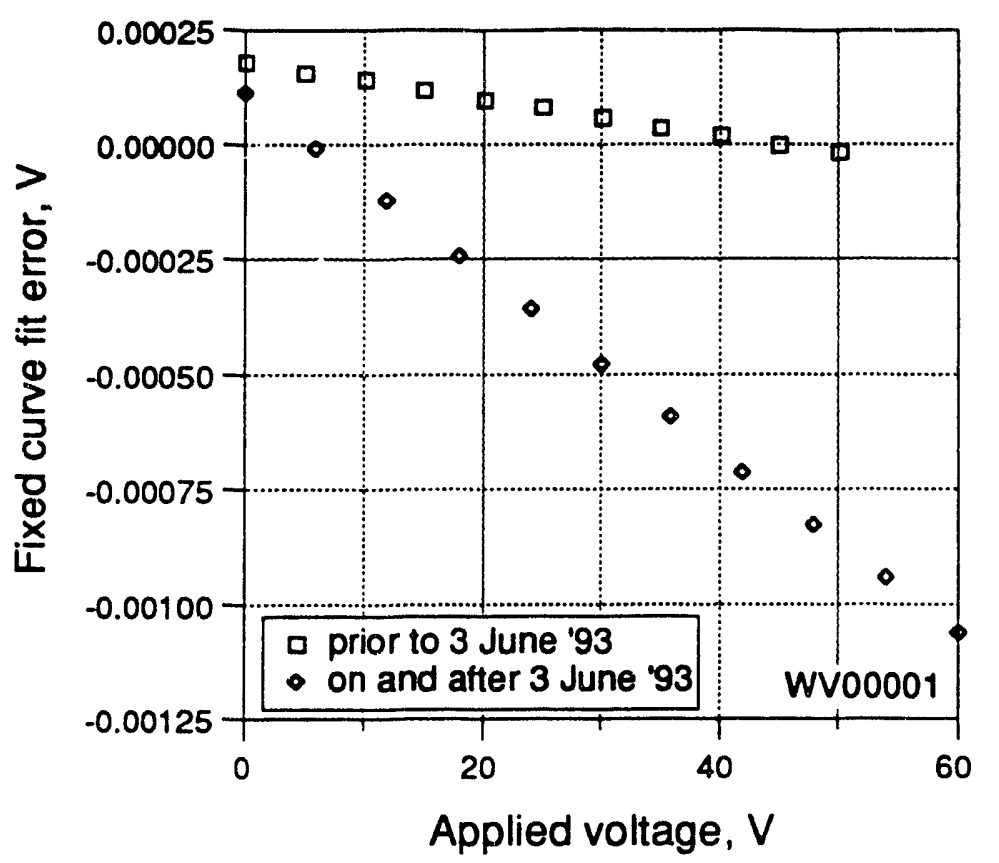

Figure 2-10. Vixed curve fit errors for WV00001

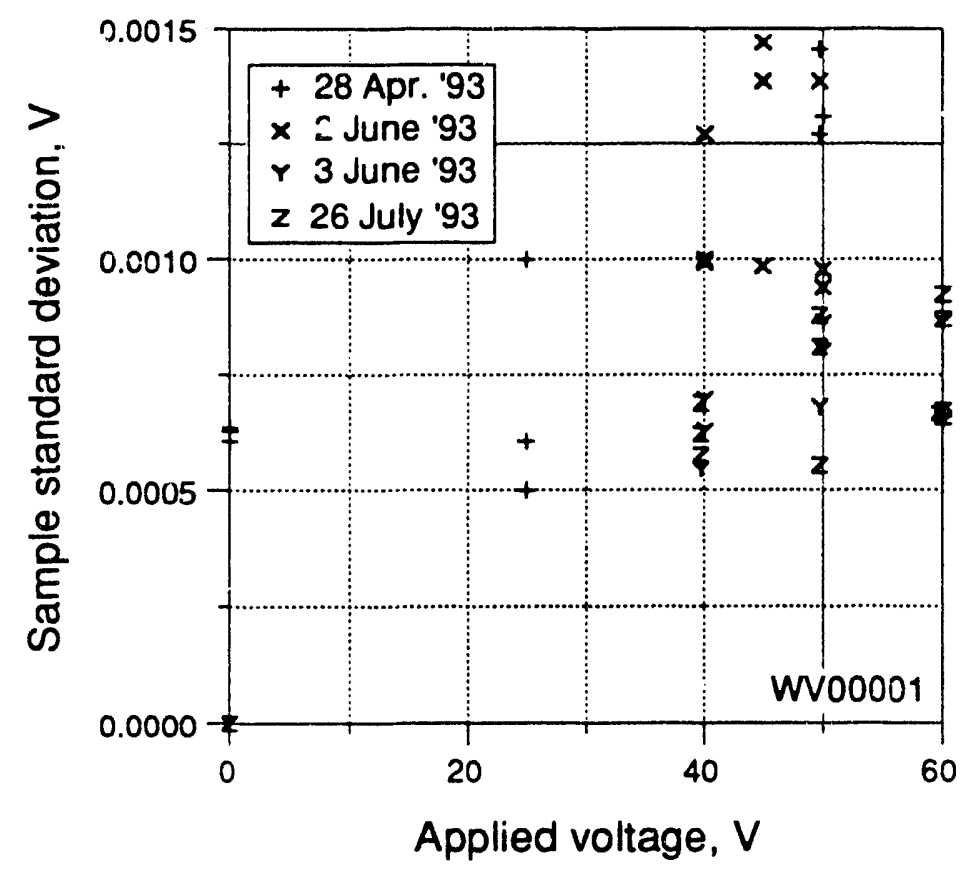

Figure 2-11 WV00001 smple standard deviation of output during calibrations 


\section{Preliminary Data $=9$ September 1993}

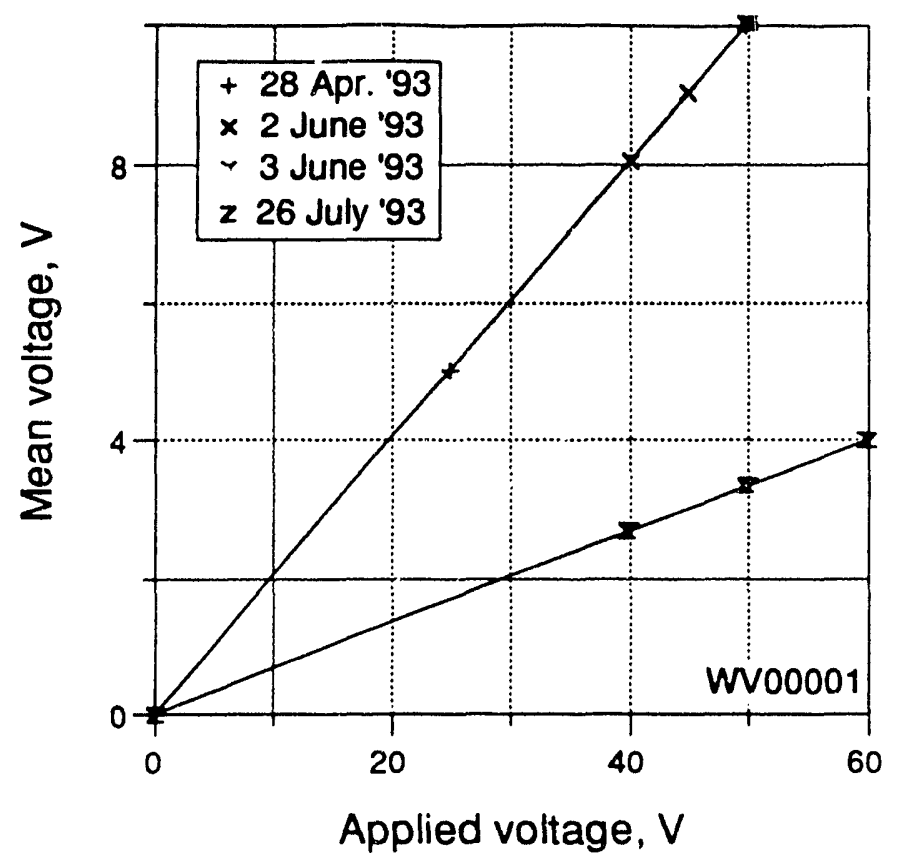

Figure 2-12. WV00001 output during calibrations. 


\section{Preliminary Data -- 9 September 1993}

\section{Current Measurement Calibration}

The current is measured using a voltmeter ( 0 to $50 \mathrm{mV}$ range) and a shunt with a resistance of $10.21 \pm 0.04 \mu \Omega$. The voltmeter is connected to the DAS through the rectifier controllers and an amplifier. To reduce the uncertainty of the current measurement the voltage loop was calibration checked by applying a millivolt signal across the shunt leads and the data displayed at the DAS. The uncertainty of the meter used to complete this calibration check was $9 \mathrm{ppm}+0.8 \mu \mathrm{V}$. This estimate is based on the HTL theoretical tolerance

The shunt resistance was measured using a Kelvin Bridge (TR-2232) on 4 August 1991. Five resistance measurements were made at that time: $10.18,10.22,10.22,10.22$, and $10.21 \mu \Omega$. The calibration uncertainty for these measurements was $0.03 \%$ reading $+0.03 \mu \Omega$.

$$
\begin{gathered}
\bar{X}=10.21 \mu \Omega \\
\omega_{E}=\frac{t \sigma}{\sqrt{N}}=\frac{(2.776)(0.01732 \mu \Omega)}{\sqrt{5}}=0.02 \mu \Omega \\
\omega_{C}=(10.21 \mu \Omega)\left(\frac{0.03 \%}{100}\right)+0.03 \mu \Omega=0.033 \mu \Omega \\
B_{\text {shunt }}=\sqrt{\left(\omega_{E}\right)^{2}+\left(\omega_{C}\right)^{2}} \\
=\sqrt{(0.02 \mu \Omega)^{2}+(0.033 \mu \Omega)^{2}} \\
=0.04
\end{gathered}
$$

A linear fit of this data where the input is in volts would be:

$$
V_{\text {out }}=-0.004278+199.70 V_{\text {in }}
$$

Using the resistance data from the shunt the final engineering conversion calculation can be derived. 


\section{Preliminary Data .. 9 September 1993}

$$
\begin{aligned}
V_{\text {DAS }} & =V_{\text {out }} \\
= & =0.004278+0.002039 i
\end{aligned}
$$

The partial differentials necessary for the calculation of the sensitivity indices are:

$$
\begin{gathered}
\frac{\partial i}{\partial V_{D A S}}=\frac{1}{0.002039 \Omega}=490.4 \Omega^{-1} \\
\frac{\partial i}{\partial R}=\frac{-i}{R}=-97,943 \frac{A}{\Omega} \\
\frac{\partial V_{\text {DAS }}}{\partial V_{\text {in }}}=199.70
\end{gathered}
$$

The total uncertainty can be estimated using the equation:

$$
\omega_{i}=\sqrt{\left[\left(\frac{\partial i}{\partial V_{D A S}}\right)\left(\frac{\partial V_{D A S}}{\partial V_{i n}}\right) \omega_{i n}\right]^{2}+\left[\left(\frac{\partial i}{\partial V_{D A S}}\right) \omega_{D A S}\right]^{2}+\left[\left(\frac{\partial i}{\partial R}\right) \omega_{i n}\right]^{2}}
$$

The random component of the curve fit has been treated as a bias and was estimated based on the confidence interval of the mean. (See Figure 2-13.) The fixed curve error was computed as described in Appendix $C$ of WSRC-TR-106 and is presented in Figure 2-14. The system noise during the calibration for the current range of 650 to $850 \mathrm{~A}$, was about $740 \mu \mathrm{V}$ as shown in Figure 2-15. This is slightly larger than the $500 \mu \mathrm{V}$ that must exist because of DAS roundoff when the data is written to a log. The random uncertainty may then be estimated as: 


\section{Preliminary Data -- 9 September 1993}

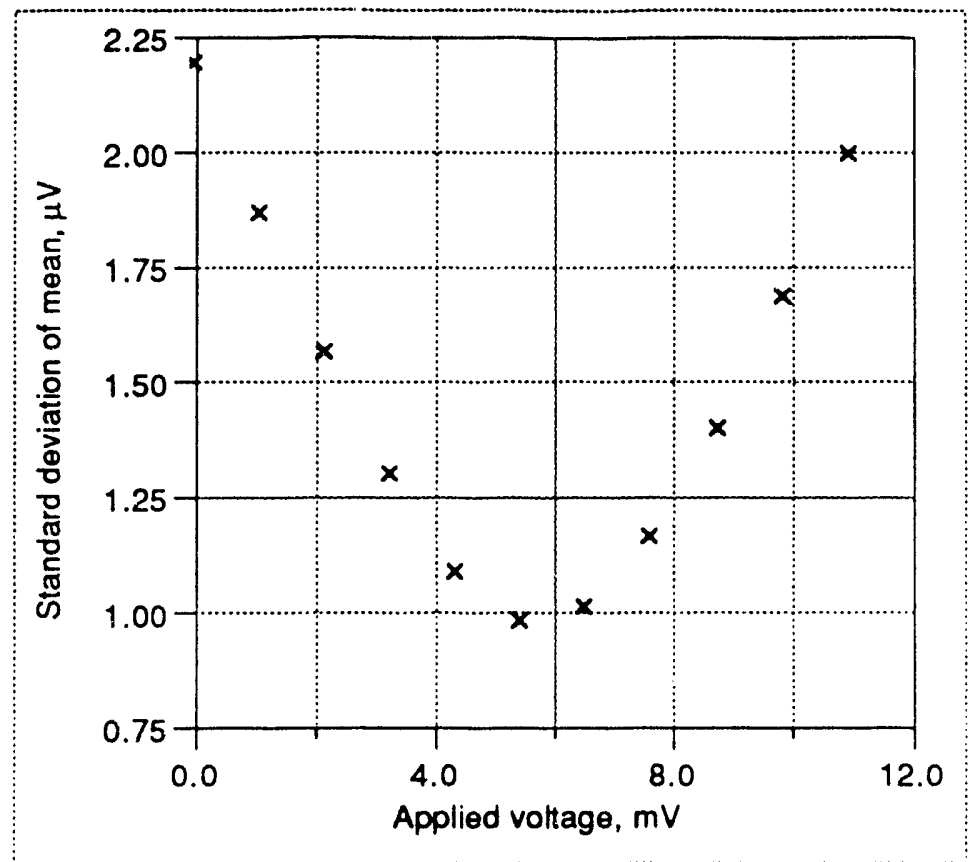

Figure 2-13. Confidence intervals for the mean response for WC00001

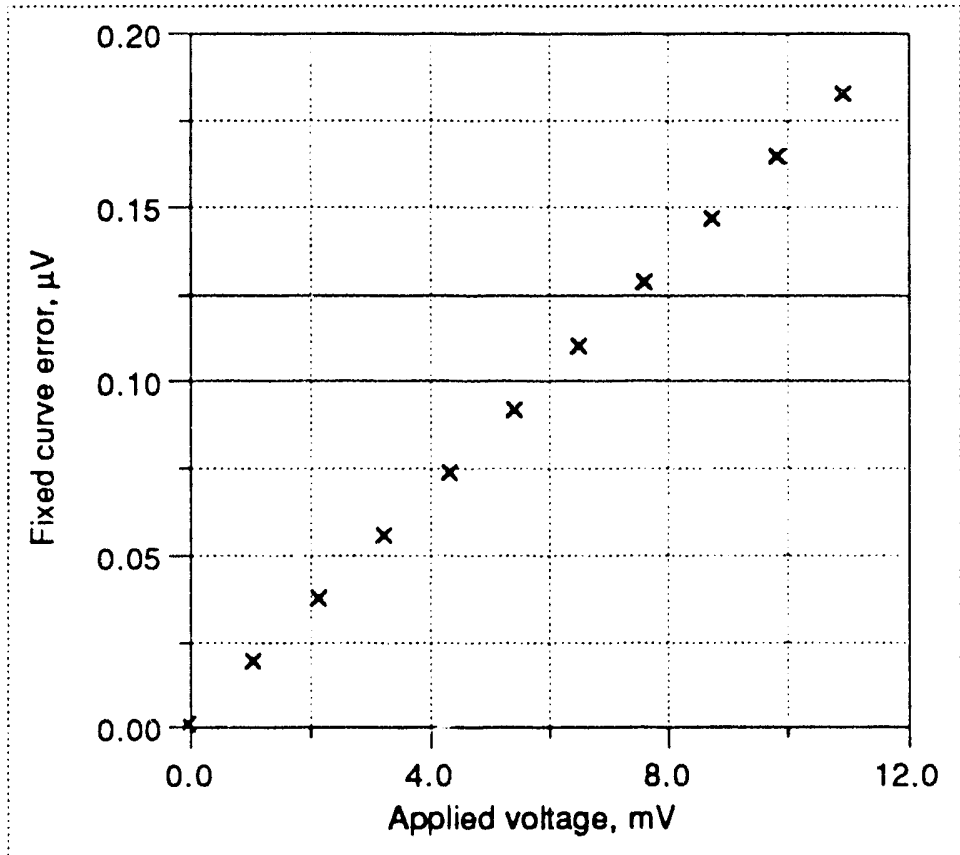

Figure 2-14. Systematic fixed curve errors for WC00001 


\section{Preliminary Data -- 9 September 1993}

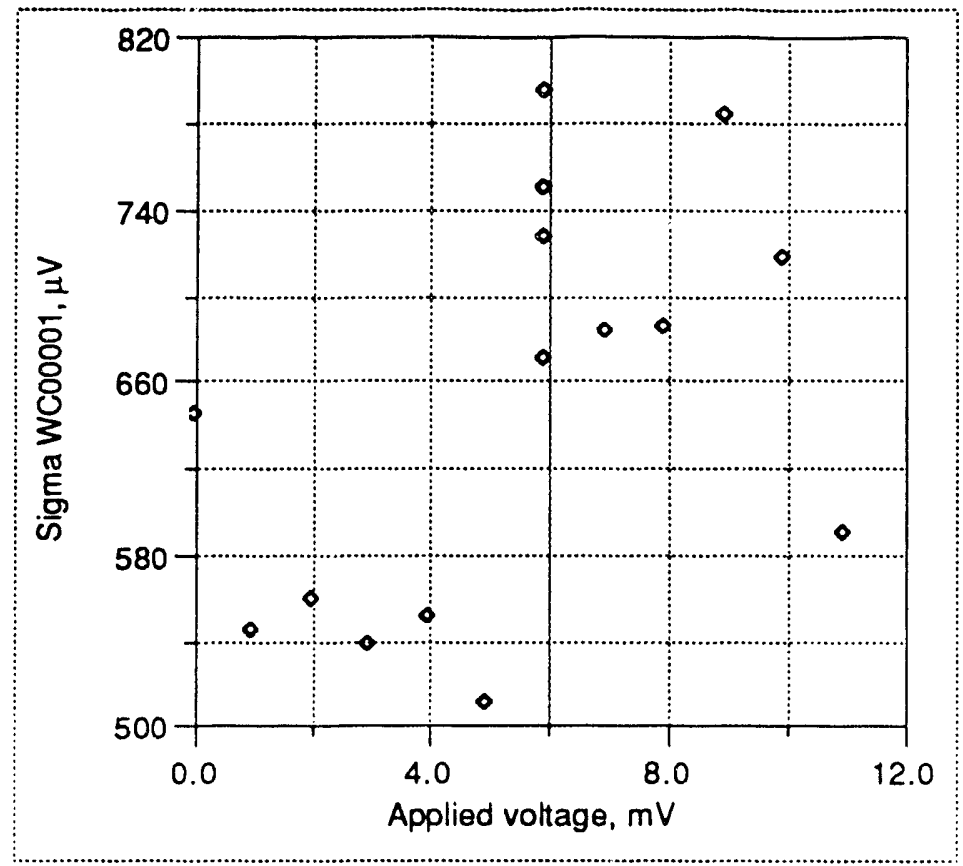

Figure 2-15 Sample standard deviation of output for WC00001 during pretest calibration

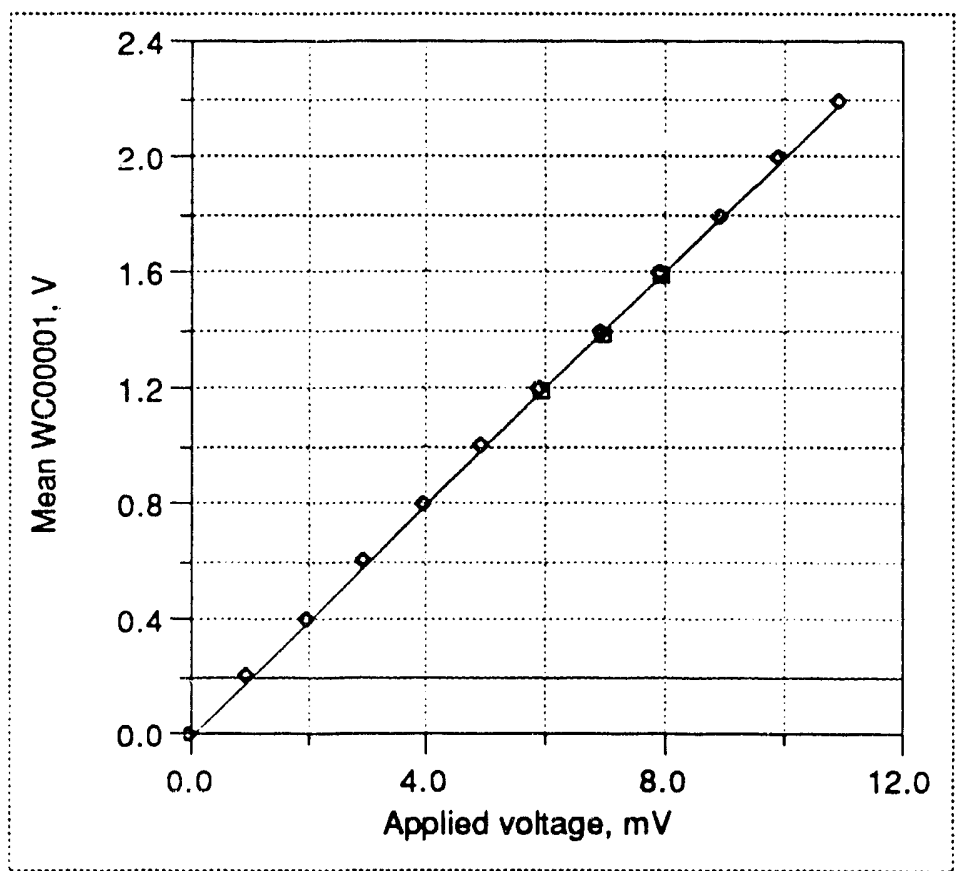

Figure 2-16. Output of WC00001 during calibrations. 


\section{Preliminary Data .. 9 September 1993}

Table 2-11.--Systematic uncertainty estimate for WC00001 loop calibration

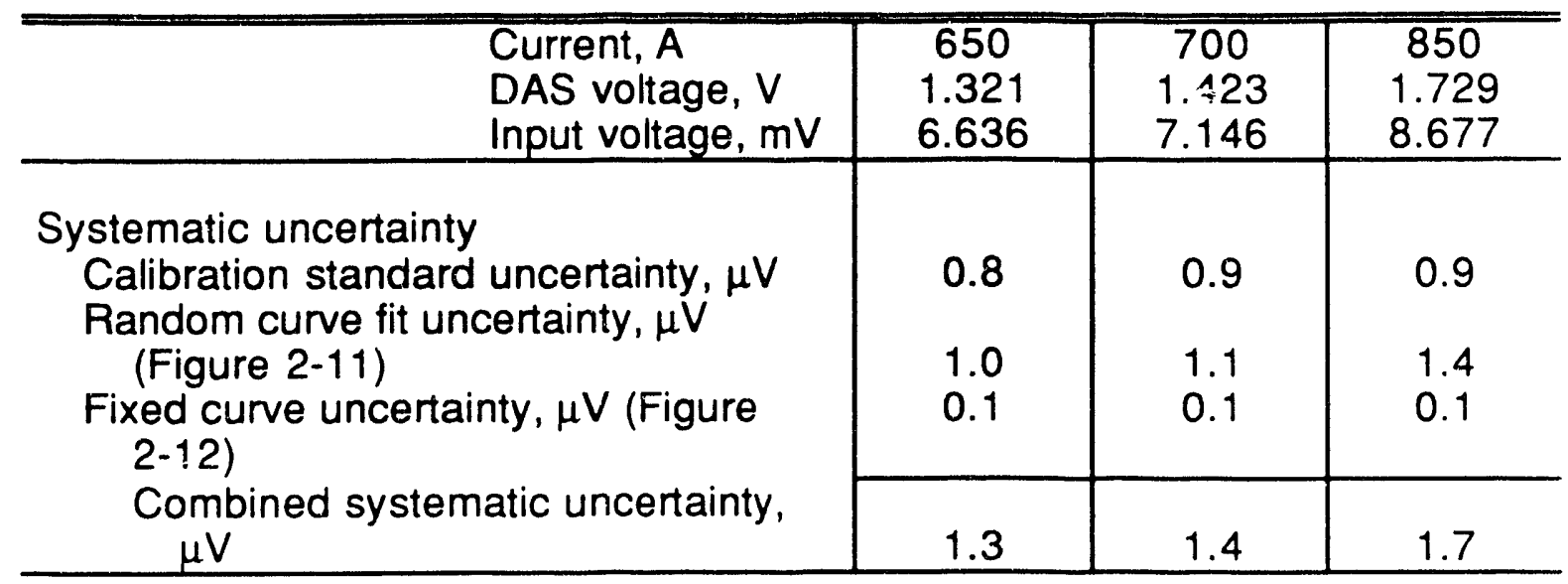

Table 12.--Current measurement systematic uncertainties

\begin{tabular}{|c|c|c|c|}
\hline & $\begin{array}{l}\text { Elemental } \\
\text { systematic } \\
\text { error, } B_{i}\end{array}$ & $\begin{array}{c}\text { Sensitively } \\
\text { index } \\
\theta_{\mathrm{i}} \\
\end{array}$ & $\begin{array}{c}\text { Systematic } \\
\text { uncertainty } \\
\theta_{\mathrm{i}} \mathrm{B}_{\mathrm{i}}\end{array}$ \\
\hline \multirow{2}{*}{$\begin{array}{l}\text { Systematic uncertainty, } 650 \mathrm{~A} \\
\text { Input voltage uncertainties, } \mathrm{mV} \\
\text { Resistance uncertainty, } \mu \Omega \\
\text { Total systematic uncertainty, A } \\
(650 \mathrm{~A})\end{array}$} & $\begin{array}{l}0.0013 \\
0.04\end{array}$ & $\begin{array}{l}97.93 \\
0.0979\end{array}$ & $\begin{array}{l}0.13 \\
0.004\end{array}$ \\
\hline & $\cdots$ & $\cdots$ & 0.13 \\
\hline \multirow{2}{*}{$\begin{array}{l}\text { Systematic uncertainty, } 700 \mathrm{~A} \\
\text { Input voltage uncertainties, } \mathrm{mV} \\
\text { Resistance uncertainty, } \mu \Omega \\
\text { Total systematic uncertainty, A } \\
(700 \mathrm{~A})\end{array}$} & $\begin{array}{l}0.0014 \\
0.04\end{array}$ & $\begin{array}{r}97.93 \\
0.0979\end{array}$ & $\begin{array}{l}0.14 \\
0.004\end{array}$ \\
\hline & $\cdots$ & $\cdots$ & 0.14 \\
\hline \multirow{2}{*}{$\begin{array}{l}\text { Systematic uncertainty, } 850 \mathrm{~A} \\
\text { Input voltage uncertainties, } \mathrm{mV} \\
\text { Resistance uncertainty, } \mu \Omega \\
\text { Total systematic uncertainty, A } \\
(850 \mathrm{~A})\end{array}$} & $\begin{array}{l}0.0017 \\
0.04\end{array}$ & $\begin{array}{l}97.93 \\
0.0979\end{array}$ & $\begin{array}{l}0.17 \\
0.004\end{array}$ \\
\hline & $\cdots$ & $\cdots$ & 0.17 \\
\hline
\end{tabular}




\section{Preliminary Data -. 9 September 1993}

$(2-25)$

$$
P=\frac{t \sigma}{\sqrt{N}}=\frac{2 \cdot 740 \mu \mathrm{V}}{\sqrt{120}}=135 \mu \mathrm{V}
$$

Figure 2-16 presents the DAS voltage to shunt voltage conversion equations. 


\section{Preliminary Data -- 9 September 1993}

\section{Temperature Measurements}

Fluid Thermocouples

Data from the daily flow checks can be used to evaluate the accuracy of the thermocouple temperature measurements. The fluid temperature as measured by TT00001 is compared with the output of each of the fluid thermocouples (except TC00003, impulse line temperature; and TL03002, head tank temperature) in Table 2-13. The nominal equation was used to convert the DAS voltage units to engineering units. Figure 2-17 demonstrates that the differences between the calculated thermocouple temperatures and TT00001 temperature are normally distributed. Table 2-14 presents the quartile information for Figure 2-17.

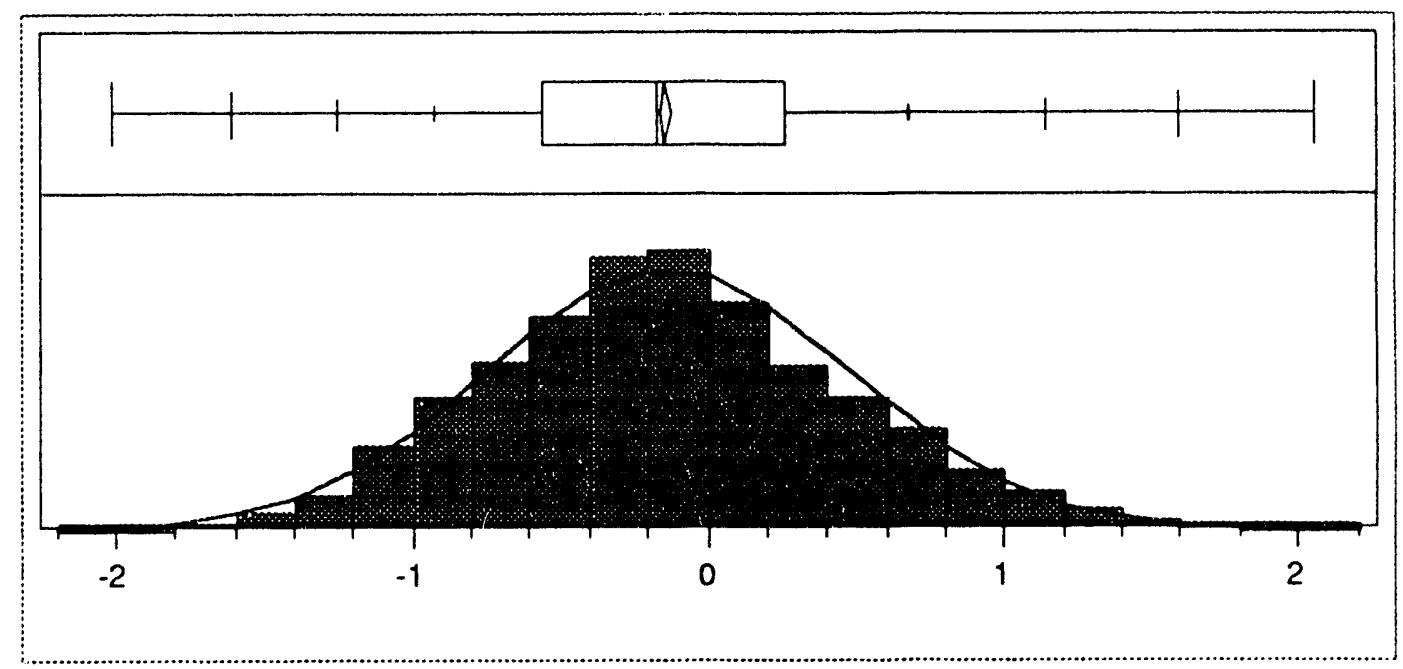

Figure 2.17, Error distribution for thermocouples as compared with TT00001 (Excluding TC00001, TC00002, TC00003, and TL03002) 
Preliminary Data -. 9 September 1993

Table 2-13.--Results from daily flow checks, temperature calculated from DAS mean as compared with TT00001.

\begin{tabular}{|c|c|c|c|c|c|c|}
\hline \multirow{2}{*}{$\begin{array}{c}\text { Instrument } \\
\text { Number }\end{array}$} & \multirow[t]{2}{*}{$N$} & \multirow{2}{*}{$\begin{array}{l}\text { Mean } \\
{ }^{\circ} \mathrm{C} \\
\end{array}$} & \multirow{2}{*}{$\begin{array}{l}\mathrm{S} \\
{ }^{\circ} \mathrm{C}\end{array}$} & \multirow{2}{*}{$\begin{array}{l}\mathrm{S}_{\mathrm{m}} \\
{ }^{\circ} \mathrm{C}\end{array}$} & \multicolumn{2}{|c|}{ Curve coefficients } \\
\hline & & & & & $\mathrm{a}, \mathrm{V}$ & $\mathrm{b}, \mathrm{V} /{ }^{\circ} \mathrm{C}$ \\
\hline TC00001 & 61 & 0.46 & 1.11 & 0.28 & 0 & 0.010000 \\
\hline TC00002 & 61 & -0.09 & 1.77 & 0.45 & 0 & 0.010000 \\
\hline TF01202 & 61 & -0.12 & 0.47 & 0.12 & 0 & 0.033333 \\
\hline TF01204 & 61 & -0.01 & 0.47 & 0.12 & 0 & 0.033333 \\
\hline TF02522 & 61 & 0.00 & 0.46 & 0.12 & 0 & 0.033333 \\
\hline TF02524 & 61 & -0.15 & 0.45 & 0.12 & 0 & 0.033333 \\
\hline TF04172 & 61 & -0.03 & 0.46 & 0.12 & 0 & 0.033333 \\
\hline TF04174 & 61 & 0.10 & 0.44 & 0.11 & 0 & 0.033333 \\
\hline TF05822 & 61 & -0.10 & 0.43 & 0.11 & 0 & 0.033333 \\
\hline TF05824 & 61 & -0.22 & 0.43 & 0.11 & 0 & 0.033333 \\
\hline TF06922 & 61 & 0.25 & 0.42 & 0.11 & 0 & 0.033333 \\
\hline TF06924 & 61 & 0.15 & 0.44 & 0.11 & 0 & 0.033333 \\
\hline TF08022 & 61 & 0.16 & 0.44 & 0.11 & 0 & 0.033333 \\
\hline TF08024 & 61 & -0.02 & 0.44 & 0.11 & 0 & 0.033333 \\
\hline TL01001 & 61 & -0.09 & 0.51 & 0.13 & 0 & 0.033333 \\
\hline TL02001 & 61 & 0.02 & 0.41 & 0.11 & 0 & 0.033333 \\
\hline TL03001 & 61 & 0.18 & 0.56 & 0.14 & 0 & 0.033333 \\
\hline TP01308 & 61 & -0.65 & 0.52 & 0.13 & 0 & 0.033333 \\
\hline TP01317 & 61 & -0.20 & 0.60 & 0.15 & 0 & 0.010000 \\
\hline TP01413 & 61 & -0.02 & 0.67 & 0.17 & 0 & 0.010000 \\
\hline TP01505 & 61 & -0.65 & 0.49 & 0.13 & 0 & 0.033333 \\
\hline TP01702 & 61 & -0.81 & 0.55 & 0.14 & 0 & 0.033333 \\
\hline TP11917 & 61 & -0.50 & 0.67 & 0.17 & 0 & 0.010000 \\
\hline TP12008 & 61 & -0.76 & 0.55 & 0.14 & 0 & 0.033333 \\
\hline TP12105 & 61 & -0.80 & 0.54 & 0.14 & 0 & 0.033333 \\
\hline TP12113 & 61 & -0.31 & 0.64 & 0.16 & 0 & 0.010000 \\
\hline TP12302 & 61 & -0.66 & 0.50 & 0.13 & 0 & 0.033333 \\
\hline TP22917 & 61 & -0.25 & 0.65 & 0.17 & 0 & 0.010000 \\
\hline TP23008" & 21 & -0.46 & 0.46 & 0.20 & 0 & 0.033333 \\
\hline TP23013 & 61 & -0.12 & 0.62 & 0.16 & 0 & 0.010000 \\
\hline TP23105 & 61 & -0.65 & 0.48 & 0.12 & 0 & 0.033333 \\
\hline TP23302 & 61 & -0.56 & 0.49 & 0.12 & 0 & 0.033333 \\
\hline TP33908 & 61 & -0.31 & 0.45 & 0.12 & 0 & 0.033333 \\
\hline TP33917 & 61 & 0.53 & 0.63 & 0.16 & 0 & 0.010000 \\
\hline TP34013 & 61 & 0.54 & 0.51 & 0.13 & 0 & 0.010000 \\
\hline TP34105 & 61 & -0.27 & 0.44 & 0.11 & 0 & 0.033333 \\
\hline TP34302† & 56 & -0.23 & 0.46 & 0.12 & 0 & 0.033333 \\
\hline TP 45008 & 61 & -0.11 & 0.45 & 0.11 & 0 & 0.033333 \\
\hline TP 45105 & 61 & -0.44 & 0.44 & 0.11 & 0 & 0.033333 \\
\hline TP45302‡ & 59 & -0.35 & 0.43 & 0.11 & 0 & 0.033333 \\
\hline TP45613 & 61 & 0.39 & 0.50 & 0.13 & 0 & 0.010000 \\
\hline
\end{tabular}


Preliminary Date _- 9 September 1993

Table 2-13.--Continued

\begin{tabular}{|c|c|c|c|c|c|c|}
\hline \multirow{2}{*}{$\begin{array}{c}\text { Instrument } \\
\text { Number }\end{array}$} & \multirow[t]{2}{*}{$\mathbf{N}$} & \multirow{2}{*}{$\begin{array}{c}\text { Mean } \\
{ }^{\circ} \mathrm{C} \\
\end{array}$} & \multirow{2}{*}{$\begin{array}{c}\mathrm{S} \\
{ }^{\circ} \mathrm{C} \\
\end{array}$} & \multirow{2}{*}{$\begin{array}{l}\mathrm{S}_{\mathrm{m}} \\
{ }^{\circ} \mathrm{C}\end{array}$} & \multicolumn{2}{|c|}{ Curve coefficients } \\
\hline & & & & & $\mathrm{a}, \mathrm{V}$ & $\mathrm{b}, \mathrm{V} /{ }^{\circ} \mathrm{C}$ \\
\hline 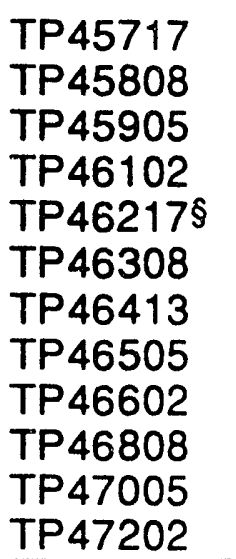 & $\begin{array}{l}61 \\
61 \\
61 \\
61 \\
44 \\
61 \\
61 \\
61 \\
61 \\
61 \\
61 \\
61\end{array}$ & $\begin{array}{c}0.27 \\
-0.21 \\
-0.27 \\
-0.20 \\
0.90 \\
-0.29 \\
0.75 \\
-0.08 \\
-0.19 \\
0.04 \\
-0.02 \\
-0.05\end{array}$ & $\begin{array}{l}0.52 \\
0.44 \\
0.46 \\
0.44 \\
0.52 \\
0.45 \\
0.53 \\
0.45 \\
0.47 \\
0.45 \\
0.46 \\
0.45\end{array}$ & $\begin{array}{l}0.13 \\
0.11 \\
0.12 \\
0.11 \\
0.16 \\
0.12 \\
0.13 \\
0.12 \\
0.12 \\
0.12 \\
0.12 \\
0.12\end{array}$ & $\begin{array}{l}0 \\
0 \\
0 \\
0 \\
0 \\
0 \\
0 \\
0 \\
0 \\
0 \\
0 \\
0\end{array}$ & $\begin{array}{l}0.010000 \\
0.033333 \\
0.033333 \\
0.033333 \\
0.010000 \\
0.033333 \\
0.010000 \\
0.033333 \\
0.033333 \\
0.033333 \\
0.033333 \\
0.033333\end{array}$ \\
\hline $\begin{array}{l}\text { Mean } \\
\text { Minimum } \\
\text { Maximum }\end{array}$ & & $\begin{array}{l}-0.12 \\
-0.81 \\
0.90\end{array}$ & $\begin{array}{l}0.53 \\
0.42 \\
1.77\end{array}$ & $\begin{array}{l}\cdots \\
\cdots \\
\cdots\end{array}$ & $\begin{array}{l}\cdots \\
\cdots \\
\cdots\end{array}$ & $\cdots$ \\
\hline
\end{tabular}

"TP23008 was damaged on 14 May 1993 during channel disassembly.

TTP34302 was functioning correctly on 16 July 1993 and did not function correctly on and after 20 July 1993.

झTP45302 did not function on 30 April 1993 because of loose connections. This was corrected for the remainder of the testing.

§TP46217 was damaged on 24 June 1993 during channel assembly.

The uncertainty of the thermometers used for $T T 00001$ was $0.5^{\circ} \mathrm{C}$. The data in Table 2-13 can be used to estimate the temperature measurement uncertainties for most of the thermocouples used for this task. The overall temperature measurement uncertainty can be estimated using Equation 2-26. 


\section{Preliminary Data -- 9 September 1993}

Table 2-14.--Statistical information for data presented in Figure 2-17.

\begin{tabular}{|c|c|}
\hline & Value, ${ }^{\circ} \mathrm{C}$ \\
\hline 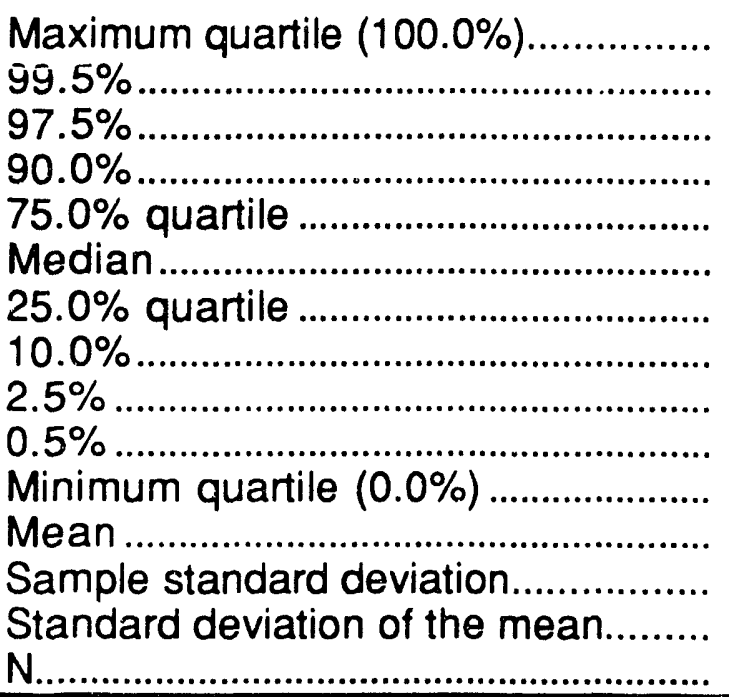 & $\begin{array}{r}2.06 \\
1.59 \\
1.14 \\
0.68 \\
0.26 \\
-0.17 \\
-0.55 \\
-0.92 \\
-1.25 \\
-1.60 \\
-2.01 \\
-0.14 \\
0.61 \\
0.01 \\
3047 \\
\end{array}$ \\
\hline
\end{tabular}

Several thermocouples failed during use. The date of failure is noted in Table $2-13$.

$$
\begin{aligned}
\mathrm{B}_{\mathrm{T}}{ }^{2} & =\mathrm{B}_{T \mathrm{~T} 00001^{2}+\bar{\Delta}^{2}+\left(\frac{2 \sigma}{\sqrt{\mathrm{N}}}\right)^{2}} \\
& =\left(0.5^{\circ} \mathrm{C}\right)^{2}+\left(-0.12^{\circ} \mathrm{C}\right)^{2}+\left(\frac{2 \cdot 0.53}{\sqrt{61}}\right)^{2} \\
\mathrm{~B}_{\mathrm{T}} & =0.53^{\circ} \mathrm{C}
\end{aligned}
$$

Thermocouples TC00003 and TL03002

The accuracy of the thermocouples TC00003, impulse line temperature, and TL03002, head tank temperature can be estimated by comparison with the ambient air or loop temperature recorded during the pretest zero checks. This is appropriate because the ambient air and loop 


\section{Preliminary Data -. 9 September 1993}

temperatures were fairly stable in after sitting idle over night. To eliminate the potential of including data where transient ambient temperatures exist only data within as specified in Equation 2-27 were considered.

$$
\left|T T 00001-T_{a m b}\right|<2^{\circ} \mathrm{C}
$$

The HTL tolerance of the thermometer used for ambient temperature checks was $\pm 1^{\circ} \mathrm{C}$. The data in Tables 2-15, and 2-16 can be used to estimate the temperature measurement uncertainties as was done previously for the fluid thermocouples. The evaluation could have been based on either the ambient air temperature or the loop temperature as measured by TT00001. Since the errors were smaller when TT00001 was used as the standard the thermocouples were evaluated based on TT00001. The uncertainties are sumarized in Table 2-17.

Table 2-15.--Statistical information for TC00003 where $\left|T T 00001-T_{a m b}\right|<2^{\circ} \mathrm{C}$

\begin{tabular}{|c|c|c|}
\hline & $\begin{array}{l}\text { Error based } \\
\text { on TT00001 }\end{array}$ & $\begin{array}{c}\text { Error based } \\
\text { on } \mathrm{T}_{\mathrm{amb}}\end{array}$ \\
\hline 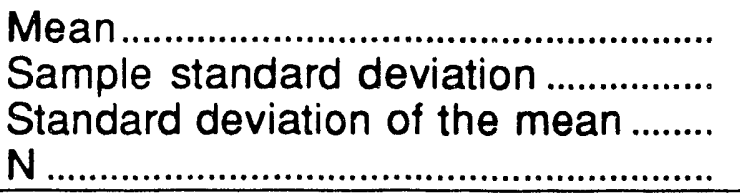 & $\begin{array}{l}0.59 \\
1.04 \\
0.23 \\
20\end{array}$ & $\begin{array}{c}1.00 \\
0.33 \\
0.074 \\
20\end{array}$ \\
\hline
\end{tabular}




\section{Preliminary Data -. 9 September 1993}

Table 2-16.--Statistical information for TL03002 where $\left|T T 00001-T_{a m b}\right|<2^{\circ} \mathrm{C}$

\begin{tabular}{|c|c|c|}
\hline & $\begin{array}{c}\text { Error based } \\
\text { on TT00001 } \\
{ }^{\circ} \mathrm{C}\end{array}$ & $\begin{array}{c}\text { Error based } \\
\text { on } \mathrm{T}_{\mathrm{amb}} \\
{ }^{\circ} \mathrm{C}\end{array}$ \\
\hline $\begin{array}{l}\text { Mean } \\
\text { Sample standard deviation, } S \ldots \ldots . . . \\
\text { Standard deviation of the mean, } S_{m} \\
N\end{array}$ & $\begin{array}{r}0.75 \\
1.16 \\
0.26 \\
20 \\
\end{array}$ & $\begin{array}{r}1.15 \\
0.62 \\
0.14 \\
20 \\
\end{array}$ \\
\hline
\end{tabular}

Table 2-17.--Uncertainty estimate for TC00003, and TLOO3002

\begin{tabular}{|c|c|c|c|c|}
\hline $\begin{array}{c}\text { Instrument } \\
\text { number }\end{array}$ & ${ }^{\mathrm{B}_{\mathrm{O}} \mathrm{C} \mathrm{C}}$ & $\begin{array}{l}\bar{\Delta} \\
{ }^{\circ} \mathrm{C}\end{array}$ & $\begin{array}{l}2 \cdot S_{m} \\
{ }^{\circ} \mathrm{C}\end{array}$ & $\begin{array}{l}{ }^{B} \\
{ }^{\circ} \mathrm{C}\end{array}$ \\
\hline $\begin{array}{l}\text { TC00003 } \\
\text { TL03002 }\end{array}$ & $\begin{array}{l}0.5 \\
0.5\end{array}$ & $\begin{array}{l}0.59 \\
0.75\end{array}$ & $\begin{array}{l}0.46 \\
0.52\end{array}$ & $\begin{array}{l}0.90 \\
1.04\end{array}$ \\
\hline
\end{tabular}


Preliminary Data _. 9 September 1993

\author{
APPENDIX 3 \\ MEASUREMENT UNCERTAINTY ANALYSIS
}




\section{Preliminary Data -. 9 September 1993}

\section{Measurement Uncertainty Efforts}

This appendix presents the systematic uncertainty estimate calculations for selected parameters (resultants). The application of these estimates is discussed in the body of this report. All uncertainties have been estimated at 95\% confidence. Uncertainties have been assumed symmetric and normal. They have been combined using Equation 80 .

\section{Geometric Uncertainties}

Most of the geometric uncertainties had negligible measurement variation There were two exceptions to this: the channel width, $a$, and the channel depth, b. Both spatial and time dependent variations were observed. Spatial variations were the result of slight variations in the channel crosssection at different longitudinal locations. Some time dependent variations are also noticeable in the data presented in Appendix 1. Table 3-0 provides a systematic uncertainty estimate for the channel width and depth. The total systematic uncertainty for the respective measurement was calculated using Equation 3-1.

$$
B_{i}=\sqrt{B_{M \& T E}{ }^{2}+\frac{t_{\alpha / 2} S^{2}}{\sqrt{N}}}
$$

Table 3.0.--Channel width and depth uncertainty estimates

\begin{tabular}{|c|c|c|c|c|c|c|}
\hline & Const. & $\begin{array}{c}\mathrm{S} \\
\mathrm{mm}\end{array}$ & $\begin{array}{c}\mathrm{B}_{\mathrm{M} \text { ITE }} \\
\mathrm{mm}\end{array}$ & $N$ & $t_{\alpha / 2}$ & $\begin{array}{c}\mathrm{B}_{\mathrm{i}} \\
\mathrm{mm}\end{array}$ \\
\hline $\begin{array}{l}\text { channel width, a } \\
\text { channel depth, b }\end{array}$ & $\begin{array}{l}2 \\
4 \\
2 \\
4\end{array}$ & $\begin{array}{l}0.113 \\
0.207 \\
0.102 \\
0.093\end{array}$ & $\begin{array}{l}0.076 \\
0.076 \\
0.076 \\
0.076\end{array}$ & $\begin{array}{r}8 \\
7 \\
10 \\
10\end{array}$ & $\begin{array}{l}2.365 \\
2.447 \\
2.262 \\
2.262\end{array}$ & $\begin{array}{l}0.1 \\
0.2 \\
0.07 \\
0.07\end{array}$ \\
\hline
\end{tabular}




\section{Preliminary Data -- 9 September 1993}

\section{Friction Factor}

The friction factor is defined by Equation 18. When written in terms of the data reduction input quantities (directly measured, estimated, and channel geometry values) Equation 18 becomes:

$$
f=\frac{\Delta \mathrm{p}_{2 \cdot 3}-\mathrm{Lg}\left(\rho_{\infty}-\rho_{23}\right)}{\left(\frac{\mathrm{L}}{\mathrm{D}}\right)\left(\frac{\rho_{23}}{2}\right)\left(\frac{\mathrm{Q}}{\mathrm{A}_{\mathrm{f}}}\right)^{2}}
$$

Most of the partial derivative equations necessary for the use of Equation 80 are not readily calculated. An iterative forward-difference calculation was used to estimate the more complex partial derivatives. These finite difference calculations are summarized in Tables 3-1, 3-2, 3-3, 3-4.

The uncertainty terms, $\rho_{\infty}$ and $\rho_{23}$ could be considered as a composite of two uncertainties: (1) the curve fit error, and (2) the measured temperature uncertainty. For this analysis the curve fit uncertainties have been handled separately from those which are the result of temperature uncertainties. The fluid property uncertainties resulting from temperature uncertainty have been folded into the temperature measurement uncertainties by the numeric evaluation method used to calculate the sensitivity coefficients.

Several of the uricertainty terms are partially correlated. The three temperature terms are correlated as well as the two density terms. For construction 4.0 operating at a Reynolds number of 10,000 the effect of the correlated tincertainty components is estimated as:

$$
\begin{aligned}
\mathrm{B}_{c o r}^{2}= & 2\left(\frac{\partial f}{\partial \mathrm{T}_{2}}\right)\left(\frac{\partial f}{\partial \mathrm{T}_{3}}\right) \mathrm{B}_{\mathrm{T}_{2}}^{*} \dot{\mathrm{B}}_{\mathrm{T}_{3}}^{*}+2\left(\frac{\partial f}{\partial \mathrm{T}_{2}}\right)\left(\frac{\partial f}{\partial \mathrm{T}_{\infty}}\right) \mathrm{B}_{\mathrm{T}_{2}} \dot{\mathrm{B}}_{\infty}^{*} \\
& +2\left(\frac{\partial f}{\partial \mathrm{T}_{3}}\right)\left(\frac{\partial f}{\partial \mathrm{T}_{\infty}}\right) \dot{\mathrm{B}}_{\mathrm{T}_{3}}^{*} \dot{\mathrm{B}}_{\infty}^{*}+2\left(\frac{\partial f}{\partial \rho_{23}}\right)\left(\frac{\partial f}{\partial \rho_{\infty}}\right) \dot{\mathrm{B}}_{\rho_{23}}^{*} \dot{B}_{\rho_{\infty}}^{*}
\end{aligned}
$$


Table 3-1.--Frict:on factor sensitivity coefficient estimates for open channel, construction 4 , inlet temperature $60^{\circ} \mathrm{C}, \mathrm{Re}=10,000$

\begin{tabular}{|c|c|c|c|c|}
\hline & & $x_{i}$ & $x_{i}+\Delta x_{i}$ & $\frac{\partial f}{\partial x_{i}}$ \\
\hline Friction factor & $f$ & 0.03160 & $\ldots$ & ... \\
\hline Channel width, $\mathrm{mm}$ & a & 79.8 & 80.6 & $811 e-6$ \\
\hline Channel depth, $\mathrm{mm}$ & b & 3.16 & 3.19 & $30.0 e-3$ \\
\hline Rib width, mm & $x_{0}$ & 0.0 & $\cdots$ & 0.000 \\
\hline Channel length & L & 1.397 & 1.411 & -0.0245 \\
\hline Measured pressure loss, $\mathrm{kPa}$ & $\Delta p_{2-3}$ & 2.414 & 2.438 & $14.3 e-3$ \\
\hline Impulse line density, $\mathrm{kg} / \mathrm{m}^{3}$ & $\rho_{\infty}$ & 997.0 & 1007.0 & $-196 e-6$ \\
\hline Bulk density, $\mathrm{kg} / \mathrm{m}^{3}$ & $\rho_{23}$ & 981.9 & 991.7 & $-31.9 e-6$ \\
\hline $\begin{array}{l}\text { Flow, } \mathrm{cm}^{3} / \mathrm{s} \\
\text { Inlet temperature, }{ }^{\circ} \mathrm{C} \\
\text { Exit temperature, }{ }^{\circ} \mathrm{C} \\
\text { Impulse line temperature, }{ }^{\circ} \mathrm{C}\end{array}$ & $\begin{array}{l}Q_{\text {in }} \\
T_{\text {int }} \\
T_{\infty}\end{array}$ & $\begin{array}{r}198.4 \\
60.00 \\
60.00 \\
25.00\end{array}$ & $\begin{array}{r}200.4 \\
60.60 \\
60.60 \\
25.30\end{array}$ & $\begin{array}{l}-314 e-6 \\
-91.1 e-6 \\
8.17 e-6 \\
71.2 e-6\end{array}$ \\
\hline
\end{tabular}

Table 3-2.--Friction factor sensitivity coefficient estimates for open channel, construction 4.0 , inlet temperature $60^{\circ} \mathrm{C}, \mathrm{Re}=20,000$

\begin{tabular}{|c|c|c|c|c|}
\hline & & $x_{i}$ & $x_{i}+\Delta x_{i}$ & $\frac{\partial f}{\partial x_{i}}$ \\
\hline Friction factor & $f$ & 0.02657 & ... & $\cdots$ \\
\hline Channel width, $\mathrm{mm}$ & a & 79.8 & 80.6 & $579 e-6$ \\
\hline Channel depth, mm & $\mathrm{b}$ & 3.16 & 3.19 & $22.4 \mathrm{e}-3$ \\
\hline Rib width, $\mathrm{mm}$ & $x_{0}$ & & $\cdots$ & 0.000 \\
\hline Channel length & $L$ & 1.397 & 1.411 & $-25.2 e-3$ \\
\hline Measured pressure loss, $\mathrm{kPa}$ & $\Delta p_{2-3}$ & 7.629 & 7.705 & $2.50 e-3$ \\
\hline Impulse line density, $\mathrm{kg} / \mathrm{m}^{3}$ & $\rho_{\infty}$ & 997.0 & 1007.0 & $-57.3 e-6$ \\
\hline Bulk density, $\mathrm{kg} / \mathrm{m}^{3}$ & $\rho_{23}$ & 981.9 & 991.7 & $-35.2 e-6$ \\
\hline $\begin{array}{l}\text { Flow, } \mathrm{cm}^{3} / \mathrm{s} \\
\text { Inlet temperature, }{ }^{\circ} \mathrm{C} \\
\text { Exit temperature, }{ }^{\circ} \mathrm{C} \\
\text { Impulse line temperature, }{ }^{\circ} \mathrm{C}\end{array}$ & $\begin{array}{c}Q \\
T_{\text {in }} \\
T_{\text {out }} \\
T_{\infty}\end{array}$ & $\begin{array}{r}396.8 \\
60.0 \\
60.0 \\
25.0 \\
\end{array}$ & $\begin{array}{r}400.8 \\
60.6 \\
60.6 \\
25.3 \\
\end{array}$ & $\begin{array}{l}-152 e-6 \\
-155 e-6 \\
-130 e-6 \\
-257 e-6\end{array}$ \\
\hline
\end{tabular}


Table 3-3.--Friction factor sensitivity coefficient estimates for rib channel, construction 2, inlet temperature $60^{\circ} \mathrm{C}, \mathrm{Re}=10,000$

\begin{tabular}{|c|c|c|c|c|}
\hline & & $x_{i}$ & $x_{i}+\Delta x_{i}$ & $\frac{\partial f}{\partial x_{i}}$ \\
\hline $\begin{array}{l}\text { Friction factor } \\
\text { Channel width, } \mathrm{mm} \\
\text { Channel depth, mm } \\
\text { Rib width, mm } \\
\text { Channel length } \\
\text { Measured pressure loss, } \mathrm{kPa}\end{array}$ & $\begin{array}{l}f \\
a \\
b \\
x_{0} \\
L \\
\Delta p_{2}-3\end{array}$ & $\begin{array}{l}0.03160 \\
79.6 \\
3.09 \\
2.07 \\
1.397 \\
2.580\end{array}$ & $\begin{array}{c}\cdots \\
80.4 \\
3.12 \\
2.09 \\
1.411 \\
2.606\end{array}$ & $\begin{array}{c}\cdots \\
850 e-6 \\
30.2 e-3 \\
-845 e-6 \\
-24.2 e-3 \\
12.0 e-3\end{array}$ \\
\hline Impulse line density, $\mathrm{kg} / \mathrm{m}^{3}$ & $\rho_{\infty}$ & 997.0 & 1007.0 & $-164 e-6$ \\
\hline Bulk density, $\mathrm{kg} / \mathrm{m}^{3}$ & $\rho_{23}$ & 981.9 & 991.7 & $-31.9 e-6$ \\
\hline $\begin{array}{l}\text { Flow, } \mathrm{cm}^{3} / \mathrm{s} \\
\text { Inlet temperature, }{ }^{\circ} \mathrm{C} \\
\text { Exit temperature, }{ }^{\circ} \mathrm{C} \\
\text { Impulse line temperature, }{ }^{\circ} \mathrm{C}\end{array}$ & $T_{\text {in }}^{Q}$ & $\begin{array}{r}200.2 \\
60.00 \\
60.00 \\
25.00\end{array}$ & $\begin{array}{r}202.2 \\
60.60 \\
60.60 \\
25.30\end{array}$ & $\begin{array}{l}-311 e-6 \\
-74.7 e-6 \\
8.13 e-6 \\
59.4 e-6\end{array}$ \\
\hline
\end{tabular}

Table 3-4.--Friction factor sensitivity coefficient estimates for rib channel, construction 2.0, inlet temperature $60^{\circ} \mathrm{C}, \mathrm{Re}=20,000$

\begin{tabular}{|c|c|c|c|c|}
\hline & & $x_{i}$ & $x_{i}+\Delta x_{i}$ & $\frac{\partial f}{\partial x_{i}}$ \\
\hline $\begin{array}{l}\text { Friction factor } \\
\text { Channel width, } \mathrm{mm} \\
\text { Channel depth, } \mathrm{mm} \\
\text { Rib width, mm } \\
\text { Channel length } \\
\text { Measured pressure loss, } \mathrm{kPa}\end{array}$ & $\begin{array}{l}f \\
a \\
b \\
x_{0} \\
L\end{array}$ & $\begin{array}{l}0.02662 \\
0.0796 \\
0.00309 \\
0.00207 \\
1.397 \\
9.112\end{array}$ & \begin{tabular}{l}
\multicolumn{1}{c}{$\cdots$} \\
0.0804 \\
0.00312 \\
0.00209 \\
1.411 \\
9.203
\end{tabular} & $\begin{array}{c}\cdots \\
716 e-6 \\
25.4 e-3 \\
-712 e-6 \\
-19.3 e-3 \\
2.99 e-3\end{array}$ \\
\hline Impulse line density, $\mathrm{kg} / \mathrm{m}^{3}$ & $\rho^{2}$ & 997.0 & 1007.0 & $-41.0 e-6$ \\
\hline Bulk density, $\mathrm{kg} / \mathrm{m}^{3}$ & $\rho^{23}$ & 981.9 & 991.7 & $-26.8 e-6$ \\
\hline $\begin{array}{l}\text { Flow, } \mathrm{cm}^{3} / \mathrm{s} \\
\text { Inlet temperature, }{ }^{\circ} \mathrm{C} \\
\text { Exit temperature, }{ }^{\circ} \mathrm{C} \\
\text { Impulse line temperature, }{ }^{\circ} \mathrm{C}\end{array}$ & $\begin{array}{c}\mathrm{T}_{\text {in }} \\
\mathrm{T}_{\text {out }} \\
\mathrm{T}_{\infty}\end{array}$ & $\begin{array}{l}400.3 \\
60.00 \\
60.00 \\
25.00\end{array}$ & $\begin{array}{l}404.3 \\
60.60 \\
60.60 \\
25.30\end{array}$ & $\begin{array}{l}-131 e-6 \\
-13.9 e-6 \\
6.85 e-6 \\
14.9 e-6\end{array}$ \\
\hline
\end{tabular}




\section{Preliminary Data -- 9 September 1993}

Using the partial derivatives presented in Table 3-5 Equation 3-3 becomes:

$$
\begin{aligned}
\mathrm{B}_{c o r}{ }^{2}=10^{-12}\left[2\left(\frac{-91.1}{{ }^{\circ} \mathrm{C}}\right)\right. & \left(\frac{8.17}{{ }^{\circ} \mathrm{C}}\right)\left(0.5^{\circ} \mathrm{C}\right)\left(0.5^{\circ} \mathrm{C}\right) \\
& +2\left(\frac{-91.1}{{ }^{\circ} \mathrm{C}}\right)\left(\frac{71.2}{{ }^{\circ} \mathrm{C}}\right)\left(0.5^{\circ} \mathrm{C}\right)\left(0.5^{\circ} \mathrm{C}\right) \\
& +2\left(\frac{8.17}{{ }^{\circ} \mathrm{C}}\right)\left(\frac{71.2}{{ }^{\circ} \mathrm{C}}\right)\left(0.5^{\circ} \mathrm{C}\right)\left(0.5^{\circ} \mathrm{C}\right) \\
& \left.+2\left(\frac{-31.9}{\mathrm{~kg} / \mathrm{m}^{3}}\right)\left(\frac{-196}{\mathrm{~kg} / \mathrm{m}^{3}}\right)\left(0.5^{\frac{\mathrm{kg}}{\mathrm{m}^{3}}}\right)\left(.5^{\frac{\mathrm{kg}}{\mathrm{m}^{3}}}\right)\right]
\end{aligned}
$$

$$
B_{c o r}^{2}=-198 e-12
$$

For the above case the correlated systematic uncertainties tend to reduce the overall uncertainty estimate by a negligible quantity. The uncertainty estimates presented in Tables 3-5, 3-6, 3-7, and 3-8 have therefore been treated as independent. 


\section{Preliminary Data -- 9 September 1993}

Table 3-5.--Friction factor systematic uncertainty estimate for open channel, construction 4 , inlet temperature $60^{\circ} \mathrm{C}, \mathrm{Re}=10,000$

\begin{tabular}{|c|c|c|c|c|}
\hline & & $\mathrm{B}_{\mathrm{i}}$ & $\theta_{i}$ & $\theta_{i} B_{i}$ \\
\hline $\begin{array}{l}\text { Channel width, } \mathrm{mm}^{\star} \\
\text { Channel depth, } \mathrm{mm} \dagger \\
\text { Rib width, mm } \\
\text { Channel length, } \mathrm{m} \\
\text { Measured pressure loss, } \mathrm{kPa}\end{array}$ & $\begin{array}{c}a \\
b \\
x_{0} \\
L \\
\Delta p_{2-3}\end{array}$ & $\begin{array}{l}0.4 \\
0.2 \\
0.04 \\
0.0008 \\
0.400\end{array}$ & $\begin{array}{c}811 e-6 \\
30.0 e-3 \\
0.000 \\
-0.0245 \\
14.3 e-3\end{array}$ & $\begin{array}{r}0.00032 \\
0.00600 \\
0.00000 \\
-0.00002 \\
0.00572\end{array}$ \\
\hline Impulse line density, $\mathrm{kg} / \mathrm{m}^{3}$ & $\rho_{\infty}$ & 1 & $-196 e-6$ & -0.00020 \\
\hline Bulk density, $\mathrm{kg} / \mathrm{m}^{3}$ & $\rho_{23}$ & 1 & $-31.9 e-6$ & -0.00003 \\
\hline $\begin{array}{l}\text { Flow, } \mathrm{cm}^{3} / \mathrm{s} \\
\text { Inlet temperature, }{ }^{\circ} \mathrm{C} \\
\text { Exit temperature, }{ }^{\circ} \mathrm{C} \\
\text { Impulse line ternperature, }{ }^{\circ} \mathrm{C}\end{array}$ & $\begin{array}{l}Q \\
T_{\text {in }} \\
T_{\infty}\end{array}$ & $\begin{array}{l}1.4 \\
0.53 \\
0.53 \\
0.53\end{array}$ & $\begin{array}{c}-314 e-6 \\
-91.1 e-6 \\
8.17 e-6 \\
71.2 e-6\end{array}$ & $\begin{array}{r}-0.00044 \\
-0.00005 \\
0.00000 \\
0.00004\end{array}$ \\
\hline Root-sum-square & & & & 0.0083 \\
\hline
\end{tabular}

*The elemental uncertainty was taken as the difference between two measurement methods. This is presented in Table 1-4.

tThe elemental uncertainty was taken as twice the standard deviation for the 1 July 1993 data as presented in Table 1-7.

Table 3-6.--Friction factor systematic uncertainty estimate for open channel, construction 4.0 , inlet temperature $60^{\circ} \mathrm{C}, \mathrm{Re}=20,000$

\begin{tabular}{|c|c|c|c|c|}
\hline & & $\mathrm{B}_{\mathrm{i}}$ & $\theta_{\mathrm{i}}$ & $\theta_{i} B_{i}$ \\
\hline $\begin{array}{l}\text { Channel width, } \mathrm{mm} \\
\text { Channel depth, } \mathrm{mm} \\
\text { Rib width, } \mathrm{mm} \\
\text { Channel length, } \mathrm{m} \\
\text { Measured pressure loss, } \mathrm{kPa}\end{array}$ & $\begin{array}{c}a \\
b \\
x_{0} \\
L \\
\Delta p_{2-3}\end{array}$ & $\begin{array}{l}0.4 \\
0.2 \\
0.04 \\
0.0008 \\
0.400\end{array}$ & $\begin{array}{l}579 e-6 \\
22.4 e-3 \\
0.000 \\
-25.2 e-3 \\
2.50 e-3\end{array}$ & $\begin{array}{r}0.00023 \\
0.00448 \\
0.00000 \\
-0.00002 \\
-0.00100\end{array}$ \\
\hline Impulse line density, $\mathrm{kg} / \mathrm{m}^{3}$ & $\rho_{\infty}$ & 1 & $-57.3 e-6$ & -0.00006 \\
\hline Bulk density, $\mathrm{kg} / \mathrm{m}^{3}$ & $\rho_{23}$ & 1 & $-35.2 e-6$ & -0.00004 \\
\hline $\begin{array}{l}\text { Flow, } \mathrm{cm}^{3} / \mathrm{s} \\
\text { Inlet temperature, }{ }^{\circ} \mathrm{C} \\
\text { Exit temperature, }{ }^{\circ} \mathrm{C} \\
\text { Impulse line temperature, }{ }^{\circ} \mathrm{C}\end{array}$ & $\begin{array}{c}Q \\
T_{\text {in }} \\
T_{\infty}\end{array}$ & $\begin{array}{l}1.2 \\
0.53 \\
0.53 \\
0.53\end{array}$ & $\begin{array}{l}-152 e-6 \\
-155 e-6 \\
-130 e-6 \\
-257 e-6\end{array}$ & $\begin{array}{l}-0.00018 \\
-0.00008 \\
-0.00007 \\
-0.00014\end{array}$ \\
\hline Root-sum-square & & & & 0.0046 \\
\hline
\end{tabular}


Table 3-7.--Friction factor systematic uncertainty estimate for rib channel, construction 2 , inlet temperature $60^{\circ} \mathrm{C}, \mathrm{Re}=10,000$

\begin{tabular}{|c|c|c|c|c|}
\hline & & $B_{i}$ & $\theta_{i}$ & $\theta_{i} B_{i}$ \\
\hline $\begin{array}{l}\text { Channel width, } \mathrm{mm} \\
\text { Channel depth, } \mathrm{mm} \\
\text { Rib width, mm } \\
\text { Channel length, } \mathrm{m} \\
\text { Measured pressure loss, } \mathrm{kPa}\end{array}$ & $\begin{array}{c}a \\
b \\
x_{0} \\
L \\
\Delta p_{2-3}\end{array}$ & $\begin{array}{l}0.4 \\
0.2 \\
0.04 \\
0.0008 \\
0.400\end{array}$ & $\begin{array}{l}850 e-6 \\
30.2 e-3 \\
-845 e-6 \\
-24.2 e-3 \\
12.0 e-3\end{array}$ & $\begin{array}{r}0.00034 \\
0.00604 \\
-0.00003 \\
-0.00002 \\
0.00480\end{array}$ \\
\hline Impulse line density, $\mathrm{kg} / \mathrm{m}^{3}$ & $\rho_{\infty}$ & 1 & $-164 e-6$ & -0.00016 \\
\hline Bulk density, $\mathrm{kg} / \mathrm{m}^{3}$ & $\rho_{23}$ & 1 & $-31.9 e-6$ & -0.00003 \\
\hline $\begin{array}{l}\text { Flow, } \mathrm{cm}^{3} / \mathrm{s} \\
\text { Inlet temperature, }{ }^{\circ} \mathrm{C} \\
\text { Exit temperature, }{ }^{\circ} \mathrm{C} \\
\text { Impulse line temperature, }{ }^{\circ} \mathrm{C}\end{array}$ & $\begin{array}{l}Q \\
T_{\text {in }} \\
T_{\text {out }}\end{array}$ & $\begin{array}{l}1.4 \\
0.53 \\
0.53 \\
0.53\end{array}$ & $\begin{array}{c}-311 e-6 \\
-74.7 e-6 \\
8.13 e-6 \\
59.4 e-6\end{array}$ & $\begin{array}{r}-0.00044 \\
-0.00004 \\
0.00000 \\
0.00003\end{array}$ \\
\hline Root-sum-square & & & & 0.0077 \\
\hline
\end{tabular}

Table 3-8.--Friction factor systematic uncertainty estimate for rib channel, construction 2.0 , inlet temperature $60^{\circ} \mathrm{C}, \mathrm{Re}=20,000$

\begin{tabular}{|c|c|c|c|c|}
\hline & & $\mathrm{B}_{\mathrm{i}}$ & $\theta_{i}$ & $\theta_{i} B_{i}$ \\
\hline $\begin{array}{l}\text { Channel width, } \mathrm{mm} \\
\text { Channel depth, } \mathrm{mm} \\
\text { Rib width, mm } \\
\text { Channel length, } \mathrm{m} \\
\text { Measured pressure loss, } \mathrm{kPa}\end{array}$ & $\begin{array}{c}a \\
b \\
x_{0} \\
L \\
\Delta p_{2-3}\end{array}$ & $\begin{array}{l}0.4 \\
0.2 \\
0.04 \\
0.0008 \\
0.400\end{array}$ & $\begin{array}{l}716 e-6 \\
25.4 e-3 \\
-712 e-6 \\
-19.3 e-3 \\
2.99 e-3\end{array}$ & $\begin{array}{r}0.00029 \\
0.00508 \\
-0.00003 \\
-0.00002 \\
0.00120\end{array}$ \\
\hline Impulse line density, $\mathrm{kg} / \mathrm{m}^{3}$ & $\rho_{\infty}$ & 1 & $-41.0 e-6$ & -0.00004 \\
\hline Bulk density, $\mathrm{kg} / \mathrm{m}^{3}$ & $\rho_{23}$ & 1 & $-26.8 e-6$ & -0.00003 \\
\hline $\begin{array}{l}\text { Flow, } \mathrm{cm}^{3} / \mathrm{s} \\
\text { Inlet temperature, }{ }^{\circ} \mathrm{C} \\
\text { Exit temperature, }{ }^{\circ} \mathrm{C} \\
\text { Impulse line temperature, }{ }^{\circ} \mathrm{C}\end{array}$ & $\begin{array}{l}Q \\
T_{\text {in }} \\
T_{\infty}\end{array}$ & $\begin{array}{l}1.4 \\
0.53 \\
0.53 \\
0.53\end{array}$ & $\begin{array}{c}-131 e-6 \\
-13.9 e-6 \\
6.85 e-6 \\
14.9 e-6\end{array}$ & $\begin{array}{r}-0.00018 \\
-0.00001 \\
0.00000 \\
0.00001\end{array}$ \\
\hline Root-suin-square & & & & 0.00523 \\
\hline
\end{tabular}




\section{Preliminary Data -. 9 September 1993}

\section{Energy Balance Ratio}

The energy balance ratio, $\eta_{p}$ is defined by Equation 3-4. For this analysis both the power and fluid energy loss terms will be considered zero.

$$
\eta_{p}=\frac{P_{\text {elec }}}{P_{\text {fluid }}}=\frac{V i-\text { losses }}{Q \rho c_{p}\left(T_{\text {out }}-T_{\text {in }}\right)+\text { losses }}
$$

The uncertainty terms for the specific heat could be considered as a composite of three uncertainties: (1) the curve fit error, (2) the error introduced by the linear property assumption, and (3) the measured temperature uncertainty. For this analysis the first two uncertainties have been handled separately. The third uncertainty has been folded into the temperature measurement uncertainty by numeric evaluation method used to calculate some of the sensitivity coefficients. The density uncertainty consists of only the first and last of the three error terms since the density is taken at inlet conditions.

The error introduced by the linear property assumption could be evaluated numerically, however this level of rigor would have little impact on the final uncertainty estimate associated with assuming that the fluid properties are linear. It must be remembered that the linear temperature rise as the fluid passes through the channel is an assumption. Figure 3-1 presents specific heat estimates obtained using two methods: (1) The specific heat is estimated using Equation 75 at the bulk temperature (the mean of the inlet and outlet temperature). (2) The specific heat is estimated as the mean of the inlet and exit specific heats as calculated using Equation 75 . The error introduced by the linearity assumption will be taken as the difference between these two values as described in Equation 3-5. The uncertainty values are tabulated in Table 3-8a. 


\section{Preliminary Data _- 9 September 1993}

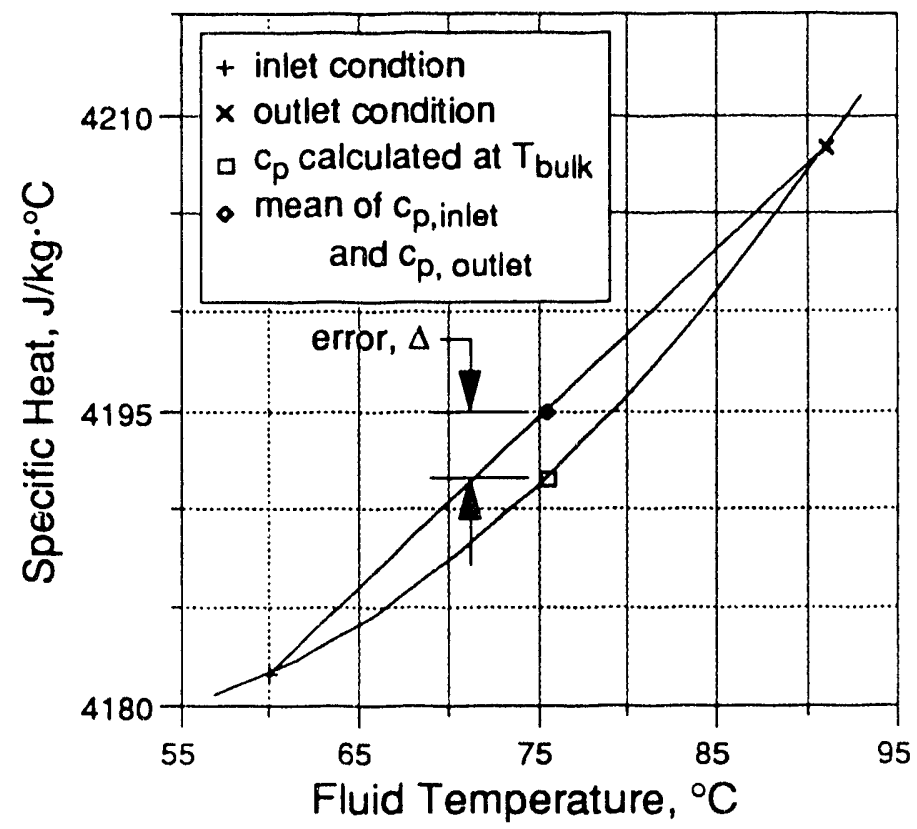

Figure 3-1, Specific heat estimates using alternate linearity assumptions.

Table 3-8a.--Specific heat estimates using alternate linearity assumptions ( $T_{\text {in }}=$ $\left.60^{\circ} \mathrm{C}\right)$

\begin{tabular}{c|c|c|c|c}
\hline $\begin{array}{c}\mathrm{T}_{\text {out }} \\
{ }^{\circ} \mathrm{C}\end{array}$ & $\begin{array}{c}\mathrm{T}_{\mathrm{b}} \\
{ }^{\circ} \mathrm{C}\end{array}$ & $\begin{array}{c}\mathrm{C}_{\mathrm{p}, ~} \mathrm{~b} \\
\mathrm{~J} / \mathrm{kg} \cdot{ }^{\circ} \mathrm{C}\end{array}$ & $\begin{array}{c}\mathrm{C}_{\mathrm{p}, \text { mean }} \mathrm{J} / \mathrm{kg} \cdot{ }^{\circ} \mathrm{C} \\
\mathrm{J}\end{array}$ & $\begin{array}{c}\Delta \\
\mathrm{J} / \mathrm{kg} \cdot{ }^{\circ} \mathrm{C}\end{array}$ \\
\hline 65.00 & 62.50 & 4182.8 & 4182.9 & 0.1 \\
70.00 & 65.00 & 4184.2 & 4184.5 & 0.4 \\
75.00 & 67.50 & 4185.6 & 4186.4 & 0.8 \\
80.00 & 70.00 & 4187.3 & 4188.7 & 1.4 \\
85.00 & 72.50 & 4189.2 & 4191.4 & 2.2 \\
90.00 & 75.00 & 4191.2 & 4194.4 & 3.2 \\
95.00 & 77.50 & 4193.4 & 4197.7 & 4.3 \\
\hline
\end{tabular}

$$
B=\Delta=\frac{\psi\left(T_{\text {out }}\right)-\psi\left(T_{\text {in }}\right)}{2}-\psi\left(T_{\text {ave }}\right)
$$

Some of the partial derivatives necessary for the solution of Equation 80 can be solved directly These solutions are listed below. 


$$
\begin{aligned}
& \frac{\partial \eta_{p}}{\partial V}=\frac{\eta_{p}}{V} \\
& \frac{\partial \eta_{p}}{\partial i}=\frac{\eta_{p}}{i} \\
& \frac{\partial \eta_{p}}{\partial Q}=\frac{-\eta_{p}}{Q} \\
& \frac{\partial \eta_{p}}{\partial \rho}=\frac{-\eta_{p}}{\rho} \quad \frac{\partial \eta_{p}}{\partial c}=\frac{-\eta_{p}}{c}
\end{aligned}
$$

The directly solved and iterative forward-difference solutions of the partial derivatives necessary to solve Equation 80 are presented in Tables 3-9 and 3-10. The systematic uncertainty estimates for the energy balance ratio are

\begin{tabular}{|c|c|c|c|c|}
\hline & & $x_{i}$ & $x_{i}+\Delta x_{i}$ & $\frac{\partial \eta_{P}}{\partial x_{i}}$ \\
\hline Energy balance ratio & $\eta_{\mathrm{P}}$ & 0.970 & ... & $\ldots$ \\
\hline $\begin{array}{l}\text { Applied voltage, V } \\
\text { Applied current, A } \\
\text { Flow, } \mathrm{cm}^{3} / \mathrm{s} \\
\text { Density, inlet (curve fit), } \mathrm{kg} / \mathrm{m}^{3}\end{array}$ & $\begin{array}{l}V \\
i \\
Q \\
\rho\end{array}$ & $\begin{array}{c}43.83 \\
699 \\
495 \\
981.9\end{array}$ & $\begin{array}{l}\cdots \\
\cdots \\
\cdots \\
\cdots\end{array}$ & $\begin{array}{c}0.0221 \\
0.00139 \\
-0.00196 \\
-0.000988\end{array}$ \\
\hline $\begin{array}{l}\text { Specific heat, bulk (curve fit), } \\
\mathrm{J} / \mathrm{kg} \cdot{ }^{\circ} \mathrm{C} \\
\text { Fluid property linearity }\end{array}$ & $c_{p}$ & 4186.0 & $\ldots$ & -0.000232 \\
\hline $\begin{array}{l}\text { assumption, } \mathrm{J} / \mathrm{kg} \cdot{ }^{\circ} \mathrm{C} \\
\text { Exit temperature, }{ }^{\circ} \mathrm{C} \\
\text { Inlet temperature, }{ }^{\circ} \mathrm{C}\end{array}$ & $\begin{array}{c}c_{p} \\
T_{\text {out }} \\
T_{\text {in }}\end{array}$ & $\begin{array}{l}4186.0 \\
60.00 \\
76.25\end{array}$ & $\begin{array}{c}\cdots \\
60.60 \\
77.01\end{array}$ & $\begin{array}{c}-0.000232 \\
0.0624 \\
-0.0571\end{array}$ \\
\hline
\end{tabular}
presented in Tables 3-11 and 3-12.

Table 3-9.--Energy balance ratio sensitivity coefficient estimates for construction 4 (open channel) at $7.5 \mathrm{gpm}$ 
Table 3-10.--Energy balance ratio sensitivity coefficient estimates for construction 4 (open channel) at $1260 \mathrm{~cm}^{3} / \mathrm{s}(20 \mathrm{gpm})$

\begin{tabular}{|c|c|c|c|c|}
\hline & & $x_{i}$ & $x_{i}+\Delta x_{i}$ & $\frac{\partial \eta_{P}}{\partial x_{i}}$ \\
\hline Energy balance ratio & $n_{p}$ & 0.970 & ... & ... \\
\hline $\begin{array}{l}\text { Applied voltage, } \mathrm{V} \\
\text { Applied current, A } \\
\text { Flow, } \mathrm{cm}^{3} / \mathrm{s} \\
\text { Density, inlet (curve fit), } \mathrm{kg} / \mathrm{m}^{3}\end{array}$ & $\begin{array}{l}\ddot{V} \\
i \\
Q\end{array}$ & $\begin{array}{l}43.83 \\
699 \\
1261 \\
981.9\end{array}$ & $\begin{array}{l}\cdots \\
\cdots \\
\cdots \\
\cdots\end{array}$ & $\begin{array}{l}0.0221 \\
0.00139 \\
-0.000769 \\
-0.000988\end{array}$ \\
\hline $\begin{array}{l}\text { Specific heat, bulk (curve fit), } \\
\mathrm{J} / \mathrm{kg} \cdot{ }^{\circ} \mathrm{C} \\
\text { Fluid property linearity }\end{array}$ & $C_{p}$ & 4183.1 & $\ldots$ & -0.000232 \\
\hline $\begin{array}{l}\text { assumption, } \mathrm{J} / \mathrm{kg} \cdot{ }^{\circ} \mathrm{C} \\
\text { Exit temperature, }{ }^{\circ} \mathrm{C} \\
\text { Inlet temperature, }{ }^{\circ} \mathrm{C}\end{array}$ & $\begin{array}{c}c_{p} \\
T_{\text {out }} \\
T_{\text {in }}\end{array}$ & $\begin{array}{c}4183.1 \\
60.00 \\
66.1\end{array}$ & $\begin{array}{c}\cdots \\
60.60 \\
77.01\end{array}$ & $\begin{array}{l}-0.000232 \\
0.1768 \\
-0.0947\end{array}$ \\
\hline
\end{tabular}

Table 3-13.--Energy balance ratio systematic uncertainty estimate for construction 4 (open channel) at $473 \mathrm{~cm}^{3} / \mathrm{s}(7.5 \mathrm{gpm}$ )

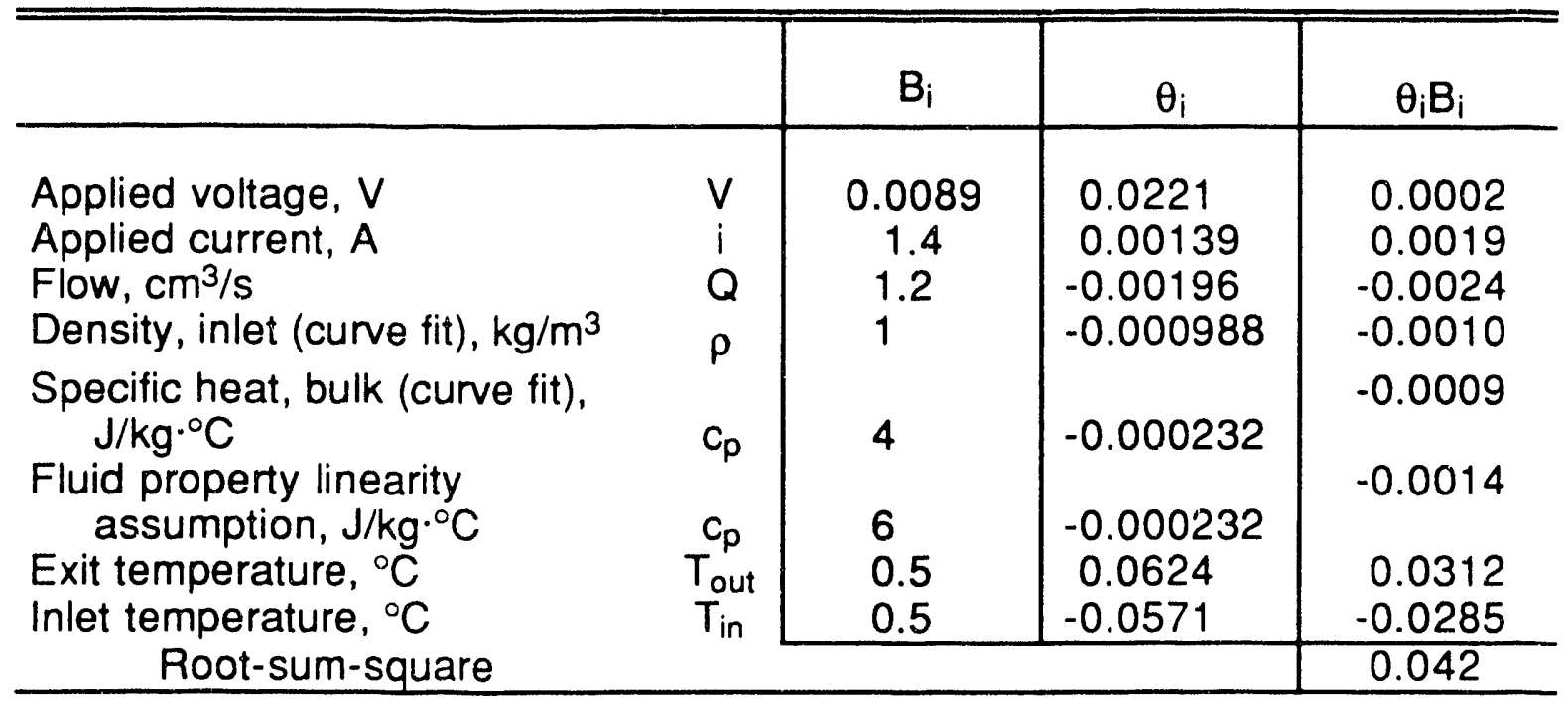


Table 3-14.--Energy balance ratio systematic uncertainty estimate for construction 4 (open channel) at $1261 \mathrm{~cm}^{3} / \mathrm{s}(20 \mathrm{gpm})$

\begin{tabular}{|c|c|c|c|c|}
\hline & & $B_{i}$ & $\theta_{i}$ & $\theta_{i} B_{i}$ \\
\hline $\begin{array}{l}\text { Applied voltage, V } \\
\text { Applied current, A } \\
\text { Flow, } \mathrm{cm}^{3} / \mathrm{s} \\
\text { Density, inlet (curve fit), } \mathrm{kg} / \mathrm{m}^{3}\end{array}$ & $\begin{array}{l}V \\
i \\
Q \\
\rho\end{array}$ & $\begin{array}{l}0.0089 \\
2^{1.4} \\
1\end{array}$ & $\begin{array}{l}0.0221 \\
0.00139 \\
-0.000769 \\
-0.000988\end{array}$ & $\begin{array}{r}0.0002 \\
0.0019 \\
-0.0015 \\
-0.0010\end{array}$ \\
\hline $\begin{array}{l}\text { Specific heat, bulk (curve fit), } \\
\mathrm{J} / \mathrm{kg} \cdot{ }^{\circ} \mathrm{C} \\
\text { Fluid property linearity }\end{array}$ & $c_{p}$ & 4 & -0.000232 & -0.0009 \\
\hline $\begin{array}{l}\text { assumption, } \mathrm{J} / \mathrm{kg} \cdot{ }^{\circ} \mathrm{C} \\
\text { Exit temperature, }{ }^{\circ} \mathrm{C} \\
\text { Inlet temperature, }{ }^{\circ} \mathrm{C}\end{array}$ & $\begin{array}{l}\mathrm{C}_{p} \\
\mathrm{~T}_{\text {out }} \\
\mathrm{T}_{\text {in }}\end{array}$ & $\begin{array}{l}6 \\
0.5 \\
0.5\end{array}$ & $\begin{array}{l}-0.000232 \\
0.1768 \\
-0.0947\end{array}$ & $\begin{array}{r}-0.0014 \\
0.0884 \\
-0.0473\end{array}$ \\
\hline Root-sum-square & & & & 0.10 \\
\hline
\end{tabular}




\section{Preliminary Data _- 9 September 1993}

\section{Heat Flux}

The heat flux can be calculated using three different methods. Two methods are based on assuming that the power applied the rig is uniform over the entire heated area so that the heat flux is then the power divided by the heated area. The third method is independent of the heated area estimate. It utilizes the thermocouples which are placed in different positions in the heated plate. These thermocouples measure the temperature gradient in the plate and therefore can be used to estimate the heat flux.

\section{Electrical}

The heat flux calculated from the electrical energy balance, $\phi_{\theta}$, is defined by Equation 3-6. As with the energy balance ratio, the loss term will be assumed zero.

$$
\phi_{e}=\frac{P_{e}}{A_{h}}=\frac{V i-\text { losses }}{L_{h} a_{h}}
$$

All of the necessary partial differential can readily be solved for directly. Their solutions are:

$$
\begin{array}{ll}
\frac{\partial \phi_{e}}{\partial V}=\frac{\phi_{e}}{V} & \frac{\partial \phi_{e}}{\partial i}=\frac{\phi_{e}}{i} \\
\frac{\partial \phi_{e}}{\partial L_{h}}=\frac{-\phi_{e}}{L_{h}} & \frac{\partial \phi_{e}}{\partial a_{h}}=\frac{-\phi_{e}}{a_{h}}
\end{array}
$$

The heat flux for Construction 2 was calculated based on the heated surface that was exposed to forced convection. This reduced the heated width by the rib width. Equation 3-6 then becomes: 


\section{Preliminary Data .. 9 September 1993}

$$
\phi_{e}=\frac{P_{e}}{A_{h}}=\frac{V i-\text { losses }}{L_{h}\left(a_{h}-x_{0}\right)}
$$

The partial differential solutions of Equation 3-7 are the same as for Equation 3-6 except as listed below.

$$
\frac{\partial \phi_{\theta}}{\partial a_{h}}=\frac{-\phi_{\theta}}{a_{h}-x_{0}} \quad \frac{\partial \phi_{\theta}}{\partial x_{0}}=\frac{-\phi_{\theta}}{a_{h}-x_{0}}
$$

The sensitivity coefficient estimates necessary to evaluate the uncertainties are presented in Tables 3-17 and 3-17b. Tables 3-18 and 3-18a provide the systematic uncertainty estimates.

Table 3-17.--Heat flux (electrical) sensitivity coefficient estimates for construction 4 (open chánnel) at $473 \mathrm{~cm}^{3} / \mathrm{s}(7.5 \mathrm{gpm}), 30.64 \mathrm{~kW}$

\begin{tabular}{lc|c|c|c}
\hline \hline & & $x_{i}$ & $x_{i}+\Delta x_{i}$ & $\frac{\partial \phi_{e}}{\partial x_{i}}$ \\
\hline Heat flux, $\mathrm{kW} / \mathrm{m}^{2}$ & & & & $\ldots$ \\
Applied voltage, V & $\phi_{\theta}$ & 330.0 & $\ldots$ & 7.53 \\
Applied current, A & $i$ & 43.83 & $\ldots$ & 0.472 \\
Heated width, mm & $a_{h}$ & 76.2 & $\ldots$ & .3 .33 \\
Rib width, mm & $x_{0}$ & 0.00 & $\ldots$ & 0.00 \\
Hei ted length, m & $L_{h}$ & 1.219 & $\ldots$ & -271 \\
\hline
\end{tabular}


Table 3-17b.--Heat flux (electrical) sensitivity coefficient estimates for construction 2 (rib) at $473 \mathrm{~cm}^{3} / \mathrm{s}(7.5 \mathrm{gpm}), 30.64 \mathrm{~kW}$.

\begin{tabular}{lc|c|c|c}
\hline \hline & & $x_{i}$ & $x_{i}+\Delta x_{i}$ & $\frac{\partial \phi_{e}}{\partial x_{i}}$ \\
\hline Heat flux, $\mathrm{kW} / \mathrm{m}^{2}$ & & & & $\ldots$ \\
Applied voltage, V & $\phi_{e}$ & 339.0 & $\ldots$ & $\ldots$ \\
Applied current, A & $\mathrm{V}$ & 43.83 & $\ldots$ & 7.73 \\
Heated width, mm & $a_{h}$ & 76.2 & $\ldots$ & 0.485 \\
Rib width, mm & $x_{0}$ & 2.07 & $\ldots$ & -4.57 \\
Heated length, m & $L_{h}$ & 1.219 & $\ldots$ & 4.57 \\
\hline
\end{tabular}

Table 3-18.--Heat flux (electrical) systematic uncertainty estimate for construction 4 (open channel) at $473 \mathrm{~cm}^{3} / \mathrm{s}(7.5 \mathrm{gpm}), 30.64 \mathrm{~kW}$

\begin{tabular}{ll|l|c|c}
\hline \hline & & \multicolumn{1}{|c|}{$\mathrm{B}_{\mathrm{i}}$} & $\theta_{\mathrm{i}}$ & $\theta_{\mathrm{i}} \mathrm{B}_{\mathrm{i}}$ \\
\hline & & & & \\
Applied voltage, $\mathrm{V}$ & $\mathrm{V}$ & 0.0089 & 7.53 & 0.07 \\
Applied current, A & $\mathrm{i}$ & 1.4 & 0.472 & 0.66 \\
Heated width, mm & $\mathrm{a}_{\mathrm{h}}$ & 1.6 & -4.33 & -6.93 \\
Rib width, mm & $\mathrm{x}_{0}$ & 0.00 & 0.00 & 0.00 \\
Heated length, m & $\mathrm{L}_{\mathrm{h}}$ & 0.001 & -271 & -0.27 \\
$\quad$ Root-sum-square & \multicolumn{3}{|r}{} & 7.0 \\
\hline
\end{tabular}

Table 3-18.--Heat fiux (electrical) systematic uncertainty estimate for construction 2 (rib) at $7.5 \mathrm{gpm}$

\begin{tabular}{|c|c|c|c|c|}
\hline & & $\mathrm{B}_{\mathrm{i}}$ & $\theta_{i}$ & $\theta_{i} B_{i}$ \\
\hline $\begin{array}{l}\text { Applied voltage, } V \\
\text { Applied current, A } \\
\text { Heated width, mm } \\
\text { Rib width, mm } \\
\text { Heated length, m } \\
\text { Root-sum-square }\end{array}$ & $\begin{array}{l}v \\
i \\
a_{h} \\
x_{0} \\
L_{h}\end{array}$ & $\begin{array}{l}0.0089 \\
1.4 \\
3.4 \\
0.04 \\
0.001 \\
\end{array}$ & $\begin{array}{c}7.73 \\
0.485 \\
-4.57 \\
4.57 \\
-278 \\
\end{array}$ & $\begin{array}{r}0.1 \\
0.7 \\
-15.5 \\
0.2 \\
-0.3 \\
15.6\end{array}$ \\
\hline
\end{tabular}




\section{Preliminary Data -- 9 September 1993}

Fluid

The heat flux calculated from the fluid energy balance, $\phi_{f}$, is defined by Equation 3-8. The loss term will again be assumed zero.

$$
\phi_{f}=\frac{P_{f}}{A_{h}}=\frac{Q \rho_{\text {in }} c_{p}\left(T_{\text {out }}-T_{\text {in }}\right)-\text { losses }}{L_{h} a_{h}}
$$

As with the energy balance ratio, the specific heat and the density uncertainty terms are a composite of several uncertainties. They will be handles in the same manner as used for the energy balance ratio uncertainty estimate.

Some of the partial derivatives listed in Equation 3-8 can be readily solved. These solutions are listed below.

$$
\begin{gathered}
\frac{\partial \phi_{f}}{\partial Q}=\frac{\phi_{f}}{Q} \quad \frac{\partial \phi_{f}}{\partial \rho_{\text {in }}}=\frac{\phi_{f}}{\rho_{\text {in }}} \quad \frac{\partial \phi_{f}}{\partial c_{p}}=\frac{\phi_{f}}{c_{p}} \\
\frac{\partial \phi_{f}}{\partial L}=\frac{-\phi_{f}}{L} \quad \frac{\partial \phi_{f}}{\partial a}=\frac{-\phi_{f}}{a}
\end{gathered}
$$

The directly solved and iterative forward-difference solutions the partial derivatives necessary to solve Equation 80 are presented in Table 3-19. The systematic uncertainty estimates for the ene:gy balance ratio are presented in Table 3-20. Since the uncertainty for this method is higher than the uncertainty calculated using the electrical energy balance, only the uncertainty estimate for Construction 4.0 is presented. 
Table 3-19.--Heat flux (fluid) sensitivity coefficient estimates for construction 4 (open channel) at $7.5 \mathrm{gpm}$

\begin{tabular}{|c|c|c|c|c|}
\hline & & $x_{i}$ & $x_{i}+\Delta x_{i}$ & $\frac{\partial \phi_{f}}{\partial x_{i}}$ \\
\hline Heat flux, $\mathrm{kW} / \mathrm{m}^{2}$ & $\phi_{f}$ & 330.0 & $\ldots$ & $\cdots$ \\
\hline $\begin{array}{l}\text { Flow, } \mathrm{cm}^{3} / \mathrm{s} \\
\text { Density, inlet (curve fit), } \mathrm{kg} / \mathrm{m}^{3}\end{array}$ & $\begin{array}{l}Q \\
\rho\end{array}$ & $\begin{array}{l}473.0 \\
981.9\end{array}$ & $\cdots$ & $\begin{array}{l}0.698 \\
0.336\end{array}$ \\
\hline $\begin{array}{l}\text { Specific heat, bulk (curve fit), } \\
\mathrm{J} / \mathrm{kg} \cdot{ }^{\circ} \mathrm{C} \\
\text { Fluid property linearity }\end{array}$ & $c_{p}$ & 4186.0 & $\cdots$ & $78.8 e-3$ \\
\hline $\begin{array}{l}\text { assumption, } \mathrm{J} / \mathrm{kg} \cdot{ }^{\circ} \mathrm{C} \\
\text { Inlet temperature, }{ }^{\circ} \mathrm{C} \\
\text { Exit temperature, }{ }^{\circ} \mathrm{C} \\
\text { Heated width, } \mathrm{mm} \\
\text { Rib width, } \mathrm{mm} \\
\text { Heated length, } \mathrm{m} \\
\end{array}$ & $\begin{array}{l}c_{p} \\
T_{\text {in }} \\
T_{\text {out }} \\
a_{h} \\
x_{0} \\
L_{h}\end{array}$ & $\begin{array}{c}4186.0 \\
60.00 \\
76.25 \\
76.2 \\
0.00 \\
1.219 \\
\end{array}$ & $\begin{array}{l}\cdots \\
60.60 \\
77.01 \\
\ldots \\
\ldots \\
\ldots \\
\end{array}$ & $\begin{array}{l}78.8 e-3 \\
-5.36 \\
34.4 \\
-4.33 \\
0.00 \\
-271\end{array}$ \\
\hline
\end{tabular}

Table 3-20.--Heat flux (fluid) systematic uncertainty estimate for construction 4 (open channel) at $7.5 \mathrm{gpm}$

\begin{tabular}{|c|c|c|c|c|}
\hline & & $\mathrm{B}_{\mathrm{i}}$ & $\theta_{i}$ & $\theta_{i} B_{i}$ \\
\hline $\begin{array}{l}\text { Flow, } \mathrm{cm}^{3} / \mathrm{s} \\
\text { Density, inlet (curve fit), } \mathrm{kg} / \mathrm{m}^{3}\end{array}$ & $\begin{array}{l}Q \\
\rho\end{array}$ & $\begin{array}{r}3 \\
20\end{array}$ & $\begin{array}{l}0.698 \\
0.336\end{array}$ & $\begin{array}{l}2.1 \\
6.7\end{array}$ \\
\hline $\begin{array}{l}\text { Specific heat, bulk (curve fit), } \\
\mathrm{J} / \mathrm{kg} \cdot{ }^{\circ} \mathrm{C}\end{array}$ & Co & 80 & $78.8 e-3$ & 6.3 \\
\hline Fluid property linearity & סט & & & 0.8 \\
\hline $\begin{array}{l}\text { assumption, } \mathrm{J} / \mathrm{kg} \cdot{ }^{\circ} \mathrm{C} \\
\text { Inlet temperature }{ }^{\circ} \mathrm{C}\end{array}$ & $\mathrm{C}_{\mathrm{p}}$ & $\begin{array}{l}10 \\
0.5\end{array}$ & $\begin{array}{l}78.8 e-3 \\
-5.36\end{array}$ & -2.7 \\
\hline Exit temperature, ${ }^{\circ} \mathrm{C}$ & $T_{\text {out }}$ & 0.5 & 34.4 & 17.2 \\
\hline Heated width, mm & $a_{h}$ & 3.4 & -4.33 & -14.7 \\
\hline $\begin{array}{l}\text { Rib width, mm } \\
\text { Heated length, } m\end{array}$ & $\begin{array}{l}x_{0} \\
L_{h}\end{array}$ & $\begin{array}{l}0.04 \\
0.001\end{array}$ & $\begin{array}{l}0.00 \\
-271\end{array}$ & $\begin{array}{r}0.0 \\
-0.3\end{array}$ \\
\hline Root-sum-square & & & & 24.7 \\
\hline
\end{tabular}




\section{Preliminary Data _- 9 September 1993}

Conduction

The wall temperature thermocouples could be used to estimate the local heat flux. The wall temperature data for File FS_930601_1136 presented in Tables 41 will be used for this analysis. The grand mean of the wetted thermocouple locations was $-0.33 \pm 0.05 \mathrm{~mm}$. The locations of the dry thermocouples were assumed to be at $-2.92 \pm 0.08 \mathrm{~mm}$. The thermal conductivity of aluminum at $130^{\circ} \mathrm{C}$ was taken as $173 \mathrm{~W} / \mathrm{m}^{\circ} \mathrm{C}$. (77)

$$
\begin{aligned}
\phi_{C} & =\frac{k\left(T_{d r y}-T_{\text {wet }}\right)}{\left|y_{d r y}-y_{\text {wet }}\right|} \\
& =\frac{\left(173 \frac{\mathrm{w}}{\mathrm{m}^{\circ} \mathrm{C}}\right)\left(133.98^{\circ} \mathrm{C}-127.43^{\circ} \mathrm{C}\right)}{|-2.92 \mathrm{~mm}+0.33 \mathrm{~mm}|} \\
& =438 \frac{\mathrm{W}}{\mathrm{m}^{2} \cdot{ }^{\circ} \mathrm{C}}
\end{aligned}
$$

The partial derivatives necessary for evaluation of the sensitivity coefficients are listed below.

$$
\begin{gathered}
\frac{\partial \phi_{c}}{\partial k}=\frac{\phi_{c}}{k} \quad \frac{\partial \phi_{c}}{\partial T_{d r y}}=\frac{\phi_{c}}{\left|T_{d r y}-T_{\text {wet }}\right|} \quad \frac{\partial \phi_{c}}{\partial T_{\text {wet }}}=\frac{\cdots \phi_{c}}{\left|T_{d r y}-T_{\text {wet }}\right|} \\
\frac{\partial \phi_{c}}{\partial y_{d r y}}=\frac{-\phi_{c}}{\left|y_{d r y}-y_{\text {wet }}\right|} \quad \frac{\partial \phi_{c}}{\partial y_{\text {wet }}}=\frac{\phi_{c}}{\left|y_{d r y}-y_{\text {wet }}\right|}
\end{gathered}
$$

The temperature uncertainty terms would be a combinution of the basic measurement uncertainty presented in Appendix 2 and the variability observed during the testing.

$$
\begin{aligned}
U_{T_{\text {dry }}} & =\sqrt{\left(0.5^{\circ} \mathrm{C}\right)^{2}+\left(2 \cdot 0.66^{\circ} \mathrm{C}\right)^{2}} \\
& =1.41^{\circ} \mathrm{C}
\end{aligned}
$$




$$
\begin{array}{ll}
\text { and } \\
\begin{aligned}
U_{T_{\text {wa }}}=\sqrt{\left(0.5^{\circ} \mathrm{C}\right)^{2}+\left(2 \cdot 0.76^{\circ} \mathrm{C}\right)^{2}} \\
=1.60^{\circ} \mathrm{C}
\end{aligned}
\end{array}
$$

Table 3-22 presents the uncertainty analysis for the heat flux calculated in Equation 3-9. The uncertainty is very large, $144 \mathrm{~W} / \mathrm{m}^{2}$. This large uncertainty bounds the heat flux calculated by alternate methods for File FS_930601_1136 and indicates that either the electrical or fluid energy balance methods are more appropriate for most of the data reduction.

Table 3-22.--Heat flux (conduction) systematic uncertainty estimate for

\begin{tabular}{|c|c|c|c|c|}
\hline & & $B_{i}$ & $\theta_{\mathrm{i}}$ & $\theta_{i} B_{i}$ \\
\hline $\begin{array}{l}\text { Thermal conductivity, } \mathrm{W} / \mathrm{m} \cdot{ }^{\circ} \mathrm{C} \\
\text { Wet wall temperature } \\
\text { Dry wall temperature } \\
\text { Wet wall location } \\
\text { Dry wall location }\end{array}$ & $\begin{array}{l}T_{\text {wet }}^{k} \\
T_{d r y} \\
y_{\text {wet }} \\
y_{d r y}\end{array}$ & $\begin{array}{l}2 \\
1.41 \\
1.60 \\
0.05 \\
0.08\end{array}$ & $\begin{array}{l}2.53 \\
-66.9 \\
66.9 \\
169 \\
-169\end{array}$ & $\begin{array}{r}5 \\
-94 \\
107 \\
8 \\
-14\end{array}$ \\
\hline Root-sum-square & & & & 144 \\
\hline
\end{tabular}
construction 4 (open channel) based on data presented in Table 403 for FS_930601_1136 


\section{Preliminary Data -- 9 September 1993}

\section{Q ratio}

The $Q_{\text {ratio }}$ is defined by Equation 3-10.

$$
Q_{\text {ratio }}=\frac{\phi_{\text {applied }}}{\phi_{\text {sat } @ \text { exit }}}
$$

When it is rewritten for directly measured or estimated values:

$$
Q_{\text {ratio }}=\frac{V i}{Q \rho_{\text {in }} c_{p}\left(T_{\text {sat }}-T_{\text {in }}\right)}
$$

As with other fluid energy terms the fluid property uncertainties are not independent of temperature uncertainties. Their uncertainties will be handled in the same manner as the energy balance ratio. Some of the partiai derivatives necessary for the solution of Equation 80 can readily be solved directly. These solutions are listed below.

$$
\begin{gathered}
\frac{\partial Q_{\text {ratio }}}{\partial V}=\frac{Q_{\text {rati, }}}{V} \quad \frac{\partial Q_{\text {ratio }}}{\partial i}=\frac{Q_{\text {ratio }}}{i} \quad \frac{\partial Q_{\text {ratio }}}{\partial Q}=\frac{-Q_{\text {ratio }}}{Q} \\
\frac{\partial Q_{\text {ratio }}}{\partial \rho_{\text {in }}}=\frac{-Q_{\text {ratio }}}{\rho_{\text {in }}} \quad \frac{\partial Q_{\text {ratio }}}{\partial c_{p}}=\frac{-Q_{\text {ratio }}}{c_{p}}
\end{gathered}
$$

The directly solved and iterative fo ward-difference solutions of the partial derivatives necessary to solve Equation 80 are presented in Table 3-23. The uncertainty estimate for Construction 4 is presented in Table 3.24a. For this estimate the effect of using the bulk specific heat based on the bulk channel temperature, rather than the bulk specific heat based on the inlet temperature and saturation temperature has been neglected. 


\section{Preliminary Data -- 9 September 1993}

Table 3-23.-- $Q_{\text {ratio }}$ sensitivity coefficient estimates for Equation 3-11 (Construction 4, open channel) at OFI

\begin{tabular}{|c|c|c|c|c|}
\hline & & $x_{i}$ & $x_{i}+\Delta x_{i}$ & $\frac{\partial Q_{\text {ratio }}}{\partial x_{i}}$ \\
\hline $\begin{array}{l}\text { Qratio } \\
\text { Applied voltage, } \\
\text { Applied current, A } \\
\text { Flow, } 10^{-6} \mathrm{~m}^{3} / \mathrm{s} \\
\text { Density, inlet (curve fit), } \mathrm{kg} / \mathrm{m}^{3} \\
\text { Spscific heat, bulk (curve fit), } \\
\mathrm{J} / \mathrm{kg} \cdot{ }^{\circ} \mathrm{C} \\
\text { Fluid property linearity } \\
\text { assumption, } \mathrm{J} / \mathrm{kg}^{\circ}{ }^{\circ} \mathrm{C} \\
\text { Inlet temperature, }{ }^{\circ} \mathrm{C} \\
\text { Outlet temperature, }{ }^{\circ} \mathrm{C} \\
\text { Exit pressure, } \mathrm{kPa} \text { abs } \\
\text { Saturation temperature, }{ }^{\circ} \mathrm{C}\end{array}$ & $\begin{array}{c}V \\
i \\
Q \\
\rho_{\text {in }} \\
c_{p} \\
c_{p} \\
T_{\text {in }} \\
T_{\text {out }} \\
P_{\text {ehl }} \\
T_{\text {sat }}\end{array}$ & $\begin{array}{l}0.7616 \\
43.83 \\
699 \\
210.2 \\
982.1 \\
4214.5 \\
4214.5 \\
59.52 \\
95.53 \\
128.5 \\
106.80 \\
\end{array}$ & $\begin{array}{c}\cdots \\
\cdots \\
\cdots \\
\cdots \\
\cdots \\
\cdots \\
\cdots \\
60.12 \\
96.49 \\
129.8 \\
107.87 \\
\end{array}$ & $\begin{array}{l}17.4 e-3 \\
1.09 e-3 \\
-4.76 e-3 \\
-775 e-6 \\
-181 e-6 \\
-181 e-6 \\
-5.11 e-3 \\
18.8 e-3 \\
-5.50 e-3 \\
-18.1 e-3\end{array}$ \\
\hline
\end{tabular}

Table 3-24.--Q $Q_{\text {ratio }}$ systematic uncertainty estimate for construction 4 (open channel) at OFI

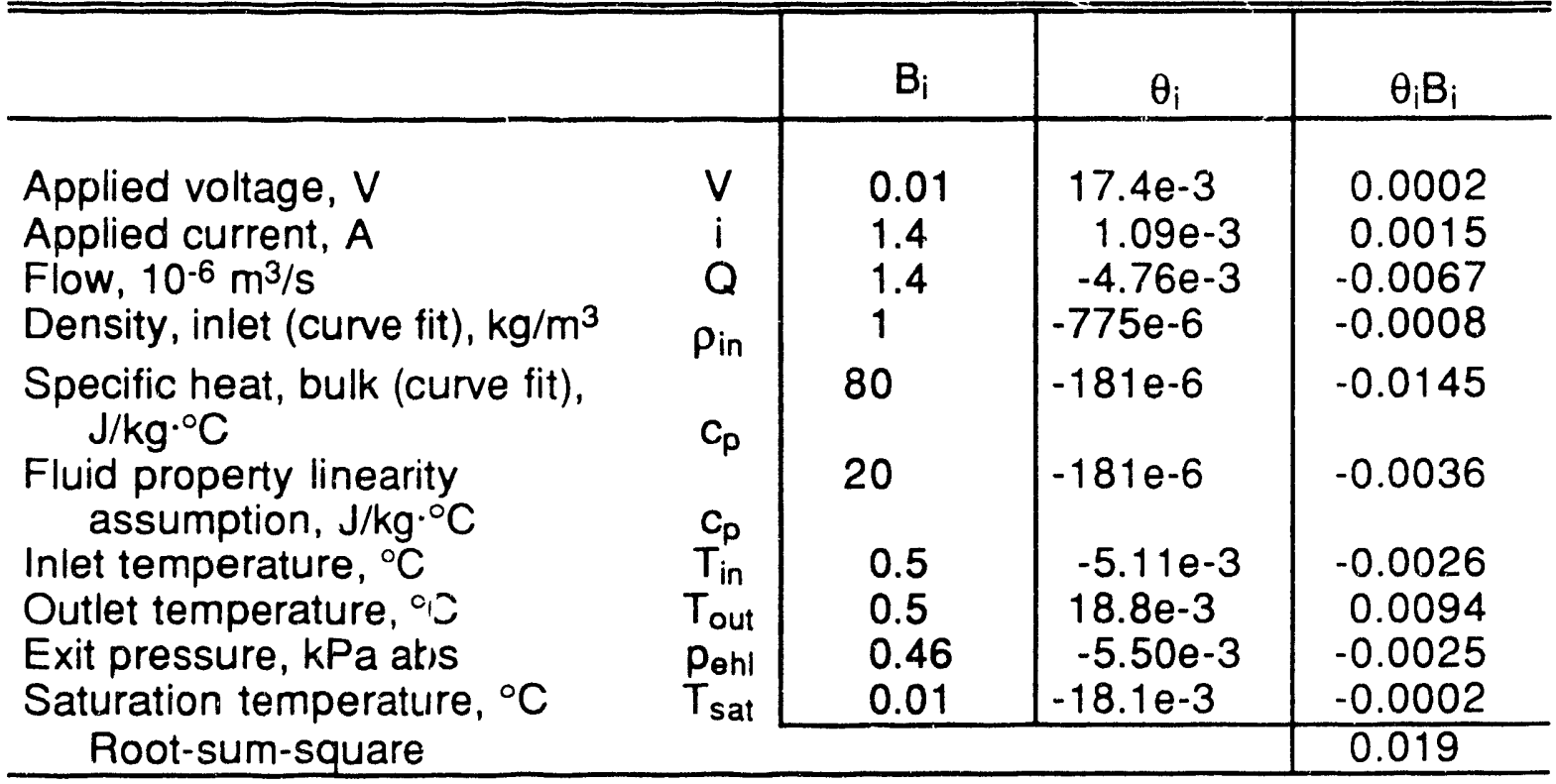




\section{Preliminary Data -- 9 September 1993}

There is a second method that can be used to calculate the $Q_{\text {ratio. }}$. For this method applied heat flux is calculated using the fluid energy balance. If the bulk specific heat calculated for the numerator is assumed equal to the bulk specific heat calculated in the denominator, Equation 3-10 then becomes:

$$
Q_{\text {ratin }}=\frac{T_{\text {out }}-T_{\text {in }}}{T_{\text {sat }}-T_{\text {in }}}
$$

Table 3-24b illustrates the difference between the bulk specific heats calculated using on the exit saturation temperature, $T_{\text {sat }}$, and the exit temperature, $T_{\text {out }}$. The specific heat assumption can be treated as a constant in the $Q_{\text {ratio }}$ equation such that:

$$
Q_{\text {ratio }}=c_{p}^{*} \frac{T_{\text {out }}-T_{\text {inlet }}}{T_{\text {sat }}-T_{\text {inlet }}}
$$

where:

$$
c_{p}{ }^{*}=\frac{C_{p, \text { subcooled }}}{C_{p, \text { sat } @ \text { exit }}}
$$

For construction 4.0:

$$
\begin{aligned}
c_{p, 4.0^{*}} & =\frac{4193.6}{4199.4} \\
& =0.9986
\end{aligned}
$$




\section{Preliminary Data -- 9 Septumber 1993}

Table 24b.--Specific heat estimates used in $Q_{\text {ratio }}$ uncertainty analysis

\begin{tabular}{c|c|c|c|c|c}
\hline \hline Construction & $\begin{array}{c}\text { Exit } \\
\text { Condition }\end{array}$ & $P_{\text {exit }}$ & $T_{\text {out }}$ & $T_{b}$ & $C_{p, b}$ \\
\hline \multirow{2}{*}{2} & Subcooled & 129.3 & 88.83 & 74.42 & 4190.7 \\
4 & Saturated & 129.3 & 106.98 & 83.49 & 4199.4 \\
& Subcooled & 128.5 & 95.53 & 77.76 & 4193.6 \\
& Saturated & 128.5 & 106.80 & 83.40 & 4199.3 \\
\hline
\end{tabular}

The forward-difference solutions of the partial derivatives for Equations 3-12 are presented in Tables $3-24 c$ and 3-24d. The systematic uncertainty estimates for the $Q_{\text {ratio }}$ calculated using Equation 3-12 are presented in Tables 3-25 and 3-26.

Table 3-24c.--Q $Q_{\text {ratio }}$ sensitivity coefficient estimates for construction 4 based on Equation 3-12 (open channel) at OFI

\begin{tabular}{lc|c|c|c}
\hline \hline & & $x_{i}$ & $x_{i}+\Delta x_{i}$ & $\frac{\partial Q_{\text {ratio }}}{\partial x_{i}}$ \\
\hline$Q_{\text {ratio }}$ & & 0.7616 & $\ldots$ & $\ldots$ \\
Inlet temperature, ${ }^{\circ} \mathrm{C}$ & $\mathrm{T}_{\text {in }}$ & 59.52 & 60.12 & $-5.11 \mathrm{e}-3$ \\
Outlet temperature, $^{\circ} \mathrm{C}$ & $\mathrm{T}_{\text {out }}$ & 95.53 & 96.49 & $21.1 \mathrm{e}-3$ \\
Exit pressure, $\mathrm{kPa}$ abs & $\mathrm{P}_{\text {ehl }}$ & 128.5 & 129.8 & $-3.62 \mathrm{e}-3$ \\
Saturation temperature, ${ }^{\circ} \mathrm{C}$ & $\mathrm{T}_{\text {sat }}$ & 106.80 & 107.87 & $-15.8 \mathrm{e}-3$ \\
Specific heat simplification & $\mathrm{C}_{\mathrm{p}^{*}}$ & 1.00 & $\ldots$ & 0.759 \\
\hline
\end{tabular}




\section{Preliminary Data -- 9 September 1993}

Table 3-24d.--Q $Q_{\text {ratio }}$ sensitivity coefficient estimates for construction 2 (rib channel) at OFI

\begin{tabular}{|c|c|c|c|c|}
\hline & & $x_{i}$ & $x_{i}+\Delta x_{i}$ & $\frac{\partial Q_{\text {ratio }}}{\partial x_{i}}$ \\
\hline $\begin{array}{l}\mathrm{Q}_{\text {ratio }} \\
\text { Inlet temperature, }{ }^{\circ} \mathrm{C} \\
\text { Outlet temperature, }{ }^{\circ} \mathrm{C} \\
\text { Exit pressure, } \mathrm{kPa} \text { abs } \\
\text { Saturation temperature, }{ }^{\circ} \mathrm{C} \\
\text { Specific heat simplification }\end{array}$ & $\begin{array}{c}T_{\text {in }} \\
T_{\text {out }} \\
P_{\text {ehl }} \\
T_{\text {sat }} \\
\text { sp }^{\star}\end{array}$ & $\begin{array}{c}0.6196 \\
59.26 \\
88.83 \\
129.3 \\
106.98 \\
1.00 \\
\end{array}$ & $\begin{array}{c}\ldots \\
59.85 \\
89.72 \\
130.6 \\
108.05 \\
\cdots \\
\end{array}$ & $\begin{array}{c}\cdots \\
-8.07 e-3 \\
21.0 e-3 \\
-2.92 e-3 \\
-12.7 e-3 \\
0.620 \\
\end{array}$ \\
\hline
\end{tabular}

Table 3-25.-- $Q_{\text {ratio }}$ systematic uncertainty estimate for construction 4 (open channel) at OFI

\begin{tabular}{|c|c|c|c|c|}
\hline & & $B_{i}$ & $\theta_{i}$ & $\theta_{i} \mathrm{~B}_{\mathrm{i}}$ \\
\hline $\begin{array}{l}\text { Inlet temperature, }{ }^{\circ} \mathrm{C} \\
\text { Outlet temperature, }{ }^{\circ} \mathrm{C} \\
\text { Exit pressure, } \mathrm{Pa} \text { abs } \\
\text { Saturation temperature, }{ }^{\circ} \mathrm{C} \\
\text { Specific heat simplification }\end{array}$ & $\begin{array}{l}T_{\text {in }} \\
T_{\text {out }} \\
\text { Peth }_{1} \\
T_{\text {sat }} \\
c_{p^{*}}\end{array}$ & $\begin{array}{l}0.5 \\
0.5 \\
0.46 \\
0.01 \\
0.0014 \\
\end{array}$ & $\begin{array}{c}-5.11 e-3 \\
21.1 \mathrm{e}-3 \\
-3.62 \mathrm{e}-3 \\
-15.8 \mathrm{e}-3 \\
0.759 \\
\end{array}$ & $\begin{array}{r}-0.0026 \\
0.0105 \\
-0.0017 \\
-0.0002 \\
0.0011 \\
\end{array}$ \\
\hline Root-sum-square & & & & 0.0110 \\
\hline
\end{tabular}

Table 3-26.-- $Q_{\text {ratio }}$ systematic uncertainty estimate for construction 2 (rib channel) at OFI

\begin{tabular}{|c|c|c|c|c|}
\hline & & $B_{i}$ & $\theta_{i}$ & $\theta_{i} \mathrm{~B}_{i}$ \\
\hline $\begin{array}{l}\text { Inlet temperature, }{ }^{\circ} \mathrm{C} \\
\text { Outlet temperature, }{ }^{\circ} \mathrm{C} \\
\text { Exit pressure, } \mathrm{Pa} \text { abs } \\
\text { Saturation temperature, }{ }^{\circ} \mathrm{C} \\
\text { Specific heat simplification }\end{array}$ & $\begin{array}{l}T_{\text {in }} \\
T_{\text {out }} \\
p_{\text {enl }} \\
T_{\text {sat }} \\
C_{p^{*}}\end{array}$ & $\begin{array}{l}0.5 \\
0.5 \\
0.46 \\
0.01 \\
0.0021\end{array}$ & $\begin{array}{c}-8.07 e-3 \\
21.0 e-3 \\
-2.92 e-3 \\
-12.7 e-3 \\
0.620\end{array}$ & $\begin{array}{r}-0.0040 \\
0.0105 \\
-0.0013 \\
-0.0001 \\
0.0013\end{array}$ \\
\hline Root-sum-square & & & & 0.0114 \\
\hline
\end{tabular}




\section{Preliminary Data .- 9 September 1993}

\section{Q ratio Rib-Effect-Ratio}

The $Q_{\text {ratio }}$ rib-effect-ratio is a comparative test result where the correlation of systematic uncertainties is important. This topic is discussed more fully in Chapter 3. The $Q_{\text {ratio }}$ rib-effect-ratio is defined as:

$$
\eta_{\mathrm{Q}_{\text {rato }}}=\frac{Q_{\text {ratio, r }}}{Q_{\text {ratio, o }}}
$$

The partial derivatives necessary for the evaluation of Equation 80 can be derived from the information in Tables $3-24 c$, or $3-24 d$, and the partial derivatives of Equation 3-14.

$$
\frac{\partial \eta_{Q_{\text {rati }}}}{\partial Q_{\text {ratio, } r}}=\frac{\eta_{Q_{\text {ratio }}}}{Q_{\text {ratio, } r}} \quad \frac{\partial \eta_{Q_{\text {rato }}}}{\partial Q_{\text {ratio, }}}=\frac{-\eta_{Q_{\text {ratio }}}}{Q_{\text {ratio, o }}}
$$

The partial derivatives necessary for the solution of Equation 80 are listed in Table 3-27. Table 3-28 provides the weighted elemental uncertainties for the first term in Equation 80. Table 28a provides the weighted uncertainties for the second term in Equation 80. These may be combined to determine the total systematic uncertainty of the $Q_{\text {ratio }}$ rib-effect-ratio.

$$
\begin{aligned}
B_{\eta_{a_{\text {tato }}}} & =\sqrt{(0.0191)^{2}-0.00353} \\
& =0.0034
\end{aligned}
$$


Table 3-27.---Q $Q_{\text {ratio }}$ rib-effect-ratio sensitivity coefficient estimates for construction 2 (rib channel) at OFI

\begin{tabular}{|c|c|c|c|c|}
\hline & & $\frac{\partial Q_{\text {ratio, } j}}{\partial x_{i}}$ & $\frac{\partial \eta_{Q_{\text {rato }}}}{\partial Q_{\text {ratio, } j}}$ & $\frac{\partial \eta_{Q_{\text {ratio }}}}{\partial x_{i}}$ \\
\hline 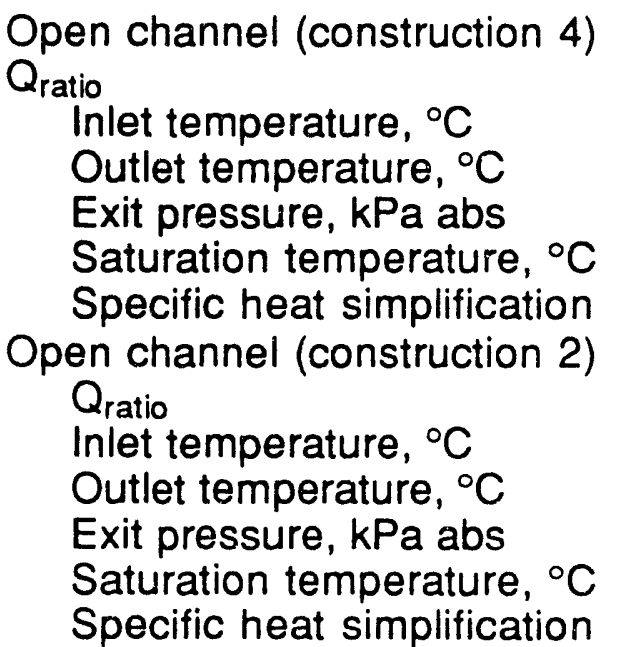 & $\begin{array}{l}T_{\text {in }} \\
T_{\text {out }} \\
p_{\text {ehl }} \\
T_{\text {sat }} \\
c_{p^{*}}\end{array}$ & $\begin{array}{c}1.00 \\
-5.11 e-3 \\
21.1 e-3 \\
-3.62 e-3 \\
-15.8 e-3 \\
0.759 \\
\\
1.00 \\
-8.07 e-3 \\
21.0 e-3 \\
-2.92 e-3 \\
-12.7 e-3 \\
0.620\end{array}$ & $\begin{array}{l}-1.076 \\
-1.076 \\
-1.076 \\
-1.076 \\
-1.076 \\
-1.076 \\
1.318 \\
1.318 \\
1.318 \\
1.318 \\
1.318 \\
1.318\end{array}$ & $\begin{array}{l}-1.07 \\
5.49 e-3 \\
-22.7 e-3 \\
3.89 e-3 \\
17.0 e-3 \\
-816 . e-3 \\
\\
1.31 \\
-10.6 e-3 \\
27.6 e-3 \\
-3.84 e-3 \\
-16.7 e-3 \\
817 . e-3\end{array}$ \\
\hline
\end{tabular}

Table 3-28.-- $Q_{\text {ratio }}$ rib-effect-ratio systematic uncertainty estimate for construction 4 (open channel) at CFI

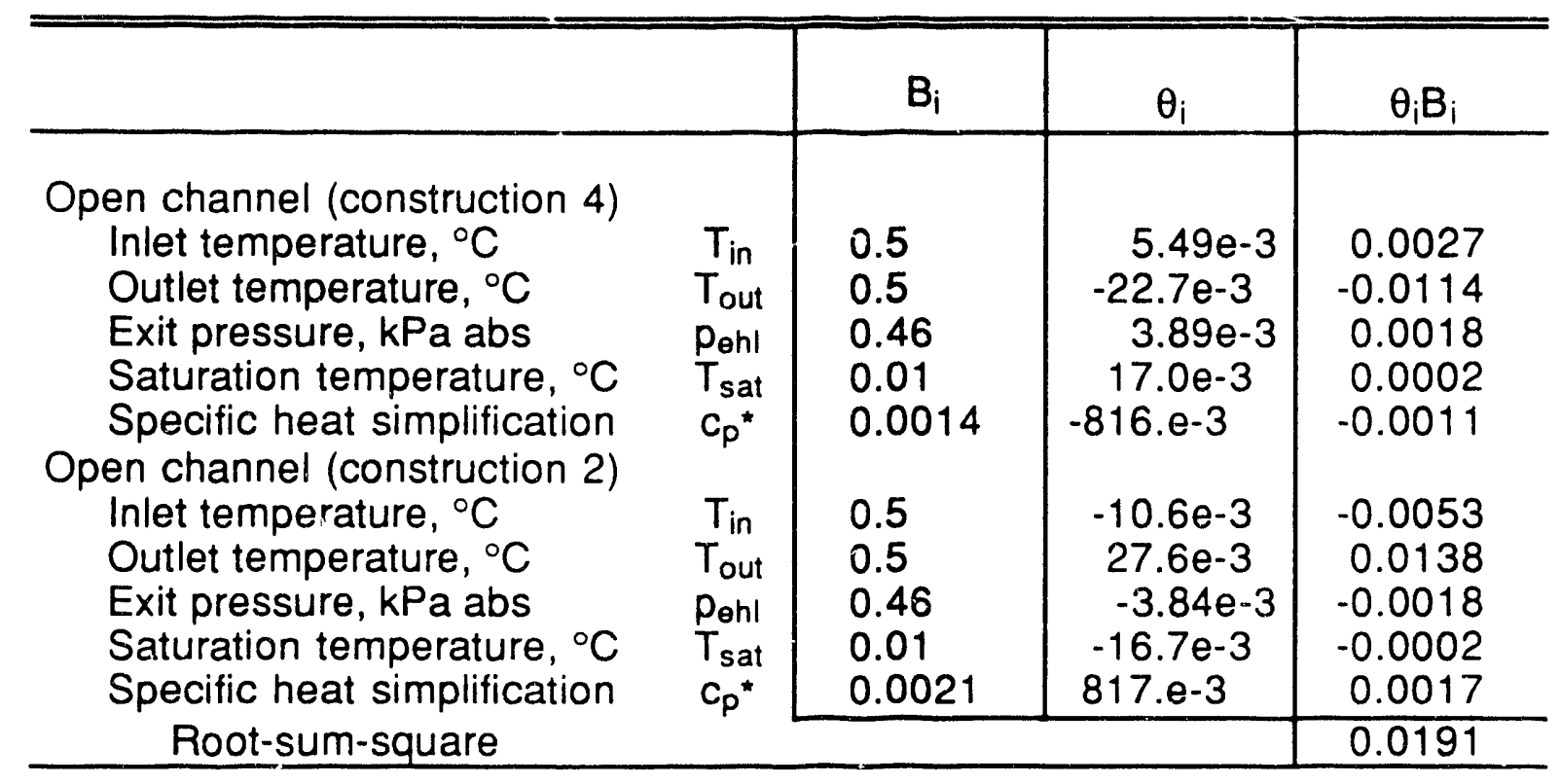




\section{Preliminary Data -- 9 September 1993}

Table 3-28a.--Stanton number rib-effect-ratio systematic uncertainty for rib channel, construction 2 at $\mathrm{OFI}$, inlet temperature $60^{\circ} \mathrm{C}$

\begin{tabular}{|c|c|c|c|c|c|c|}
\hline & \multirow[t]{2}{*}{$\rho_{\text {ik }}$} & \multicolumn{2}{|c|}{$\mathrm{B}_{\mathrm{i}}$} & \multicolumn{2}{|c|}{$\theta_{i}$} & \multirow[t]{2}{*}{$2 \rho_{i k} \theta_{i, o} \theta_{i, r} B_{i, o} B_{i, r}$} \\
\hline & & open & rib & open & rib & \\
\hline $\begin{array}{l}T_{\text {in }} \\
T_{\text {out }} \\
p_{\text {ehl }} \\
T_{\text {sat }} \\
c_{p^{*}}\end{array}$ & $\begin{array}{l}1 \\
1 \\
1 \\
1 \\
1\end{array}$ & $\begin{array}{l}0.5 \\
0.5 \\
0.46 \\
0.01 \\
0.0014\end{array}$ & $\begin{array}{l}0.5 \\
0.5 \\
0.46 \\
0.01 \\
0.0021\end{array}$ & $\begin{array}{c}5.49 e-3 \\
-22.7 e-3 \\
3.89 e-3 \\
17.0 e-3 \\
-816 . e-3\end{array}$ & $\begin{array}{c}-10.6 e-3 \\
27.6 e-3 \\
-3.84 e-3 \\
-16.7 e-3 \\
817 . e-3\end{array}$ & $\begin{array}{l}-0.000029 \\
-0.000313 \\
-0.000006 \\
-0.000000 \\
-0.000004\end{array}$ \\
\hline \multicolumn{6}{|c|}{ Sum } & -0.000353 \\
\hline
\end{tabular}

\section{Reynolds Number}

Equation 3-17 provides the Reynolds number in terms of the data reduction input quantities

$$
R e=\frac{Q \rho_{b} D}{A F \mu_{b}}
$$

As with the friction factor, the physical property terms are correlated with the temperature measurements. The analysis will be completed using the same methodology as used for the friction factor. Some of the partial derivatives of Equation 3-17 are listed below.

$$
\frac{\partial R e}{\partial Q}=\frac{R e}{Q} \quad \frac{\partial R e}{\partial \rho_{b}}=\frac{R e}{\rho_{b}} \quad \frac{\partial R e}{\partial \mu_{b}}=\frac{-R e}{\mu_{b}}
$$

The more complicated partial derivatives have been solved using a forwarddifference technique. The partial derivatives are listed in Tables 3-29, 3-30, 331, ana 3-32. The uncertainty estimates are contained in Table 3-33, 3-34, 335, arid 3-36. 
Table 3-29.--Reynolds number sensitivity coefficient estimates for open channel, construction 4 , inlet temperature $60^{\circ} \mathrm{C}, \mathrm{Re}=10,000$

\begin{tabular}{lc|c|c|c}
\hline & & $x_{i}$ & $x_{i}+\Delta x_{i}$ & $\frac{\partial R e}{\partial x_{i}}$ \\
\hline Reynolds number & & & & $\ldots$ \\
Channel width, mm & Re & 10,000 & $\ldots$ & -119 \\
Channel depth, mm & $\mathrm{m}$ & 79.8 & 80.6 & -121 \\
Rib width, mm & 3.16 & 3.19 & 0.000 \\
Bulk density, $\mathrm{kg} / \mathrm{m}^{3}$ & $\mathrm{x}_{0}$ & 0.00 & $\ldots$ & 10.2 \\
Flow, $\mathrm{cm}^{3} / \mathrm{s}$ & $\rho_{b}$ & 981.9 & 991.7 & 50.4 \\
Inlet temperature, ${ }^{\circ} \mathrm{C}$ & $\mathrm{Q}$ & 198.4 & 200.4 & 72.73 \\
Exit temperature, ${ }^{\circ} \mathrm{C}$ & $\mathrm{T}_{\text {in }}$ & 60.00 & 60.60 & 72.73 \\
Viscosity, bulk, $\mu \mathrm{Pa} \cdot \mathrm{s}$ & $\mathrm{T}_{\text {out }}$ & 60.00 & 60.60 & -21.1 \\
\hline
\end{tabular}

Table 3-30.--Reynolds number sensitivity coefficient estimates for open channel, construction 4.0 , inlet temperature $60^{\circ} \mathrm{C}, R e=20,000$

\begin{tabular}{lc|c|c|c}
\hline & & $x_{i}$ & $x_{i}+\Delta x_{i}$ & $\frac{\partial R e}{\partial x_{i}}$ \\
\hline Reynolds number & & & & $\ldots$ \\
Channel width, mm & Re & 20,000 & $\ldots$ & -239 \\
Channel depth, mm & $\mathrm{a}$ & 79.8 & 80.6 & -241 \\
Rib width, mm & 3.16 & 3.19 & 0.000 \\
Bulk density, $\mathrm{kg} / \mathrm{m}^{3}$ & $\mathrm{x}_{\mathrm{o}}$ & 0 & $\ldots$ & 20.4 \\
Flow, $\mathrm{cm}^{3} / \mathrm{s}$ & $\rho_{\mathrm{b}}$ & 981.9 & 991.7 & $101 \mathrm{e}-3$ \\
Inlet temperature, ${ }^{\circ} \mathrm{C}$ & $\mathrm{Q}$ & 396.8 & 400.8 & 145 \\
Exit temperature, ${ }^{\circ} \mathrm{C}$ & $\mathrm{T}_{\text {in }}$ & 60.00 & 60.60 & 145 \\
Viscosity, bulk, $\mu \mathrm{Pa} \cdot \mathrm{s}$ & $\mathrm{T}_{\text {out }}$ & 60.00 & 60.60 & -42.2 \\
\hline
\end{tabular}




\section{Preliminary Data -- 9 September 1993}

Table 3-31.--Reynolds number sensitivity coefficient estimates for rib channel, construction 2, inlet temperature $60^{\circ} \mathrm{C}, \mathrm{Re}=10,000$

\begin{tabular}{lc|c|c|c}
\hline \hline & & $x_{i}$ & $x_{i}+\Delta x_{i}$ & $\frac{\partial R e}{\partial x_{i}}$ \\
\hline Reynolds number & $R e$ & 10,000 & $\ldots$ & $\ldots$ \\
Channel width, mm & $a$ & 79.6 & 80.4 & -118 \\
Channel depth, mm & $b$ & 3.09 & 3.12 & -239 \\
Rib width, mm & $x_{0}$ & 2.07 & 2.09 & 120 \\
Bulk density, $\mathrm{kg} / \mathrm{m}^{3}$ & $\rho_{b}$ & 981.9 & 991.7 & 10.2 \\
Flow, $\mathrm{cm}^{3} / \mathrm{s}$ & $\mathrm{Q}$ & 200.2 & 202.2 & 50.0 \\
Inlet temperature, ${ }^{\circ} \mathrm{C}$ & $\mathrm{T}_{\text {in }}$ & 60.00 & 60.60 & 72.7 \\
Exit temperature, ${ }^{\circ} \mathrm{C}$ & $\mathrm{T}_{\text {out }}$ & 60.00 & 60.30 & 72.7 \\
Viscosity, bulk, $\mu \mathrm{Pa} \cdot \mathrm{s}$ & $\mu_{b}$ & 469.6 & 474.3 & -21.1 \\
\hline
\end{tabular}

Table 3-32.--Reynolds number sensitivity coefficient estimates for rib channel, construction 2.0 , inlet temperature $60^{\circ} \mathrm{C}, R e=20,000$

\begin{tabular}{|c|c|c|c|c|}
\hline & & $x_{i}$ & $x_{i}+\Delta x_{i}$ & $\frac{\partial R e}{\partial x_{i}}$ \\
\hline $\begin{array}{l}\text { Reynolds number } \\
\text { Channel width, mm } \\
\text { Channel depth, mm } \\
\text { Rib width, } \mathrm{mm} \\
\text { Bulk density, } \mathrm{kg} / \mathrm{m}^{3}\end{array}$ & $\begin{array}{l}\mathrm{Re} \\
a \\
b \\
x_{0} \\
\rho_{b}\end{array}$ & $\begin{array}{l}20,000 \\
79.6 \\
3.09 \\
2.07 \\
981.9\end{array}$ & $\begin{array}{c}\cdots \\
80.4 \\
3.12 \\
2.09 \\
991.7\end{array}$ & $\begin{array}{c}\cdots \\
-237 \\
-477 \\
239 \\
20.4\end{array}$ \\
\hline $\begin{array}{l}\text { Flow, } \mathrm{cm}^{3} / \mathrm{s} \\
\text { Inlet temperature, }{ }^{\circ} \mathrm{C} \\
\text { Exit temperature, }{ }^{\circ} \mathrm{C} \\
\text { Viscosity, bulk, } \mu \mathrm{Pa} \cdot \mathrm{s}\end{array}$ & $\begin{array}{c}Q \\
T_{\text {in }} \\
T_{\text {out }} \\
\mu_{b}\end{array}$ & $\begin{array}{c}400.3 \\
60.00 \\
60.00 \\
469.6 \\
\end{array}$ & $\begin{array}{l}404.3 \\
60.60 \\
60.60 \\
474.30 \\
\end{array}$ & $\begin{array}{l}50.0 \\
145.4 \\
145.4 \\
-42.2 \\
\end{array}$ \\
\hline
\end{tabular}


Table 3-33.--Reynolds number systematic uncertainty estimate for open channel, construction 4 , inlet temperature $60^{\circ} \mathrm{C}, R e=10,000$

\begin{tabular}{lc|c|c|r}
\hline \hline & & $B_{i}$ & $\theta_{i}$ & $\theta_{i} B_{i}$ \\
\hline Channel width, mm & $\mathrm{a}$ & 0.4 & -119 & -48 \\
Channel depth, mm & $\mathrm{b}$ & 0.2 & -121 & -24 \\
Rib width, mm & $\mathrm{x}_{\mathrm{o}}$ & 0.04 & 0.000 & 0 \\
Bulk density, $\mathrm{kg} / \mathrm{m}^{3}$ & $\rho_{\mathrm{b}}$ & 1 & 10.2 & 10 \\
Flow, $10^{-6} \mathrm{~m}^{3} / \mathrm{s}$ & $\mathrm{Q}$ & 1.4 & 50.4 & 71 \\
Inlet temperature, ${ }^{\circ} \mathrm{C}$ & $\mathrm{T}_{\text {in }}$ & 0.53 & 72.73 & 39 \\
Exit temperature, ${ }^{\circ} \mathrm{C}$ & $\mathrm{T}_{\text {out }}$ & 0.53 & 72.73 & 39 \\
Viscosity, bulk, $\mu \mathrm{Pa} \cdot \mathrm{s}$ & $\mu_{\mathrm{b}}$ & 2 & -21.1 & -42 \\
Root-sum-square & & & & 113 \\
\hline
\end{tabular}

Table 3-34.--Reynolds number systematic uncertainty estimate for open channel, construction 4.0 , inlet temperature $60^{\circ} \mathrm{C}, \operatorname{Re}=20,000$

\begin{tabular}{|c|c|c|c|c|}
\hline & & $B_{i}$ & $\theta_{i}$ & $\theta_{i} B_{i}$ \\
\hline $\begin{array}{l}\text { Channel width, } \mathrm{mm} \\
\text { Channel depth, } \mathrm{mm} \\
\text { Rib width, } \mathrm{mm} \\
\text { Bulk density, } \mathrm{kg} / \mathrm{m}^{3}\end{array}$ & $\begin{array}{l}a \\
b \\
x_{0} \\
\rho_{b}\end{array}$ & $\begin{array}{l}0.4 \\
0.2 \\
0.04 \\
1\end{array}$ & $\begin{array}{c}-239 \\
-241 \\
0.000 \\
20.4\end{array}$ & $\begin{array}{r}-96 \\
-48 \\
0 \\
20\end{array}$ \\
\hline $\begin{array}{l}\text { Flow, } 10^{-6} \mathrm{~m}^{3} / \mathrm{s} \\
\text { Inlet temperature, }{ }^{\circ} \mathrm{C} \\
\text { Exit temperature, }{ }^{\circ} \mathrm{C} \\
\text { Viscosity, bulk, } \mu \mathrm{Pa} \cdot \mathrm{s}\end{array}$ & $\begin{array}{c}Q \\
T_{\text {in }} \\
T_{\text {out }} \\
\mu_{b}\end{array}$ & $\begin{array}{l}1.4 \\
0.53 \\
0.53 \\
2 \\
\end{array}$ & $\begin{array}{l}101 \mathrm{e}-3 \\
145 \\
145 \\
-42.2 \\
\end{array}$ & $\begin{array}{r}0 \\
77 \\
77 \\
-84 \\
\end{array}$ \\
\hline Root-sum-square & & & & 176 \\
\hline
\end{tabular}




\section{Preliminary Data .. 9 September 1993}

Table 3-35.--Reynolds number systematic uncertainty estimate for rib channel, construction 2 , inlet temperature $60^{\circ} \mathrm{C}, \mathrm{Re}=10,000$

\begin{tabular}{lc|c|c|c}
\hline & & $\mathrm{B}_{\mathrm{i}}$ & $\theta_{\mathrm{i}}$ & $\theta_{\mathrm{i}} \mathrm{B}_{\mathrm{i}}$ \\
\hline Channel width, mm & & 0.4 & -118 & -47 \\
Channel depth, mm & $\mathrm{a}$ & 0.2 & -239 & -48 \\
Rib width, mm & $\mathrm{x}_{\mathrm{o}}$ & 0.04 & 120 & 5 \\
Bulk density, $\mathrm{kg} / \mathrm{m}^{3}$ & $\rho_{\mathrm{b}}$ & 1 & 10.2 & 10 \\
Flow, 10-6 $\mathrm{m}^{3 / \mathrm{s}}$ & $\mathrm{Q}$ & 1.4 & 50.0 & 70 \\
Inlet temperature, ${ }^{\circ} \mathrm{C}$ & $\mathrm{T}_{\text {in }}$ & 0.53 & 72.7 & 39 \\
Exit temperature, ${ }^{\circ} \mathrm{C}$ & $\mathrm{T}_{\text {out }}$ & 0.53 & 72.7 & 39 \\
Viscosity, bulk, $\mu \mathrm{Pa} \cdot \mathrm{s}$ & $\mu_{\mathrm{b}}$ & 2 & -21.1 & -42 \\
Root-sum-square & & & & 120 \\
\hline
\end{tabular}

Table 3-36.--Reynolds number systematic uncertainty estimate for rib channel, construction 2.0 , inlet temperature $60^{\circ} \mathrm{C}, \mathrm{Re}=20,000$

\begin{tabular}{lc|c|c|c}
\hline \hline & & $B_{i}$ & $\theta_{i}$ & $\theta_{i} B_{i}$ \\
\hline Channel width, mm & $\mathrm{a}$ & 0.4 & -237 & -95 \\
Channel depth, mm & $\mathrm{b}$ & 0.2 & -477 & -95 \\
Rib width, mm & $\mathrm{x}_{\mathrm{o}}$ & 0.04 & 239 & 10 \\
Bulk density, $\mathrm{kg} / \mathrm{m}^{3}$ & $\rho_{\mathrm{b}}$ & 1 & 20.4 & 20 \\
Flow, 10.6 $\mathrm{m}^{3} / \mathrm{s}$ & $\mathrm{Q}$ & 1.4 & 50.0 & 70 \\
Inlet temperature, ${ }^{\circ} \mathrm{C}$ & $\mathrm{T}_{\text {in }}$ & 0.53 & 145.4 & 77 \\
Exit temperature, ${ }^{\circ} \mathrm{C}$ & $\mathrm{T}_{\text {out }}$ & 0.53 & 145.4 & 77 \\
Viscosity, bulk, $\mu \mathrm{Pa} \cdot \mathrm{s}$ & $\mu_{\mathrm{b}}$ & 2 & -42.2 & -84 \\
Root-sum-square & & & & 206 \\
\hline
\end{tabular}




\section{Preliminary Data -- 9 September 1993}

\section{Stanton Number}

The Stanton number is defined in Equation 3. When it is rewritten for directly measured or estimated values:

$$
S t=\frac{a b V i}{A_{h} Q \rho_{\text {in }} c_{p, \text { out }}\left(T_{\text {sat }}-T_{\text {out }}\right)}
$$

As with other fluid energy terms, the fluid property uncertainties are not independent of temperature uncertainties. Their uncertainties will be handled in the same manner as the energy balance ratio. Some of the partial derivatives necessary for the solution of Equation 80 can readily be solved directly. These solutions are listed below.

$$
\begin{aligned}
& \frac{\partial S t}{\partial a}=\frac{S t}{a} \quad \frac{\partial S t}{\partial b}=\frac{S t}{b} \quad \frac{\partial S t}{\partial V}=\frac{S t}{V} \\
& \frac{\partial S t}{\partial i}=\frac{S t}{i} \quad \frac{\partial S t}{\partial Q}=\frac{-S t}{Q} \quad \frac{\partial S t}{\partial \rho_{\text {in }}}=\frac{-S t}{\rho_{\text {in }}} \\
& \frac{\partial S t}{\partial c_{p, \text { out }}}=\frac{-S t}{c_{p, \text { out }}} \quad \frac{\partial S t}{\partial L_{h}}=\frac{-S t}{L_{h}} \quad \frac{\partial S t}{\partial a}=\frac{S t}{\left(a_{h}-x_{0}\right)}
\end{aligned}
$$

The directly solved and iterative forward-difference solutions of the partial derivatives necessary to solve Equation 80 are presented in Table 3-37 and 3-38. The uncertainty estimates are presented in Tables 3-39 and 3-40. 


\section{Preliminary Data - 9 September 1993}

Table 3-37.--Stanton number sensitivity coefficient estimates for open channel, construction 4 at OFI, inlet temperature $60^{\circ} \mathrm{C}$

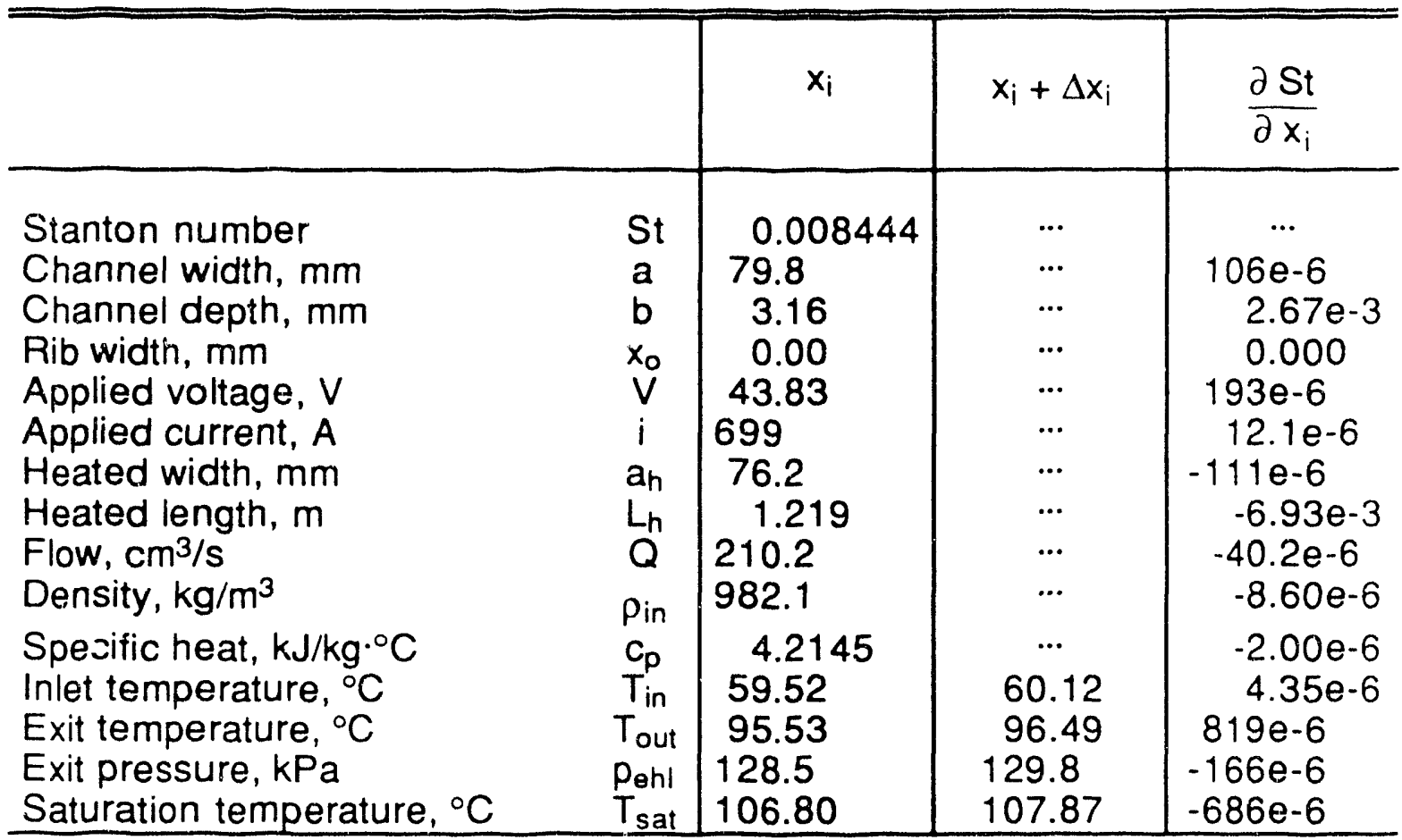

Table 3-38.--Stanton number sensitivity coefficient estimates for rib channel, construction 2 at $\mathrm{OFI}$, inlet temperature $60^{\circ} \mathrm{C}$

\begin{tabular}{|c|c|c|c|c|}
\hline & & $x_{i}$ & $x_{i}+\Delta x_{i}$ & $\frac{\partial S t}{\partial x_{i}}$ \\
\hline $\begin{array}{l}\text { Stanton number } \\
\text { Channel width, } \mathrm{mm} \\
\text { Channel depth, } \mathrm{mm} \\
\text { Rib width, mm } \\
\text { Applied voltage, V } \\
\text { Applied current, A } \\
\text { Heated width, } \mathrm{mm} \\
\text { Heated length, } \mathrm{m} \\
\text { Flow, } \mathrm{cm}^{3} / \mathrm{s} \\
\text { Density, } \mathrm{kg} / \mathrm{m}^{3}\end{array}$ & $\begin{array}{l}S t \\
a \\
b \\
x_{0} \\
V \\
i \\
a_{h} \\
L_{h} \\
Q \\
\rho_{\text {in }}\end{array}$ & $\begin{array}{c}0.004141 \\
79.6 \\
3.09 \\
2.07 \\
43.83 \\
699 \\
67.2 \\
1.219 \\
261.0 \\
981.9\end{array}$ & $\begin{array}{l}\cdots \\
\cdots \\
\cdots \\
2.09 \\
\cdots \\
\cdots \\
\cdots \\
\cdots \\
\cdots \\
\cdots\end{array}$ & $\begin{array}{c}\ldots \\
53.4 e-6 \\
1.34 e-3 \\
-67.0 e-6 \\
94.5 e-6 \\
5.92 e-6 \\
-63.6 e-6 \\
-45.6 e-6 \\
-15.9 e-6 \\
-4.22 e-6\end{array}$ \\
\hline $\begin{array}{l}\text { Specific heat, } \mathrm{kJ} / \mathrm{kg} \cdot{ }^{\circ} \mathrm{C} \\
\text { Inlet temperature, }{ }^{\circ} \mathrm{C} \\
\text { Exit temperature, }{ }^{\circ} \mathrm{C} \\
\text { Exit pressure, } \mathrm{kPa} \\
\text { Saturation temperature, }{ }^{\circ} \mathrm{C}\end{array}$ & $\begin{array}{l}C_{p} \\
T_{\text {in }} \\
T_{\text {out }} \\
p_{\text {ehl }} \\
T_{\text {sat }}\end{array}$ & $\begin{array}{l}4.2056 \\
59.26 \\
88.83 \\
129.3 \\
106.98\end{array}$ & $\begin{array}{l}\cdots \\
59.85 \\
89.72 \\
130.6 \\
108.05\end{array}$ & $\begin{array}{l}-985 e-6 \\
-2.90 e-6 \\
238 e-6 \\
-51.7 e-6 \\
-217 e-6\end{array}$ \\
\hline
\end{tabular}




\section{Preliminary Data -- 9 September 1993}

Table 3-39.--Stanton number rib-effect-ratio systematic uncertainty for open channel, construction 4 at $\mathrm{OFi}$, inlet temperature $60^{\circ} \mathrm{C}$

\begin{tabular}{|c|c|c|c|c|}
\hline & & $B_{i}$ & $\theta_{i}$ & $\theta_{i} B_{i}$ \\
\hline $\begin{array}{l}\text { Channel width, mm } \\
\text { Channel depth, mm } \\
\text { Rib width, mm } \\
\text { Applied voltage, V } \\
\text { Applied current, A } \\
\text { Heated width, } \mathrm{mm} \\
\text { Heated length, m } \\
\text { Flow, } \mathrm{cm} 3 / \mathrm{s} \\
\text { Density, } \mathrm{kg} / \mathrm{m}^{3}\end{array}$ & $\begin{array}{c}a \\
b \\
x_{0} \\
V \\
i \\
a_{h} \\
L_{h} \\
Q\end{array}$ & $\begin{array}{l}0.4 \\
0.2 \\
0.04 \\
0.0089 \\
1.4 \\
3.4 \\
0.001 \\
1.4 \\
1\end{array}$ & $\begin{array}{c}106 e-6 \\
2.67 e-3 \\
0.000 \\
193 e-6 \\
12.1 e-6 \\
-111 e-6 \\
-6.93 e-3 \\
-40.2 e-6 \\
-8.60 e-6\end{array}$ & $\begin{array}{r}0.000042 \\
0.000534 \\
0.000000 \\
0.000002 \\
0.000017 \\
-0.000377 \\
-0.000007 \\
-0.000056 \\
-0.000009\end{array}$ \\
\hline $\begin{array}{l}\text { Specific heat, } \mathrm{kJ} / \mathrm{kg} \cdot{ }^{\circ} \mathrm{C} \\
\text { Inlet temperature, } \cdot{ }^{\circ} \mathrm{C} \\
\text { Exit temperature, }{ }^{\circ} \mathrm{C} \\
\text { Exit pressure, } \mathrm{kPa} \\
\text { Saturation temperature, }{ }^{\circ} \mathrm{C} \\
\text { Root-sum-square }\end{array}$ & $\begin{array}{l}\vec{T}_{p} \\
T_{\text {in }} \\
T_{\text {out }} \\
\text { Pehl }_{\text {ohl }} \\
T_{\text {sat }}\end{array}$ & $\begin{array}{l}0.08 \\
0.5 \\
0.5 \\
0.4 \\
0.01\end{array}$ & $\begin{array}{l}-2.00 e-3 \\
4.35 e-6 \\
819 e-6 \\
-166 e-6 \\
-686 e-6\end{array}$ & $\begin{array}{r}0.000000 \\
0.000160 \\
0.000409 \\
-0.000066 \\
-0.000007 \\
0.00079\end{array}$ \\
\hline
\end{tabular}

Table 3-40.--Stanton number rib-effect-ratio systematic uncertainty ior rib channel, construction 2 at $\mathrm{OFI}$, inlet temperature $60^{\circ} \mathrm{C}$

\begin{tabular}{|c|c|c|c|c|}
\hline & & $B_{i}$ & $\theta_{i}$ & $\theta_{i} B_{i}$ \\
\hline $\begin{array}{l}\text { Channel width, } \mathrm{mm} \\
\text { Channel depth, mm } \\
\text { Rib width, mm } \\
\text { Applied voltage, V } \\
\text { Applied current, A } \\
\text { Heated width, } \mathrm{mm} \\
\text { Heated length, } \mathrm{m} \\
\text { Flow, } \mathrm{cm}^{3} / \mathrm{s} \\
\text { Density, } \mathrm{kg} / \mathrm{m}^{3}\end{array}$ & $\begin{array}{l}a \\
b \\
x_{0} \\
V \\
i \\
a_{h} \\
L_{h} \\
Q \\
\rho_{\text {in }}\end{array}$ & $\begin{array}{l}0.4 \\
0.2 \\
0.04 \\
0.0089 \\
1.4 \\
3.4 \\
0.001 \\
1.4 \\
1\end{array}$ & $\begin{array}{c}53.4 e-6 \\
1.34 e-3 \\
-67.0 e-6 \\
94.5 e-6 \\
5.92 e-6 \\
-63.6 e-6 \\
-45.6 e-6 \\
-15.9 e-6 \\
-4.22 e-6\end{array}$ & $\begin{array}{r}0.000021 \\
0.000268 \\
-0.000003 \\
0.000001 \\
0.000008 \\
-0.000216 \\
-0.000000 \\
-0.000022 \\
-0.000004\end{array}$ \\
\hline $\begin{array}{l}\text { Specific heat, } \mathrm{J} / \mathrm{kg} \cdot{ }^{\circ} \mathrm{C} \\
\text { Inlet temperature, } \cdot{ }^{\circ} \mathrm{C} \\
\text { Exit temperature, }{ }^{\circ} \mathrm{C} \\
\text { Exit pressure, } \mathrm{kPa} \\
\text { Saturation temperature, }{ }^{\circ} \mathrm{C}\end{array}$ & $\begin{array}{l}c_{p} \\
T_{\text {in }} \\
T_{\text {out }} \\
\mathrm{p}_{\text {ehl }} \\
T_{\text {sat }}\end{array}$ & $\begin{array}{l}0.08 \\
0.5 \\
0.5 \\
0.4 \\
0.01\end{array}$ & $\begin{array}{l}-985 e-6 \\
-2.90 e-6 \\
238 e-6 \\
-51.7 e-6 \\
-217 e-6 \\
\end{array}$ & $\begin{array}{r}-0.000079 \\
-0.000001 \\
0.000119 \\
-0.000021 \\
-0.000002 \\
\end{array}$ \\
\hline Root-sum-square & & & & 0.00037 \\
\hline
\end{tabular}




\section{Preliminary Data _. 9 September 1993}

\section{Stanton Number Rib-Effect-Ratio}

The Stanton number rib-effect-ratio is defined by Equation 3-19

$$
\eta_{S t}=\frac{S t_{p}}{S t_{0}}
$$

This quantity is a comparative test result and as with the $Q_{\text {ratio }}$ rib-effect-ratio the correlation of systematic uncertainties is important. The partial derivatives necessary for the evaluation of Equation 80 can be derived from the information in Tables 3-37, or 3-38, and the partial derivatives of Equation 3-19.

$$
\frac{\partial \eta_{S t}}{\partial S t_{r}}=\frac{\eta_{S t}}{S t_{r}} \quad \frac{\partial \eta_{S t}}{\partial S t_{0}}=\frac{-\eta_{S t}}{S t_{0}}
$$

The partial derivatives necessary for the evaluation of Equation 80 are listed in Table 3-41. Table 3-42 provides the weighted elemental uncertainties for the first term in Equation 80. Table 3-43 provides the weighted uncertainties for the second term in Equation 80. These may be combined to determine the total systematic uncertainty of the Stanton number rib-effect-ratio.

$$
\begin{aligned}
B_{\eta_{s t}} & =\sqrt{(0.063891)^{2}-0.003383} \\
& =0.026
\end{aligned}
$$


Table 3-41.--Stanton number ratio sensitivity coefficient estimates at OFI, inlet temperature $60^{\circ} \mathrm{C}$

\begin{tabular}{|c|c|c|c|c|}
\hline & & $\frac{\partial S t_{j}}{\partial x_{i}}$ & $\frac{\partial \eta_{s t}}{\partial S t_{j}}$ & $\frac{\partial \eta_{S t}}{\partial x_{i}}$ \\
\hline $\begin{array}{l}\text { Open channel } \\
\text { Stanton number } \\
\text { Channel width, mm } \\
\text { Channel depth, mm } \\
\text { Rib width, mm } \\
\text { Applied voltage, V } \\
\text { Applied current, A } \\
\text { Heated width, mm } \\
\text { Heated length, m } \\
\text { Flow, } \mathrm{cm}^{3} / \mathrm{s} \\
\text { Density, } \mathrm{kg} / \mathrm{m}^{3}\end{array}$ & $\begin{array}{l}\text { St } \\
a \\
b \\
x_{0} \\
V \\
i \\
a_{h} \\
L_{h} \\
Q \\
\rho\end{array}$ & $\begin{array}{c}1.0 \\
106 e-6 \\
2.67 e-3 \\
0.000 \\
193 e-6 \\
12.1 e-6 \\
-111 e-6 \\
-6.93 e-3 \\
-40.2 e-6 \\
-8.60 e-6\end{array}$ & $\begin{array}{l}-58.08 \\
-58.08 \\
-58.08 \\
-58.08 \\
-58.08 \\
-58.08 \\
-58.08 \\
-58.08 \\
-58.08 \\
-58.08\end{array}$ & $\begin{array}{c}-58.0 e 0 \\
-6.15 e-3 \\
-155 . e-3 \\
0.00 \\
-11.2 e-3 \\
-702 . e-6 \\
6.44 e-3 \\
402 . e-3 \\
2.33 e-3 \\
499 . e-6\end{array}$ \\
\hline $\begin{array}{l}\text { Specific heat, } \mathrm{J} / \mathrm{kg} \cdot{ }^{\circ} \mathrm{C} \\
\text { Inlet temperature, } \cdot{ }^{\circ} \mathrm{C} \\
\text { Exit temperature, }{ }^{\circ} \mathrm{C} \\
\text { Exit pressure, } \mathrm{KPa} \\
\text { Saturation temperature, }{ }^{\circ} \mathrm{C} \\
\text { Ribbed channel }\end{array}$ & $\begin{array}{l}c_{p} \\
T_{\text {in }} \\
T_{\text {out }} \\
\text { pehl }_{\text {ehl }} \\
T_{\text {sat }}\end{array}$ & $\begin{array}{l}-2.00 e-3 \\
4.35 e-6 \\
819 e-6 \\
-166 e-6 \\
-686 e-6\end{array}$ & $\begin{array}{l}-58.08 \\
-58.08 \\
-58.08 \\
-58.08 \\
-58.08\end{array}$ & $\begin{array}{l}116 . e-3 \\
-252 . e-6 \\
-47.5 e-3 \\
9.64 e-3 \\
39.8 e-3\end{array}$ \\
\hline $\begin{array}{l}\text { Stanton number } \\
\text { Channel width, } \mathrm{mm} \\
\text { Channel depth, } \mathrm{mm} \\
\text { Rib width, mm } \\
\text { Applied voltage, } \mathrm{V} \\
\text { Applied current, A } \\
\text { Heated width, } \mathrm{mm} \\
\text { Heated length, } \mathrm{m} \\
\text { Flow, } \mathrm{cm}^{3} / \mathrm{s} \\
\text { Density, } \mathrm{kg} / \mathrm{m}^{3}\end{array}$ & $\begin{array}{l}\text { St } \\
a \\
b \\
x_{0} \\
V \\
i \\
a_{h} \\
L_{h} \\
Q \\
\rho\end{array}$ & $\begin{array}{c}1.0 \\
53.4 e-6 \\
1.34 e-3 \\
-67.0 e-6 \\
94.5 e-6 \\
5.92 e-6 \\
-63.6 e-6 \\
-45.6 e-6 \\
-15.9 e-6 \\
-4.22 e-6\end{array}$ & $\begin{array}{l}118.4 \\
118.4 \\
118.4 \\
118.4 \\
118.4 \\
118.4 \\
118.4 \\
118.4 \\
118.4 \\
118.4\end{array}$ & $\begin{array}{c}118 . e 0 \\
6.32 e-3 \\
158 . e-3 \\
-7.93 e-3 \\
11.1 e-3 \\
700 . e-6 \\
-7.53 e-3 \\
-5.39 e-3 \\
-1.88 e-3 \\
-499 . e-6\end{array}$ \\
\hline $\begin{array}{l}\text { Specific heat, } \mathrm{J} / \mathrm{kg} \cdot{ }^{\circ} \mathrm{C} \\
\text { Inlet temperature, } \cdot \cdot \mathrm{C} \\
\text { Exit temperature, }{ }^{\circ} \mathrm{C} \\
\text { Exit pressure, } \mathrm{kPa} \\
\text { Saturation temperature, }{ }^{\circ} \mathrm{C}\end{array}$ & $\begin{array}{l}\mathrm{C}_{\mathrm{p}} \\
\mathrm{T}_{\text {in }} \\
\mathrm{T}_{\text {out }} \\
\mathrm{p}_{\text {ehl }} \\
\mathrm{T}_{\text {sat }} \\
\end{array}$ & $\begin{array}{l}-985 e-6 \\
-2.90 e-6 \\
238 e-6 \\
-51.7 e-6 \\
-217 e-6 \\
\end{array}$ & $\begin{array}{l}118.4 \\
118.4 \\
118.4 \\
118.4 \\
118.4 \\
\end{array}$ & $\begin{array}{l}-116 . e-3 \\
-343 . e-6 \\
28.1 e-3 \\
-6.12 e-3 \\
-25.6 e-3 \\
\end{array}$ \\
\hline
\end{tabular}


Table 3-42.--Stanton number rib-effect-ratio systematic uncertainty for rib channel, construction 2 at $\mathrm{OFI}$, inlet temperature $60^{\circ} \mathrm{C}$

\begin{tabular}{|c|c|c|c|c|}
\hline & & $B_{i}$ & $\theta_{\mathrm{i}}$ & $\theta_{i} B_{i}$ \\
\hline $\begin{array}{l}\text { Open channel } \\
\text { Channel width, } \mathrm{mm} \\
\text { Channel depth, mm } \\
\text { Rib width, mm } \\
\text { Applied voltage, V } \\
\text { Applied current, A } \\
\text { Heated width, mm } \\
\text { Heated length, m } \\
\text { Flow, } \mathrm{cm}^{3} / \mathrm{s} \\
\text { Density, } \mathrm{kg} / \mathrm{m}^{3}\end{array}$ & $\begin{array}{l}S t \\
a \\
b \\
x_{0} \\
V \\
i \\
a_{h} \\
L_{h} \\
Q\end{array}$ & $\begin{array}{l}0.4 \\
0.2 \\
0.04 \\
0.0089 \\
1.4 \\
3.4 \\
0.001 \\
1.4 \\
1\end{array}$ & $\begin{array}{c}-6.15 e-3 \\
-155 . e-3 \\
0.00 \\
-11.2 e-3 \\
-702 . e-6 \\
6.44 e-3 \\
402 . e-3 \\
2.33 e-3 \\
499 . e-6\end{array}$ & $\begin{array}{r}-0.002460 \\
-0.031000 \\
0.000000 \\
-0.000100 \\
-0.000983 \\
0.021896 \\
0.000402 \\
0.003262 \\
0.000499\end{array}$ \\
\hline $\begin{array}{l}\text { Specific heat, } \mathrm{J} / \mathrm{kg} \cdot{ }^{\circ} \mathrm{C} \\
\text { Inlet temperature, } \cdot{ }^{\circ} \mathrm{C} \\
\text { Exit temperature, }{ }^{\circ} \mathrm{C} \\
\text { Exit pressure, } \mathrm{kPa} \\
\text { Saturation temperature, }{ }^{\circ} \mathrm{C} \\
\text { Ribbed channel }\end{array}$ & $\begin{array}{l}c_{p} \\
T_{\text {in }} \\
T_{\text {out }} \\
\text { pehl }_{\text {ehl }} \\
T_{\text {sat }}\end{array}$ & $\begin{array}{l}0.08 \\
0.5 \\
0.5 \\
0.4 \\
0.01\end{array}$ & $\begin{array}{l}116 . e-3 \\
-252 . e-6 \\
-47.5 e-3 \\
9.64 e-3 \\
39.8 e-3\end{array}$ & $\begin{array}{r}0.009280 \\
-0.000126 \\
-0.023750 \\
0.003856 \\
0.000398\end{array}$ \\
\hline $\begin{array}{l}\text { Channel width, } \mathrm{mm} \\
\text { Channel depth, } \mathrm{mm} \\
\text { Rib width, mm } \\
\text { Applied voltage, } \mathrm{V} \\
\text { Applied current, A } \\
\text { Heated width, } \mathrm{mm} \\
\text { Heated length, } \mathrm{m} \\
\text { Flow, } \mathrm{cm}^{3} / \mathrm{s} \\
\text { Density, } \mathrm{kg} / \mathrm{m}^{3}\end{array}$ & $\begin{array}{l}a \\
b \\
x_{0} \\
V \\
i \\
a_{h} \\
L_{h} \\
Q \\
\rho\end{array}$ & $\begin{array}{l}0.4 \\
0.2 \\
0.04 \\
0.0089 \\
1.4 \\
3.4 \\
0.001 \\
1.4 \\
1\end{array}$ & $\begin{array}{l}6.32 e-3 \\
158 . e-3 \\
-7.93 e-3 \\
11.1 e-3 \\
700 . e-6 \\
-7.53 e-3 \\
-5.39 e-3 \\
-1.88 e-3 \\
-499 . e-6\end{array}$ & $\begin{array}{r}0.002528 \\
0.031600 \\
-0.000317 \\
0.000099 \\
0.000980 \\
-0.025602 \\
-0.000005 \\
-0.002632 \\
-0.000499\end{array}$ \\
\hline $\begin{array}{l}\text { Specific heat, } \mathrm{J} / \mathrm{kg} \cdot{ }^{\circ} \mathrm{C} \\
\text { Inlet temperature, } \cdot{ }^{\circ} \\
\text { Exit temperature, }{ }^{\circ} \mathrm{C} \\
\text { Exit pressure, } \mathrm{kPa} \\
\text { Saturation temperature, }{ }^{\circ} \mathrm{C}\end{array}$ & $\begin{array}{l}c_{p} \\
T_{\text {in }} \\
T_{\text {out }} \\
\text { pehi }_{\text {ehi }} \\
T_{\text {sat }}\end{array}$ & $\begin{array}{l}0.08 \\
0.5 \\
0.5 \\
0.4 \\
0.01\end{array}$ & $\begin{array}{l}-116 . e-3 \\
-343 . e-6 \\
28.1 e-3 \\
-6.12 e-3 \\
-25.6 e-3\end{array}$ & $\begin{array}{r}-0.009280 \\
-0.000171 \\
0.014050 \\
-0.002448 \\
-0.000256\end{array}$ \\
\hline Root-sum-square & & & & 0.063891 \\
\hline
\end{tabular}




\section{Preliminary Data -- 9 September 1993}

Table 3-43.--Stanton number rib-effect-ratio systematic uncertainty for rib channel, construction 2 at $\mathrm{OFI}$, inlet temperature $60^{\circ} \mathrm{C}$

\begin{tabular}{|c|c|c|c|c|c|c|}
\hline & \multirow[t]{2}{*}{$\rho_{\text {ik }}$} & \multicolumn{2}{|c|}{$\mathrm{B}_{i}$} & \multicolumn{2}{|c|}{$\theta_{i}$} & \multirow[t]{2}{*}{$2 \rho_{i k} \theta_{i, o} \theta_{i, r} B_{i, o} B_{i, i}$} \\
\hline & & open & rib & open & rib & \\
\hline a & 1 & 0.4 & 0.4 & $-6.15 e-3$ & $6.32 e-3$ & -0.000012 \\
\hline$b$ & 0.7 & 0.2 & 0.2 & $-155 \cdot e-3$ & 158.e-3 & -0.001371 \\
\hline$x_{0}$ & 0 & 0.04 & 0.04 & 0.00 & $-7.93 e-3$ & -0.000000 \\
\hline V & 0.5 & 0.0089 & 0.0089 & $-11.2 e-3$ & $11.1 \mathrm{e}-3$ & -0.000000 \\
\hline $\mathrm{i}$ & 1 & 1.4 & 1.4 & $-702 . e-6$ & $700 . e-6$ & -0.000002 \\
\hline$a_{h}$ & 1 & 3.4 & 3.4 & $6.44 e-3$ & $-7.53 e-3$ & -0.001121 \\
\hline$L_{h}$ & 1 & 0.001 & 0.001 & 402.e-3 & $-5.39 e-3$ & -0.000000 \\
\hline$Q$ & 1 & 1.4 & 1.4 & $2.33 e-3$ & $-1.88 e-3$ & -0.000017 \\
\hline$\rho$ & 1 & 1 & 1 & $499 . e-6$ & $-499 . e-6$ & -0.000000 \\
\hline $\mathrm{C}_{\mathrm{p}}$ & 1 & 0.08 & 0.08 & 116.e-3 & $-116 \cdot e-3$ & -0.000172 \\
\hline $\mathrm{T}_{\text {in }}^{r}$ & 1 & 0.5 & 0.5 & $-252 . e-6$ & $-343 . e-6$ & 0.000000 \\
\hline$T_{\text {out }}$ & 1 & 0.5 & 0.5 & $-47.5 e-3$ & $28.1 e-3$ & -0.000667 \\
\hline Pehl & 1 & 0.4 & 0.4 & $9.64 e-3$ & $-6.12 e-3$ & -0.000019 \\
\hline$T_{\text {sat }}$ & 1 & 0.01 & 0.01 & $39.8 e-3$ & $-25.6 e-3$ & -0.000000 \\
\hline \multicolumn{6}{|c|}{ Sum } & -0.003383 \\
\hline
\end{tabular}


Preliminary Data -. 9 September 1993

\section{APPENDIX 4}

TASK REFERENCE DOCUMENTS 


\section{Preliminary Data -- 9 September 1993}

Table 4-1.--Procedures and Test Plans

\begin{tabular}{|c|c|c|c|}
\hline Description & $\begin{array}{c}\text { Document } \\
\text { Number }\end{array}$ & Date & Revision \\
\hline $\begin{array}{l}\text { Heat Transfer Laboratory Rectifier } \\
\text { Operation/Startup/Stin tdown } \\
\text { Local FI Rig - Operation } \\
\text { Task Plan } \\
\text { Task Plan } \\
\text { Test Plan and Pretest Predictions } \\
\text { Test Plan and Pretest Predictions } \\
\text { Test Plan and Pretest Predictions } \\
\text { Test Plan and Pretest Predictions } \\
\text { Test Plan and Pretest Predictions } \\
\text { Test Plan and Pretest Predictions } \\
\text { Test Plan and Pretest Predictions } \\
\text { Test Plan and Pretest Predictions } \\
\text { Test Plan and Pretest Predictions } \\
\text { Test Plan and Pretest Predictions }\end{array}$ & $\begin{array}{c}\text { HTL-92-017 } \\
\text { TP-93-005 } \\
91-063-1 \\
91-063-1 \\
\ldots \\
\ldots \\
\ldots \\
\ldots \\
\ldots \\
\ldots \\
\ldots \\
\ldots \\
\ldots \\
\ldots\end{array}$ & $\begin{array}{l}1 \text { Apr } 93 \\
21 \text { Apr } 93 \\
30 \text { Apr } 93 \\
8 \text { May } 93 \\
11 \text { May } 93 \\
20 \text { May } 93 \\
3 \text { June } 93 \\
21 \text { June } 93 \\
6 \text { July } 93 \\
7 \text { July } 93\end{array}$ & $\begin{array}{l}0 \\
0 \\
0 \\
1 \\
0 \\
1 \\
2 \\
3 \\
4 \\
5 \\
6 \\
7 \\
8 \\
9\end{array}$ \\
\hline
\end{tabular}

Table 4-2.--Design drawings

\begin{tabular}{|c|c|c|}
\hline Drawing Number & Revision & Title \\
\hline $\begin{array}{l}\text { ST-MDX4-10178 } \\
\text { ST-MDX5-10!71 }\end{array}$ & $\begin{array}{l}0 \\
0\end{array}$ & $\begin{array}{l}\text { P\&I Diagram for FI Test Rig } \\
\text { Transient Boiling Behavior Tests, Heater Plate } \\
\text { Machining Detail }\end{array}$ \\
\hline ST-MDX5-10172 & 0 & $\begin{array}{c}\text { Transient Boiling Behavior Tests, T/C } \\
\text { Installation \& Plasma Spray Details }\end{array}$ \\
\hline ST-MDX5-10175 & 0 & $\begin{array}{l}\text { Transient Boiling Behavior Tests, Flat Plate } \\
\text { Assembly }\end{array}$ \\
\hline ST-MDX5-10176 & 5 & $\begin{array}{l}\text { Transient Boiling Behavior Tests, Detail Sheet } \\
\# 1\end{array}$ \\
\hline ST-MDX5-10177 & 1 & $\begin{array}{l}\text { Transient Boiling Behavior Tests, Detail Sheet } \\
\text { \#2 }\end{array}$ \\
\hline ST-MDX5-10188 & 0 & $\begin{array}{c}\text { Transient Boiling Behavior Tests, Piping } \\
\text { Arrangement \& Bill of Material }\end{array}$ \\
\hline ST-MDX5-10189 & 0 & $\begin{array}{c}\text { Transient Boiling Behavior Tests, Piping } \\
\text { Details and Pump-Motor Stand }\end{array}$ \\
\hline ST-MDX5-10198 & 0 & $\begin{array}{l}\text { Transient Boiling Behavior Tests, Flat Plate } \\
\text { Heater Shipping Box Details }\end{array}$ \\
\hline
\end{tabular}


Table 4-3.--Photographs

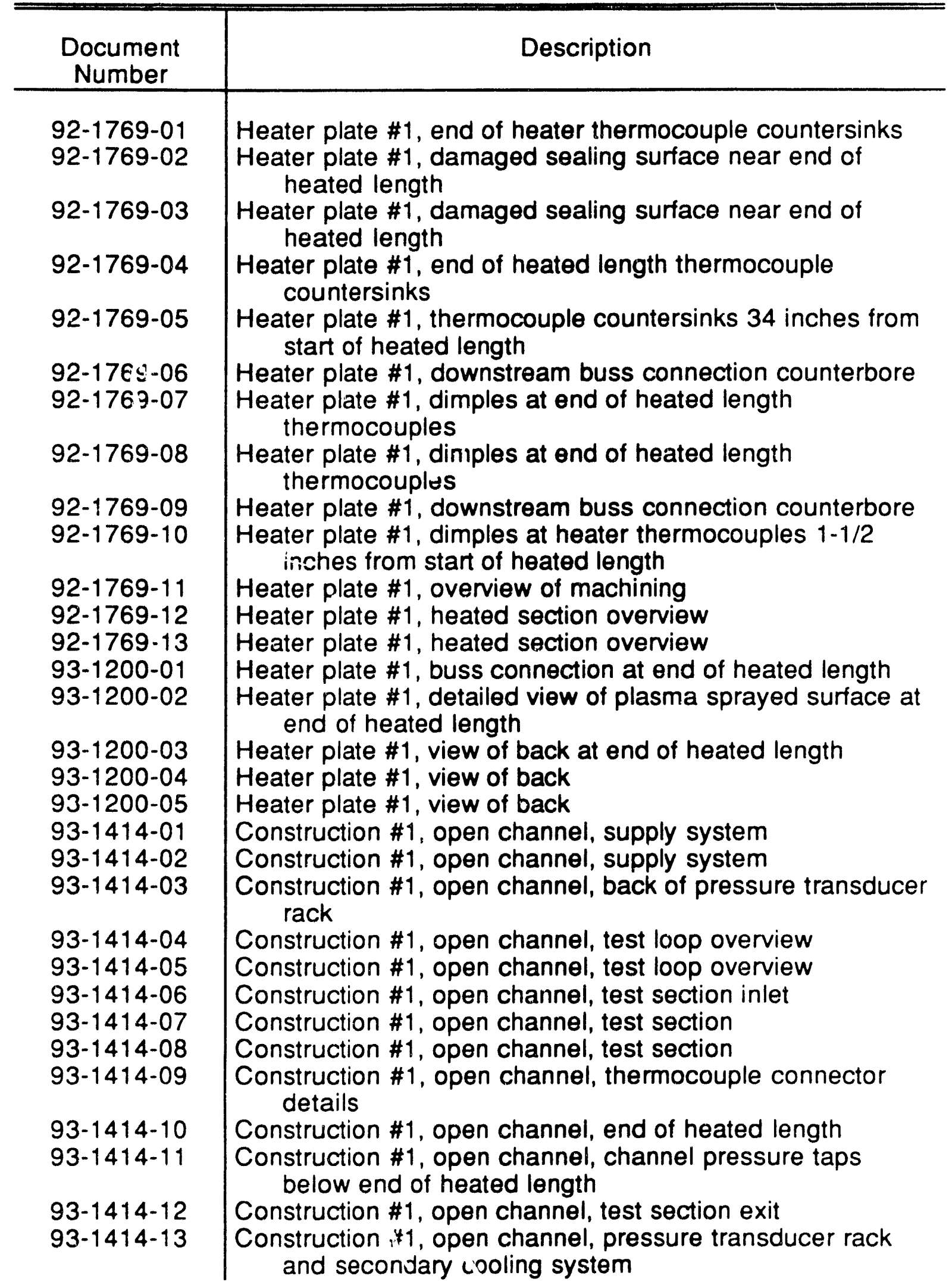


Preliminary Data -. 9 September 1993

Table 4-3.--Continued

\begin{tabular}{|c|c|}
\hline $\begin{array}{c}\text { Document } \\
\text { Number }\end{array}$ & Description \\
\hline $\begin{array}{l}93-1414-14 \\
93-1414-15 \\
93-1414-16\end{array}$ & $\begin{array}{l}\text { Construction \#1, open channil, pressure transducer rack } \\
\text { Construction \#1, open channel, amplifier rack interior } \\
\text { Construction \#1, open channel, amplifier rack cable } \\
\text { connections }\end{array}$ \\
\hline $\begin{array}{l}93-1414-17 \\
93-1414-18 \\
93-1414-19 \\
93-1566-01 \\
93-1566-02 \\
93-1566-03\end{array}$ & $\begin{array}{l}\text { Construction \#1, open channel, amplifier rack, front view } \\
\text { Construction \#1, open channel, test loop overview, right side } \\
\text { Construction \#1, open channel, test loop overview, left side } \\
\text { Construction } \# 2 \text {, ribbed channel, test loop overview } \\
\text { Construction \#2, ribbed channel, test loop overview } \\
\text { Construction \#2, ribbed channel, buss connections and back } \\
\text { of pressure transducer rack }\end{array}$ \\
\hline $\begin{array}{l}93-1566-04 \\
93-1566-05 \\
93-1566-06 \\
93-1566-07 \\
93-1566-08 \\
93-1566-09\end{array}$ & $\begin{array}{l}\text { Construction } \# 2 \text {, ribbed channel, top buss connection } \\
\text { Construction } \# 2 \text {, ribbed channel, DAS and power controller } \\
\text { Construction } \# 2 \text {, ribbed channel, DAS and power controller } \\
\text { Construction } \# 2 \text {, ribbed channel, amplifier rack } \\
\text { Construction } \# 2 \text {, ribbed channel, pressure transducer rack } \\
\text { Construction } \# 2 \text {, ribbed channel, pressure transducer rack } \\
\text { and secondary cooling system }\end{array}$ \\
\hline $\begin{array}{l}93-1566-10 \\
93-1566-11 \\
93-1566-12 \\
93-1566-13 \\
93-1566-14\end{array}$ & $\begin{array}{l}\text { Construction } \# 2 \text {, ribbed channel, secondary cooling system } \\
\text { Construction } \# 2 \text {, ribbed channel, top buss connection } \\
\text { Construction } \# 2 \text {, ribbed channel, end of heated length detail } \\
\text { Construction } \# 2 \text {, ribbed channel, end of heated length detail } \\
\text { Construction } \# 2 \text {, ribbed channel, channel thermocouple } \\
\text { details }\end{array}$ \\
\hline $\begin{array}{l}93-1697-01 \\
93-1697-02 \\
93-1697-03\end{array}$ & $\begin{array}{l}\text { Construction \#4, open channel, test loop overview } \\
\text { Construction \#4, open channel, heater frame back view } \\
\text { Construction \#4, open channel, pressure transducer rack } \\
\text { and secondary cooling system }\end{array}$ \\
\hline $\begin{array}{l}93-1697-0 \\
93-1697-0\end{array}$ & $\begin{array}{c}\text { Construction \#4, open channel, shims near top of channel } \\
\text { Construction \#4, open channel, shims just above end of } \\
\text { heated length }\end{array}$ \\
\hline
\end{tabular}


Preliminary Data -. 9 September 1993

Table 4-4.--Video Tapes

\begin{tabular}{c|l}
\hline \hline $\begin{array}{c}\text { Document } \\
\text { Number }\end{array}$ & \\
\hline LFIE-93-01-M & Local FI Effects \\
LFIE-93-02-M & Local FI Effects \\
LFIE-93-03-M & Local FI Effects \\
LFIE-93-04-M & Local FI Effects \\
LFIE-93-05-M & Local FI Effects \\
LFIE-93-06-M & Local FI Effects \\
LFIE-93-07-M & Local FI Effects \\
LFIE-93-08-M & Local FI Effects \\
LFIE-93-09-M & Local FI Effects \\
LFIE-93-10-M & Local FI Effects \\
LFIE-93-11-M & Local FI Effects \\
\hline
\end{tabular}


Table 4-5.--Data Files Listing

\begin{tabular}{|c|c|c|c|}
\hline File name & Date & Size* & Comments \\
\hline SF_930414_0141a & $4 / 14 / 93$ & 109 & \\
\hline SF_930415_1436 & $4 / 15 / 93$ & 123 & \\
\hline SF_930415_1450 & $4 / 15 / 93$ & 122 & \\
\hline SF_930415_1455 & $4 / 15 / 93$ & 154 & \\
\hline SF_930415_1506 & $4 / 15 / 93$ & 123 & \\
\hline SF_930415_1515 & $4 / 15 / 93$ & 129 & \\
\hline SF_930415_1445 & $4 / 15 / 93$ & 122 & \\
\hline SF_930415_1524 & $4 / 15 / 93$ & 122 & \\
\hline SF_930415_1536 & $4 / 15 / 93$ & 121 & \\
\hline SF_930415_1540 & $4 / 15 / 93$ & 138 & \\
\hline SF_930415_1546 & $4 / 15 / 93$ & 121 & \\
\hline SF_930415_1554 & $4 / 15 / 93$ & 121 & \\
\hline SF_930415_1601 & $4 / 15 / 93$ & 167 & \\
\hline$S F_{-} 930415 \_1609$ & $4 / 15 / 93$ & 122 & \\
\hline SF_930416_0906 & $4 / 16 / 93$ & 122 & \\
\hline SF_930416_0917 & $4 / 16 / 93$ & 122 & \\
\hline$S F-930416-0927$ & $4 / 16 / 93$ & 121 & \\
\hline SF_930416_0933 & $4 / 16 / 93$ & 195 & \\
\hline SF_930416_0939 & $4 / 16 / 93$ & 121 & \\
\hline SF_930416_0951 & $4 / 16,93$ & 121 & \\
\hline SF_930416_0958 & $4 / 16 / 93$ & 133 & \\
\hline SF_930416_1004 & $4 / 16 / 93$ & 74 & \\
\hline SF_930416_1013 & $4 / 16 / 93$ & 123 & \\
\hline SF_930416_1018 & $4 / 16 / 93$ & 135 & \\
\hline SF_930416_1022 & 4/16/93 & 127 & \\
\hline SF_930416_1028 & $4 / 16 / 93$ & 181 & \\
\hline SF_930416_1034 & $4 / 16 / 93$ & 121 & \\
\hline SF_930416_1040 & $4 / 16 / 93$ & 160 & \\
\hline$S F-930416-1045$ & $4 / 16 / 93$ & 122 & \\
\hline SF_930416_1050 & $4 / 16 / 93$ & 125 & \\
\hline$S F=930416 \_1054$ & $4 / 16 / 93$ & 119 & \\
\hline LP_930428_1330 & $4 / 28 / 93$ & 131 & \\
\hline LP_930428_1350 & $4 / 28 / 93$ & 123 & \\
\hline LP_930428_1352 & $4 / 28 / 93$ & 126 & \\
\hline LP_930428_1354 & $4 / 28 / 93$ & 122 & \\
\hline LP_930428_1357 & $4 / 28 / 93$ & 122 & \\
\hline LP_930428_1400 & $4 / 28 / 93$ & 130 & \\
\hline LP_930428_1403 & $4 / 28 / 93$ & 133 & \\
\hline LP_930428_1407 & 4/28/93 & 122 & \\
\hline LP_930428_1408 & $4 / 28 / 93$ & 123 & \\
\hline LP_930428_1413 & $4 / 28 / 93$ & 127 & \\
\hline LP_930428_1416 & $4 / 28 / 93$ & 126 & \\
\hline LP_930428_1419 & $4 / 28 / 93$ & 141 & \\
\hline LP_930428_1424 & $4 / 28 / 93$ & 156 & \\
\hline
\end{tabular}


Preliminary Data -- 9 September 1993

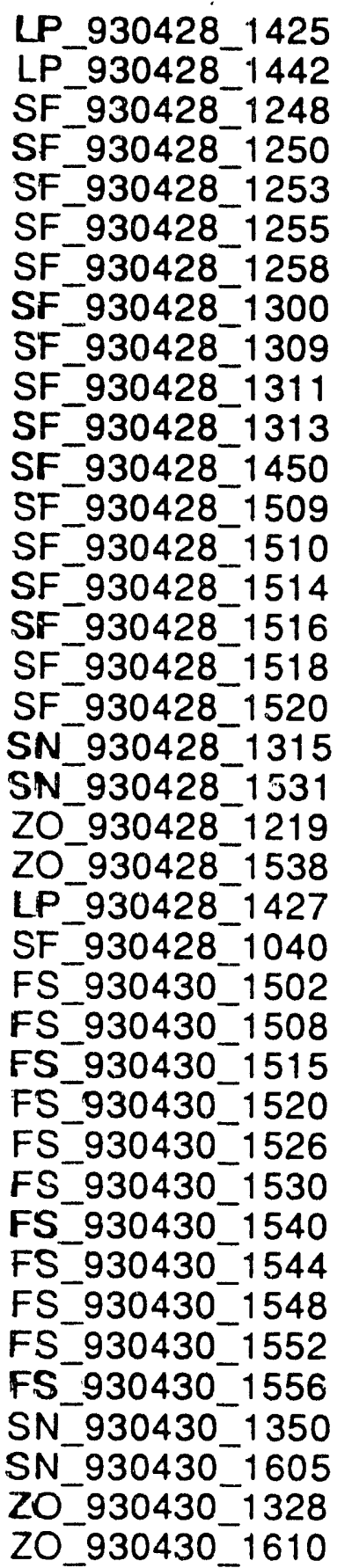

\begin{tabular}{l|l}
$4 / 28 / 93$ & 122 \\
$4 / 28 / 93$ & 132 \\
$4 / 28 / 93$ & 122 \\
$4 / 28 / 93$ & 125 \\
$4 / 28 / 93$ & 122 \\
$4 / 28 / 93$ & 124 \\
$4 / 28 / 93$ & 124 \\
$4 / 28 / 93$ & 148 \\
$4 / 28 / 93$ & 124 \\
$4 / 28 / 93$ & 122 \\
$4 / 28 / 93$ & 122 \\
$4 / 28 / 93$ & 123 \\
$4 / 28 / 93$ & 123 \\
$4 / 28 / 93$ & 123 \\
$4 / 28 / 93$ & 126 \\
$4 / 28 / 93$ & 138 \\
$4 / 28 / 93$ & 123 \\
$4 / 28 / 93$ & 123 \\
$4 / 28 / 93$ & 135 \\
$4 / 28 / 93$ & 124 \\
$4 / 28 / 93$ & 132 \\
$4 / 28 / 93$ & 121 \\
$4 / 28 / 93$ & 127 \\
$4 / 28 / 93$ & 123 \\
$4 / 30 / 93$ & 121 \\
$4 / 30 / 93$ & 123 \\
$4 / 30 / 93$ & 122 \\
$4 / 30 / 93$ & 120 \\
$4 / 30 / 93$ & 121 \\
$4 / 30 / 93$ & 124 \\
$4 / 30 / 93$ & 121 \\
$4 / 30 / 93$ & 120 \\
$4 / 30 / 93$ & 123 \\
$4 / 30 / 93$ & 120 \\
$4 / 30 / 93$ & 122 \\
$4 / 30 / 93$ & 118 \\
$4 / 30 / 93$ & 120 \\
$4 / 30 / 93$ & 120 \\
$4 / 30 / 93$ & 121
\end{tabular}

*number of rows 
Preliminary Data -- 9 September 1993

APPENDIX 5

REFERENCE DATA 


\section{Preliminary Data -- 9 September 1993}

Table 5-1.--Experimental OSV data calculated from the tables prepared by Dorra, Lee, and Bankoff (69)

\begin{tabular}{|c|c|c|c|c|c|}
\hline Pe number & St number & Pe number & St number & Pe number & St number \\
\hline \multicolumn{6}{|c|}{ Sekoguchi, et al. (tube) } \\
\hline $\begin{array}{l}29,011 \\
29,113 \\
43,861 \\
66,216 \\
43,887 \\
66,132 \\
\end{array}$ & $\begin{array}{l}0.00366 \\
0.00323 \\
0.00237 \\
0.00204 \\
0.00276 \\
0.00289 \\
\end{array}$ & $\begin{array}{r}29,000 \\
43,600 \\
47,300 \\
40700 \\
53,500 \\
165,000 \\
\end{array}$ & $\begin{array}{l}0.00368 \\
0.00372 \\
0.00284 \\
0.00404 \\
0.00264 \\
0.00286 \\
\end{array}$ & $\begin{array}{r}164,000 \\
40,000 \\
39,700 \\
26,200 \\
50,500 \\
104,000 \\
\end{array}$ & $\begin{array}{l}0.00305 \\
0.00472 \\
0.00374 \\
0.00446 \\
0.00527 \\
0.00369 \\
\end{array}$ \\
\hline \multicolumn{6}{|c|}{ Edelman \& Elias (tube) } \\
\hline $\begin{array}{l}1,928 \\
2,138 \\
2,313 \\
2,629 \\
3,014 \\
3,435 \\
\end{array}$ & $\begin{array}{l}0.18465 \\
0.20717 \\
0.17439 \\
0.15798 \\
0.18107 \\
0.13972 \\
\end{array}$ & $\begin{array}{l}3,891 \\
4,311 \\
5,188 \\
5,609 \\
6,801 \\
7,994 \\
\end{array}$ & $\begin{array}{l}0.11258 \\
0.11211 \\
0.07160 \\
0.07243 \\
0.06653 \\
0.06041 \\
\end{array}$ & $\begin{array}{c}9,470 \\
10,734 \\
11,858 \\
12,981 \\
\ldots \\
\ldots \\
\end{array}$ & $\begin{array}{c}0.03967 \\
0.03455 \\
0.03214 \\
0.03157 \\
\ldots \\
\ldots \\
\end{array}$ \\
\hline \multicolumn{6}{|c|}{ Staub, et al. (rectangle) } \\
\hline $\begin{array}{r}60,900 \\
60,900 \\
166,000 \\
249,000 \\
\end{array}$ & $\begin{array}{l}0.02235 \\
0.02297 \\
0.00972 \\
0.00967 \\
\end{array}$ & $\begin{array}{r}260,000 \\
265,000 \\
524,000 \\
64,400 \\
\end{array}$ & $\begin{array}{l}0.00984 \\
0.00843 \\
0.00702 \\
0.01876 \\
\end{array}$ & $\begin{array}{c}258,000 \\
516,000 \\
516,000 \\
\ldots \\
\end{array}$ & $\begin{array}{c}0.00764 \\
0.00793 \\
0.00732 \\
\ldots \\
\end{array}$ \\
\hline \multicolumn{6}{|c|}{ Evangelisti \& Lupoli (annulus) } \\
\hline 150,000 & 0.00580 & 152,000 & 0.00693 & 64,900 & 0.00986 \\
\hline \multicolumn{6}{|c|}{ Rogers, et al. (annulus) } \\
\hline $\begin{array}{r}9,850 \\
10,100 \\
10,300 \\
12,300 \\
29,300 \\
47,900 \\
\end{array}$ & $\begin{array}{l}0.14525 \\
0.12505 \\
0.11072 \\
0.08422 \\
0.05124 \\
0.03783 \\
\end{array}$ & $\begin{array}{l}62,200 \\
27,200 \\
38,600 \\
54,000 \\
32,700 \\
37,800 \\
\end{array}$ & $\begin{array}{l}0.02726 \\
0.06641 \\
0.04399 \\
0.02965 \\
0.05965 \\
0.04773 \\
\end{array}$ & $\begin{array}{c}48,000 \\
48,800 \\
55,700 \\
65,100 \\
\ldots \\
\ldots \\
\end{array}$ & $\begin{array}{c}0.03329 \\
0.04189 \\
0.03210 \\
0.02482 \\
\ldots \\
\ldots \\
\end{array}$ \\
\hline \multicolumn{6}{|c|}{ Ferrell (tube) } \\
\hline 39,700 & 0.01340 & 78,400 & 0.01017 & $\cdots$ & $\cdots$ \\
\hline
\end{tabular}




\section{Preliminary Data -- 9 September 1993}

Table 5-2.--Selected data from Columbia University tube tests (20)

\begin{tabular}{c|l||l|l|l|l}
\hline \hline Pe number & St number & Pe number & St number & Pe number & St number \\
\hline 280,000 & 0.00723 & 564,000 & 0.00653 & 190,000 & 0.00607 \\
240,000 & 0.00608 & 465,000 & 0.00552 & 395,000 & 0.00538 \\
360,000 & 0.00612 & 571,000 & 0.00605 & 470,000 & 0.00608 \\
673,000 & 0.00233 & 699,000 & 0.00653 & 161,000 & 0.00767 \\
391,000 & 0.00606 & 271,000 & 0.00734 & 213,000 & 0.00519 \\
479,000 & 0.00610 & 225,000 & 0.00514 & 247,000 & 0.00468 \\
616,000 & 0.00573 & 226,000 & 0.00574 & 202,000 & 0.00106 \\
493,000 & 0.00557 & 358,000 & 0.00684 & 339,000 & 0.00173 \\
296,000 & 0.00739 & 527,000 & 0.00742 & 402,000 & 0.00218 \\
478,000 & 0.00520 & 732,000 & 0.00592 & 404,000 & 0.00687 \\
625,000 & 0.00576 & 269,000 & 0.00727 & 326,000 & 0.00206 \\
471,000 & 0.00619 & 414,000 & 0.00656 & 397,000 & 0.00326 \\
590,000 & 0.00595 & 543,000 & 0.00683 & 556,000 & 0.00083 \\
807,000 & 0.00525 & 690,000 & 0.00621 & 200,000 & 0.00165 \\
328,000 & 0.00770 & 911,000 & 0.00625 & 261,000 & -0.00371 \\
414,000 & 0.00724 & 233,000 & 0.00722 & 220,000 & 0.00105 \\
\hline
\end{tabular}




\section{Preliminary Data -. 9 September 1993}

Table 5-3.--OFI data derived from the work of Whittle and Forgan

\begin{tabular}{c|c|c|c|c|c}
\hline \hline Pe number & St number & Pe number & St number & Pe number & St number \\
\hline \multicolumn{6}{c}{ Test section 1, rectangle, $25.4 \mathrm{~mm} \times 3.23 \mathrm{~mm}, \mathrm{~L}_{\mathrm{h}} / \mathrm{D}_{\mathrm{h}}=94.5$, uniform heat flux } \\
\hline 83,300 & 0.01131 & 133,000 & 0.00938 & 144,000 & 0.01058 \\
119,000 & 0.00995 & 164,000 & 0.00995 & 165,000 & 0.00995 \\
146,000 & 0.01203 & 108,000 & 0.01058 & 174,000 & 0.01297 \\
205,000 & 0.00995 & 121,000 & 0.01058 & 78,500 & 0.01058 \\
66,500 & 0.01058 & 136,000 & 0.01131 & $\ldots$ & $\ldots$ \\
110,000 & 0.01058 & 99,300 & 0.01058 & $\ldots$ & $\ldots$ \\
\hline
\end{tabular}

Test section $1 A$, rectangle, $25.4 \mathrm{~mm} \times 3.23 \mathrm{~mm}, L_{h} / D_{h}=94.5$, non-uniform heat

\begin{tabular}{c|c||c|c|c|c}
\hline$\ldots$ & 0.01430 & $\ldots$ & 0.01495 & $\ldots$ & 0.01131 \\
$\ldots$ & 0.01058 & $\ldots$ & 0.01297 & $\ldots$ & 0.00995 \\
$\ldots$ & 0.01131 & $\ldots$ & 0.01203 & $\ldots$ & $\ldots$ \\
\hline
\end{tabular}

Test section 1, rectangle, $25.4 \mathrm{~mm} \times 3.23 \mathrm{~mm}, \mathrm{~L}_{\mathrm{h}} / \mathrm{D}_{\mathrm{h}}=94.5$, uniform heat flux

\begin{tabular}{l|l||r|c||c|c}
\hline 53,300 & 0.00995 & 94,500 & 0.00995 & 29,100 & 0.00938 \\
79,200 & 0.00995 & 61,600 & 0.00995 & $\ldots$ & $\ldots$ \\
99,800 & 0.01058 & 118,000 & 0.01060 & $\ldots$ & $\ldots$ \\
\hline
\end{tabular}

Test section 2, rectangle, $25.4 \mathrm{~mm} \times 2.43 \mathrm{~mm}, \mathrm{~L}_{\mathrm{h}} / \mathrm{D}_{\mathrm{h}}=83$, uniform heat flux

\begin{tabular}{r|c||c|c|c|c}
83,513 & 0.01064 & 85,000 & 0.01064 & 132,000 & 0.01064 \\
96,580 & 0.01064 & 125,000 & 0.01128 & 70,600 & 0.01282 \\
102,000 & 0.01064 & 143,000 & 0.01128 & 90,200 & 0.01130 \\
121,000 & 0.01128 & 153,000 & 0.01149 & 82,300 & 0.01064 \\
92,606 & 0.01064 & 87,700 & 0.01064 & $\ldots$ & $\ldots$ \\
118,000 & 0.01064 & 95,600 & 0.01200 & $\ldots$ & $\ldots$ \\
\hline
\end{tabular}

Test section 3 , rectangle, $25.4 \mathrm{~mm} \times 2.03 \mathrm{~mm}, L_{h} / \mathrm{L}_{i,}=100$, uniform heat flux

\begin{tabular}{r|r||r|r|r|r}
101,000 & 0.00940 & 212,000 & 0.01000 & 89,100 & 0.00940 \\
125,000 & 0.00940 & 77,900 & 0.01000 & 74,500 & 0.00940 \\
158,000 & 0.00940 & 105,000 & 0.00940 & 55,300 & 0.01000 \\
99,807 & 0.01000 & 134,000 & 0.01070 & 212,000 & 0.01000 \\
154,000 & 0.01000 & 117,000 & 0.00890 & 38,200 & 0.00889 \\
\hline
\end{tabular}

Test section 4 , rectangle, $25.4 \mathrm{~mm} \times 140 \mathrm{~mm}, \mathrm{~L}_{\mathrm{h}} / \mathrm{D}_{\mathrm{h}}=191$, uniiorm heat flux

\begin{tabular}{r|r||r|r|r|r|}
\hline 120,000 & 0.00803 & 103,000 & 0.00803 & 104,000 & 0.00879 \\
65,530 & 0.00803 & 39,242 & 0.00803 & 84,684 & 0.00963 \\
91,602 & 0.00803 & 133,957 & 0.00740 & 73,408 & 0.00803 \\
76,192 & 0.00689 & 61,887 & 0.007340 & 93,728 & 0.00803 \\
\hline
\end{tabular}

Test section 5, tube, $6.45 \mathrm{~mm}$ dia., $\mathrm{L}_{\mathrm{h}} / \mathrm{D}_{\mathrm{h}}=94.5$, uniform heat flux

\begin{tabular}{l|l||l|l|l|l}
\hline 185,000 & 0.00754 & 119,000 & 0.00840 & 104,000 & 0.00840 \\
261,000 & 0.00754 & 223,000 & 0.00754 & 222,000 & 0.00754 \\
136,000 & 0.00840 & 296,000 & 0.00680 & 449,000 & 0.00618 \\
\hline
\end{tabular}




\section{Preliminaiy Data .- 9 September 1993}

Table 5-4.--Conditions at the demand curve minimums for the Creare OFI program (9)

\begin{tabular}{c|c|r|r|l}
\hline \hline $\begin{array}{c}\text { Test } \\
\text { Number }\end{array}$ & Geometry & $Q_{\text {ratio }}$ & Pe number & St number \\
\hline 1 & annulus & 0.898 & 77,250 & 0.00747 \\
$1 \mathrm{~A}$ & annulus & 0.797 & 87,380 & 0.00335 \\
2 & annulus & 0.940 & 65,734 & 0.01329 \\
3 & annulus & 0.905 & 75,983 & 0.00800 \\
4 & annulus & 0.904 & 155,573 & 0.00799 \\
1 & ribbed & 0.867 & 69,704 & 0.00564 \\
2 & ribbed & 0.849 & 64,907 & 0.00482 \\
3 & ribbed & 0.835 & 73,711 & 0.00437 \\
$1 \mathrm{~A}$ & ribbed & 0.842 & 73,117 & 0.00459 \\
4 & ribbed & 0.822 & 151,586 & 0.00399 \\
10 & ribbed & 0.818 & 90,927 & 0.00351 \\
15 & ribbed & 0.762 & 80,141 & 0.00278 \\
16 & ribbed & 0.842 & 154,261 & 0.00438 \\
5 & ribbed & 0.810 & 76,021 & 0.00367 \\
6 & ribbed & 0.837 & 223,928 & 0.00438 \\
7 & ribbed & 0.828 & 197,891 & 0.00414 \\
9 & ribbed & 0.849 & 281,362 & 0.00483 \\
13 & ribbed & 0.805 & 76,689 & 0.00354 \\
$3 \mathrm{~A}$ & ribbed & 0.799 & 76,962 & 0.00341 \\
\hline
\end{tabular}




\section{Preliminary Data -- 9 September 1993}

Table 5-5.--Demand curve minimum data from work of Johnston and Neff (40)

\begin{tabular}{|c|c|c|c|c|c|}
\hline $\begin{array}{c}\text { Test } \\
\text { number }\end{array}$ & $\mathrm{Pe}$ at $\mathrm{OFI}$ & St at OFI & $\begin{array}{c}\text { Test } \\
\text { number }\end{array}$ & $\mathrm{Pe}$ at OFI & St at OFI \\
\hline \multicolumn{6}{|c|}{ "open" annulus } \\
\hline $\begin{array}{l}\text { snbnr4 } \\
\text { snbnr4x } \\
\text { snbnr5 } \\
\text { snbnr5x } \\
\text { snbnr6 } \\
\text { snbnr7 } \\
\text { snbnr8 } \\
\text { snbnr8x } \\
\text { snbnr8x } \\
\text { snbnr9 } \\
\text { snbnr9x }\end{array}$ & $\begin{array}{r}68,000 \\
65,500 \\
95,000 \\
10,500 \\
107,000 \\
113,000 \\
93,000 \\
118,000 \\
136,000 \\
131,000 \\
121,500 \\
\end{array}$ & $\begin{array}{l}0.00841 \\
0.00984 \\
0.00747 \\
0.00701 \\
0.00755 \\
0.00717 \\
0.00689 \\
0.00740 \\
0.00660 \\
0.00751 \\
0.00927 \\
\end{array}$ & $\begin{array}{l}\text { snbnr10 } \\
\text { snbnr11 } \\
\text { snbnr12 } \\
\text { snbnr13 } \\
\text { snbnr14 } \\
\text { snbnr15x } \\
\text { snbnr15x1 } \\
\text { snbnr15 } \\
\text { snbnr4h } \\
\text { snbnr5h } \\
\text { snbnr6h } \\
\end{array}$ & $\begin{array}{c}121,500 \\
159,500 \\
148,000 \\
132,500 \\
157,500 \\
170,000 \\
150,500 \\
161,000 \\
45,000 \\
50,000 \\
63,000 \\
\end{array}$ & $\begin{array}{l}0.00675 \\
0.00630 \\
0.00844 \\
0.00670 \\
0.00610 \\
0.00736 \\
0.00931 \\
0.00825 \\
0.00533 \\
0.00824 \\
0.00754 \\
\end{array}$ \\
\hline \multicolumn{6}{|c|}{ ribbed annulus } \\
\hline $\begin{array}{l}\text { snbx4 } \\
\text { snbx5 } \\
\text { snbx6 } \\
\text { snbx7 } \\
\text { snbx8 } \\
\text { snbx9 } \\
\text { snbx } 10 \\
\text { snbx } 11 \\
\text { snbx } 11 x\end{array}$ & $\begin{array}{l}104,500 \\
131,000 \\
123,000 \\
115,000 \\
141,000 \\
143,000 \\
100,500 \\
142,500 \\
110,000\end{array}$ & $\begin{array}{l}0.00447 \\
0.00477 \\
0.00571 \\
0.00527 \\
0.00578 \\
0.00626 \\
0.00621 \\
0.00569 \\
0.00711\end{array}$ & $\begin{array}{l}\text { snbx13 } \\
\text { snbx14 } \\
\text { snbx15 } \\
\text { snbx15x } \\
\text { snbx15x1 } \\
\text { half } \\
\text { half1 } \\
\text { half2 } \\
\text { mid }\end{array}$ & $\begin{array}{c}120,000 \\
158,000 \\
193,000 \\
165,000 \\
180,000 \\
51,000 \\
50,500 \\
53,000 \\
58,000\end{array}$ & $\begin{array}{l}0.00588 \\
0.00585 \\
0.00598 \\
0.00633 \\
0.00690 \\
0.00383 \\
0.00356 \\
0.00420 \\
0.00599\end{array}$ \\
\hline
\end{tabular}




\section{Preliminary Data -- 9 September 1993}

APPENDIX 6

OPERATIONAL DETAILS 


\section{Preliminary Data -- 9 September 1993}

The tests described in this document were conducted to the requirements of the technical procedure TP-93-005, Local FI Rig - Operation. This procedure provided the directions necessary to: (1) verify M\&TE operation, and (2) produce steady state demand curves. The operating procedure was supplemented with routinely issued test plans that specified the operating parameters for each specific set of demand curves. (These test plans are part of the task records.) This appendix summarizes the contents of the Test Procedure TP-93-005 and test plans.

\section{Test Phases}

The testing of each channel was separated into 3 phases. Each phase had a separate purpose. These are described in Table 6-1. The isothermal tests were completed both before and after diabatic testing. The isothermal tests, Phases 1 and 2, were directed towards verifying if the test channel was operating as expected by current theory, establishing flow constants for the rig, and establishing that the channel behavior did not vary with use. Phase 3 generated the data necessary to compare OFI behavior in a ribbed and unobstructed channel.

Table 6-1.--Test phase descriptions

\begin{tabular}{c|c|c}
\hline \hline Phase & Description & Comment \\
\hline 1 & Cold isothermal tests & $\begin{array}{r}\text { Establish the channel demand curves at } \\
\text { ambient temperatures. }\end{array}$ \\
2 & Hot isothermal tests & $\begin{array}{c}\text { Establish the channel demand curves at } \\
\text { elevated temperatures. } \\
\text { Establish the diabatic (heated) demand } \\
\text { curves. }\end{array}$ \\
\hline
\end{tabular}




\section{Preliminary Data -. 9 September 1993}

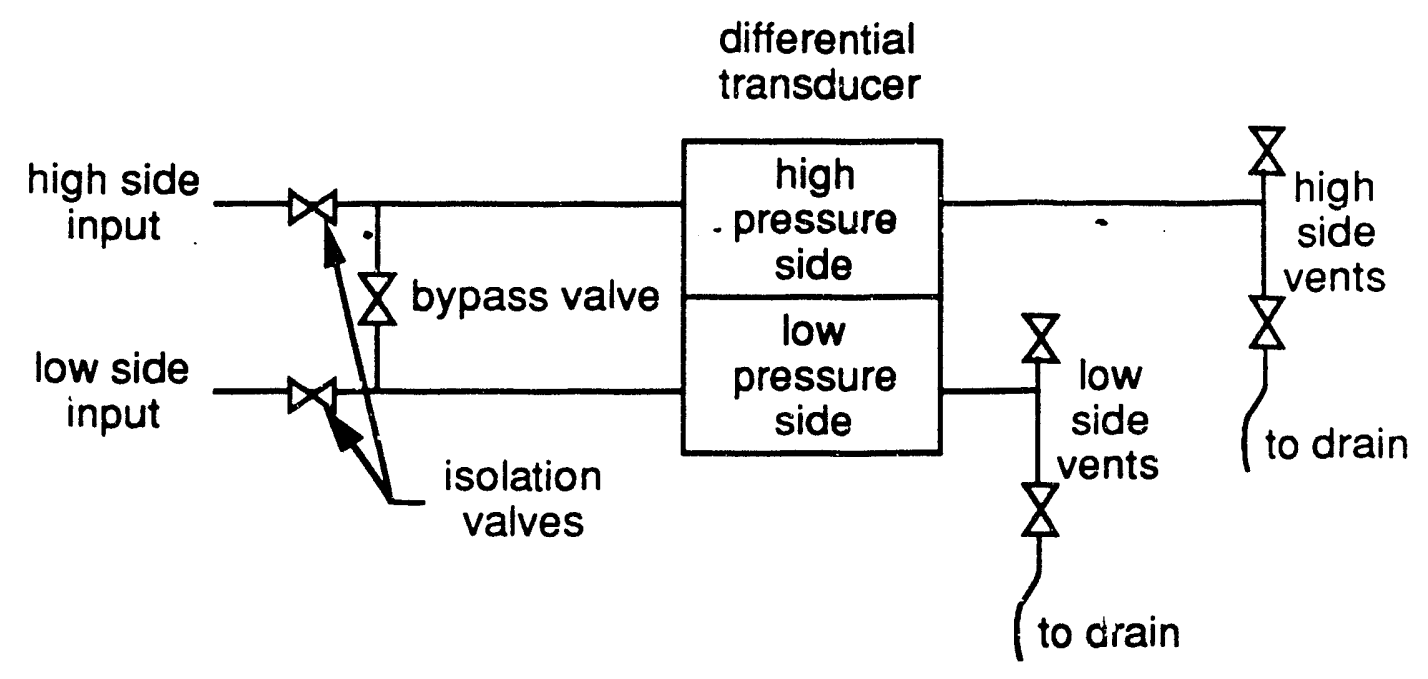

Figure 6-1, Differential pressure transducer schematic

\section{Daily Function Checks}

Three types of daily checks were conducted both before and after each day of demand curve testing. The data presented in Figure 6-1 was recorded for each function check. Sixty seconds of data was recorded on the DAS for each function check.

\section{Zero Check}

The purpose of the zero check was to verify the operation (at zero pressure) of the pressure gauges and transducers. This was accomplished by venting the instruments to atmosphere while recording a set of data. Prior to recording the zero data the toggle valving for the pressure transducers and gauges were set as stated in Table 6-2. The valving nomenclature is provided in Figure 6-1. 
Table 6-2.--Valving arrangements for zero, span and flow function checks

\begin{tabular}{|c|c|c|c|}
\hline & Zero & Span & Flow \\
\hline $\begin{array}{l}\text { Differential pressure trànsducers } \\
\text { HP isolation valves } \\
\text { LP isolation valves } \\
\text { Bypass valves } \\
\text { HP vent valves (2) } \\
\text { LP vent valves (2) }\end{array}$ & $\begin{array}{l}\text { closed } \\
\text { closed } \\
\text { open } \\
\text { open } \\
\text { open }\end{array}$ & $\begin{array}{l}\text { open } \\
\text { closed } \\
\text { closed } \\
\text { closed } \\
\text { open }\end{array}$ & $\begin{array}{l}\text { open } \\
\text { open } \\
\text { closed } \\
\text { closed } \\
\text { closed }\end{array}$ \\
\hline $\begin{array}{l}\text { Local pressure transducers } \\
\text { isolation valves } \\
\text { vent valves (2) }\end{array}$ & $\begin{array}{l}\text { closed } \\
\text { open }\end{array}$ & $\begin{array}{l}\text { open } \\
\text { closed }\end{array}$ & $\begin{array}{l}\text { open } \\
\text { closed }\end{array}$ \\
\hline $\begin{array}{l}\text { Local pressure gauges } \\
\text { isolation valves } \\
\text { vent valves }\end{array}$ & $\begin{array}{l}\text { closed } \\
\text { open }\end{array}$ & $\begin{array}{c}\text { open } \\
\text { closed }\end{array}$ & $\begin{array}{c}\text { open } \\
\text { closed }\end{array}$ \\
\hline
\end{tabular}

\section{Span Check}

The purpose of the span check was to verify the operation (at a specified pressure) of the pressure gauges and transducers. This was accomplished by measuring their output for an applied static head of water. The head tank was filled to $3.5 \pm 0.1 \mathrm{~m}(11.5 \pm 0.3$ feet) at the start of testing. The valving for the pressure transducers and gauges was set as stated in Table 6-2 for the span checks. Prior to collecting data the valves were cycled to purge air from the impulse lines. Purging continued until no air was visible in the vent discharge lines.

\section{Flow Check}

The purpose of the flow check was to verify the operation of the thermocouples, and flow instruments. It also served as a check of the channel integrity. The flow check was conducted by measuring the output of each instrument while flowing $473 \mathrm{~cm}^{3} / \mathrm{s}(7.5 \mathrm{gpm})$ of water through the test channel 


\section{Preliminary Data -- 9 September 1993}

as measured by the digital output from the turbine meter FT00001. The valving for the pressure transducers and gauges was set as stated in Table 6-2 for the flow checks. Prior to collecting data the valves were cycled to purge air from the impulse lines. Purging continued until no air was visible in the vent discharge lines.

\section{Test Procedures}

Three types of steady-state demand curves were completed during this testing. The types and the principle purpose of each type are listed in Table 61. The loop piping valving during demand curve testing was set as specified in Table 6-3; the valving for the pressure transducers was as specified for the flow function check in Table 6-2. The manual data recorded for these tests is listed in Figure 6-2.

For diabatic testing, rectifier operation was controlled using the HTL Building Procedure HTL-92-017, revision 0. The flow was initially set at the maximum available. The rectifiers were then used to increase the test section inlet water temperature to that specified in the test plan. The power to accomplish this was normally kept below $10 \mathrm{~kW}$. After the specified inlet conditions were achieve the power was then increased to that specified by the test plan. The backpressure was then set by decreasing the head tank level.

When the inlet temperature, power, and exit pressure conditions specified in the test plan were achieved a 60 second data set was recorded. The flow would then be decreased to a new rate specified by the test plan. The conditions would then be allowed to stabilize prior to data collection. This iterative process was repeated in decreasing flow increments until the flow was reduced below OFI flow. This was recognized as an increased in pressure drop across the heated section for a step decrease in flow. If time permitted the flow 
Table 6-3.--Standard valving arrangements

\begin{tabular}{|c|c|c|}
\hline $\begin{array}{c}\text { Valve } \\
\text { number }\end{array}$ & Description & Normal position \\
\hline LW001 & Flow regulator & $\begin{array}{l}\text { throttled to provide required test } \\
\text { flow }\end{array}$ \\
\hline $\begin{array}{l}\text { LW006 } \\
\text { LW007 } \\
\text { LW008 } \\
\text { LW011 } \\
\text { LW014 } \\
\text { LW015 } \\
\text { LW016 } \\
\text { LW017 } \\
\text { LW018 } \\
\text { LW019 } \\
\text { LW020 } \\
\text { LW022 } \\
\text { LW023 } \\
\text { CW003 } \\
\text { CW004 } \\
\text { CW005 } \\
\text { CW006 }\end{array}$ & $\begin{array}{l}\text { Channel inlet } \\
\text { Impulse line for PL11000 } \\
\text { Impulse line for PL11000 } \\
\text { Vent } \\
\text { Impulse line for PL33000 } \\
\text { Impulse line for PL12002 } \\
\text { Quench line } \\
\text { Bypass line } \\
\text { Bypass line } \\
\text { Bypass line } \\
\text { Channel exit } \\
\text { Tank drain } \\
\text { Loop drain } \\
60^{\circ} \mathrm{C} \text { cooling water valve } \\
80^{\circ} \mathrm{C} \text { cooling water valve } \\
\text { Roughing cooling water valve } \\
\text { Tuning cooling water valve }\end{array}$ & $\begin{array}{l}\text { open } \\
\text { closed } \\
\text { open } \\
\text { closed } \\
\text { open } \\
\text { open } \\
\text { closed } \\
\text { open } \\
\text { open } \\
\text { open } \\
\text { open } \\
\text { closed } \\
\text { closed } \\
\text { closed } \\
\text { closed } \\
\text { closed } \\
\text { throttled to provide required test } \\
\quad \text { loop temperature }\end{array}$ \\
\hline
\end{tabular}

was increase to eliminate boiling in the channel and the demand curve minimum was traced two additional times for each demand curve.

The flow to the test section for isothermal testing was set as specified in Table 6-4. These flows were selected to provide equidistant spacing of the Reynolds number on a log-log plot. The specified exit pressure was controlled by regulating the standpipe volume. Once established during a test run the standpipe level was not reset. If leakage occurred during the test the standpipe level would decrease. For elevated temperature $\left(40\right.$ and $\left.60^{\circ} \mathrm{C}\right)$ the rectifiers were used to heat the loop to operating condition and the pump heat was able to maintain the specified temperature. 
Preliminary Data -- 9 September 1993

Table 6-4.--Phase 1 and 2 test conditions

\begin{tabular}{c|c|c|c|c}
\hline $\begin{array}{c}\text { Test } \\
\text { number }\end{array}$ & $\begin{array}{c}\text { Phase or } \\
\text { replicate }\end{array}$ & $\begin{array}{c}\text { Temperature } \\
{ }^{\circ} \mathrm{C} \cdot\end{array}$ & $\begin{array}{c}\text { Back } \\
\text { pressure } \\
\text { psig }\end{array}$ & $\begin{array}{c}\text { Flow rate } \\
\text { gpm. }\end{array}$ \\
\hline 1.001 & replicate & 20.00 & 6.0781 & 7.50 \\
1.002 & 1 & 20.00 & 6.0781 & 2.00 \\
1.003 & 1 & 20.00 & 6.0781 & 3.56 \\
1.004 & 1 & 20.00 & 6.0781 & 6.32 \\
1.005 & 1 & 20.00 & 6.0781 & 11.25 \\
1.006 & 1 & 20.00 & 6.0781 & 20.00 \\
1.007 & 2 & 60.00 & 6.0781 & 1.70 \\
1.008 & 2 & 60.00 & 6.0781 & 3.03 \\
1.009 & 2 & 60.00 & 6.0781 & 5.39 \\
1.010 & 2 & 60.00 & 6.0781 & 9.58 \\
1.011 & 2 & 60.00 & 6.0781 & 17.04 \\
1.012 & 2 & 60.00 & 6.0781 & 20.00 \\
1.019 & 2 & 40.00 & 6.0781 & 1.70 \\
1.020 & 2 & 40.00 & 6.0781 & 2.35 \\
1.021 & 2 & 40.00 & 6.0781 & 4.18 \\
1.022 & 2 & 40.00 & 6.0781 & 7.44 \\
1.023 & 2 & 40.00 & 6.0781 & 13.22 \\
1.024 & 2 & 40.00 & 6.0781 & 20.00 \\
\hline
\end{tabular}

- Test numbers 1.013 through 1.018 were for conditions not used during the testing. 
Preliminary Data -- 9 September 1993

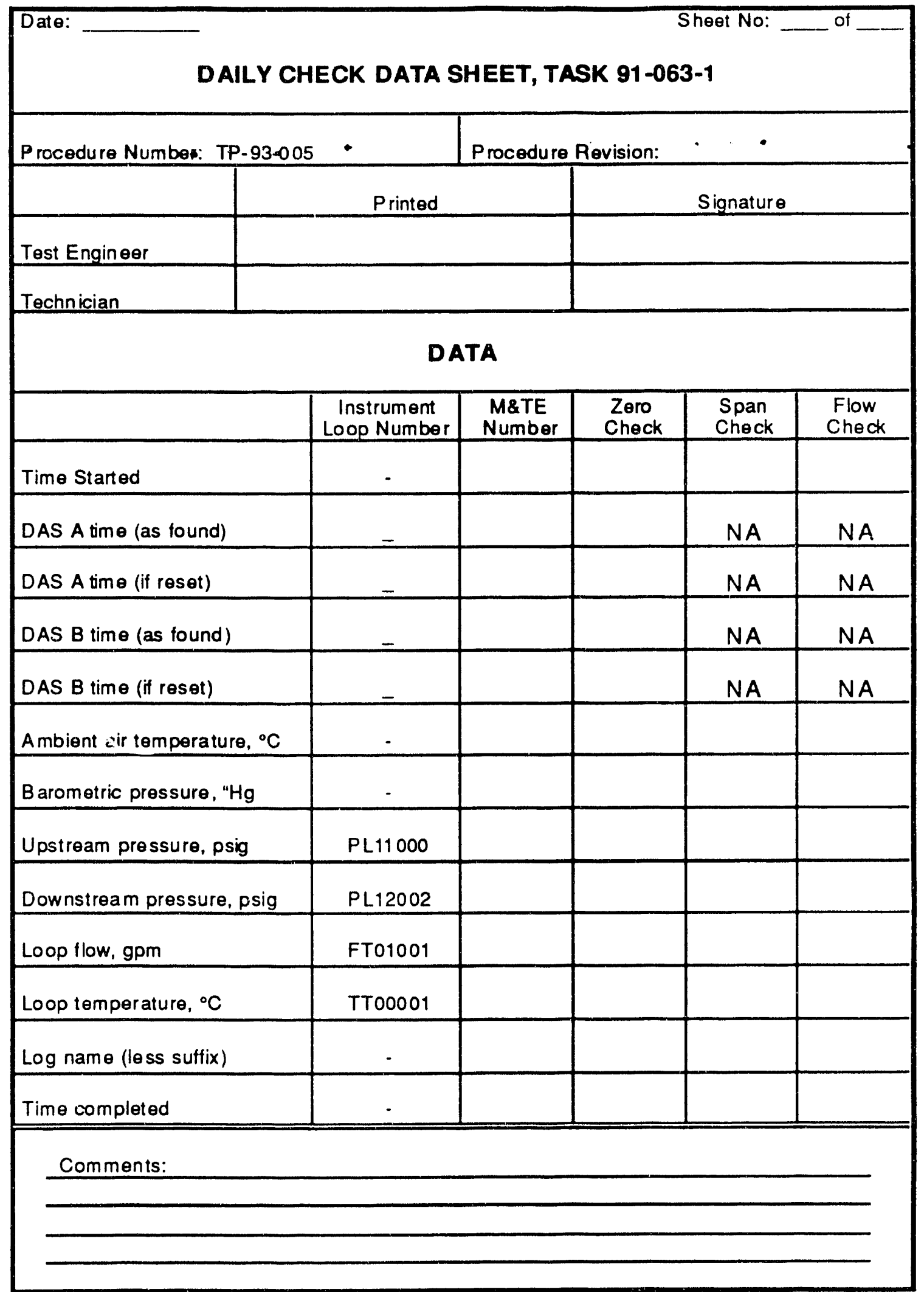

Figure 6-1, Typical daily check log sheet 


\section{Preliminary Data -- 9 September 1993}

Date:

Sheot No:

of

STEADY STATE AND TRANSIENT DATA SHEET, TASK 91-063-1

Procedure Number: TP-93-005

Procedure Revision:

P\&ID Drawing Revision:

HTL-92-017 Revision:

Rig Construction Number:

Test Matrix Revision:

\begin{tabular}{|l|l|l|}
\hline & Printed & Signature \\
\hline Test Engineer & & \\
\hline Technician & & \\
\hline
\end{tabular}

DATA

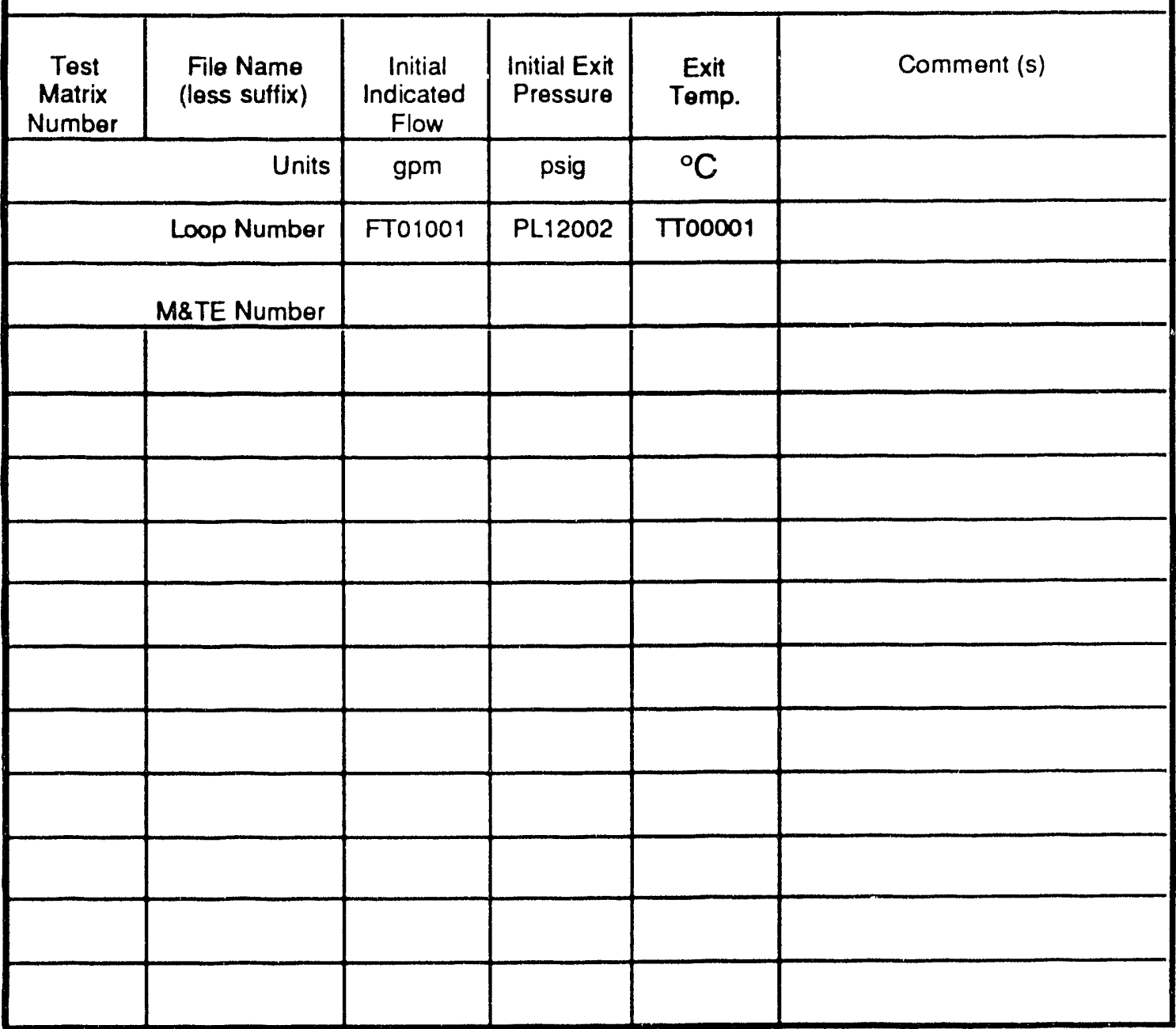

Figure 6-2, Typical steady-state log sheet 


\section{APPENDIX 7 \\ CALCULATIONS AND DATA REDUCTION}




\section{Development of a Generalized $Q_{\text {ratlo }}$ Equation}

Dougherty, et al. (29) present a relationship that combines the Qratio

- and Stanton number correlations." The form of this equation is:

$$
\mathrm{Q}_{\text {ratio }}=\frac{1}{1+\frac{0.25}{\mathrm{St}(\mathrm{L} / \mathrm{D})}}
$$

This equation is applicable only to round tubes. For other geometries this equation will not necessarily hold. Starting with the definition for the $Q_{\text {ratio: }}$ :

$$
\begin{aligned}
Q_{\text {ratio }} & =\frac{\phi}{\phi_{\text {sat }}}=\frac{T_{\text {out }}-T_{\text {in }}}{T_{\text {sat }}-T_{\text {in }}} \\
& =\frac{T_{\text {out }}-T_{\text {in }}}{\frac{\phi}{G c_{p} S t}+T_{\text {out }}-T_{\text {in }}} \\
& =\frac{1}{\frac{\phi}{G c_{p} S t\left(T_{\text {out }}-T_{\text {in }}\right)}+1} \\
Q_{\text {rati }} & =\frac{1}{1+\frac{A_{t}}{A_{h} S t}}
\end{aligned}
$$


Table 7-1.--Raw data and reduced data file columns and formats

\begin{tabular}{|c|c|c|c|c|}
\hline \multicolumn{2}{|c|}{ Raw data file } & \multicolumn{2}{|c|}{ Reduced raw data file } & \multirow[t]{2}{*}{ Data type } \\
\hline Column name & \begin{tabular}{|l|} 
Column \\
number \\
\end{tabular} & Column name & \begin{tabular}{|l|} 
Column \\
number \\
\end{tabular} & \\
\hline Date & 1 & Date & 3 & Date \\
\hline $\operatorname{Tim}$ & 2 & & $\cdots$ & Character \\
\hline Al:1 TP01317 & 3 & $\begin{array}{l}\operatorname{Mean}(A 1: 1 \text { TP01317) } \\
\text { Std(Al:1 TP01317) }\end{array}$ & $\begin{array}{r}4 \\
79\end{array}$ & $\begin{array}{l}\text { Numeric } \\
\text { Numeric }\end{array}$ \\
\hline Al:2 TP01308 & 4 & $\begin{array}{l}\text { Mean(Al:2 TP01308) } \\
\text { Std(Al:2 TP01308) }\end{array}$ & $\begin{array}{r}5 \\
80\end{array}$ & $\begin{array}{l}\text { Numeric } \\
\text { Numeric }\end{array}$ \\
\hline Al:3 TP01413 & 5 & $\begin{array}{l}\text { Mean(Al:3 TP01413) } \\
\text { Std(Al:3 TP01413) }\end{array}$ & $\begin{array}{r}6 \\
81\end{array}$ & $\begin{array}{l}\text { Numeric } \\
\text { Numeric }\end{array}$ \\
\hline Al:4 TP01702 & 6 & $\begin{array}{l}\text { Mean(Al:4 TP01702) } \\
\text { Std(Al:4 TP01702) }\end{array}$ & $\begin{array}{r}7 \\
82\end{array}$ & $\begin{array}{l}\text { Numeric } \\
\text { Numeric }\end{array}$ \\
\hline Al:5 TP01505 & 7 & $\begin{array}{l}\text { Mean(Al:5 TP01505) } \\
\text { Std(Al:5 TP01505) }\end{array}$ & $\begin{array}{r}8 \\
83\end{array}$ & $\begin{array}{l}\text { Numeric } \\
\text { Numeric }\end{array}$ \\
\hline Al:6 TP11917 & 8 & $\begin{array}{l}\text { Mean(Al:6 TP11917) } \\
\text { Std(Al:6 TP11917) }\end{array}$ & $\begin{array}{r}9 \\
84\end{array}$ & $\begin{array}{l}\text { Numeric } \\
\text { Numeric }\end{array}$ \\
\hline Al:7 TP12008 & 9 & $\begin{array}{l}\text { Mean(Al:7 TP12008) } \\
\text { Std(Al:7 TP12008) }\end{array}$ & $\begin{array}{l}10 \\
85\end{array}$ & $\begin{array}{l}\text { Numeric } \\
\text { Numeric }\end{array}$ \\
\hline Al:8 TP12113 & 10 & $\begin{array}{l}\text { Mean(Al:8 TP12113) } \\
\text { Std(Al:8 TP12113) }\end{array}$ & $\begin{array}{l}11 \\
86\end{array}$ & $\begin{array}{l}\text { Numeric } \\
\text { Numeric }\end{array}$ \\
\hline Al:9 TP12105 & 11 & $\begin{array}{l}\text { Mean(Al:9 TP12105) } \\
\text { Std(Al:9 TP12105) }\end{array}$ & $\begin{array}{l}12 \\
87\end{array}$ & $\begin{array}{l}\text { Numeric } \\
\text { Numeric }\end{array}$ \\
\hline Al:10 TP12302 & 12 & $\begin{array}{l}\text { Mean(Al:10 TP12302) } \\
\text { Std(Al:10 TP12302) }\end{array}$ & $\begin{array}{l}13 \\
88\end{array}$ & $\begin{array}{l}\text { Numeric } \\
\text { Numeric }\end{array}$ \\
\hline Al:11 TP22917 & 13 & $\begin{array}{l}\text { Mean(Al:11 TP22917) } \\
\text { Std(Al:11 TP22917) }\end{array}$ & $\begin{array}{l}14 \\
89\end{array}$ & $\begin{array}{l}\text { Numeric } \\
\text { Numeric }\end{array}$ \\
\hline Al:12 TP23008 & 14 & $\begin{array}{l}\text { Mean(Al:12 TP23008) } \\
\text { Std(Al:12 TP23008) }\end{array}$ & $\begin{array}{l}15 \\
90\end{array}$ & $\begin{array}{l}\text { Numeric } \\
\text { Numeric }\end{array}$ \\
\hline Al:13 TP23013 & 15 & $\begin{array}{l}\text { Mean(Al:13 TP23013) } \\
\text { Std(Al:13 TP23013) }\end{array}$ & $\begin{array}{l}16 \\
91\end{array}$ & $\begin{array}{l}\text { Numeric } \\
\text { Numeric }\end{array}$ \\
\hline Al:14 TP23105 & 16 & $\begin{array}{l}\text { Mean(Al:14 TP23105) } \\
\text { Std(Al:14 TP23105) }\end{array}$ & $\begin{array}{l}17 \\
92\end{array}$ & $\begin{array}{l}\text { Numeric } \\
\text { Numeric }\end{array}$ \\
\hline Al:15 TP23302 & 17 & $\begin{array}{l}\text { Mean(Al:15 TP23302) } \\
\text { Std(Al:15 TP23302) }\end{array}$ & $\begin{array}{l}18 \\
93\end{array}$ & $\begin{array}{l}\text { Numeric } \\
\text { Numeric }\end{array}$ \\
\hline Al:16 TP33917 & 18 & $\begin{array}{l}\text { Mean(Al:16 TP33917) } \\
\text { Std(Al:16 TP33917) }\end{array}$ & $\begin{array}{l}19 \\
94\end{array}$ & $\begin{array}{l}\text { Numeric } \\
\text { Numeric }\end{array}$ \\
\hline Al:17 TP34013 & 19 & $\begin{array}{l}\text { Mean(Al:17 TP34013) } \\
\text { Std(Al:17 TP34013) }\end{array}$ & $\begin{array}{l}20 \\
95\end{array}$ & $\begin{array}{l}\text { Numeric } \\
\text { Numeric }\end{array}$ \\
\hline Al:18 TP33908 & 20 & $\begin{array}{l}\text { Mean(Al:18 TP33908) } \\
\text { Std(Al:18 TP33908) }\end{array}$ & $\begin{array}{l}21 \\
96\end{array}$ & $\begin{array}{l}\text { Numeric } \\
\text { Numeric }\end{array}$ \\
\hline Al: 1 & 21 & $\begin{array}{l}\text { Mean(Al:19 TP34105) } \\
\text { Std(Al:19 TP34105) }\end{array}$ & $\begin{array}{l}22 \\
97\end{array}$ & $\begin{array}{l}\text { Numeric } \\
\text { Numeric }\end{array}$ \\
\hline Al: $:$ & 22 & $\begin{array}{l}\text { Mean(Al:20 TP34302) } \\
\text { Std(Al:20 TP34302) }\end{array}$ & $\begin{array}{l}23 \\
98\end{array}$ & $\begin{array}{l}\text { Numeric } \\
\text { Numeric }\end{array}$ \\
\hline
\end{tabular}


Table 7-1.--Continued

\begin{tabular}{|c|c|c|c|c|}
\hline \multicolumn{2}{|c|}{ Raw data file } & \multicolumn{2}{|c|}{ Reduced raw data file } & \multirow[t]{2}{*}{ Data type } \\
\hline Column name & $\begin{array}{l}\text { Column } \\
\text { numíber }\end{array}$ & Column name & $\begin{array}{l}\text { Column } \\
\text { number }\end{array}$ & \\
\hline Al:21 TP45008 & 23 & Mean(Al:21 TP45008) & 24 & Numeric \\
\hline Al:22 TP45105 & 24 & Mean(Al:22 TP45105) & $\begin{array}{r}25 \\
100\end{array}$ & $\begin{array}{l}\text { Numeric } \\
\text { Numeric }\end{array}$ \\
\hline Al:23 TP45302 & 25 & $\begin{array}{l}\text { Mean(Al:23 TP45302) } \\
\text { Std(Al.23 TP45302) }\end{array}$ & 26 & Numeric \\
\hline Al:24 TP45613 & 26 & Mean(Al:24 TP45613) & $\begin{array}{r}27 \\
102\end{array}$ & $\begin{array}{l}\text { Numeric } \\
\text { Numeric }\end{array}$ \\
\hline Al:25 TP45717 & 27 & $\begin{array}{l}\text { Mean(Al:25 TP45717) } \\
\text { Std(Al:25 TP45717) }\end{array}$ & $\begin{array}{r}28 \\
103\end{array}$ & $\begin{array}{l}\text { Numeric } \\
\text { Numeric }\end{array}$ \\
\hline Al:26 TP45808 & 28 & $\begin{array}{l}\text { Mean(Al:26 TP45808) } \\
\text { Std(Al:26 TP45808) }\end{array}$ & $\begin{array}{r}29 \\
104\end{array}$ & $\begin{array}{l}\text { Numeric } \\
\text { Numeric }\end{array}$ \\
\hline Al:27 TP45905 & 29 & $\begin{array}{l}\text { Mean(Al:27 TP45905) } \\
\text { Std(Al:27 TP45905) }\end{array}$ & $\begin{array}{r}30 \\
105\end{array}$ & $\begin{array}{l}\text { Numeric } \\
\text { Numeric }\end{array}$ \\
\hline Al:28 TP46102 & 30 & $\begin{array}{l}\text { Mean(Al:28 TP46102) } \\
\text { Std(Al:28 TP46102) }\end{array}$ & $\begin{array}{r}31 \\
106\end{array}$ & $\begin{array}{l}\text { Numeric } \\
\text { Numeric }\end{array}$ \\
\hline Al:29 TP46308 & 31 & $\begin{array}{l}\text { Mean(Al:29 TP46308) } \\
\text { Std(Al:29 TP46308) }\end{array}$ & $\begin{array}{r}32 \\
107\end{array}$ & $\begin{array}{l}\text { Numeric } \\
\text { Numeric }\end{array}$ \\
\hline Al:30 TP46217 & 32 & $\begin{array}{l}\operatorname{Mean}(A 1: 30 \text { TP46217) } \\
\text { Std(Al:30 TP46217) }\end{array}$ & $\begin{array}{r}33 \\
108\end{array}$ & $\begin{array}{l}\text { Numeric } \\
\text { Numeric }\end{array}$ \\
\hline Al:31 TP 46413 & 33 & $\begin{array}{l}\text { Mean(Al:31 TP46413) } \\
\text { Std(Al:31 TP46413) }\end{array}$ & $\begin{array}{r}34 \\
109\end{array}$ & $\begin{array}{l}\text { Numeric } \\
\text { Numeric }\end{array}$ \\
\hline Al:32 TP46505 & 34 & $\begin{array}{l}\text { Mean(Al:32 TP46505) } \\
\text { Std(Al:32 TP46505) }\end{array}$ & $\begin{array}{r}35 \\
110\end{array}$ & $\begin{array}{l}\text { Numeric } \\
\text { Numeric }\end{array}$ \\
\hline Al:33 TP46602 & 35 & $\begin{array}{l}\text { Mean(Al:33 TP46602) } \\
\text { Std(Al:33 TP46602) }\end{array}$ & 36 & $\begin{array}{l}\text { Numeric } \\
\text { Numeric }\end{array}$ \\
\hline Al:34 TP46808 & 36 & $\begin{array}{l}\text { Mean(Al:34 TP46808) } \\
\text { Std(Al:34 TP46808) }\end{array}$ & $\begin{array}{r}37 \\
112\end{array}$ & $\begin{array}{l}\text { Numeric } \\
\text { Numeric }\end{array}$ \\
\hline Al:35 TP47005 & 37 & $\begin{array}{l}\text { Mean(Al:35 TP47005) } \\
\text { Std(Al:35 TP47005) }\end{array}$ & $\begin{array}{r}38 \\
113\end{array}$ & $\begin{array}{l}\text { Numeric } \\
\text { Numeric }\end{array}$ \\
\hline Al:36 TP47202 & 38 & $\begin{array}{l}\text { Mean(Al:36 TP47202) } \\
\text { Std(Al:36 TP47202) }\end{array}$ & $\begin{array}{r}39 \\
114\end{array}$ & $\begin{array}{l}\text { Numeric } \\
\text { Numeric }\end{array}$ \\
\hline Al:37 TC00001 & 39 & $\begin{array}{l}\text { Mean(Al:37 TC00001) } \\
\text { Std(Al:37 TC00001) }\end{array}$ & $\begin{array}{r}40 \\
115\end{array}$ & $\begin{array}{l}\text { Numeric } \\
\text { Numeric }\end{array}$ \\
\hline Al:38 TC00002 & 40 & $\begin{array}{l}\text { Mean(Al:38 TCO0002) } \\
\text { Std(Al:38 TC00002) }\end{array}$ & $\begin{array}{r}41 \\
116\end{array}$ & $\begin{array}{l}\text { Numeric } \\
\text { Numeric }\end{array}$ \\
\hline Al:39 TC00003 & 41 & $\begin{array}{l}\text { Mean(Al:39 TCO0003) } \\
\text { Std(Al:39 TCO0003) }\end{array}$ & $\begin{array}{r}42 \\
117\end{array}$ & $\begin{array}{l}\text { Numeric } \\
\text { Numeric }\end{array}$ \\
\hline A!:40 TF01202 & 42 & $\begin{array}{l}\text { Mean(Al:40 TF01202) } \\
\text { Std(Al:40 TF01202) }\end{array}$ & $\begin{array}{r}43 \\
118\end{array}$ & $\begin{array}{l}\text { Numeric } \\
\text { Numeric }\end{array}$ \\
\hline Al:41 TF01204 & 43 & $\begin{array}{l}\text { Mean(Al:41 TF01204) } \\
\text { Std(Al:41 TF01204) }\end{array}$ & $\begin{array}{r}44 \\
119\end{array}$ & $\begin{array}{l}\text { Numeric } \\
\text { Numeric }\end{array}$ \\
\hline
\end{tabular}


Table 7-1.--Centinued

\begin{tabular}{|c|c|c|c|c|}
\hline \multicolumn{2}{|c|}{ Raw data file } & \multicolumn{2}{|c|}{ Reduced raw data file } & \multirow{2}{*}{ Data type } \\
\hline Column name & $\begin{array}{l}\text { Column } \\
\text { number }\end{array}$ & Cólumn namie & $\begin{array}{l}\text { Column } \\
\text { number } \\
\end{array}$ & \\
\hline Al:42 TF02522 & 44 & $\begin{array}{l}\text { Mean(Al:42 TF02522) } \\
\text { Std(Al:42 TF02522) }\end{array}$ & $\begin{array}{r}45 \\
120\end{array}$ & $\begin{array}{l}\text { Numeric } \\
\text { Numeric }\end{array}$ \\
\hline Al:43 TF02524 & 45 & $\begin{array}{l}\text { Mean(Al:43 TF02524) } \\
\text { Std(Al:43 TF02524) }\end{array}$ & $\begin{array}{r}46 \\
121\end{array}$ & $\begin{array}{l}\text { Numeric } \\
\text { Numeric }\end{array}$ \\
\hline Al:44 TF04172 & 46 & $\begin{array}{l}\text { Mean(Al:44 TF04172) } \\
\text { Std(Al:44 TF04172) }\end{array}$ & $\begin{array}{r}47 \\
122\end{array}$ & $\begin{array}{l}\text { Numeric } \\
\text { Numeric }\end{array}$ \\
\hline Al:45 TF04174 & 47 & $\begin{array}{l}\text { Mean(Al:45 TF04174) } \\
\text { Std(Al:45 TF04174) }\end{array}$ & $\begin{array}{r}48 \\
123\end{array}$ & $\begin{array}{l}\text { Numeric } \\
\text { Numeric }\end{array}$ \\
\hline Al:46 TF05822 & 48 & $\begin{array}{l}\text { Mean(Al:46 TF05822) } \\
\text { Std(Al:46 TF05822) }\end{array}$ & $\begin{array}{r}49 \\
124\end{array}$ & $\begin{array}{l}\text { Numeric } \\
\text { Numeric }\end{array}$ \\
\hline Al:47 TF05824 & 49 & $\begin{array}{l}\text { Mean(Al:47 TF05824) } \\
\text { Std(Al:47 TF05824) }\end{array}$ & $\begin{array}{r}50 \\
125\end{array}$ & $\begin{array}{l}\text { Numeric } \\
\text { Numeric }\end{array}$ \\
\hline Al:48 TF06922 & 50 & $\begin{array}{l}\text { Mean(Al:48 TF06922) } \\
\text { Std(Al:48 TF06922) }\end{array}$ & $\begin{array}{r}51 \\
126\end{array}$ & $\begin{array}{l}\text { Numeric } \\
\text { Numeric }\end{array}$ \\
\hline Al:49 TF06924 & 51 & $\begin{array}{l}\text { Mean(Al:49 TF06924) } \\
\text { Std(Al:49 TF06924) }\end{array}$ & $\begin{array}{r}52 \\
127\end{array}$ & $\begin{array}{l}\text { Numeric } \\
\text { Numeric }\end{array}$ \\
\hline Al:50 TF08022 & 52 & $\begin{array}{l}\text { Mean(Al:50 TF08022) } \\
\text { Std(Al:50 TF08022) }\end{array}$ & $\begin{array}{r}53 \\
128\end{array}$ & $\begin{array}{l}\text { Numeric } \\
\text { Numeric }\end{array}$ \\
\hline Al:51 TF08024 & 53 & $\begin{array}{l}\text { Mean(Al:51 TF08024) } \\
\text { Std(Al:51 TF08024) }\end{array}$ & $\begin{array}{r}54 \\
129\end{array}$ & $\begin{array}{l}\text { Numeric } \\
\text { Numeric }\end{array}$ \\
\hline Al:52 TL01001 & 54 & $\begin{array}{l}\text { Mean(Al:52 TL01001) } \\
\text { Std(Al:52 TL01001) }\end{array}$ & $\begin{array}{r}55 \\
130\end{array}$ & $\begin{array}{l}\text { Numeric } \\
\text { Numeric }\end{array}$ \\
\hline Al:53 TL02001 & 55 & $\begin{array}{l}\text { Mean(Al:53 TL02001) } \\
\text { Std(Al:53 TL02001) }\end{array}$ & $\begin{array}{r}56 \\
131\end{array}$ & $\begin{array}{l}\text { Numeric } \\
\text { Numeric }\end{array}$ \\
\hline Al:54 TL03001 & 56 & $\begin{array}{l}\operatorname{Mean}(A 1: 54 \text { TL03001) } \\
\text { Std(Al:54 TL03001) }\end{array}$ & $\begin{array}{r}57 \\
132\end{array}$ & $\begin{array}{l}\text { Numeric } \\
\text { Numeric }\end{array}$ \\
\hline Al:55 TL03002 & 57 & $\begin{array}{l}\text { Mean(Al:55 TL03002) } \\
\text { Std(Al:55 TLO3002) }\end{array}$ & $\begin{array}{r}58 \\
133\end{array}$ & $\begin{array}{l}\text { Numeric } \\
\text { Numeric }\end{array}$ \\
\hline Al:56 Analog Input & 58 & $\begin{array}{l}\text { Mean(Al:56 Analog Input) } \\
\text { Std(Al:56 Analog Input) }\end{array}$ & $\begin{array}{r}59 \\
134\end{array}$ & $\begin{array}{l}\text { Numeric } \\
\text { Numeric }\end{array}$ \\
\hline Al:57 Analog Input & 59 & $\begin{array}{l}\text { Mean(Al:57 Analog Input) } \\
\text { Std(Al:57 Analog Input) }\end{array}$ & $\begin{array}{r}60 \\
135\end{array}$ & $\begin{array}{l}\text { Numeric } \\
\text { Numeric }\end{array}$ \\
\hline Al:58 Analog Input & 60 & $\begin{array}{l}\text { Mean(Al:58 Analog Input) } \\
\text { Std(Al:58 Analog Input) }\end{array}$ & $\begin{array}{r}61 \\
136\end{array}$ & $\begin{array}{l}\text { Numeric } \\
\text { Numeric }\end{array}$ \\
\hline Al:59 Analog Input & 61 & $\begin{array}{l}\text { Mean(Al:59 Analog Input) } \\
\text { Std(Al:59 Analog Input) }\end{array}$ & $\begin{array}{r}62 \\
137\end{array}$ & $\begin{array}{l}\text { Numeric } \\
\text { Numeric }\end{array}$ \\
\hline Al:60 Analog Input & 62 & $\begin{array}{l}\text { Mean(Al:60 Analog Input) } \\
\text { Std(Al:60 Analog Input) }\end{array}$ & $\begin{array}{r}63 \\
138\end{array}$ & $\begin{array}{l}\text { Numeric } \\
\text { Numeric }\end{array}$ \\
\hline Al:61 PA20072 & 63 & $\begin{array}{l}\text { Mean(Al:61 PA20072) } \\
\text { Std(Al:61 PA20072) }\end{array}$ & $\begin{array}{r}64 \\
139\end{array}$ & $\begin{array}{l}\text { Numeric } \\
\text { Numeric }\end{array}$ \\
\hline Al:62 PD22472 & 64 & $\begin{array}{l}\text { Mean(Al:62 PD22472) } \\
\text { Std(Al:62 PD22472). }\end{array}$ & $\begin{array}{r}65 \\
140\end{array}$ & $\begin{array}{l}\text { Numeric } \\
\text { Numeric }\end{array}$ \\
\hline
\end{tabular}


Table 7-1.--Continued

\begin{tabular}{|c|c|c|c|c|}
\hline \multicolumn{2}{|c|}{ Raw data file } & \multicolumn{2}{|c|}{ Reduced raw data file } & \multirow[t]{2}{*}{ Data type } \\
\hline Columin name & \begin{tabular}{|l} 
Column \\
number \\
\end{tabular} & Column näme & $\begin{array}{l}\text { Column } \\
\text { number }\end{array}$ & \\
\hline Al:63 FT01002 & 65 & Mean(Al:63 FT01002) & 66 & Numeric \\
\hline Al:64 PG00024 & 66 & $\begin{array}{l}\text { Mean(Al:64 PG00024) } \\
\text { Std(Al:64 PG00024) }\end{array}$ & $\begin{array}{r}67 \\
142\end{array}$ & $\begin{array}{l}\text { Numeric } \\
\text { Numeric }\end{array}$ \\
\hline Al:65 PL00001 & 67 & $\begin{array}{l}\text { Mean(Al:65 PLo0001) } \\
\text { Std(Al:65 PL00001) }\end{array}$ & $\begin{array}{r}68 \\
143\end{array}$ & $\begin{array}{l}\text { Numeric } \\
\text { Numeric }\end{array}$ \\
\hline Al:66 PD00024 & 68 & $\begin{array}{l}\text { Mean(Al:66 PD00024) } \\
\text { Std(Al:66 PD00024) }\end{array}$ & $\begin{array}{r}69 \\
144\end{array}$ & $\begin{array}{l}\text { Numeric } \\
\text { Numeric }\end{array}$ \\
\hline Al:67 PA00072 & 69 & $\begin{array}{l}\text { Mean(Al:67 PA00072) } \\
\text { Std(Al:67 PA00072) }\end{array}$ & $\begin{array}{r}70 \\
145\end{array}$ & $\begin{array}{l}\text { Numeric } \\
\text { Numeric }\end{array}$ \\
\hline Al:68 PD02472 & 70 & $\begin{array}{l}\text { Mean(Al:68 PD02472) } \\
\text { Std(Al:68 PD02472) }\end{array}$ & $\begin{array}{r}71 \\
146\end{array}$ & $\begin{array}{l}\text { Numeric } \\
\text { Numeric }\end{array}$ \\
\hline Al:69 PD00072 & 71 & $\begin{array}{l}\text { Mean(Al:69 PD00072) } \\
\text { Std(Al:69 PD00072) }\end{array}$ & $\begin{array}{r}72 \\
147\end{array}$ & $\begin{array}{l}\text { Numeric } \\
\text { Numeric }\end{array}$ \\
\hline Al:70 PL00002 & 72 & $\begin{array}{l}\text { Mean(Al:70 PL00002) } \\
\text { Std(Al:70 PL00002) }\end{array}$ & $\begin{array}{r}73 \\
148\end{array}$ & $\begin{array}{l}\text { Numeric } \\
\text { Numeric }\end{array}$ \\
\hline Al:71 PD07284 & 73 & $\begin{array}{l}\text { Mean(Al:71 PD07284) } \\
\text { Std(Al:71 PD07284) }\end{array}$ & $\begin{array}{r}74 \\
149\end{array}$ & $\begin{array}{l}\text { Numeric } \\
\text { Numeric }\end{array}$ \\
\hline Al:72 PD00084 & 74 & $\begin{array}{l}\text { Mean(Al:72 PD00084) } \\
\text { Std(Al:72 PD00084) }\end{array}$ & $\begin{array}{r}75 \\
150\end{array}$ & $\begin{array}{l}\text { Numeric } \\
\text { Numeric }\end{array}$ \\
\hline Al:73 FT01001 & 75 & $\begin{array}{l}\text { Mean(Al:73 FT01001) } \\
\text { Std(Al:73 FT01001) }\end{array}$ & $\begin{array}{r}76 \\
151\end{array}$ & $\begin{array}{l}\text { Numeric } \\
\text { Numeric }\end{array}$ \\
\hline Al:74 WV00001 & 76 & $\begin{array}{l}\text { Mean(Al:74 WV00001) } \\
\text { Std(Al:74 WV00001) }\end{array}$ & $\begin{array}{r}77 \\
152\end{array}$ & $\begin{array}{l}\text { Numeric } \\
\text { Numeric }\end{array}$ \\
\hline Al:75 WC00001 & 77 & $\begin{array}{l}\text { Mean(Al:75 WC00001) } \\
\text { Std(Al:75 WC00001) }\end{array}$ & $\begin{array}{r}78 \\
153\end{array}$ & $\begin{array}{l}\text { Numeric } \\
\text { Numeric }\end{array}$ \\
\hline $\begin{array}{l}\text { DI:81 Digital Input } \\
\text { MT11 Stopwatch } \\
\text { File name } \\
\text { Number of rows }\end{array}$ & $\begin{array}{r}78 \\
79 \\
80 \\
\ldots\end{array}$ & $\begin{array}{ll} & \cdots \\
\text { File name } & \cdots \\
\mathrm{N} & \end{array}$ & $\begin{array}{l}\cdots \\
\cdots \\
1 \\
2\end{array}$ & $\begin{array}{l}\text { Numeric } \\
\text { Numeric } \\
\text { Character } \\
\text { Numeric }\end{array}$ \\
\hline
\end{tabular}




\section{Engineering Unit Conversions}

Table 7-2 presents the conversion equations used in the JMP® Worksheet "Engineering Units.06". This worksheet converts the voltage units "from the Reduced Data Worksheet "Raw Data Table.25" and converts it to SI engineering units. The majority of the conversions take the form:

$$
\psi=\frac{v-a}{b}
$$

where:

$$
S_{\psi}=\frac{V}{b}
$$

The orifice flow meter, FT01002, is of the form:

$$
\psi=\sqrt{\frac{V-a}{b}}
$$

where:

$$
S_{\psi}=\frac{1}{2 \sqrt{b(V-a)}}
$$


Table 7-2..--Engineering units conversions

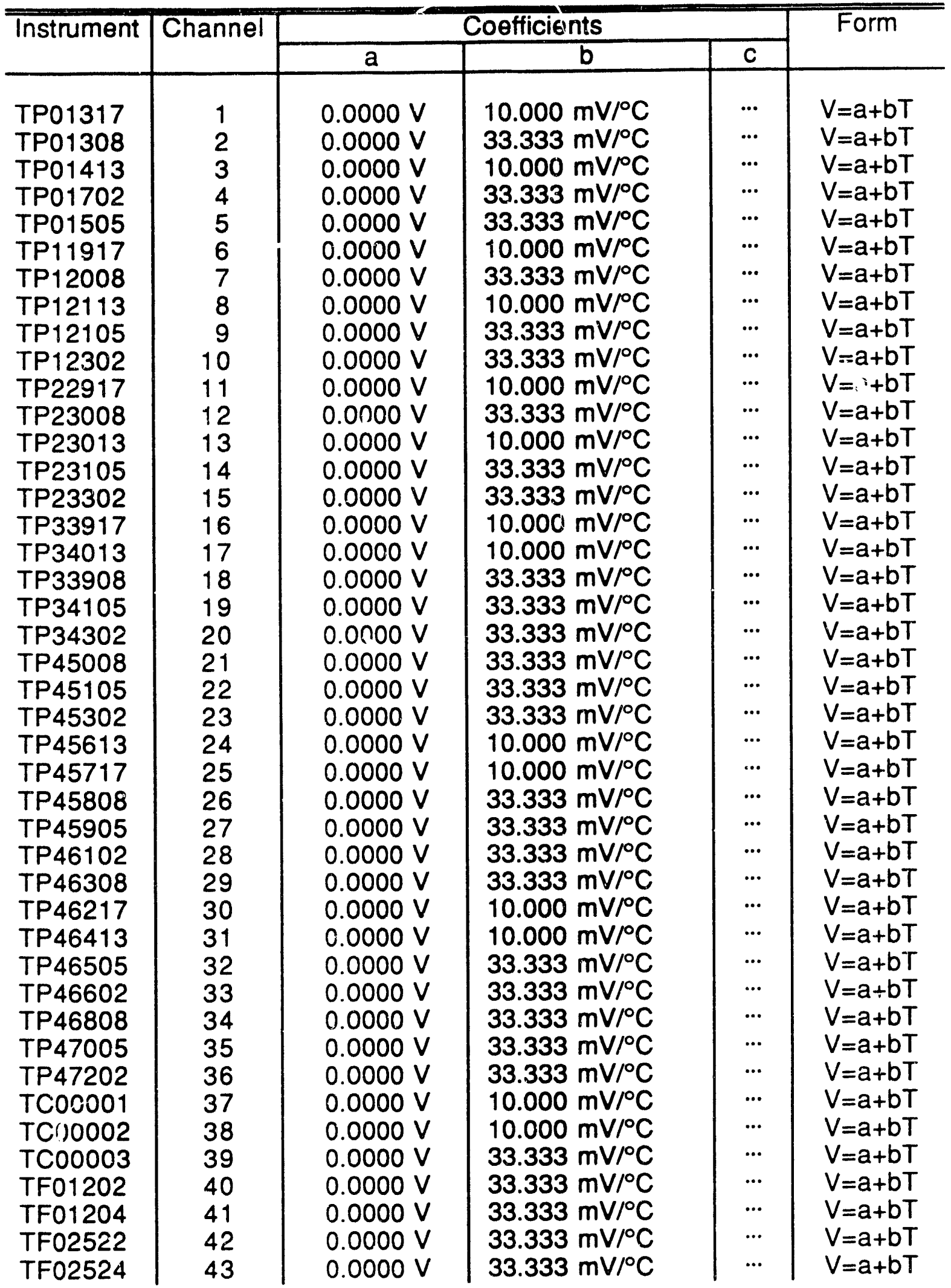


Table 7-2..---Continued

\begin{tabular}{|c|c|c|c|c|c|}
\hline \multirow[t]{2}{*}{ Instrument } & \multirow[t]{2}{*}{ Channel } & \multicolumn{3}{|c|}{ Coefficients } & \multirow[t]{2}{*}{ Form } \\
\hline & & $\bar{a}$ & $\mathrm{~b}$ & c & \\
\hline TF04172 & 44 & $0.0000 \mathrm{~V}$ & $33.333 \mathrm{mV} /{ }^{\circ} \mathrm{C}$ & $\ldots$ & $V=a+b T$ \\
\hline TF04174 & 45 & $0.0000 \mathrm{~V}$ & $33.333 \mathrm{mV} /{ }^{\circ} \mathrm{C}$ & $\ldots$ & $V=a+b T$ \\
\hline TF05822 & 46 & $0.0000 \mathrm{~V}$ & $33.333 \mathrm{mV} /{ }^{\circ} \mathrm{C}$ & $\ldots$ & $V=a+b T$ \\
\hline TF05824 & 47 & $0.0000 \mathrm{~V}$ & $33.333 \mathrm{mV} /{ }^{\circ} \mathrm{C}$ & ... & $V=a+b T$ \\
\hline TF06922 & 48 & $0.0000 \mathrm{~V}$ & $33.333 \mathrm{mV} /{ }^{\circ} \mathrm{C}$ & ... & $V=a+b T$ \\
\hline TF06924 & 49 & $0.0000 \mathrm{~V}$ & $33.333 \mathrm{mV} /{ }^{\circ} \mathrm{C}$ & ... & $V=a+b T$ \\
\hline TF08022 & 50 & $0.0000 \mathrm{~V}$ & $33.333 \mathrm{mV} /{ }^{\circ} \mathrm{C}$ & ... & $V=a+b T$ \\
\hline TF08024 & 51 & $0.0000 \mathrm{~V}$ & $33.333 \mathrm{mV} /{ }^{\circ} \mathrm{C}$ & ... & $V=a+b T$ \\
\hline TL01001 & 52 & $0.0000 \mathrm{~V}$ & $33.333 \mathrm{mV} /{ }^{\circ} \mathrm{C}$ & ... & $V=a+b T$ \\
\hline TL02001 & 53 & $0.0000 \mathrm{~V}$ & $33.333 \mathrm{mV} /{ }^{\circ} \mathrm{C}$ & ... & $V=a+b T$ \\
\hline TL03001 & 54 & $0.0000 \mathrm{~V}$ & $33.333 \mathrm{mV} /{ }^{\circ} \mathrm{C}$ & $\ldots$ & $V=a+b T$ \\
\hline TL03002 & 55 & $0.0000 \mathrm{~V}$ & $33.333 \mathrm{mV} /{ }^{\circ} \mathrm{C}$ & $\cdots$ & $V=a+b T$ \\
\hline unused & 56 & $\ldots$ & $\ldots$ & ... & $\ldots$ \\
\hline un & 57 & ... & ... & ... & .. \\
\hline un! & 58 & $\ldots$ & ... & $\cdots$ & ... \\
\hline un & 59 & ... & ... & ... & ... \\
\hline unused & 60 & ... & ... & ... & $\cdots$ \\
\hline PA20072 & 61 & $-1.8352 \mathrm{~V}$ & $26.37 \mu V / P$ & $\begin{array}{l}\cdots \\
\ldots\end{array}$ & $V=a+b P$ \\
\hline PD22472 & 62 & $0.8963 \mathrm{~V}$ & $26.36 \mu V / P$ & $\cdots$ & $V=a+b P$ \\
\hline FT01002 & 63 & $\begin{array}{l}0.7580 \mathrm{~V} \\
-00920 \mathrm{~V}\end{array}$ & $\begin{array}{l}5.5578 \mathrm{MV} \cdot \mathrm{s}^{2} / \mathrm{m}^{6} \\
\end{array}$ & $\begin{array}{l}2 \\
\ldots\end{array}$ & $\begin{array}{l}V=a+b Q^{2} \\
V=a+b P\end{array}$ \\
\hline $\begin{array}{l}\text { PG00024 } \\
\text { PL00001 }\end{array}$ & $\begin{array}{l}64 \\
65\end{array}$ & $\begin{array}{r}-0.0922 \mathrm{~V} \\
0.0016 \mathrm{~V}\end{array}$ & $\begin{array}{l}28.84 \mu \mathrm{V} / \mathrm{P} \\
7.25 \mu \mathrm{V} / \mathrm{Pa}\end{array}$ & $\ldots$ & $V=a+b P$ \\
\hline PD00024 & 66 & $1.1820 \mathrm{~V}$ & $181.22 \mu \mathrm{V} /$ & $\ldots$ & $V=a+b P$ \\
\hline PA00072 & 67 & $-1.8218 \mathrm{~V}$ & $26.38 \mu \mathrm{V} / \mathrm{P}$ & ... & $V=a+b P$ \\
\hline PD02472 & 68 & $0.9108 \mathrm{~V}$ & $26.38 \mu \mathrm{V} / \mathrm{P}$ & ... & $V=a+b P$ \\
\hline PD00072 & 69 & $-0.0145 \mathrm{~V}$ & $14.51 \mu \mathrm{V} / \mathrm{P}$ & ... & $V=a+b P$ \\
\hline PL00002 & 70 & $-0.1618 \mathrm{~V}$ & $28.92 \mu \mathrm{V} / \mathrm{P}$ & ... & $V=a+b P$ \\
\hline PD07284 & 71 & $0.0671 \mathrm{~V}$ & $85.31 \mu \mathrm{V} / \mathrm{P}$ & ... & $V=a+b P$ \\
\hline PD00084 & 72 & $0.9152 \mathrm{~V}$ & $26.38 \mu \mathrm{V} / \mathrm{P}$ & ... & $V=a+b P$ \\
\hline FT01001 & 73 & $-0.0169 \mathrm{~V}$ & $6.414 \mathrm{kV} \cdot \mathrm{s} / \mathrm{m}^{3}$ & ... & $V=a+b Q$ \\
\hline WVo & 74 & $\begin{array}{c}-0.1 \mathrm{mV} \\
0.3 \mathrm{mV}\end{array}$ & $\begin{array}{l}0.20075 \\
0.06668\end{array}$ & $\ldots$ & $V=a+b V$ \\
\hline WC00001 & 75 & $-4.278 \mathrm{mV}$ & $2.039 \mathrm{~m} \Omega$ & $\ldots$ & $V=a+b C$ \\
\hline
\end{tabular}

The top coefficients should be used for data collected prior to 3 June 1993. The lower coefficients should be used to reduce raw data collected on or after this date. 
Table 7-3.--Demand curve inputs JMP worksheet description

\begin{tabular}{|c|c|c|c|}
\hline Column name & $\begin{array}{c}\text { Column } \\
\text { type }\end{array}$ & Source & Comment \\
\hline $\begin{array}{l}\text { File name } \\
N \\
\text { Date } \\
\text { TP33917 } \\
\text { TP34013 } \\
\text { TP33908 } \\
\text { TP34105 } \\
\text { TP34302 } \\
\text { TC00003 } \\
\text { TL01001 } \\
\text { TL02001 } \\
\text { PA20072 } \\
\text { PD22472 } \\
\text { PA00072 } \\
\text { PD02472 } \\
\text { FT01001 } \\
\text { WV00001 } \\
\text { WC00001 } \\
\text { T inlet } \\
\text { T exit, C } \\
\text { T impulse, C } \\
\text { P exit } \\
\\
\text { DP24-72 }\end{array}$ & $\begin{array}{l}\text { character } \\
\text { numeric } \\
\text { date } \\
\text { numeric } \\
\text { numeric } \\
\text { numeric } \\
\text { numeric } \\
\text { numeric } \\
\text { numeric } \\
\text { numeric } \\
\text { numeric } \\
\text { numeric } \\
\text { numeric } \\
\text { numeric } \\
\text { numeric } \\
\text { numeric } \\
\text { numeric } \\
\text { numeric } \\
\text { numeric } \\
\text { numeric } \\
\text { numeric } \\
\text { numeric } \\
\\
\text { numeric } \\
\\
\text { numeric } \\
\\
\text { numeric } \\
\text { numeric } \\
\text { numeric }\end{array}$ & $\begin{array}{l}\text { input value } \\
\text { input value } \\
\text { input value } \\
\text { input value } \\
\text { input value } \\
\text { input value } \\
\text { input value } \\
\text { input value } \\
\text { input value } \\
\text { input value } \\
\text { input value } \\
\text { input value } \\
\text { input value } \\
\text { input value } \\
\text { input value } \\
\text { input value } \\
\text { input value } \\
\text { input value } \\
\text { calculation } \\
\text { calculation } \\
\text { calculation } \\
\text { calculation } \\
\text { calculation } \\
\text { calculation } \\
\text { calculation } \\
\text { calculation } \\
\text { calculation } \\
\text { calculation }\end{array}$ & 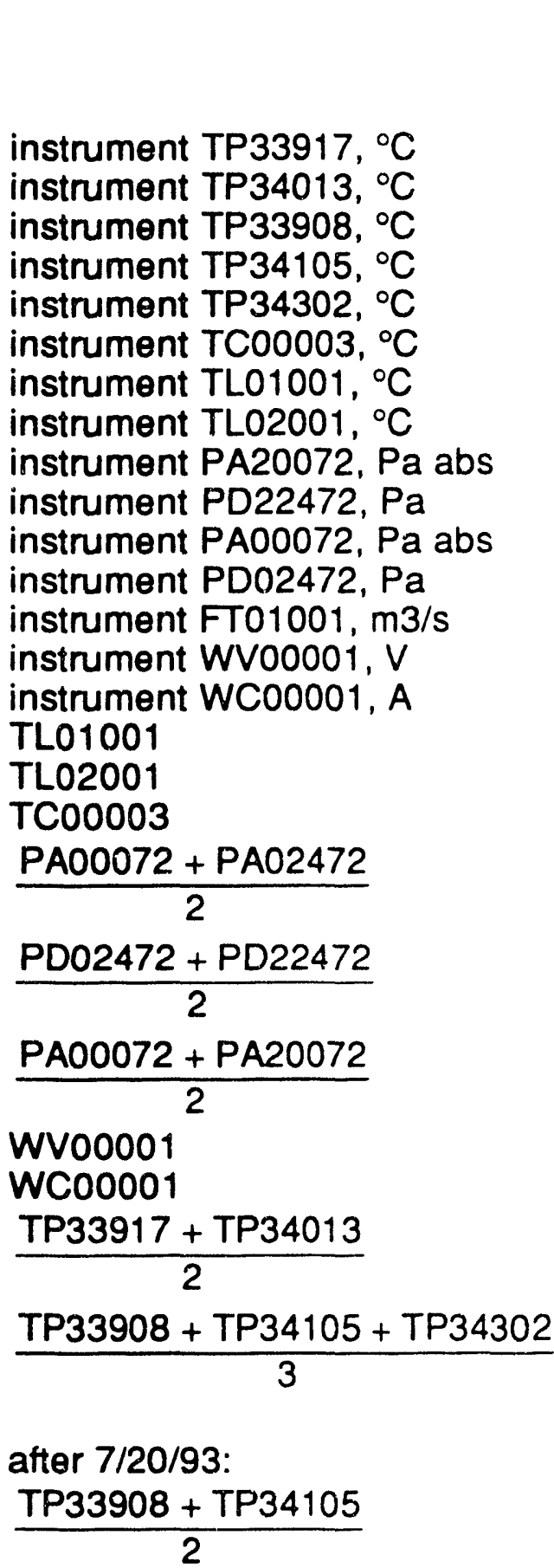 \\
\hline
\end{tabular}




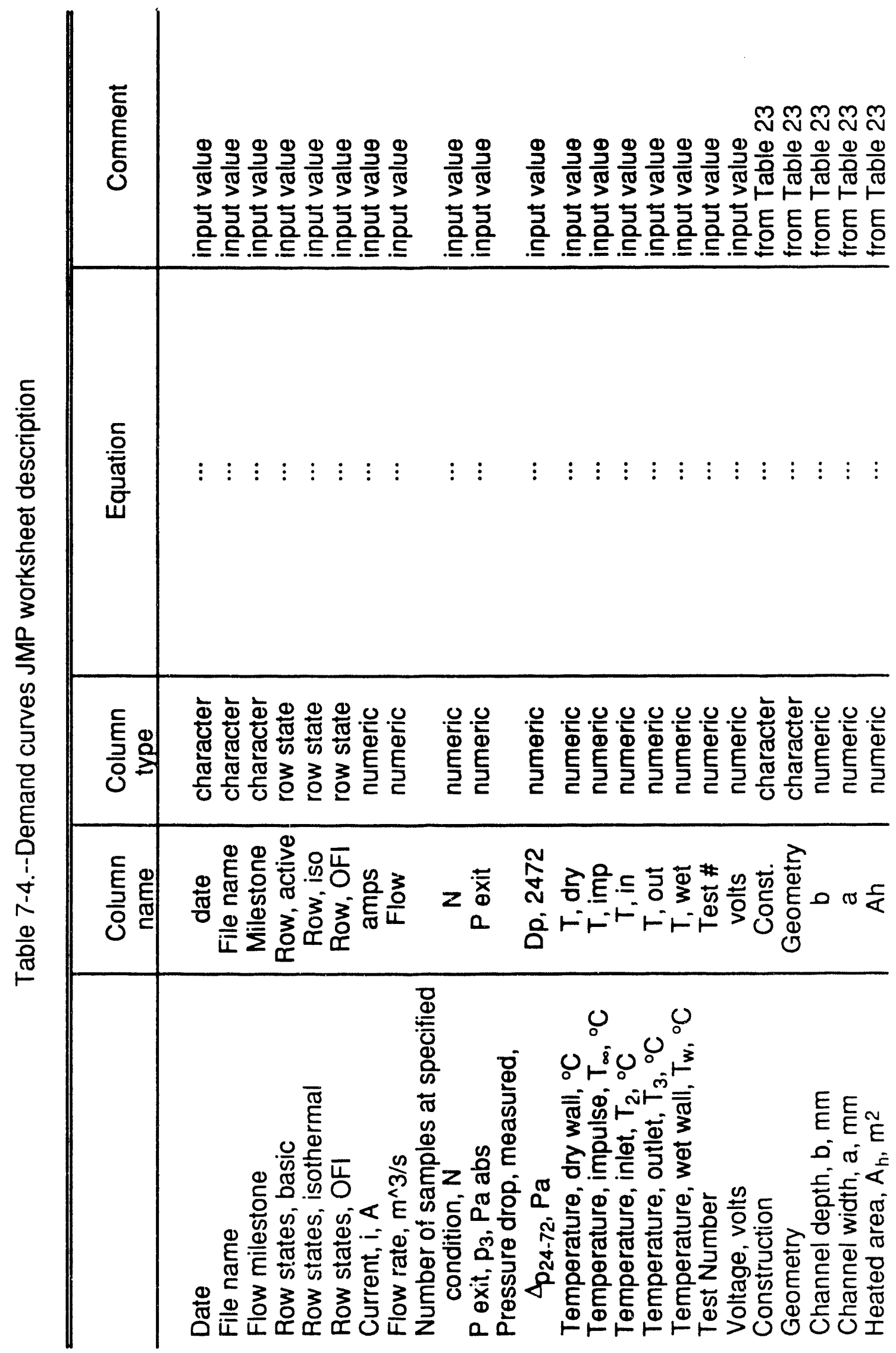




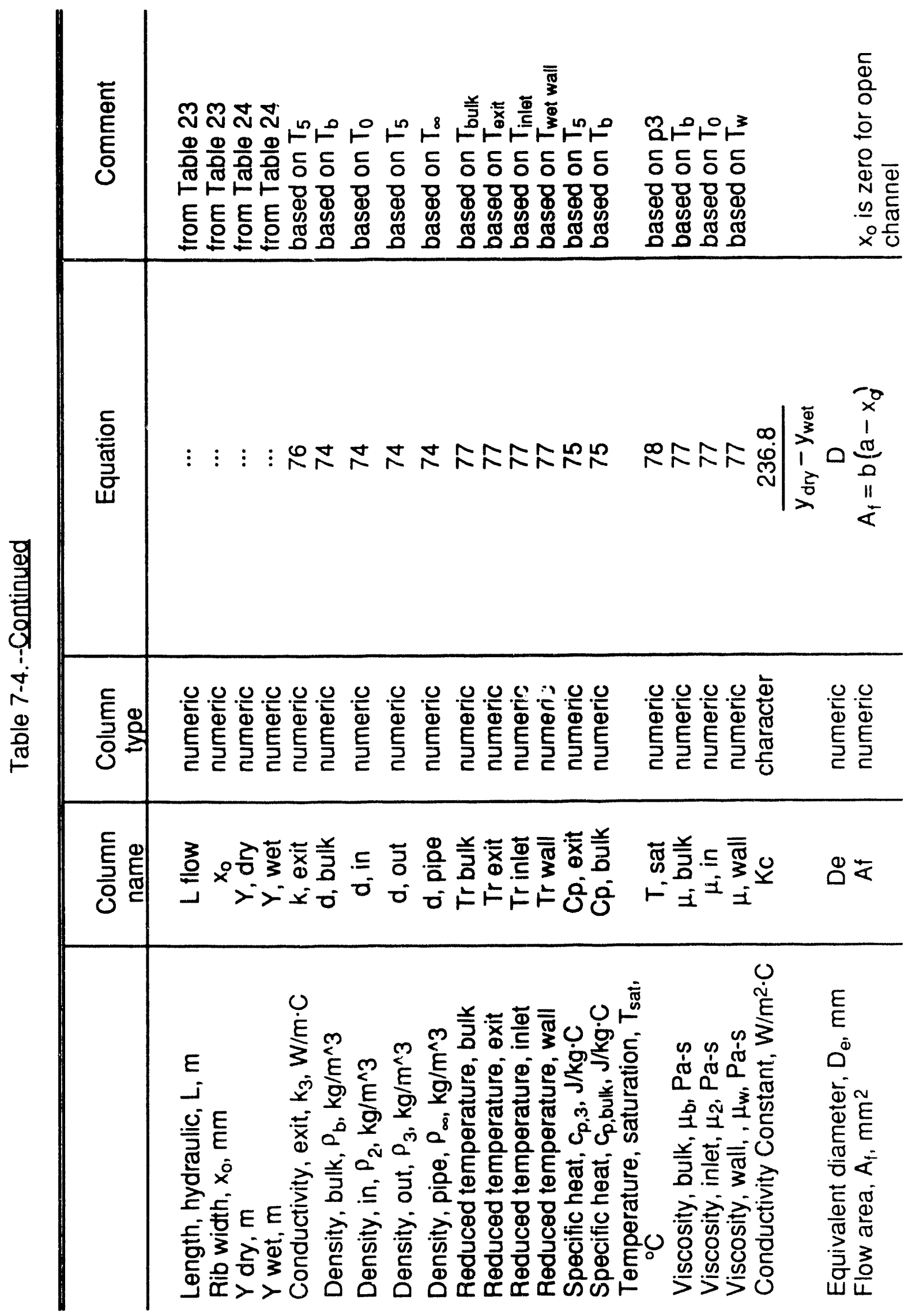




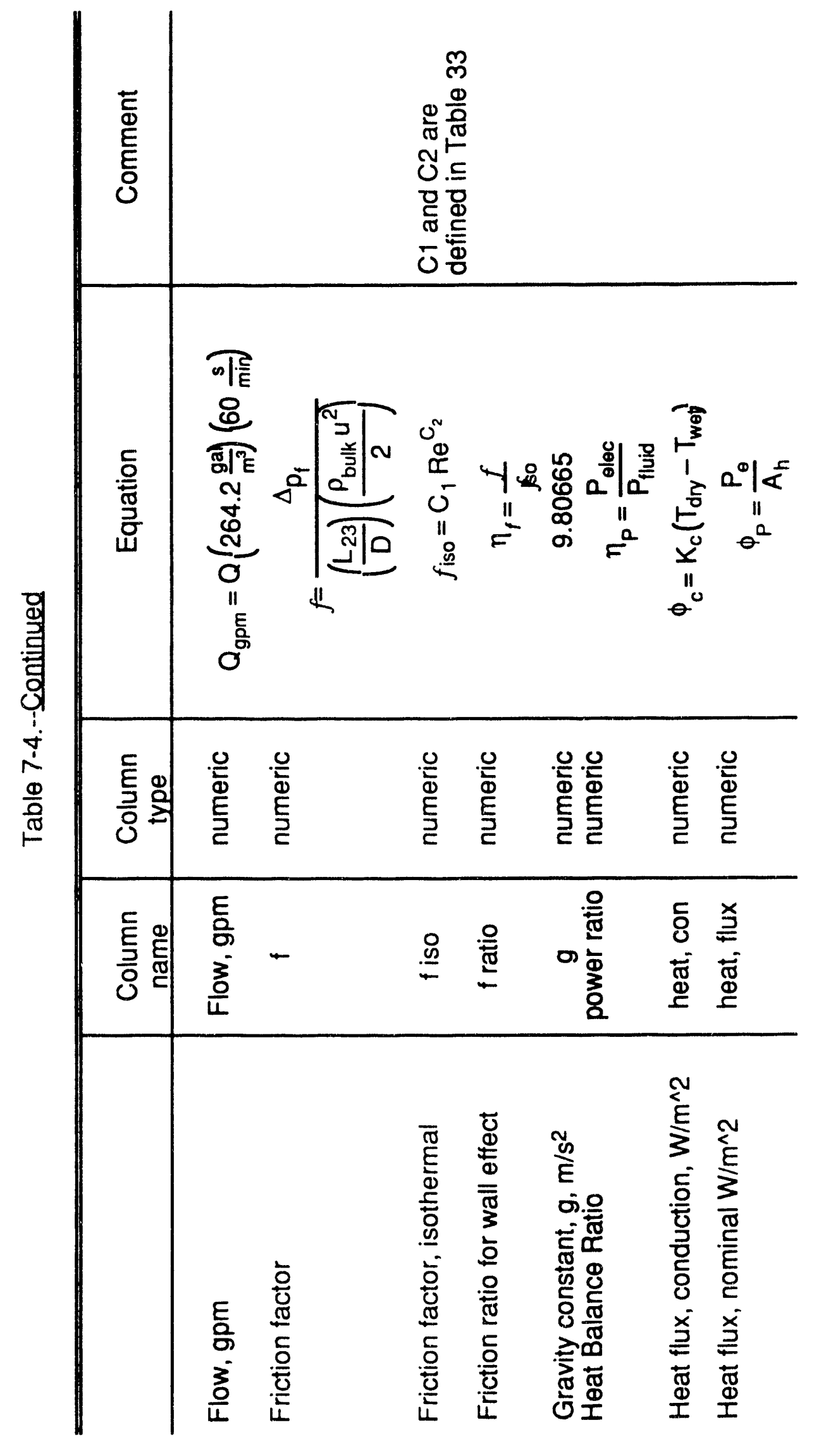




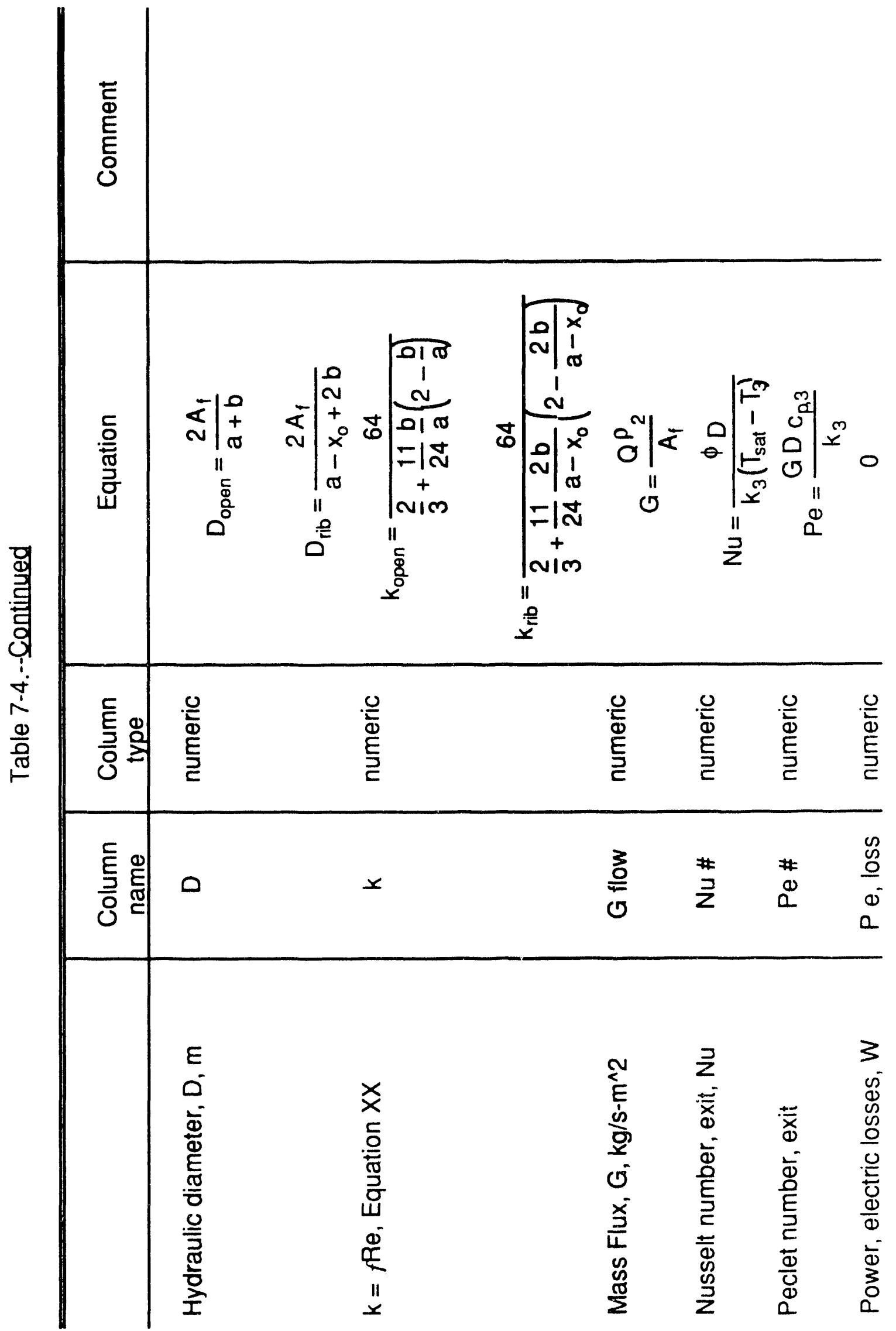




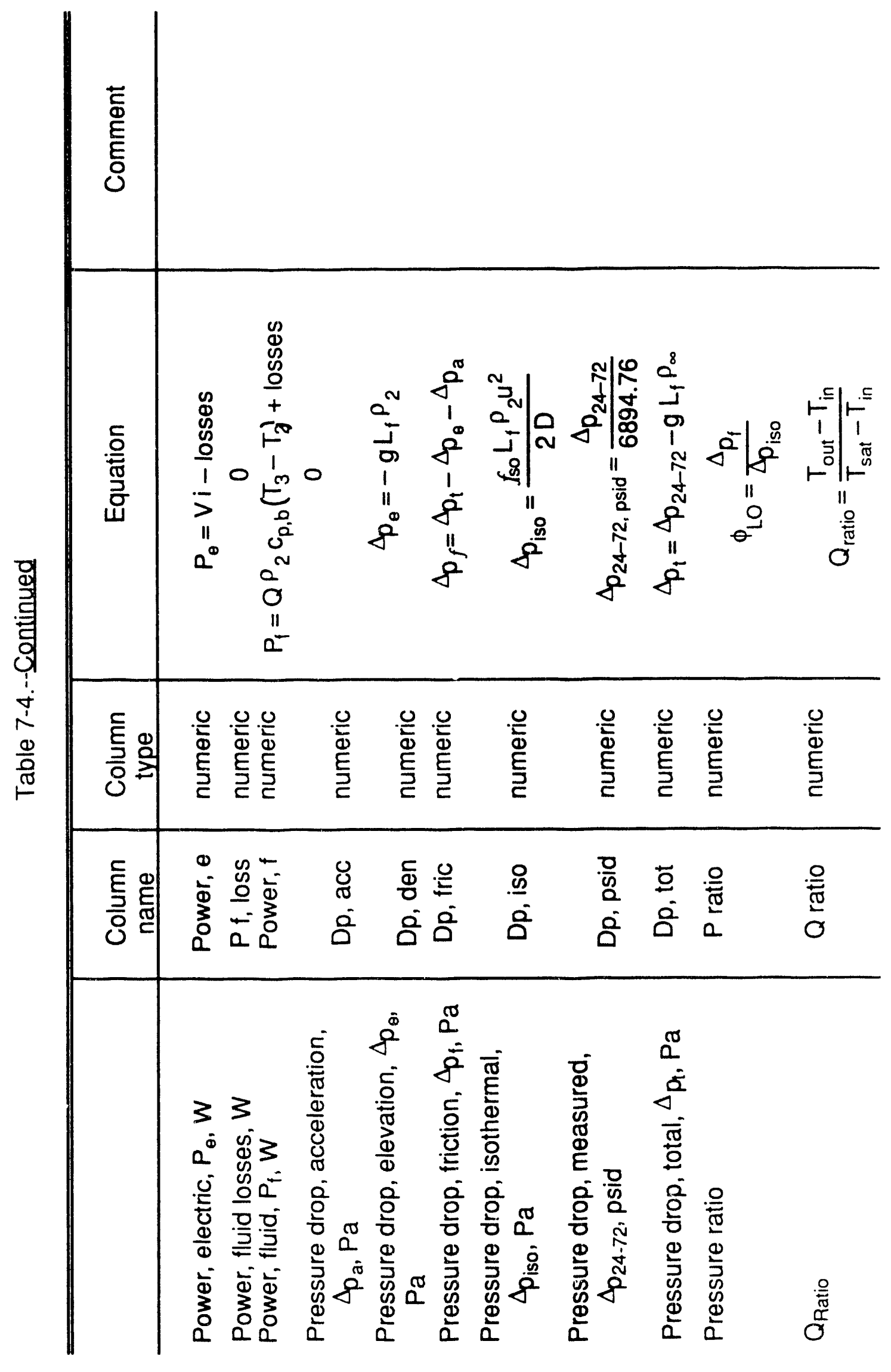




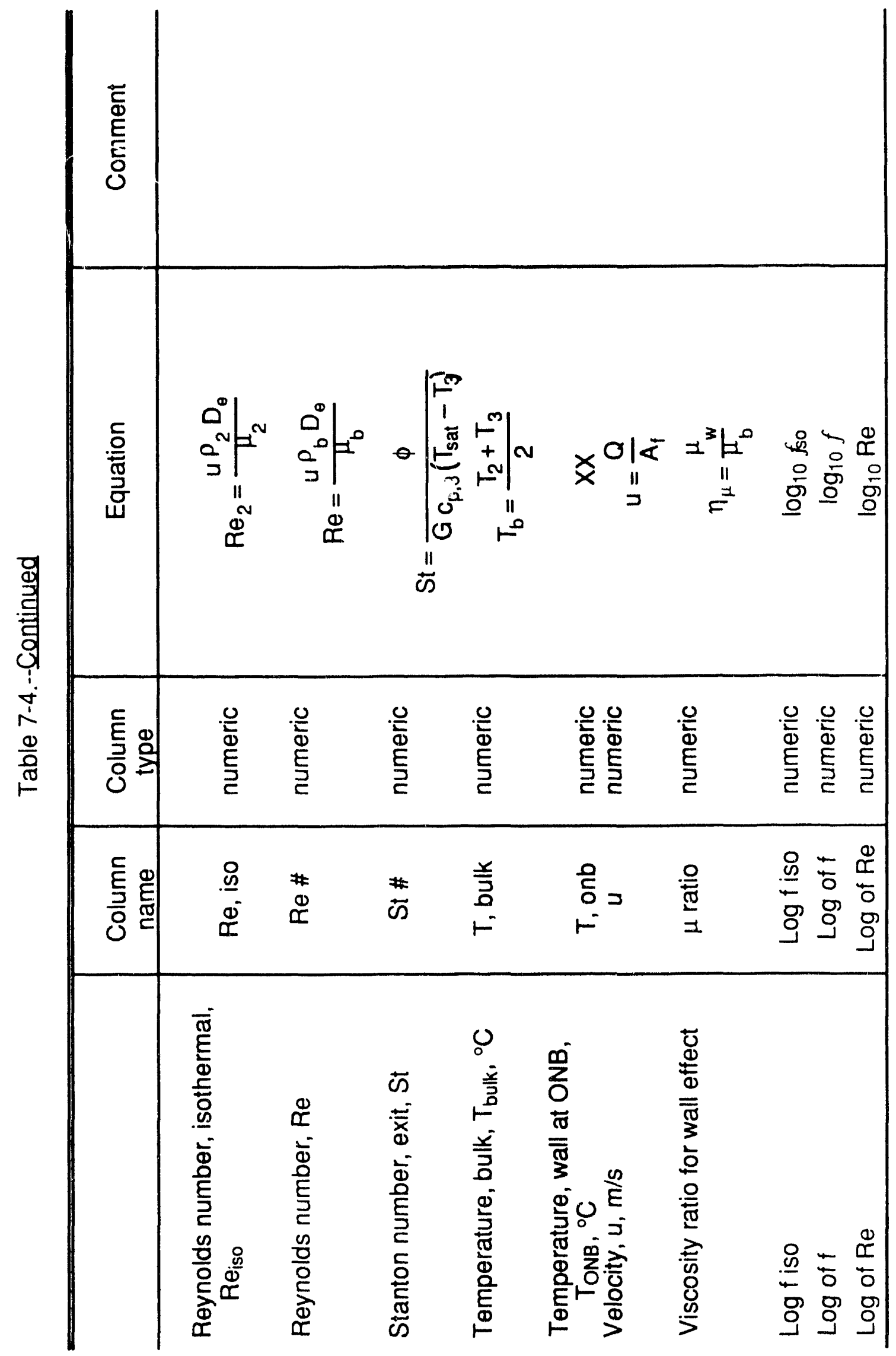


Table 7-5.--Temperature profiles JMP worksheet description

\begin{tabular}{|c|c|c|c|}
\hline Column Name & $\begin{array}{c}\text { Column } \\
\text { Type }\end{array}$ & Source & Comment \\
\hline $\begin{array}{l}\text { Axial Temp, C } \\
\text { Paste File } \\
\text { a Volts } \\
\text { b Volts } /{ }^{\circ} \mathrm{C} \\
\text { Channel \# } \\
\text { z location, meters } \\
\text { y location, mm } \\
x, \text { mm } \\
\text { in and out } \\
\text { Instrument Number } \\
\text { Surface } \\
\text { Prefix } \\
\text { M\&TE Number } \\
\text { Temperature, }{ }^{\circ} \mathrm{C} \\
\text { Range } \\
\text { Description }\end{array}$ & $\begin{array}{l}\text { character } \\
\text { row state } \\
\text { row state } \\
\text { numeric } \\
\text { numeric } \\
\text { numeric } \\
\text { numeric } \\
\text { numeric } \\
\text { numeric } \\
\text { character } \\
\text { character } \\
\text { character } \\
\text { character } \\
\text { character } \\
\text { numeric } \\
\text { character } \\
\text { character }\end{array}$ & $\begin{array}{c}\text {... } \\
\ldots \\
\text { Table } 7-2 \\
\text { Table } 7-2 \\
\text { Table } 24 \\
\text { Table } 24 \\
\text { Table } 24 \\
\text { Table } 24 \\
\text { Table } 24 \\
\text { Table } 24 \\
\text { Table } 24 \\
\text { Table } 24 \\
\text { Table 2-0 } \\
\text {... }\end{array}$ & $\begin{array}{l}\text { Mean voltage units from } \\
\text { reduced raw data file for } \\
\text { one file. } \\
\text { Selects rows to be plotted. } \\
\text { Selects rows to be pasted } \\
\text { with new data }\end{array}$ \\
\hline
\end{tabular}


Table 7-6.--Pressure profiles JMP worksheet description

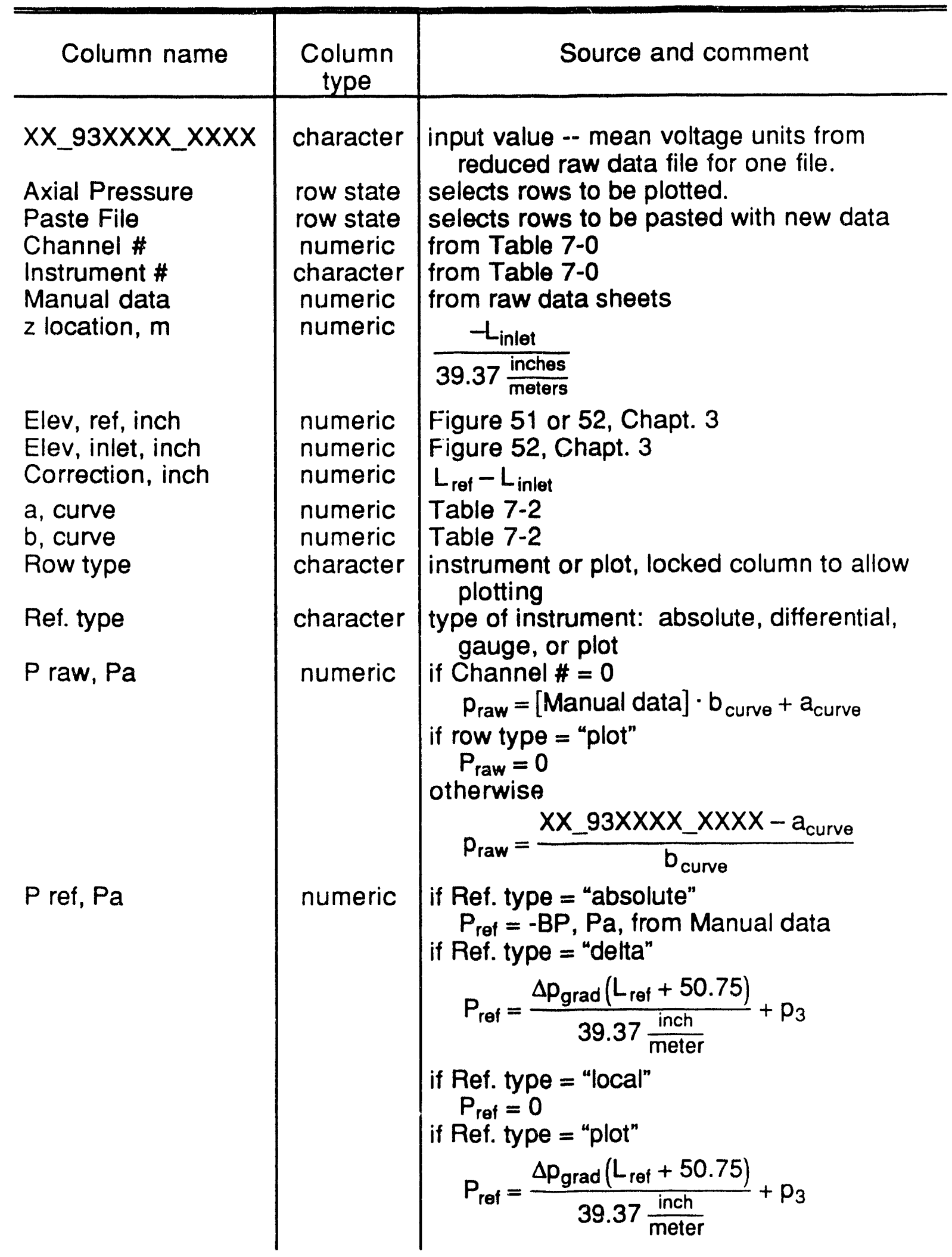


Table 7-6.--Continued

\begin{tabular}{|c|c|c|}
\hline Column name & $\begin{array}{l}\text { Column } \\
\text { type }\end{array}$ & Source and comment \\
\hline \multirow[t]{2}{*}{$\mathrm{P}$ corrected, $\mathrm{Pa}$} & \multirow[t]{2}{*}{ numeric } & $L_{\text {ref }} \rho_{\text {pipe }} 9.80665 \mathrm{~m} / \mathrm{s}^{2}$ \\
\hline & & $39.37 \frac{\text { inch }}{\text { meter }}$ \\
\hline $\mathrm{P}$ local, kPa & numeric & $\frac{p_{\text {raw }}+p_{\text {cor }}+p_{\text {ref }}}{1000}$ \\
\hline$P$ error, $\mathrm{kPa}$ & numeric & $p_{\text {error }}=p_{\text {local }}-\frac{\Delta p_{\text {grad }}\left(L_{\text {inlet }}-50.75\right)}{\left(39.37 \frac{\text { Inch }}{\text { meter }}\right)(1000)}+\frac{P_{3}}{1000}$ \\
\hline T, pipe & numeric & $T_{\text {pipe }}=\frac{T_{T C 00003}-a_{T C 00003}}{b_{T C 00003}}$ \\
\hline $\mathrm{T}$, bulk & numeric & $T_{T 01001}-a_{T L 01001}+T_{T L 2001}-a_{T L 02001}$ \\
\hline & & $\mathrm{T}_{\text {bulk }}=\frac{\mathrm{b}_{\text {TL01001 }}+\frac{\mathrm{b}_{\text {TL02001 }}}{2}}{2}$ \\
\hline $\begin{array}{l}\text { density, pipe } \\
\text { density, bulk } \\
\text { BP, Pa }\end{array}$ & $\begin{array}{l}\text { numeric } \\
\text { numeric } \\
\text { numeric }\end{array}$ & $\begin{array}{l}\text { Equation } 74, \text { based on } T_{\text {pipe }} \\
\text { Equation } 74 \text {, based on } T_{\text {bulk }} \\
p_{B P}=[B P \text { in manual data] }] \cdot \frac{3386.4 \mathrm{~Pa}}{{ }^{\mathrm{Hg}}}\end{array}$ \\
\hline $\begin{array}{l}\text { Flow rate, } \mathrm{cm}^{\wedge} 3 / \mathrm{s} \\
\text { Tr bulk } \\
\mu, \text { bulk }\end{array}$ & $\begin{array}{l}\text { numeric } \\
\text { numeric } \\
\text { numeric }\end{array}$ & $\begin{array}{l}1,000,000 \cdot Q_{m^{\wedge} 3 / s} \\
\text { Equation } 77, \text { based on } T_{\text {bulk }} \\
\text { Equation } 77 \text {, based on } T_{r, \text { bulk }}\end{array}$ \\
\hline$u$ & numeric & $\frac{Q_{m^{\wedge} 3 / s}}{A_{f}}$ \\
\hline $\mathrm{Re}$ & numeric & $R e=\frac{u \rho_{\text {bulk }} D}{\mu_{\text {bulk }}}$ \\
\hline$f$, iso & numeric & $0.316 R e^{-0.25}$ \\
\hline & $\begin{array}{l}\text { numeric } \\
\text { numeric }\end{array}$ & $\begin{array}{l}\text { from Table } 23 \\
D_{\text {open }}=\frac{2 A_{f}}{a+b}\end{array}$ \\
\hline & & $D_{\text {rib }}=\frac{2 A_{f}}{a-x_{0}+2 b}$ \\
\hline $\begin{array}{l}\text { xo } \\
\text { Geometry } \\
\text { Af }\end{array}$ & $\begin{array}{l}\text { numeric } \\
\text { character } \\
\text { numeric }\end{array}$ & $\begin{array}{l}\text { from Table } 23 \\
\text { from Table } 23 \\
A_{f}=b\left(a-x_{0}\right)\end{array}$ \\
\hline
\end{tabular}


Table 7-6.--Continued

\begin{tabular}{|c|c|c|}
\hline Column name & $\begin{array}{c}\text { Column } \\
\text { type }\end{array}$ & Source and comment \\
\hline $\begin{array}{l}\text { D grad, } \mathrm{Pa} / \mathrm{m} \\
\text { Zero flow } \\
\text { Construction } \\
\text { Flow rate, } \mathrm{m}^{\wedge} 3 / \mathrm{s} \\
\mathrm{P} \text { expand, } \mathrm{Pa} \\
\mathrm{P} 3, \mathrm{~Pa}\end{array}$ & $\begin{array}{c}\text { numeric } \\
\text { numeric } \\
\text { numeric } \\
\text { character } \\
\text { numeric } \\
\text { numeric } \\
\text { numeric }\end{array}$ & 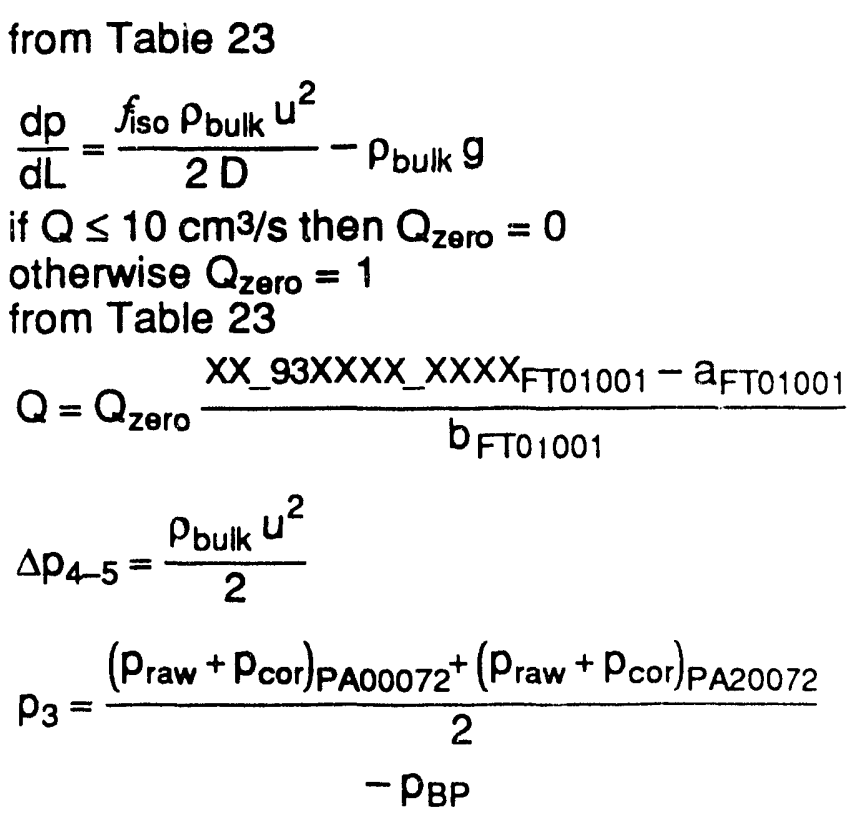 \\
\hline
\end{tabular}


Preliminary Data -. 9 September 1993

\section{APPENDIX 8}

TEST DATA 


\section{Preliminary Deta -- 9 September 1993}

\section{Diabatic Test Results}

This appendix section contains a summary of all diabatic demand curves produced during this test program. Information is presented in four formats. The first table provides the boundary condtions for each data file collectec Juring the production of a demand curve. The files are presented in the order they were produced. The second table presents the flow and channnel pressure drop condtions for each file. The pressure drop is the mean measured by PD02472 and PD202472 after adjustments for impulse line corrections. The files in this table are sorted by flow rate. The boiling conditon at the EHL has been included in this table. The file at the lowest observe pressure drop has been highlighted. Two figures comprise the last two formats. These figures present the same data. The second figure provides a detail of the region in the vicinity of the demand curve minimum. 


\section{Preliminary Data $\ldots .9$ September 1993}

Table 8-1.--Boundary conditiorss for demand curve 2.001, construction 1.0, open channel

\begin{tabular}{l|c|c|c|c|c}
\hline \hline File name & $\begin{array}{c}\text { Row } \\
\text { number }\end{array}$ & $\begin{array}{c}\text { Inlet } \\
\text { Temperature } \\
{ }^{\circ} \mathrm{C}\end{array}$ & $\begin{array}{c}\text { EHL } \\
\text { pressure } \\
\mathrm{kPa} \text { abs }\end{array}$ & $\begin{array}{c}\text { Power } \\
\mathrm{kW}\end{array}$ & $\begin{array}{c}\text { Energy } \\
\text { balance }\end{array}$ \\
\hline FS_930510_1500 & 64 & 59.86 & 134.1 & 30.50 & 0.954 \\
FS_930510_1515 & 65 & 58.56 & 133.9 & 30.23 & 0.952 \\
FS_930510_1525 & 66 & 57.60 & 133.9 & 30.36 & 0.953 \\
FS_930510_1535 & 67 & 58.99 & 133.3 & 30.54 & 0.954 \\
FS_930510_1542 & 68 & 58.85 & 132.2 & 30.39 & 0.946 \\
FS_930510_1745 & 72 & 62.44 & 130.9 & 30.29 & 0.947 \\
FS_930510_1752 & 73 & 60.86 & 130.0 & 30.57 & 0.957 \\
FS_930510_1800 & 74 & 61.33 & 129.8 & 30.51 & 0.963 \\
FS_930510_1801 & 75 & 58.36 & 129.7 & 30.49 & 0.951 \\
FS_930510_1802 & 76 & 58.37 & 129.7 & 30.12 & 0.952 \\
FS_930510_1804. & 77 & 57.86 & 129.6 & 30.25 & 0.960 \\
FS_930510_1831 & 78 & 57.27 & 129.7 & 30.22 & 0.953 \\
FS_930510_1842† & 79 & 57.22 & 129.6 & 30.21 & 0.952 \\
FS_930510_1848 & 80 & 59.52 & 129.6 & 30.17 & 0.965 \\
FS_930510_1858 & 81 & 60.38 & 129.5 & 30.19 & 0.957 \\
FS_930510_1900 & 82 & 60.50 & 129.5 & 30.21 & 0.952 \\
FS_930510_1901 & 83 & 60.78 & 129.9 & 30.22 & 0.960 \\
FS9930510_1904 & 84 & 62.00 & 130.9 & 30.28 & 0.926 \\
\hline Mean & $\ldots$ & 59.49 & 130.9 & 30.32 & 0.9528 \\
S & $\ldots$ & 1.61 & 1.7 & 0.14 & 0.0084 \\
\hline
\end{tabular}

- The test engineer identified this as a transient point where the temperature chaneged with time.

tThis point was taken while the temperature was dropping. 
Table 8-2.--Test data for demand curve 2.001, construction 1.0, open channel

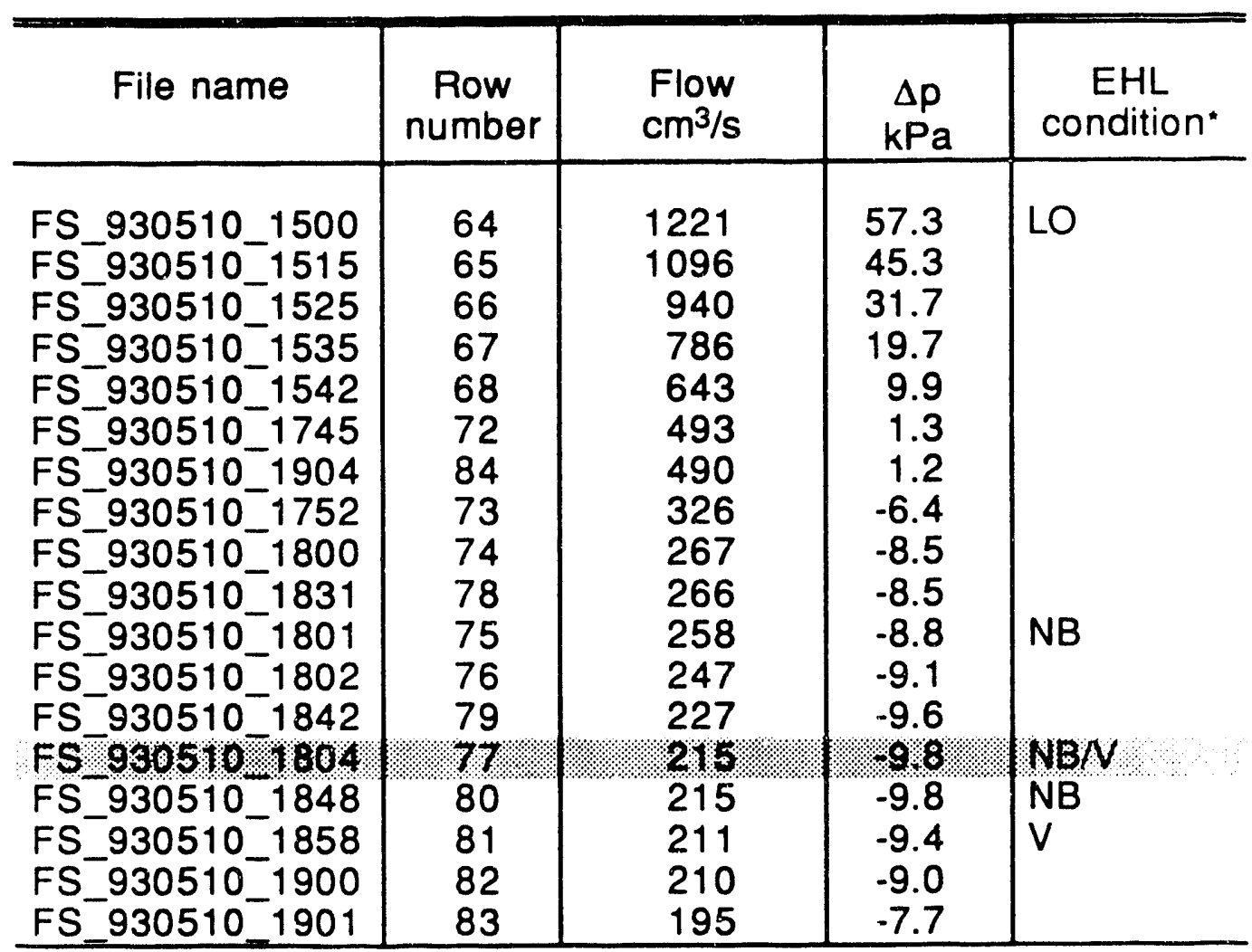

- $L O$, liquid only; NB, nucleate boiling; RB, nucleate boiling at the rib; V, signficant void; NBN , a transitions beteen nucleate boiling and significant void during the log (These transitions were long-term and not related to the cyclic behavior discussed in Chapter 4 . They appearred to be a transition between two different boiling conditons.) 
Preliminary Data _. 9 September 1993

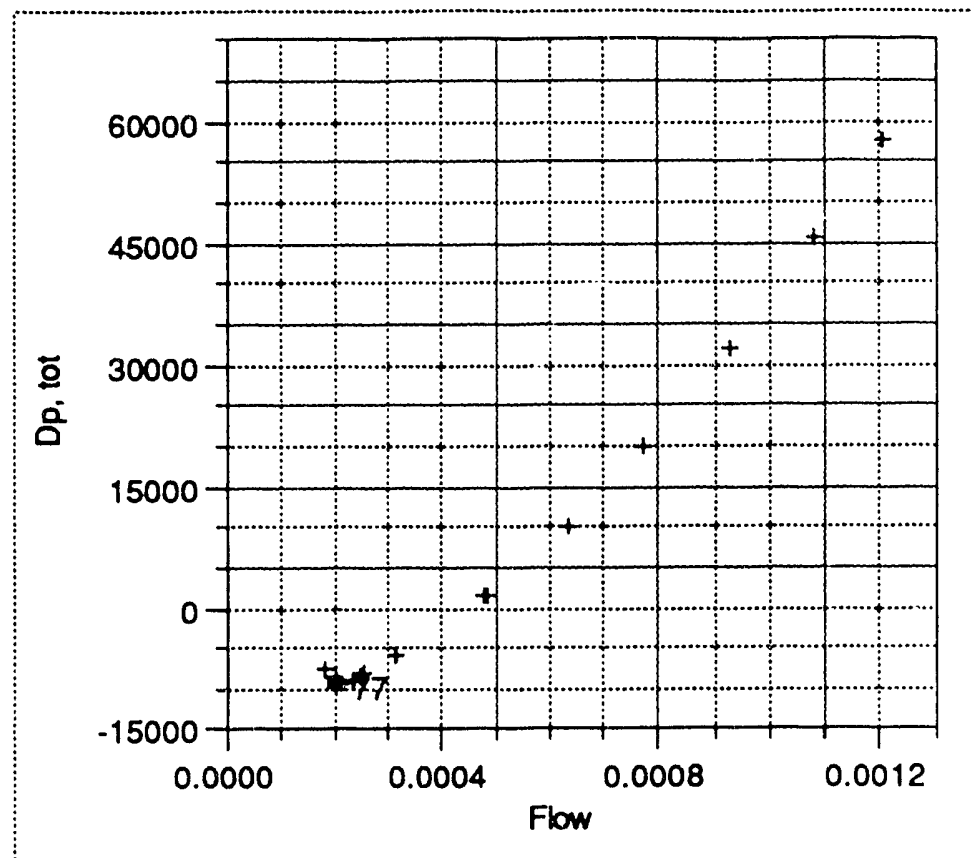

Figure 8-1, Demand curve 2.001, construction 1.0, open channel

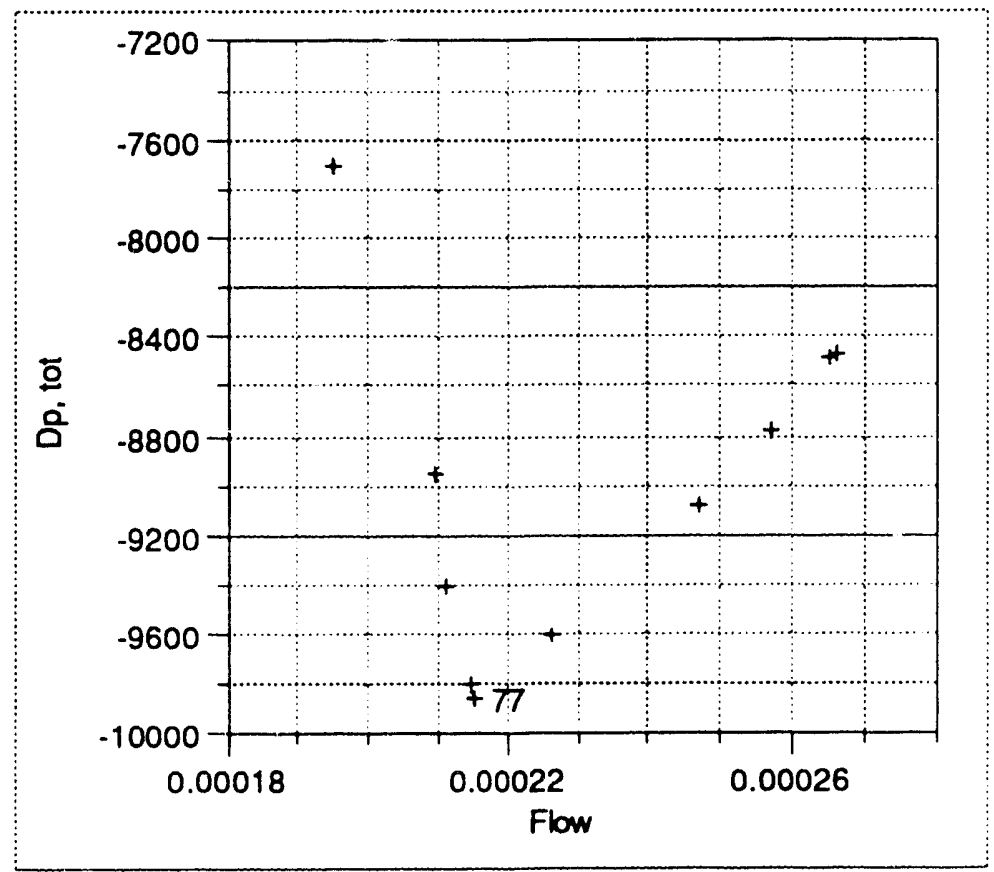

Figure 8-2, Detail of minima region for demand curve 2.001, construction 1.0, open channel 


\section{Preliminary Data -- 9 September 1993}

Table 8-3.--Boundary conditions for demand curve 2.002, construction 1.0, open channel

\begin{tabular}{|c|c|c|c|c|c|}
\hline File name & $\begin{array}{c}\text { Row } \\
\text { number }\end{array}$ & $\begin{array}{c}\text { Inlet } \\
\text { Temperature } \\
{ }^{\circ} \mathrm{C}\end{array}$ & $\begin{array}{c}\text { EHL } \\
\text { pressure } \\
\text { KPa abs }\end{array}$ & $\begin{array}{l}\text { Power } \\
\text { kW }\end{array}$ & $\begin{array}{l}\text { Energy } \\
\text { balance }\end{array}$ \\
\hline $\begin{array}{l}\text { FS_930511-1118 } \\
\text { FS_930511-1125 } \\
\text { FS_930511-1130 } \\
\text { FS_930511-1140 } \\
\text { FS_930511-1150 } \\
\text { FS_930511-1200 } \\
\text { FS_930511-1207 } \\
\text { FS_930511-1214 } \\
\text { FS_930511-1224 } \\
\text { FS_930511-1241 } \\
\text { FS_930511-1246 } \\
\text { FS_930511-1252 } \\
\text { FS_930511-1256 } \\
\text { FS_930511-1304 } \\
\text { FS_930511-1314 } \\
\text { FS_930511-1328 } \\
\text { FS_930511-1412 } \\
\text { FS_930511-1420 } \\
\text { FS_930511-1430 } \\
\text { FS_930511-1445 } \\
\text { FS_930511-1455 } \\
\text { FS_930511- } 1456 \\
\text { FS } 930511-1458\end{array}$ & $\begin{array}{r}88 \\
89 \\
90 \\
91 \\
92 \\
93 \\
94 \\
95 \\
96 \\
97 \\
98 \\
99 \\
100 \\
101 \\
102 \\
103 \\
104 \\
105 \\
107 \\
108 \\
109 \\
110\end{array}$ & $\begin{array}{l}62.58 \\
61.29 \\
61.27 \\
59.07 \\
60.60 \\
60.21 \\
59.49 \\
59.69 \\
59.67 \\
59.53 \\
59.52 \\
59.34 \\
60.73 \\
61.00 \\
59.02 \\
60.86 \\
59.99 \\
59.06 \\
59.36 \\
59.28 \\
59.91 \\
60.05\end{array}$ & $\begin{array}{l}132.5 \\
129.3 \\
133.2 \\
132.0 \\
130.9 \\
130.1 \\
130.0 \\
129.9 \\
129.8 \\
129.7 \\
129.7 \\
129.7 \\
129.7 \\
129.7 \\
130.0 \\
130.1 \\
130.0 \\
129.8 \\
129.7 \\
129.6 \\
129.6 \\
129.6\end{array}$ & $\begin{array}{l}30.38 \\
30.69 \\
30.62 \\
30.54 \\
30.67 \\
30.57 \\
30.68 \\
30.62 \\
30.59 \\
30.59 \\
30.58 \\
30.57 \\
30.53 \\
30.53 \\
30.51 \\
30.52 \\
30.55 \\
30.60 \\
30.60 \\
30.64 \\
30.54 \\
30.52\end{array}$ & $\begin{array}{l}0.939 \\
0.935 \\
0.936 \\
0.933 \\
0.933 \\
0.945 \\
0.946 \\
0.947 \\
0.947 \\
0.943 \\
0.941 \\
0.940 \\
0.949 \\
0.938 \\
0.949 \\
0.937 \\
0.943 \\
0.944 \\
\\
0.947 \\
0.944 \\
0.947 \\
0.943\end{array}$ \\
\hline $\begin{array}{l}\text { Mean } \\
\mathrm{S}\end{array}$ & $\begin{array}{l}\cdots \\
\cdots\end{array}$ & $\begin{array}{r}60.07 \\
0.91\end{array}$ & $\begin{array}{r}130.2 \\
1.0\end{array}$ & $\begin{array}{r}30.57 \\
0.07\end{array}$ & $\begin{array}{l}0.9421 \\
0.0050\end{array}$ \\
\hline
\end{tabular}




\section{Preliminary Data _. 9 September 1993}

Table 8-4.--Test data for demand curve 2.002, construction 1.0, open channel

\begin{tabular}{|c|c|c|c|c|}
\hline File name & $\begin{array}{c}\text { Row } \\
\text { number }\end{array}$ & $\begin{array}{l}\text { Flow } \\
\mathrm{cm}^{3} / \mathrm{s}\end{array}$ & $\begin{array}{c}\Delta \mathrm{p} \\
\mathrm{kPa}\end{array}$ & $\begin{array}{c}E H L \\
\text { condition }\end{array}$ \\
\hline $\begin{array}{l}\text { FS_930511-1118 } \\
\text { FS_930511-1125 } \\
\text { FS_930511-1130 } \\
\text { FS_930511-1140 } \\
\text { FS_930511-1150 } \\
\text { FS_930511-1328 } \\
\text { FS_930511-1200 } \\
\text { FS_930511-1412 } \\
\text { FS_930511-1207 } \\
\text { FS_930511-1214 } \\
\text { FS_930511-1420 } \\
\text { FS_930511-1224 } \\
\text { FS_930511-1430 } \\
\text { FS_930511-1241 } \\
\text { FS_930511-1445 } \\
\text { FS_930511-1246 } \\
\text { FS_930511-1455 } \\
\text { FS_930511-1252 } \\
\text { FS_930511-1456 } \\
\text { FS_930511_1256 } \\
\text { FS_930511-1304 } \\
\text { FS_930511-1458 } \\
\text { FS-930511-1314 }\end{array}$ & $\begin{array}{r}88 \\
89 \\
90 \\
91 \\
92 \\
103 \\
93 \\
104 \\
94 \\
95 \\
105 \\
96 \\
106 \\
97 \\
107 \\
98 \\
108 \\
99 \\
109 \\
100 \\
101 \\
110 \\
102\end{array}$ & $\begin{array}{r}1202 \\
941 \\
941 \\
634 \\
480 \\
323 \\
321 \\
296 \\
290 \\
266 \\
265 \\
239 \\
\\
231 \\
228 \\
223 \\
219 \\
218 \\
216 \\
212 \\
212 \\
208 \\
196\end{array}$ & $\begin{array}{r}55.7 \\
32.3 \\
31.9 \\
9.4 \\
0.5 \\
-6.5 \\
-6.6 \\
-7.4 \\
-7.7 \\
-8.5 \\
-8.5 \\
-9.2 \\
\\
-9.4 \\
-9.4 \\
-9.6 \\
-9.6 \\
-9.7 \\
-9.7 \\
-9.0 \\
-8.6 \\
-8.9 \\
-8.5\end{array}$ & $\begin{array}{l}\text { NB/ } \\
\mathrm{V}\end{array}$ \\
\hline
\end{tabular}


Preliminary Data -- 9 September 1993

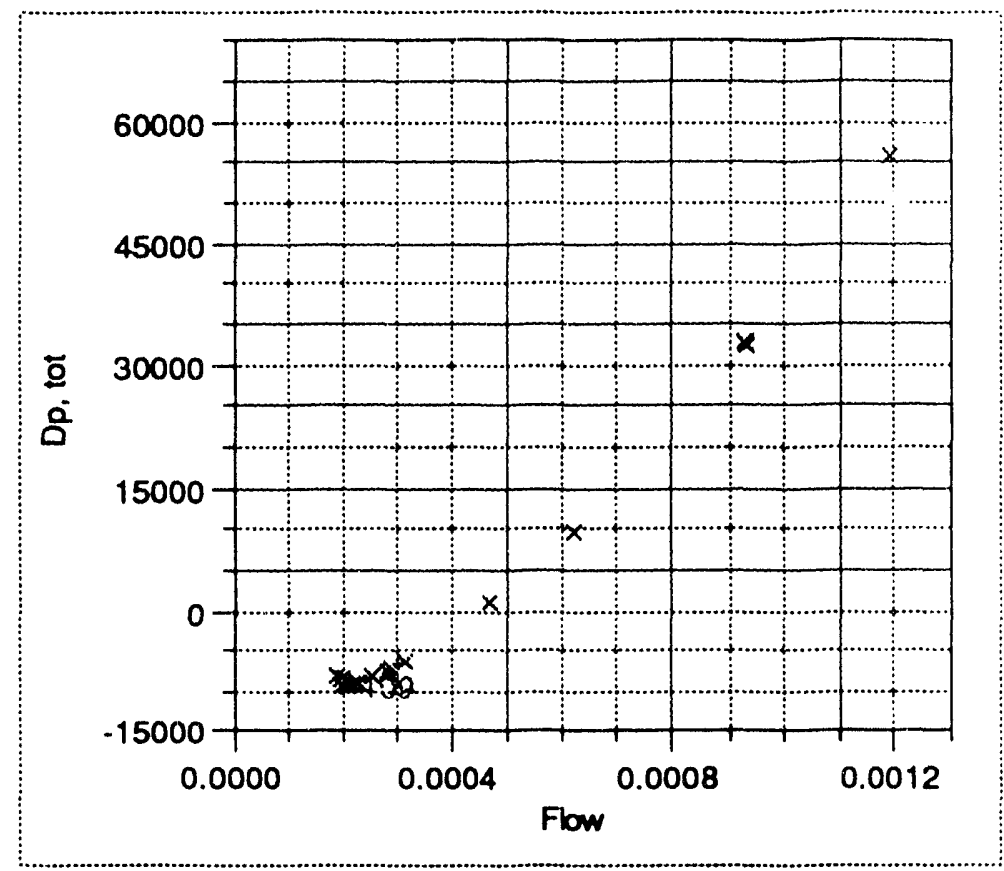

Figure 8-3, Demand curve 2.002, construction 1.0, open channel

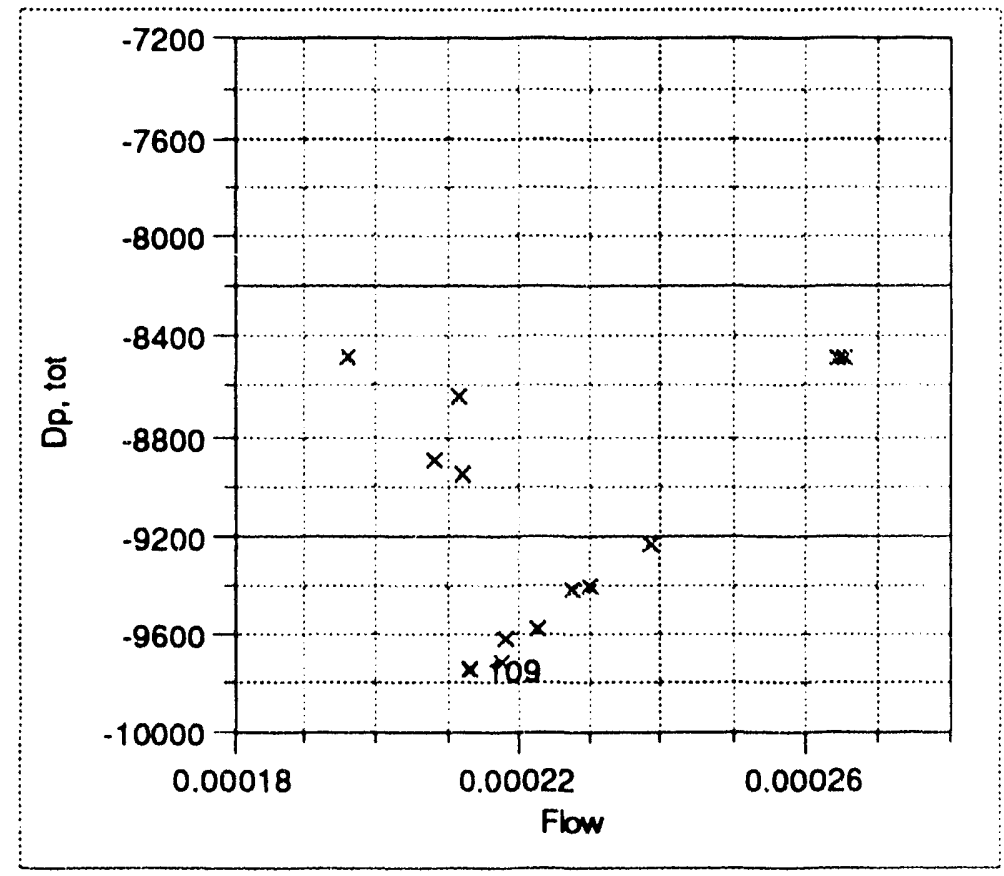

Figure 8-4, Detail of minima region for demand curve 2.002, construction 1.0 , open channel 


\section{Preliminary Data -- 9 September 1993}

Table 8-5.--Boundary conditions for demand curve 2.003, construction 1.0, open channel

\begin{tabular}{|c|c|c|c|c|c|}
\hline File name & $\begin{array}{c}\text { Row } \\
\text { number }\end{array}$ & $\begin{array}{c}\text { Inlet } \\
\text { Temperature } \\
{ }^{\circ} \mathrm{C}\end{array}$ & $\begin{array}{c}\text { EHL } \\
\text { pressure } \\
\text { kPa abs } \\
\end{array}$ & $\begin{array}{c}\text { Power } \\
\text { kW }\end{array}$ & $\begin{array}{c}\text { Energy } \\
\text { balance }\end{array}$ \\
\hline $\begin{array}{l}\text { FS_930511_-1605 } \\
\text { FS_930511-1630 } \\
\text { FS_930511-1648 } \\
\text { FS_930511-1705 } \\
\text { FS_930511-1715 } \\
\text { FS_930511-1725 } \\
\text { FS_930511-1735 } \\
\text { FS_930511-1750 } \\
\text { FS_930511-1755 } \\
\text { FS_930511-1810 } \\
\text { FS_930511-1811 } \\
\text { FS_930511-1812 } \\
\text { FS_930511-1816 } \\
\text { FS_930511-1830 } \\
\text { FS_930511-1835 } \\
\text { FS_930511-1840 } \\
\text { FS_930511-1850 } \\
\text { FS_930511- } 1900 \\
\text { FS_930511-1910 } \\
\text { FS_930511-1915 } \\
\text { FS_930511-1920 } \\
\text { FS_930511-1925 }\end{array}$ & $\begin{array}{l}111 \\
112 \\
114 \\
115 \\
116 \\
117 \\
118 \\
119 \\
120 \\
121 \\
122 \\
123 \\
124 \\
125 \\
126 \\
127 \\
128 \\
129 \\
130 \\
131 \\
132 \\
133\end{array}$ & $\begin{array}{l}59.12 \\
60.94 \\
59.08 \\
59.37 \\
59.32 \\
59.96 \\
60.65 \\
59.92 \\
60.36 \\
60.30 \\
59.69 \\
59.38 \\
59.09 \\
60.05 \\
60.43 \\
59.49 \\
60.77 \\
61.60 \\
59.55 \\
59.29 \\
59.47 \\
61.10\end{array}$ & $\begin{array}{l}133.2 \\
130.0 \\
132.0 \\
130.8 \\
129.9 \\
129.7 \\
129.6 \\
129.4 \\
129.4 \\
129.4 \\
129.4 \\
129.4 \\
129.3 \\
130.7 \\
129.6 \\
129.4 \\
129.4 \\
129.4 \\
129.5 \\
129.4 \\
129.4 \\
129.4\end{array}$ & $\begin{array}{l}30.59 \\
30.43 \\
30.62 \\
30.82 \\
30.77 \\
30.50 \\
30.66 \\
30.59 \\
30.74 \\
30.64 \\
30.60 \\
30.55 \\
30.47 \\
30.68 \\
30.56 \\
30.65 \\
30.66 \\
30.71 \\
30.52 \\
30.67 \\
30.54 \\
30.54\end{array}$ & $\begin{array}{l}0.927 \\
0.937 \\
0.939 \\
0.943 \\
0.952 \\
0.952 \\
0.950 \\
0.945 \\
0.943 \\
0.943 \\
0.941 \\
0.942 \\
0.941 \\
0.949 \\
0.943 \\
0.944 \\
0.956 \\
0.938 \\
0.941 \\
0.948 \\
0.950 \\
0.954\end{array}$ \\
\hline $\begin{array}{l}\text { Mean } \\
\mathrm{S}\end{array}$ & $\begin{array}{l}\cdots \\
\cdots\end{array}$ & $\begin{array}{r}59.95 \\
0.73\end{array}$ & $\begin{array}{r}129.9 \\
0.9\end{array}$ & $\begin{array}{r}0.61 \\
0.10\end{array}$ & $\begin{array}{l}0.9444 \\
0.0067\end{array}$ \\
\hline
\end{tabular}

This file is not plotted since the inlet temperature is much greater than the mean inlet temperature. 


\section{Preliminary Date -- 9 September 1993}

Table 8-6.--Test data for demand curve 2.003, construction 1.0, open channel

\begin{tabular}{|c|c|c|c|c|}
\hline File name & $\begin{array}{c}\text { Row } \\
\text { number }\end{array}$ & $\begin{array}{l}\text { Flow } \\
\mathrm{cm}^{3} / \mathrm{s}\end{array}$ & $\begin{array}{c}\Delta p \\
k P a\end{array}$ & $\begin{array}{c}\text { EHL } \\
\text { condition* }\end{array}$ \\
\hline $\begin{array}{l}\text { FS_930511-1605 } \\
\text { FS_930511-1630 } \\
\text { FS_930511-1648 } \\
\text { FS_930511-1705 } \\
\text { FS_930511-1715 } \\
\text { FS_930511-1725 } \\
\text { FS_930511-1835 } \\
\text { FS_930511-1735 } \\
\text { FS_930511-1910 } \\
\text { FS_930511-1915 } \\
\text { FS_930511-1840 } \\
\text { FS_930511-1750 } \\
\text { FS_930511-1755 } \\
\text { FS_930511-1810 } \\
\text { FS_930511-1920 } \\
\text { FS_930511-1850 } \\
\text { FS_930511-1900 } \\
\text { FS_930511-1925 } \\
\text { FS_930511-1811 } \\
\text { FS_930511-1812 } \\
\text { FS_930511-1816 } \\
\text { FS_930511-1830 }\end{array}$ & $\begin{array}{l}111 \\
112 \\
114 \\
115 \\
116 \\
117 \\
126 \\
118 \\
130 \\
131 \\
127 \\
119 \\
120 \\
121 \\
132 \\
128 \\
129 \\
133 \\
122 \\
123 \\
124 \\
125\end{array}$ & $\begin{array}{l}1218.1 \\
945.9 \\
637.6 \\
482.0 \\
326.2 \\
292.1 \\
272.5 \\
266.3 \\
246.8 \\
234.7 \\
233.9 \\
231.1 \\
227.1 \\
223.8 \\
220.9 \\
219.9 \\
219.4 \\
218.6 \\
218.6 \\
246.7 \\
206.6 \\
197.8\end{array}$ & $\begin{array}{r}58.55 \\
33.30 \\
10.20 \\
0.96 \\
-6.28 \\
-7.56 \\
-8.19 \\
-8.41 \\
-8.97 \\
-9.26 \\
-9.27 \\
-9.37 \\
-9.41 \\
-9.50 \\
-9.56 \\
-9.44 \\
-8.16 \\
-9.26 \\
-9.66 \\
-9.71 \\
-8.94 \\
-7.39\end{array}$ & $\begin{array}{l}\text { LO } \\
\text { ONB }\end{array}$ \\
\hline
\end{tabular}

-The log were voiding was first observed was not recorded. 


\section{Preliminary Data -- 9 September 1993}

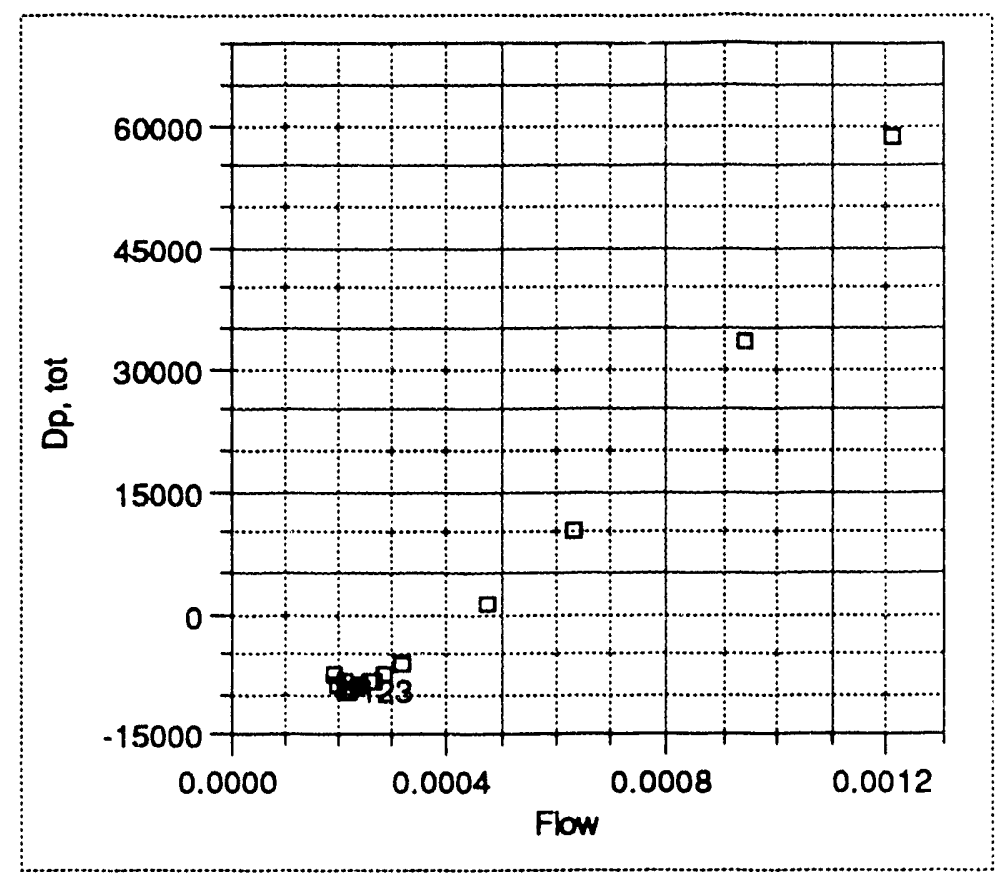

Figure 8-5, Demand curve 2.003, construction 1.0, open channel

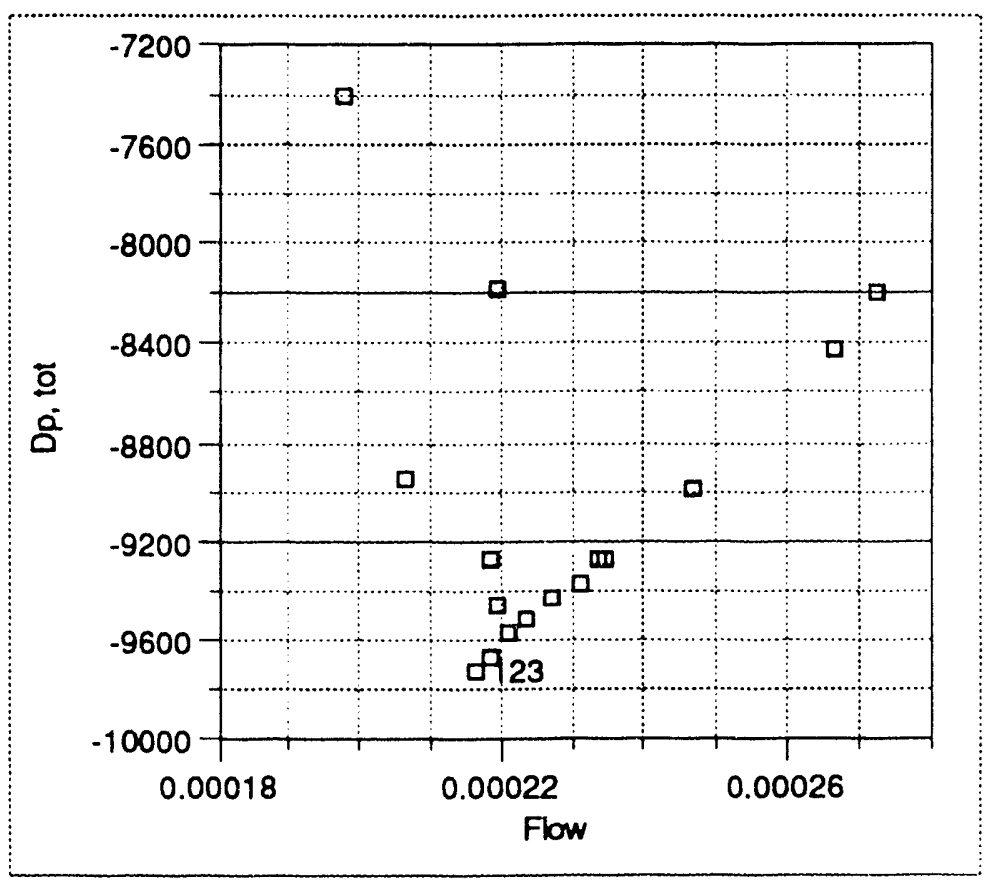

Figure 8-6, Detail of the demand curve minimum 2.003, construction 1.0, open channel 


\section{Preliminary Data $=9$ September 1993}

Table 8-7.--Boundary conditions for demand curve 2.004, construction 1.0 , open channel

\begin{tabular}{l|c|c|c|c|c}
\hline \hline File name & $\begin{array}{c}\text { Row } \\
\text { number }\end{array}$ & $\begin{array}{c}\text { Inlet } \\
\text { Temperature } \\
{ }^{\circ} \mathrm{C}\end{array}$ & $\begin{array}{c}\text { EHL } \\
\text { pressure } \\
\mathrm{kPa} \text { abs }\end{array}$ & $\begin{array}{c}\text { Power } \\
\mathrm{kW}\end{array}$ & $\begin{array}{c}\text { Energy } \\
\text { balance }\end{array}$ \\
\hline FS_930512_1015 & 136 & 60.47 & 135.8 & 30.69 & 0.960 \\
FS_930512_1016 & 137 & 60.79 & 131.3 & 30.64 & 0.953 \\
FS_930512_1025 & 138 & 59.93 & 131.4 & 30.65 & 0.943 \\
FS_930512_1035 & 139 & 59.11 & 130.2 & 30.67 & 0.943 \\
FS_930512_1045 & 140 & 59.62 & 129.4 & 30.70 & 0.955 \\
FS_930512_1055 & 141 & 60.19 & 129.2 & 30.60 & 0.953 \\
FS_930512-1105 & 142 & 60.10 & 129.2 & 30.60 & 0.957 \\
FS_930512_1107 & 143 & 59.60 & 129.1 & 30.69 & 0.947 \\
FS_930512_1115 & 144 & 60.47 & 129.1 & 30.57 & 0.953 \\
FS_930512_1125 & 145 & 59.81 & 129.1 & 30.66 & 0.946 \\
FS_930512_1130 & 146 & 60.19 & 129.1 & 30.51 & 0.943 \\
FS_930512_1131 & 147 & 59.94 & 129.5 & 30.63 & 0.949 \\
FS_930512_1155 & 148 & 60.92 & 129.2 & 30.70 & 0.948 \\
FS_930512_1200 & 149 & 59.55 & 129.1 & 30.51 & 0.953 \\
FS_930512_1205 & 150 & 60.79 & 129.1 & 30.62 & 0.948 \\
FS_930512_1210 & 151 & 60.99 & 129.1 & 30.47 & 0.950 \\
FS_930512-1211 & 152 & 61.68 & 129.4 & 30.60 & 0.953 \\
\hline Mean & $\cdots$ & 60.24 & 129.9 & 30.62 & 0.9503 \\
S & $\cdots$ & 0.65 & 1.7 & 0.70 & 0.0051 \\
\hline
\end{tabular}

"This file is not plotted since the inlet temperature is much greater than the mean inlet temperature. 


\section{Preliminary Data _- 9 September 1993}

Table 8-8.--Test data for demand curve 2.004, construction 1.0, open channel

\begin{tabular}{|c|c|c|c|c|}
\hline File name & $\begin{array}{c}\begin{array}{c}\text { Row } \\
\text { number }\end{array} \\
\end{array}$ & $\begin{array}{l}\text { Flow } \\
\mathrm{cm}^{3} / \mathrm{s}\end{array}$ & $\begin{array}{r}\Delta \mathrm{p} \\
\mathrm{kPa}\end{array}$ & $\begin{array}{c}\text { EHL } \\
\text { condition }\end{array}$ \\
\hline $\begin{array}{l}\text { FS_930512_1015 } \\
\text { FS_930512_1016 } \\
\text { FS_930512_1025 } \\
\text { FS_930512_1035 } \\
\text { FS_930512_1045 } \\
\text { FS_930512_1055 } \\
\text { FS_930512_1105 } \\
\text { FS_930512_1155 } \\
\text { FS_930512_1107 } \\
\text { FS_930512_1115 } \\
\text { FS_930512_1200 } \\
\text { FS_930512_1205 } \\
\text { FS_938512_.1125. } \\
\text { FS_930512_1210 } \\
\text { FS_930512_1211 } \\
\text { FS_930512_1130 } \\
\text { FS_930512_11 } 1131\end{array}$ & $\begin{array}{l}136 \\
137 \\
138 \\
139 \\
140 \\
141 \\
142 \\
148 \\
143 \\
144 \\
149 \\
150 \\
145 \\
151 \\
152 \\
146 \\
147\end{array}$ & $\begin{array}{r}1283.9 \\
946.5 \\
638.7 \\
474.0 \\
324.9 \\
291.8 \\
264.7 \\
260.8 \\
248.2 \\
231.5 \\
229.1 \\
222.5 \\
221.8 \\
218.3 \\
213.7 \\
212.9 \\
206.3\end{array}$ & $\begin{array}{r}66.29 \\
33.79 \\
10.54 \\
0.76 \\
-6.24 \\
-7.50 \\
-8.40 \\
-8.44 \\
-8.89 \\
-9.27 \\
-9.33 \\
-9.41 \\
-9.50 \\
-9.42 \\
-7.76 \\
-9.48 \\
-7.88\end{array}$ & LO \\
\hline
\end{tabular}

- The log where voiding was first observed was not noted.

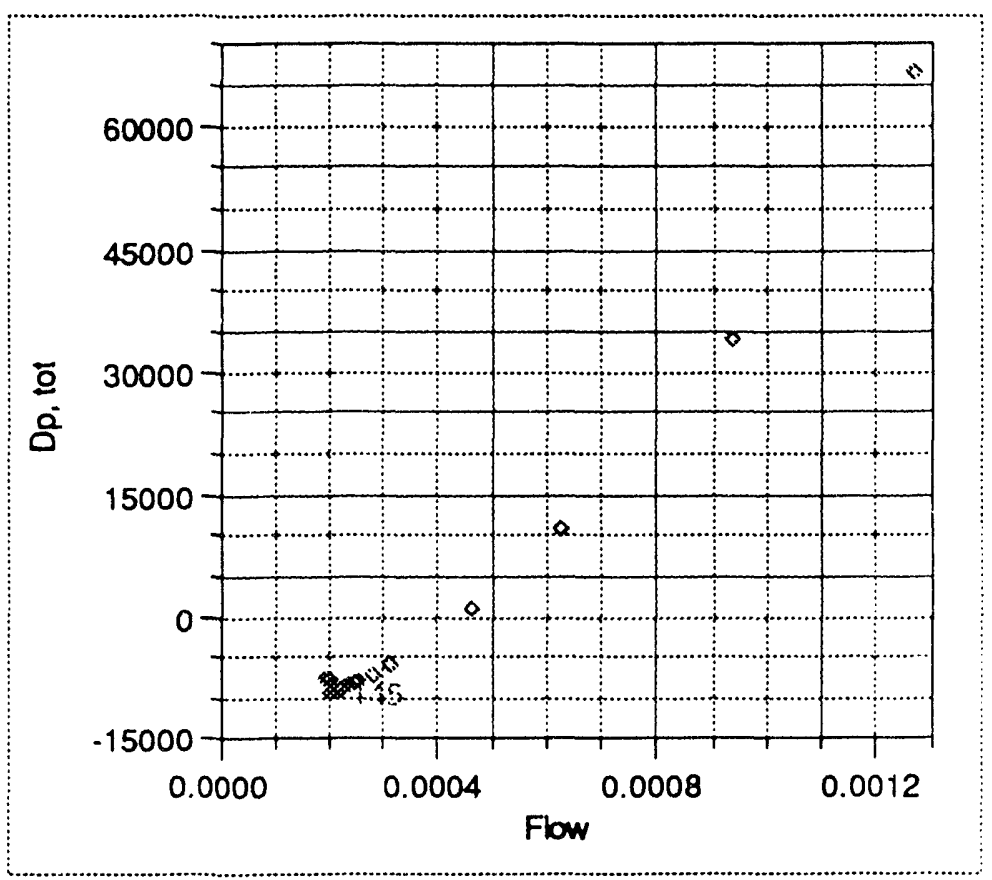

Figum 8-7, Demand curve 2.004, construction 1.0, open channel 


\section{Preliminary Data _- 9 September 1993}

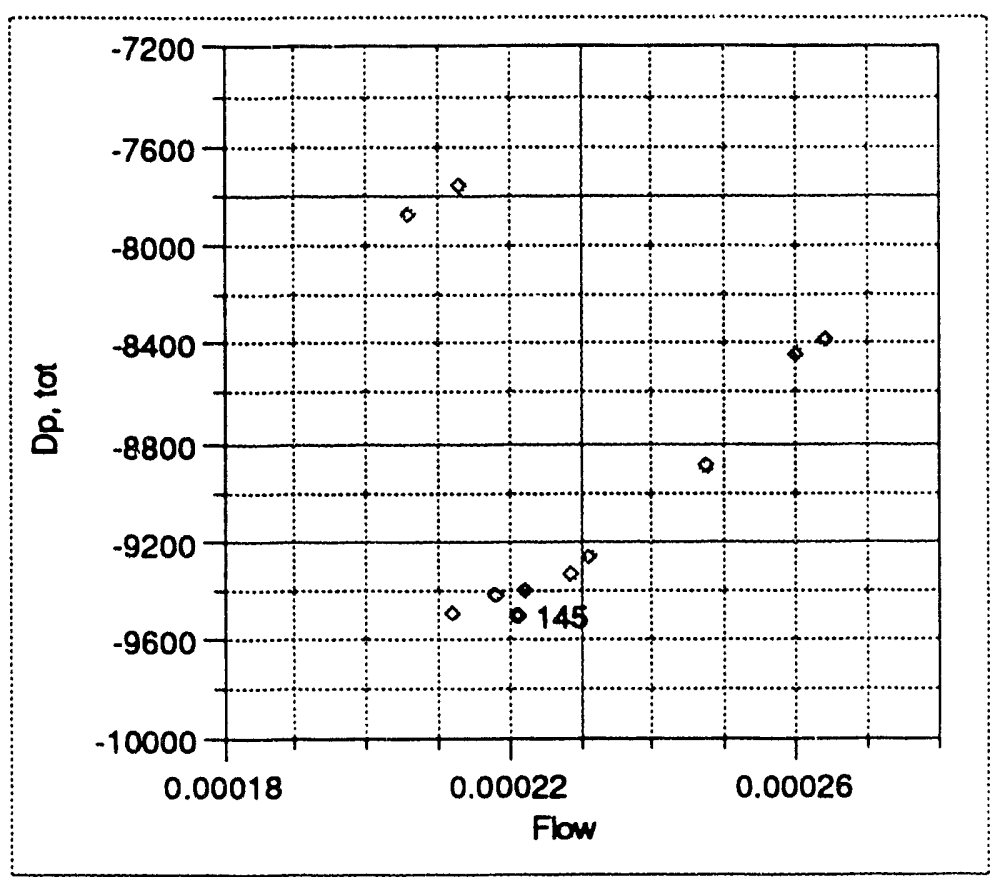

Figure 8-8, Detail of minima region for demand curve 2.004, construction 1.0, open channel 


\section{Preliminary Data -- 9 September 1993}

Table 8-9.--Boundary conditions for demand curve 3.001, construction 2.0, rib channel

\begin{tabular}{l|c|c|c|c|c}
\hline \hline File name & $\begin{array}{c}\text { Row } \\
\text { number }\end{array}$ & $\begin{array}{c}\text { Inlet } \\
\text { Temperature } \\
\text { oC }\end{array}$ & $\begin{array}{c}\text { EHL } \\
\text { pressure } \\
\text { kPa abs }\end{array}$ & $\begin{array}{c}\text { Power } \\
\text { kW }\end{array}$ & $\begin{array}{c}\text { Energy } \\
\text { balance }\end{array}$ \\
\hline FS_930526_1527 & 234 & 60.67 & 135.5 & 30.52 & 0.944 \\
FS_930526_1539. & 235 & 59.42 & 131.2 & 30.47 & 0.939 \\
FS_930526_1545 & 236 & 59.45 & 134.8 & 30.56 & 0.938 \\
FS_930526_1554 & 237 & 59.19 & 131.0 & 30.60 & 0.942 \\
FS_930526_1630 & 238 & 59.98 & 131.2 & 30.61 & 0.935 \\
FS_930526_1645 & 239 & 60.38 & 130.2 & 30.63 & 0.956 \\
FS_930526_1650 & 240 & 60.72 & 130.1 & 30.60 & 0.946 \\
FS_930526_1705 & 241 & 59.13 & 130.0 & 30.62 & 0.946 \\
FS_930526_1715 & 242 & 59.39 & 129.9 & 30.57 & 0.951 \\
FS_930526_1720 & 243 & 59.24 & 129.9 & 30.63 & 0.950 \\
FS_930526_1725 & 244 & 59.13 & 129.9 & 30.55 & 0.954 \\
FS_930526_1740 & 245 & 59.20 & 129.9 & 30.44 & 0.956 \\
FS_930526_1750 & 246 & 59.43 & 129.4 & 30.53 & 0.959 \\
FS_930526_1810 & 247 & 59.37 & 129.9 & 30.62 & 0.947 \\
FS_930526_1811 & 248 & 59.64 & 129.8 & 30.57 & 0.951 \\
FS_930526_1820 & 249 & 59.21 & 129.8 & 30.43 & 0.952 \\
FS_930526_1825 & 250 & 59.32 & 129.7 & 30.58 & 0.952 \\
FS_930526_1830 & 251 & 59.46 & 129.3 & 30.55 & 0.955 \\
FS_930526_1840 & 252 & 59.84 & 129.9 & 30.28 & 0.947 \\
FS_930526_1850 & 253 & 59.33 & 129.9 & 30.62 & 0.948 \\
FS_930526_1900 & 254 & 59.12 & 129.9 & 30.65 & 0.945 \\
FS_930526_1910 & 255 & 59.27 & 129.9 & 30.56 & 0.942 \\
FS_930526_1925 & 256 & 59.31 & 130.0 & 30.49 & 0.942 \\
FS_930526_1945 & 257 & 59.95 & 130.2 & 30.62 & 0.936 \\
FS_930526_1950 & 258 & 59.23 & 130.1 & 30.71 & 0.936 \\
FS_930526_2005 & 259 & 59.55 & 129.8 & 30.57 & 0.945 \\
FS_930526_2010 & 260 & 59.31 & 129.7 & 30.63 & 0.948 \\
FS_930526_2015 & 261 & 59.39 & 129.7 & 30.66 & 0.947 \\
FS_930526_2020 & 262 & 59.39 & 129.7 & 30.51 & 0.948 \\
FS_930526_2021 & 263 & 59.25 & 129.3 & 30.53 & 0.953 \\
\hline Mean & $\cdots$ & 59.51 & 130.3 & 30.56 & 0.9420 \\
S & $\ldots$ & 0.43 & 1.4 & 0.08 & 0.0064 \\
\hline & & & & & \\
\hline
\end{tabular}

•Low EHL pressure. 
Table 8-10.--Test data for demand curve 3.001, construction 2.0, rib channel

\begin{tabular}{|c|c|c|c|c|}
\hline File name & $\begin{array}{c}\text { Row } \\
\text { number }\end{array}$ & $\begin{array}{l}\text { Flow } \\
\mathrm{cm}^{3} / \mathrm{s}\end{array}$ & $\begin{array}{c}\Delta p \\
k P a\end{array}$ & $\begin{array}{c}E H L \\
\text { condition }\end{array}$ \\
\hline $\begin{array}{l}\text { FS_930526_1527 } \\
\text { FS_930526_1545 } \\
\text { FS_930526_1539 } \\
\text { FS_930526_1554 } \\
\text { FS_930526_1630 } \\
\text { FS_930526_1945 } \\
\text { FS_930526_1950 } \\
\text { FS_930526_1645 } \\
\text { FS_930526_1650 } \\
\text { FS_930526_1925 } \\
\text { FS_930526_1910 } \\
\text { FS_930526_1705 } \\
\text { FS_930526_1900 } \\
\text { FS_930526_1715 } \\
\text { FS_930526_1810 } \\
\text { FS_930526_1850 } \\
\text { FS_930526_2005 } \\
\text { FS_930526_1720 } \\
\text { FS_930526_1840 } \\
\text { FS_930526_1811 } \\
\text { FS_930526_2010 } \\
\text { FS_930526_1725 } \\
\text { FS_930526_1820 } \\
\text { FS_930526_2015 } \\
\text { FS _9805\%6- } 1190 \\
\text { FS_930526_1825 } \\
\text { FS_930526_2020 } \\
\text { FS_930526_2021 } \\
\text { FS_930526_1830 } \\
\text { FS_930526_1750 }\end{array}$ & $\begin{array}{l}234 \\
236 \\
235 \\
237 \\
238 \\
257 \\
258 \\
239 \\
240 \\
256 \\
255 \\
241 \\
254 \\
242 \\
247 \\
253 \\
259 \\
243 \\
252 \\
248 \\
260 \\
244 \\
249 \\
261 \\
245 \text {. } \\
250 \\
262 \\
263 \\
251 \\
246\end{array}$ & $\begin{array}{r}1207.7 \\
938.4 \\
938.0 \\
630.7 \\
482.4 \\
364.2 \\
353.7 \\
329.1 \\
316.5 \\
313.6 \\
308.6 \\
303.8 \\
303.2 \\
291.8 \\
291.6 \\
289.7 \\
285.3 \\
280.4 \\
280.3 \\
279.1 \\
271.4 \\
267.6 \\
266.5 \\
263.2 \\
2261.6 \\
260.5 \\
260.5 \\
254.8 \\
253.9 \\
252.0\end{array}$ & $\begin{array}{r}49.77 \\
26.81 \\
26.82 \\
6.18 \\
-1.39 \\
-6.18 \\
-6.54 \\
-7.33 \\
-7.77 \\
-7.88 \\
-8.04 \\
-8.16 \\
-8.20 \\
-8.53 \\
-8.55 \\
-8.61 \\
-8.72 \\
-8.85 \\
-8.87 \\
-8.90 \\
-9.09 \\
-9.18 \\
-9.22 \\
-9.25 \\
9.931 \\
-9.14 \\
-9.30 \\
-8.54 \\
-8.41 \\
-8.34\end{array}$ & $\begin{array}{l}\text { NB } \\
\text { RB } \\
\text { NB }\end{array}$ \\
\hline
\end{tabular}


Preliminary Data -- 9 September 1993

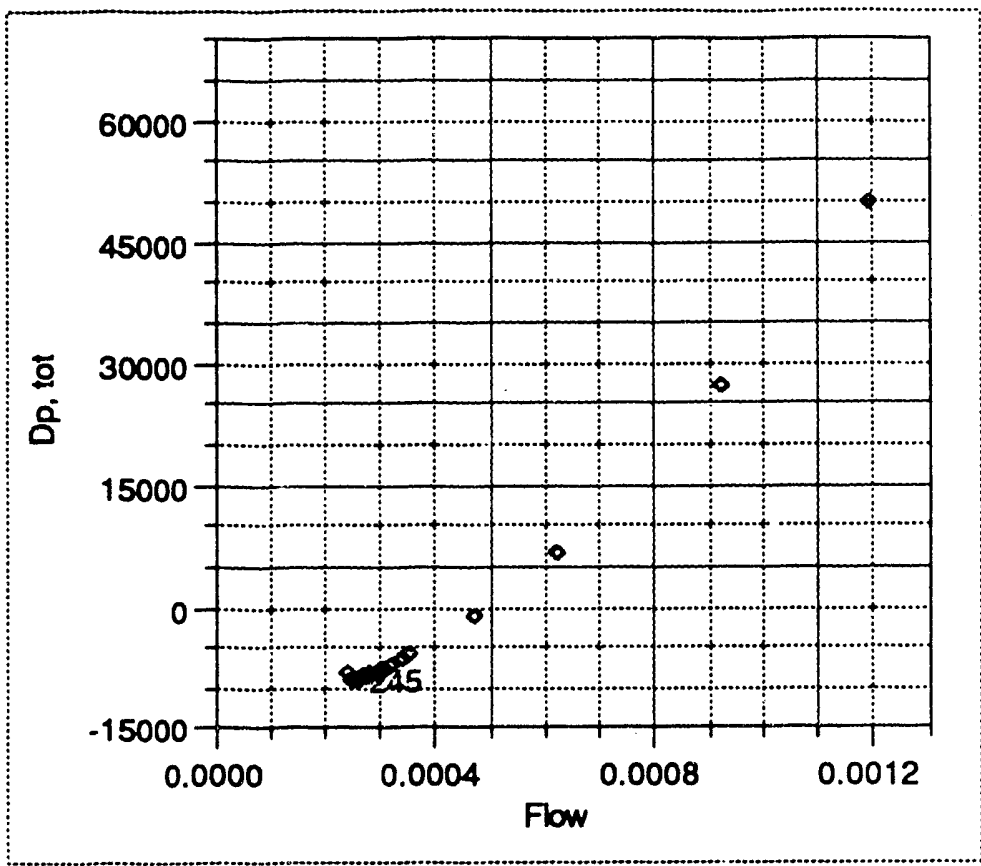

Figure 8-9, Demand curve 3.001, construction 2.0, rib channel

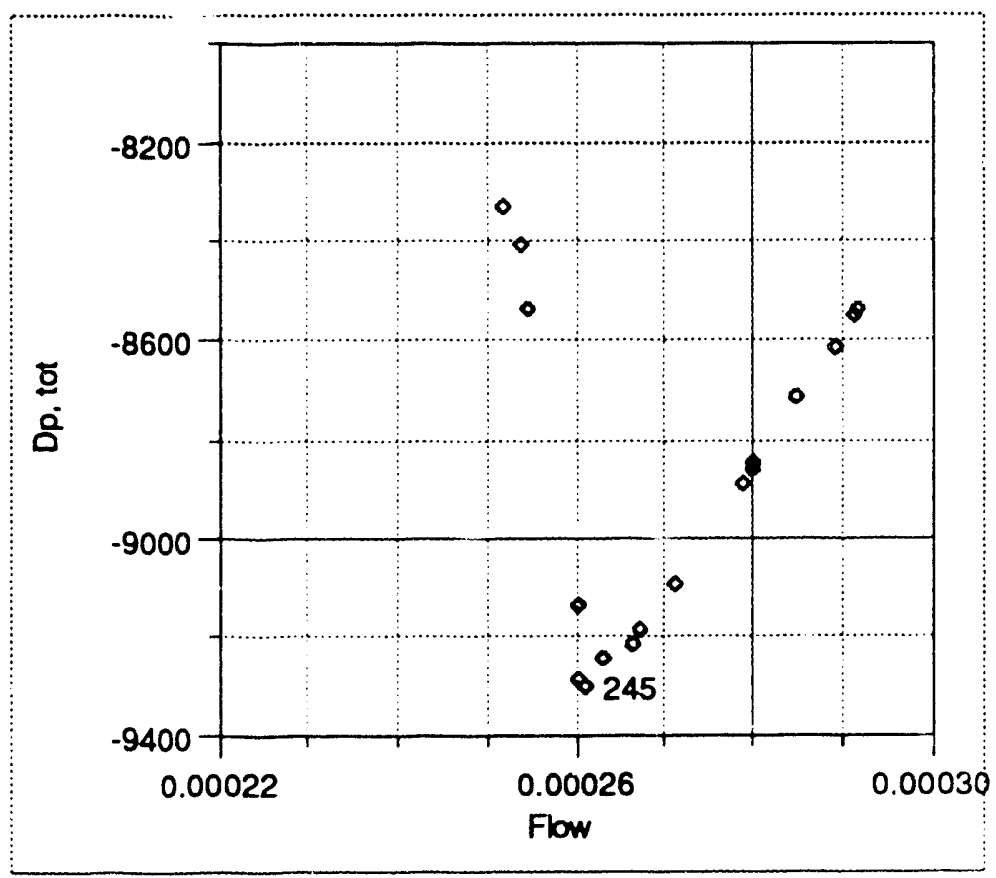

Figure 8-10, Detail of minima region for demand curve 3.001, construction 2.0, rib channel 


\section{Preliminary Data _- 9 September 1993}

Table 8-11.--Boundary conditions for demand curve 3.002, construction 2.0, rib channel

\begin{tabular}{|c|c|c|c|c|c|}
\hline File name & $\begin{array}{l}\text { Row } \\
\text { number }\end{array}$ & $\begin{array}{c}\text { Inlet } \\
\text { Temperature } \\
{ }^{\circ} \mathrm{C}\end{array}$ & $\begin{array}{c}\text { EHL } \\
\text { pressure } \\
\text { kPa abs } \\
\end{array}$ & $\begin{array}{l}\text { Power } \\
\mathrm{kW}\end{array}$ & $\begin{array}{l}\text { Energy } \\
\text { balance }\end{array}$ \\
\hline 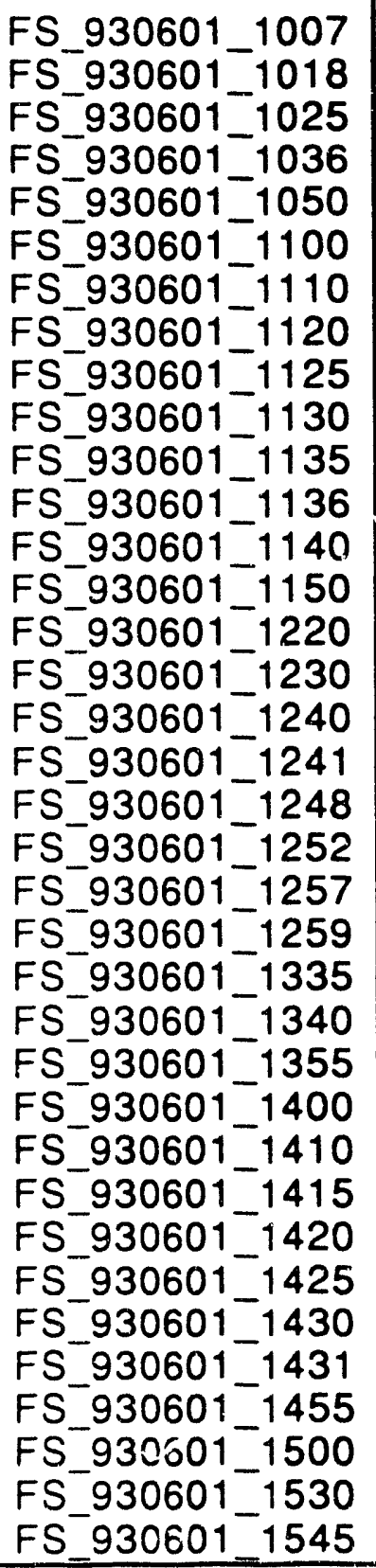 & $\begin{array}{l}267 \\
268 \\
269 \\
270 \\
271 \\
272 \\
273 \\
274 \\
275 \\
276 \\
277 \\
278 \\
279 \\
280 \\
281 \\
282 \\
283 \\
284 \\
285 \\
286 \\
287 \\
288 \\
289 \\
290 \\
291 \\
292 \\
293 \\
294 \\
295 \\
296 \\
297 \\
298 \\
299 \\
300 \\
301 \\
302 \\
\end{array}$ & $\begin{array}{l}60.33 \\
59.58 \\
59.47 \\
59.58 \\
60.26 \\
59.76 \\
59.40 \\
59.24 \\
59.17 \\
59.21 \\
59.25 \\
59.19 \\
59.30 \\
59.09 \\
59.18 \\
59.29 \\
59.32 \\
59.59 \\
59.54 \\
59.65 \\
59.84 \\
59.97 \\
59.56 \\
59.59 \\
59.27 \\
59.62 \\
59.53 \\
59.21 \\
59.69 \\
59.69 \\
59.27 \\
59.83 \\
59.41 \\
59.76 \\
60.14 \\
60.37 \\
\end{array}$ & $\begin{array}{l}133.8 \\
135.1 \\
132.4 \\
130.2 \\
129.2 \\
129.1 \\
129.0 \\
129.0 \\
128.9 \\
129.1 \\
129.0 \\
129.0 \\
128.7 \\
128.8 \\
129.3 \\
129.1 \\
129.1 \\
129.0 \\
129.0 \\
128.9 \\
128.9 \\
128.5 \\
129.2 \\
129.1 \\
129.0 \\
129.0 \\
128.9 \\
128.9 \\
128.9 \\
128.4 \\
128.4 \\
128.4 \\
129.2 \\
130.2 \\
131.7 \\
135.3 \\
\end{array}$ & $\begin{array}{l}30.61 \\
30.60 \\
30.51 \\
30.64 \\
30.59 \\
30.59 \\
30.50 \\
30.59 \\
30.62 \\
30.58 \\
30.61 \\
30.65 \\
30.73 \\
30.57 \\
30.60 \\
30.77 \\
30.55 \\
30.48 \\
30.65 \\
30.80 \\
30.50 \\
30.67 \\
30.62 \\
30.11 \\
30.59 \\
30.80 \\
30.42 \\
30.49 \\
30.51 \\
30.35 \\
30.66 \\
30.52 \\
30.69 \\
30.82 \\
30.53 \\
30.56 \\
\end{array}$ & $\begin{array}{l}0.961 \\
0.958 \\
0.957 \\
0.953 \\
0.956 \\
0.960 \\
0\end{array}$ \\
\hline $\begin{array}{l}\text { Mean } \\
\text { S }\end{array}$ & $\cdots$ & $\begin{array}{r}59.55 \\
0.34 \\
\end{array}$ & $\begin{array}{r}129.7 \\
1.8\end{array}$ & $\begin{array}{r}30.59 \\
0.13\end{array}$ & $\begin{array}{l}0.962 \\
0.007\end{array}$ \\
\hline
\end{tabular}


Table 8-12.--Test data for demand curve 3.002, construction 2.0, rib channel

\begin{tabular}{|c|c|c|c|c|}
\hline File name & $\begin{array}{c}\text { Row } \\
\text { number }\end{array}$ & $\begin{array}{l}\text { Flow } \\
\mathrm{cm}^{3} / \mathrm{s}\end{array}$ & $\begin{array}{c}\Delta p \\
\mathrm{KPa}\end{array}$ & $\begin{array}{c}\mathrm{EHL} \\
\text { condition }\end{array}$ \\
\hline 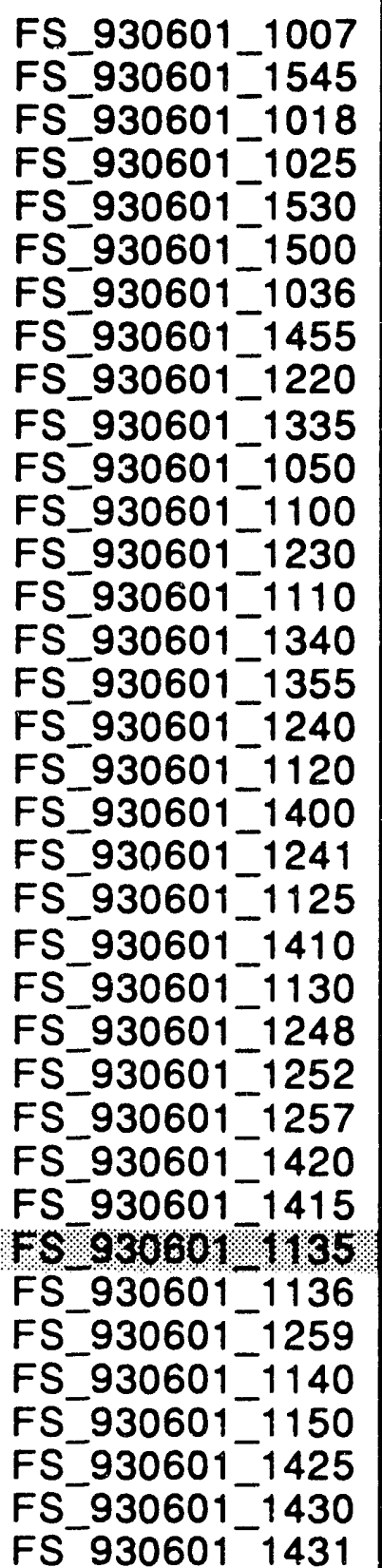 & $\begin{array}{l}267 \\
302 \\
268 \\
269 \\
301 \\
300 \\
270 \\
299 \\
281 \\
289 \\
271 \\
272 \\
282 \\
273 \\
290 \\
291 \\
283 \\
274 \\
292 \\
284 \\
275 \\
293 \\
276 \\
285 \\
286 \\
287 \\
295 \\
294 \\
277 \\
278 \\
288 \\
279 \\
280 \\
296 \\
297 \\
298\end{array}$ & $\begin{array}{r}1163.8 \\
941.0 \\
923.6 \\
701.3 \\
644.1 \\
489.8 \\
474.7 \\
330.9 \\
329.1 \\
328.8 \\
323.9 \\
323.7 \\
298.7 \\
297.9 \\
296.0 \\
287.0 \\
285.3 \\
283.6 \\
273.2 \\
270.5 \\
269.4 \\
267.2 \\
265.6 \\
264.5 \\
262.5 \\
262.3 \\
261.5 \\
261.4 \\
259.5 \\
259.5 \\
255.4 \\
254.1 \\
253.4 \\
253.1 \\
248.8 \\
238.7\end{array}$ & $\begin{array}{r}46.87 \\
27.60 \\
26.25 \\
10.74 \\
7.39 \\
-0.73 \\
-1.48 \\
-7.15 \\
-7.24 \\
-7.24 \\
-7.42 \\
-7.42 \\
-8.22 \\
-8.24 \\
-8.27 \\
-8.53 \\
-8.59 \\
-8.66 \\
-8.90 \\
-8.99 \\
-9.05 \\
-9.06 \\
-9.13 \\
-9.13 \\
-9.05 \\
-9.08 \\
-9.15 \\
-9.18 \\
-9.23 \\
-9.19 \\
-8.23 \\
-8.43 \\
-8.67 \\
-8.39 \\
-8.24 \\
-8.20\end{array}$ & $N B^{*}$ \\
\hline
\end{tabular}

'The EHL conditions were only noted for logs between FS_930601_1120 through FS_930601_1150. 
Prellminary Rate - 9 September 1993

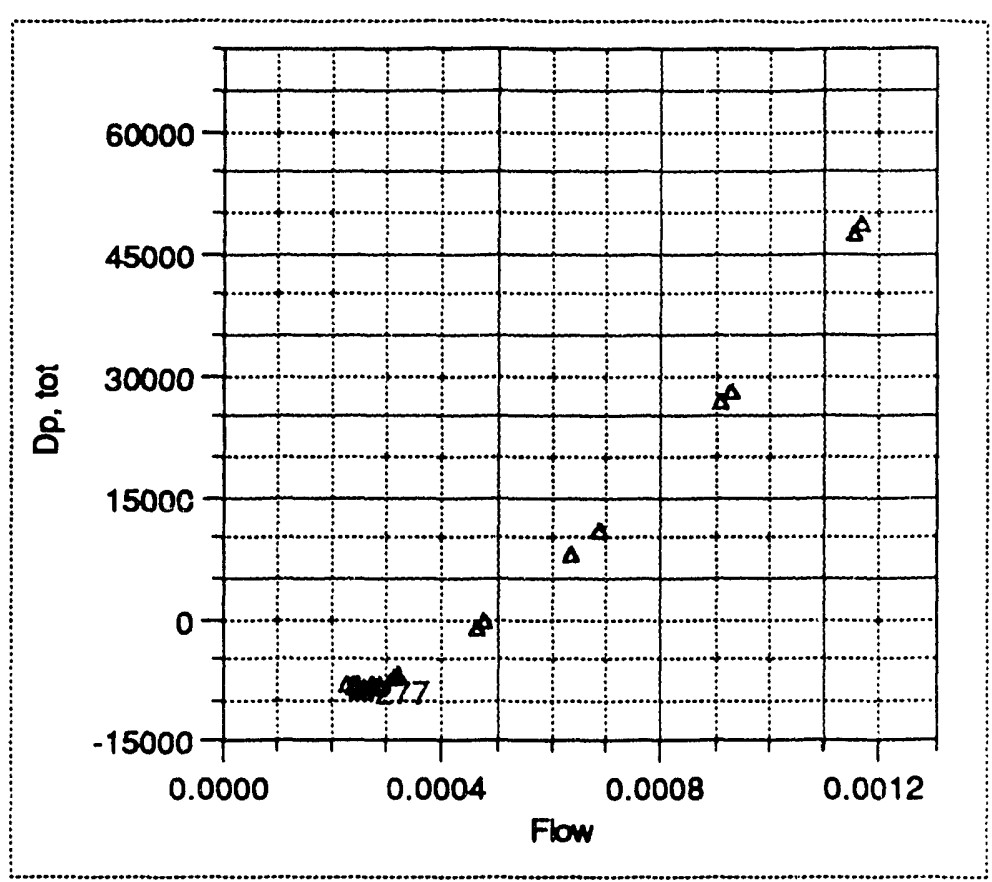

Figure 8-11, Demand curve 3.002, construction 2.0, rib channel

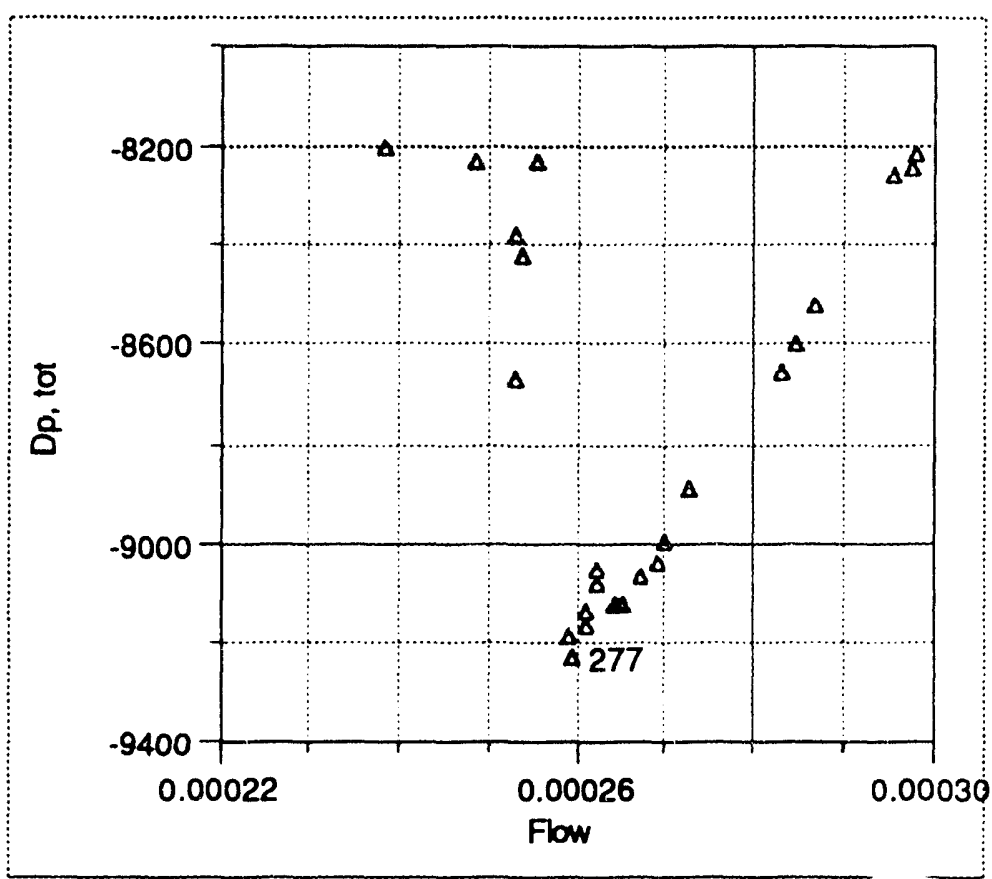

Figure 8-12, Detail of minima region for demand curve 3.002, construction 2.0, rib channel 
Table 8-13.--Boundary conditions for demand curve 3.003, construction 2.0, rib channel

\begin{tabular}{|c|c|c|c|c|c|}
\hline File name & $\begin{array}{c}\text { Row } \\
\text { number }\end{array}$ & $\begin{array}{c}\text { Inlet } \\
\text { Temperature } \\
{ }^{\circ} \mathrm{C}\end{array}$ & $\begin{array}{c}\text { EHL } \\
\text { pressure } \\
\text { kPa abs }\end{array}$ & $\begin{array}{c}\text { Power } \\
\text { kW }\end{array}$ & $\begin{array}{l}\text { Energy } \\
\text { balance }\end{array}$ \\
\hline $\begin{array}{l}\text { FS_930601-1600 } \\
\text { FS_930601-1610 } \\
\text { FS_930601-1630 } \\
\text { FS_930601-1645 } \\
\text { FS_930601-1646 } \\
\text { FS_930601-1650 } \\
\text { FS_930601-1710 } \\
\text { FS_930601-1715 } \\
\text { FS_930601-1720 } \\
\text { FS_930601-1730 } \\
\text { FS_930601-1735 } \\
\text { FS_930601-1736 } \\
\text { FS_930601-1745 } \\
\text { FS_930601-1750 } \\
\text { FS_930601-1810 } \\
\text { FS_930601-1830 } \\
\text { FS_930601-1831 } \\
\text { FS_930601-1835 } \\
\text { FS_930601-1845 } \\
\text { FS_930601-1900 } \\
\text { FS_930601-1910 } \\
\text { FS_930601-1915 } \\
\text { FS_930601-1916 } \\
\text { FS_930601-1917 } \\
\text { FS_930601-1930 } \\
\text { FS_930601-1935 } \\
\text { FS_930601-1940 } \\
\text { FS_930601-1945 }\end{array}$ & $\begin{array}{l}303 \\
304 \\
305 \\
306 \\
307 \\
308 \\
310 \\
311 \\
312 \\
313 \\
314 \\
315 \\
316 \\
317 \\
318 \\
319 \\
320 \\
321 \\
322 \\
323 \\
324 \\
325 \\
326 \\
327 \\
328 \\
329 \\
330 \\
331 \\
\end{array}$ & $\begin{array}{l}59.26 \\
59.71 \\
59.52 \\
60.23 \\
59.37 \\
59.17 \\
59.54 \\
59.90 \\
60.00 \\
59.40 \\
59.30 \\
59.12 \\
59.51 \\
59.20 \\
59.19 \\
59.48 \\
59.39 \\
59.78 \\
59.54 \\
59.28 \\
59.32 \\
59.40 \\
59.37 \\
59.13 \\
59.36 \\
59.91 \\
59.88 \\
59.89\end{array}$ & $\begin{array}{l}132.4 \\
134.0 \\
133.9 \\
131.9 \\
130.3 \\
129.3 \\
129.1 \\
129.0 \\
129.0 \\
128.9 \\
128.9 \\
128.5 \\
128.5 \\
128.5 \\
129.2 \\
129.1 \\
129.1 \\
129.0 \\
128.9 \\
128.9 \\
128.9 \\
128.5 \\
128.4 \\
128.5 \\
129.2 \\
129.3 \\
129.3 \\
129.4\end{array}$ & $\begin{array}{l}30.58 \\
30.59 \\
30.59 \\
30.68 \\
30.59 \\
30.55 \\
30.69 \\
30.49 \\
30.40 \\
30.86 \\
30.55 \\
30.54 \\
30.60 \\
30.59 \\
30.53 \\
30.50 \\
30.67 \\
30.65 \\
30.55 \\
30.69 \\
30.58 \\
30.69 \\
30.57 \\
30.63 \\
30.63 \\
30.76 \\
30.56 \\
30.62 \\
\end{array}$ & $\begin{array}{l}0.953 \\
0.952 \\
0.948 \\
0.947 \\
0.942 \\
0.966 \\
0.962 \\
0.965 \\
0.965 \\
0.958 \\
0.957 \\
0.964 \\
0.964 \\
0.963 \\
0.955 \\
0.951 \\
0.954 \\
0.957 \\
0.955 \\
0.959 \\
0.959 \\
0.961 \\
0.964 \\
0.963 \\
0.960 \\
0.956 \\
0.950 \\
0.951\end{array}$ \\
\hline $\begin{array}{l}\text { Mean } \\
\mathrm{S}\end{array}$ & $\cdots$ & $\begin{array}{r}59.51 \\
0.30 \\
\end{array}$ & $\begin{array}{r}129.5 \\
1.5 \\
\end{array}$ & $\begin{array}{r}0.61 \\
0.09 \\
\end{array}$ & $\begin{array}{l}0.9573 \\
0.0064 \\
\end{array}$ \\
\hline
\end{tabular}




\section{Preliminary Data _- 9 September 1993}

Table 8-14.--Test data for demand curve 3.003, construction 2.0, rib channel

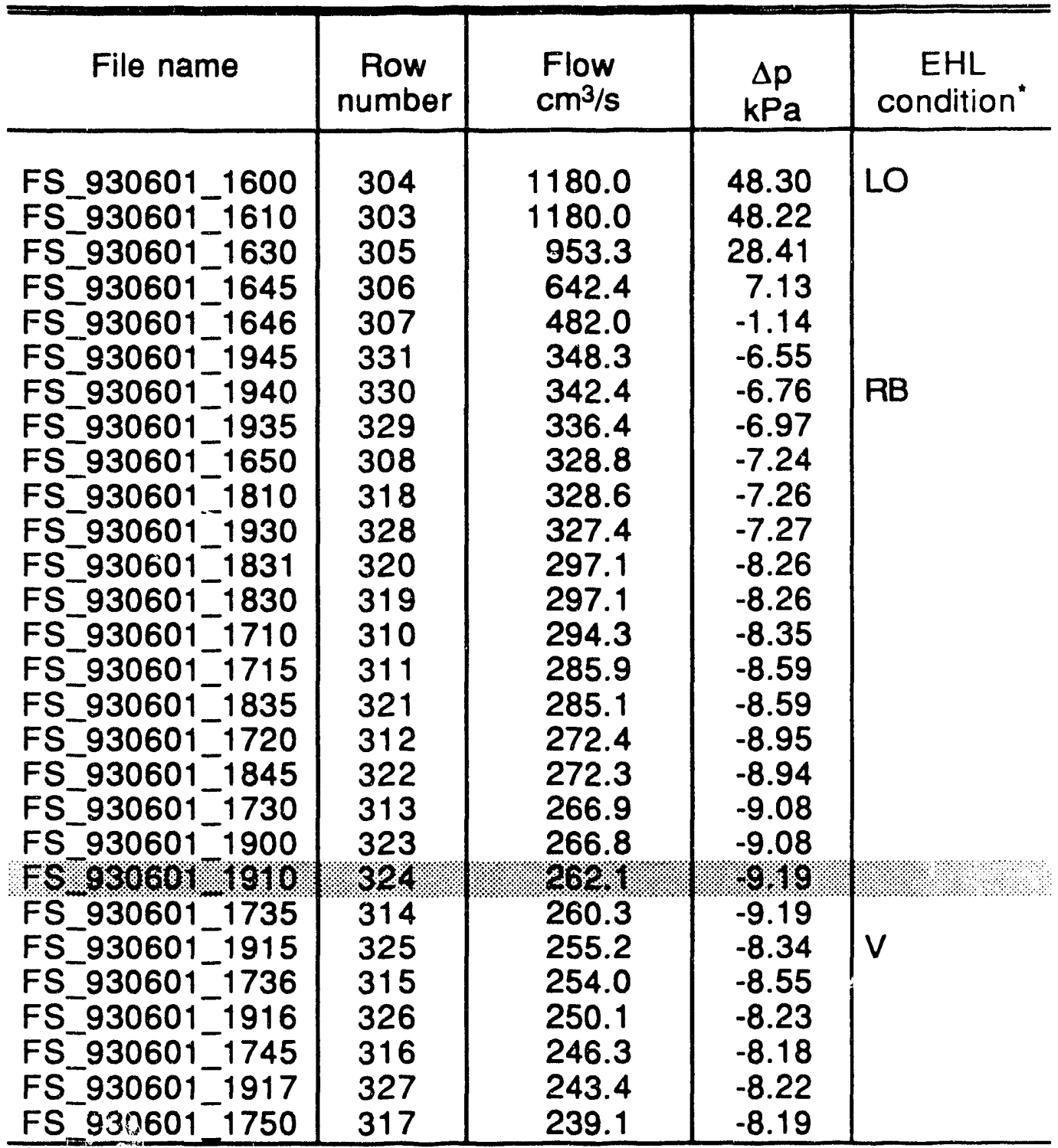

"The point of nucleate boiling (NB) was not noted during this test. 
Preliminary Data -. 9 September 1993

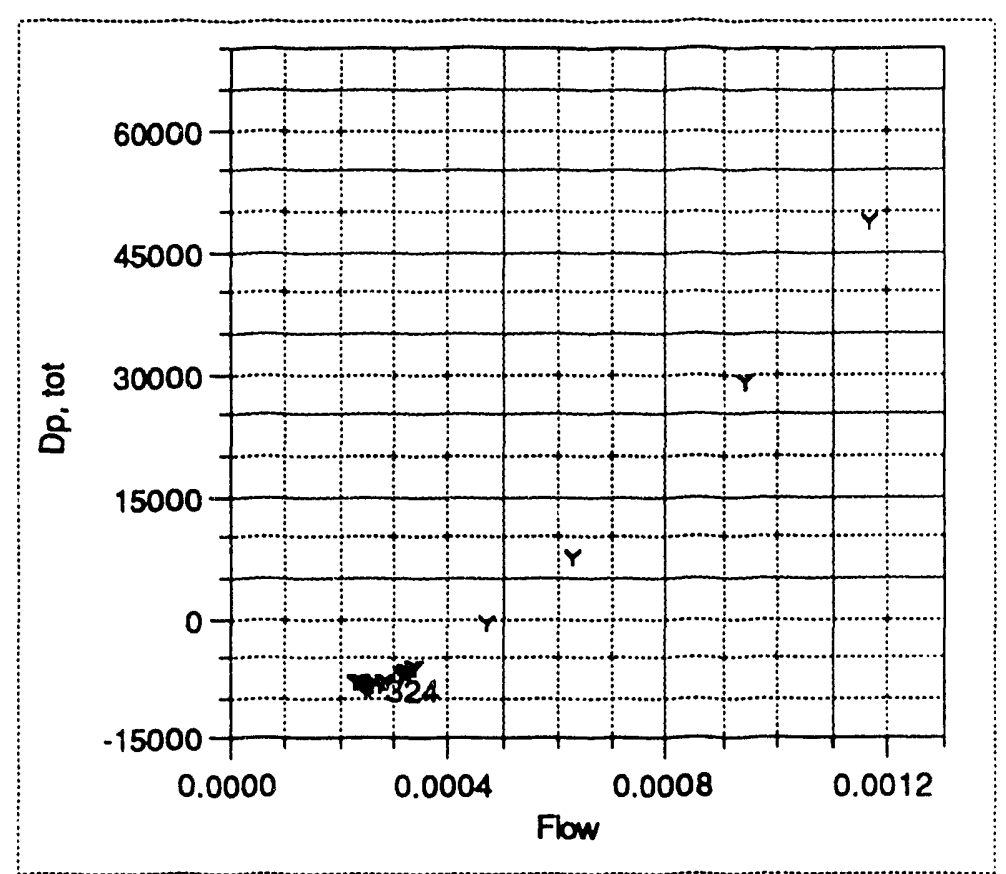

Figure 8-13, Demand curve 3.003, construction 2.0, rib channel

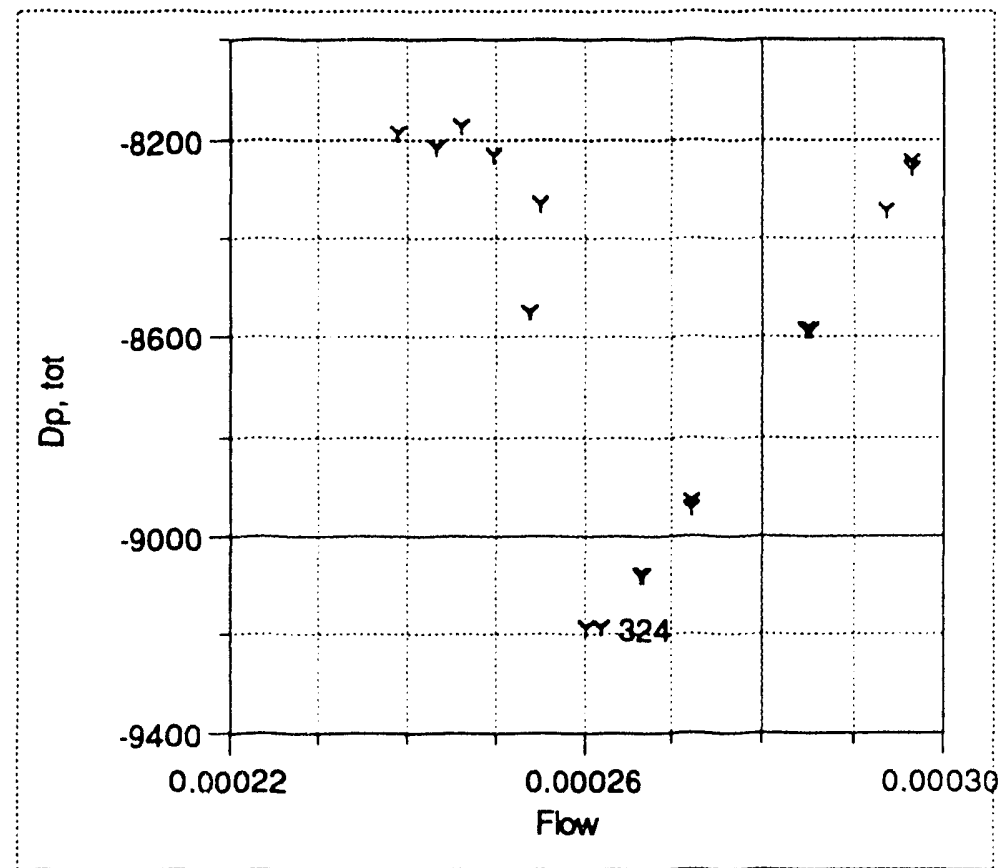

Figure 8-14, Detail of minima region for demand curve 3.003, construction 2.0, rib channel 


\section{Preliminary Date _- 9 September 1993}

Table 8-15.--Boundary conditions for demand curve 4.001, construction 2.0, rib channel

\begin{tabular}{|c|c|c|c|c|c|}
\hline File name & $\begin{array}{c}\text { Row } \\
\text { number }\end{array}$ & $\begin{array}{c}\text { Inlet } \\
\text { Temperature } \\
{ }^{\circ} \mathrm{C}\end{array}$ & $\begin{array}{c}\text { EHL } \\
\text { pressure } \\
\text { kPa abs } \\
\end{array}$ & $\begin{array}{c}\text { Power } \\
\text { kW }\end{array}$ & $\begin{array}{l}\text { Energy } \\
\text { balance }\end{array}$ \\
\hline 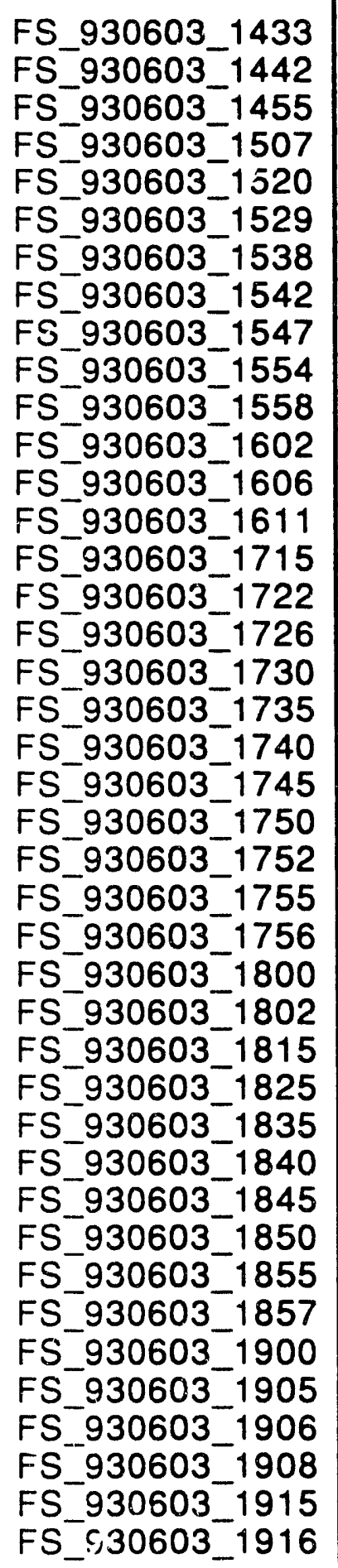 & $\begin{array}{l}337 \\
338 \\
339 \\
340 \\
341 \\
342 \\
343 \\
344 \\
345 \\
346 \\
347 \\
348 \\
349 \\
350 \\
352 \\
353 \\
354 \\
355 \\
356 \\
357 \\
358 \\
359 \\
360 \\
361 \\
362 \\
363 \\
364 \\
365 \\
366 \\
367 \\
368 \\
369 \\
370 \\
371 \\
372 \\
373 \\
374 \\
375 \\
376 \\
377 \\
378\end{array}$ & $\begin{array}{l}59.47 \\
58.66 \\
59.71 \\
59.75 \\
59.77 \\
59.55 \\
59.78 \\
59.55 \\
59.61 \\
59.76 \\
59.72 \\
59.61 \\
59.58 \\
59.30 \\
59.72 \\
59.94 \\
59.67 \\
59.68 \\
59.89 \\
59.76 \\
59.74 \\
59.66 \\
59.93 \\
59.89 \\
59.80 \\
59.73 \\
59.60 \\
59.44 \\
59.78 \\
59.32 \\
59.76 \\
59.63 \\
59.91 \\
59.65 \\
59.69 \\
59.79 \\
59.50 \\
59.39 \\
59.30 \\
59.44 \\
59.30\end{array}$ & $\begin{array}{l}139.5 \\
134.5 \\
133.8 \\
133.3 \\
131.6 \\
131.3 \\
130.9 \\
130.7 \\
130.4 \\
130.2 \\
130.2 \\
130.1 \\
130.1 \\
130.0 \\
130.9 \\
130.5 \\
130.3 \\
129.9 \\
129.9 \\
129.8 \\
129.7 \\
129.7 \\
129.6 \\
129.6 \\
129.6 \\
129.6 \\
129.5 \\
130.2 \\
129.9 \\
129.8 \\
129.7 \\
129.6 \\
129.5 \\
129.4 \\
129.2 \\
129.2 \\
129.2 \\
129.1 \\
129.1 \\
129.1 \\
128.9\end{array}$ & $\begin{array}{l}52.43 \\
52.26 \\
52.32 \\
51.97 \\
51.99 \\
52.23 \\
52.22 \\
52.33 \\
52.15 \\
52.18 \\
52.12 \\
52.24 \\
52.07 \\
51.97 \\
52.28 \\
52.18 \\
52.23 \\
52.13 \\
52.23 \\
51.90 \\
52.02 \\
52.13 \\
51.96 \\
52.02 \\
51.89 \\
52.03 \\
52.06 \\
52.12 \\
52.05 \\
51.77 \\
51.87 \\
52.60 \\
52.16 \\
51.78 \\
52.17 \\
52.07 \\
51.89 \\
51.99 \\
52.02 \\
52.05 \\
52.16\end{array}$ & $\begin{array}{l}0.985 \\
0.982 \\
0.978 \\
0.976 \\
0.979 \\
0.983 \\
0.985 \\
0.988 \\
0.991 \\
0.990 \\
0.989 \\
0.989 \\
0.987 \\
0.987 \\
0.982 \\
0.985 \\
0.985 \\
0.987 \\
0.985 \\
0.983 \\
0.983 \\
0.985 \\
0.988 \\
0.987 \\
0.986 \\
0.985 \\
0.988 \\
0.981 \\
0.979 \\
0.979 \\
0.988 \\
0.989 \\
0.984 \\
0.982 \\
0.986 \\
0.986 \\
0.985 \\
0.984 \\
0.989 \\
0.987 \\
0.987\end{array}$ \\
\hline
\end{tabular}


Preliminary Data _- 9 September 1993

\begin{tabular}{l|c|r|r|r|r} 
FS_930603_1918 & 379 & 59.29 & 128.9 & 52.15 & 0.990 \\
FS_930603_1920 & 380 & 59.21 & 128.7 & 52.11 & 0.987 \\
FS_930603_1925 & 381 & 59.22 & 128.6 & 52.01 & 0.988 \\
FS_930603_1928 & 382 & 59.18 & 128.6 & 52.10 & 0.989 \\
FS_930603_1930 & 383 & 59.37 & 128.3 & 52.12 & 0.990 \\
\hline Mean & $\cdots$ & 59.59 & 130.2 & 52.10 & 0.9854 \\
S & $\cdots$ & 0.25 & 1.9 & 0.16 & 0.0034 \\
\hline
\end{tabular}




\section{Preliminary Data - 9 September 1993}

Table 8-16.--Test data for demand curve 4.001, construction 2.0, rib channel

\begin{tabular}{|c|c|c|c|c|}
\hline File name & $\begin{array}{c}\text { Row } \\
\text { number }\end{array}$ & $\begin{array}{l}\text { Flow } \\
\mathrm{cm}^{3} / \mathrm{s}\end{array}$ & $\begin{array}{c}\Delta p \\
k P a\end{array}$ & $\begin{array}{c}\text { EHL } \\
\text { condition }\end{array}$ \\
\hline 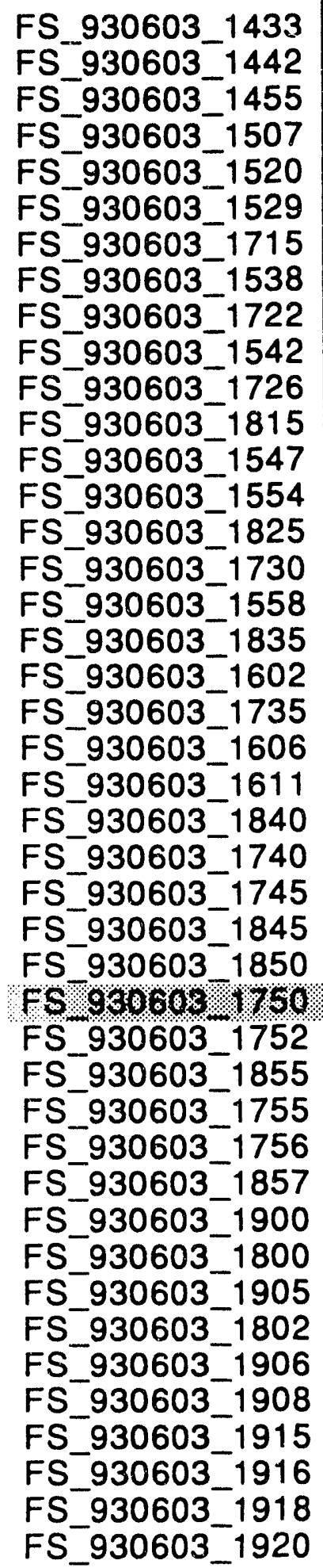 & $\begin{array}{l}337 \\
338 \\
339 \\
340 \\
341 \\
342 \\
352 \\
343 \\
353 \\
344 \\
354 \\
365 \\
345 \\
346 \\
366 \\
355 \\
347 \\
367 \\
348 \\
356 \\
349 \\
350 \\
368 \\
357 \\
358 \\
369 \\
370 \\
359 \\
360 \\
371 \\
361 \\
362 \\
372 \\
373 \\
363 \\
374 \\
364 \\
375 \\
376 \\
377 \\
378 \\
379 \\
380\end{array}$ & $\begin{array}{l}1183.8 \\
1183.5 \\
947.0 \\
795.0 \\
633.3 \\
603.4 \\
581.2 \\
563.7 \\
543.5 \\
541.6 \\
519.3 \\
515.2 \\
509.1 \\
484.2 \\
483.9 \\
476.9 \\
475.5 \\
471.4 \\
471.3 \\
466.8 \\
465.4 \\
458.8 \\
458.2 \\
453.0 \\
447.4 \\
446.1 \\
442.1 \\
439.2 \\
434.0 \\
432.2 \\
427.9 \\
427.5 \\
425.9 \\
425.3 \\
423.5 \\
418.2 \\
414.9 \\
409.0 \\
401.5 \\
398.0 \\
390.6 \\
385.4 \\
377.4\end{array}$ & $\begin{array}{r}47.04 \\
47.22 \\
26.84 \\
15.84 \\
5.96 \\
4.34 \\
3.11 \\
2.28 \\
1.20 \\
1.20 \\
0.05 \\
-0.15 \\
-0.31 \\
-1.41 \\
-1.53 \\
-1.81 \\
-1.79 \\
-2.06 \\
-1.95 \\
-2.22 \\
-2.19 \\
-2.46 \\
-2.57 \\
-2.75 \\
-2.92 \\
-2.91 \\
-2.97 \\
-1060 \\
-2.92 \\
-3.16 \\
-2.76 \\
-2.88 \\
-2.77 \\
-2.73 \\
-2.77 \\
-2.85 \\
-2.72 \\
-2.77 \\
-2.77 \\
-2.56 \\
-2.19 \\
-1.94 \\
-1.40\end{array}$ & $\begin{array}{l} \\
\text { NB } \\
\text { RB } \\
\text { NB } \\
\text { RB } \\
\text { NB } \\
\ldots \\
\text { RB } \\
\text { NB }\end{array}$ \\
\hline
\end{tabular}




\section{Preliminary Data .. 9 September 1993}

\begin{tabular}{l|l|l|l|l} 
FS_930603_1925 & 381 & 371.7 & -1.08 & \\
FS_930603_1928 & 382 & 365.7 & -0.65 & \\
\hline FS_930603_1930 & 383 & 359.3 & 0.10 & \\
\hline
\end{tabular}

-The EHL flow condtions were not recorded for files FS_930603_1850 through FS_930603_1815.

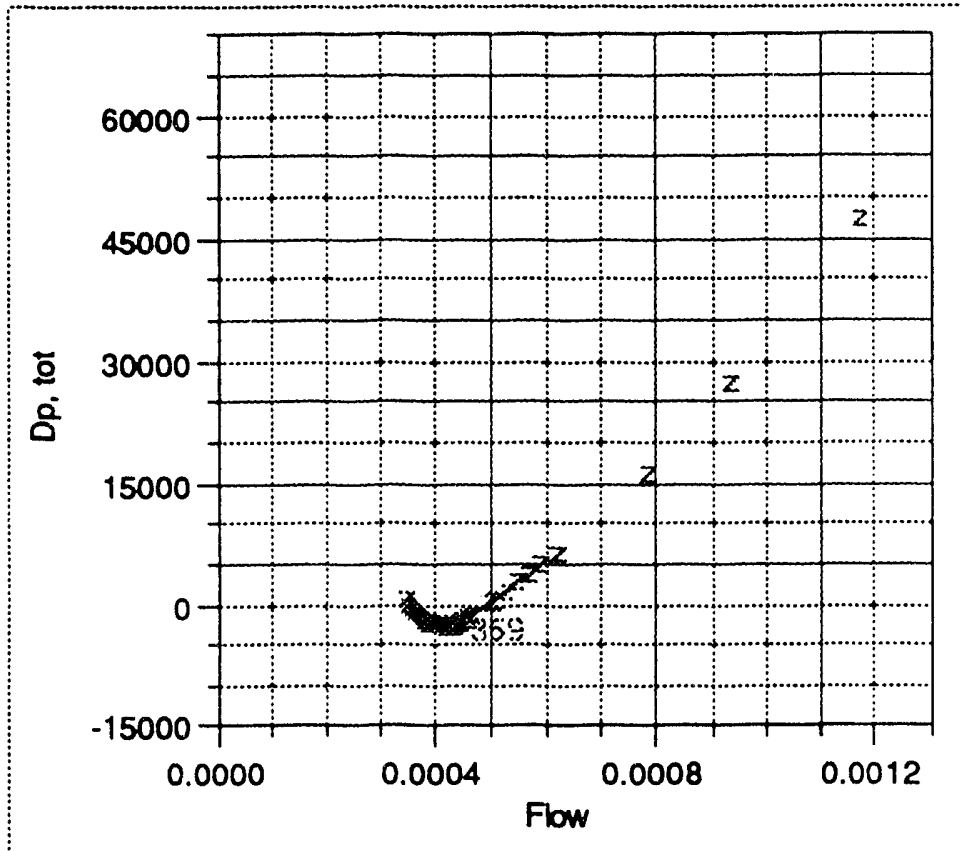

Figure 8-15, Demand curve 3.004, construction 2.0, rib channel 


\section{Preliminary Data -- 9 September 1993}

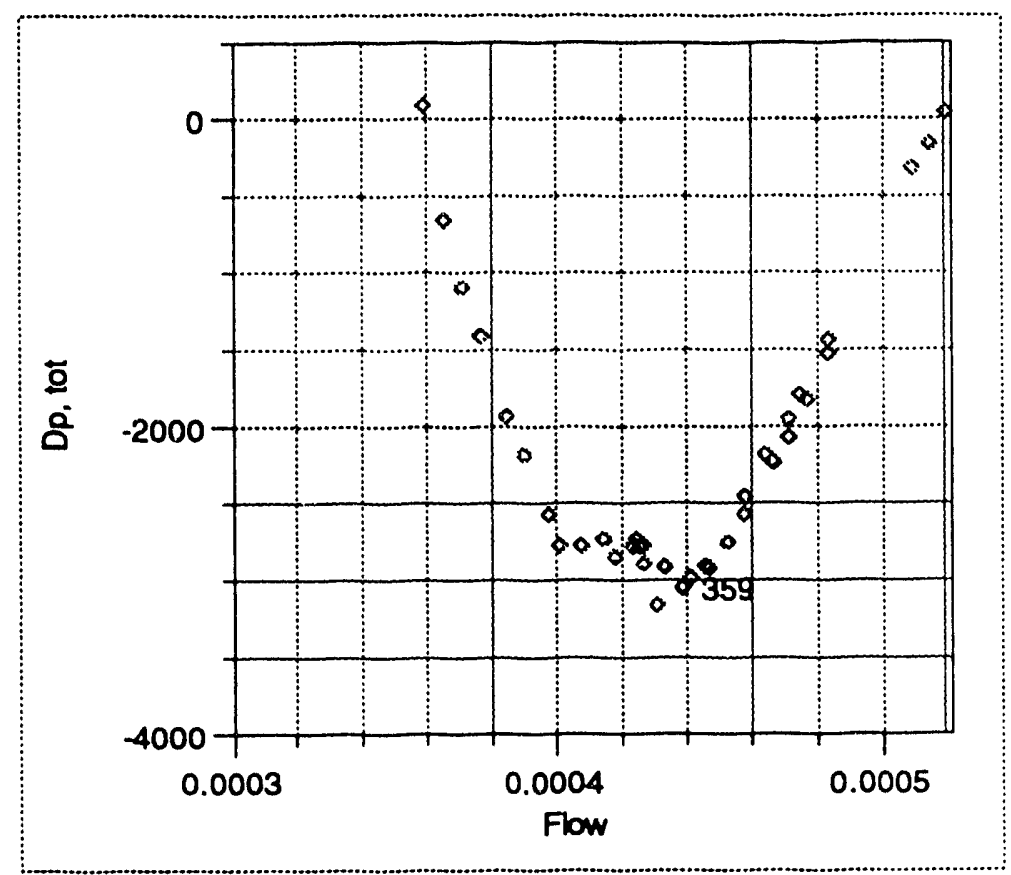

Figure 8-16, Detail of minima region for demand curve 3.004, construction 2.0, rib channel 


\section{Preliminary Data -- 9 September 1993}

Table 8-17.--Boundary conditions for demand curve 2.005, construction 4.0, open channel

\begin{tabular}{l|c|c|c|c|c}
\hline \hline File name & $\begin{array}{c}\text { Row } \\
\text { number }\end{array}$ & $\begin{array}{c}\text { Inlet } \\
\text { Temperature } \\
{ }^{\circ} \mathrm{C}\end{array}$ & $\begin{array}{c}\text { EHL } \\
\text { pressure } \\
\text { kPa abs }\end{array}$ & $\begin{array}{c}\text { Power } \\
\mathrm{kW}\end{array}$ & $\begin{array}{c}\text { Energy } \\
\text { balance }\end{array}$ \\
\hline FS_930707_1123 & 468 & 60.86 & 138.6 & 30.54 & 0.845 \\
FS_930707_1128 & 469 & 60.94 & 133.4 & 30.49 & 0.843 \\
FS_930707_1139 & 470 & 60.17 & 129.0 & 30.43 & 0.843 \\
FS_930707_1156 & 471 & 61.03 & 127.4 & 30.46 & 0.841 \\
FS_930707_1209 & 472 & 60.65 & 126.1 & 30.52 & 0.864 \\
FS_930707_1223 & 473 & 60.27 & 126.1 & 30.48 & 0.859 \\
FS_930707_1229 & 474 & 60.53 & 126.2 & 30.50 & 0.867 \\
FS_930707_1234 & 475 & 60.71 & 126.4 & 30.50 & 0.867 \\
FS_930707_1239 & 476 & 61.07 & 126.4 & 30.62 & 0.864 \\
FS_930707_1325 & 477 & 61.01 & 126.4 & 30.45 & 0.852 \\
FS_930707_1329 & 478 & 60.15 & 126.2 & 30.52 & 0.861 \\
FS_930707_1336 & 479 & 60.20 & 126.2 & 30.44 & 0.856 \\
FS_930707_1353 & 480 & 60.86 & 126.3 & 30.47 & 0.857 \\
FS_930707_1414 & 481 & 60.25 & 126.3 & 30.55 & 0.863 \\
FS_930707_1418 & 482 & 60.42 & 126.3 & 30.53 & 0.863 \\
FS_930707_1422 & 483 & 60.86 & 126.3 & 30.52 & 0.866 \\
FS_930707_1426 & 484 & 60.89 & 126.3 & 30.53 & 0.861 \\
FS_930707_1428 & 485 & 60.29 & 126.3 & 30.50 & 0.855 \\
FS_930707_1432 & 486 & 60.23 & 126.6 & 30.54 & 0.861 \\
FS_930707_1441 & 487 & 60.98 & 126.8 & 30.53 & 0.848 \\
FS_930707_1520 & 488 & 60.13 & 126.2 & 30.56 & 0.861 \\
FS_930707_1541 & 489 & 60.05 & 126.1 & 30.51 & 0.864 \\
FS_930707-1550 & 490 & 60.78 & 126.1 & 30.53 & 0.879 \\
\hline Mean & $\cdots$ & 60.58 & 127.3 & 30.51 & 0.8583 \\
FS & $\ldots$ & 0.35 & 2.9 & 0.04 & 0.0093 \\
\hline
\end{tabular}




\section{Preliminary Data _- 9 September 1993}

Table 8-18.--Test data for demand curve 2.005, construction 4.0, open channel

\begin{tabular}{|c|c|c|c|c|}
\hline File name & $\begin{array}{c}\text { Row } \\
\text { number }\end{array}$ & $\begin{array}{l}\text { Flow } \\
\mathrm{cm}^{3} / \mathrm{s}\end{array}$ & $\begin{array}{c}\Delta p \\
k P a\end{array}$ & $\begin{array}{c}E H L \\
\text { condition }\end{array}$ \\
\hline 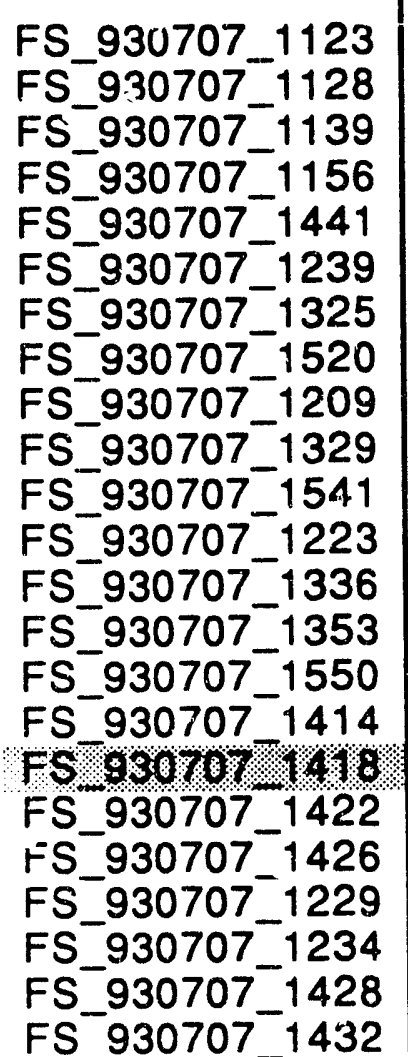 & $\begin{array}{l}468 \\
469 \\
470 \\
471 \\
48 \% \\
476 \\
477 \\
488 \\
472 \\
478 \\
489 \\
473 \\
479 \\
480 \\
495 \\
481 \\
489 \\
483 \\
484 \\
474 \\
475 \\
485 \\
486\end{array}$ & $\begin{array}{l}1184.0 \\
919.4 \\
627.8 \\
470.9 \\
411.1 \\
358.7 \\
358.2 \\
328.4 \\
323.0 \\
315.8 \\
295.3 \\
280.7 \\
277.6 \\
273.0 \\
266.6 \\
263.6 \\
954.9 \\
247.8 \\
247.8 \\
246.3 \\
244.9 \\
242.4 \\
225.5\end{array}$ & $\begin{array}{l}34.27 \\
17.77 \\
2.81 \\
-3.58 \\
-5.44 \\
-7.12 \\
-7.16 \\
-7.91 \\
-8.05 \\
-8.27 \\
-8.73 \\
-8.97 \\
-9.14 \\
-9.18 \\
-9.31 \\
-9.38 \\
-6.58 \\
-9.32 \\
-9.12 \\
-8.29 \\
-8.19 \\
-8.99 \\
-7.77\end{array}$ & $\begin{array}{l}\text { } \\
V\end{array}$ \\
\hline
\end{tabular}




\section{Prellminary Data -- 9 September 1993}

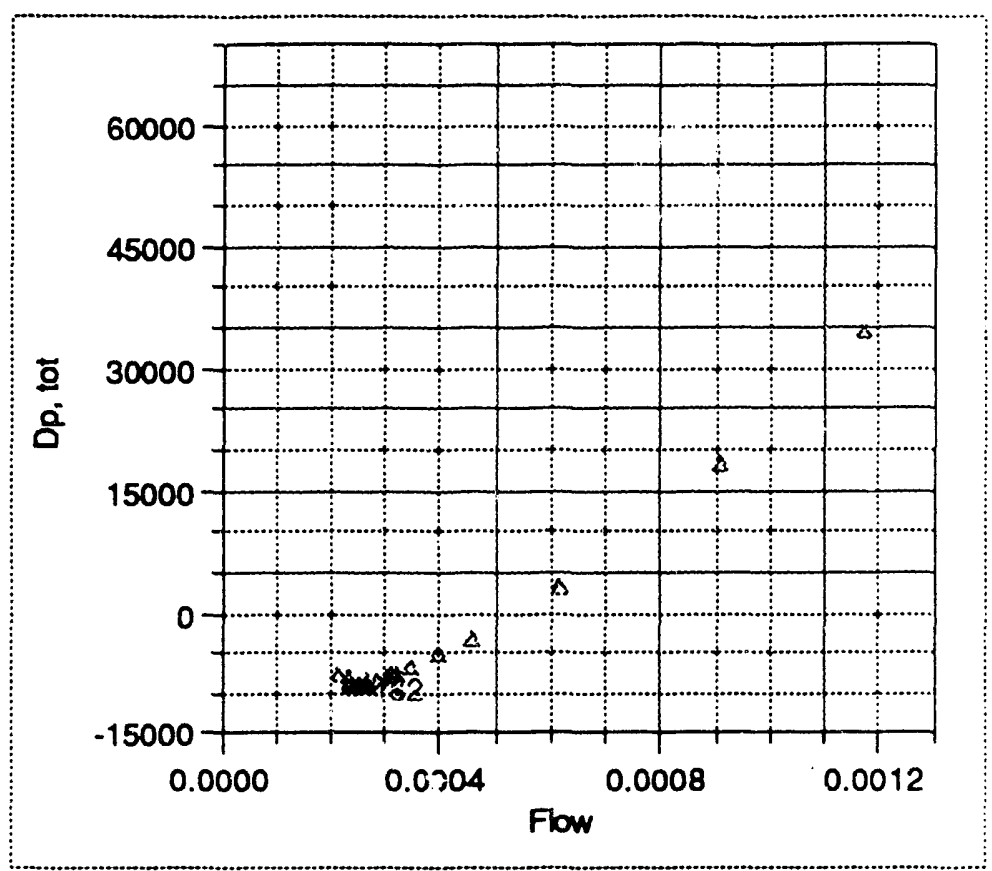

Figure 8-17, Demand curve 2.005, construction 4.0, open channel

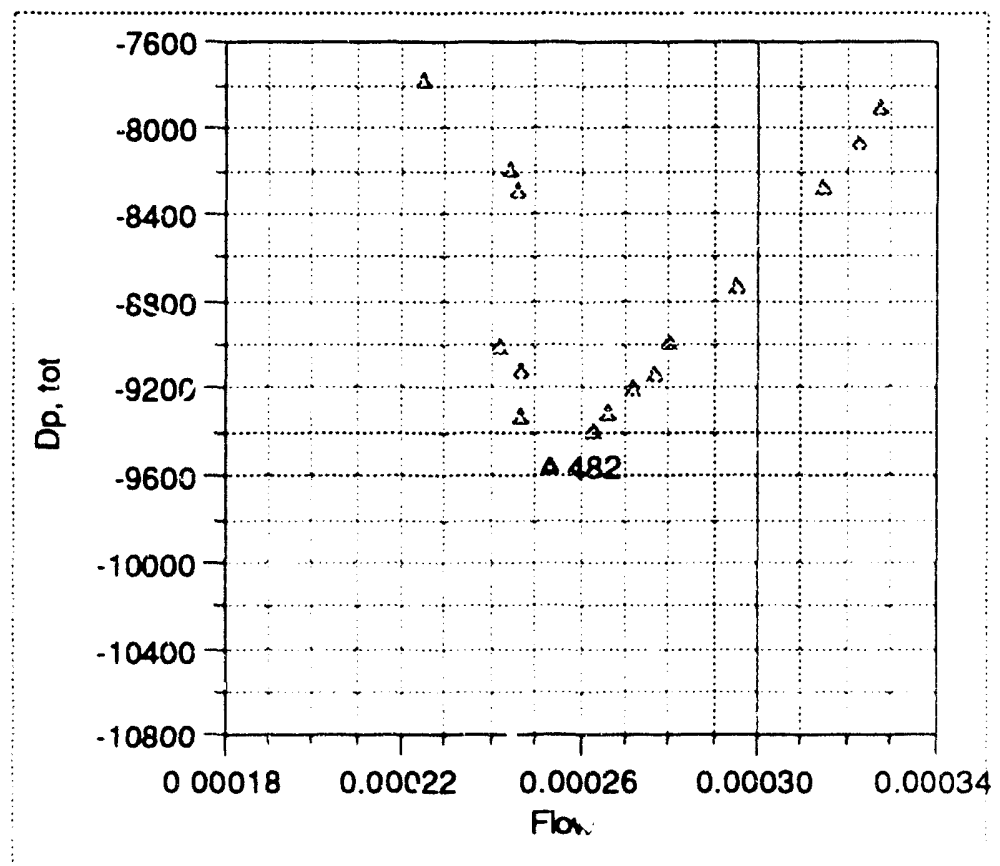

Figure 8-18, Detail of minima region for demand curve 2.005, construction 4.0, open channel 
Table 8-19.--Boundary conditions for demand curve 2.006, construction 4.0, open channel

\begin{tabular}{l|c|c|c|c|c}
\hline \hline File name & $\begin{array}{c}\text { Row } \\
\text { number }\end{array}$ & $\begin{array}{c}\text { Inlet } \\
\text { Temperature } \\
\text { oC }\end{array}$ & $\begin{array}{c}\text { EHL } \\
\text { pressure } \\
\text { kPa abs }\end{array}$ & $\begin{array}{c}\text { Power } \\
\text { kW }\end{array}$ & $\begin{array}{c}\text { Energy } \\
\text { balance }\end{array}$ \\
\hline FS_930712_1359 & 493 & 60.96 & 139.5 & 30.51 & 0.953 \\
FS_930712_1431 & 494 & 60.75 & 134.1 & 30.47 & 0.953 \\
FS_930712_1440 & 495 & 60.06 & 129.4 & 30.53 & 0.947 \\
FS_930712_1454 & 496 & 60.06 & 127.7 & 30.47 & 0.946 \\
FS_930712_1509* & 497 & 61.10 & 126.5 & 30.87 & 0.965 \\
FS_930712_1529 & 493 & 60.08 & 126.5 & 30.50 & 0.953 \\
FS_930712_1534 & 499 & 60.08 & 126.2 & 30.52 & 0.964 \\
FS_930712_1542 & 500 & 60.39 & 126.1 & 30.60 & 0.971 \\
FS_930712_1553 & 501 & 60.86 & 126.1 & 30.46 & 0.980 \\
FS_930712_1602 & 502 & 60.63 & 126.1 & 30.54 & 0.972 \\
FS_930712_1608 & 503 & 60.20 & 126.1 & 30.59 & 0.981 \\
FS_930712_1617 & 504 & 60.00 & 126.3 & 30.41 & 0.961 \\
FS_930712_1621 & 505 & 60.18 & 126.5 & 30.46 & 0.966 \\
FS_930712_1645 & 506 & 60.80 & 126.2 & 30.65 & 0.968 \\
FS_930712_1653 & 507 & 59.99 & 126.1 & 30.48 & 0.977 \\
FS_930712_1703 & 508 & 60.05 & 126.1 & 30.70 & 0.976 \\
FS_930712_1714 & 509 & 59.97 & 126.1 & 30.50 & $0.97 i$ \\
FS_930712_1718 & 510 & 60.66 & 126.1 & 30.65 & 0.987 \\
FS_930712_1724 & 511 & 60.98 & 126.1 & 30.42 & 0.973 \\
FS_930712_1732 & 512 & 61.02 & 126.2 & 30.53 & 0.971 \\
FS_930712_1735 & 513 & 60.50 & 126.3 & 30.66 & 0.962 \\
FS_930712_1739 & 514 & 60.73 & 126.7 & 30.51 & 0.959 \\
FS_930712_1757 & 515 & 60.39 & 126.1 & 30.36 & 0.979 \\
FS_930712_1806 & 516 & 60.14 & 126.1 & 30.55 & 0.990 \\
FS_930712_1820 & 517 & 60.30 & 126.1 & 30.51 & 0.979 \\
FS_930712_1825 & 518 & 59.84 & 126.1 & 30.46 & 0.975 \\
FS_930712_1827 & 519 & 59.60 & 126.1 & 30.48 & 0.981 \\
FS_930712_1837 & 520 & 59.74 & 126.1 & 30.63 & 0.978 \\
FS_930712_1841 & 521 & 59.95 & 126.2 & 30.64 & 0.974 \\
FS_930712_1847 & 522 & 59.79 & 126.3 & 29.61 & 0.951 \\
\hline Mean & $\cdots$ & 60.33 & 127.1 & 30.51 & 0.9690 \\
S & $\ldots$ & 0.43 & 2.8 & 0.20 & 0.0119 \\
\hline
\end{tabular}

'The power and inlet temperature are higher than acceptable. This point has not been plotted. 
Preliminary Data -- 9 September 1993

Table 8-20.--Test data for demand curve 2.006, construction 4.0, open channel

\begin{tabular}{|c|c|c|c|c|}
\hline File name & $\begin{array}{c}\text { Row } \\
\text { number }\end{array}$ & $\begin{array}{l}\text { Flow } \\
\mathrm{cm}^{3} / \mathrm{s}\end{array}$ & $\underset{k P a}{\Delta p}$ & $\begin{array}{c}\text { EHL } \\
\text { condition }\end{array}$ \\
\hline 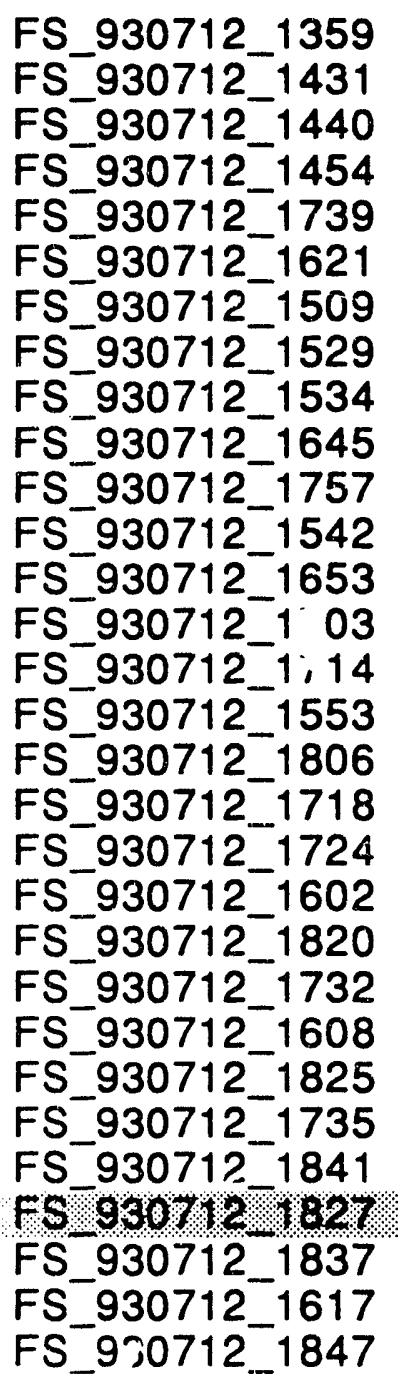 & $\begin{array}{l}493 \\
494 \\
495 \\
496 \\
514 \\
505 \\
497 \\
498 \\
499 \\
506 \\
515 \\
500 \\
507 \\
508 \\
509 \\
501 \\
516 \\
510 \\
511 \\
502 \\
517 \\
512 \\
503 \\
518 \\
513 \\
521 \\
519 \\
520 \\
504 \\
522\end{array}$ & $\begin{array}{l}1189.4 \\
926.2 \\
616.5 \\
473.7 \\
357.5 \\
331.5 \\
323.8 \\
323.5 \\
286.1 \\
286.1 \\
266.7 \\
265.7 \\
261.8 \\
244.6 \\
236.4 \\
232.3 \\
231.3 \\
230.8 \\
225.9 \\
225.3 \\
224.4 \\
223.4 \\
218.6 \\
215.6 \\
212.5 \\
211.4 \\
211.3 \\
211.3 \\
208.1 \\
203.0\end{array}$ & $\begin{array}{r}36.48 \\
19.37 \\
2.93 \\
-3.11 \\
-7.09 \\
-7.86 \\
-8.10 \\
-8.10 \\
-9.07 \\
-9.06 \\
-9.50 \\
-9.54 \\
-9.62 \\
-9.95 \\
-10.10 \\
-10.15 \\
-10.17 \\
-10.15 \\
-10.25 \\
-10.28 \\
-10.27 \\
-10.30 \\
-10.41 \\
-10.45 \\
-9.29 \\
-9.86 \\
-10648 \\
-10.07 \\
-9.38 \\
-9.90\end{array}$ & $\begin{array}{l}\text { NB } \\
\text { NB } \\
\text { LO } \\
\text { LO } \\
\text { NB }\end{array}$ \\
\hline
\end{tabular}


Preliminary Data - 9 September 1993

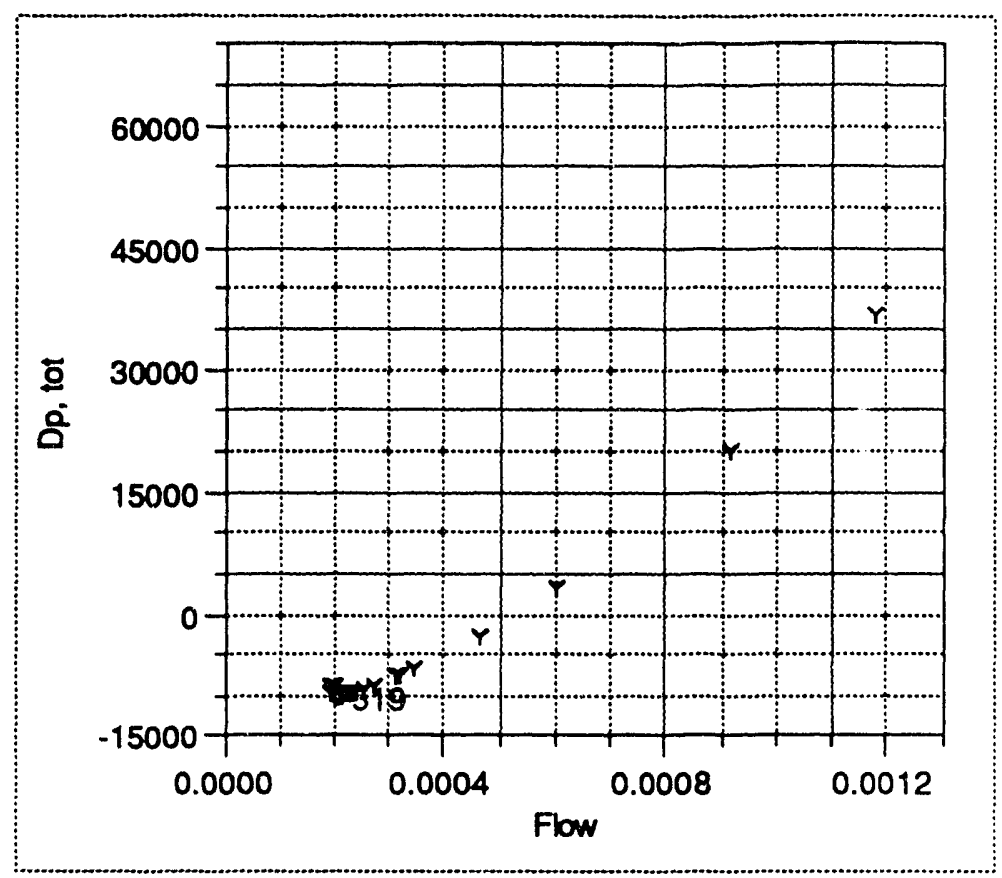

Figure 8-19, Demand curve 2.006, construction 4.0, open channel

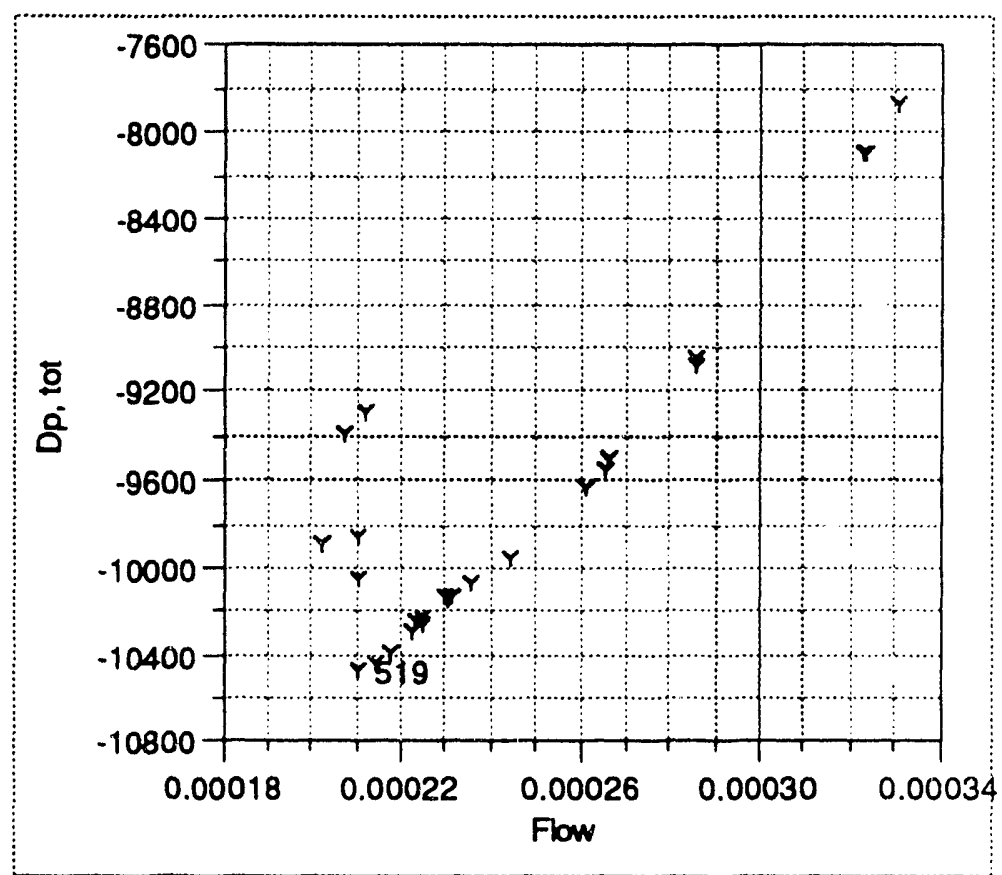

Figure 8-20, Detail of minima region for demand curve 2.006, construction 4.0, open channel 


\section{Preliminary Data -- 9 September 1993}

Table 8-21.--Boundary conditions for demand curve 2.007, construction 4.0, open channel

\begin{tabular}{l|c|c|c|c|c}
\hline \hline File name & $\begin{array}{c}\text { Row } \\
\text { number }\end{array}$ & $\begin{array}{c}\text { Inlet } \\
\text { Temperature } \\
{ }^{\circ} \mathrm{C}\end{array}$ & $\begin{array}{c}\text { EHL } \\
\text { pressure } \\
\mathrm{kPa} \text { abs }\end{array}$ & $\begin{array}{c}\text { Power } \\
\mathrm{kW}\end{array}$ & $\begin{array}{c}\text { Energy } \\
\text { balance }\end{array}$ \\
\hline FS_930715_1148 & 527 & 59.79 & 140.2 & 30.60 & 0.958 \\
FS_930715_1153 & 528 & 59.78 & 138.7 & 30.61 & 0.956 \\
FS_930715_1207 & 529 & 59.22 & 133.9 & 30.47 & 0.955 \\
FS_930715_1216 & 530 & 61.12 & 130.5 & 30.55 & 0.944 \\
FS_930715_1252 & 531 & 59.55 & 128.5 & 30.68 & 0.942 \\
FS_930715_1324 & 532 & 59.62 & 129.7 & 30.51 & 0.956 \\
FS_930715_1337 & 533 & 59.21 & 129.5 & 30.60 & 0.965 \\
FS_930715_1400 & 534 & 59.79 & 129.4 & 30.30 & 0.972 \\
FS_930715_1420 & 535 & 59.43 & 129.3 & 30.35 & 0.979 \\
FS_930715_1430 & 536 & 59.87 & 129.3 & 30.47 & 0.984 \\
FS_930715_1440 & 537 & 59.56 & 129.4 & 30.24 & 0.977 \\
FS_930715_1442 & 538 & 59.39 & 129.3 & 30.90 & 0.996 \\
FS_930715_1455 & 539 & 59.42 & 129.4 & 30.38 & 0.978 \\
FS_930715_1459 & 540 & 59.40 & 129.4 & 30.32 & 0.975 \\
FS_930715_1505 & 541 & 59.68 & 129.4 & 30.44 & 0.979 \\
FS_930715_1525 & 542 & 59.69 & 129.8 & 30.45 & 0.964 \\
FS_930715_1550 & 543 & 60.63 & 129.4 & 30.71 & 0.973 \\
FS_930715_1600 & 544 & 59.20 & 129.3 & 30.57 & 0.975 \\
FS_930715_1605 & 545 & 60.32 & 129.7 & 30.60 & 0.983 \\
\hline Mean & $\cdots$ & 59.72 & 130.7 & 30.51 & 0.9689 \\
MS & $\ldots$ & 0.50 & 3.3 & 0.16 & 0.0142 \\
\hline
\end{tabular}


Preliminary Data - 9 September 1993

Table 8-22.--Test data for demand curve 2.007, construction 4.0, open channel

\begin{tabular}{|c|c|c|c|c|}
\hline File name & $\begin{array}{c}\text { Row } \\
\text { number }\end{array}$ & $\begin{array}{l}\text { Flow } \\
\mathrm{cm}^{3} / \mathrm{s}\end{array}$ & $\underset{\mathrm{kPa}}{\Delta \mathrm{p}}$ & $\begin{array}{c}E H L \\
\text { condition }\end{array}$ \\
\hline $\begin{array}{l}\text { FS_930715_1148 } \\
\text { FS_930715_1153 } \\
\text { FS_930715_1207 } \\
\text { FS_930715_1216 } \\
\text { FS_930715_1252 } \\
\text { FS_930715_1324 } \\
\text { FS_930715_1337 } \\
\text { FS_930715_1400 } \\
\text { FS_930715_1420 } \\
\text { FS_930715_1430 } \\
\text { FS_930715_1440 } \\
\text { FS_930715_1455 } \\
\text { FS_930715_1442 } \\
\text { FS_930715_1550 } \\
\text { FS_930715.1459 } \\
\text { FS_930715_1600 } \\
\text { FS_930715_1505 } \\
\text { FS_930715_1605 } \\
\text { FS_930715_1525 }\end{array}$ & $\begin{array}{l}527 \\
528 \\
529 \\
530 \\
531 \\
532 \\
533 \\
534 \\
535 \\
536 \\
537 \\
539 \\
538 \\
543 \\
548 \\
544 \\
541 \\
545 \\
542\end{array}$ & $\begin{array}{r}1178.7 \\
1178.2 \\
952.3 \\
644.4 \\
478.5 \\
331.0 \\
299.4 \\
268.8 \\
238.0 \\
229.7 \\
221.1 \\
217.6 \\
217.6 \\
212.1 \\
2111.6 \\
206.5 \\
206.4 \\
197.1 \\
196.1\end{array}$ & $\begin{array}{r}36.78 \\
36.88 \\
21.86 \\
4.49 \\
-2.78 \\
-7.82 \\
-8.71 \\
-9.49 \\
-10.14 \\
-10.26 \\
-10.43 \\
-10.48 \\
-10.45 \\
-10.00 \\
-10.58 \\
-10.45 \\
-10.33 \\
-8.64 \\
-8.85 \\
\end{array}$ & VI: \\
\hline
\end{tabular}

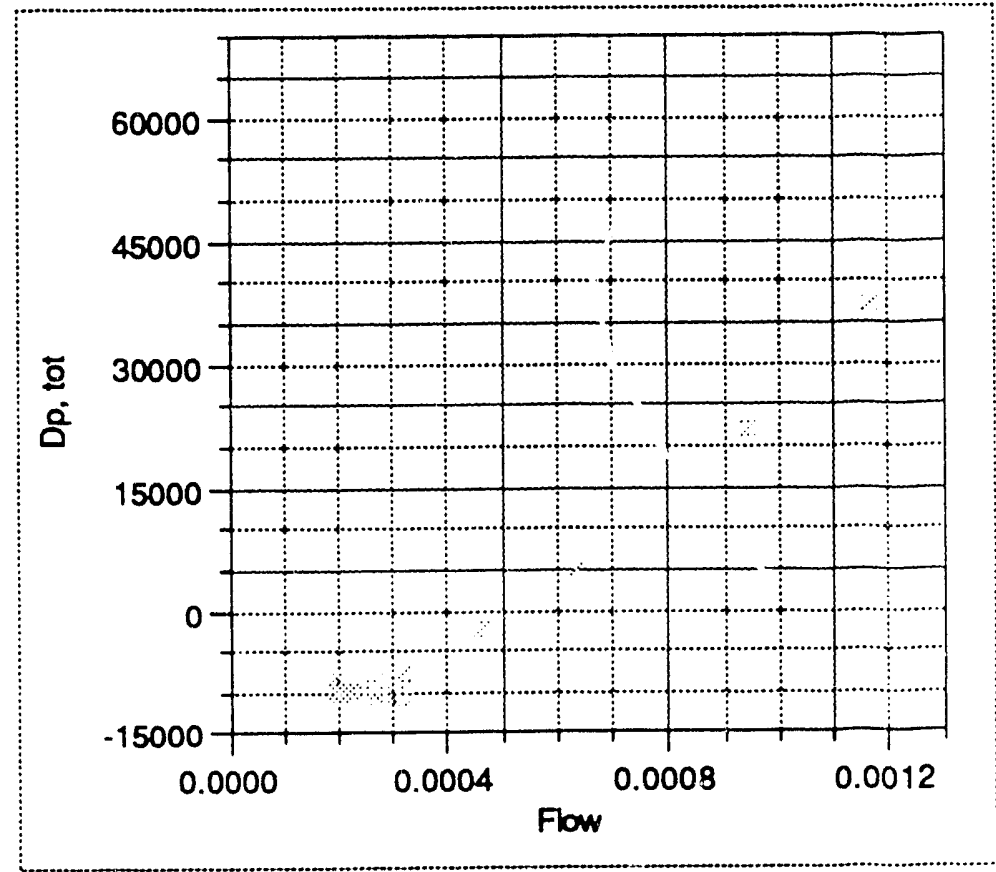

Figure 8-21, Demand curve 2.007, construction 4.0, open channel 
Preliminary Data -- 9 September 1993

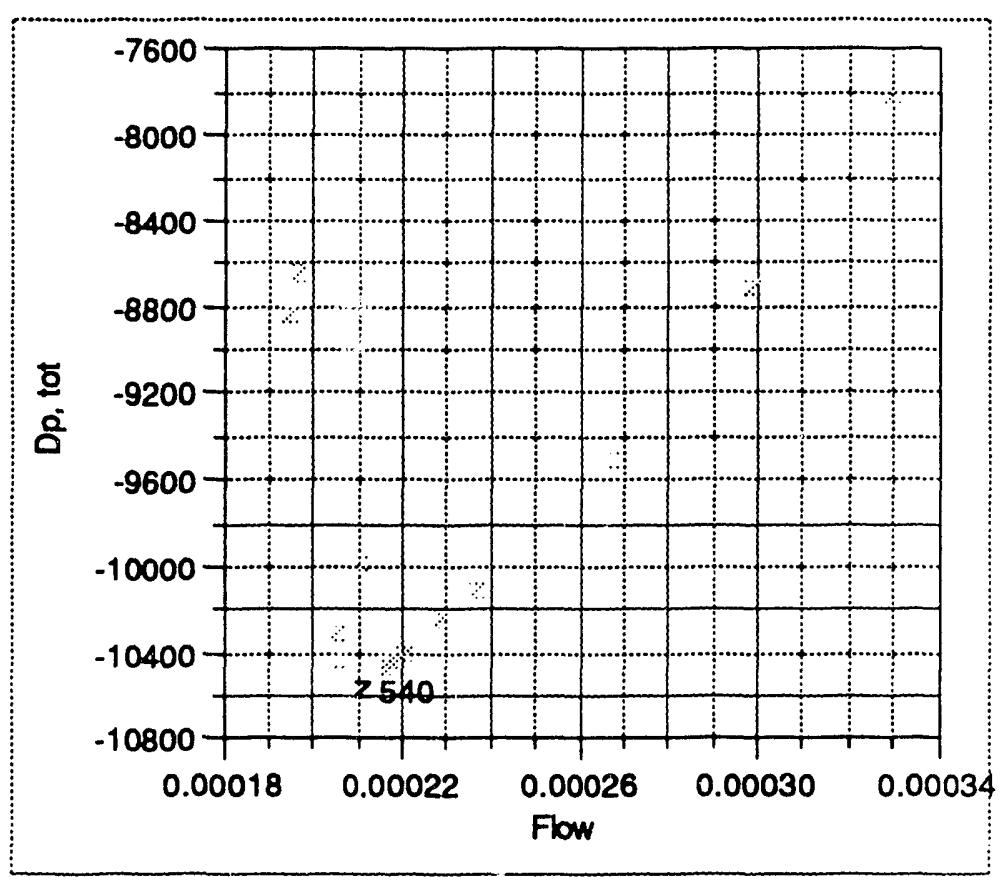

Figure 8-22, Detail of minima region for demand curve 2.007, construction 4.0, open channel 
Table 8-23.--Boundary conditions for demand curve 2.008, construction 4.0, open channel

\begin{tabular}{|c|c|c|c|c|c|}
\hline Filo name & $\begin{array}{c}\text { Row } \\
\text { number }\end{array}$ & $\begin{array}{c}\text { Inlet } \\
\text { Temperature } \\
{ }^{\circ} \mathrm{C}\end{array}$ & $\begin{array}{c}\text { EHL } \\
\text { pressure } \\
\text { kPa abs } \\
\end{array}$ & $\begin{array}{l}\text { Power } \\
\text { kW }\end{array}$ & $\begin{array}{c}\text { Energy } \\
\text { balance }\end{array}$ \\
\hline 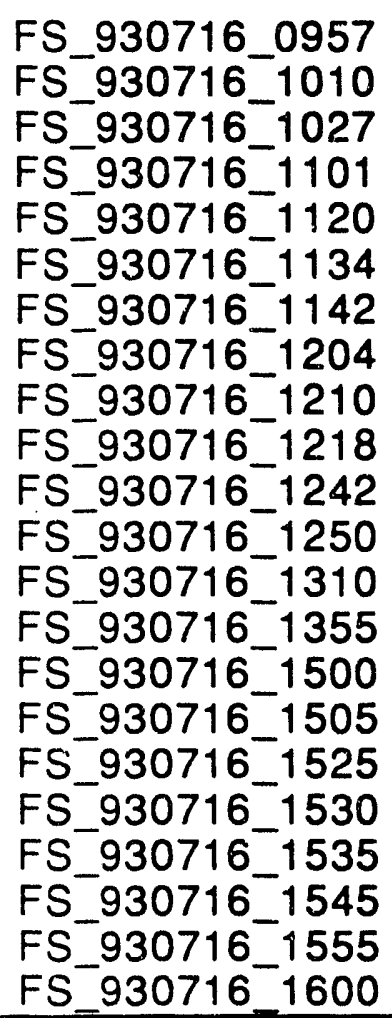 & $\begin{array}{l}548 \\
549 \\
550 \\
551 \\
552 \\
553 \\
554 \\
555 \\
556 \\
557 \\
558 \\
559 \\
560 \\
562 \\
563 \\
564 \\
565 \\
566 \\
567 \\
568 \\
569\end{array}$ & $\begin{array}{l}59.53 \\
59.59 \\
59.41 \\
59.69 \\
60.09 \\
60.15 \\
60.00 \\
59.22 \\
59.26 \\
59.30 \\
59.30 \\
59.32 \\
60.04 \\
59.79 \\
59.76 \\
59.56 \\
59.31 \\
59.33 \\
59.52 \\
60.09 \\
59.52\end{array}$ & $\begin{array}{l}138.4 \\
137.8 \\
132.5 \\
130.7 \\
129.4 \\
129.2 \\
129.1 \\
129.1 \\
129.1 \\
129.1 \\
129.2 \\
129.3 \\
129.3 \\
129.3 \\
129.2 \\
129.0 \\
128.9 \\
129.0 \\
129.0 \\
129.2 \\
129.1\end{array}$ & $\begin{array}{l}30.45 \\
30.47 \\
30.41 \\
30.37 \\
30.54 \\
30.45 \\
30.48 \\
30.67 \\
30.34 \\
30.50 \\
30.56 \\
30.58 \\
30.54 \\
30.48 \\
30.38 \\
30.40 \\
30.55 \\
30.02 \\
30.10 \\
30.50 \\
30.60\end{array}$ & $\begin{array}{l}0.955 \\
0.948 \\
0.948 \\
0.945 \\
0.958 \\
0.968 \\
0.965 \\
0.975 \\
0.981 \\
0.993 \\
0.986 \\
0.983 \\
0.988 \\
0.991 \\
0.975 \\
0.954 \\
0.975 \\
0.973 \\
0.986 \\
0.962 \\
0.991\end{array}$ \\
\hline $\begin{array}{l}\text { Mean } \\
S\end{array}$ & $\begin{array}{l}\cdots \\
\cdots\end{array}$ & $\begin{array}{r}59.54 \\
0.42\end{array}$ & $\begin{array}{r}130.2 \\
2.7 \\
\end{array}$ & $\begin{array}{r}30.44 \\
0.15 \\
\end{array}$ & $\begin{array}{l}0.9706 \\
0.0155 \\
\end{array}$ \\
\hline
\end{tabular}


Preliminary Data -- 9 September 1993

Table 8-24.--Test data for demand curve 2.008, construction 4.0, open channel

\begin{tabular}{|c|c|c|c|c|}
\hline File name & $\begin{array}{c}\text { Row } \\
\text { number }\end{array}$ & $\begin{array}{l}\text { Flow } \\
\mathrm{cm}^{3} / \mathrm{s}\end{array}$ & $\begin{array}{c}\Delta \mathrm{p} \\
\mathrm{kPa}\end{array}$ & $\begin{array}{c}\text { EHL } \\
\text { condition }\end{array}$ \\
\hline 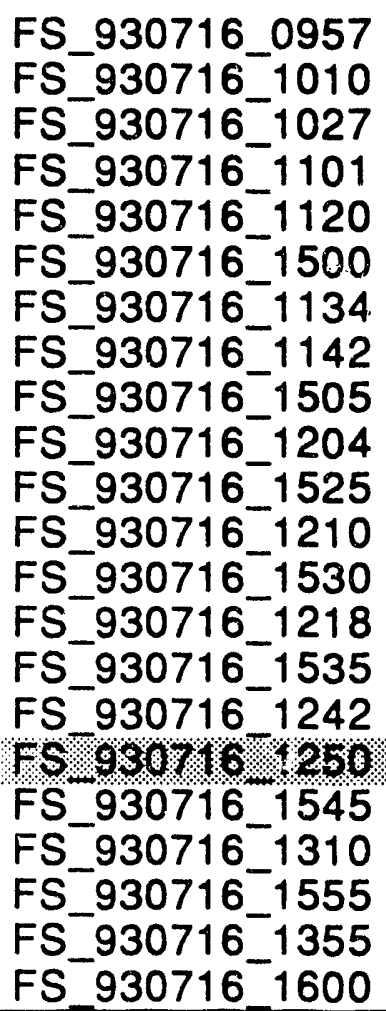 & $\begin{array}{l}548 \\
549 \\
550 \\
551 \\
552 \\
563 \\
553 \\
554 \\
564 \\
555 \\
565 \\
556 \\
566 \\
557 \\
567 \\
558 \\
559 \\
568 \\
560 \\
569 \\
562 \\
570\end{array}$ & $\begin{array}{r}1168.8 \\
950.8 \\
640.1 \\
482.4 \\
332.3 \\
330.1 \\
295.2 \\
267.8 \\
265.1 \\
235.7 \\
234.3 \\
228.4 \\
222.5 \\
222.0 \\
217.3 \\
216.4 \\
209.4 \\
209.2 \\
204.6 \\
202.9 \\
200.4 \\
196.1\end{array}$ & $\begin{array}{r}36.50 \\
21.55 \\
4.50 \\
-2.48 \\
-7.65 \\
-7.68 \\
-8.68 \\
-9.36 \\
-9.38 \\
-10.05 \\
-10.03 \\
-10.18 \\
-10.26 \\
-10.27 \\
-10.34 \\
-10.36 \\
-10.45 \\
-10.01 \\
-9.85 \\
-9.77 \\
-9.50 \\
-8.92\end{array}$ & LO \\
\hline
\end{tabular}

"The EHL flow condtions were not recorded for files FS_930716_1500 through FS_930716_1600. 
Preliminary Data _- 9 September 1993

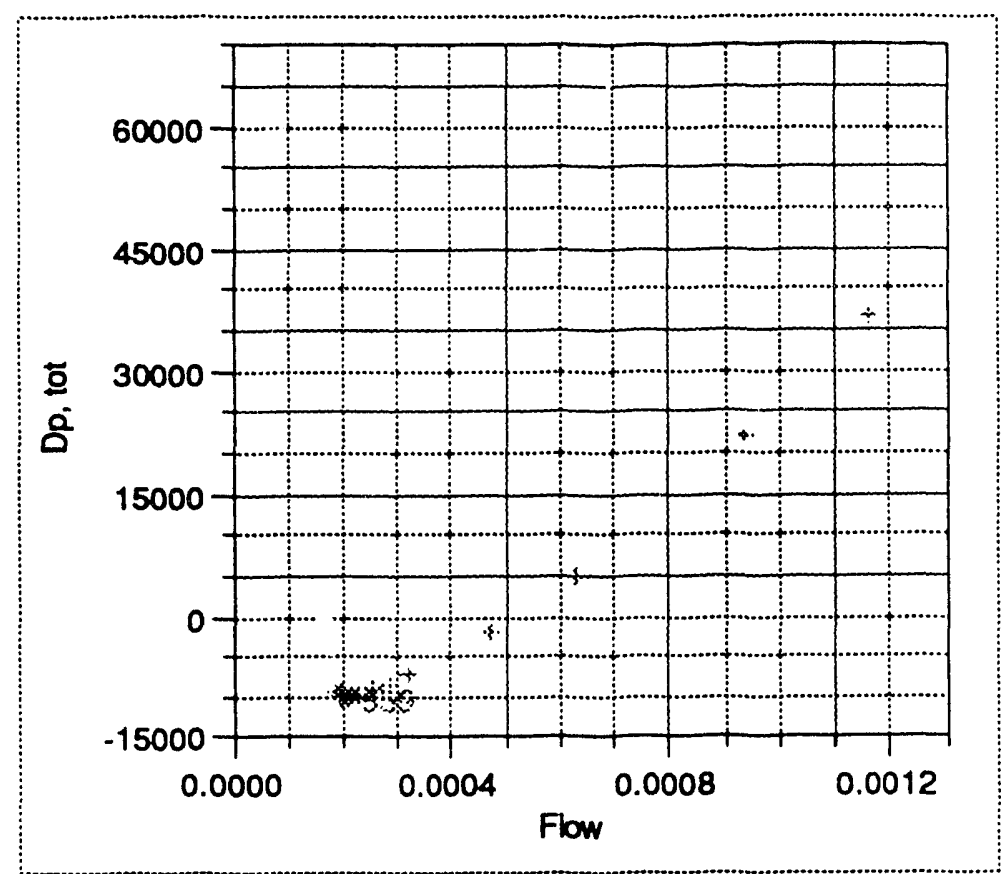

Figure 8-23, Demand curve 2.008, construction 4.0, open channel

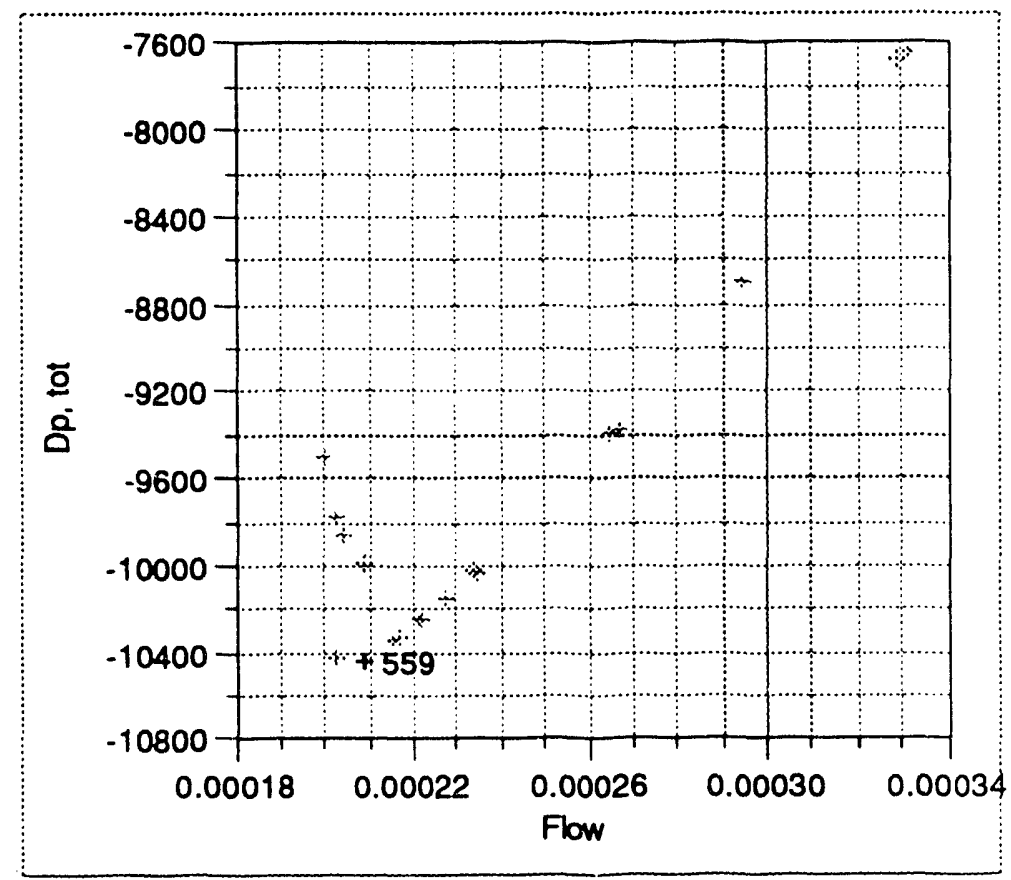

Figure 8-24, Detail of minima region for demand curve 2.008, construction 4.0, open channel 
Table 8-25.--Boundary conditions for demand curve 2.009, construction 4.0, open channel

\begin{tabular}{|c|c|c|c|c|c|}
\hline File name & $\begin{array}{c}\text { Row } \\
\text { number }\end{array}$ & $\begin{array}{c}\text { Inlet } \\
\text { Temperature } \\
{ }^{\circ} \mathrm{C}\end{array}$ & $\begin{array}{c}\text { EHL } \\
\text { pressure } \\
\text { kPa abs } \\
\end{array}$ & $\begin{array}{c}\text { Power } \\
k W\end{array}$ & $\begin{array}{l}\text { Energy } \\
\text { balance }\end{array}$ \\
\hline 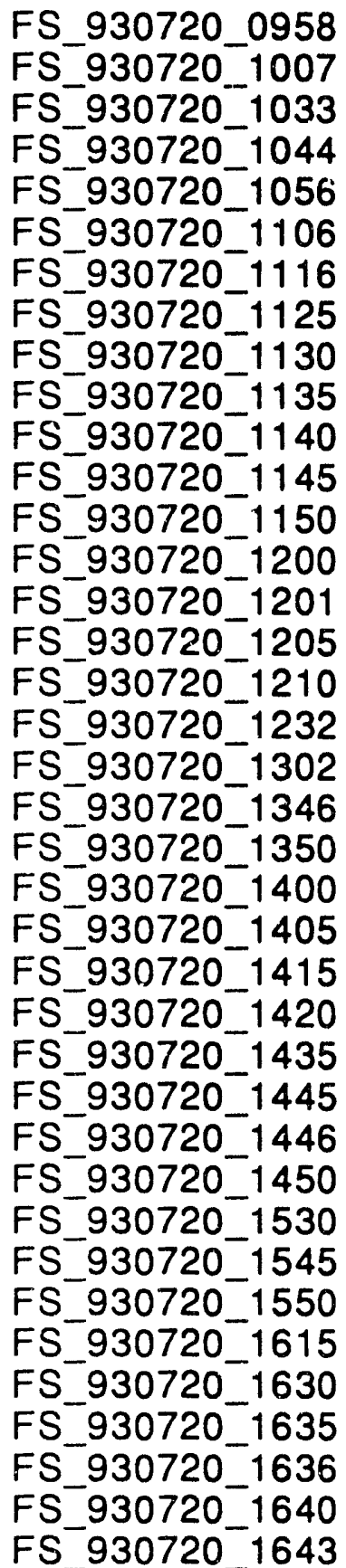 & $\begin{array}{l}573 \\
574 \\
575 \\
576 \\
577 \\
578 \\
579 \\
580 \\
581 \\
582 \\
583 \\
584 \\
585 \\
586 \\
587 \\
588 \\
589 \\
590 \\
591 \\
592 \\
593 \\
594 \\
595 \\
596 \\
597 \\
598 \\
599 \\
600 \\
601 \\
602 \\
603 \\
604 \\
605 \\
606 \\
607 \\
608 \\
609 \\
610\end{array}$ & $\begin{array}{l}60.28 \\
59.79 \\
59.63 \\
59.80 \\
59.91 \\
59.78 \\
59.85 \\
59.55 \\
59.59 \\
60.15 \\
60.01 \\
59.95 \\
59.87 \\
59.75 \\
59.60 \\
59.65 \\
60.61 \\
60.47 \\
59.59 \\
60.46 \\
59.77 \\
59.70 \\
59.50 \\
59.60 \\
59.59 \\
59.66 \\
59.80 \\
59.29 \\
60.28 \\
59.51 \\
59.80 \\
60.63 \\
60.75 \\
60.10 \\
60.13 \\
60.64 \\
60.74 \\
60.17\end{array}$ & $\begin{array}{l}140.7 \\
135.6 \\
132.9 \\
130.8 \\
129.3 \\
129.1 \\
129.0 \\
129.0 \\
129.0 \\
129.1 \\
129.1 \\
129.2 \\
129.2 \\
129.3 \\
129.3 \\
129.3 \\
129.6 \\
129.5 \\
129.3 \\
129.1 \\
129.0 \\
129.0 \\
129.0 \\
129.1 \\
129.1 \\
129.1 \\
129.2 \\
129.2 \\
129.5 \\
129.4 \\
129.0 \\
129.1 \\
129.2 \\
129.1 \\
129.2 \\
129.2 \\
129.5 \\
129.8\end{array}$ & $\begin{array}{l}30.51 \\
30.51 \\
30.53 \\
30.52 \\
30.53 \\
30.51 \\
30.65 \\
30.58 \\
30.46 \\
30.27 \\
30.53 \\
30.52 \\
30.44 \\
30.44 \\
30.51 \\
30.50 \\
30.44 \\
30.61 \\
30.53 \\
30.26 \\
30.66 \\
30.63 \\
30.68 \\
30.43 \\
30.70 \\
30.46 \\
30 \\
30.66 \\
30.42 \\
30.69 \\
30.63 \\
30.44 \\
30.39 \\
30.66 \\
30.55 \\
30.70 \\
30 \\
30.41 \\
30.19 \\
30.69\end{array}$ & $\begin{array}{l}0.949 \\
0.948 \\
0.946 \\
0.946 \\
0.964 \\
0.958 \\
0.975 \\
0.970 \\
0.971 \\
0.976 \\
0.977 \\
0.976 \\
0.976 \\
0.968 \\
0.968 \\
0.976 \\
0.979 \\
0.953 \\
0.961 \\
0.963 \\
0.968 \\
0.961 \\
0.972 \\
0.973 \\
0.983 \\
0.980 \\
0.972 \\
0.975 \\
0.986 \\
0.985 \\
0.980 \\
0.979 \\
0.975 \\
0.974 \\
0.980 \\
0.980 \\
0.971 \\
0.970\end{array}$ \\
\hline $\begin{array}{l}\text { Mean } \\
\text { S }\end{array}$ & $\begin{array}{l}\cdots \\
\cdots\end{array}$ & $\begin{array}{r}59.95 \\
0.39\end{array}$ & $\begin{array}{r}129.8 \\
2.2 \\
\end{array}$ & $\begin{array}{r}0.52 \\
0.12 \\
\end{array}$ & $\begin{array}{l}0.9701 \\
0.0107 \\
\end{array}$ \\
\hline
\end{tabular}


Table 8-26.--Test data for demand curve 2.009, construction 4.0, open channel

\begin{tabular}{|c|c|c|c|c|}
\hline File name & $\begin{array}{c}\text { Row } \\
\text { number }\end{array}$ & $\begin{array}{l}\text { Flow } \\
\mathrm{cm}^{3} / \mathrm{s}\end{array}$ & $\begin{array}{c}\Delta p \\
k P a\end{array}$ & $\begin{array}{c}\mathrm{EHL} \\
\text { condition }\end{array}$ \\
\hline 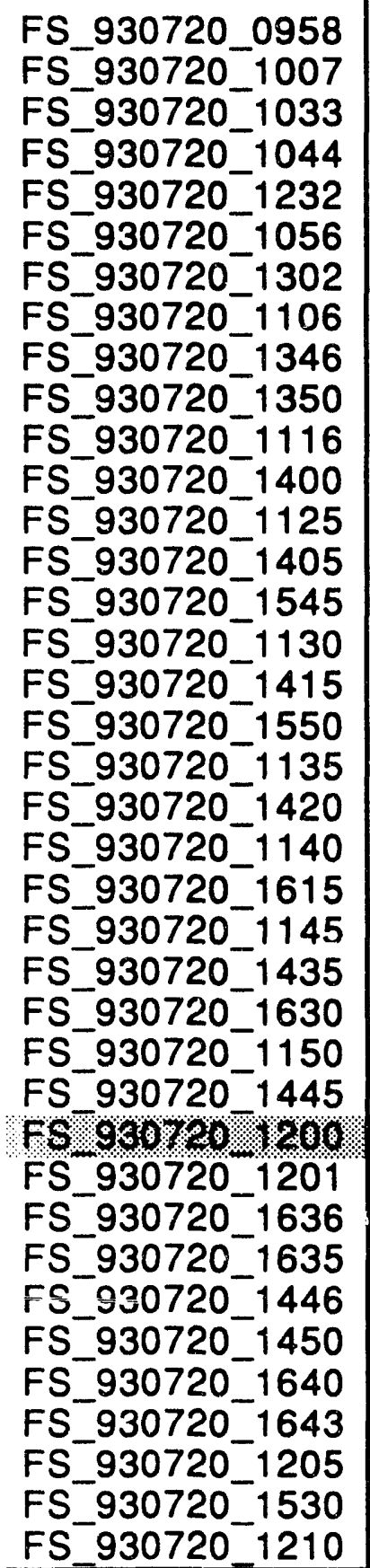 & $\begin{array}{l}573 \\
574 \\
575 \\
576 \\
590 \\
577 \\
591 \\
578 \\
592 \\
593 \\
579 \\
594 \\
580 \\
595 \\
603 \\
581 \\
596 \\
604 \\
582 \\
597 \\
583 \\
605 \\
584 \\
598 \\
606 \\
585 \\
599 \\
5886 \\
587 \\
608 \\
607 \\
600 \\
601 \\
609 \\
610 \\
588 \\
602 \\
589\end{array}$ & $\begin{array}{r}1166.2 \\
944.9 \\
639.9 \\
486.0 \\
347.5 \\
327.4 \\
315.0 \\
294.9 \\
281.3 \\
266.1 \\
265.8 \\
248.3 \\
243.5 \\
235.8 \\
232.9 \\
232.4 \\
230.0 \\
236.0 \\
229.3 \\
222.0 \\
221.7 \\
219.8 \\
217.1 \\
216.1 \\
215.3 \\
212.9 \\
212.2 \\
208.4 \\
208.3 \\
208.1 \\
207.8 \\
205.9 \\
204.3 \\
203.7 \\
203.3 \\
203.2 \\
198.4 \\
196.5\end{array}$ & $\begin{array}{r}36.30 \\
21.49 \\
4.45 \\
-2.38 \\
-7.29 \\
-7.87 \\
-8.21 \\
-8.77 \\
-9.11 \\
-9.48 \\
-9.49 \\
-9.87 \\
-9.96 \\
-10.10 \\
-10.15 \\
-10.18 \\
-10.21 \\
-10.16 \\
-10.22 \\
-10.31 \\
-10.34 \\
-10.29 \\
-10.42 \\
-10.42 \\
-10.39 \\
-10.49 \\
-10.48 \\
10.57 \\
-10.57 \\
-10.19 \\
-10.17 \\
-10.58 \\
-9.36 \\
-9.11 \\
-8.67 \\
-10.19 \\
-9.30 \\
-8.81\end{array}$ & $\begin{array}{l}\% \\
\mathrm{~V}\end{array}$ \\
\hline
\end{tabular}

"The EHL flow condtions were not recorded for files FS_930720_1232 through FS_930720_1615. 


\section{Preliminary Data -- 9 September 1993}

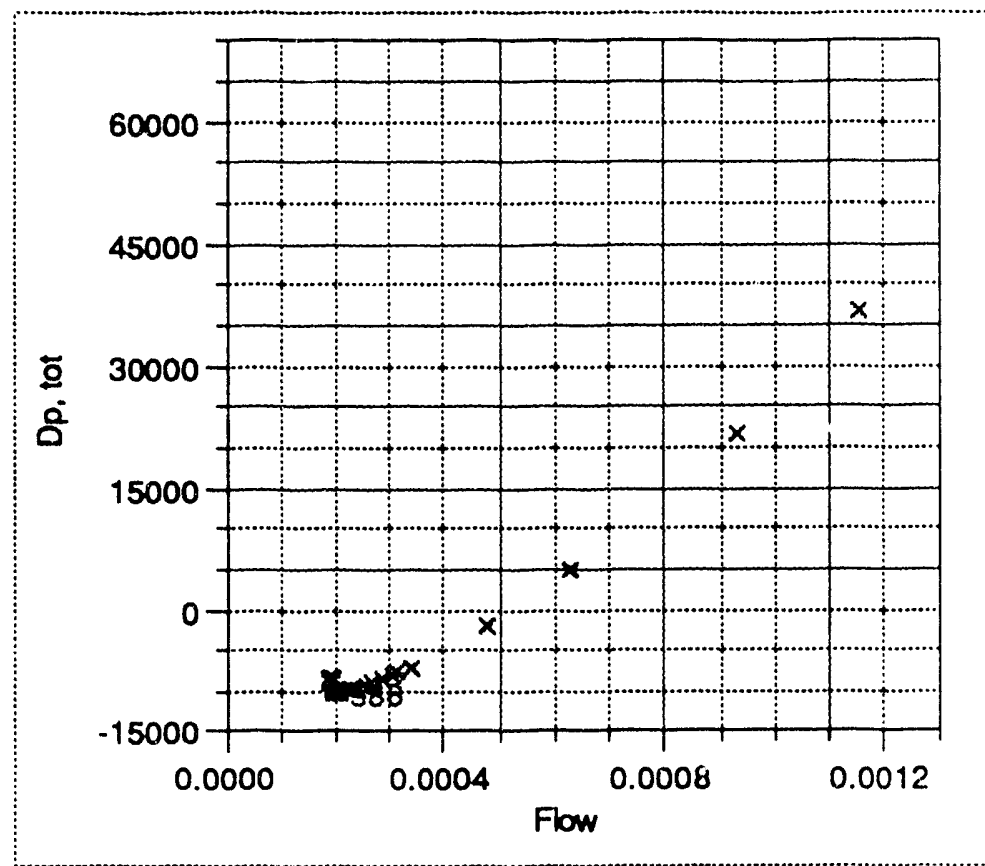

Figure 8-25, Demand curve 2.009, construction 4.0, open channel

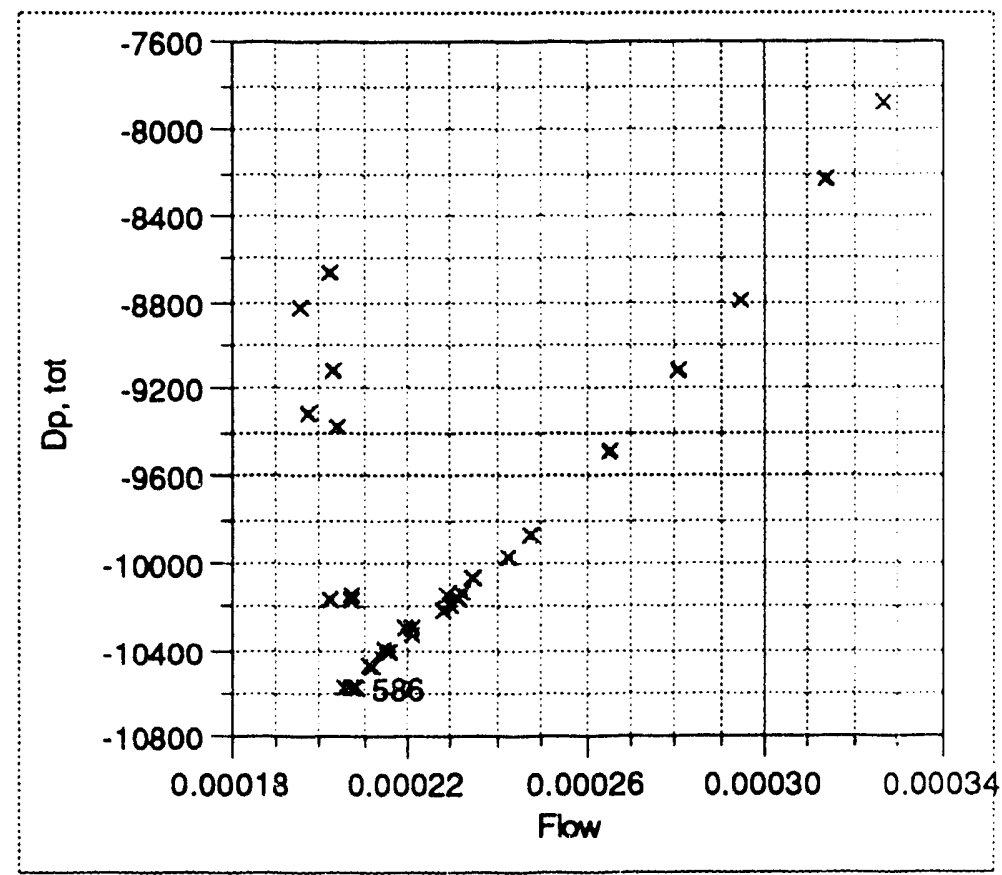

Figure 8-26, Detail of minima region for demand curve 2.009, construction 4.0, open channel 


\section{Preliminary Date - 9 September 1993}

\section{Isothermal Test Results}

This appendix section contains a summary of the isothermal demand curve data for the four test sections. Information is presented in a graphical format in terms of the friction factor and the Reynolds number. Two different curves are provided on the graphs. The bold line is calculated from Equation 22 , it is the expected curve for a smooth channel. The second curve is a linear fit of the plotted data. This second curve is provided with two confidence intervals. The larger intermal contains the data at $95 \%$ and the tighter interval contains the curve fit at $95 \%$. Both these intervals do not include systematic errors.

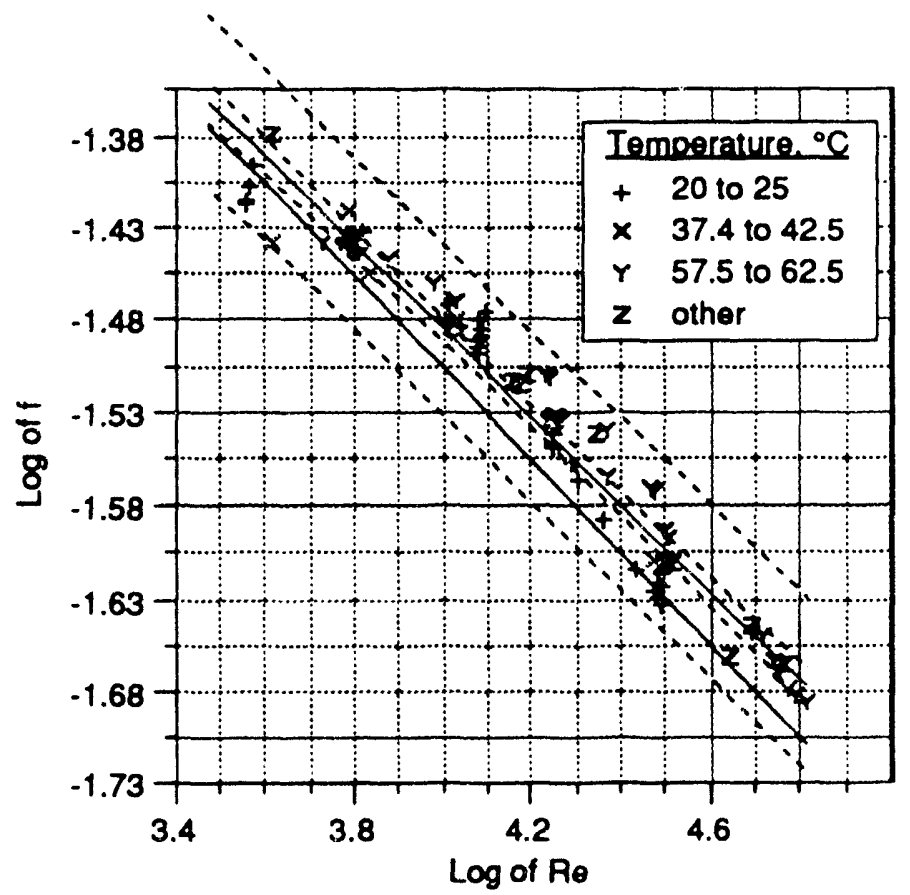

Figure 8-27, Isothermal demand curve for construction 1.0, open channel, 


\section{Prellminary Data _. 9 September 1993}

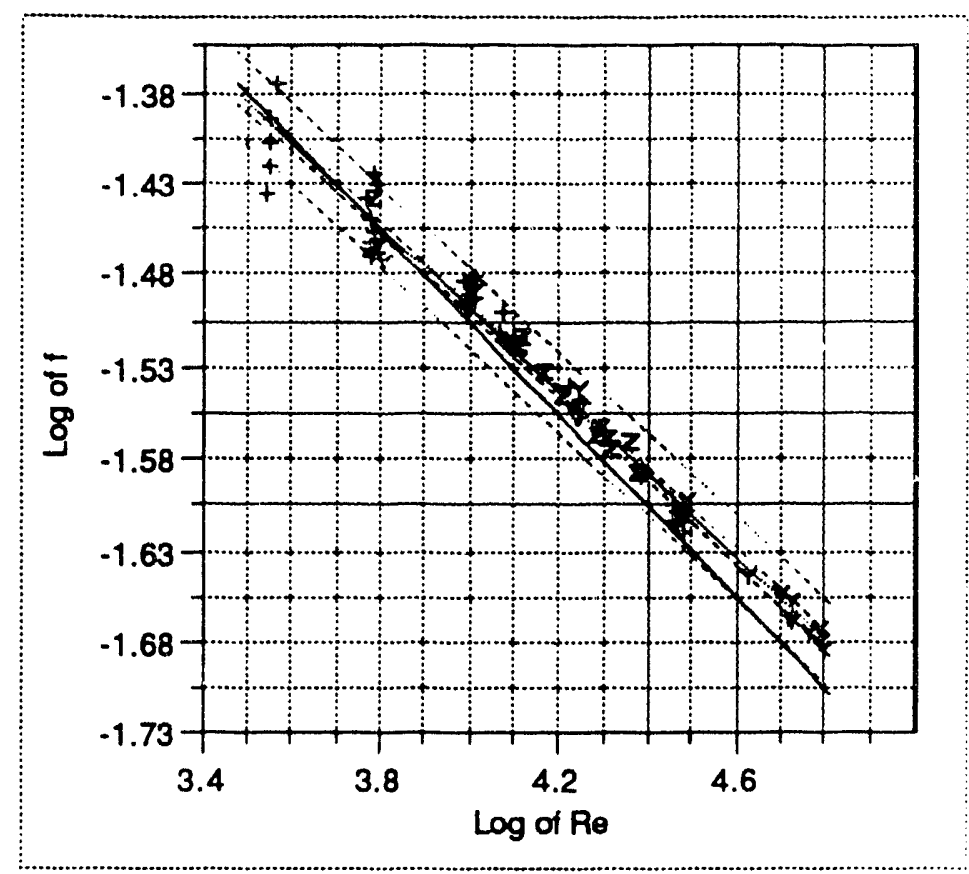

Figure 8-28, Isothermal demand curve for construction 2.0, rib channel

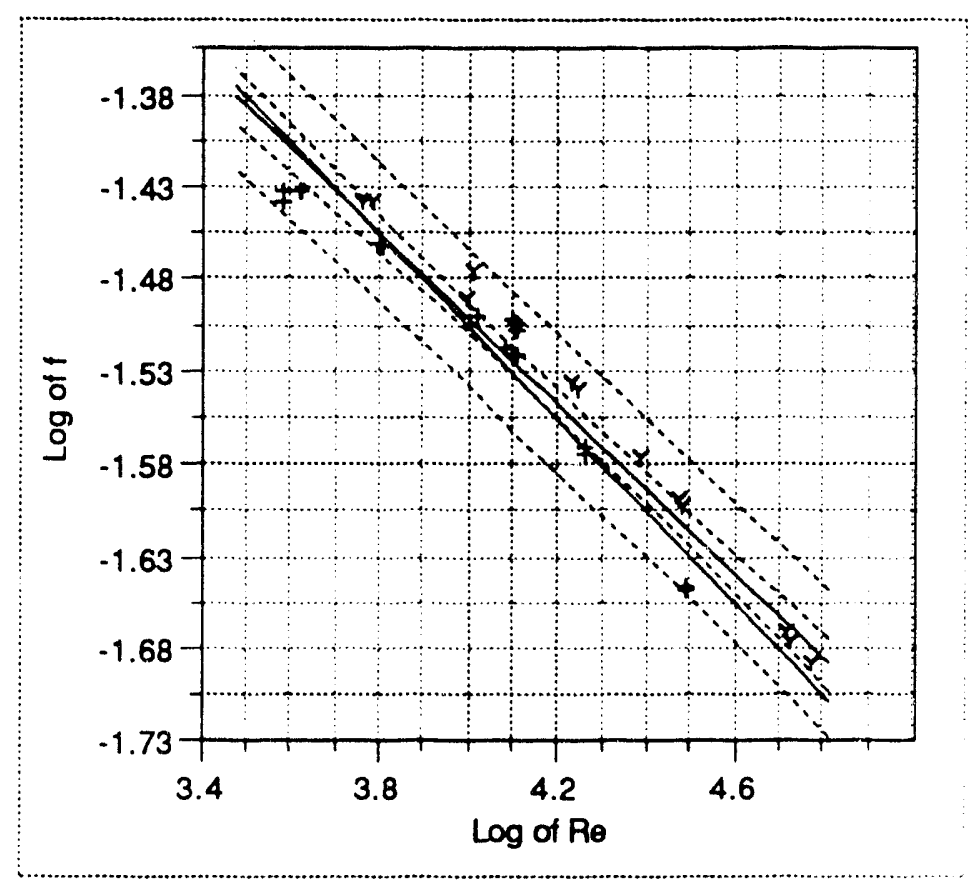

Figure 8-29, Isothermal demand curve for construction 3.0, open channel 
Preliminary Data -- 9 September 1993

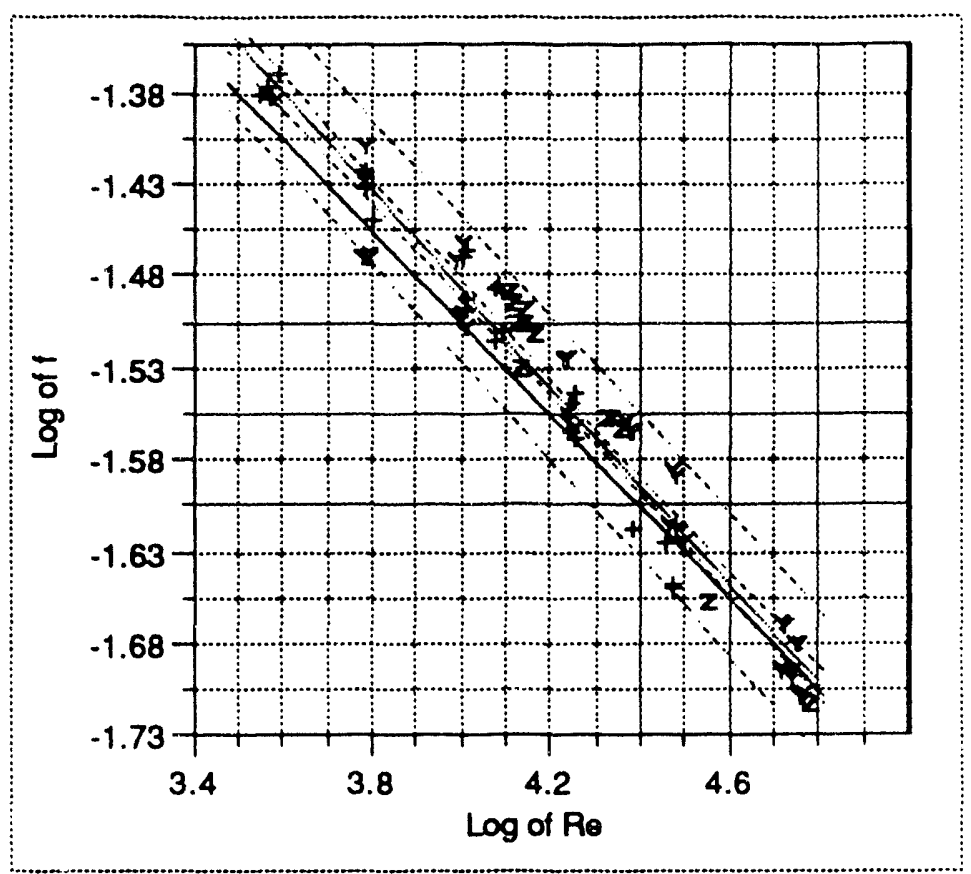

Figure 8--30, Isothermal demand curve for construction 4.0, open channel 


\section{Prellminary Data _- 9 September 1993}

\section{WORKS CITED}

1. American Society of Mechanical Engineers. 1987. Pressure Measurement.. New York: American Society of Mechanical Engineers, ASME/ASTM PTC 19.2-1987.

2. American Society of Mechanical Engineers. 1958. Measurement of Time Measurement.. New York: American Society of Mechanical Engineers, ASME/ASTM PTC 19.12-1958.

3. Automatic Flow Rate Controllers, Ferndale, Michigan: Kates Co. Bulletin 186.

4. Bankoff, S. G., S. C. Lee and A. Knaani. 1991. Literature Review on Forced-Convection Subcooled Boiling (U), Westinghouse Savannah River Company. WSRC-TR-91-98. February.

5. Bartolini, R., Bartolini, B. Guglielmini and E. Nannei, "Experimental Study on Nucleate Boiling of Water in Vertical Upflow and Downflow", International Journal Multiphase Flow, Volume 9, no. 2, pp 161-165, 1983.

6. Bergles, A. E., R. F. Lopina, and M. P. Fiori, 1967. Critical-Heat-Flux and Flow-Pattern Observations for Low-Pressure Water Flowing in Tubes. In ASME Journal of Heat Transfer 89: 69-74.

7. Bergles, A. E., and T. Dormer, Jr. 1969. Subcooled Boiling Pressure Drop with Water at Low Pressure. In International Journal of Heat and Mass Transfer 12: 459-70.

8. Blevins, Robert D., 1984. Applied Fluids Dynamics Handbook. New York: Von Nostrand Reihold Co.

9. Block, James A., Christopher J. Crowley, Francis X. Dolan, Richard G. Sam, and Brant $H$. Stoedefalke. 1990. Nucleate Boiling Pressure Drop in an Annulus. Hanover, N.H., Creare TN-499, October.

10. Bouré, J. A., A. E. Bergles, and L. S. Tong. 1973. Review of TwoPhase Flow Instability. Nuclear Engineering and Design 25: 165-92.

11. Bowring, R. W. 1962. Physical Model, Based on Bubble Detachment, and Calculation of Steam Voidage in the Subcooled Region of a Heated Channel. Oak Ridge, TN: Department of Energy, Office of Scientific and Technical Information. December. HPR-10. 
12. Carrano, V., C. F. Fighetti, S. Kokolis, C. Maciuca, E. V. McAssey, Jr., D. G. Reddy, and B. W. Yang, September 1992, Westinghouse Savannah River Company Flow Excursion Experimental Program, Single Annulus Tests. Transeint Test Program, Columbia Unviersity HTRF, NY, CU-HTRF-T3B.

13. Chakroun, Walid, Robert P. Taylor, W. G. Steele, and H. W. Coleman. 1993. Bias Error Reduction in Experimental Results by Presentation as a Ratio to a Baseline Experiment--A Heat Transfer Case Study. Washington: American Institute of Aeronautics and Astronautics. AIAA 93-0922.

14. Cheh, H. Y., and C. F. Fighetti. 1990, Westinghouse Savannah River Company Flow Excursion Experimental Program, Non-uniformly Heated Tube Tests. New York: Heat Transfer Research Facility, Columbia University, (October) CU-HTRF-T5, CU-90-05.

15. Cheh, H. Y., and C. F. Fighetti. 1990. Westinghouse Savannah River Company Flow Excursion Experimental Program, Parallel Flow Tests. New York: Heat Transfer Research Facility, Columbia University, (June) CU-HTRFT6, CU-90-04.

16. Cheh, H. Y., and C. F. Fighetti. 1990. Westinghouse Savannah River Company Flow Excursion Experimental Program, Single Tube Uniformly Heated Tests. New York: Heat Transfer Research Facility, Columbia University, (January) CU-HTRF-T4, CU-90-01.

17. Cheh, H. Y., and C. F. Fighetti. 1991. Westinghouse Savannah River Company Flow Excursion Experimental Program, Single Annulus Tests, Steady State Test Program. New York: Heat Transfer Research Facility, Columbia University, (July) CU-HTRF-T3A.

18. Cheh, H. Y., E. V. McAssey, Jr., and C. F. Fighetti. 1992, Westinghouse Savannah River Company Flow Excursion Experimental Program, Single Tube Tests, Critical Heat Flux Test Program. New York: Heat Transfer Research Facility, Columbia University, (September) CU-HTRF-T8.

19. Cheh, H. Y., E. V. McAssey, Jr., and C. F. Fighetti. 1993, Westinghouse Savannah River Company Flow Excursion Experimental Program, Single Annulus Tests, Final Report. New York: Heat Transfer Research Facility, Columbia University, (October) CU-HTRF-05-92.

20. Chen, K., P. K. Paul, and K. L. Barbour. 1990. FLOWTRAN Benchmarking with Onset of Flow Instability Data from 1988 Columbia University Single-Tube OFI Experiment.. Aiken SC: Westinghouse Savannah River Company, WSRC-RP-89-870 (June).

21. Chen, K.. 1991. Benchmarking of FLOWTRAN with Mark-22 Mockuo Flow Excursion Test Data from Babcock \& Wilcox. Aiken SC: Westinghouse Savannah River Company, WSRC-TR-91-629 (November). 


\section{Preliminary Data -- 9 September 1993}

22. Cheng, S. C., W. W. L. Ng, K. T. Heng, D. C. Groeneveld. 1978. Measurements of Transition Boiling Data for Water Under Forced Convective Conditions. ASME Journal of Heat Transfer 100: 382-4.

23. Cheng, S. C., W. W. L. Ng, and K. T. Heng. 1978. Measurements of Boiling Curves of Subcooled Water Under Forced Convective Conditions. International Joumal of Heat and Mass Transfer 21: 1385-92.

24. Collier, John G. 1972. Convective Boiling and Condensation. 2d ed., New York, McGraw-Hill Book Co.

25. Coleman, Hugh W., and W. Glenn Steele, Jr., 1989. Experimentalation and Uncertainty Analysis for Engineers. New York: John Wiley \& Sons.

26. Coutts, D. A. 1991. Uncertainty and Calibration Analysis (U). Aiken, SC.: Savannah River Laboratory. DCE. (March) WSRC-TR-91-106.

27. Coutts, D. A. 1993. SRS OFI Program (U). Aiken, SC: Savanah River Technology Center. DOE. draft.

28. Dormer Jr., Thomas, and Arthur E. Bergles. 1964. Pressure Drop with Surface Boiling in Small-Diameter Tubes, Cambridge: MIT Department of Mechanical Engineering 8767-31. September 1.

29. Dougherty, T., C. Fighetti, G. Reddy, B. Yang, E. McAssey, Jr., and Z. Qureshi. 1991. Flow Instability in Vertical Channels. In Phase Change Heat Transfer, HTD-Vol. 159. American Society of Mechanical Engineers. 177-86.

30. Feng, Qijing, and Klaus Johannsen. 1990. The High-Temperature Limit of the Transition Boiling Regime for Water in Vertical Upflow at Medium Pressure. In 9th International Heat Transfer Conference, Jerusalem, Israel, August 19-24, 1990, 29-34.

31. Figliola, Richard S., and Donald E. Beasley. 1991. Theory and Design for Mechanical Measurements. New York: John Wiley \& Sons.

32. Hewitt, G. F. 1982. Flow Regimes. In Handbook of Multiphase Systems, ed. Gad Hetsroni, chapt. 2. Hemisphere Publishing Corporation, Washington.

33. Hino, Ryutaro, and Tatsuhiro Ueda. 1985. Studies on Heat Transfer and Flow Characteristics in Subcooled Flow Boiling - Part 1. Boiling Characteristics. International Journal of Multiphase Flow 11: 269-281.

34. Hodges, M. W. 1971. Technical Memorandum from Aiken, to J. M. Boswell, Aiken, 8 April. Effect of Rib on Burnout Heat Flux. Aiken, SC.: Savannah River Laboratory. AEC. DPST-71-317. 


\section{Preliminary Data _- 9 September 1993}

35. Hodges, M. W. 1973. Technical Memorandum from Aiken, to J. M. Boswell, Aiken, 6 March. Burnout Heat Flux with Rib Contact.. Aiken, SC.: Savannah River Laboratory. AEC. DPST-73-206.

36. Insulating Button Assembly (Single Annulus with Fins), [1991]. fabrication drawing. New York: Columbia University Chemical Engineering Research Lab. 10 October. SR-2-T3-500-85.

37. Ishibashi, E., and K. Nishikawa. 1969. Saturated Boiling Heat Transfer in Narrow Spaces. International Journal of Heat and Mass Transfer 12: 86394.

38. Jones, G. F., E. V. McAssey, Jr., B.W. Yang. 1993. Heat Conduction in an Energy-Generating Slab Subject to a Nonuniform Heat Transfer Coefficient. New York: Heat Transfer Research Facility, Chemical Engineering Research Laboratories, Columbia University. proposed for publication in ASME Journal of Heat Transfer.

39. JMP@. version 2.0.4. SAS Institute Inc. Cary NC.

40. Johnston, B. S., and J. M. Neff. 1990. Effect of Longitudinal Spacer Ribs on the Minimum Pressure Drop in a Heated Annulus, Advances in Nuclear Reactors 150: 159-64.

41. Johnston, B. S., A Sharon, and S. G. Bankoff. 1983. Boiling Heat Transfer in a Narrow Eccentric Annulus, Part II: Heat Transfer. Transactions of the American Nuclear Society, Journal of Engineering for Power 105: 748-54.

42. Johnston, B. S., A Sharon, Y. Kozawa, and S. G. Bankoff. 1983. Boiling Heat Transfer in a Narrow Eccentric Annulus, Part I: Dryout. Transactions of the American Nuclear Society, Journal of Engineering for Power 105: 742-47.

43. Johnston, B. S. 1990. Technical Memorandum from Aiken, SU, to J. E. Laurinat, Aiken, SC, 4 January. Savannah River Site, Aiken, SC. NES-ECS890222.

44. Johnston, B. S. 1989. Subcooled Boiling of Downward Flow in a Vertical Annulus. In the proceedings of the 1989 National Heat Transfer Conference, HTD-Vol 109, Multiphase Flow, Heat and Mass Transfer 149-156.

45. Kawamura, Hiroshi, Fujio Tachibana, and Mamoru Akiyama, "Heat Transfer and DNB Heat Flux in Transient Boiling", Forth International Heat Transfer Conference, Paper B3.3, Paris-Versailles. France, August 31, 1970, pp $1-11$.

46. Klausner, J. F, B. T. Chao, and S. L. Soo. 1990. An Improved Method for Simultaneous Determination of Frictional Pressure drop and Vapor volume fraction in Vertical Flow Boiling. Experimental Thermal and Fluid Science 3: 404-415. 


\section{Preliminary Data -- 9 September 1993}

47. Kowalski, J. E., P. J. Mills, and S. Y. Shim. 1990. Onset of Nucleate Boiling and Significant Void on Finned Surfaces. In Advances in Gas-Liquid Flows: Presented at The Winter Annual Meeting of the American Society of Mechanical Engineers, Dallas, Texas, November 25-30, 1990. edited by J. H. Kim, U. S. Rohatgi, and A Hashemi. 405-11. New York: American Society of Mechanical Engineers.

48. Lahey, Jr., R. T. 1981. The Analysis of System Pressure Drop Characteristics During Flow Boiling. Transactions of the American Nuclear Society 38: 770-71.

49. Laurinat, J. E., 1991. Inter-office Memorandum from Aiken, SC, to J. D. Menna, Aiken, SC, 5 September. Savannah River Site, Aiken, SC. NES-ART910338.

50. Ledinegg, M. 1938. Instability of Flow During Natural And Forced Circulation. Die Wärme 61: 891-898. trans. R. B. Lees. Chicago: Argonne National Laboratory.

51. Leung, J. C. M., Critical Heat Flux under Transient Conditions: A Literature Survey, NUREG/CR-0056, ANL-78-39, Argonne National Laboratory, June 1978.

52. Maulbetsch, John S., and Peter Griffith. 1965. A Study of SystemInduced Instabilities in Forced Convection Flows with Subcooled Boilirig. Cambridge: MIT, Department of Mechanical Engineering 5382-35. April 15.

53. Mirshak, S. 1955. Two-Phase Flow in Tubes with Outlet Orifices. Aiken, SC.: Savannah River Laboratory. AEC. (April) DP-109.

54. Mirshak, S. 1958. Transient Flow of Boiling Water in Heated Tubes. Aiken, SC.: Savannah River Laboratory. AEC. (July) DP-301.

55. Mirshak, S., W. S. Durant, and R. H. Towell, Heat flux at Burnout, DP355, Savannah River Laboratory, Aiken, SC, February 1959.

56. Ozawa, M., K. Akagawa, and T Sakaguchi, "Flow Instabilities in Parallel-Channel Flow Systems of Gas-Liquid Two-Phase Mixtures", International Journal of Multiphase Flow, Vol 15, No 4, 1989, 639-657.

57. Ramilison, J. M., and J. H. Lienhard. 1987. Transition Boiling Heat Transfer and the Film Transition Regime. ASME Journal of Heat Transfer 109: 746-752.

58. Ramilison, Jean Masy. 1985. Transition boiling heat transfer and the film-transition regime. Ph. D. diss, University of Houston.

59. Rogers, J. T., M. Salcuclean, Z. Abdullah, D. McLeod, and D. Poirier, "The Onset of Significant Void in Up-Flow Boiling of Water at Low Pressure and 
Velocities", International Journal Multiphase Flow, Volume 30, No. 11, pp 2247$2260,1987$.

60. Rohsenow, Warren M., and Harry Choi. 1961. Heat, Mass and Momentum Transfer. Englewood Cliffs, NJ: Prentice-Hall Inc.

61. Rush, G. C., J. E. Blake, R. M. Privette, and C. A. Nash. 1990. Flow Excursion Experiments With a Savannah River Mark 22 Fuel Assembly Mockup, Executive Summary. Alliance, OH: Babcock \& Wilcox Research \& Development Division, RDD:90:4427-13-01-01:01 (February).

62. Saha, P. and N. Zuber. 1974. Point of Net Vapor Generation and Vapor Void Fraction in Subcooled Boiling. In Proceedings of the 5th International Heat Transfer Conference, Tokyo, Japan, September 3-7, 1974, 175-79.

63. Sharon, A., L. Chen, and S. G. Bankoff. Convective Boiling Heat Transfer in a Concentric Annular Gap. In International Journal of Multiphase Flow 9: 545-60.

64. Streeter, Victor L., and E. Benjamin Wylie. 1979. Fluid Mechanics. 7th ed., New York: McGraw-Hill Book Co.

65. Teel Industrial Series Operating Instructions \& Parts Manual Booster Pumps, Chicago, IL, Dayton Electric Mfg. Co. Form 5S1843-04223

66. Witte, L. C., and J. H. Lienhard. 1987. On the Existence of Two 'Transition' Boiling Curves. International Journal of Heat and Mass Transfer 25: 771-79.

67. Whittle, R. H. and R. Forgan. 1967. A Correlation for the Minima in the Pressure Drop Versus Flow-Rate Curves for Sub-Cooled Water Flowing in Narrow Channels. Nuclear Engineering and Design 6: 89-99.

68. Zigrang, D. J., and N. D. Sylvester. 1982. Explicit Approximations to the Solution of Colebrook's Friction Factor Equation. American Institute of Chemical Engineers Journal 28 (May, no. 3) 514-15.

69. Dorra, H., S. C. Lee, and S. G. Bankoff. 1993. A Critical Reviewve Models for the Onset of Significant Boid in Forceed-Convection Subcooled Boiling (U). Aiken SC, Savannah River Technology Center. DOE. (June) WSRC-TR-93-404.

70. not used

71. Chen, K., and J. F. King. 1988. FLOWTRAN Benchmarking with Onset of Flow Instability Data from 1963 Columbia University Experiment. Aiken SC: Savannah River Laboratory, COE, DPST-88-666 (October). 


\section{Preliminary Data -- 9 September 1993}

72. Thom, J. R. S., W. M. Walker, T. A. Fallon, and G. F. S. Reising. 1965. "Boiling in Sub-cooled Water During Flow Up Heated Tubes or Annuli. In Symposium on Boiling Heat Transfer in Steam Generating Units and Heat Exchangers, Manchester, England, September 15-16, 1965. paper 6, 226-46.

73. Workbench ${ }^{\mathrm{TM}}$. version 3.0.4 Mac II. Strawberry Tree Inc. Sunnyvale Ca.

74. Brown, W., Harold Midlin, and C. Y.Hu. 1991. Nonferrous Alloys. Vol. 3. Aerospace Strutural Metals Handbook. West Lafayette, IN: CINDAS, Purdue University

75. Yang, Bao-Wen 1992. letter from New York, to Allan Coutts, Aiken, SC, 7 April. Columbia University, New York. AX-721092. Task 92-92-033-1.

76. Aleman, S. E., M. V. Gregory, L. L. Hamm, L. D. Koffman, R. E. Pevey, W. H. Reed, and F. G. Smith. 1989. FLOWTRAN: An Algorithm for Describing the Thermal-Hydraulic Behavior of SRP Assemblies (U). Aiken, SC.: Savannah River Laboratory. DOE. (15 September) DPSTM-140, Revision 0, Version 16.2 .

77. Beaton, C. F., and G. F. Hewitt. 1989. Physical Property Data for the Design Engineer. New York: Hemisphere Publishing Corp.

78. Gehrke, Volker, and S. G. Bankoff. 1993. Stability of ForcedConvection Subcooled Boiling in Steady-State and Transient Annular Flow (U). Aiken SC: Savannah River Technology Center. DOE. (June) WSRC-TR-93406. 

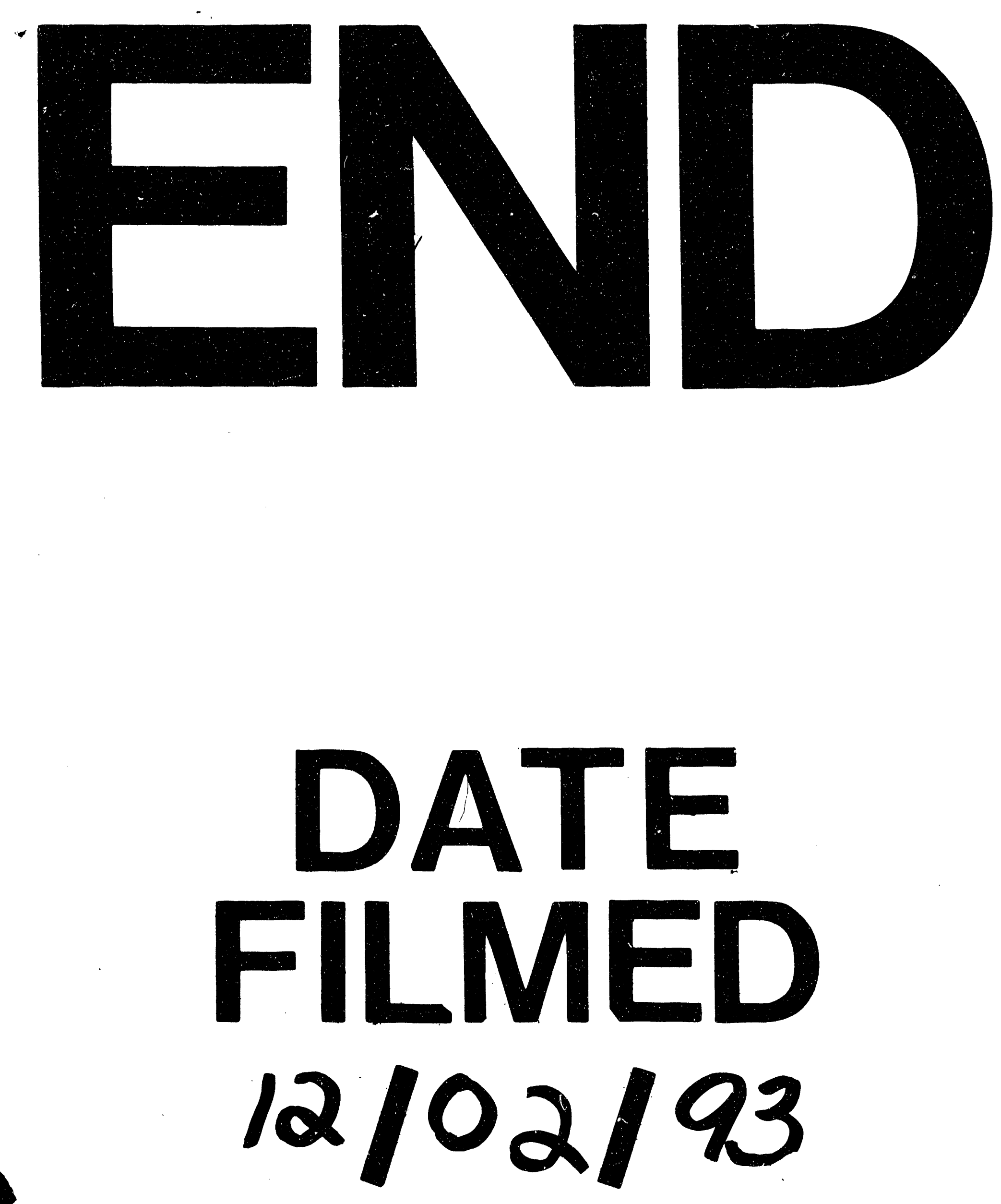

1 
